NIST GCR 15-986-1

\title{
Proceedings of the Measurement Science for Sustainable Construction and Manufacturing Workshop Volume I. Position Papers and Findings
}

\author{
Bilal M. Ayyub \\ Gerald E. Galloway \\ Richard N. Wright \\ University of Maryland
}

This publication is available free of charge from: http://dx.doi.org/10.6028/NIST.GCR.15-986-1

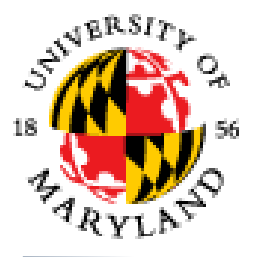

\section{A. JAMES CLARK}

SCHOOL OF ENGINEERING
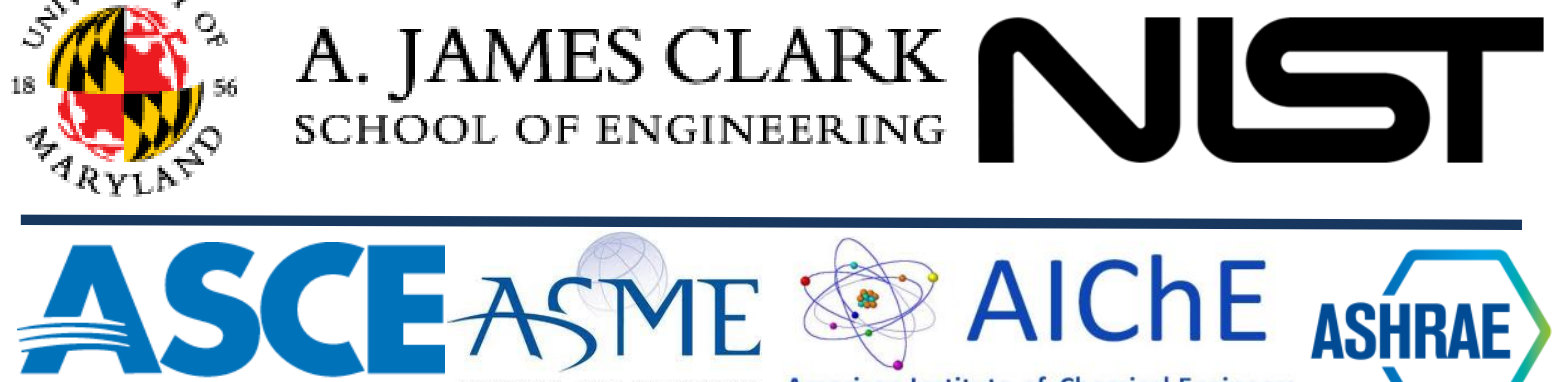

AMERICAN SOCIETY OF CIVIL ENGINEERS
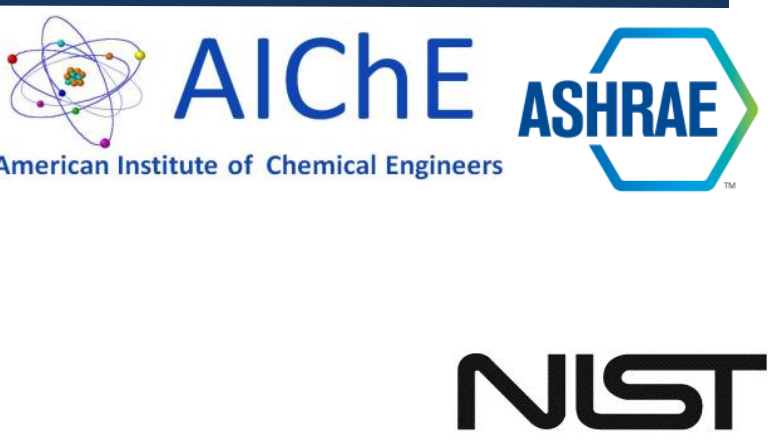

National Institute of Standards and Technology U.S. Department of Commerce 

NIST GCR 15-986-1

\title{
Proceedings of the Measurement Science for Sustainable Construction and Manufacturing Workshop Volume I. Position Papers and Findings
}

\author{
Prepared for \\ U.S. Department of Commerce \\ Engineering Laboratory \\ National Institute of Standards and Technology \\ Gaithersburg, MD 20899-8600 \\ By \\ Bilal M. Ayyub \\ Gerald E. Galloway \\ Richard N. Wright \\ University of Maryland
}

This publication is available free of charge from: http://dx.doi.org/10.6028/NIST.GCR.15-986-1

February 2015

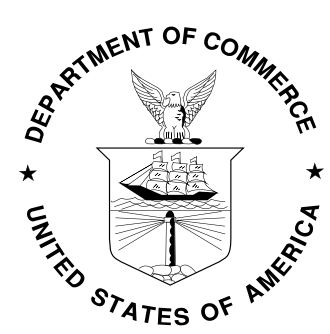

U.S. Department of Commerce Penny Pritzker, Secretary

National Institute of Standards and Technology Willie May, Acting Under Secretary of Commerce for Standards and Technology and Director 
This publication was produced as part of Cooperative Agreement 70NANB13H211 with the National Institute of Standards and Technology. The contents of this publication do not necessarily reflect the views or policies of the National Institute of Standards and Technology or the US Government 


\section{Organizing Committee}

Bilal M. Ayyub, University of Maryland

Robert Chapman, National Institute of Standards and Technology

Joannie Chin, National Institute of Standards and Technology

Gerald E. Galloway, University of Maryland

I. S. Jawahir, University of Kentucky

Josh Kneifel, National Institute of Standards and Technology

Sudarsan Rachuri, National Institute of Standards and Technology

Jelena Srebric, University of Maryland

Richard N. Wright, University of Maryland

\section{Sponsors}

National Institute of Standards and Technology

American Society of Civil Engineers (ASCE)

American Institute of Chemical Engineers (AIChE)

American Society of Mechanical Engineers (ASME)

American Society of Heating, Refrigerating and Air Conditioning Engineers (ASHRAE)

University of Maryland

\section{Recommended Citations}

Ayyub, B. M., Galloway, G. E., and Wright, R. N. (editors), 2014, Measurement Science for Sustainable Construction and Manufacturing, Volume I. Position Papers, University of Maryland Report to the National Institute of Standards and Technology, Office of Applied Economics, NIST Grant/Contractor Report 15-986-1, Gaithersburg, MD.

Ayyub, B. M., Galloway, G. E., and Wright, R. N. (editors), 2014, Measurement Science for Sustainable Construction and Manufacturing, Volume II. Presentations, University of Maryland Report to the National Institute of Standards and Technology, Office of Applied Economics, NIST Grant/Contractor Report 15-986-2, Gaithersburg, MD. 
[This page is internationally left blank] 


\section{Chapman, Robert, National Institute of Standards and Technology}

\section{Foreword}

An environmentally conscious public is increasingly demanding products that are more sustainable. Manufacturers are seeking to meet the expectations of consumers and the demands of regulators while becoming more environmentally responsible. For consumers, regulators, and manufacturers alike, this requires that credible processes be implemented to accurately measure the environmental impacts of products. As a result, sustainability considerations can drive new materials and technologies for sustainable products, process innovation for sustainable manufacturing, and innovation and creativity in supply and value chain operations. Therefore, progress toward greater sustainability in the built environment and the manufacturing sector is a necessary step to better enable resource efficiency in our nation.

The National Institute of Standards and Technology (NIST) develops unbiased, state-of-the-art measurement science that advances the nation's technology infrastructure and is needed by industry to continually improve products and services. The mission of NIST's Engineering Laboratory is to promote U.S. innovation and industrial competitiveness in areas of critical national priority by anticipating and meeting the measurement science and standards needs for technology-intensive manufacturing, construction, and cyber-physical systems in ways that enhance economic prosperity and improve the quality of life. Sustainability is a recognized critical national priority - one that requires meaningful and rigorous measurement science for establishing suitable performance metrics.

To address this need, NIST launched an effort to develop, organize, and convene an invitational workshop on sustainability to promote the adoption and use of sustainable construction and manufacturing and guide NIST in developing a portfolio of programs that are focused on providing the enabling measurement science to key industry stakeholders. The University of Maryland in collaboration with the American Society of Civil Engineers, the American Society of Mechanical Engineers, the American Institute of Chemical Engineers, and the American Society of Heating, Refrigerating and Air-Conditioning Engineers undertook and performed that effort. The workshop was organized around four cross-cutting themes: (1) measurement science; (2) systems; (3) planning, design, and supply chains; and (4) economic, environmental, and social aspects. Plenary session presentations were commissioned covering each of the four cross-cutting themes. The plenary session presentations set the stage for focused breakout sessions organized around the four cross-cutting themes. Workshop participants were assigned to the breakout sessions in a manner that facilitated discussions among the key stakeholder groups represented at the workshop. The breakout sessions were co-facilitated by each theme's plenary speakers, which provided a firm base from which to develop a snapshot of the current state-of-the-art in that topic area, as well as identify gaps and research opportunities. Change agents were also identified for key stakeholder groups in industry, academia, government, standards development organizations, and hardware and software developers. 
The results of the workshop breakout sessions presented herein provide a path forward for key stakeholders. These results are augmented by short, executive summary papers from workshop participants that lay out the challenges and opportunities associated with the increased use of sustainability-related products and processes in their areas of expertise within the construction and manufacturing industries. Thus, this report provides the elements of a roadmap useful not only for NIST but for other key industry stakeholders on potential opportunities for their sustainability-related research, development, and deployment efforts.

The workshop provided many useful insights for NIST as it moves forward with its portfolio of programs focused on sustainability-related research. Specifically, the four cross-cutting themes resonate with NIST's vision for the future, which is itself evolving around several cross-cutting themes. These include: innovative materials and the new classes of products they enable; additive manufacturing; distributed energy generation associated with net-zero energy, highperformance buildings and their interactions with the electric power grid; and the promise that systems-based sustainability thinking has for increased resilience to natural and man-made disasters.

The material contained in this report will promote an increased awareness of sustainabilityrelated issues - both challenges and opportunities - in the construction and manufacturing industries. The report identifies definitional and methodological disconnects and analyzes them from a systems perspective. The report also identifies barriers to the increased use of sustainability-related products and processes in the construction and manufacturing industries and recommends actions for NIST and others to address these barriers. 


\section{Harary, Howard, National Institute of Standards and Technology}

\section{Preface - Opening Remarks}

Good morning. I'm very pleased to welcome you all to this Workshop on Measurement Science for Sustainable Construction and Manufacturing, jointly hosted by NIST, ASCE, ASME, and the University of Maryland.

At NIST, our mission is to promote U.S. innovation and industrial competitiveness by advancing measurement science, standards, and technology in ways that enhance economic security and improve our quality of life. Since our inception -- in addition to maintaining the more traditional National physical standards -- we have also focused a significant portion of our research and measurement services activities on addressing contemporary societal needs, such as sustainability.

Sustainability is a term that is used frequently these days -- perhaps even over-used. And multiple definitions exist. One of the more frequently quoted definitions -- originating from the Brundtland Report -- focuses on the concept of "meeting the needs of the present without compromising the ability of future generations to meet their own needs." We might all agree that incorporating a concept of sustainability into construction and manufacturing is valuable. If you didn't, you probably wouldn't be here today. But how is this conceptual definition to be operationalized? We contend that a critical, even foundational step, in operationalizing the concept of sustainability requires that we develop meaningful, science-based measurements for characterizing suitable sustainability metrics for lifecycle considerations. Sustainability issues occur at all scales, and in all sectors. It is fundamentally a systems level challenge, in which all consequences, trade-offs, and synergies in economic, environmental, and social domains must be considered.

A little bit of history. The Engineering Laboratory -- and its predecessor organizations -- has conducted sustainability-related research for well over 20 years. One of our better-know products is BEES, that stands for Building for Environmental and Economic Sustainability. BEES enables a science-based evaluation of the environmental performance of building materials and products across 12 environmental attributes. It also includes cost information to promote more cost-effective decision making. We are currently expanding the BEES concept to BIRDS, that stands for Building Industry Reporting and Design for Sustainability, which enables the analysis of whole building characteristics, including the calculation of carbon footprints.

Here at NIST, our research on sustainable manufacturing has two broad thrusts. The first is concerned with developing science-based methodologies for characterizing, analyzing, and assessing the sustainability of individual manufacturing processes. The second focuses on development of a framework that will combine sustainability measurements for individual manufacturing processes into a generic information model with the ability to track the sustainability performance of all of the processes in a manufacturing network. This information model will allow industrial managers to analyze sustainability performance throughout an entire supply chain. 
On another front of the sustainability issue, the NIST Net-Zero Energy Residential Test Facility is being used to demonstrate that a desirable residential house can produce as much energy from renewable energy resources as it consumes on an annual basis. I am pleased to report that as of June 3rd, as we enter the final month of the year-long trial, the NIST Net-Zero Energy

Residential Test Facility had already achieved the net-zero energy goal; it is now a net producer.

Despite our experience and history with sustainability issues, we are not optimally equipped to address the crosscutting nature of sustainability. Moreover, those crosscuts are often the crucial points where progress can be made, and generally involve agencies and organizations at levels other than federal.

The objective of these next two days is to engage all of you in utilizing your combined expertise to critically think about the measurement science needed to guide decisions for sustainability throughout the life cycle of design, construction/manufacturing, operations, and even maintenance of facilities and systems of the built environment and manufactured products. These outcomes will inform NIST, and guide NIST and other key stakeholders, in developing a portfolio of inter-related programs that will ultimately help promote the use of sustainable manufacturing and construction practices. You have all been invited here to participate because we believe you are in a position to make significant contributions to key issues in sustainable construction and manufacturing. We are very pleased to have with us a number of national and international thought leaders and experts from the construction and manufacturing domains, including codes and standards development organizations, industry, and academia.

I would like to thank all of you for taking time away from all of your other responsibilities to be here, and take on the challenge of identifying the critical measurement science gaps in sustainable construction and manufacturing. Many thanks also to our workshop partners at the University of Maryland, ASCE, and ASME for all of the hard work that went into planning and organizing this event. Once again, welcome. I greatly look forward to hearing about the outcomes of your work. 
Ayyub, Bilal M., Galloway, Gerald E., and Wright, Richard N., University of Maryland

\section{About the Workshop on Measurement Science for Sustainable Construction and Manufacturing}

\section{Background}

Achieving long-term suitability poses a linked-systems challenge for policy makers to assess the consequences, trade-offs and synergies in economic, environmental and social domains. A sustainable society can be defined as the one that can thrive over generations; one that is farseeing enough, flexible enough, and wise enough not to undermine its economic, environmental and social systems of support. A major need for achieving sustainable construction and manufacturing is to establish meaningful measurements for the complex attributes of sustainability suitable for lifecycle considerations. What one can measure, one can manage. NIST, ASCE, ASME and the University of Maryland are hold this workshop to address this challenge.

\section{Objectives}

The objective of the workshop was to examine the measurement science needed to guide decisions for sustainability throughout the life cycle of design, construction/manufacturing, operations, and maintenance of facilities and systems of the built environment and manufactured products, and to guide NIST and other key stakeholders in developing a portfolio of related programs. The workshop engaged key international and domestic thought leaders and experts from stake-holding disciplines including construction, manufacturing, codes and standards development, economics, government, industry, and academia, and addressed trends and needs relating to sustainable construction and manufacturing. The results from this effort are documented herein in coordination with NIST, ASCE and ASME.

\section{Discussion Topics}

Discussion topics included:

- Measurement science (definition, standards, metrics, indicators and ratings)

- Systems (aggregation, linkages, system of systems, sustainability-resilience synergy and interdependencies)

- Planning, design and supply chain (lifecycle analyses and treatments, and material and energy efficiency), or

- Economic, environmental and social aspects (valuation, impacts and behavior).

\section{Participants}

The workshop was attended by about 77 people. A complete list is provided in Appendix A. 


\section{Agenda}

\begin{tabular}{|c|c|c|c|c|}
\hline \multicolumn{5}{|c|}{ Day 1: June 12, 2014} \\
\hline Time & Topic & Duration & Room & Speakers \\
\hline $8: 00-8: 30$ & Breakfast & & & \\
\hline \multirow{4}{*}{$8: 30-9: 00$} & Welcome and Introduction & \multirow{4}{*}{30} & \multirow{4}{*}{ ASCE } & Darryll Pines, Dean, School of Engineering, Un. Maryland (UMD) \\
\hline & Opening remarks & & & Howard Harary, Acting Director, Engineering Laboratory, NIST \\
\hline & Symposium program & & & $\begin{array}{l}\text { Bilal Ayyub, Director, Center for Technology \& Systems Management, } \\
\text { CEE Professor, UMD }\end{array}$ \\
\hline & Perspectives on sustainability for the Nation & & & $\begin{array}{l}\text { Nabil Nasr, Associate Provost for Academic Affairs \& Director of Golisano } \\
\text { Institute for Sustainability, Rochester Institute of Tech., NY }\end{array}$ \\
\hline 9:00-9:25 & Sustainable manufacturing & $20+5$ & ASCE & $\begin{array}{l}\text { William Flanagan, Director, Ecoassessment Center of Excellence, GE } \\
\text { Global Research, General Electric Company }\end{array}$ \\
\hline 9:25-9:50 & Sustainable construction & $20+5$ & ASCE & Nancy Kralik, Fluor and Construction Industry Institute \\
\hline 9:50-10:00 & Break & 10 & & \\
\hline $10: 00-10: 20$ & Sustainability metrics-measurement science & $17+3$ & ASCE & $\begin{array}{l}\text { Subhas Sikdar, Associate Director for Science, National Risk Management } \\
\text { Research Lab, EPA, and AIChE }\end{array}$ \\
\hline $10: 20-10: 40$ & System sustainability: aggregation \& linkages & $17+3$ & ASCE & Joseph Fiksel, Director, Center for Resilience at The Ohio State Un. \\
\hline $10: 40-11: 00$ & Planning, design and supply chain & $17+3$ & ASCE & Gül Kremer, Professor, Industrial \& Manufacturing Eng., Penn State \\
\hline 11:00-11:20 & Economic, environmental and social aspects & $17+3$ & ASCE & $\begin{array}{l}\text { Cliff Davidson, Director, Center for Sustainable Engineering, Thomas and } \\
\text { Colleen Wilmot CEE Professor, Syracuse University }\end{array}$ \\
\hline $11: 20-12: 40$ & Quantified Urban Community at Hudson Yards & $17+3$ & ASCE & Constantine E. Kontokosta, NYU Polytechnic School of Engineering \\
\hline $11: 40-12: 00$ & $\begin{array}{l}\text { Population and Carrying Capacity: Metrics for } \\
\text { Sustainability }\end{array}$ & $17+3$ & ASCE & $\begin{array}{l}\text { Eugenia Kalnay, NAE, Distinguished University of Maryland Professor of } \\
\text { Atmospheric and Oceanic Science }\end{array}$ \\
\hline $12: 00-1: 00$ & Hosted Lunch (sandwiches) & 60 & & \\
\hline \multirow{7}{*}{$1: 00-2: 48$} & $\begin{array}{l}\text { Perspectives on sustainable construction and } \\
\text { manufacturing }\end{array}$ & 108 & ASCE & $\begin{array}{l}\text { Gerald Galloway (Moderator), NAE, Glenn L. Martin Institute Professor } \\
\text { of Engineering, UMD }\end{array}$ \\
\hline & Implementation and challenges for metrics & $15+3$ & ASCE & David Dise, Director of General Services, MD Montgomery County \\
\hline & A Case study on the role of metrics & $15+3$ & ASCE & Fulya Kocak, Clark Construction Group, Bethesda, MD \\
\hline & Perspectives of a federal agency on metrics & $15+3$ & ASCE & $\begin{array}{l}\text { Joe Cresko, Lead internal analysis and strategic planning, Advanced } \\
\text { Manufacturing Office, DOE }\end{array}$ \\
\hline & Metrics for sustainable products and process & $15+3$ & ASCE & $\begin{array}{l}\text { I. S. Jawahir, Director, Institute for Sustainable Manufacturing } \\
\text { James F. Hardymon Chair, University of Kentucky }\end{array}$ \\
\hline & Perspectives of owner and builder on metrics & $15+3$ & ASCE & $\begin{array}{l}\text { James Dalton, Chief, Engineering and Construction, Directorate of Civil } \\
\text { Works, USACE }\end{array}$ \\
\hline & International perspectives on metrics & $15+3$ & ASCE & $\begin{array}{l}\text { Bohumil Kasal, Director of Fraunhofer Institute at Braunsweig, Germany } \\
\text { and Professor at the Technical University of Braunschweig }\end{array}$ \\
\hline 2:48-3:00 & Break & 12 & & \\
\hline $3: 00-4: 00$ & Panel 1 - Perspectives from users & 60 & ASCE & $\begin{array}{l}\text { Richard Wright (Moderator, Research Professor, UMD), Michele Russo } \\
\text { (McGraw Hill/ENR), Chris Pyke (US Green Building Council), William } \\
\text { Bertera (Instit. for Sustain. Infrastructure), William Flanagan (General } \\
\text { Electric Company) }\end{array}$ \\
\hline 4:00-5:00 & Panel 2 - Perspectives from researchers & 60 & ASCE & $\begin{array}{l}\text { Jelena Srebric (Moderator, Professor, UMD), Nabil Nasr (Rochester } \\
\text { Institute of Tech), Damon Fordham (TRB), Andrew Persily (NIST), Subhas } \\
\text { Sikdar (AIChE/ EPA) }\end{array}$ \\
\hline $5: 00-5: 15$ & Second day breakout sessions & 10 & ASCE & Richard Wright, NAE, Research Professor, UMD (NIST retired) \\
\hline $6: 00-8: 30$ & Hosted Dinner (participants seated per breakouts) & 150 & Ballroom A & Joannie Chin, Acting Deputy Director, Engineering Laboratory, NIST \\
\hline
\end{tabular}

\section{Day 2: June 13, 2014}

\begin{tabular}{|c|c|c|c|c|}
\hline Time & Topic & Duration & Room & Speakers \\
\hline $8: 00-8: 30$ & Breakfast & & & \\
\hline $8: 30-8: 45$ & Getting oriented and allocated to breakout sessions & 15 & ASCE & Gerald Galloway, UMD \\
\hline $8: 45-9: 45$ & Breakout 1: Measurement science & 60 & $\mathrm{CH} 2 \mathrm{MHill}$ & Co-moderators: I. S. Jawahir and Subhas Sikdar \\
\hline $8: 45-9: 45$ & Breakout 2: Systems & 60 & Harris & Co-moderators: Joseph Fiksel \& John Carberry (affiliation, invited) \\
\hline $8: 45-9: 45$ & Breakout 3: Planning, design and supply chain & 60 & President & $\begin{array}{l}\text { Co-moderators: Nabil Nasr (Rochester Instit. of Tech) and Fazleena } \\
\text { Badurdeen (U. Kentucky) }\end{array}$ \\
\hline $8: 45-9: 45$ & Breakout 4: Economic, environmental and social aspects & 60 & ASCE & Co-moderators: Cliff Davidson and William Flanagan \\
\hline $9: 45-10: 00$ & Break & 15 & & \\
\hline 10:00-11:00 & Breakout 1: Measurement science & 60 & $\mathrm{CH} 2 \mathrm{MHill}$ & Co-moderators: I. S. Jawahir and Subhas Sikdar \\
\hline 10:00-11:00 & Breakout 2: Systems & 60 & Harris & Co-moderators: Joseph Fiksel \& John Carberry (affiliation, invited) \\
\hline 10:00-11:00 & Breakout 3: Planning, design and supply chain & 60 & President & $\begin{array}{l}\text { Co-moderators: Nabil Nasr (Rochester Instit. of Tech) and Fazleena } \\
\text { Badurdeen (U. Kentucky) }\end{array}$ \\
\hline 10:00-11:00 & Breakout 4: Economic, environmental and social aspects & 60 & ASCE & Co-moderators: Cliff Davidson and William Flanagan \\
\hline $11: 00-11: 15$ & Break to regroup & 15 & & \\
\hline $11: 15-12: 15$ & Summaries of breakouts $1,2,3$ and 4 & 60 & ASCE & By Co-moderators, report requirements (facilitor Richard Wright, UMD) \\
\hline $12: 15-12: 30$ & Expected products and adjournment & 15 & ASCE & Bilal Ayyub, UMD \\
\hline
\end{tabular}




\section{Disclaimer and Limitations}

This report was prepared for the National Institute of Standards and Technology (hereafter referred to as NIST) as the primary sponsor, and the American Society of Civil Engineers (hereafter referred to as ASCE), the American Society of Mechanical Engineers (hereafter referred to as ASME), the American Institute of Chemical Engineers (hereafter referred to as AIChE) and the American Society of Heating, Refrigerating and Air Conditioning Engineers (hereafter referred to as ASHRAE) by the Center for Technology and Systems Management of the University of Maryland and its associates and subcontractors (hereafter referred to as the UMD). Although this product was prepared using the best available resources, NIST, ASCE, ASME, AIChE and UMD do not make any warranty, expressed or implied, or assume any legal liability or responsibility for the accuracy, completeness, or usefulness of any information, apparatus, product or process disclosed, or represent that its uses would not infringe on privately owned rights. Reference herein to any specific commercial product, process, or service by trade name, trademark, manufacturer, or otherwise does not necessarily constitute or imply its endorsement, recommendation, or favoring by NIST, ASCE, ASME, AIChE, ASHRAE and UMD. Opinions expressed in this report are personal opinions of the participants and do not reflect the opinions of the respective employers of the participants. 
[This page is internationally left blank] 


\section{Table of Contents}

[Papers are provided in alphabetical order of last name of first author.]

Organizing Committee

Sponsors V

Recommended Citations . $\mathrm{V}$ .. V

Chapman, Robert, National Institute of Standards and Technology ....................................... vii

Foreword vii

Harary, Howard, National Institute of Standards and Technology ......................................... ix

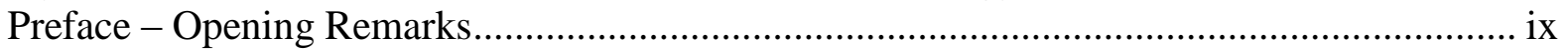

Ayyub, Bilal M., Galloway, Gerald E., and Wright, Richard N., University of Maryland .......... xi

About the Workshop on Measurement Science for Sustainable Construction and

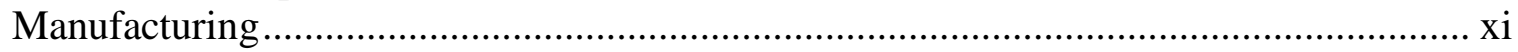

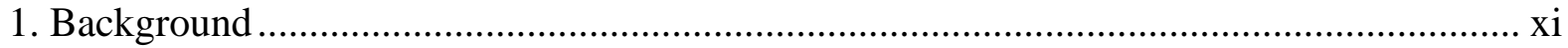

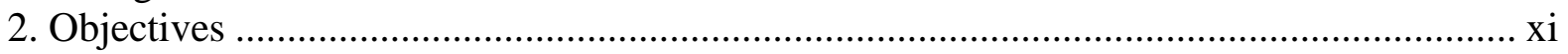

3. Discussion Topics ................................................................................................. xi

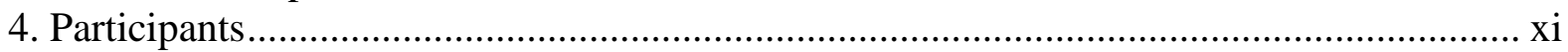

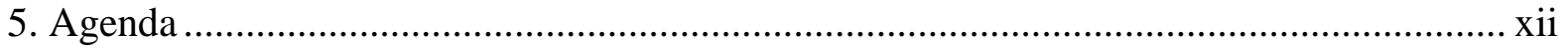

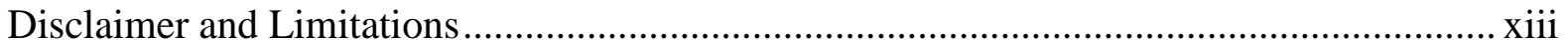

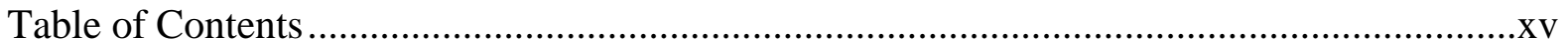

Ayyub, Bilal M., University of Maryland, College Park .........................................................1

Value Systems and Information Necessary for Sustainable Construction and

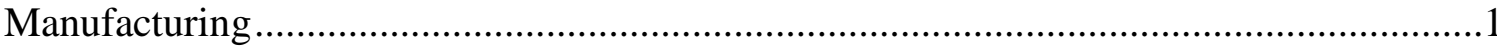

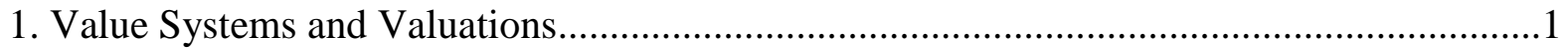

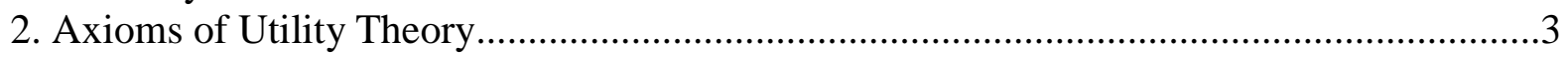

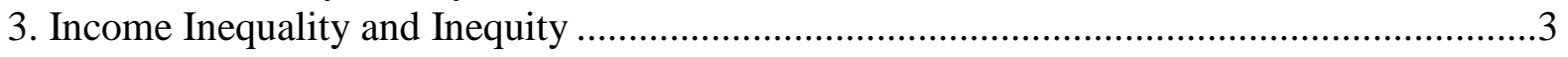

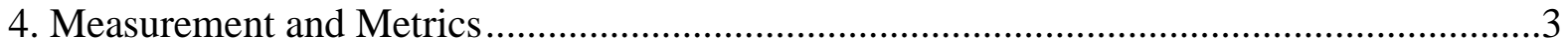

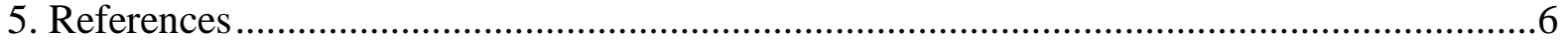

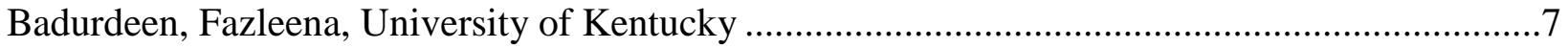

Planning, Design and Management of Supply Chains for Sustainability .............................

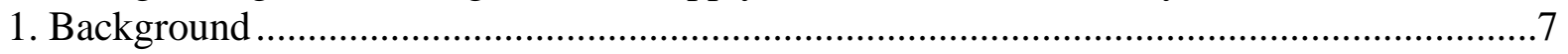

2. Current Practice and Challenge to Sustainable Manufacturing ........................................9

3. Vision for Planning, Design and Management of Sustainable Supply Chains ...................10

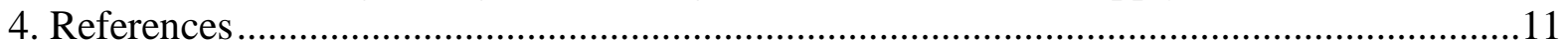

Begley, Loida, National Nuclear Security Administration, DOE..........................................13

Measuring the Benefits of Green Buildings.............................................................. 13

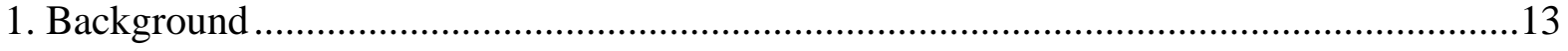


2. Gaps in Measuring Building Certification Systems........................................................14

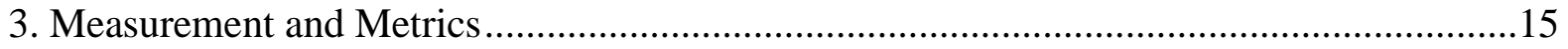

3.1. LEED as a Baseline for Green Building ............................................................ 15

3.2. Federal Guiding Principles as a Baseline for Green Building ................................... 15

3.3. Traditional Green Building Benefits .................................................................... 16

3.4. Potential Green Building Benefits ……………….............................................. 16

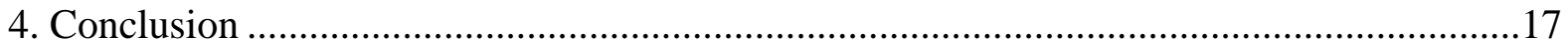

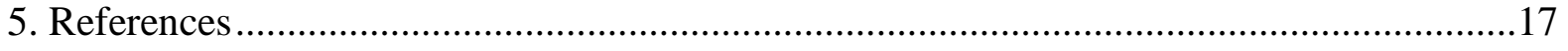

Bertera, William J., Institute for Sustainable Infrastructure …………………………................19

Sustainability and How We Value It ............................................................................19

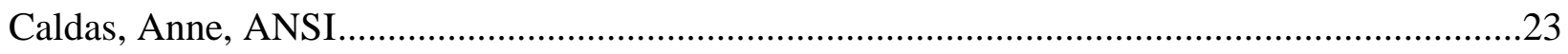

ANSI's Role in the U.S. Standards and Conformity Assessment Infrastructure.....................23

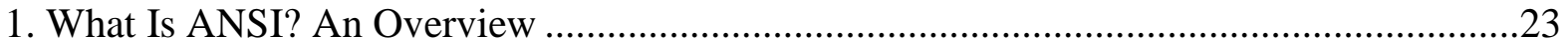

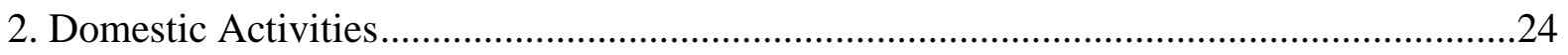

3. International Engagement: ISO, IEC, and Other Standardization Organizations .................24

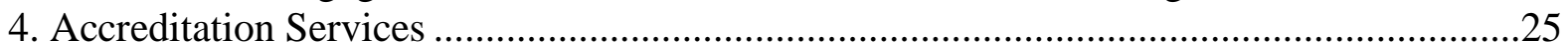

5. Conformity Assessment Activities ..............................................................................25

6. Sample Standards and Conformance Activities: Sustainable Construction and

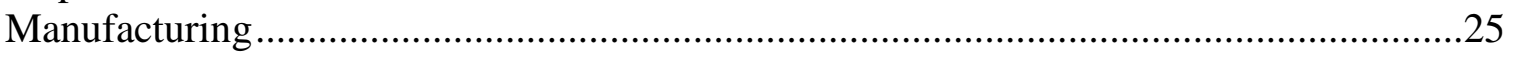

7. Education and Training: Standards and Conformity Assessment.......................................27

8. Why are standards and conformance so important? ............................................................2

Carberry, John, Carberry EnviroTech - (Retired) DuPont Director of Environmental Technology29

Metrics and Systems Issues When Analyzing Chlorine Use ...............................................29

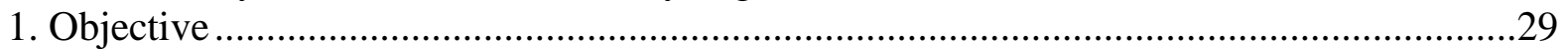

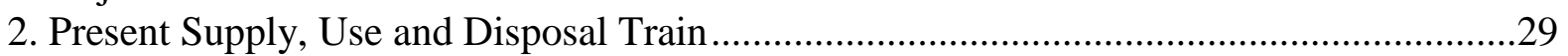

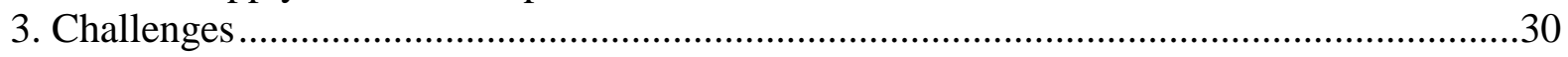

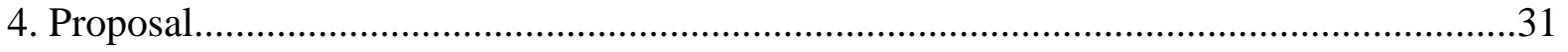

Castro-Lacouture, Daniel, Georgia Institute of Technology ...........................................................33

Resource Management and Closed-Loop Systems: Advancing Sustainable

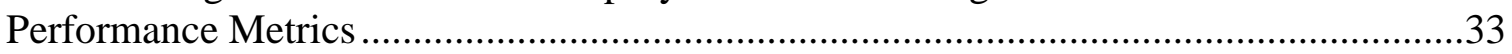

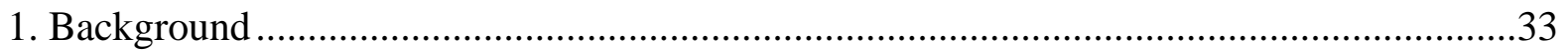

2. Closed-Loop Systems and Resource Management............................................................34

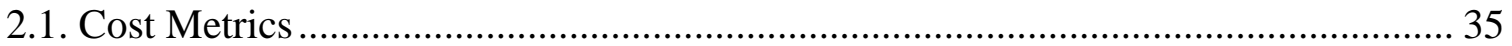

2.2. Life-Cycle Assessment Metrics ………………………....................................... 36

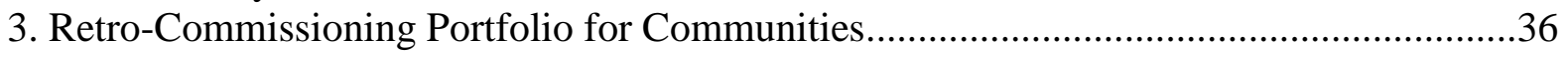

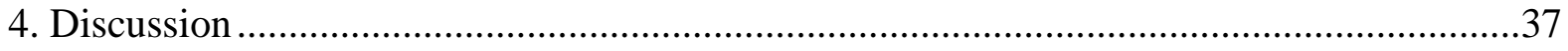

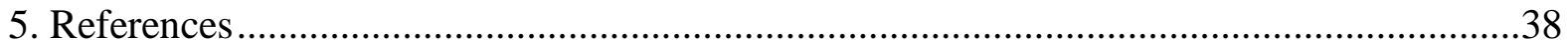

Chapman, Robert, Joannie Chin, Sudarsan Rachuri, Joshua Kneifel, Andrew Persily, and Anthony Hamins, Engineering Laboratory, National Institute of Standards and Technology 39 Measurement Science for Sustainable Construction and Manufacturing: A NIST

Perspective 39

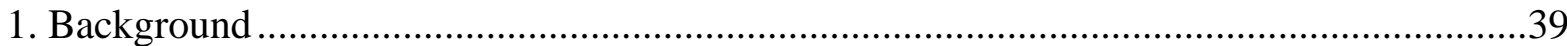




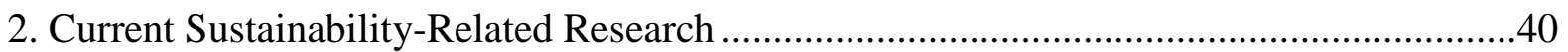

2.1. The Business Case for Sustainability..................................................................... 40

2.2. Service Life Prediction .......................................................................................... 41

2.3. Net-Zero Energy, High-Performance Buildings ........................................................ 41

2.4. Manufacturing Processes and Standards............................................................... 42

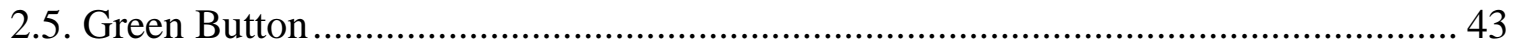

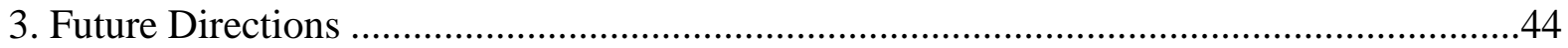

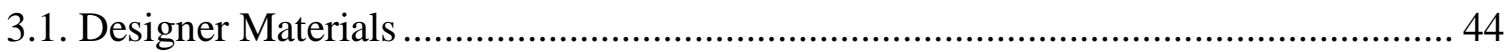

3.2. The Additive Transformation .............................................................................. 44

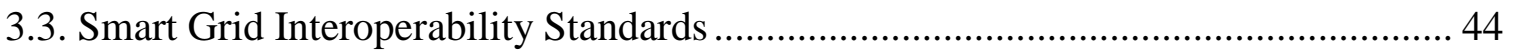

3.4. The Business Case for Sustainability Revisited...................................................... 45

3.5. Interactions between Sustainability and Resilience ...................................................4 45

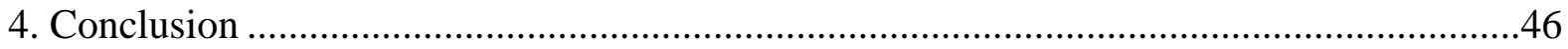

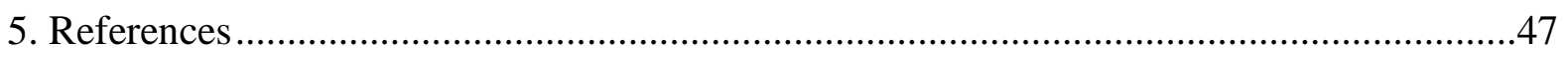

Colker, Ryan M., National Institute of Building Sciences .........................................................49

Achieving High-Performance Buildings: Metrics, Data and Tools .......................................49

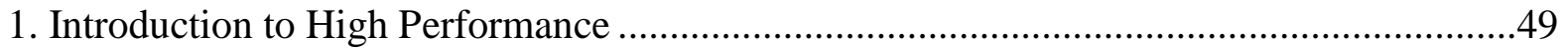

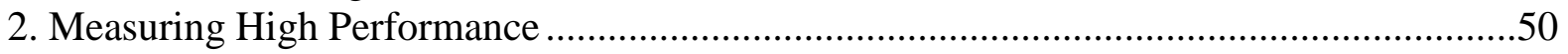

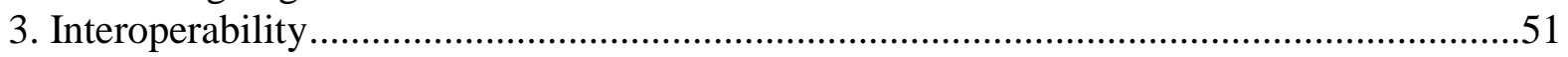

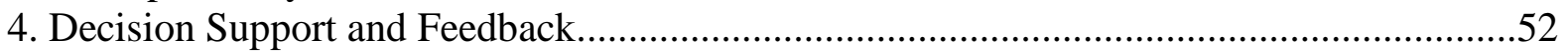

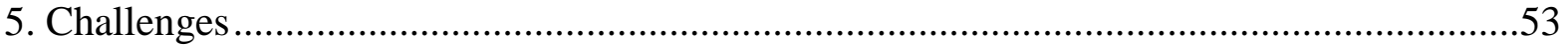

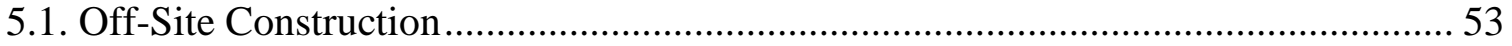

5.2. Energy/Water Nexus ......................................................................................... 53

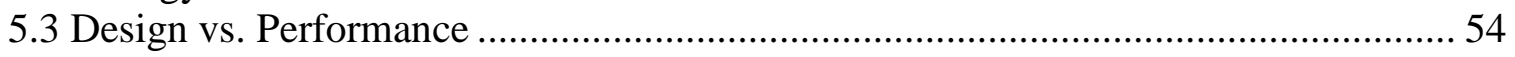

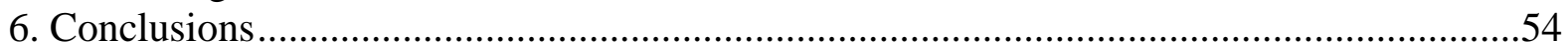

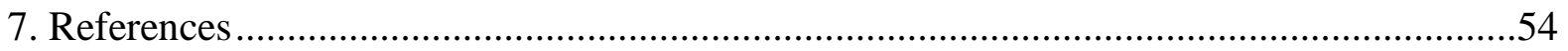

Cross, John, American Institute of Steel Construction LLC …………………….......................57

Life Cycle Assessment Valuation: the Economic Precedent ....................................................57

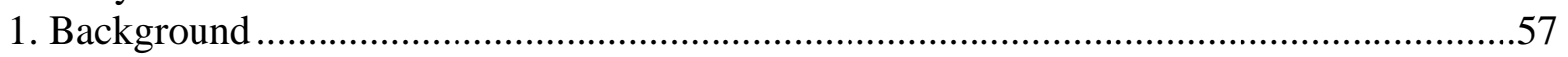

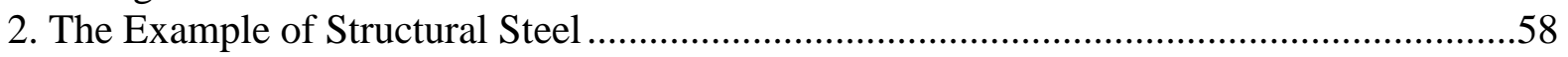

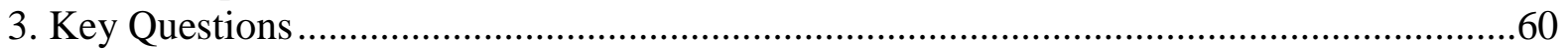

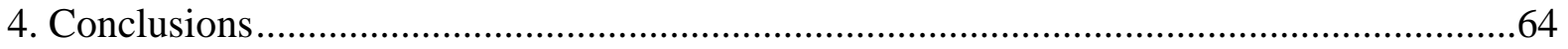

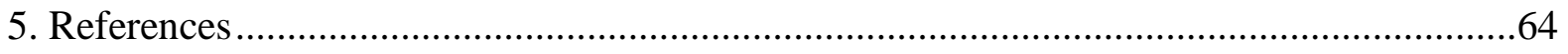

Davidson, Cliff I., Syracuse University, and Shahzeen Z. Attari, Indiana University ..................65

Metrics of Sustainability in Human Development: How Well Do People Understand the Impacts of their Activities? ...............................................................................65

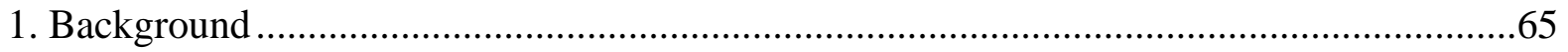

2. Types of Sustainability Metrics ....................................................................................66

3. Metrics Related to Human Understanding .....................................................................67

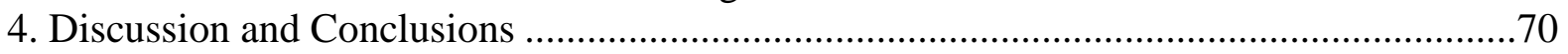

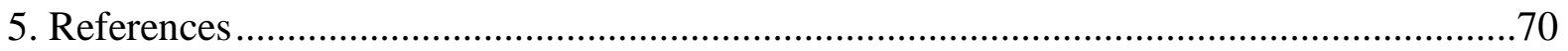

Dise, David E., Rassa Davoodpour, and Eric R. Coffman, Montgomery County, Maryland ........73 
Vegetative Roofs and Rainwater Harvesting Systems on Montgomery County,

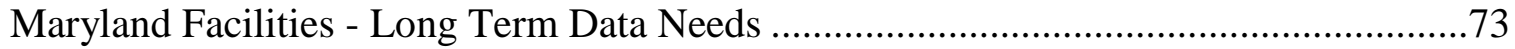

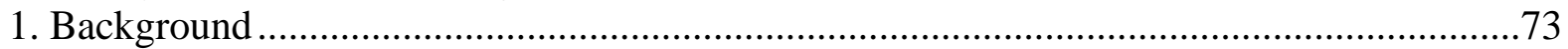

2. Equipment Maintenance and Transportation Operations Center ......................................74

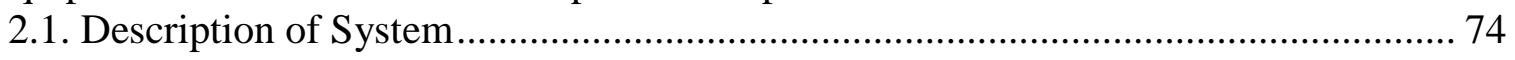

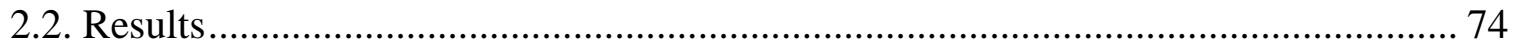

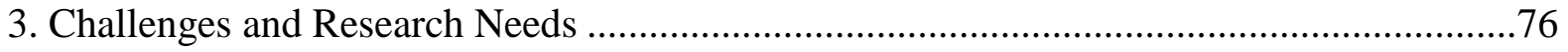

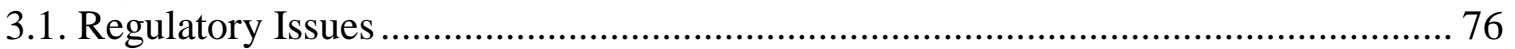

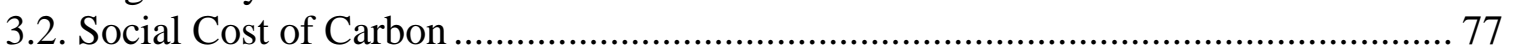

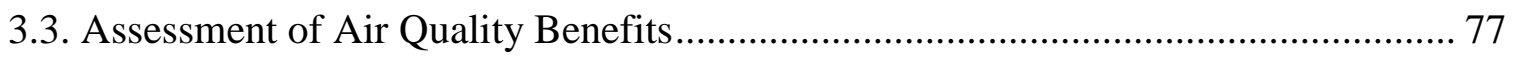

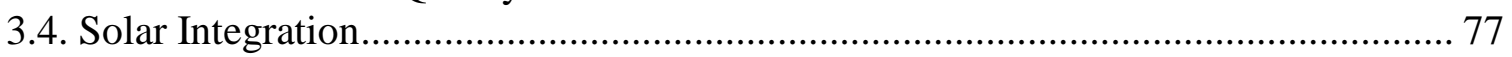

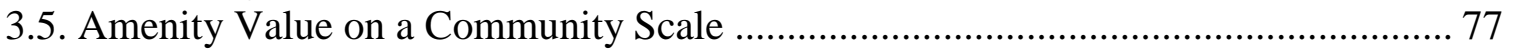

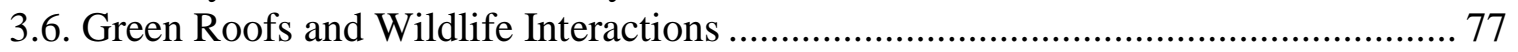

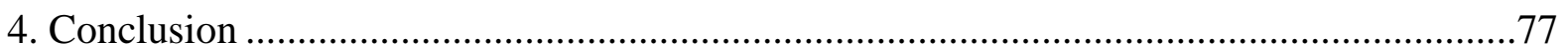

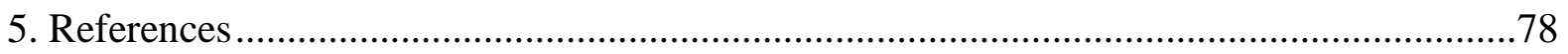

Eckelman, Matthew J., and David Fannon, Northeastern University.....................................79

Information Barriers and Enablers for Sustainable Buildings and Construction...................79

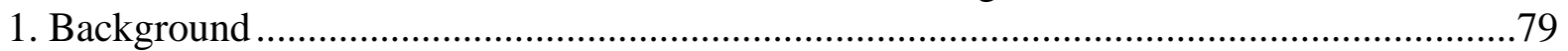

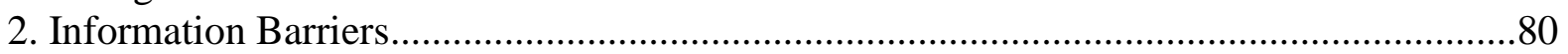

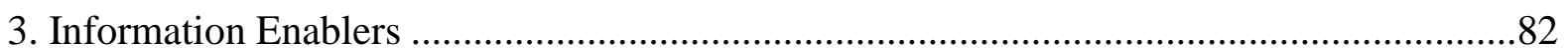

4. What Can the Construction Sector Learn from the Manufacturing Sector?......................83

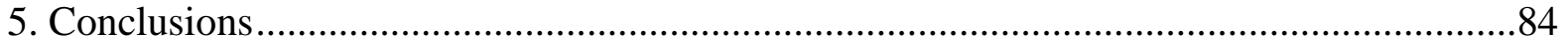

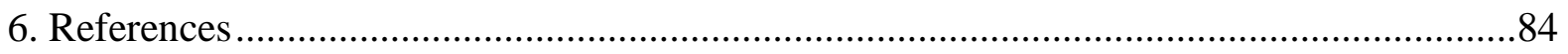

Fiksel, Joseph, The Ohio State University ............................................................................85

A Systems Approach to Sustainability and Resilience Based on the Triple Value

Model of Coupled Human-Natural Systems ................................................................85

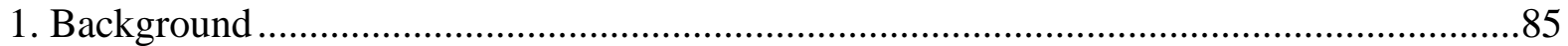

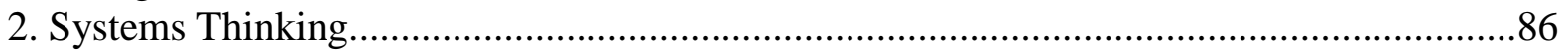

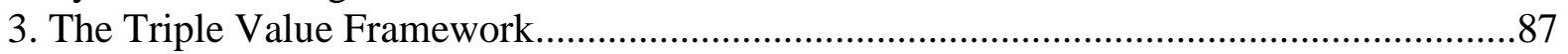

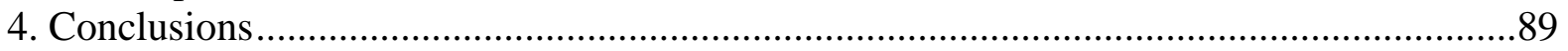

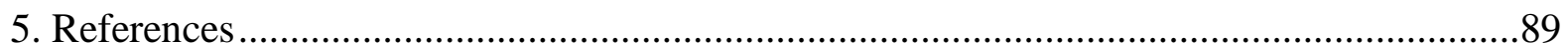

Flanagan, William P., GE Global Research, General Electric Company ...................................91

Sustainable Manufacturing from a Life Cycle Perspective ..............................................91

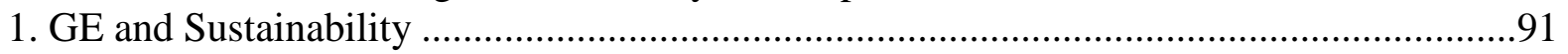

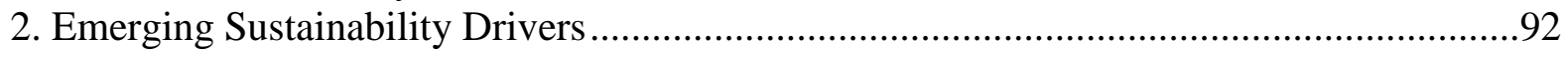

3. Streamlined LCA/LCC in Defense Acquisitions .....................................................93

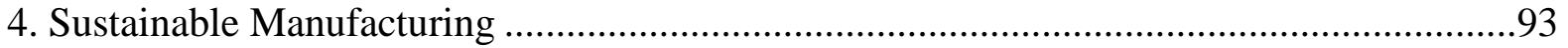

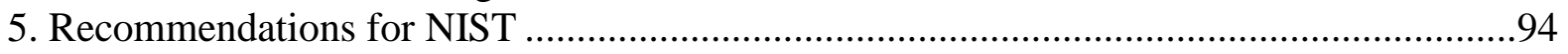

Futornick, Kathi, Mt. Hood Community College, Oregon .....................................................95

Greening the Supply Chain: Direct Influences on Sustainability Reporting and What

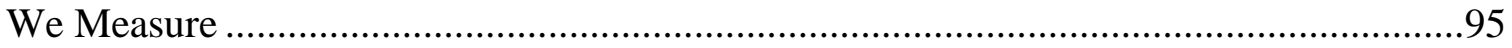

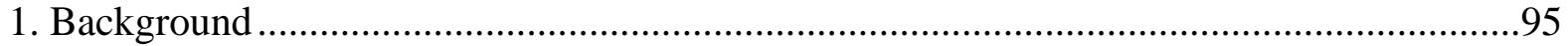

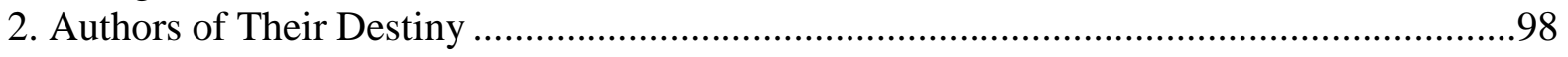




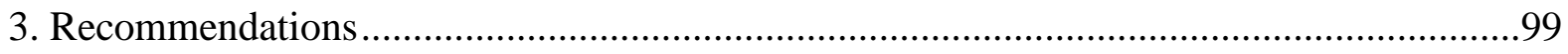

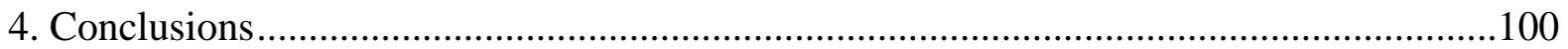

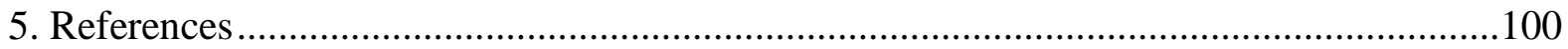

Jawahir, I. S., F. Badurdeen, and K. E. Rouch, University of Kentucky ......................................103

Towards Implementing and Advancing Sustainable Manufacturing: A Metrics-based Evaluation of Product and Process Sustainability .........................................................103

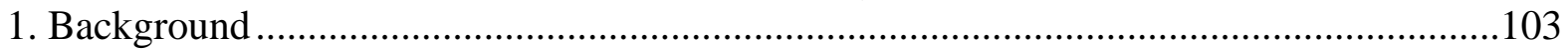

1.1. Sustainability Interactions: Innovation - Manufacturing - Education and Training 103

1.2. Sustainable Manufacturing ……………………….......................................... 104

2. Sustainability Elements at Product and Process Levels.....................................................104

3. A Metrics-based Approach for Evaluating Product and Process Sustainability ................106

4. Implementing Product and Process Sustainability Metrics ………….............................109

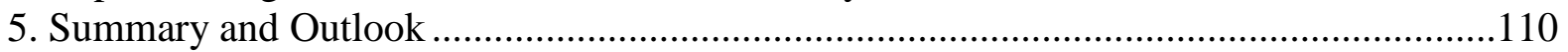

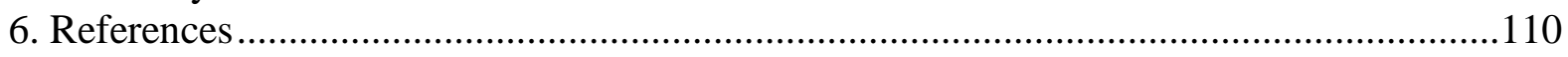

Kasal, Bohumil, Carolo-Wilhelmina University, Braunschweig, Germany ..................................112 International Perspectives on Metrics .........................................................................112

1. Building Instrumentation and Measured Parameters ......................................................113

2. Standards and Codes Related to Sustainability ................................................................114

Kearney, Michael S., University of Maryland ...........................................................................118

Coastal Infrastructure, Storms, and Sea Level Rise: Measuring the Effects ........................118

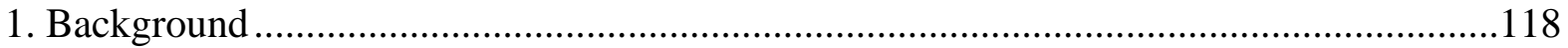

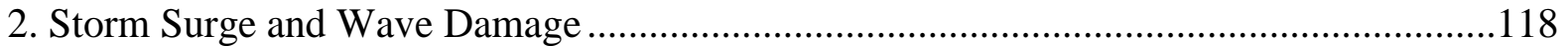

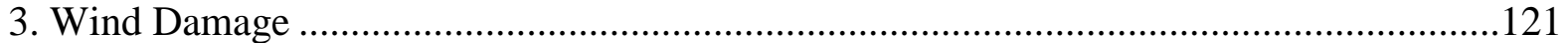

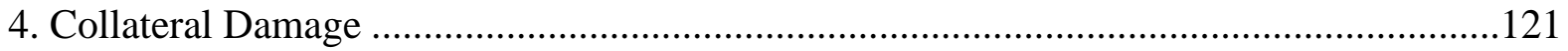

5. Conclusions and Gaps in Knowledge ...........................................................................122

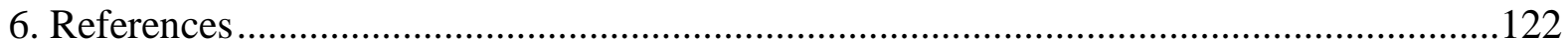

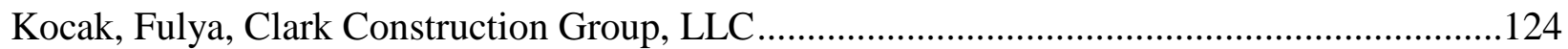

Perspectives for Sustainability in Construction Industry ……...........................................124

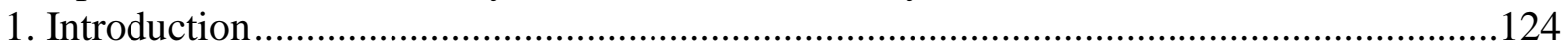

2. What Does Sustainability Mean in Construction? .....................................................124

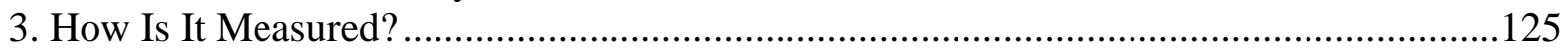

4. Examples Environmental Construction Operations........................................................125

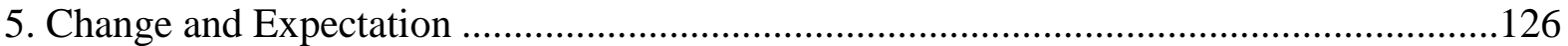

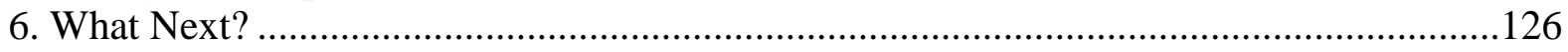

7. Examples of Commitment to Sustainability and Green Buildings ...................................126

8. Beyond Building: Shaping a Green Future ......................................................................126

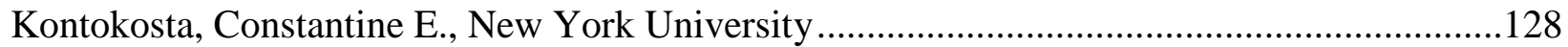

The Urban Quantified Community ................................................................................128

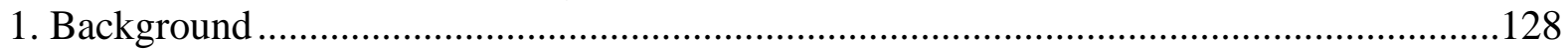

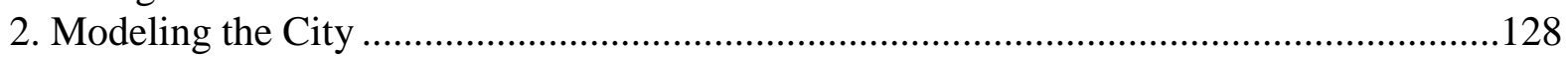

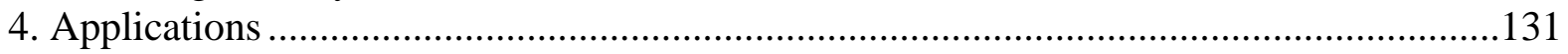

4.1. Quality-of-Life for Urban Residents...................................................................... 131 
4.2. Evidenced-based Urban Planning and Design ......................................................... 132

4.3. Infrastructure Operations and Resource Flows .................................................. 132

4.4. Transportation and Mobility ........................................................................ 132

4.5. Emergency Response and Safety:...................................................................... 132

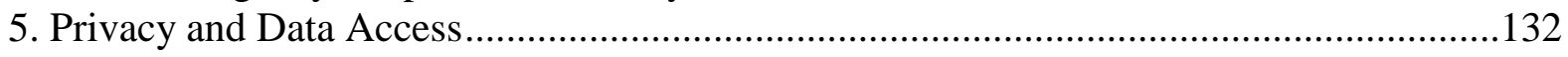

6. Implications and Next Steps ................................................................................133

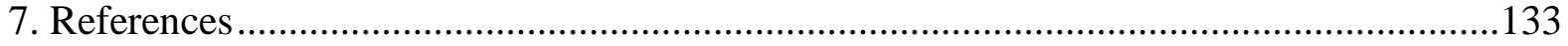

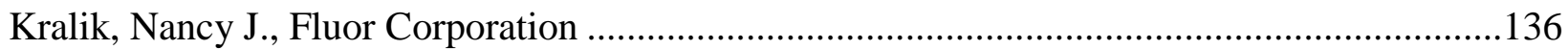

Sustainable Construction: An EPC Perspective............................................................136

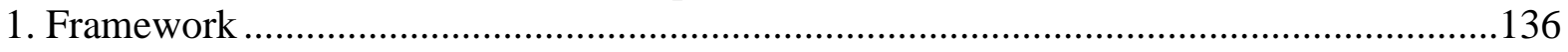

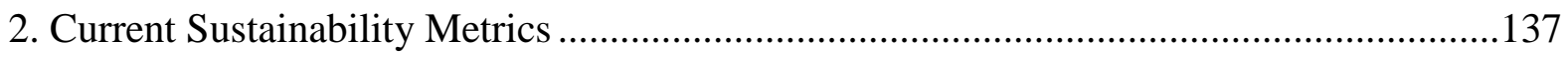

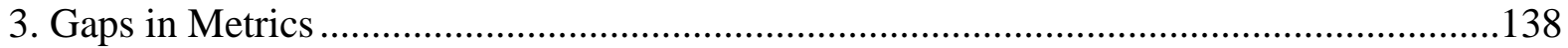

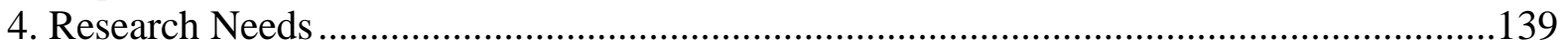

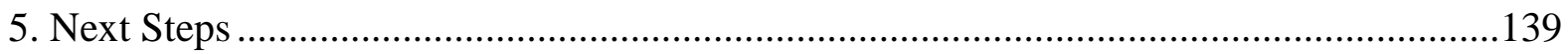

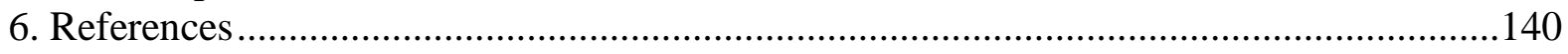

Kremer, Gül E. Okudan, The Pennsylvania State University, Karl Haapala, Oregon State University, and Ratna Chinnam, Leslie Monplaisir, Kyoung-yun Kim, and Alper Murat,

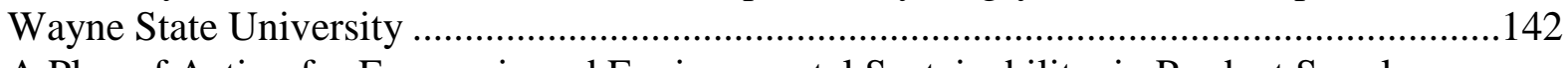

A Plan of Action for Economic and Environmental Sustainability in Product Supply

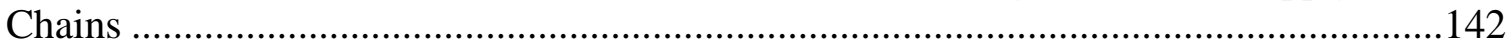

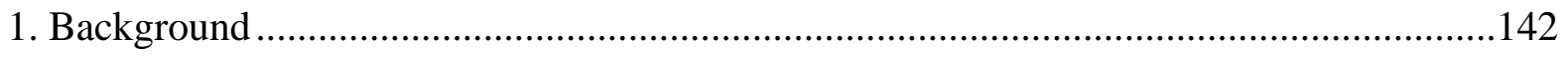

2. Promising Foci for Improving Sustainability in Supply Chains .......................................143

2.1. FOCUS AREA 1: Reengineering the Design to Match the Intended Product End-of-

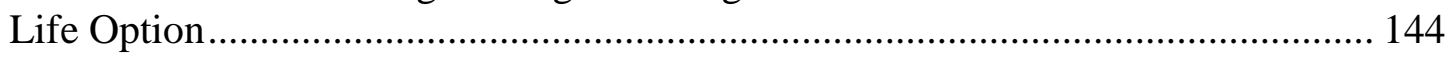

2.2. FOCUS AREA 2: Assembly/Disassembly Operation Modeling and Analysis for Environmental Sustainability ............................................................................... 145

2.3. FOCUS AREA 3: Manufacturing Process Modeling for Sustainability Assessment

2.4. FOCUS AREA 4: Joint Optimization of the Best Subset of Design Variants with Mathematical Models of Life Cycle Processes........................................................... 147

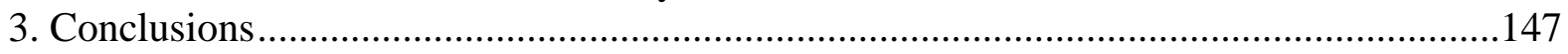

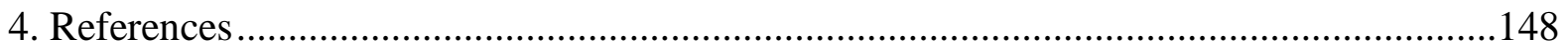

Lambert, James H., and Michelle C. Hamilton, University of Virginia ..........................................152

Emergent and Future Conditions Influencing Risk, Sustainability, and Resilience of

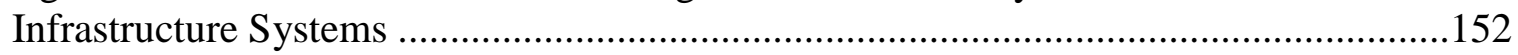

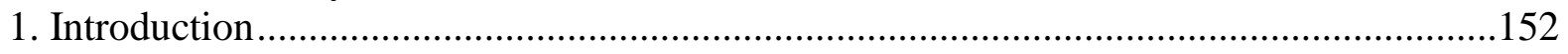

2. Emergent Conditions of Energy Systems Islanding and Electricity Microgrids ...............152

3. Coastal Infrastructure Systems Impacted by Climate and Other Factors ...........................153

4. Mobility, Accessibility, and Sustainability for Transportation Corridors ..........................154

5. Population and Workforce Behaviors and Infrastructure Performance .............................154

6. Land and Economic Development Affecting Infrastructure Systems ...............................155

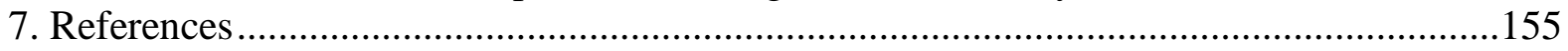

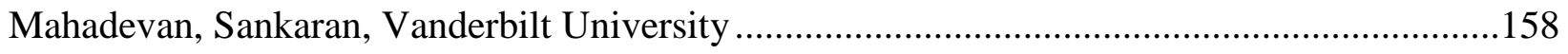


Uncertainty Quantification in Sustainability Assessment.................................................158

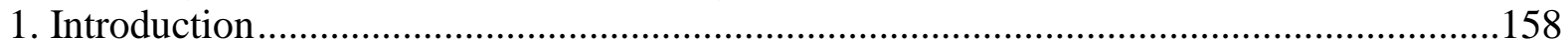

2. Uncertainty Quantification: Current Status …………................................................159

3. Uncertainty Quantification Research Needs ....................................................................160

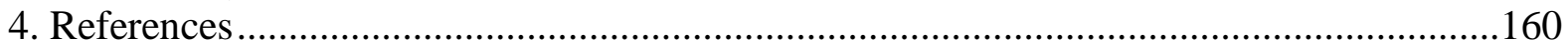

McDowell, Bruce D., Intergovernmental Management Associates, MD ....................................162

Balancing Sustainability's Triple Bottom Line ……….....................................................162

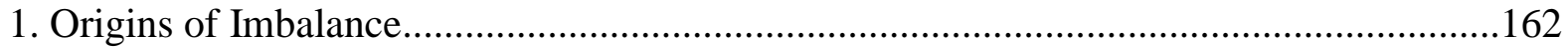

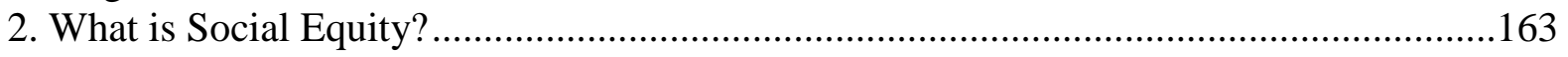

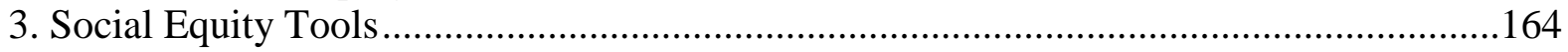

4. Performance Management: Making a Difference ..............................................................164

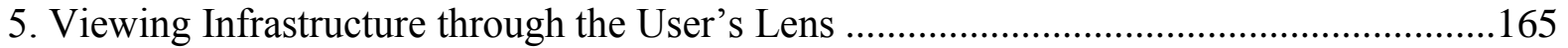

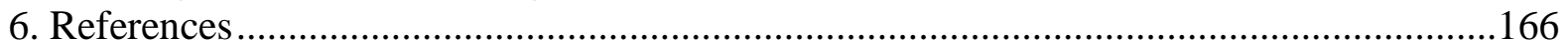

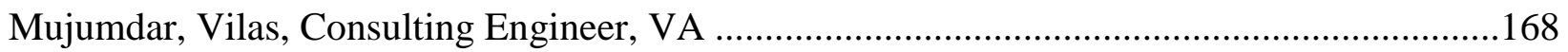

Sustainable Built Environment - Measurement questions .....................................................168

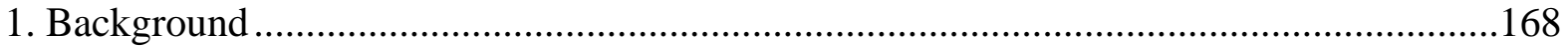

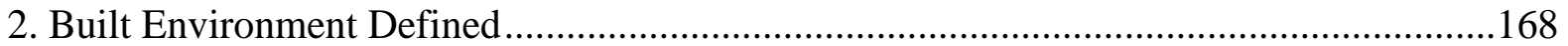

3. Commonalities among Systems …………………...................................................169

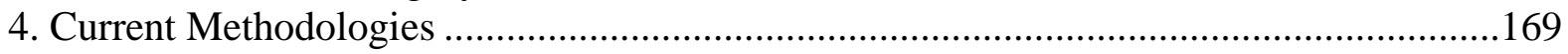

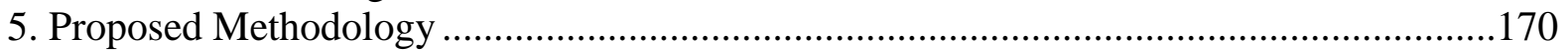

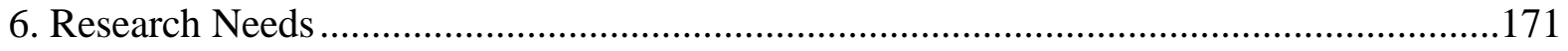

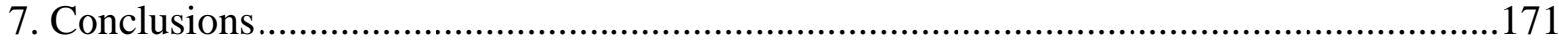

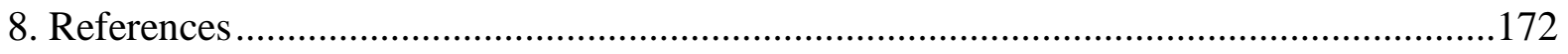

Nasr, Nabil, and Michael Thurston, Rochester Institute of Technology .....................................174

Measurements for Sustainable Manufacturing …………....................................................174

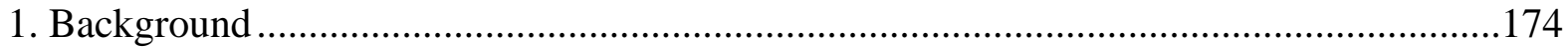

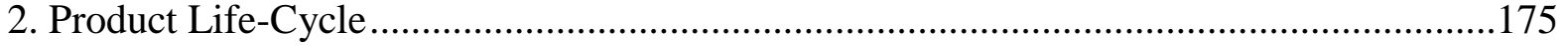

3. Measurement and Analysis of Energy Use and GHG Emissions ......................................176

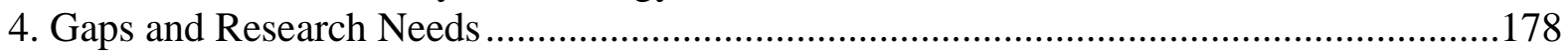

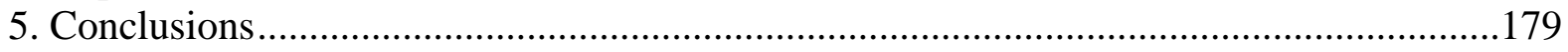

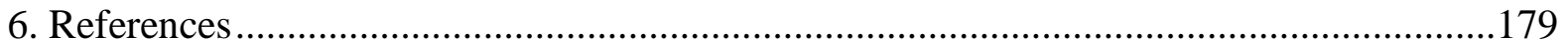

Pyke, Christopher R., and Maija Krizmane, US Green Building Council.....................................182

Challenges and Opportunities Integrating Measures of Energy and Human

Performance for Residential and Commercial Buildings ...............................................182

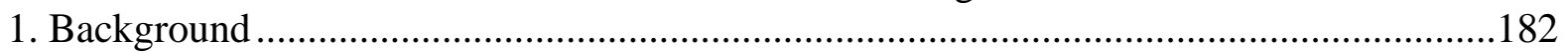

2. Prevailing Performance Metrics ................................................................................183

3. Integrating Human and Environmental Performance ……….........................................186

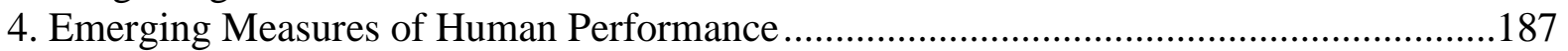

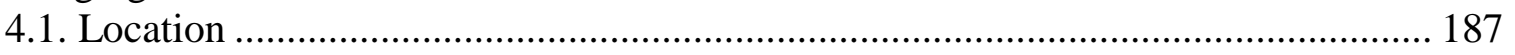

4.2. Experiential Performance................................................................................ 188

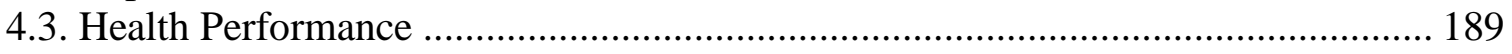

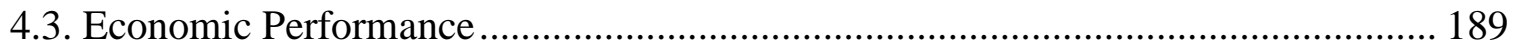

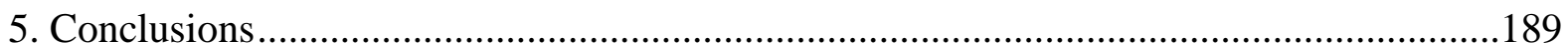




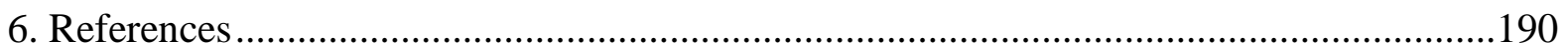

Ratterman, David B., American Institute of Steel Construction..............................................192

Sustainability, Society, and the Law As Applied to the Built Environment.......................192

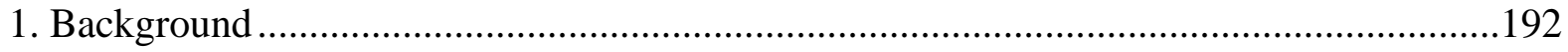

2. The Issue .............................................................................................................. 193

3. Questions Concerning Current Sustainability Codes, Standards, Contract Terms, and Certification Agencies Operating in the Built Environment.........................................195

4. Assessment of Societal and Economic Values and Research Needs ..............................196

Renschler, Chris S., The State University of New York, Buffalo .............................................198

The PEOPLES Resilience Framework: Integrating Quantitative Measures and Modeling for Disaster Risk Reduction and Sustainable Development...........................198

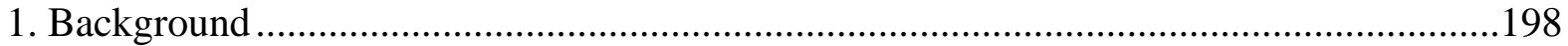

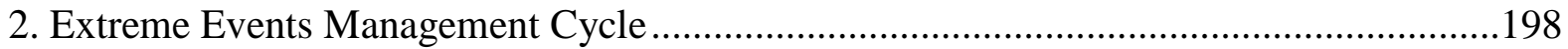

3. Proposed Methodology: The PEOPLES Resilience Framework ......................................199

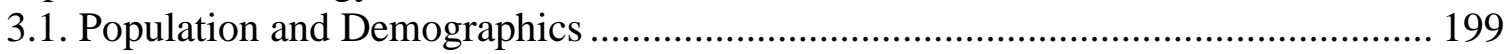

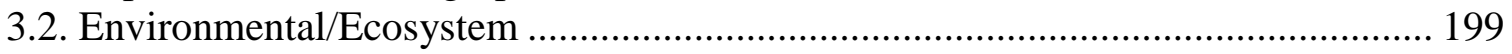

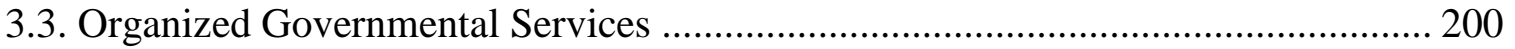

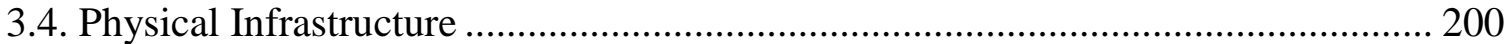

3.5. Lifestyle and Community Competence ........................................................ 200

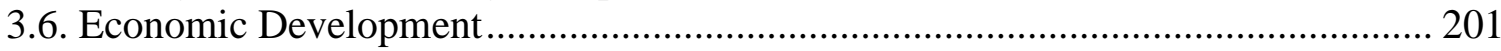

3.7. Social-Cultural Capital................................................................................... 201

4. Measuring Policy Impacts on Systems: Infiltration \& Wetlands vs. Harvest \& Floods....201

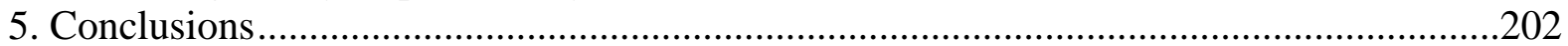

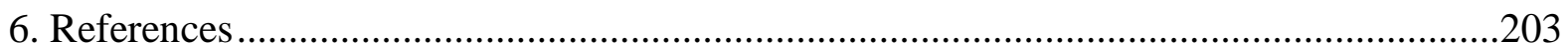

Sikdar, Subhas K., National Risk Management Research Laboratory, US EPA, and Humberto S.

Brandi, Instituto Nacional de Metrologia, Qualidade e Tecnologia, INMETRO, Xerém -

Duque de Caxias - RJ, Brazil .........................................................................................204

How to Quantify Sustainability Advancement in Construction and Manufacturing and

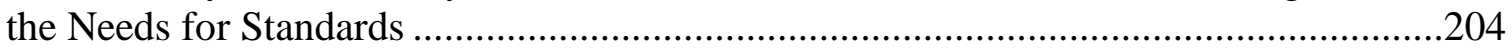

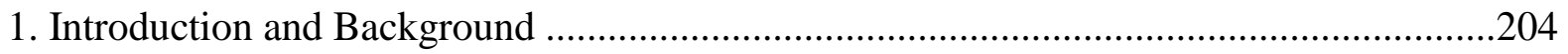

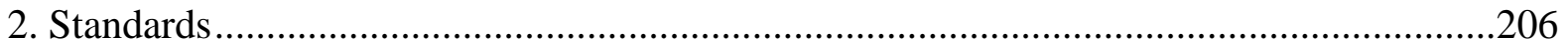

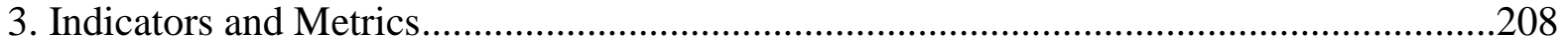

4. Sustainability Analysis.........................................................................................209

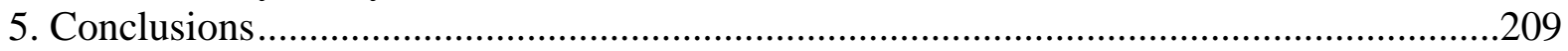

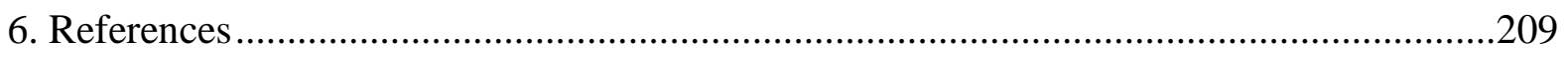

Srebric, Jelena, and Mohammad Heidarinejad, University of Maryland .................................212

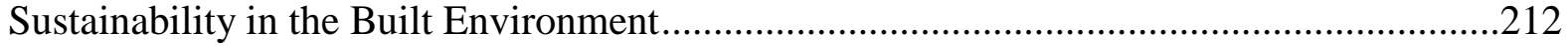

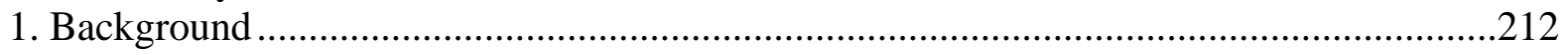

2. Quantitative vs. Quantitative Criteria .........................................................................213

3. GB Rating Systems for the Built Environment..........................................................213

4. Opportunities to Facilitate the Building Design at the Built Environment Scale .............214

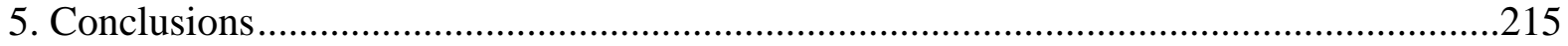

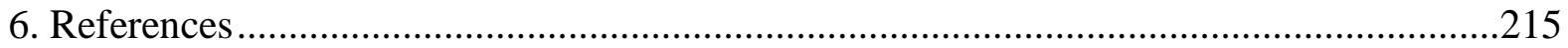


Stumpf, Annette L., Franklin H. Holcomb, Ilker Adiguzel, and James C. Dalton, U.S. Army

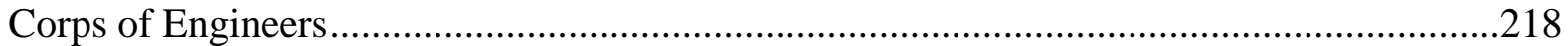

Measuring High Performance Army Facility Construction and Renovation........................218

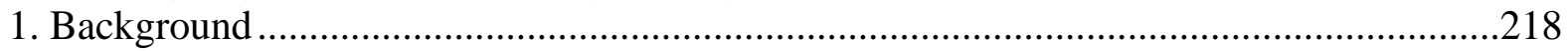

2. Holistic Life-Cycle Approach to Facility Management................................................219

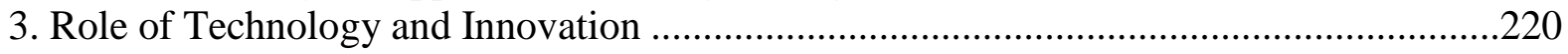

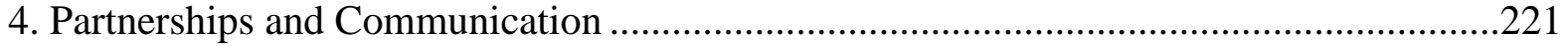

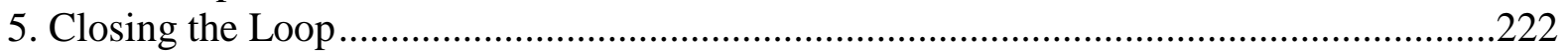

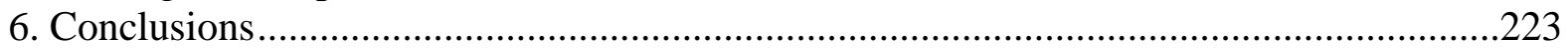

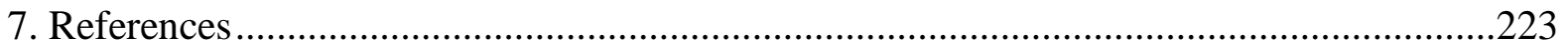

Tatari, Omer, Murat Kucukvar, and Nuri C. Onat, University of Central Florida ....................226

Towards a Triple Bottom Line Life Cycle Sustainability Assessment of Buildings ............226

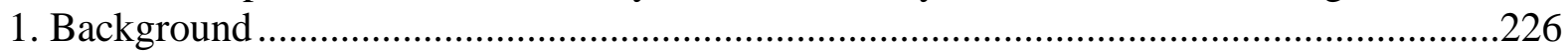

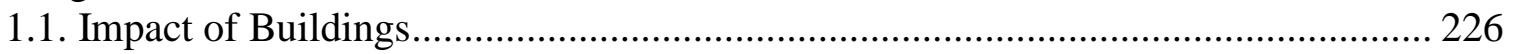

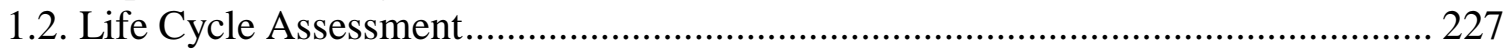

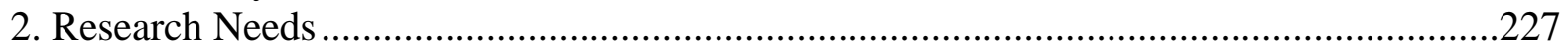

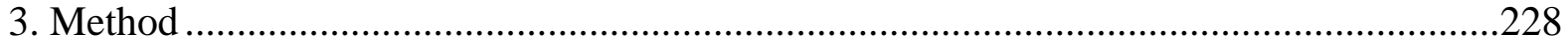

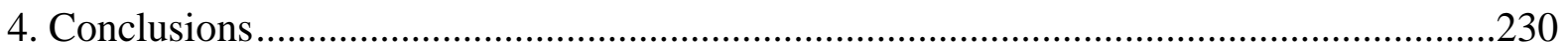

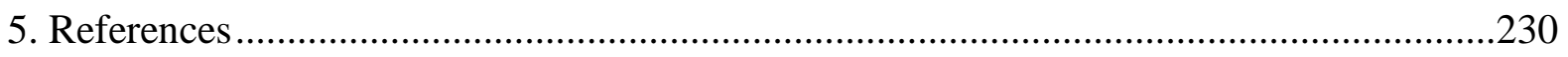

Tinkleman, Michael, Point of Contact, ASME .....................................................................2.232

ASME Sustainable Products \& Processes Strategic Plan, February 2011 ..........................232

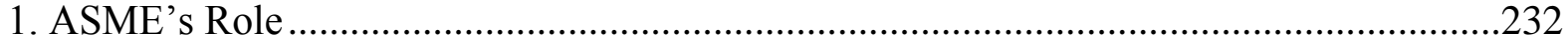

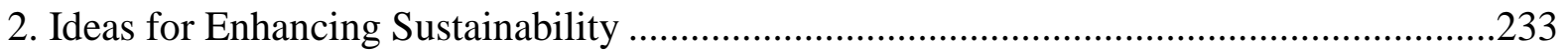

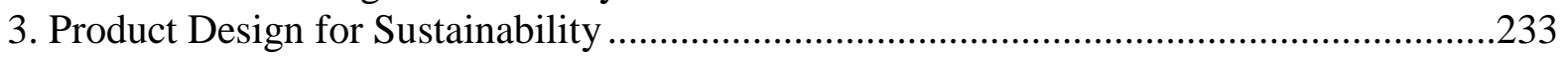

4. Sustainable Manufacturing Processes .......................................................................235

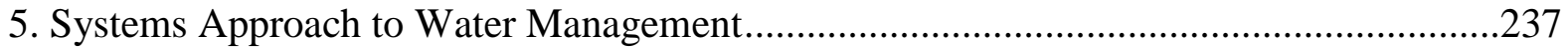

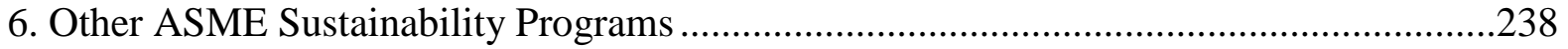

Uddin, Nasim, University of Alabama at Birmingham and Craig Taylor, Imagecat, Inc. .........240

Advances in Measurement Science to Enhance the Resilience of Infrastructure to

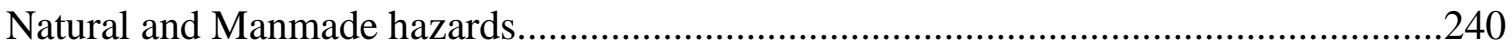

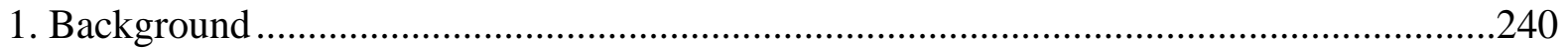

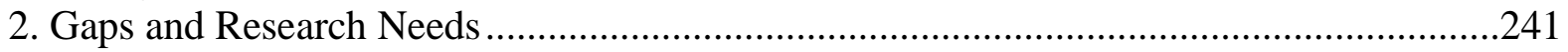

2.1. Improvement in Performance Prediction of Infrastructure .................................. 241

2.2. Developing Risk Consistent Design Approach for Innovative Hazard Resistant

Structures and Ensuring Infrastructure Performance under all Weather Conditions 242

2.3. Developing Risk Consistent Design Approach for Multiperil............................... 244

2.4. Robust Simulation as Assessment Tools to Predict Consequences of Disasters,

Leading in Turn to Increased Resilience ...................................................... 245

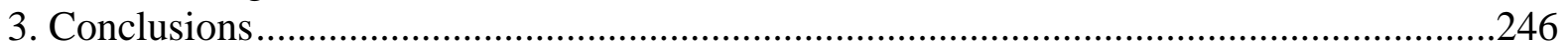

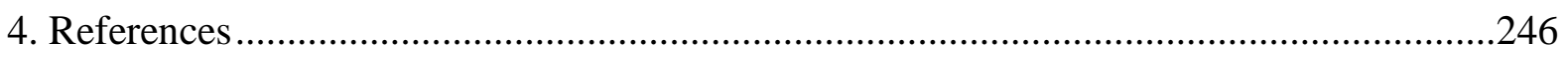

Wallace, William A., Founder and President, Wallace Futures Group, LLC...........................248

Research Needs for Sustainable Infrastructure Engineering for a New Harsh and

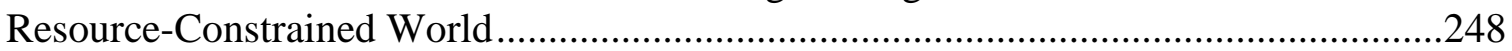




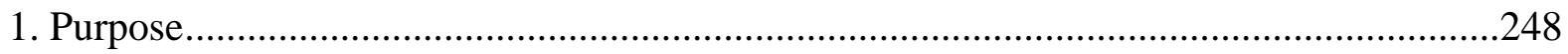

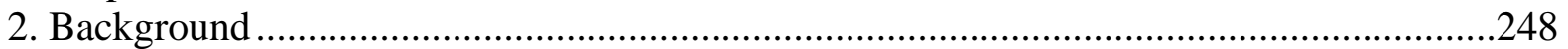

3. Three Challenges to Solve Simultaneously …………..................................................249

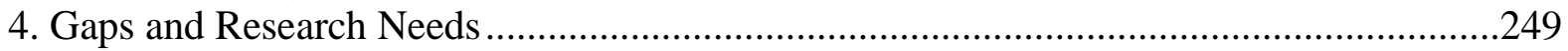

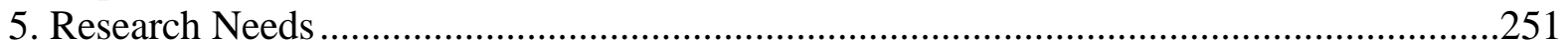

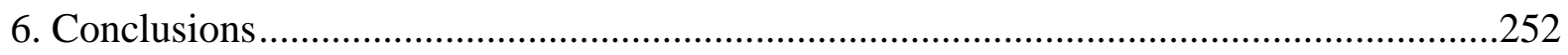

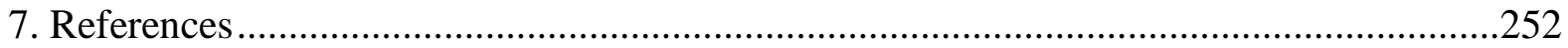

Wang, Zhichao, Shapour Azarm, and P. K. Kannan, University of Maryland............................254

Design for Supply Chain and Interoperability in Profit-Sustainable Market Systems .........254

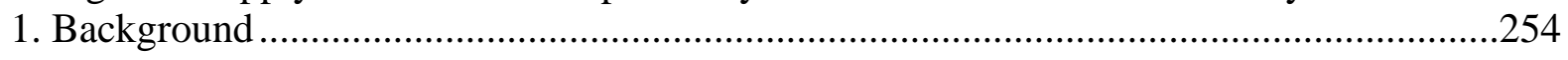

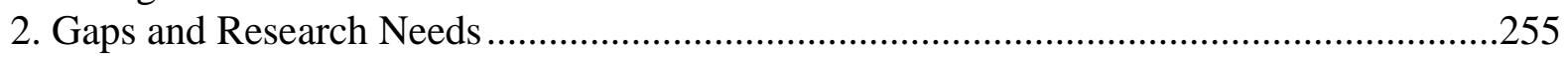

3. Design for Supply Chain and Interoperability Considerations .........................................256

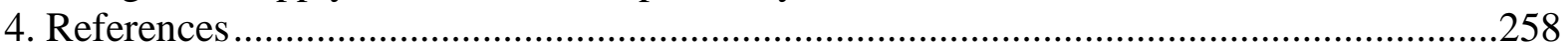

Wei, Hsi-Hsien, and Miroslaw J. Skibniewski, University of Maryland ......................................261

Catastrophe Modeling for Assessing Sustainability of Hazard Mitigation ............................261

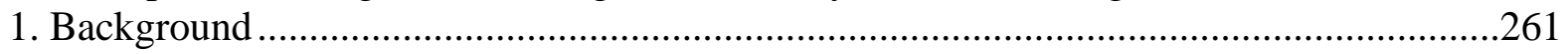

1.1. The Triple Bottom Lines of Sustainability ........................................................... 261

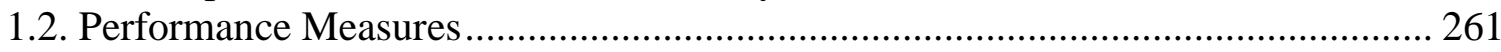

1.3. Catastrophe Theory and Modeling ...................................................................... 262

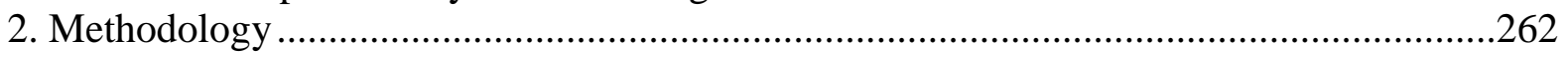

2.1. Seismic Risk Assessment Tools........................................................................ 262

2.2. HAZUS Methodology and Application ................................................................. 262

2.3. Life Cycle Greenhouse Gas Analysis for Reconstruction and Replacement........... 263

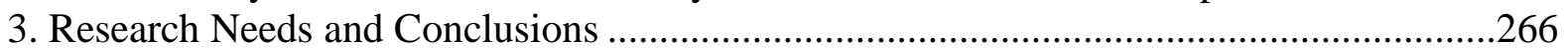

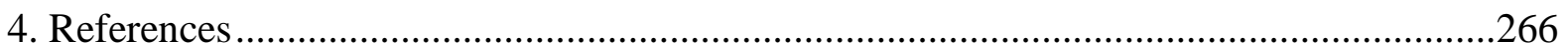

Wright, Richard N., and Bilal M. Ayyub, University of Maryland .............................................269

Measurement Needs for Adaptation to Climate Change ...................................................269

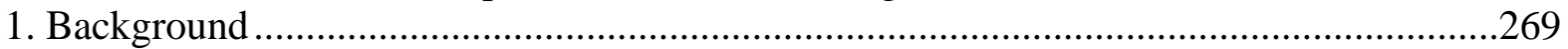

2. Measurement Needs of the Building Community …………………................................273

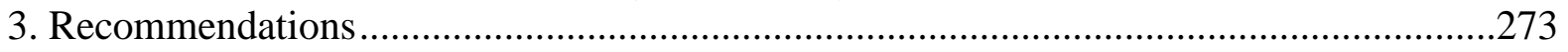

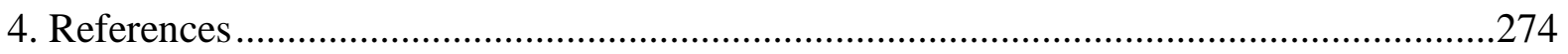

Yudelson, Jerry, Green Building Initiative, Portland, Oregon …………………………….......2275

Problems with Measuring and Achieving High-Performance Green Buildings: Case

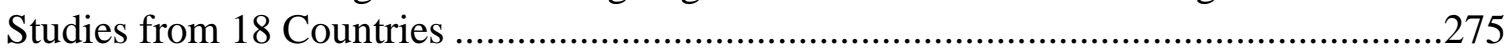

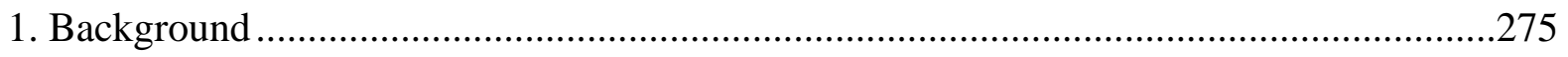

2. Energy Use in Case Study Projects.................................................................................27

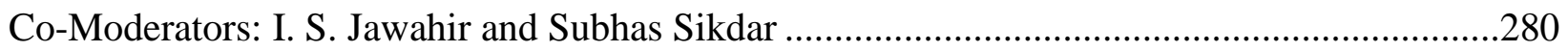

Outcomes of Breakout Session 1 on Measurement Science (Definition, Standards,

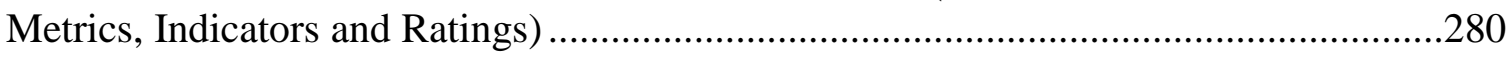

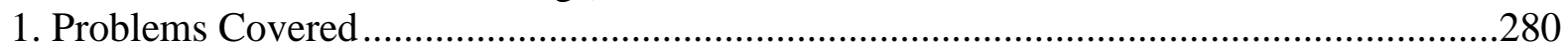

2. Lack of Clarity on Sustainability Science and Engineering ………................................28

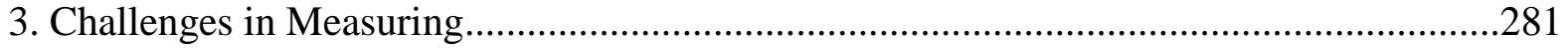


4. Unmeasurable Sustainability Values/Factors/Elements ..........................................282

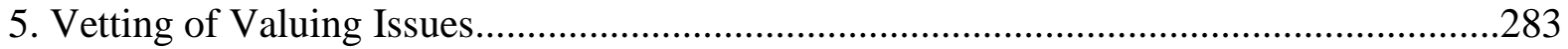

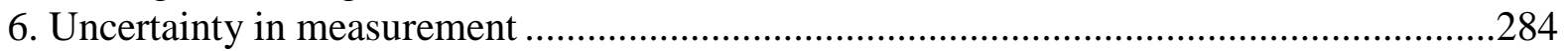

Co-Moderators: Joseph Fiksel and John Carberry .............................................................287

Outcomes of Breakout Session 2 on Systems (aggregation, linkages, system of systems, sustainability- resilience synergy and interdependencies) .............................287

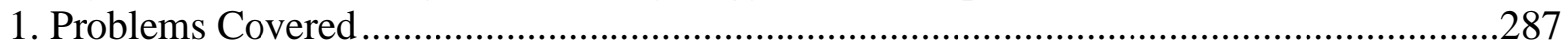

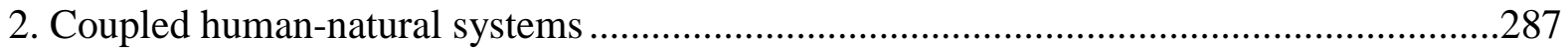

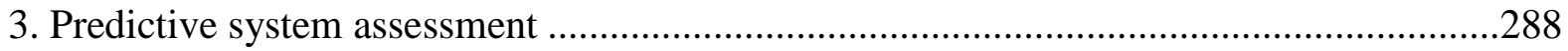

4. Are there tractable methods for practitioners to understand the complex interactions within a system of systems across multiple spatial and temporal scales?.............................289

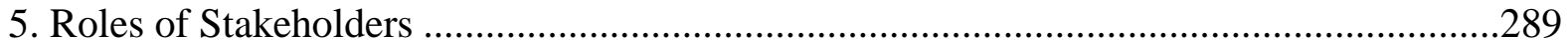

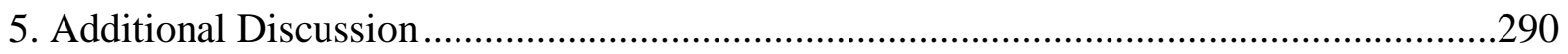

Co-Moderators: Nabil Nasr and Fazleena Badurdeen ..........................................................293

Outcomes of Breakout Session 3 on Planning, Design and Supply Chain (lifecycle analyses and treatments, and material and energy efficiency) ..................................293

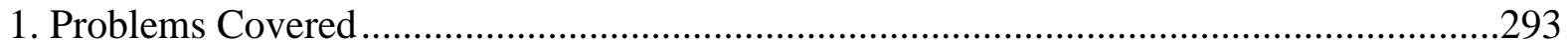

2. Systems not Designed for EOL................................................................................293

3. Limited data sharing and lack of interoperability ....................................................294

4. Lack of Predictive Models ........................................................................................295

5. Lack of Systems-based Approach..............................................................................296

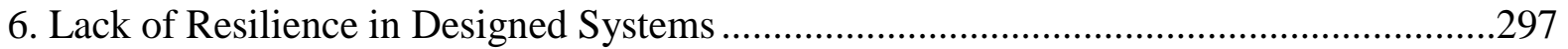

7. Lack of a Common Sustainability Nomenclature .......................................................299

Co-Moderators: Cliff Davidson and William Flanagan.......................................................301

Outcomes of Breakout Session 4 on Economic, Environmental and Social Aspects

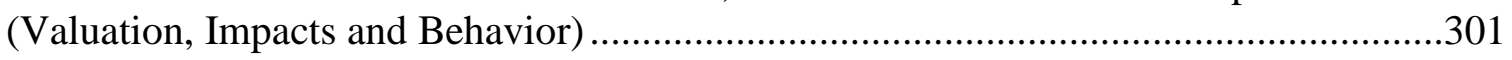

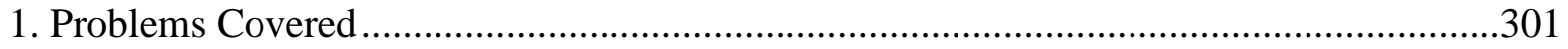

2. Measuring the value to society of incorporating sustainability .....................................301

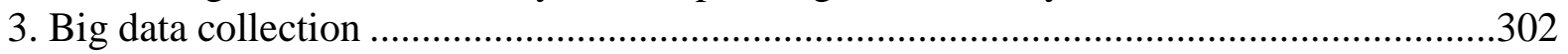

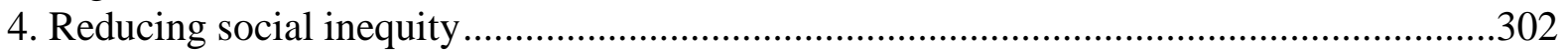

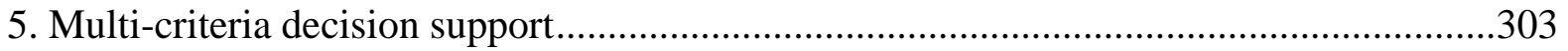

6. Human health, feelings of well-being, and work performance in green buildings............304

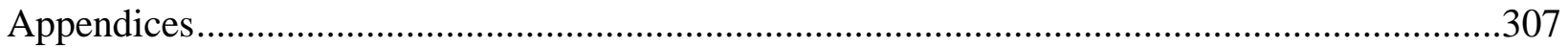

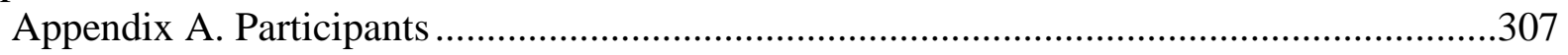

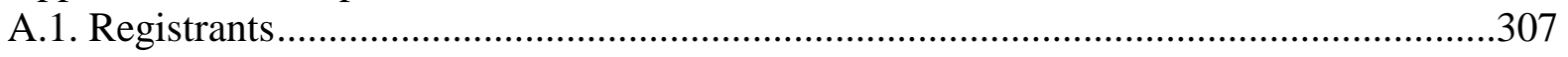

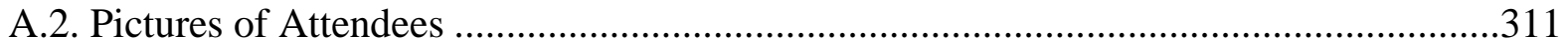

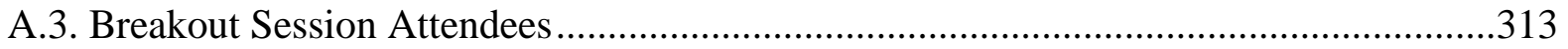

Appendix B. Biographical Information on Speakers, Panelists and Moderators ..................317 
[This page is internationally left blank] 
Ayyub, Bilal M., University of Maryland, College Park

\title{
Value Systems and Information Necessary for Sustainable Construction and Manufacturing
}

\author{
Abstract \\ Many cultural transformations in recent history, such as abolition of slavery, prohibition of \\ alcohol, assertion of women's rights, restriction of smoking, and most recently same-sex \\ marriage, were facilitated by memes - ideas that spread within a culture through various media \\ of communication. There is a need to understand the linkages among information, societal value \\ systems, and cultural and behavioral areas as they relate to sustainable construction and \\ manufacturing.
}

\section{Keywords}

Behavior, culture, construction, information, manufacturing, measurement, memetics, valuation, values

\section{Value Systems and Valuations}

Value systems define respective cultures, and cultures in turn generate behaviors based on conscious decisions. The behaviors can be beneficial or harmful to sustainability. Decision and policy makers rely on information and knowledge. Information is plentiful although it has its deficiencies, and knowledge is accessible with also its deficiencies.

Many decision analysis frameworks require valuations in economic or monetary terms. Approached broadly from philosophy and particularly from ethics, we can make distinctions among values as: (1) instrumental and intrinsic values, (2) anthropocentric and biocentric (or ecocentric) values, (3) existence value, and (4) utilitarian and deontological values. These distinctions are described using an ecosystem as an example. This section is based on Ayyub (2014).

For an ecosystem, the instrumental value is derived from its role as a means toward an end other than itself, i.e., its value is derived from its usefulness in achieving a goal. In contrast, intrinsic value, also called non-instrumental value, is its existence independently of any such contribution defined by usefulness. For example, if an animal population provides a source of food for either humans or other species, it has instrumental value that stems from its contribution or usefulness to the goal of sustaining the consuming population. If it continues to have value even if it were no longer useful to these populations, e.g., if an alternative, preferred food source were discovered, such a remaining value would be its intrinsic value. For example, a national park, such as the Grand Canyon, has an intrinsic value component that exists unrelated or independent of direct or indirect use by humans for recreation or investigation. Such an intrinsic value can also stem from cultural sources, such as monuments and burial grounds (NRC 2004).

An anthropocentric value system considers humankind as the central focus or final goal of the universe, human beings as the only thing with intrinsic value, and the instrumental value of everything else is derived from its usefulness in meeting human goals. On the other hand, biocentric value system, i.e., non-anthropocentric, assigns intrinsic value to all individual living 
systems, including but not limited to humans, and assumes that all living systems have value even it its usefulness to human beings cannot be determined or can be harmful to human beings.

Existence value reflects the desire of human beings to preserve and ensure the continued existence of certain species or environments to provide for humankind welfare, making it an anthropocentric and utilitarian concept of value and within the domain of instrumental value system. Therefore, utilitarian values are instrumental in that they are viewed as a means toward the end result of increased human welfare as defined by human preferences, without any value judgment about these preferences. The value of certain species or environments comes from generating welfare to human beings, rather than from the intrinsic value of these nonhuman species. This definition permits the potential for substitution or replacement of this source of welfare with an alternative source, i.e., the possibility of a welfare-neutral trade-off between continued existence of species or environments and other things that also provide the same utility.

The deontological value system is based on an ethical doctrine which holds that the worth of an action is determined by its conformity to some binding rule rather than by its consequences. In this case, deontological value system implies a set of rights that include the right of existence. Something with intrinsic value is irreplaceable and its loss cannot be offset by having more of something else. For example, the death of person is a loss of an intrinsic value because it cannot be offset or compensated by that person having more of something else. The contentious issue is whether this concept should be extended to non-human species, for example animals, either individual animals or species, or all biological creatures, i.e., all plant and animal life, collectively called the biota. In the context of ecosystem valuation, the modern notion of intrinsic value extends the rights beyond human beings. On the other hand, utilitarian values are based on providing utilities.

Many decision analysis frameworks use a valuation approach with the following characteristics:

- Anthropocentric in nature based on utilitarian principles;

- Consideration of all instrumental values, including existence value;

- Its utilitarian basis to permit the potential for substitutability among different sources of value that contribute to human welfare;

- Individual's preferences or marginal willingness to trade one good or service for another that can be influenced by culture, income level and information making it time- and context-specific; and

- Societal values as the aggregation of individual values.

Such an approach is consistent with NRC (2004) and does not capture non-anthropocentric values, e.g., biocentric values and intrinsic values as it relates to rights. In some decisions including environmental policy and law, biocentric intrinsic values should be included as was done previously, e.g., the Endangered Species Act of 1973.

A total economic value (TEV) framework can be constructed based on these characteristics and using individual preferences and values. The TEV framework is necessary to ensure that all components of value are recognized and included while avoiding double counting of values (Bishop et al. 1987, Randall 1991). Figure 1 provides a classification of total economic values for aquatic ecosystem services with examples (Ayyub 2014, NRC 2004, Barbier 1994). 
These characteristics should be examined in the context of sustainability.

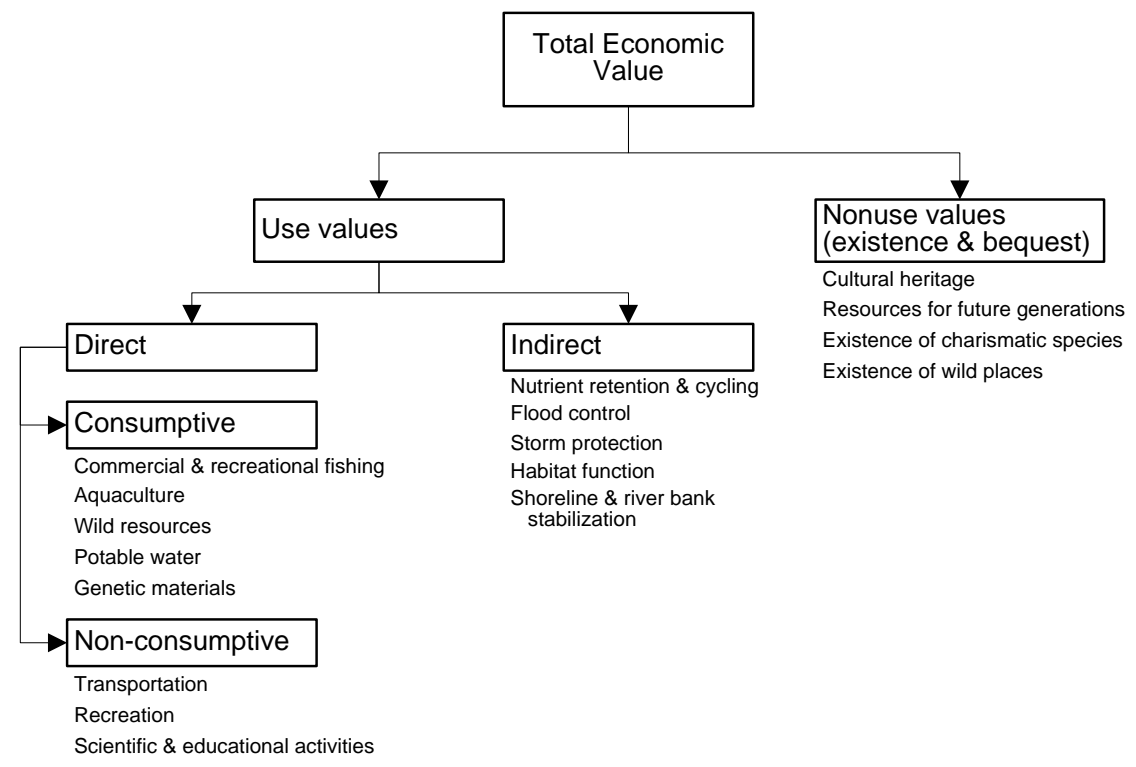

Figure 1. Classification of Total Economic Value for Aquatic Ecosystem Services with Examples (Ayyub 2014)

\section{Axioms of Utility Theory}

The concept of utility under uncertainty is based on the following axioms (Ayyub 2014):

- Decision making is always rational.

- Decision making takes into considerations all available alternatives.

- Decision makers prefer more consumption or wealth to less.

These axioms define what is termed cardinal utility. A primary question can be posed herein about their appropriateness for addressing sustainability related decisions.

\section{Income Inequality and Inequity}

It is generally recognized at a societal level that inequality and inequity could motivate and change behavior adversely toward sustainability. Are these relationships relevant to manufacturers, builders, contractors, infrastructure owners, etc.? For example, would income gaps between executives and workers contribute to behavioral changes?

\section{Measurement and Metrics}

Sustainable construction and manufacturing depend on broad, often diverse, cultures within these sectors. A culture (or subculture) that encourages waste and ignores sustainability is dysfunctional with respect to attaining sustainability. It is now feasible with new neurosciencebased technology to identify and modify a dysfunctional culture and its consequent adverse behavior.

There are many definitions of "meme," but in our pragmatic definition a meme is information (as defined by Claude Shannon (Shannon, 1948) that propagates, has impact, and persists (Finkelstein, 2011). Memetic metrics should be identified, defined and evaluated for the 
meaning of "information," "propagation," "impact," and "persistence." Memes can alter the values of individuals, and the aggregated altered values across a population can change a culture. A culture is the entire way of life of a group; a repertoire of socially transmitted ideas about how to live and make judgments; a set of values and norms shared by a group. Values and norms ultimately determine the group's members' behavior and interactions with each other and with people outside the group. Values consist of general criteria, standards, or guiding principles that people use to determine which types of behaviors, events, situations, and outcomes are desirable or undesirable; the bases for holding beliefs and attitudes, making decisions and taking actions; and the bases for defining a culture. Norms are the methods of culture; practices, standards, or styles of behavior considered acceptable for people in a culture. Culture drives individual and group behavior, such as preferences in goods, services, and lifestyle, e.g.: consumption of energy, choice of food, jobs, education, social interactions, transactions, manners, conservation, and self-actualization. Culture can change unintentionally and organically, with punctuated equilibrium, from major natural or human-made catastrophic disasters, such as a prolonged drought or war. Culture can be changed intentionally with political leadership, social and technological pressure, media campaigns, and entertainment with embedded cultural lessons. Culture can be changed more effectively and efficiently within a framework of a science of memetics, employing new tools and techniques developed for neuro-science, neuro-economics, and neuro-marketing, along with social media networks. A dysfunctional culture (or subculture), determined quantitatively as such with suitably defined metrics, can be transformed into a functional culture by using those new tools and techniques to change the dysfunctional values and norms of individuals.

An overall research methodology is required for the evaluation of products, processes, and systems in order to consider their impacts on sustainability as provided in Figure 2. There are substantial challenges to identifying and understanding the social impacts associated with engineered systems as well as the socially and culturally derived effects on these systems. Research is needed to identify, quantify, and standardize metrics of social impact as well as socially-oriented drivers of sustainability. 


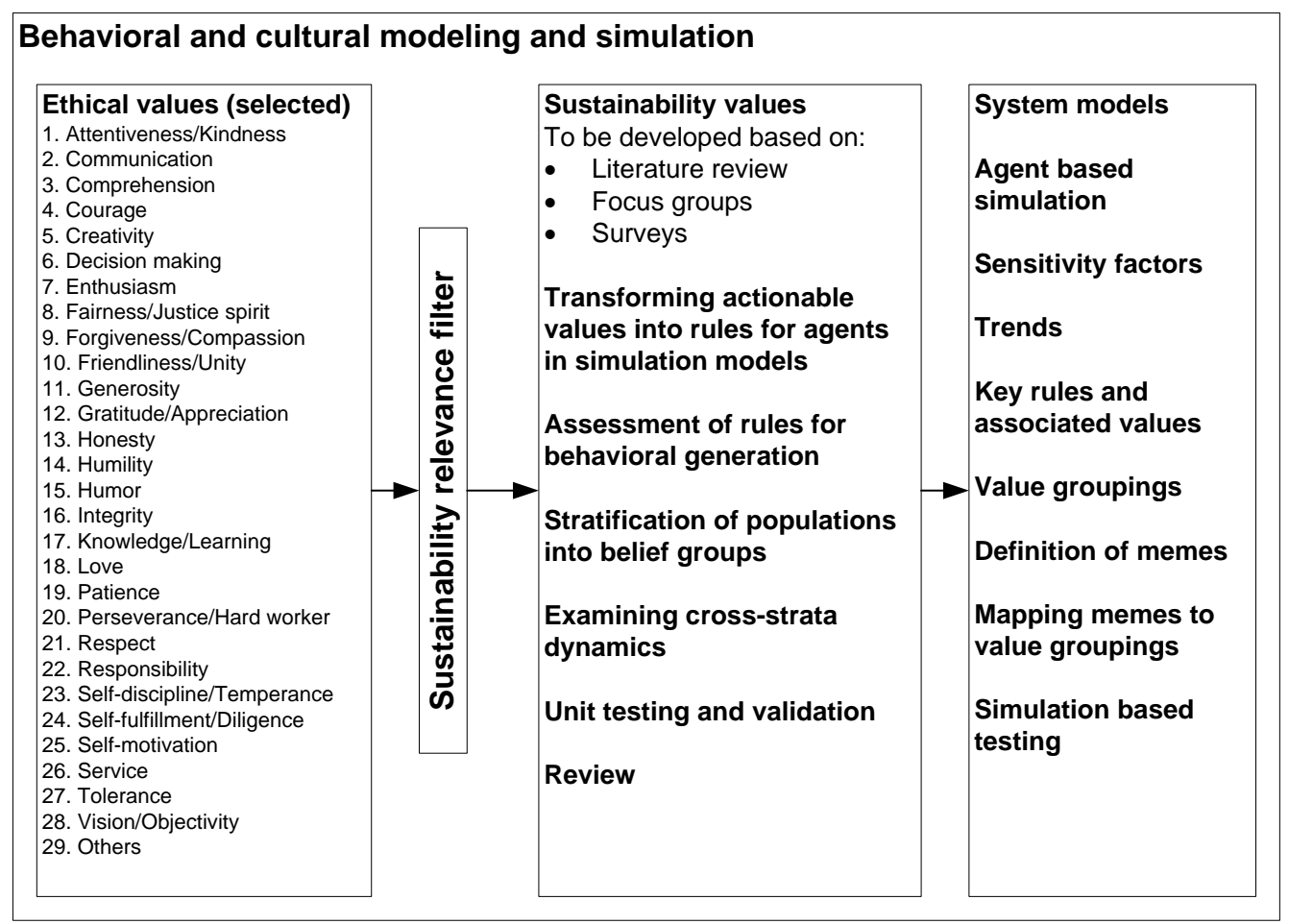

Figure 2. Behavioral and Cultural Modeling and Simulation

Methods should be developed to prioritize sustainability metrics in different contexts. Given the large number of social sustainability metrics that have already been identified and the desire to enable decision makers to take immediate action related to the social performance of their areas of purview, it will be necessary to develop a method to prioritize social sustainability impacts. A multivariate decision-making approach similar to the analytic hierarchy process (Saaty 1980) will underpin the methodology. It will facilitate consideration of characteristics of the metrics and organization as well as different objectives based on different stakeholder interests. Organizational characteristics of interest include the economic sector, level of risk aversion, and approach to sustainability. Characteristics of metrics such as data type (e.g., quantitative or qualitative); data source; geographic, political, and sector-level applicability will also be considered. Additionally, the methodology will enable decision-makers to consider the interests of different stakeholders (e.g., corporations, customers, and suppliers).

Developing messages directed at various populations to enhance awareness and inform behaviors are necessary. Concepts from memetics, and tools and techniques from neuroscience, can be employed to impact the value systems of selected populations, and tests can be developed to assess their effectiveness.

Many cultural transformations in recent history, such as abolition of slavery, prohibition of alcohol, assertion of women's rights, restriction of smoking, and most recently same-sex marriage, were facilitated by memes - ideas that spread within a culture through various media of communication. By the same token, memes can hasten a transformation toward sustainability, perhaps avoiding future crises. There is a need to understand the linkages among information, 
societal value systems, culture and behavior areas as they relate to sustainable construction and manufacturing.

\section{References}

Ayyub, B. M., 2014. Risk Analysis in Engineering and Economics, Second Edition, Chapman \& Hall/CRC, Taylor \& Francis Group, Boca Raton, NY.

Barbier, E.B. 1994. "Valuing Environmental Functions: Tropical Wetlands," Land Economics, 70(2):155-173.

Bishop, R.C., Boyle, K. J., and Welsh, M. P. 1987, “Toward Total Economic Value of Great Lakes Fishery Resources," Transactions of the American Fisheries Society 116 (3):339-345.

Finkelstein, Robert, 2011. "Tutorial: Military Memetics" Social Media for Defense Summit, Alexandria, VA.

National Research Council, 2004. Valuing Ecosystem Services: Toward Better Environmental Decision-Making, The national Academies Press, Washington, DC.

Randall, A. 1991. Chapter 10 Total and Nonuse Values in Measuring the Demand for

Environmental Quality, Braden, J.B., and C.D. Kolstad (eds.). North Holland, Amsterdam.

Saaty, 1980, Analytic Hierarchy Process

Shannon, C.E., 1948. "A Mathematical Theory of Communication,” The Bell System Technical Journal, Vol. 27, pp. 379-423, 623-656, July, October, 1948.

\section{Acknowledgements}

The author would like to acknowledge comments received from Dr. Robert Finkelstein and Professor Joseph Fiksel on parts of this paper. The financial support of the National Institute of Standards and Technology is greatly appreciated. Opinions presented herein are of the author and not the sponsors. 
Badurdeen, Fazleena, University of Kentucky

\title{
Planning, Design and Management of Supply Chains for Sustainability
}

\begin{abstract}
Sustainable manufacturing involves the manufacture of more sustainable products through the use of manufacturing processes and systems (including supply chains) that are more sustainable. Achieving optimal performance at the product, process and systems level is feasible only when the interconnectivity of these three aspects is considered in their planning, design and management. When it comes to the supply chain level, historically, the emphasis has been only on the first three stages of the product life-cycle which involve pre-manufacturing, manufacturing and use; the post-use stage has often been considered as an afterthought. However, emphasis on all the four stages is essential to enable closed-loop, near perpetual material flow to promote more sustainable manufacturing. This paper addresses some of the issues that arise due to the poor integration and coordination of activities across the supply chain and potential steps that can be taken to overcome those challenges.
\end{abstract}

\section{Keywords}

Sustainable supply chain, life-cycle, integration, 6R, closed-loop flow

\section{Background}

Numerous definitions of sustainable manufacturing have been put forward in recent years. While they each address some aspects that must be covered to promote economic, environmental and societal performance in various domains pertinent to sustainable manufacturing, most are inadequate. This is primarily because many of those attempts fail to address all the three integral elements of products, processes and systems essential to promoting manufacturing sustainability more importantly, they also fail to stress the interconnectivity between the these elements as shown in Figure 1. Sustainable manufacturing does offer a new way of producing functionally superior products using sustainable technologies and advanced manufacturing methods, but only if product design, process design, production, supply chain design and management and enterprise-level logistics can be understood and managed in a holistic integrated way (Jayal et al., 2010). 


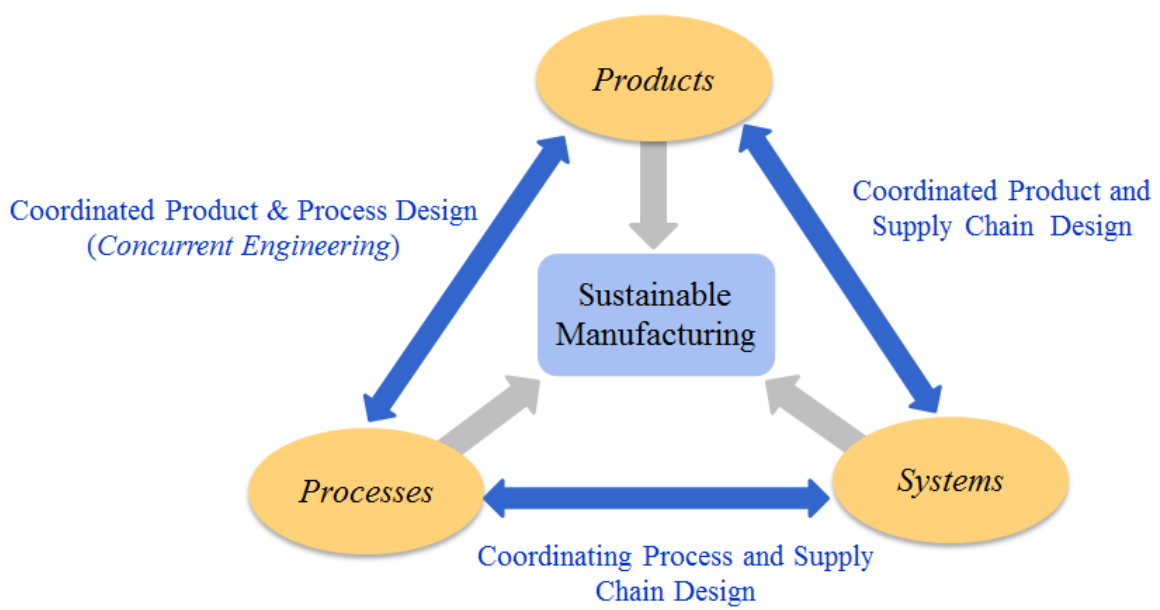

Figure 1. Product-Process-System Integration for Sustainable Manufacturing (Badurdeen, 2012)

The life-cycle of a manufactured product can be divided broadly into four stages as premanufacturing, manufacturing, use and post-use. The activities carried out in each of these stages can be mapped to the supply chain, whose members engage in sourcing, converting, delivering and collecting products at end-of-life. Conventionally, however, supply chain management practices have focused only on the first three stages of the life-cycle; the fourth stage, post-use, probably the most important from a sustainability perspective, is often addressed on a piece-meal basis and as an afterthought, only when such practices deliver economic benefits. Thus, at the systems level there is a need to consider all aspects of the entire supply chain, taking into account all the major life-cycle stages and also considering multiple life-cycles to enable value recovery from end-of-life products to be channeled into subsequent life-cycles of the same or different products (Badurdeen et al., 2009).

In order to enhance sustainability performance at the supply chain level, product and process sustainability must be integrated and coordinated with system (manufacturing system and supply chain) design across all life-cycle stages. This implies that a closed-loop systems approach must be followed in the planning and management of sourcing, procurement, conversion (manufacturing), and logistics activities involved during all four life-cycle stages while explicitly considering the environmental and societal impacts, in addition to the economic benefits alone.

Supply chain management has conventionally been approached as the process of '... coordinating the operations of (a) independently managed entities (b) who seek to maximize profits (only) individually' (Badurdeen et al., 2009), an approach that serves as a major obstacle to enhancing coordination across the supply chain to enhance sustainability in supply chain operations. To the contrary, for sustainability, supply chains must be designed and managed as an integrated system. The 6R methodology which integrates the previous $3 \mathrm{Rs}$-reduce, reuse and recycle - with additional steps of recover, redesign and remanufacture (Jawahir, 2008) provides a means to achieve this integration across all life-cycle stages (Figure 9). Closed-loop flow in supply chains, as shown in the figure, is heavily dependent on the product design; while almost $80 \%$ of a product's costs are determined during design the reuse, remanufacturing and recycle costs (and therefore reverse flows) of the product and the resulting environmental and societal implications are heavily influenced by the number/variety of materials used, design for ease of 
disassembly and whether product-inherent information is included in the product to make recovery and reprocessing easier, etc., etc. This interdependency between the selection of products, processes and the system used material conversion and reverse flow, makes it imperative that a holistic and systems-based approach is followed in the design and management of sustainable supply chains.

Thus, sustainable supply chain management can be described as "the planning and management of sourcing, procurement, conversion and logistics activities involved during pre-manufacturing, manufacturing, use and post-use stages in the life cycle in closed-loop through multiple lifecycles with seamless information sharing about all product life-cycle stages between companies by explicitly considering the social and environmental implications to achieve a shared vision" (Badurdeen et al., 2009).

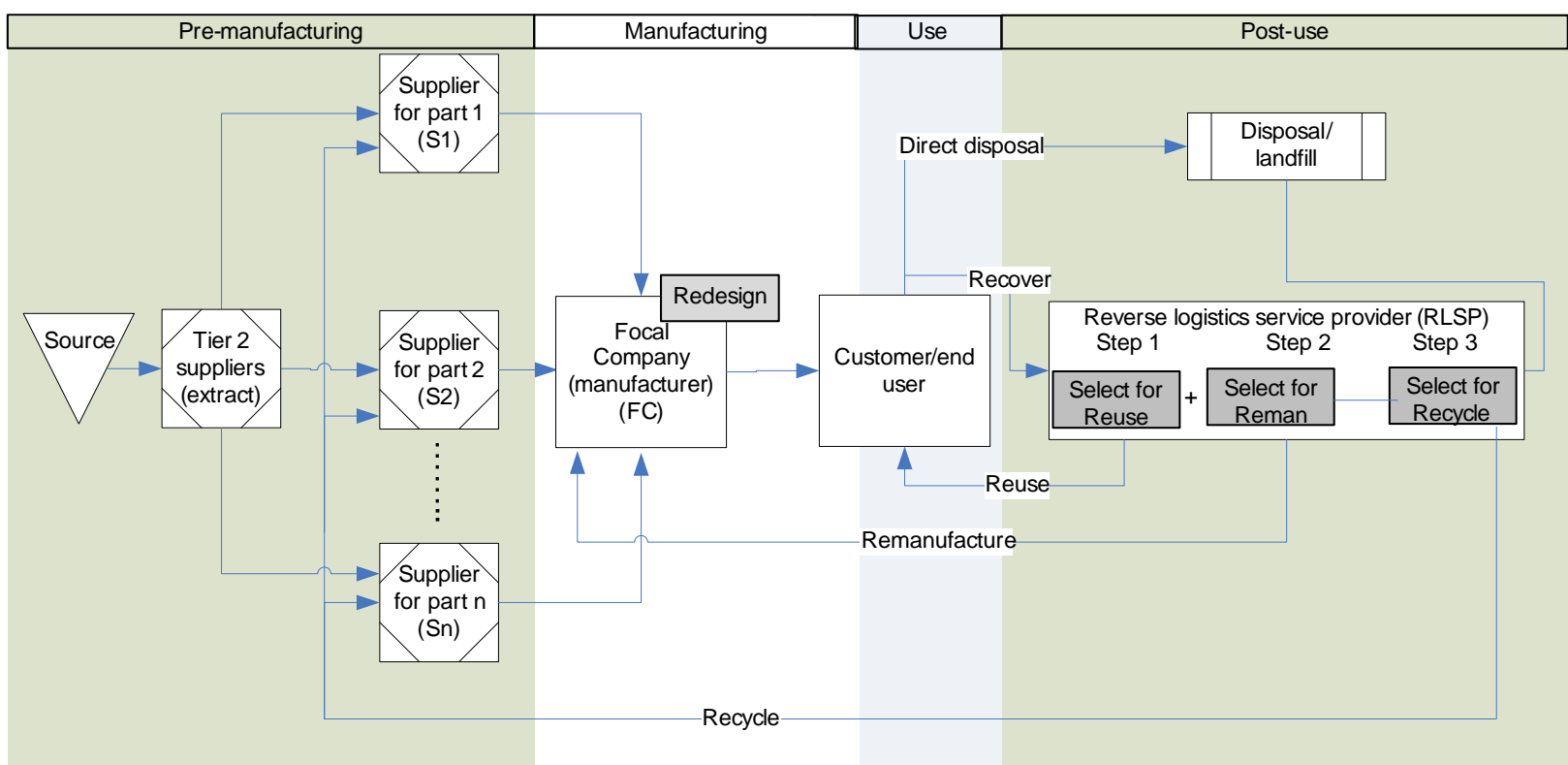

Figure 2. 6R Integration for Closed-loop Flow in Sustainable Supply Chains (Badurdeen et al., 2009)

\section{Current Practice and Challenge to Sustainable Manufacturing}

Numerous recent efforts have examined the current practices in supply chain planning, design, management and integration in an effort to identify challenges to promoting sustainable manufacturing and closed-loop material flow in supply chains to enable sustainable supply chain management (Badurdeen, 2011; SMART Report, 2013; ASME Report, 2013). These can be summarized as follows.

- Implementing closed-loop flow in supply chains requires better collaboration and coordination of activities. However, there is limited visibility in most supply chains as companies have limited visibility beyond their tier 1 suppliers. Lack of visibility restricts access to information about performance in other life-cycle stages.

- Improving sustainability performance in supply chains requires comprehensive models that can integrate sustainability considerations across the entire life-cycle as well as their interdependencies and trade-offs. Complex modeling capabilities that integrates these aspects is lacking. 
- Global supply chains are increasingly exposed to uncertain events and disruptions. The sustainability performance of supply chains is catastrophically affected when such unpredictable events occur (e.g.: earthquake and tsunami in Japan). However, quantitatively models for evaluating interdependent risks between supply chain partners and methods to analyze their propagation through the supply chains are lacking.

- Effective collaboration between supply chain partners requires the capability to exchange information on a real-time (or near real-time) basis pertaining to life-cycle of products. However, the lack of interoperability between information management systems and enterprise resource management systems used by different supply chain partners limits their ability to collaborate effectively.

- For sustainability, supply chains must be designed and managed as an integrated system. To enable closed-loop flow and increase sustainability performance, the optimization of supply chain design and product design must be intrinsically linked. However, these two aspects are addressed, mostly, independent of each other, leading to increased cost, poor environmental performance and/or adverse societal consequences.

- Sustainability improvements often take a long-term to materialize and benefits are likely to accrue across the supply chain. However, existing accounting frameworks do not lend themselves to accurately determine cross-company benefits, economic or otherwise.

- Small and medium scale companies often do not have the resources nor know how to implement sustainability improvements.

- Comprehensive metrics to evaluate total life-cycle sustainability across the supply chain with respect to economic, environmental and societal performance is lacking

\section{Vision for Planning, Design and Management of Sustainable Supply Chains}

Addressing the above challenges requires developing the tools and capabilities necessary to comprehensively measure, model, evaluate and integrate performance across supply chain partners across all life-cycle stages. Thus, the vision for planning, design and management of sustainable supply chains must incorporate a variety of aspects, including (Badurdeen, 2011; SMART Report, 2013; ASME Report, 2013):

- A common nomenclature and taxonomy developed to enhance interoperability and information exchange between supply chain partners that will help improved coordination of operations.

- Tools that can integrate sustainability considerations (e.g.: energy consumption, emissions, water consumption, etc.) for supply chain planning and scheduling for optimized operation are developed.

- All modeling tools for manufacturing system design and sustainable supply chain design must incorporate quantifiable risk assessment to enable a realistic evaluation of tradeoffs. The models will handle uncertainties more efficiently through better modeling to enable developing more robust supply chains.

- Supply chain disruptions, which are low likelihood events that have catastrophic impacts are studied to determine methods to increase the robustness to withstand such impacts and enhance resilience to recover and return to pre-disruption status as quickly as possible.

- A comprehensive framework and metrics to evaluate environmental and societal sustainability performance of supply chain operations are developed to enable supply 
chain managers to quantitatively evaluate the impact of various supply chain related decisions and the trade-offs involved.

- Lean and green manufacturing tools are extended to incorporate sustainability considerations whereby the flow of material through the supply chain is perfectly matched between the supply side and the demand side minimizing economic, environmental and societal wastes.

- Post-use life-cycle stage management for value recovery from end-of-life products and for channeling products back for reuse, remanufacture, and/or recycling must be incorporated into regular supply chain operations.

Thus, developing such advanced capabilities to address these challenges faced by supply chain partners during planning, design and management of activities across all life-cycle stages can enhance the sustainability performance.

\section{References}

ASME Sustainable Manufacturing Open Research Forum: Preparing for a New Business Imperative, ASME, June 18, 2013, Washington, DC.

Badurdeen, F., Goldsby, T.J., Iyengar, D., Metta, H., Gupta, S., Jawahir, I.S., Extending Total Life-cycle Thinking to Sustainable Supply Chain Design, International Journal of Product Lifecycle Management, 4/1/2/3: 49-67, 2009.

Badurdeen, F., Next Steps in Sustainable Manufacturing R\&D: Report of a Two-day Workshop on Innovation for Sustainable Manufacturing \& Workforce Effectiveness, Institute for Sustainable Manufacturing (ISM), University of Kentucky, Lexington KY, June 21-22, 2011.

Badurdeen, F., Sustainable Manufacturing: Recent Advances in the Total Lifecycle-based Approach, Keynote Presentation, 22nd International Conference on Flexible Automation and Intelligent Manufacturing (FAIM), June 10-13, 2012.

Jayal, A.D., Badurdeen, F., Dillon Jr., O.W., Jawahir, I.S., Sustainable manufacturing: modeling and optimization challenges at the product, process and system levels, CIRP Journal of Manufacturing Science and Technology, 2: 144-152, 2010.

Jawahir, I.S., (2008), Beyond the 3Rs: 6R Sustainability Concepts for Next Generation Manufacturing, IIT MMAE Symposium on Sustainability and Product Development, Chicago, IL, August 7-8, 2008.

PCAST Report: Capturing Domestic Competitive Advantage in Advanced Manufacturing, Advanced Manufacturing Partnership (AMP) Steering Committee, President's Council of Advisors on Science and Technology (PCAST) July 2012.

Sustainable Manufacturing Advances in Research and Technology (SMART) Coordination Network: Output from the Roadmap Workshop on Sustainable Manufacturing, Compiled by IMTI, Inc.; NSF-sponsored Workshop Held in Cincinnati, Ohio on August 15-16, 2013; Document Released September 8, 2013. 
[This page is internationally left blank] 


\title{
Begley, Loida, National Nuclear Security Administration, DOE
}

\section{Measuring the Benefits of Green Buildings}

\author{
Abstract ${ }^{1}$ \\ Green, sustainable, and high performance can all describe a building that is constructed or \\ maintained better than code. The popularity of Leadership in Energy and Environmental Design \\ $\left(\right.$ LEED $\left.^{\circledR}\right)$, administered by the U.S. Green Building Council ${ }^{\mathrm{TM}}$, and the advent of other systems \\ (Green Globes ${ }^{\circledR}$, Living Building Challenge ${ }^{\mathrm{TM}}$ ), further solidify green buildings as a mainstay in \\ the world's built environment. The federal government operates almost one million facilities \\ (National Research Council, 2013, p. vii). The federal Guiding Principles (GPs) for high \\ performance sustainable buildings is similar to other green building systems and is required for a \\ fraction of existing and all new federal buildings. Despite the acceptance of green building \\ systems, measurement gaps remain in quantifying the benefits of systems. American National \\ Standards Institute (ANSI) and National Institute of Standards and Technology (NIST) have a \\ unique opportunity to address measurement gaps that can be implemented in the near-term.
}

\section{Keywords}

Green building certification, green building systems, high-performance building, LEED ${ }^{\circledR}$, federal Guiding Principles (GPs), performance measures

\section{Background}

A recent report on green building certification confirms that "the terms 'green' and 'sustainable' are often used interchangeably with high-performance buildings, but there are no standard definitions for those terms," (National Research Council, 2013, p. 2). Although not standardized, green buildings can be explained as such:

Building standards and green building certification systems have been developed by nonprofit organizations to provide a framework for the design and operation of highperformance and green buildings. Building standards typically establish minimum requirements for the design of one aspect of a building's performance (for example, energy). Green building certification systems, in contrast, take a "whole building" approach to design by accounting for the interrelationships among building design, materials, mechanical systems, technologies, and operating practices.

(National Research Council, 2013, p. 3).

Another report confirms the popularity of LEED, and suggests why LEED could be synonymous with green building. The report compares different third-party green building systems, and demonstrates that LEED is the oldest and most used system:

- Green Globes was launched in 2006 and has 176 facilities awarded certification,

- LEED was launched in 1999 and has 10,000 facilities awarded certification,

\footnotetext{
${ }^{1}$ Reference herein to any specific commercial product, process, or service by trade name, trademark, manufacturer, or otherwise do not constitute or imply its endorsement, recommendation, or favoring by the United States Government or any agency thereof. The views and opinions of the author expressed herein do not necessarily state or reflect those of the United States Government or any agency thereof.
} 
- Living Building Challenge was launched in 2006, and has 4 facilities awarded certification

(Wang, Fowler, \& Sullivan, 2012, pp. 4.10-4.11)

Even with the popularity of LEED, a lack of definition for a green building has complicated measurement and analysis of the benefits of green buildings. These complications were described in a report completed to fulfill section 2830 of the National Defense Authorization Act for fiscal year 2012 (National Research Council, 2013, p. vii). Per the report, the Act required that the National Research Council report analyze cost-benefit, return on investment, and longterm payback of the energy-efficiency and sustainability standards used by the U.S. Department of Defense (DoD).

The federal Guiding Principles (GPs) for High Performance Sustainable Buildings are similar to other green building systems. Like other green building systems, to gain the status of being a GP building, a set of requirements must be met. There is a set of GPs for existing buildings and a set for new construction and major renovation. The GPs were developed to further clarify what needed to be done in order to meet the requirements of Presidential Executive Order 13423, "Strengthening Federal Environmental, Energy, and Transportation Management," in Section 2, Part (f) and Executive Order 13514, "Federal Leadership in Environmental, Energy, and Economic Performance," Section 2, Part (g) (iii).

For LEED and Green Globes the user can select which requirements to meet. These systems are structured such that if performance metrics, in particular, energy is not met, the building will not be able to obtain a certification. In contrast, all the GP requirements must be met in order to obtain GP status. Living Building Challenge is similar to the GPs in that the building cannot attain full status unless all requirements are met, but Living Building Challenge allows for temporary exceptions for market limitations (Wang, Fowler, \& Sullivan, 2012, p. 3.5). In addition, an agency can decide how to verify that the GP's are met. LEED, Green Globes, and Living Building Challenge all require third-party verification by a trained certifier to attain full status as a green building.

\section{Gaps in Measuring Building Certification Systems}

The NRC report evaluated the DoD sustainable building standards, and identified several gaps in definition and measurement, some of which include (emphasis added):

- "The diversity in building design and multitude of factors that contribute to any building's performance make it difficult to isolate the specific factors that contribute to energy use, water use, or other performance measures," (2013, pp. 3-4).

- "There are no national baselines from which to measure the performance of multiple factors associated with high-performance or green buildings... The Commerical Buildings Energy Consumption Survey (CBECS) is the only national data source for detailed characteristics and energy use of U.S. commercial buildings." The report also states that deficiencies in the CBECS database has well-documented deficiencies, (2013, p. 4).

- "There are no national databases for water use, operations and maintenance, indoor environmental quality, or worker productively as it relates to buildings. Baselines for 
comparing those factors are typically developed differently for individual studies," (2013, p. 4).

- "There is no standard protocol for conducting research on high-performance or green buildings, although some studies do use similar methodologies or evaluation methods," (2013, p. 4).

The report concludes that "together all of these factors hinder objective comparisons across studies and preclude definitive, fully documented findings. The subjectivity inherent in making comparisons across research studies instead requires judgments based on a 'preponderance' of evidence," (2013, p. 4). This data suggests that findings about green building benefits are limited.

Wang, N., Fowler, K., \& Sullivan, R. (2012) identified that 2,671 buildings had signed up to participate in Green Globes; 31,696 for LEED; and 87 for Living Building Challenge (p. 4.11). With thousands of buildings presently considering certification as a green building, the opportunity to test different methods that can address data gaps is incredible. For example, with regards to the gap in research protocol, if a research protocol is developed, it can be tested on buildings that are in currently design and seeking certification. Within the next five years-a conservative estimate for the time it takes for a typical building design to go from concept to completion (National Research Council, 2013, p. 70) - the green building community could apply results of the research. Furthermore, green building systems have strong mechanisms to incorporate changes. Recognized green building systems have rigorous documentation requirements and active mechanisms by which to revise requirements.

\section{Measurement and Metrics}

\subsection{LEED as a Baseline for Green Building}

As popular as it is, LEED may not be able to serve as a sufficient definition for green building measurement. A recent report concludes that "although there are hundreds of publications related to high-performance or green buildings, relatively few are well-designed empirical studies. Of these, several focused specifically on LEED-certified buildings; none focused on Green Globes-certified buildings," (National Research Council, 2013, p. 4). This implies that research can be applied to LEED facilities, but the lack of research limits comparisons to other building systems and methods. In addition, this NRC report identified other data problems in the studies that it evaluated, stating that "other factors that made the task more complex included issues related to qualitative and quantitative measurements of building performance, measured data versus modeled data for energy and water use, and the inclusion of a mix of buildings types in most empirical studies," (p. 4).

\subsection{Federal Guiding Principles as a Baseline for Green Building}

Another recent report has demonstrated how third-party ${ }^{2}$ systems compared to the federal GPs. Wang, Fowler, \& Sullivan (2012) showed how closely the GPs align with third-party systems. The analysis comparing new construction certification systems with the GPs showed that:

- Green Globes can be used to meet 25 out of 27 GP requirements,

- LEED can be used to meet 20 out of 27 GP requirements, and

\footnotetext{
2 "Third-party" refers to the characteristic that the requirements to certify the building must be verified by someone
} who has no vested interest in the outcome of the certification. 
- Living Building Challenge can be used to meet 14 out of 27 GP requirements (pp. iii-vi)

The same report (pp. ix-x) showed a similar relationship between third-party green building systems and the GPs for existing building systems:

- Green Globes Continual Improvement of Existing Buildings (CIEB) can be used to meet 22 out of 28 requirements,

- LEED Existing Buildings Operations and Maintenance (EBO\&M) can be used to meet 27 out of 28 requirements, and

- Living Building Challenge can be used to meet 17 out of 28 requirements.

This relatedness between the GPs and the evaluated building systems suggests that the GPs are subject to the same baseline and measurement concerns as other green building systems.

\subsection{Traditional Green Building Benefits}

Despite the challenges of measuring the benefits of green buildings, the NRC report (2013) concluded that "the evidence from the literature search indicates that high-performance or green buildings can result in significant reductions in energy and water use," (p. 7). On average, green buildings reduce water use by 8 to 11 percent (p. 68), and "on average, used 5 to 30 percent less energy than conventional buildings," (p. 68). However, the same report also notes that realized benefits can also be affected by geographic region, climate zone, building type, and the skill of facility managers (pp. 7-8). Also, not every green "certified" building will outperform every similar, "conventional," non-certified building (p. 7).

These findings suggest that the choices the user of the system makes can affect the benefits, even if the building is certified. With all else being equal, an average green building will save more money during its life-cycle than an average "conventional" building. However, this report suggests that owners investing in green certification systems may not have the data they need to calculate the full life-cycle cost savings of their green building.

\subsection{Potential Green Building Benefits}

Section 2 of this paper, Gaps in Measuring Building Certification Systems, lists some of the limitations of evaluating the benefits of green building. One challenge identified was the inability to measure other benefits. While green building certification may "also result in improved indoor environmental quality, improved worker productivity, and lower operations and maintenance costs...the evidence is very limited," (National Research Council, 2013, p. 9). An area of focus for filling data gaps is in the area of maintenance and operations. The report mentioned that the majority of property that the DoD owns is more than 40 years old (p. 22). Other agencies, such as the Department of Energy, also own older facilities. Better data about how to apply green building systems to produce the best outcomes for maintenance and operations may provide the most immediate benefit for agencies that must maintain older properties.

Quantifying the benefits of improved indoor environmental quality and worker productivity can also improve outcomes for federal agencies. The NRC report states that green buildings affect indoor environmental quality, and that existing evidence suggested that "high-performance 
buildings result in improvements in some aspects of indoor environmental quality..." (p. 68). While difficult to measure and quantify, the impacts of indoor environmental quality and worker productivity can outweigh other savings if labor is significant to the cost of operations. Some studies have started to measure indoor environmental quality and worker productivity by evaluating: worker satisfaction in LEED and green buildings vs. conventional buildings; worker satisfaction with thermal comfort; satisfaction with air quality; perceived productivity; and perceived health (National Research Council, 2013, pp. 64-66).

\section{Conclusion}

The NRC report suggests "development of a body of empirical research for any building-related topic takes many years: it typically takes at least 5 years to program, design and construct a building, which will then be operated for 30 years or longer," (2013, p. 70). However, green building certification is a market reality and has proven its appeal as a strategy to save money and improve working conditions in new and existing buildings.

On average, a building owner who uses green building certification is more likely to reduce lifecycle costs than an owner who chooses not to. Furthermore, a green building system can be used as tool to reduce other life-cycle costs, such as costs associated with maintenance and operations, workplace health, and productivity. However, the full benefit of a green building remains unknown. The continued use of green building systems provides a unique opportunity for ANSI and NIST to address measurement and data gaps. Given the relatively short amount of time it takes to design and build facilities, even shorter amount of time to modify behavior in existing buildings, and the tens of thousands of buildings seeking green building status, relevant data can have an immediate and widespread impact on the world's built environment.

\section{References}

National Research Council. (2013). Energy-Efficiency Standards and Green Building Certification Systems Used by the Department of Defense for Military Construction and Major Renovations. Washington, DC: National Academies Press.

Wang, N., Fowler, K., \& Sullivan, R. (2012). Green Building Certification System Review. Pacific Northwest National Laboratory, Operated by Battelle for the U.S. Department of Energy. Washington, D.C.: U.S. General Services Administration. 
[This page is internationally left blank] 


\title{
Bertera, William J., Institute for Sustainable Infrastructure
}

\section{Sustainability and How We Value It}

\author{
Abstract \\ Sustainability in infrastructure development is not an option... it is an imperative. It is especially \\ important that we not only build projects right, but that we build the right projects... with \\ attention to the social, economic and environmental variables in infrastructure decision making. \\ Measurement and standards are extremely important...too important to leave as a technical \\ discussion among experts. We need to find ways to actively engage the public so that they will \\ be sufficiently informed to influence the allocation of scarce resources.
}

\section{Keywords}

Sustainability, Triple bottom line, Sustainable infrastructure, Sustainable practices, Metrics

The measurement science required to help policy makers make good decisions about investment in sustainable infrastructure is critical in the face of increasing demand for scarce resources, changing demographics, the absence of geopolitical stability and the growing evidence that externalities on a cosmic scale are affecting issues associated with quality of life in ways that ordinary citizens can see for themselves.

Issues of changing weather patterns are the most recognizable manifestations of global warming, but there are others that are reflected in the human condition and its reaction to cataclysmic changes unknown to our species in its time of this planet. The science is becoming clear and the threats demonstrable. Yet the terms of the public debate become more opaque as time goes on, with fear and uncertainty the controlling conditions.

Jurisdictions at the state and local levels have enacted statutes prohibiting even the mention of sustainability as if pretending the reason for sustainable practices either does not exist or will go away if we ignore it. Finding ways to make both the problem and solutions manageable in the minds of the general public is essential if political leaders are to seriously address the matter. Traditional cost-benefit analysis and like measurement schemes are not likely to be up to the challenge.

What makes people focus is attention to those things in their every-day lives that matter...things that the Triple Bottom Line focuses upon...value systems and societal priorities, environmental considerations and economics. This suggests that just focusing on costs without attention to benefits creates disincentives to proactive decision making...forces us to pay attention to tactics rather than strategies...the hear and now rather than the distant tomorrows.

Doing good is important of course, but is not enough. We need to be able to demonstrate that doing good is not only in our interest, but that it makes good business sense. This is as true for public sector projects as it is for those in the private sector. Profit margin is important for going 
concerns, but return on investment is equally important for public sector entities, though that return will certainly be vastly different than a simple surplus on the bottom line.

Back to the triple bottom line and measuring and valuing subjective variables. LCA does a great job in measuring things we can grab hold of, especially over time, but all of political science is about the basis on which decisions really get made...the things that matter that are hard to measure and value and sometimes, even to articulate.

Monetizing the easy variables associated with sustainable investments, i.e., resource allocation, only takes us so far. We need to be able to place values on those variables that are less obvious and that relate to process, citizen satisfaction and the elusive quality of life paradigm.

Inevitably, we need to find a way to value the important variables that cannot be monetized but which nevertheless often drive critical decision-making. And then we need to find a way to integrate those non-monetized variables with those that can be monetized to make a business case for sustainable investment. Academia is doing the same, notably at the Zofnass Program for Sustainable Infrastructure at the Harvard Graduate School of Design.

As long as infrastructure investment remains only a matter of cost, and not benefit over the life cycle, we will continue to have procurement-based decisions, in turn, based on delivery cost rather that societal return on investment.

We are making some headway. Several private sector companies have developed proprietary business case evaluators for their clients for assessing the benefit derived from added levels of investment in sustainable infrastructure; some public entities have done the same for their citizens, voters and tax payers. Recently, both companies and public agencies have developed models for assessing the value of sustainability. These initial models are developmental, but suggest the task is not beyond our capability.

Not everything can or should be monetized. Decision making about sustainability in infrastructure is as much an art as a science. The Consumer Confidence Index is a case in point. This highly influential report is the "result of measuring consumer perceptions" and little more... but it has a significant impact on the movement of capital, stock markets and on spending habits of consumers. Less precise in many ways than the Triple Bottom Line, it nevertheless drives decision-making.

And just as not everything should or can be monetized, all that can be monetized should not necessarily be totaled, and even when totaling is appropriate, we have to be careful about mindlessly combining metrics using different value systems. Social indexes and monetized indexes, when mixed, do not always yield useable or useful results. That is especially relevant when trying to measure sustainability and to value the results of that sustainability effort.

Scores can be deceptive not for what they tell us, but for what they exclude. And in that omission, traditional LCA has not always served fully. Focusing on costs without consideration of benefit over the life of the investment creates a distortion that almost always manifests itself 
negatively at the point of procurement... where costs are most obvious and benefits most elusive... especially when projected far into the distant future.

Decisions to create more sustainable infrastructure are not a new thing. The best practices that professions use to produce relevant and efficient goods and services have evolved over decades and stand the test of time. The very first project to have been rated by the Envision Sustainable Infrastructure Rating System earned a Gold designation for sustainability... and it was built before Envision was invented. It did so well not by happenstance, but because it was designed and constructed using precepts that had stood the test of time.

The added imperative of today and tomorrow is that there is less forgiveness in the system. Getting close is not good enough; getting it right the first time is increasingly a public priority. Measurement science and its application can help us assure that we do not miss anything that we take advantage not only of what is tried and true, but to look for new technologies, techniques and processes to continuously improve what we already know.

In this context, our metrics and how we measure become more important still, and how and in what form we make results available to decision makers critical. This information is not just of academic interest and our ability to weave it into understandable stories and experiences influences our public priorities and societal outcomes.

In all of this, defining sustainability becomes problematic because in the minds of the general public it implies longevity...making things last longer. It can of course do that, but the Bruntland Commission had something more strategic in mind in 1987 when it set the framework for not just a result, but also a way of thinking about the future. In this context it not only matters that we do the project right, but that we do the right project in the first place... that the result address the real problem and not only the symptom.

Returning to the science of measurement and its application to real world policy making, it is foolish to think that cost does not matter and that doing the right thing is always paramount. Cost should matter because resources are finite and demand for those resources growing. How a community prioritizes its allocation of those scarce resources is a primary function of government. The science of measurement can help us weight the options, but only if it remains relevant. Being right is only a part of the conversation; being listened to is more important still. 
[This page is internationally left blank] 
Caldas, Anne, ANSI

\title{
ANSI's Role in the U.S. Standards and Conformity Assessment Infrastructure
}

\begin{abstract}
The American National Standards Institute (ANSI) is a private, non-profit organization that administers and coordinates the U.S. voluntary standards and conformity assessment system. Founded in 1918, the Institute works in close collaboration with stakeholders from industry, government, academia, consumers and others to identify and develop standards and conformance-based solutions to national and global priorities.
\end{abstract}

ANSI (www.ansi.org) is the sole U.S. representative and dues-paying member of the two major non-treaty international standards organizations, the International Organization for Standardization (ISO), and, via the U.S. National Committee (USNC), the International Electrotechnical Commission (IEC). The Institute is the sole accreditor of standards developers in the U.S. and is also actively engaged in accrediting programs that assess conformance to standards - including, among others, globally-recognized cross-sector programs such as the ISO 9000 (quality), ISO 14000 (environmental) and ISO 50001 (energy) management systems. ANSI serves as a resource for information on standards and conformity assessment.

\section{Keywords}

Standards, ANSI, ANS, ISO, IEC, Process

\section{What Is ANSI? An Overview}

The American National Standards Institute (ANSI) is a private, non-profit organization that administers and coordinates the U.S. voluntary standards and conformity assessment system. Founded in 1918, the Institute works in close collaboration with stakeholders from industry and government to identify and develop standards and conformance-based solutions to national and global priorities.

Together, standards and the conformity assessment measures that ensure their effective use directly impact more than $80 \%$ of global trade - or over $\$ 3$ trillion annually - by helping to increase efficiency, open markets, and reduce costs. And ANSI is the U.S. leader in fostering that potential for the benefit of businesses across every industry and consumers around the world. ANSI is not itself a standards developing organization. Rather, the Institute oversees the development and use of thousands of standards and guidelines by accrediting the procedures of standards developers and approving their documents as American National Standards. A list of ANSI-Accredited Standards Developers is available at www.ansi.org/asd.

As an accreditation body, the Institute assesses the competence of these organizations - as well as conformity assessment bodies in a variety of disciplines - in assuring marketplace trust and confidence that goods and services meet standards' requirements. A summary of ANSI's accreditation programs is available at www.ansi.org/accreditation. 
With a long history as a trusted, neutral forum, ANSI bridges the gap between industry and government and enables information exchange and access among standards developing organizations, the general public and public-sector leaders, agencies, and legislators.

ANSI's mission is to enhance the global competitiveness of U.S. business and the U.S. quality of life by promoting and facilitating voluntary consensus standards and conformity assessment systems, and safeguarding their integrity.

\section{Domestic Activities}

Responding to national priorities and areas requiring cross- sector collaboration are key focuses for ANSI's activities. The Institute establishes ongoing standards panels, collaboratives, and partnerships as well as timely workshops to address standardization needs. These initiatives coordinate the efforts of the private and public sectors to identify gaps in existing standards and make recommendations for future work. They rely on the cooperation of stakeholders from across industries and sectors.

Recent areas of standards coordination activity include:

- Energy efficiency

- Electric vehicles

- Homeland security

- Cybersecurity

- Nuclear energy

- Nanotechnologies

- ID theft

- Healthcare IT

\section{International Engagement: ISO, IEC, and Other Standardization Organizations}

Strong U.S. leadership in international standardization is critical for continued competitiveness in the global economy. Among efforts that strengthen that position, ANSI serves as the U.S. member of the International Organization for Standardization (ISO), the International Electrotechnical Commission (IEC) via the U.S. National Committee (all IEC activities are undertaken by the USNC, a committee of ANSI), the Pacific Area Standards Congress (PASC), and the Pan American Standards Commission (COPANT); and a member of the International Accreditation Forum (IAF) and the Pacific Accreditation Cooperation (PAC). The Institute represents U.S. interests in work with the European standardization organizations (CEN, CENELEC, ETSI); serves as a liaison to regional standardization organizations in Africa, Asia, and the Middle East; and fosters bilateral agreements with national standards bodies.

With the support of dedicated stakeholders and experts across all industries, ANSI participates in almost the entire technical program of both ISO and the IEC, and administers many key committees, U.S. Technical Advisory Groups (TAGs) and international Secretariats.

ANSI accredits U.S. TAGs to ISO committees, and delegates ISO and IEC committee Secretariats to appropriate U.S. organizations. And to further strengthen the U.S. voice and promote participation, ANSI offers guidance and support services to members serving as U.S. and USNC TAG Administrators and ISO and IEC committee Secretariats. 


\section{Accreditation Services}

American National Standards www.ansi.org/psa

To help make standards development in the U.S. an equitable and open process that serves both industry and the public good, ANSI accredits standards developing organizations (SDOs) against a set of criteria to assure openness, balance, due process, and consensus in standards development - ANSI's Essential Requirements (www.ansi.org/essentialrequirements).

The Institute does not develop standards itself; rather, some 230 ANSI- accredited SDOs may submit their documents for approval as American National Standards (ANS). An ANS is a document that has been sponsored by an ANSI-accredited SDO and then approved by ANSI's Board of Standards Review as meeting certain criteria regarding due process in its development. ANSI's SDO accreditation and ANS approval processes work in tandem to safeguard the value of the ANS designation, and ANSI's impartial audits oversee the integrity of this system. To date, there are more than 10,500 American National Standards, comprising the work of thousands of experts from hundreds of SDOs representing every industry sector.

\section{Conformity Assessment Activities}

www.ansi.org/accreditation

Quality conformity assessment programs enhance confidence and trust in market transactions. ANSI administers a broad portfolio of third-party accreditation programs that recognize the competence of a range of conformity assessment bodies in accordance with guidelines and requirements defined in international standards.

These programs are increasingly specified by local, state, and federal governments, and include organizations that:

- Certify products, personnel, processes, services, and systems

- Validate or verify greenhouse gas assertions

- Issue education and training certificates

In partnership with the American Society for Quality (ASQ), ANSI also serves the marketplace via the ANSI-ASQ National Accreditation Board affiliate's accreditation services under the ACLASS and ANAB brands. ACLASS accredits testing and calibration laboratories, inspection bodies, and reference material producers. ANAB is the U.S. accreditation body for management systems and certification bodies.

\section{Sample Standards and Conformance Activities: Sustainable Construction and Manufacturing}

A sampling of standards and conformance activities relevant to Sustainable Construction and Manufacturing include:

- ANSI Accreditation Programs, including accreditation of certification programs relative to building products and other related options: www.ansi.org/accreditation

○ A list of ANSI-Accredited Standards Developers, many of whose work incorporates sustainability in building codes and related standards is available here: www.ansi.org/asd.

- ANSI held a Smart and Sustainable Cities Workshop in 2013 and issued a report that is available on ANSI's website. 
- The Energy Efficiency Standardization Coordination Collaborative (EESCC) is a crosssector group working to develop a standardization roadmap to advance energy efficiency in the built environment. Slated for publication in the summer of 2014, the EESCC Roadmap provides a national framework for action and coordination on energy efficiency standardization, charting more than 100 actionable recommendations to advance five areas of focus:

- Chapter One: Building energy and water assessment and performance standards

○ Chapter Two: System integration and systems communications

- Chapter Three: Building energy rating, labeling, and simulation

$\circ$ Chapter Four: Evaluation, measurement, and verification (EM\&V)

○ Chapter Five: Workforce credentialing

The EESCC is convened by the American National Standards Institute (ANSI) and led by co-chairs from the U.S. Department of Energy and Schneider Electric. More than 160 experts from industry, standards and code developing organizations, energy efficiencyfocused organizations, educational institutions, and other groups have taken part in the roadmap's development. The Roadmap is supplemented by the EESCC Inventory Database - a comprehensive, online source of information on standards, codes, guidelines, and conformity assessment programs that support energy efficiency in the built environment. For more information, visit www.ansi.org/eescc. (ANSI Contact: eescc@ansi.org )

- ANSI works with industry in assisting the Department of Energy's initiatives related to the US CEEM and the Superior Energy Performance Program: http://www.ase.org/projects/us-council-energy-efficient-manufacturing and http://superiorenergyperformance.energy.gov/

- As the US member body to the ISO, ANSI is involved in a range of related activities including:

○ ISO Advisory Group on Smart Cities (2014): http://www.ansi.org/news_publications/news_story.aspx?menuid=7\&articleid=38 94

○ ISO/IEC Joint Technical Committee One, Information technology (JTC1):

- Study Group on Smart Cities (JTC1/SG1)

- Through the US National Committee of the IEC, ANSI represents the US in IEC activities. These descriptions of IEC activities may be of interest:

○ IEC/SEG1, IEC/SMB SEG1: http://www.iec.ch/etech/2013/etech_1113/tech1.htm

○ IEC September 2011: http://www.iec.ch/etech/2011/pdf/etech_2011-09_LR.pdf

- IEC May 2013 - Constructing Sustainable Infrastructure: http://www.iec.ch/etech/2013/etech_0513/wld-3.htm

○ IEC September 2011 - Sustainable Manufacturing: http://www.iec.ch/etech/2011/etech_0911/wld-1.htm

- Other relevant activities include:

○ NIBS High Performance Building Activities: http://www.nibs.org/?page=hpbc

$\circ$ Visit the websites of ANSI-Accredited Standards Developers for current information about relevant work: www.ansi.org/asd. Six ASDs also hold the status of ANSI Audited Designator and are allowed to designate their standards as 
ANS upon conclusion of their consensus process. These are: ASHRAE, ASTM, IAPMO, NFPA, NSF and UL.

- International Telecommunication Union Telecommunication Standardization Sector (ITU-T) Strategic Group 5 (SG5) Focus Group on Smart Sustainable Cities (FG SSC)

- European Committee for Standardization (CEN) / European Committee for Electrotechnical Standardization (CENELEC) / European Telecommunication Standards Institute (ETSI) Smart and Sustainable Cities and Communities Coordination Group (SSCC-CG)

\section{Education and Training: Standards and Conformity Assessment}

Designed for newcomers and longtime standards professionals alike, ANSI's education and training programs offer a range of services that promote understanding of and participation in standards activities, and maximize the benefits of getting involved. For more information, please see www.StandardsLearn.org .

\section{Why are standards and conformance so important?}

Behind the scenes, standards make everyday life work. They establish quality and performance specifications for products, processes, personnel, and systems. Voluntary consensus standards are those developed through a process where all views are considered, and affected parties (including government, consumers, and business) have reached consensus on the contents. Hundreds of standards developing organizations (SDOs) and consortia are engaged in the creation and maintenance of voluntary consensus standards used in virtually every industry sector. These SDOs - and the experts who populate their committees - work to enhance quality of life and improve the competitiveness of U.S. businesses operating in the global marketplace.

Conformity assessment is a vital link between standards that define product characteristics and the products themselves. It provides demonstration that a product, process, system, person, or service fulfills the requirements identified in a specific standard. It can verify whether a particular product meets a given level of quality or safety. And it can provide information about the product's characteristics, the consistency of those characteristics, and the performance of the product. Testing, inspection, and auditing of products and management systems is as important as the standard in ensuring that products and systems are safe and perform as expected.

"Today, more than ever, standards are an imperative undertaking. Standards are the building blocks for innovation and competitiveness. Our nation's ability to compete and lead in a rapidly changing global economy is closely related to our leadership in the development and effective use of standards and standardization processes. Standards provide the common language that keeps domestic and international trade flowing. It is difficult to overestimate their critical value to both the U.S. and global economy."

- Patrick Gallagher, Director, National Institute of Standards and Technology, United States Standards Strategy, December 2, 2010

Standardization helps companies in every sector to strengthen their bottom line. Find out how at: www.standardsboostbusiness.org. 
[This page is internationally left blank] 


\title{
Carberry, John, Carberry EnviroTech - (Retired) DuPont Director of Environmental Technology
}

\section{Metrics and Systems Issues When Analyzing Chlorine Use}

\author{
Abstract \\ This paper is based on manufacturing experience, emphasizing environmental issues that started \\ in the late 1980's and is continuing. It is a brief synopsis of one of the issues we continually \\ reviewed. Generally these issues were analyzed individuals from similar companies in a \\ working group organized by the AIChE, the ACS or the American Chemistry (Industry) Council \\ and frequently facilitated by various EPA "green" initiatives.
}

\section{Keywords}

Sustainable manufacturing, chemical, green initiatives

\section{Objective}

The objective of sustainable manufacturing is:

- To optimize (probably reduce) the global warming footprint of the use of chlorine across its entire "cradle-to-grave" life cycle from collection of salt for electrolysis through disposal of waste by-product hydrogen chloride AND disposal of chlorine containing end-use products.

It should be noted that

- There is no attempt to include a secondary metric such as "toxic releases" on the assumption that the law will be enforced, and the hopeful assumption that the cost of obeying the law will somehow relate back to the energy and yield metrics for the use of chlorine.

- There is even less interest in including an even less directly connected metric such as social impact on employment. (For example, chemical plant operators are a significantly higher level job in terms of pay and benefits, than fast food servers, but there is a significant economic incentive to reduce the number of chemical operators.)

\section{Present Supply, Use and Disposal Train}

Chlorine is manufactured by primary companies (e.g., Dow) from salt by electrolysis. Chlorine manufacture is highly energy and capital intensive. Secondary manufacturers (e.g., DuPont) use chlorine as an "operator" to enable subsequent chemical operations or as an ingredient in the production of higher value chemicals. Market facing companies convert higher value chemicals to products which are sold. Companies such as DuPont, GE, and BASF are frequently secondary and market facing. There are less than 10 primary manufacturers of chlorine, dozens of secondary companies, perhaps thousands market facing companies, and hundreds of millions of end users. Use of chlorine as a chemical operator frequently generates by-product hydrogen chloride. That by-product is infrequently recycled, but rather is usually sold to a secondary market. At the end of their useful life, chlorine containing products are rarely recycled to their original use. (This author cannot presently think of a single example.) They are sometimes reused in lower value subsequent products with their own end-of-life challenges. 
At the end of their useful life, most chlorine containing products are disposed of through wastewater treatment facilities, or landfills, or incinerators (with and without energy recovery). The quality of operation of these facilities is variable, particularly world-wide.

Material substitution, product and process optimization, and advanced treatment concepts are almost always superior to recycle.

\section{Challenges}

Most systems approaches appear to wish to consider multiple issues simultaneously. Developing a metric that equitably considers highly divergent sustainability issues has, thus far, seemed far too diffiucult and not particularly useful. For example, how would one numerically include and compile; 1) One thousand tons of $\mathrm{CO} 2$ equivalent global warming emission, 2) One hundred pounds of a modestly toxic, chlorine containing emission, and 3) Ten very high level "wage roll" jobs, all in a single metric.

Normalizing the data to account for different levels of chlorine production or use will probably be seriously challenging. Per unit of mass (of chlorine in this case) works well for a single product and a single use. However, varying uses may provide varying value to society and varying end products may require dramatically different mass to accomplish the same task. A leading example is the transition from "brute force" herbicides to bio-tech based alternatives. The alternatives are very much less toxic on a per-pound basis, and are used at application rates that are about $1 / 200$ th of that for their predecessors. However, on a per pound basis their energy demand and emissions may be 10-20x that of their predecessors.

Commonly accepted, valid data for any of the following challenges is difficult, time consuming and expensive, or just plain unavailable. Tracking the use of chlorine containing products becomes very difficult at the level of market facing companies and (at least seemingly) outright impossible at the end-user level. Reasonable estimates might be made. However, most market facing companies would strongly resist providing such detailed information.

Assigning the amount of energy associated with production of chlorine should be the most straight-forward for the primary manufacturer. Even then, difficult choices for allocation to other operations (e.g. co-generation facilities or the use of waste heat for another process) cause large uncertainty. Further downstream that problem is geometrically magnified at each subsequent level. Assigning "average" global warming impact for energy consumption is variable among regions in the US, and more-so world-wide.

There are at least two technologies for recycling hydrogen chloride back to chlorine that would reduce overall system energy demand but locally would increase the energy footprint of the user while decreasing that of the supplier by an even larger amount. In addition, those recycle technologies are also capital and (to a lesser degree) energy intensive. The user generally has a higher cost of capital than the supplier. Thus by-product hydrogen chloride is usually sold on the secondary market, even when upgrading is necessary, or even neutralized and discarded. Different "approved" LCA methodologies give different answers. In addition, they all are dependent on choices made for technologies, yields, and allocation of impacts among coproducts. All these choices are usually at the discretion of the person or group doing the 
calculation. A high level of transparency of those choices is not common. A notable example that has been presented at national meetings is the difference in assessing the carbon footprint of bio-fuels using the "GHGenius Model" with Canadian data versus the same bio-fuel crop assessed with the "Biograce" model and EU data.

\section{Proposal}

Well run companies that have high quality technical workers would, over time, would reduce (at least) the energy and impacts of chlorine to sustainable levels if their business environment included:

- Environmentally sound, passively safe, terrorist resistant nuclear electrical power.

- Economically and environmentally sound bio-derived liquid fuels.

- Economically and environmentally sound emissions regulations, world-wide, uniformly enforced.

- World class, uniformly required, treatment and incineration (with energy recovery) technologies.

- A considerably reduced presence of activist and political grandstanding in this area.

Complex systems analysis protocols would not be needed. Simple economics would do the rest. 
[This page is internationally left blank] 


\title{
Castro-Lacouture, Daniel, Georgia Institute of Technology
}

\section{Resource Management and Closed-Loop Systems: Advancing Sustainable Performance Metrics}

\begin{abstract}
Sustainable performance metrics for buildings have been traditionally and intrinsically associated with green building rating systems. Such approach, however, has not fully considered the implications of interrelations among building components and systems, not only within its surroundings, but also as part of a larger system of systems. This extrapolation brings more complexity to the measurement of sustainability performance, as buildings become one element of the system rather than the system itself. Furthermore, this conventional approach has overlooked other holistic considerations that may have an impact on the measurement of sustainable performance. Such considerations include resource allocation for optimizing energy portfolios and the implications of closed-loops systems at different scales of the built environment. This paper presents these alternative approaches as a discussion toward a more holistic view that could have consequences in the metrics used to measure sustainability in building construction.
\end{abstract}

\section{Keywords}

Sustainable, Performance, Development, Metrics, Resource, Management

\section{Background}

In the last decade, sustainable performance metrics for buildings have been intrinsically associated with green building rating systems. Buildings have a significant impact on the environment because they are responsible for a large portion of carbon emissions (Keysar and Pierce 2007, Yudelson 2008) and use a considerable number of resources and energy (Pulselli et al 2007). The green building movement emerged to mitigate the impact of buildings on the environment and to improve the building construction process, bringing significant economic, financial, social, and environmental benefits (Thormark 2006, Ross et al 2006). The Leadership in Energy and Environmental Design (LEED) rating system is a widely applied rating system used to determine the level of accomplishment of environmental goals. The LEED rating system is based on credits, evaluating specific requirements of the candidate building, and has established a strong credibility among experts (Pulselli et al 2007, Ding 2008). In fact, variations of the LEED system have been chosen in countries like México, Brazil, Canada, Colombia and India. Such approach, however, has not fully considered the implications of interrelations among building components and systems, not only within its surroundings, but also as part of a larger system of systems. This extrapolation brings more complexity to the measurement of sustainability performance, as buildings become one element of the system rather than the system itself. Until recently, rating systems started focusing on options for measuring sustainability at larger scales, such as LEED for Neighborhood Development, aimed at integrating the principles of smart growth, new urbanism, and green building (US Green Building Council, 2009). 
The concept of sustainable development has become an important objective in construction projects, requiring a continuous process to meet economic, environmental, and social targets (ALwaer and Clements-Croome 2010). When aiming to achieve these targets, construction practitioners need tools that can guide them to assess their project's sustainability performance (Fernandez-Sanchez and Rodriguez-Lopez 2010). Indicators are recognized as useful tools to measure sustainable development (Ramos and Caeiro 2010) and performance across a range of sustainable principles (Singh et al 2009). A number of studies have been developed to identify sets of indicators. ALwaer and Clements-Croome (2010) proposed a consensus based model for measuring the level of sustainability for sustainable intelligent buildings. Fernandez-Sanchez and Rodriguez-Lopez (2010) developed a method to identify and select an indicator set for civil engineering projects.

Although the existing sets of indicators assess sustainability performance, there is a need to integrate them into systems to provide more useful guidance for efforts to a transition towards sustainability (Singh et al 2009). By integrating indicators into models, the interrelationships and the overlapping dimensions of the criteria could be covered (Castro-Lacouture et al 2009). Models can be used to help identify the way in which activities are unsustainable and assist decision makers to determine which actions should or should not be taken (Singh et al 2009). Furthermore, models may give effective feedback (ALwaer and Clements-Croome 2010) which can provide useful evidence to support project management (Fernandez-Sanchez and RodriguezLopez 2010). This paper discusses two integrative approaches for sustainable development that are expected to advance existing indicators and metrics of sustainable performance.

\section{Closed-Loop Systems and Resource Management}

The potential of closed-loop systems based on biofuels, that is, to manage the liquid and solid waste from a community and recycle the carbon stream into energy of sufficient quality to power the same community in a sustainable manner, has been proven elsewhere (Scott et al 2010, Amaroa et al 2011). Using the example of algae technology, maximum reductions can be made with respect to resource utilization, while efficiencies are realized using green, conservationdriven design principles. Waste streams must be considered for opportunities for reuse, recycling, and treatment processes that maximize the extraction of resources. Novel sources of inputs may then be developed that take advantage of the holistic approach to resource management. Primary residential waste streams include wastewater and municipal solid waste. In addition, thermal and other energy losses due to inefficiencies require additional demands on resource inputs. In addition to the current first-choice renewable energy generating technologies available to residential and even some commercial communities (e.g., solar photovoltaic, solar thermal, wind turbine, fuel cell), novel technologies are currently under development that may be able to address the desire for sustainable energy generation while, at the same time, address waste stream management issues through resource recovery. Among alternative energy sources for residential buildings, algae technology has emerged as a promising option due to its closedloop configuration and the ability to produce biofuel energy while reducing waste stream flow and capturing carbon. Furthermore, this technology has the potential of integrating resource and waste management, and can be complemented with other alternatives, such as photovoltaic, wind or fuel cells. A framework for integrating information from geographic information systems, building information models, construction schedules, construction cost estimates, and constructability reviews has been discussed elsewhere (Castro-Lacouture et al 2014). The 
integration is aimed at designing an algae-powered residential building environment at the level of urban neighborhood, in which the algae technology is taken as a design intervention to promote energy performance and carbon reduction within the urban system. This framework couples the design intervention with impact simulations influenced by geographic contexts, construction considerations, and digital building technology. By extending the system boundary from a closed algae cultivation system to an open neighborhood-scale urban environment, urban renewable resources such as energy, water, material and carbon flows are connected to the algae cultivation process. The framework would further advance the possibilities for sharing information among planners, architects, engineers and construction managers for innovative closed-loop sustainable energy systems in residential construction (Castro-Lacouture et al 2014). Figure 1 shows selected materials and energy inputs and outputs for a building.

This approach will address challenges such as cost, governmental incentives, regulatory barriers, or need of research and development that could overcome limitations for automating predesign, design, construction and facility management. Impact on sustainability performance metrics can be discussed in terms of cost and life-cycle assessment.

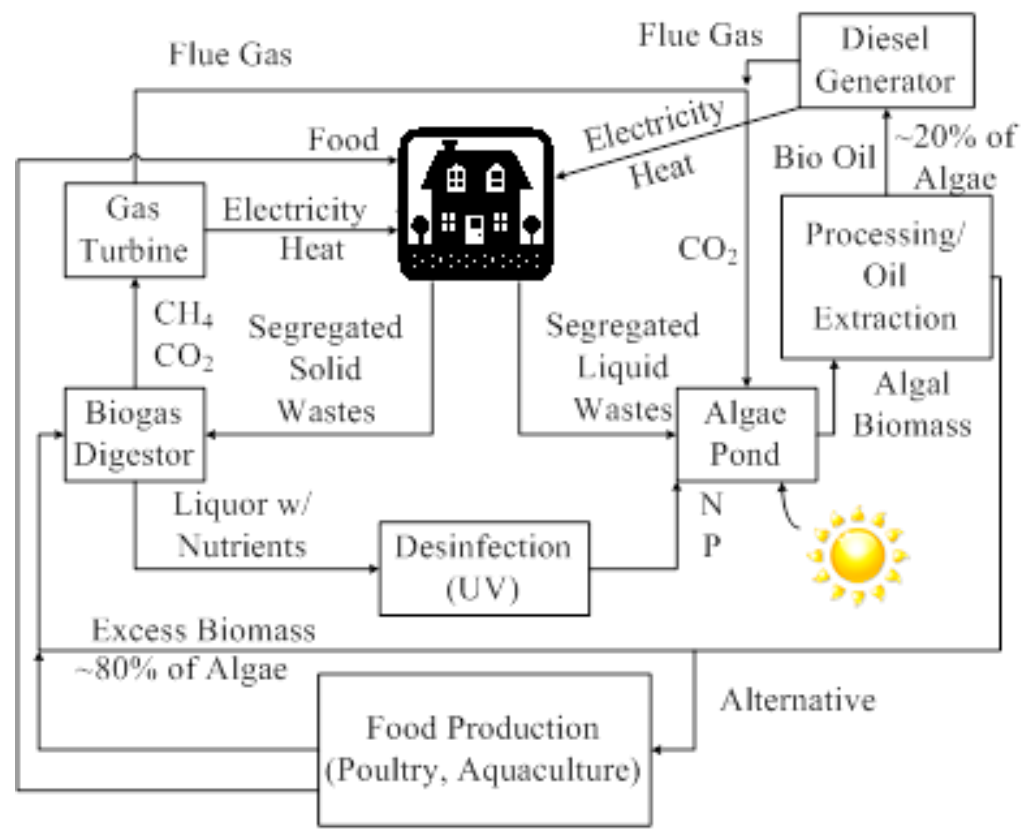

Figure 1. Closed-Loop System Using Algae Biofuel (Castro-Lacouture et al 2014)

\subsection{Cost Metrics}

Constructability considerations for algal cultivation and processing to manage the liquid and solid waste from a house or residential community and recycle the carbon stream into energy, include the following:

- Investigating costs of installing and putting in operation the system, including the collection of wastewater (i.e. toilets, sinks, showers); delivery to the pond; transfer to the bioreactor; installation of bioreactor and all ancillary systems.

- Establishing a maintenance plan for all systems mentioned above and estimate training requirements for safe and ongoing operation.

- Calculating life expectancy of the system and estimate the replacement cost. 
- Life Cycle Costs: Thorough analysis of entire value chain from a cost perspective; track and evaluate costing from the research and development phase of the system's life, through to the decline and eventual conclusion of its life.

\subsection{Life-Cycle Assessment Metrics}

To evaluate the system's environmental aspects and its potential impacts in general and specifically, the following steps are required:

- Assessing the raw materials or inputs needed to effectively operate the system and it's probable releases to the environment.

- Investigating possible reuse, maintenance and waste management.

- Analyzing different deployment schemes for the system.

- Investigating the embodied energy of the system put in place and operating.

- Determining different forms of ownership for end users and their implications in initial and running costs, maintenance and upgrades.

- Establishing training levels and parameters for the different deployment schemes.

- Investigating the safety implications of installing such a system in a residential environment. For example: Maintaining a wastewater pond in proximity to residential dwellings is not the same as a storm water retention pond.

- Experimenting and modeling issues of scalability. Siting concerns, size of reactor, size of waste water pond, distribution of energy produced, maintenance, handling of by-products and recycling.

\section{Retro-Commissioning Portfolio for Communities}

An investment strategy model for facility managers in allotting funds to the poorly performing buildings on a set community and at the same time forecasting the possible benefits of allotted investments under uncertainty has been proposed earlier (Augenbroe et al 2009). The investment strategy model is intended for use by facility and portfolio managers, to determine the best retrocommissioning investment portfolio for their campus under the given budget, optimization criteria and designated uncertainty in energy costs.

For a given a set of portfolio buildings and an applicable range of retrofit, re-commissioning, or new energy saving technologies, the portfolio optimization tool will select the best combination of improvements within a given investment budget, time horizon and risk tolerance. The tool calculates the optimal investment portfolio under uncertainty, and driven by optimization criteria of the decision makers, e.g. investment risk attitudes and/or commitment to "greenness". Benefits of investments are represented in terms of "Investment Return" and "Energy Savings"; where Investment return is the monetary value that will be saved in the operations, when a particular technology is deployed in the campus building, while Energy saving is the total energy saved by the modifying technology. Energy saving value can be considered as a measure of "Greenness", which is more significant from a pure energy saving perspective than credits provided by any green building rating system. Energy saving in this case is translated as "amount of total energy saving for all selected options, within the period of the investment horizon, expressed in primary fossil energy units. Figure 2 illustrates the schematic diagram of the strategic investment model. 
As shown in the Figure 2, the core of this model is an existing energy performance assessment tool (Augenbroe et al 2009) that allows very fast and efficient assessment of the energy use of a building, and all its separate energy consumers: heating, cooling, lighting, pump/fans, hot water, humidification, and appliances plug load. This investment model is developed as a decision making shell around the performance assessment toolkit.

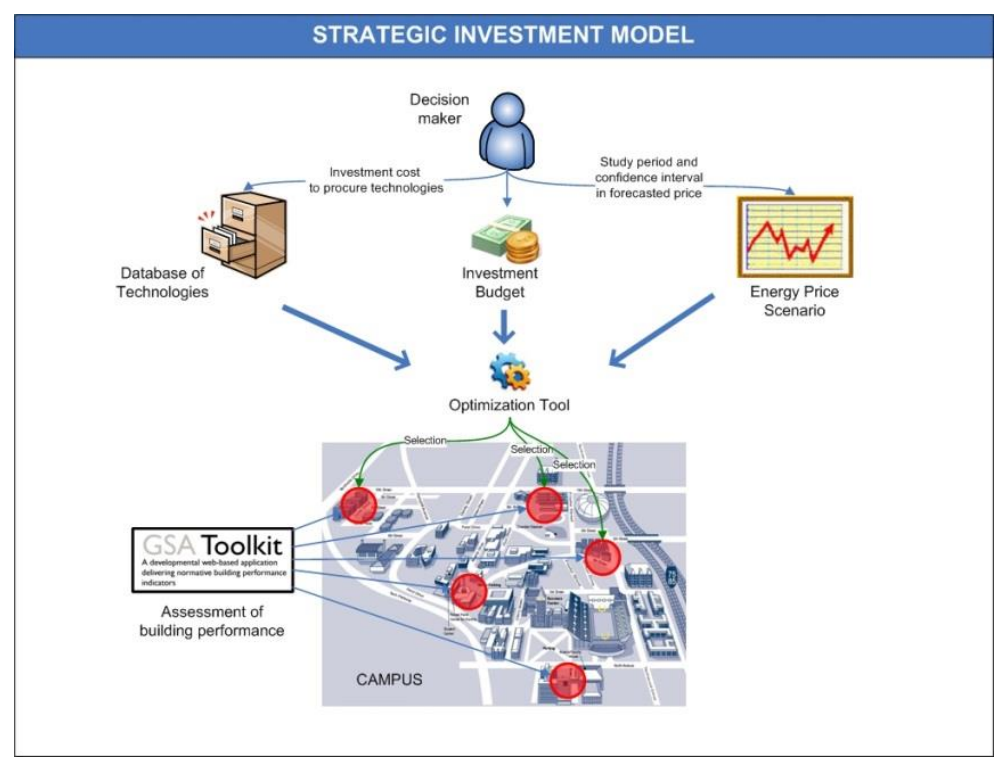

Figure 2. Schematic diagram of strategic investment model (Augenbroe et al 2009)

\section{Discussion}

As the construction industry moves toward sustainability, environmental criteria need to be considered in a systematic way when assessing sustainable performance. Sustainable performance metrics for buildings have been traditionally and intrinsically associated with green building rating systems. Such approach, however, has not fully considered the implications of interrelations among building components and systems, not only within its surroundings, but also as part of a larger system of systems, such as neighborhoods, cities, or mega regions.

Using the concept of sustainable development as continuous process to meet economic, environmental, and social targets, the use of green building rating systems needs to include modeling needs that arise from the needs of owners, decision makers, users, and the public, to assess impacts from the use of emerging energy technologies and systems. The case of algae biofuels serve as basis to illustrate how by closing the loop of waste streams, using a portion to power the building and another portion as feed, it is possible to not only complement existing energy alternatives such as photovoltaic or solar thermal, but also to address other sustainable living needs such as food, resource management, reuse or redirection of waste streams, etc.

For the case of the portfolio model for optimizing investments in retro-commissioning buildings, it was shown how the interactions among buildings and their marginal improvements could play a role in the metrics used to allocate resources. This can bring news perspectives to the way current green building rating systems measure its output values, not from an individual entity but as a component that interacts with other entities. 


\section{References}

ALwaer H., and Clements-Croome D.J., 2010, "Key Performance Indicators (KPIs) and Priority Setting Using the Multi-Attribute Approach for Assessing Sustainable Intelligent Buildings," Building and Environment, 45(4), 799-807.

Amaroa, H.M., Guedesb, A.C., and Malcatac, F.X., (2011), "Advances and Perspectives in Using Microalgae to Produce Biodiesel,” Applied Energy, Special Issue of Energy from Algae: Current Status and Future Trends, 88(10), 3402-3410.

Augenbroe, G., Castro-Lacouture, D., and Ramkrishnan, K. (2009), "Decision Model for Energy Performance Improvements in Existing Buildings," Journal of Engineering Design and Technology, Special Issue on Green Construction, 7(1), 21-36.

Castro-Lacouture, D., Sefair, J.A., Florez, L., and Medaglia, A.L., (2009), “Optimization Model for the Selection of Materials Using the LEED Green Building Rating System," Proceedings of the 2009 ASCE Construction Research Congress, Seattle, Washington, USA, April 5-7, p. 608-617.

Castro-Lacouture, D., Quan, S.J., Yang, P. P.-J., and Marshall, T., (2014), “GIS-BIM Framework for Integrating Urban Systems, Waste Stream and Algal Cultivation in Residential Construction," Proceedings of the International Symposium of Automation and Robotics in Construction, Sydney, Australia, July 9-11, 2014, forthcoming.

Ding, G.K.C., (2008), "Sustainable Construction: the Role of Environmental Assessment Tools," Journal of Environmental Management, 8(1), 451-464.

Fernandez-Sanchez, G., and Rodriguez-Lopez, F., (2010). “A Methodology to Identify Sustainability Indicators in Construction Project Management - Application to Infrastructure Projects in Spain," Ecological Indicators, 10(6), 1193--1201.

Keysar, E., and Pierce, A.R., (2007), "Decision Support Tool for Green Building: Facilitating Selection among New Adopters on Public Sector Projects," Journal of Green Building, 2(3), 153-171.

Pulselli, R.M., Simoncini, E., Pulselli, F.M., and Bastianoni, S, (2007), "Emergy Analysis of Building Manufacturing, Maintenance and Use: Em-Building Indices to Evaluate Housing Sustainability," Energy and Buildings, 39(5), 620-628.

Ramos, T.B., and Caeiro, S., (2010), "Meta-Performance Evaluation of Sustainability Indicators," Ecological Indicators, 10(2), 157-166.

Ross, B., Lopez-Alcala, M., and Small, III A.A., (2006), "Modeling the Private Financial Returns from Green Building Investments," Journal of Green Building, 2(1), 97-105.

Scott, S.A., Davey, M.P., Dennis, J.S., Horst, I., Howe, C.H., Lea-Smith, D.J., and Smith, D.G., (2010), "Biodiesel from Algae: Challenges and Prospects," Current Opinion in Biotechnology, 21(3), 277-286.

Singh, R.K., Murty, H.R., Gupta, S.K., and Dikshit, A.K., (2007), "Development of Composite Sustainability Performance Index for Steel Industry," Ecological Indicators, 7(2), 565-588.

Thormark, C. (2006), "The Effect of Material Choice on the Total Energy Need and Recycling Potential of a Building," Building and Environment, 41(8), 1019-1026.

U.S. Green Building Council, (2009), LEED for Neighborhood Development, US Green Building Council, http://www.usgbc.org/Docs/Archive/General/Docs3357.pdf (Accessed: 4 April 2014).

Yudelson, J., (2008). The Green Building Revolution, Washington, D.C., Island Press. 
Chapman, Robert, Joannie Chin, Sudarsan Rachuri, Joshua Kneifel, Andrew Persily, and Anthony Hamins, Engineering Laboratory, National Institute of Standards and Technology

\title{
Measurement Science for Sustainable Construction and Manufacturing: A NIST Perspective
}

\begin{abstract}
The mission of NIST's Engineering Laboratory (EL) is to promote U.S. innovation and industrial competitiveness in areas of critical national priority by anticipating and meeting the measurement science and standards needs for technology-intensive manufacturing, construction, and cyber-physical systems in ways that enhance economic prosperity and improve the quality of life. Sustainability is a recognized critical national priority-one that requires meaningful and rigorous measurement science for establishing suitable performance metrics. EL and its predecessor organizations have conducted sustainability-related research for over 20 years. This paper summarizes key elements of that research, beginning with BEES - Building for Environmental and Economic Sustainability - and EL's service life prediction program. More recent research on net-zero energy buildings, manufacturing processes and standards, and cyberphysical systems is also described. The paper highlights EL's vision for the future and how the results of the June 12-13, 2014 workshop on Measurement Science for Sustainable Construction and Manufacturing will help shape that vision and provide insights to other key industry stakeholders on potential opportunities for their sustainability-related research, development, and deployment efforts.
\end{abstract}

\section{Keywords}

Economic evaluation, life cycle assessment, material and energy efficiency, metrics, standards, synergies and interdependencies

\section{Background}

An environmentally conscious public is demanding products that are more sustainable. Manufacturers are seeking to meet the expectations of consumers and the demands of regulators while becoming more environmentally responsible. For consumers, regulators, and manufacturers alike, this requires that credible processes be implemented to accurately measure the environmental impacts of products (Lippiatt, 2013).

This paper describes the National Institute of Standards and Technology's (NIST's) Engineering Laboratory's (EL) current and planned research aimed at meeting critical national needs for measurement science and standards for sustainable construction and manufacturing. Measurement science provides the technical basis for standards, codes, and practices and it includes: performance metrics; measurement and testing methods; predictive modeling and simulation tools; test and calibration protocols; and evaluation technologies, systems, and practices. Because sustainability-related research is inherently inter-disciplinary, certain sections of this paper describe other NIST research that supports or complements EL's efforts. 


\section{Current Sustainability-Related Research}

EL's current sustainability-related research is focused in three areas: (1) construction; (2) manufacturing; and (3) cyber-physical systems. EL's research in the construction arena is covered first followed by manufacturing and cyber-physical systems. Cyber-physical systems are integrated networks of information technology and engineered physical elements co-designed and co-engineered to create adaptive and predictive systems that respond in real time to enhance performance.

\subsection{The Business Case for Sustainability}

NIST develops unbiased, state-of-the-art measurement science that advances the nation's technology infrastructure and is needed by industry to continually improve products and services. With that objective in mind, the Building and Fire Research Laboratory, one of EL's two predecessor organizations, began development of Building for Environmental and Economic Sustainability (BEES) in 1994, with the goal of producing a rational, systematic technique for selecting environmentally preferred, cost-effective products. The BEES software takes a multidimensional, environmental life cycle approach, in that, it considers multiple environmental and economic impacts over the entire life — cradle to grave - of a product. Considering multiple impacts and life cycle stages is necessary because product selection decisions based on single impacts or stages could obscure other impacts or stages that might cause equal or greater damage. In other words, a multidimensional approach is necessary for a comprehensive, balanced analysis of environmental and economic impact. The BEES software, which applies the technique to 230 building products, is in widespread use today, with more than 24000 users in over 80 countries (Lippiatt, 2013).

It is important to point out that BEES is product focused. The life cycle analysis approach taken in BEES is a "bottom up" process. Environmental flows are mapped to each of the 12 BEES environmental attributes. This produces a rigorous, science-based set of outcomes. For example, global warming potential is measured by $\mathrm{CO} 2$ equivalent emissions. Because buildings contain a multitude of products, a different approach is needed to measure building-level sustainability performance. A mapping of environmental flows to the National Income and Product Accounts - specifically the benchmark U.S. input-output tables - provides a mechanism to translate the BEES methodology to the whole building level. Combining this "top down" approach with the "bottom up" approach from BEES facilitates analysis through a hybrid modeling framework (Suh and Lippiatt, 2012). Those building components or systems that are crucial to the sustainability performance of the building are modeled with the bottom up life cycle analysis approach. All others are represented by their dollar values translated into environmental flows via the top-down, input-output approach. The hybrid modeling framework produces whole building environmental footprints for all 12 BEES environmental attributes.

The new software tool BIRDS - Building Industry Reporting and Design for Sustainabilityallows users to measure the sustainability performance of 11 prototypical new commercial building designs. Analyses are published covering 228 cities across the U.S. and for five different versions of ASHRAE's energy standards (Kneifel, 2013). A version of BIRDS covering new residential buildings will be released in the near future. In addition to measuring environmental footprints for the "12 environmental impact categories," BIRDS estimates lifecycle costs for each prototypical design, location, and energy standard combination. 


\subsection{Service Life Prediction}

Developing the scientific basis for linking laboratory-based, accelerated-aging studies to field exposure studies is the goal of EL's service life prediction program. While this is still a work in progress, tremendous strides have been made towards attaining that goal in two areas: polymeric materials and cementitious materials. The service life of a material is linked to sustainability in that a material that does not perform up to expectation or does not perform for its intended lifetime needs to be replaced more frequently, requiring additional environmental and economic resources

Polymeric materials include coatings, sealants, and adhesives; they are widely used products that are critical in protecting a building's interior spaces from adverse weather conditions-affecting energy consumption as well as occupant comfort - and the building envelope from moisture penetration. The NIST Integrating Sphere provides the ability to independently vary spectral irradiance, mechanical loads, temperature, and humidity with a high level of flexibility in designing artificial weathering experiments for polymeric materials (Chin et al, 2004). Smaller versions of the NIST Integrating Sphere device utilizing similar technology are currently being developed that are intended for commercial use by materials producers and researchers. EL's research has resulted in ASTM's C24 Committee on Building Joints and Sealants requiring all its weathering standards for sealants and building joints to include mechanical movement.

New results covering the concrete curing process have identified ways to reduce cracking, resulting in a significant increase in the useful life of concrete. Additional research on add mixtures and aggregates has shown how to reduce the carbon footprint of concrete-producing a ton of cement produces approximately a ton of $\mathrm{CO} 2$ emissions. Specifications on the use of fly ash as an add mixture produces a double benefit by reducing the carbon footprint associated with cement production and extending the service life of concrete. A comprehensive resource on EL's cementitious materials research is the Virtual Cement and Concrete Testing Laboratory (VCCTL) software tool. This software provides a virtual testing laboratory environment that can be used by concrete scientists, engineers, and technologists for virtual testing of cement paste and concrete materials. With this software the user can: (1) create virtual materials, using carefully characterized cement powders, supplementary cementitious materials, fillers, and aggregates; (2) simulate the curing of these materials under a wide range of conditions; and (3) calculate their thermal, mechanical, and transport properties as a function of their processing.

\subsection{Net-Zero Energy, High-Performance Buildings}

Buildings account for $41 \%$ of the primary energy consumption and $74 \%$ of the electricity consumption in the U.S., while accounting for $40 \%$ of the CO2 emissions (NSTC, 2008). To minimize the costs associated with building energy consumption, EL is developing and deploying the measurement science to move the nation towards net-zero energy, highperformance buildings in a cost-effective manner while maintaining a healthy indoor environment. A net-zero energy building is one that over the course of a year produces as much energy as it consumes.

EL's research targets the objective of net-zero energy operation by: (1) reducing the heating and cooling loads within the building; (2) developing measurement science for efficient heating and cooling equipment; (3) advancing the measurement of onsite energy generation technologies, such as photovoltaics and micro-cogeneration; (4) evaluating the energy consumption, 
greenhouse gas emissions, economics, and sustainability from a whole-building perspective; and (5) promoting implementation of research results in building energy codes, standards, and practices.

A number of green building standards, model codes, and certification systems (LEED, Green Globes, IgCC, Standard 189.1) have been developed or are being developed to measure environmental performance (Suh et al, 2014). ASHRAE/IES/USGBC Standard 189.1, Standard for the Design of High-Performance Green Buildings (ASHRAE, 2011), is the only national consensus standard for the design of sustainable buildings (other than low-rise residential). The measurement science challenge related to Standard 189.1 and other building sustainability standards is the fact that design measures to achieve one goal of the standard may be counter to another goal. For example, some measures to increase energy efficiency can compromise indoor air quality (IAQ), or vice versa. Reduced window-to-wall ratios are sometimes advocated due to the improved thermal performance of the envelope. On the other hand, less daylight and reduced connection to the outdoors can reduce occupant satisfaction with the space. Another energy-IAQ example is higher outdoor air ventilation rates. Research has shown that increased outdoor air rates reduce occupant symptoms and other health complaints, provided that the outdoor air is clean and dry. But this additional outdoor air must be heated or cooled, which consumes energy. The challenge again is how to balance the IAQ improvements with the energy costs. In order to consider such tradeoffs, improved metrics are being developed for energy and indoor environmental quality as well as tools to compare the impacts on both.

The NIST Net-Zero Energy Residential Test Facility, a home similar to many in the greater Washington, DC area, is being used to demonstrate that it can produce as much energy from renewable energy resources as it consumes on an annual basis. It also serves as a test bed to: (1) measure in-situ performance of advanced components and systems; (2) quantify energy use reductions using embedded intelligence; and (3) compare actual installed performance to controlled laboratory measurements.

\subsection{Manufacturing Processes and Standards}

Assessments of sustainability in manufacturing require a foundation of reliable metrics for all aspects of these processes. At present, standards for these metrics are not well developed, measurement methods and tools for computing the metrics lack scientific foundation, and the data needed to compute supply chain sustainability are not readily available.

Recognizing these problems, the White House Office of Science and Technology Policy has called for "accessible and affordable measurement systems and analytical tools for assessing and managing sustainability across the production process" (STPI, 2010). Constructing such systems and tools is beyond the expertise or economic interest of any single firm, industry, or business sector. The EL sustainable manufacturing program fills that gap by working to provide U.S. industry with the knowledge and tools it needs to improve its performance and competitiveness.

Research in this program has two broad thrusts. The first is concerned with developing sciencebased methodologies for characterizing, analyzing, and assessing the sustainability of individual processes and resources. Traditionally, this work has been done in an ad hoc manner for individual cases, with the consequence that methods devised for one industry sector rarely translate to another. This program, by contrast, is developing a generic, science-based and 
transferable approach to assessing sustainability. EL's research combines computational and informational models of inputs and outputs with process models based on knowledge of energy and material transformations. This approach will result in a wide range of metrics that any industry can implement to address its particular needs.

The second thrust focuses on the development of an integration framework that will combine sustainability measurements for individual manufacturing processes into a generic information model with the ability to track the sustainability performance of all the processes in a manufacturing network. This information model will, for the first time, allow industrial managers to compute total sustainability performance throughout an entire supply chain.

The program works closely with ASTM Committee E60 on Sustainability to develop standards for measures of sustainability and tools to analyze and improve those measures. A new E60 subcommittee on manufacturing has been established, with NIST leadership and technical contributions. The program also collaborates with a number of industrial partners, and is building a virtual testbed for sustainable manufacturing that will make possible more general evaluation of tools and methods than can be achieved through work with specific industries.

\subsection{Green Button}

Building on NIST's century-long partnership with the electric industry, the Smart Grid program is embarking with key industry stakeholders on one of this generation's grand challengesmodernizing the electric power grid so that it incorporates information technology to deliver electricity efficiently, reliably, sustainably, and securely. Unlike the grid of the 20th century, which primarily delivered electricity in a one-way flow from generator to outlet, the modernized grid permits the two-way flow of both electricity and information. However, creating that twoway flow requires active participation by electricity consumers.

Green Button is a mechanism enabling electricity customers to securely download their own easy-to-understand energy usage information from their utility or electricity supplier. It is an industry-led effort that responds to a White House call-to-action: provide electricity customers with easy access to their energy usage data in a consumer-friendly and computer-friendly format via a "Green Button" on electric utilities' websites (OSTP, 2013).

Armed with this energy usage information, consumers can use a growing array of new web and smartphone tools to make more informed energy decisions, optimize the size and costeffectiveness of solar panels for their home, or verify that energy-efficiency retrofit investments are performing as promised.

The Green Button initiative is designed to work with industry to support utilities and energy service providers where they are today, and also to lead the path forward towards more consumer engagement. Initially launched in January 2012, utilities committed to provide Green Button capability to nearly 12 million households in 2012. As of May 2013, 15 more major utilities and electricity suppliers signed on to the initiative. In total, these commitments ensure that more than 30 million households will be able to access their own energy information. And this number is continuing to grow as utilities nation-wide voluntarily make energy data more available in this common, machine-readable format. 


\section{Future Directions}

NIST's vision for the future is evolving around several cross-cutting themes. These include: innovative materials and the new classes of products they enable; additive manufacturing; distributed energy generation associated with net-zero energy, high-performance buildings and their interactions with the electric power grid; and the promise of increased resilience to natural and man-made disasters.

\subsection{Designer Materials}

Sustainability considerations can drive new materials and technologies for sustainable products, process innovation for sustainable manufacturing, and innovation and creativity in supply/value chain operations. Combining materials science principles and computational capabilities has resulted in quantitative conceptual design of materials. A design approach utilizing sciencebased mechanistic models combined with a small number of prototypes reduces the time and cost of product development, but also produces materials with more predictable behavior.

To address these needs, NIST has launched the Materials Genome Initiative; which will create a new era of materials innovation that will serve as a foundation for strengthening domestic industries in these fields. This initiative offers a unique opportunity for the U.S. to discover, develop, manufacture, and deploy advanced materials at least twice as fast as possible today, at a fraction of the cost. Essential to this effort is the development of a data infrastructure that will provide the needed data and tools to support this effort.

\subsection{The Additive Transformation}

Additive manufacturing (AM) refers to a class of emerging technologies for producing highlycomplex, customized components by building up materials to make objects based on a threedimensional (3D) computer model, typically built layer upon layer. Parts are fabricated directly from an electronic file representing the 3D part design that is virtually sliced into many thin layers and sent to an AM system where the layers are built up in sequence into a complete part.

AM provides the agility needed to rapidly make innovative customized complex products and replacement parts that are not realizable by more traditional manufacturing technologies or are required to be produced in low volumes. It offers additional advantages, including reduced material waste, lower energy intensity, reduced time-to-market, and just-in-time production.

Several technical barriers exist, however, that prevent AM processes from reaching their full potential. The recent road-mapping activities for AM (The University of Texas, 2009; NIST, 2013a) outline research recommendations in several areas to advance the industry and emphasize that the ability to achieve predictable and repeatable operations is critical. The issues with surface quality, part accuracy, fabrication speed, material properties, and computational requirements are significant barriers to and/or limitations for widespread implementation of AM processes throughout U.S. manufacturers. To mitigate these challenges, research is needed to focus on the problems associated with AM material characterization, real-time control of AM processes, qualification methodologies, and system integration for AM.

\subsection{Smart Grid Interoperability Standards}

EL's Smart Grid program facilitates development and implementation of the measurement science underpinning modernization of the nation's electric power grid; its aim is to improve system efficiency, reliability, and sustainability, by incorporating distributed intelligence, 
bidirectional communications and power flows, and additional advancements to create a smart grid. In response to a mandate given by Congress and the Administration, NIST, through its Smart Grid program and public-private Smart Grid Interoperability Panel, is leading the coordination and acceleration of smart grid interoperability and security standards in collaboration with the private sector (NIST, 2013b).

New measurement science and industry standards are needed to enable building systems and consumers to interact with a future smart grid, which supports the national goal to modernize the electric system by making it more robust and reliable. As building-scale renewable energy systems become more common, buildings will increasingly become generators of electricity as well as consumers. Future electric vehicles will be charged through plug-in connections managed by home and building automation systems. Utility-scale renewable generation systems will require responsive loads to match the fluctuations caused by varying wind and solar conditions. Consumers will need access to their own energy consumption data to make informed decisions about their energy consuming habits. For all these reasons, research is needed on the integration of building systems with the grid to insure the stability and success of the smart grid.

\subsection{The Business Case for Sustainability Revisited}

The BIRDS software tool provides a snapshot of both environmental performance and economic performance of prototypical new building designs. Expansion of the BIRDS analysis strategy to existing buildings - both commercial and residential - is underway. Existing buildings represent the vast majority of the nation's building stock. Thus, even modest improvements in these buildings' sustainability can have a major impact. However, additional research on the characteristics of existing buildings is needed to insure that the prototypes selected cover a large and representative cross-section of the nation's stock of buildings. The comprehensive sustainability performance metrics and database that results will be embodied in a decision framework including sustainability measures, codes and standards options, and assessment and reporting tools to help building industry stakeholders develop business cases and policies for sustainability investment choices. Research is also needed on a user-friendly interface that will extend the BIRDS analysis concept to include a design tool for use by architects and engineers. A user-based design would allow architects and building designers to test the sustainability of their buildings at the early stages of design.

The hybrid approach used in BIRDS includes an input-output matrix of environmental flows linked to the National Income and Product Accounts. While the BIRDS tool is clearly a construction-related application, the input-output matrix and the associated North American Industrial Classification System (NAICS) codes included within it permit industry-level analyses of industries other than construction to be performed. Current sustainable manufacturing research would benefit from a rigorous study of those manufacturing sectors and subsectors that represent environmental "hot spots;" these hot spots can subsequently be prioritized with the help of industry experts in terms of measurement science needs.

\subsection{Interactions between Sustainability and Resilience}

Developing and implementing sustainability strategies and improving the disaster resilience of communities both require systems-level thinking. Sustainability strategies that improve the service life of building materials and components, flexible supply chain management strategies for manufacturers, and improvements in the reliability and security of the electric power grid may also increase the resilience of communities to natural and man-made disasters. Although 
EL is also conducting research on the disaster resilience of communities, there are two promising research topics linking sustainability concepts to resilience that would benefit from focused research efforts.

Measurement science is needed to ensure sustainable and effective fire prevention, fire protection, and fire-fighting. Much of the world is moving towards sustainable construction, products, and processes. Green buildings and products, like all others, are subject to fire hazards. As the nation considers the disaster resilience of structures and communities, sustainability and sustainable solution approaches must be a primary consideration. Research is needed to close technical gaps in the interface between established fire safety practices and new "green" building technologies by developing test methods to assess green materials, products, and practices in terms of fire safety performance. Performance metrics are needed for the new building materials and methods with an emphasis on fire safety for green design. Early and reliable detection and suppression would reduce fire losses and reduce the risk to fire fighters and building occupants. Fire losses impact the building's carbon footprint which needs to be considered as part of a comprehensive analysis of the total social cost of fire. There has been recent public interest in the environmental health and safety (EHS) associated with fire retardants in furniture. California's Technical Bulletin 117 (State of California, 2000) flammability standard, the only U.S. regulation associated with furniture flammability, has typically been met by adding chemical fire retardants. At typical levels, experimental studies indicate that fire retardants provide only small improvements in burning behavior. Technical Bulletin 117 was recently revised (State of California, 2013). How industry will respond to meet the new test method remains to be seen. To address these challenges, new and innovative approaches to reduce material and product flammability are needed that carefully consider EHS effects.

As the "smart grid" becomes reality, the amount of distributed energy generation will grow in importance and potentially stimulate the creation of microgrids, which are grid architectures that can be uncoupled from the main grid and run independently. Microgrids also provide resiliency and power quality advantages to consumers and can contribute to overall stability of the grid. Future grid architectures involving fleets of stationary microgrids plus tactical mobile microgrids can play a critical role during disaster response involving wide-area electricity outages by enabling individual microgrids to continue to operate or to be brought back up before transmission lines and substations are restored. An important issue underlying the evolution of the smart grid is the way in which energy transfers back into the grid are compensated. Research is needed on this "transactive energy" aspect of the smart electric power grid to insure compensation to consumers and the return on investment to energy providers is fair and equitable.

\section{Conclusion}

This paper summarizes key elements of EL's sustainability-related research. Particular emphasis is placed on the business case for sustainability and how the various EL research efforts provide the scientific and technical underpinnings for improvements in the sustainability of buildings, manufactured products, and manufacturing processes. The paper builds on those topics to highlight EL's vision for the future. Finally, the paper opens the door for learning how the results of the June 12-13, 2014 workshop will help shape EL's vision and provide insights to 
other key industry stakeholders on potential opportunities for their sustainability-related research, development, and deployment efforts.

\section{References}

American Society of Heating Refrigeration and Air-Conditioning Engineers (ASHRAE), 2011. ANSI/ASHRAE/IES/USGBC Standard 189.1-2011, Standard for the Design of HighPerformance Green Buildings Except Low-Rise Residential Buildings. Atlanta, GA: American Society of Heating Refrigeration and Air-Conditioning Engineers.

Chin, J.W., Byrd, E., Embree, E., Garver, J., Dickens, B., Finn, T., Martin, J., 2004. "Accelerated UV Weathering Device Based on Integrating Sphere Technology," Review of Scientific Instruments, 75(11):4951-4959.

Kneifel, J.D., 2013. Benefits and Costs of Energy Standard Adoption in New Commercial Buildings: State-by-State Summaries, NIST Special Publication 1165. Gaithersburg, MD: National Institute of Standards and Technology.

Lippiatt, B.C., 2013. "Science-Based Metrics for Product Sustainability Assessment," in Treatise on Sustainability Science and Engineering, Jawahir, I.S., S.K. Sikdar, and Y. Huang (eds.). New York: Springer.

National Institute of Standards and Technology, 2013a. Measurement Science Roadmap for Metal-Based Additive Manufacturing. Gaithersburg, MD: National Institute of Standards and Technology.

National Institute of Standards and Technology, 2013b. Strategic R\&D Opportunities for the Smart Grid: Advancing Measurement Science and Standards for Smart Grid Technologies. Gaithersburg, MD: National Institute of Standards and Technology.

National Science and Technology Council (NSTC), 2008. Federal Research and Development Agenda for Net-Zero Energy, High-Performance Green Buildings. Washington, DC: National Science and Technology Council, Committee on Technology, Subcommittee on Building Technology Research and Development.

Office of Science and Technology Policy (OSTP), 2013. Expanded “Green Button” Will Reach Federal Agencies and More American Energy Consumers. Washington, DC: The White House, Office of Science and Technology Policy.

Science and Technology Policy Institute (STPI), 2010. White Papers on Advanced Manufacturing Questions. Washington, DC: Institute for Defense Analyses.

Suh, S., and Lippiatt, B.C., 2012. "Framework for Hybrid Life Cycle Inventory Databases: A

Case Study of the Building for Environmental and Economic Sustainability (BEES)

Database," International Journal of Life Cycle Assessment, 17:604-612.

Suh, S., Tomar, S., Leighton, M., Kneifel, J., 2014. "Environmental Performance of Green Building Code and Certification Systems," Environmental Science \& Technology, 48(5):2551-2560.

State of California, 2000. Requirements, Test Procedure and Apparatus for Testing the Flame

Retardance of Resilient Filling Materials Used in Upholstered Furniture, Technical Bulletin 117. North Highlands, CA: Department of Consumer Affairs.

State of California, 2013. Requirements, Test Procedure and Apparatus for Testing the Smolder Resistance of Materials Used in Upholstered Furniture, Technical Bulletin 117-2013.

Sacramento, CA: Department of Consumer Affairs.

The University of Texas at Austin, 2009. Roadmap for Additive Manufacturing: Identifying the Future of Freeform Processing. Austin, TX: The University of Texas at Austin. 
[This page is internationally left blank] 
Colker, Ryan M., National Institute of Building Sciences

\title{
Achieving High-Performance Buildings: Metrics, Data and Tools
}

\begin{abstract}
Buildings are a significant element of the national economy and a significant user of natural resources. They also support numerous other high-performance attributes. Understanding the interactions and synergies across these attributes is important to realization of owner, occupant and community goals. Having tools to assist in optimizing and integrating these attributes is essential. Some tools already exist and additional ones are emerging. However, only through a concerted focus on holistic approaches that address both design and performance can sustainability and resilience goals be achieved. Interoperability across existing and new data sets will be essential to unlocking the value of such information and facilitate understanding of synergies. Investment in metrics, tools and technologies by federal agencies and building industry participants is required.
\end{abstract}

\section{Keywords}

High-performance, interoperability, Building Information Modeling (BIM), decision support, off-site construction, energy/water nexus

\section{Introduction to High Performance}

Buildings are a significant element of the national economy responsible for over $\$ 1$ trillion of the nation's gross domestic product (GDP) and over 5.5 million jobs (BEDB 2011). They are also responsible for a large proportion of the nation's resource use - forty-one percent of all primary energy use, 70 percent of all electricity use, and 10 percent of national water use (BEDB 2011). In addition, the commercial building stock alone is responsible for carbon emissions that equal those produced by the entire economies of Canada and Mexico combined. However, sustainability and efficient resource use is not the only priority placed on buildings - they must provide safety from hazards, a conducive environment for the activities conducted within them and be cost effective for their owners.

The concept of a high-performance building captures all the performance requirements for a building and calls for the integration and optimization of such attributes to achieve a building that best satisfies the owner's intent and the use of the building. Within the Energy Independence and Security Act of 2007 (EISA), the U.S. Congress defined a high-performance buildings as, "A building that integrates and optimizes on a life-cycle basis all major high-performance building attributes, including energy conservation, environment, safety, security, durability, cost-benefit, productivity, functionality and operational consideration" (EISA, 2007). The National Institute of Building Sciences (Institute) Whole Building Design Guide (WBDG) provides further clarification and implementation strategies including focus on eight high-performance attributes - sustainability, safety/security, functionality, historic preservation, accessibility, productivity, aesthetics and cost-effectiveness (WBDG, 2014).

Given the numerous building attributes designers, contractors, owners and operators must address along with the goals and requirements provided by federal, state and local governments, 
the ability to achieve the desired results is complicated. The availability of metrics, measurement protocols and other guidance will be essential to achieve high-performance buildings.

\section{Measuring High Performance}

The Institute's Consultative Council has been focused on defining high-performance and common metrics since 2010. The Council has identified numerous challenges in the quest to measuring and demonstrating achievement of high-performance buildings - not the least of which is the establishment of a performance results index (PRI), a consistent method for evaluating across multiple buildings (Consultative 2011). In establishing such an index, the underlying metrics should be consistent and measurable. A potential method for expressing the measured results for individual buildings and providing comparisons across buildings is illustrated in Figure 1.

However, many of the high-performance building attributes identified by Congress and referenced in the WBDG can only be assessed subjectively because there is currently no sciencebased way to evaluate a building's performance in these areas. Not only does the building industry need to understand how to evaluate the subjective criteria, it must establish metrics and methods for assessing and labeling when high-performance attributes are achieved, which may require subjective evaluation.

Technical resources and metrics already exist for some performance attributes. However, in other cases, additional standards and research are needed to provide the appropriate guidance. To measure the achievement of high performance requires having a set of baseline metrics to measure against. In some cases, the baseline can be the level of performance arrived at through the current building code. In other cases, the baseline could reflect the current performance of an existing building.

This baseline performance level and additional levels of higher performance would reference current standards and other criteria as identified in the establishment of the baseline. For levels above the baseline, evaluators could use stretch codes and standards or a percentage of improvement beyond the current baseline. (Consultative 2012)

The U.S. General Services Administration (GSA) and the Department of Homeland Security (DHS) have embraced the concept of high-performance and have supported the development of tools that identify metrics and associated standards. GSA's latest update to their overall design criteria (P100) shifts from a prescriptive document to one focused on performance in a variety of the high-performance attributes (GSA, 2014).

As described by then Commissioner of the Public Buildings Service Dorothy Robyn, "In the new, performance-based P100, PBS defines the required end and leaves it to our professional partners to determine the best way to achieve it. . The new P100 is more flexible in other ways as well. Whereas the old version specified just the minimum acceptable standard, the new P100 specifies four acceptable performance levels, or tiers: a mandatory minimum tier and three tiers that correspond to increasingly higher levels of performance. This multi-tiered approach provides clear, standardized high-performance benchmarks across our portfolio, and allows a project manager to optimize desired results given a project's own unique circumstances (Robyn, 2014)." 
The methodology used by GSA is now being developed into a guide for use by the private sector. The National Performance Based Design Guide (NPBDG) is currently in beta form and currently addresses only a few of the high-performance attributes mentioned above (NPBDG, 2014). However, it is a first step in attempting to provide guidance and metrics for achieving highperformance.

While the new P100 and the NPBDG are a significant step forward (along with the DHS Owners Performance Requirements Tool), the ability to understand and take advantage of synergies across approaches to addressing high-performance is lacking. For example, how do decisions made that impact the insulation value of the building enclosure impact the ability of the enclosure to withstand hazardous events? Identifying and understanding these synergies will require additional research and data from actual buildings to provide meaningful results.

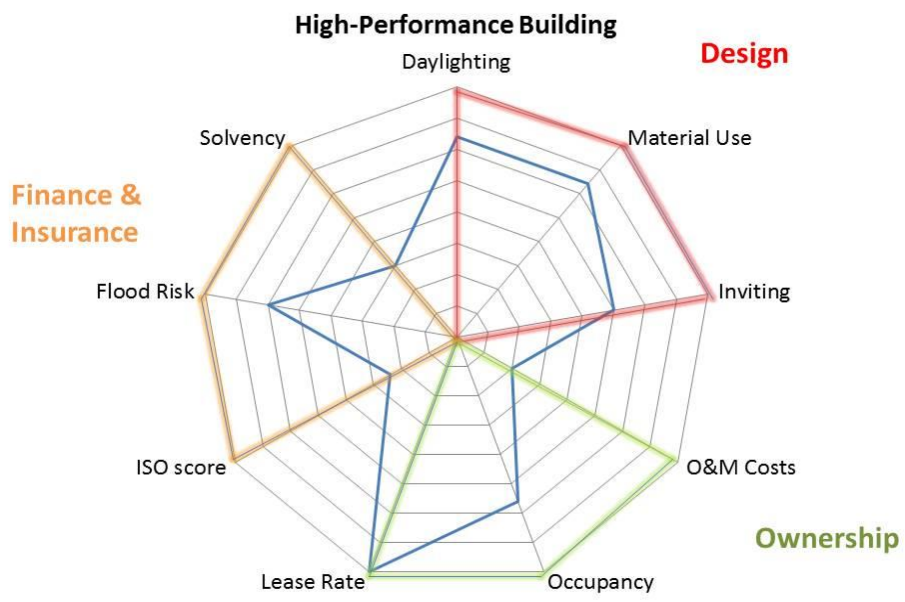

Figure 1. Methodology for Expressing Multi-Attribute Performance

\section{Interoperability}

The building industry has come relatively late to the Information Age. However, the past few years have seen a significant expansion in the availability of data and the devices that collect and generate such data. Despite this increase in availability of data, the ability to relate data across data sets is severely limited. For example, the Commercial Buildings Energy Consumption Survey (CBECS) produced by the Energy Information Administration (EIA), which is the most comprehensive survey of energy use by the U.S. building stock with information by building type and climate zone, cannot be linked with any other data set to potentially understand the correlation between building characteristics, energy use and indoor environmental quality or response to hazards. The Department of Energy is developing a taxonomy to help address interoperability across energy related data sets, but addressing interoperability across highperformance attributes has not yet occurred.

In a study conducted in 2011, the Institute found that most data sets are inadequate to support achievement of high-performance building goals. In addition, it would be beneficial 
(both in terms of cost and time) to integrate the datasets that do exist and those developed in the future to the extent practical. This would require the development of standards and protocols for data collection, data quality, anonymization, metrics and definitions (NIBS, 2011).

While data availability at a macro level is important for understanding the state of the building industry at large and its progress toward established goals, data for individual buildings is also essential to assisting building owners, operators and designers in meeting both community and individual goals. Given the diversity of participants in the design, construction and management of buildings, their relationship with data is different - how it is used, how it is collected and how it is expressed. However, the value of data increases if it is collected and maintained over time. Supporting the interoperability of data across a building's life-cycle and providing access to various users at a time and a format that is usable to them is essential to capturing the value of data and avoiding inefficiencies associated with multiple rounds of data collection. Tools like building information modeling (BIM) can help facilitate interoperability at the individual building level.

\section{Decision Support and Feedback}

While having access to data and metrics around high-performance attributes is important for achieving project goals, the ability to make decisions based on such data and metrics is essential. However, the diversity of attributes to consider often makes such decisions dizzying. Decision support tools can help designers, owners and managers navigate the complex decision making process and identify optimum solutions based on the project need. As indicated above, the NPBDG is one such tool to facilitate identification of building attributes and assist the design team and owners in identifying the ideal outcomes and providing standards to measure such outcomes against (see Figure 2 for a sample piece of this resource).

Utilization of a commissioning process to identify the owner's performance requirements (OPR) and then verify the design and construction process deliver on those requirements is essential. When utilized effectively by design teams and owners, this will provide feedback to the design and construction team resulting in improved projects that deliver on the goals established at the beginning of the project. Today, feedback loops in the design and construction process are relatively short - often members of the design and construction team are on to their next project with little budget or resources to follow-up on completed projects. However, several changes within the industry are starting to drive increased feedback loops including new project delivery methods and outcome-based performance requirements.

While not a decision support tool on its own, BIM is an important tool for facilitating decision making and allowing access to consistent information across the project life-cycle-particularly if based in open standards of interoperability. BIM must be the center of all high performance building projects because it is intended to be the repository of the information that all tools will use to optimize the attributes of the whole building (Smith, 2011).

For any decision support tool to be effective in optimizing a building's performance the project owner must shift focus from a first-cost mentality to one based on life-cycle cost of the facility. While sustainability (and other high-performance attributes) certainly has a short-term component, the realization of many goals occurs in operations over the long-term. Recognizing 
these long-term benefits and incorporating them into the initial project decision making is essential. Having access data to support such decision making is important and again highlights the need for interoperable data sets with utility for a variety of stakeholders in the process (from finance and insurance representatives to designers, owners and operators).

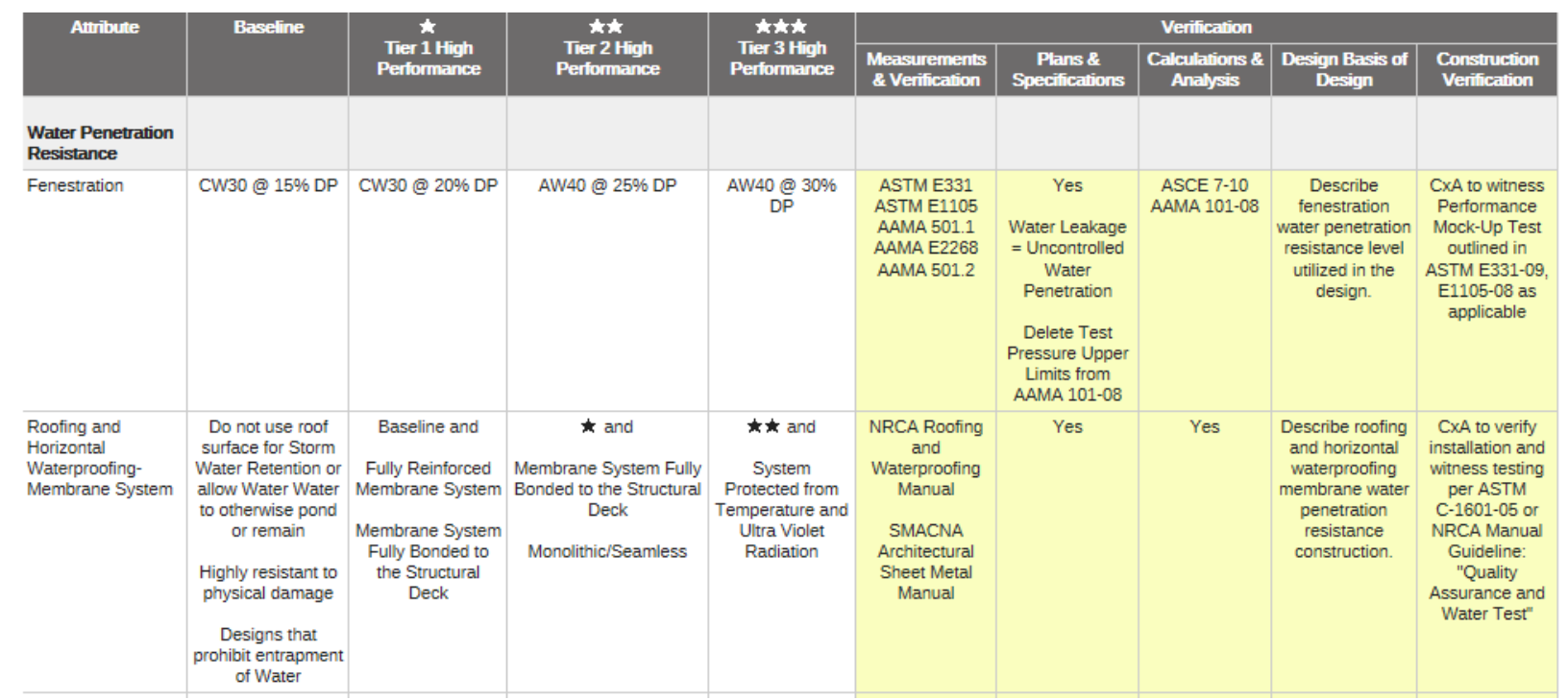

Figure 2. Sample of NPBDG Criteria

\section{Challenges}

Within the building industry, several specific challenges and opportunities have been identified that should be addressed to support realization of high-performance building goals. Just a few are outlined here.

\subsection{Off-Site Construction}

The promise of off-site construction has been discussed within the industry for decades, but its use has not taken off as one would expect. Several reasons have been identified — not the least of which is the availability of data from an unbiased source on the realization of many of the benefits touted for use of such a process. The current focus on sustainability coupled with increased pressure on project costs and schedules and the decreasing availability of skilled labor appears to indicate a perfect storm resulting in significant uptake in the process.

The Institute's newly formed Off-Site Construction Council has undertaken the task of being an unbiased resource to help advance achievement of high-performance buildings through the use of off-site construction techniques. The Council defines off-site construction as "the planning, design, fabrication and assembly of building elements at a location other than their final installed location to support the rapid and efficient construction of a permanent structure. Such building elements may be prefabricated at a different location and transported to the site or prefabricated on the construction site and then transported to their final location. Off-site construction is characterized by an integrated planning and supply chain optimization strategy (OSCC, 2014).

\subsection{Energy/Water Nexus}

One current area in sustainability where optimization has come to the fore is the energy and water nexus. Significant amounts of water are used to generate energy and energy is used to procure, treat and pump water. Thermoelectric power generation, for example, accounted for 
$41 \%$ of our nation's total water withdrawals in 2005 , according to the U.S. Geological Survey (USGS, 2009). Energy is consumed in the conveyance of water from the source to the point of treatment, the treatment process itself, the distribution of water to the point of use, the heating of water during use, and the wastewater treatment process. Of the energy consumed in the State of California, $19 \%$ is consumed in the movement, storage, treatment and heating of water (CEC, 2005).

Addressing energy and water use holistically is necessary to optimize the reduction in energy use. Some research is currently underway in this realm, but it is woefully inadequate given the scope of the issue. While the plumbing industry is interested in reducing the quantity of water wasted in buildings, little research is being conducted to understand the implication of decreased water use on existing plumbing systems and the overall water infrastructure. Re-establishment of the plumbing research facility at the National Institute of Standards and Technology (NIST) would be a valuable step in measurement science and fundamental research in this area.

\subsection{Design vs. Performance}

The building industry is undergoing a significant transition in how projects are designed and delivered. The shift is from a strictly design focused methodology to one focused on providing a solid design backed up with effective performance. Numerous shifts are underway to support this new paradigm - design processes are becoming more integrated to include members of the operations and maintenance staff, contracts with performance requirements are emerging (whether as part of public-private partnership or outcome-based performance requirement), outcome-based requirements are being incorporated into codes, and standards are increasingly focused on performance and not prescriptive requirements.

Achieving a truly sustainable and resilient built environment depends on the actual achievement of results and not just an intention during design. Advancing the shift to a performance-based design process will require engagement of all building industry participants. Tools to facilitate such a transition must be developed and enhanced. This includes modeling tools that are used to help inform the design process but do not necessarily translate to actual performance (again access to real data will assist in such updates).

\section{Conclusions}

Assuring that buildings — both new and existing — meet the variety of requirements placed on them by owners, occupants and the communities they serve is a complex task. Understanding these various requirements and being able to integrate and optimize them to achieve the desired results is necessary. While the desire to integrate and optimize such attributes is growing within the industry, the tools, techniques, technologies, metrics and other guidance to make it happen has not caught up. Investment in these types of resources by both the public and private sectors is essential.

\section{References}

Buildings Energy Data Book, 2011. Department of Energy, Washington, DC. http://buildingsdatabook.eren.doe.gov/.

California Energy Commission, 2005. California's Water - Energy Relationship, Sacramento, CA. 
Consultative Council, 2011. Moving Forward: Findings and Recommendations from the Consultative Council, National Institute of Building Sciences, Washington, DC.

Consultative Council, 2012. Moving Forward: Findings and Recommendations from the Consultative Council, National Institute of Building Sciences, Washington, DC.

Energy Independence and Security Act of 2007. U.S. Congress, P.L 110-140.

GSA, 2014. P100: Facilities Standards for the Public Buildings Service, Washington, DC. http://gsap100.wbdg.org.

NIBS 2011. Data Needs for Achieving High-Performance Buildings, Washington, DC.

NPBDG, 2014. National Performance Based Design Guide, National Institute of Building Sciences, Washington, DC. http://npbdg.wbdg.org.

Off-Site Construction Council, accessed May 27, 2014. http://www.nibs.org/?page=oscc.

Robyn, D., 2014. PBS Announces New, Performance-based Facilities Standards. GSA blog, Washington, DC. http://gsablogs.gsa.gov/gsablog/2014/03/14/pbs-announces-newperformance-based-facilities-standards-affects-all-new-construction-and-major-ra-projects/.

Smith, D.K. and R.M. Colker, 2011, "Why High Performance Buildings Require Building Information Modeling," NEMA electroindustry, August 2011.

USGS, 2009. Estimated Use of Water in the United States in 2005.

WBDG Whole Building Design Guide, accessed May 23, 2014. Whole Building Approach, National Institute of Building Sciences. http://wbdg.org/wbdg_approach.php. 
[This page is internationally left blank] 
Cross, John, American Institute of Steel Construction LLC

\title{
Life Cycle Assessment Valuation: the Economic Precedent
}

\begin{abstract}
The development of a system of metrics for sustainable performance of the built environment is a daunting task. Even more daunting is the challenge of integrating the value represented by those metrics into the decision process of owners, designers and construction professionals. The linkage between definable metrics and the value associated with them must take into account the relative value of each impact category and the time spectrum over which they occur. This paper suggests that four questions are critical to this process: (1) Are the assessment categories currently being used in standard LCA analyses capturing the value difference between products flowing through dissimilar supply chains? (2) What common basis of value exists to assess the relative value of different environmental impacts? (3) How are impacts allocated over the service life of the product and subsequent product lives for recycled products? (4) How are the impacts associated with a virgin product transferred to subsequent products when the virgin product no longer has economic value?
\end{abstract}

\section{Keywords}

Life Cycle Assessment, time series, impact categories, allocation

\section{Background}

The development of a simple system of metrics to measure sustainable performance of the built environment is a daunting task. Even more daunting is the challenge of integrating the value represented by those metrics into the decision process of project owners, developers, design professionals, general contractors, trade contractors and the ultimate occupants of the building.

The current trend toward the use of Life Cycle Assessments (LCAs) for comparison of alternative products within an overall system such as a building in some ways parallels the development of current monetary practice related to financial transactions. Even though the stated purpose of a LCA is to compare like products (particularly variants of a single product), the LCA is being viewed as a means of measuring the relative value of alternative solutions of combined product systems or, in particular, one building design containing specific materials and products with an alternative building design containing a different set of product and material selections. This process is analogous to the economic selection of one product over another based on product cost. From a cost or economic perspective, if all else is assumed to be equal the less expensive product is chosen.

However, all else is never truly equal. This inevitable inequality between products was originally addressed through bartered transactions as an alternative to direct trades. Two individuals may have the desire to exchange cows, but what if one cow happens to be older than the other cow? The older cow would be of lesser value because of a shorter life span to produce milk. Yet both are cows, both are producing milk, both consume equal amounts of feed and both weigh the same amount. The solution was to add value to the older cow to compensate for a shorter period of milk production. The transaction moved from a simple exchange to a bartered transaction in which an old cow and a lamb were exchanged for the younger cow. 
Over time value was assigned to certain transactional substitutes. The younger cow was no longer "priced" in terms of a similar product, but in terms of a measure of a common, valuable item that could then be exchanged for other items. Aristotle describe this nearly 3000 years ago: When the inhabitants of one country became more dependent on those of another, and they imported what they needed, and exported what they had too much of, money necessarily came into use. For the various necessaries of life are not easily carried about, and hence men agreed to employ in their dealings with each other something which was intrinsically useful and easily applicable to the purposes of life, for example, iron, silver, and the like. Of this the value was at first measured simply by size and weight, but in process of time they put a stamp upon it, to save the trouble of weighing and to mark the value.

So a system of currency with a defined metric enabling it to be related to value became a reality.

But soon currency became an economic entity in its own right with an inherent value, not just a barter value. Those who lacked currency sold possessions for it, labored to earn it or borrowed against a future commitment of repayment to gain it. Those who lent this new currency suddenly realized that they could demand more for repayment than the amount they had lent in the original transaction and the concept of interest and usury was born. And with it the common financial principle popularized today as "a dollar today is not the same as a dollar tomorrow."

So why this over-simplified economic lesson in a paper dealing with the measurement of environmental impacts for sustainable construction? The simple answer is that the current process associated with performing LCAs and accounting for comparative environmental impacts is still at a stage that is the equivalent of early direct trades. No consistent measures of value categories exist. No mechanism exists for assessing the relative value of various impact categories. No currency exists to consolidate sustainability related metrics. And, most telling, no comprehensive recognition of the time value of the impacts is considered.

\section{The Example of Structural Steel}

The evaluation of the environmental impacts of structural steel compared to other materials and available production methods serves as an interesting illustration of this lack of maturity in the LCA process.

Steel is commonly produced through two processes. One process uses a basic oxygen furnace (BOF) and utilizes iron ore, coke, limestone and steel scrap as primary feedstock. The steel produced by a BOF is considered virgin steel originating from raw materials that are extracted through a mining process. The other process uses an electric arc furnace (EAF) to melt steel scrap which has been recovered from post-industrial and post-consumer recycling material flows.

The economic cost of production is not the same for the two processes. The per ton cost of producing steel using BOF method is primarily dependent on the capital cost of equipment and the cost of labor, iron ore, coke and steel scrap (the steel scrap content of BOF steel is $25 \%$ to $30 \%$ ). The per ton cost of EAF production is primarily dependent on the capital cost of equipment and the cost of labor, steel scrap (the steel scrap content of EAF steel is $90 \%$ to $99 \%$ ) and the cost of electricity. In most cases BOF production requires greater man-hours per ton and 
the cost of the feedstock materials, while variable, is greater than that of EAF production resulting in a lower economic cost of production for EAF material.

The environmental impacts measured on a cradle-to-mill gate basis for the two processes vary significantly. Carbon equivalent emissions (greenhouse gases) for the BOF process range are roughly 2.5 times that of the EAF process. Variations also exist in the other commonly used impact categories.

All steel products used in construction (such as structural steel sections, steel deck, reinforcing bar, plate and pipe) can be produced using either method of production as can common consumer products such as steel cans, packaging, vehicle bodies and appliances. Every steel product must meet ASTM grade standards that specify not only minimum and maximum material strength parameters but also the metallurgical makeup of the product. As steel products must conform to a grade standard that is independent of production method, there is no functional difference between products produced using the BOF or EAF method.

All steel mills are product specific even though they can produce that product to the requirements of differing ASTM grades. For instance a structural steel mill can produce hotrolled structural sections that meet the requirements of ASTM A36 or ASTM A992, but the same mill cannot readily switch from producing hot-rolled structural sections to producing hot-rolled coil steel.

At the same time different products have different service lives. This not a function of the production method, but rather of the type of product produced. Structural steel sections and other steel products used in construction can easily outlast the service life of the building structure they are part of - typically assumed to be an average of 60 years. Steel cans made from coil steel may have an average service life of less than a single year. Steel used in vehicle manufacture survives for the life of the vehicle which on average for light vehicles in the US is 11.4 years.

At the end of the useful life of the building or the consumer product, the building is deconstructed or the consumer product is disposed of with the steel components entering the waste stream. As the waste is collected and processed an attempt is made to recover the steel content through magnetic separation and sorting for the purpose of recycling. The recovery rate, sometimes referred to as the recycling rate, of the steel varies by product. Construction components such as structural sections, deck and piping have a very high recovery rate of $98 \%$, while reinforcing steel used in concrete construction has a recovery rate of $70 \%$. The recovery rates for consumer products also vary by product type. The recovery rate for steel used in automobiles is $93 \%$ while the rate for cans is $71 \%$. The recovery rate for a product and the ability of that product to be recycled into new steel with no loss of attributes is not a function of the process (BOF or EAF) used to produce the steel used in the product.

Recovered steel from one steel product can serve as the recycled feedstock for a different steel product. Shredded automobiles can become hot-rolled structural steel sections. Reinforcing bar can become steel coil for appliances. And hot-rolled structural sections can become reinforcing bars. 
In 20136.5 million tons of hot-rolled structural steel was produced in the United States. Of these 6.5 million tons, 5.5 million tons were used for domestic construction while 1 million tons were exported outside the United States. At the same time 400,000 tons of steel were imported from foreign structural steel mills. Unlike the rest of the world where structural steel is produced by both the BOF and EAF processes, all structural steel produced in the United States is produced using the EAF process. In terms of the two production methods $60 \%$ of all types of steel produced in the US are produced by EAFs while on a global basis only $30 \%$ is produced using the EAF process.

\section{Key Questions}

The fact that hot-rolled structural sections are only produced in the US using the EAF process with fully recycled feedstock materials (no iron ore, coke or limestone) and very little imported BOF product is used in the US raises several issues with LCA comparisons of building framing products that are very similar to the early challenges faced by economic transactions:

1. Are the assessment categories currently being used in standard LCA analyses capturing the value difference between products flowing through dissimilar supply chains such as between virgin products like wood and concrete versus a fully recycled product such as hot-rolled structural steel? Is the type of feed consumed by the older cow considered in the barter transaction?

2. What common basis of value exists to assess the relative value of different environmental impacts? Based on all the factors how many shekels is the younger cow worth?

3. How are impacts allocated over the service life of the product and subsequent product lives for recycled products? How long will the younger cow live and how many calves will be produced and how long will the calves live...?

4. How are the impacts associated with a virgin product transferred to subsequent products when the virgin product no longer has economic value? How much can a calf be sold for in the future and how much is that worth to the seller today?

These questions have been raised and wrestled with over the past several years but no common agreement as to their answers has been reached. That is not surprising as our system of currency and financial trading has taken millennia to reach its current level of sophistication and arguments still occur over exchange rates and the manipulation of national currencies. In a sense, the sustainability community is attempting to do in a decade what has taken the economic system over 3,000 years to mature into.

The purpose of this paper is not to answer these four questions, but to posit why answering those questions is critical for the proper evaluation of a construction product such as hot-rolled structural steel.

\section{Question \#1}

Are the assessment categories currently being used in standard LCA analyses capturing the value difference between products flowing through dissimilar supply chains such as between virgin products like wood and concrete versus a fully recycled product such as hot-rolled structural steel? 
The current assessment categories used in the majority of LCA evaluations include (1) global warming potential; (2) ozone depletion; (3) ozone formation; (4) acidification; (5) non-renewable energy consumption; and (6) eutrophication. These are important and critical assessment categories, but are they the only assessment categories that matter? No, a large number of other assessment categories exist as well, including but not limited to: (1) depletion of elemental abiotic resources; (2) depletion of fossil abiotic resources; (3) smog; (4) respiratory emissions; (5) eco-toxicity; (6) land usage and (7) fresh water consumption.

These additional categories are not considered in the vast majority of LCA analyses. Why? In some cases (smog) they are seen to be only of regional importance or in other cases (land resource usage) they are dismissed out of hand by the proponents of virgin material production as unquantifiable. While both assumptions are very questionable, it is more important to note that the lack of consistent agreement on impact categories will always result in marketplace confusion and disagreement between the proponents of various product types.

For example, the strength of recycled products is their limited use of depleteable resources and minimal land usage, yet these categories are set aside in favor of the use of a set of "least common denominator" categories that focus on the impacts associated with virgin products. It is often the case that recycled products have lesser or equal impacts than virgin products in the six categories currently being assessed, but the additional, incremental value brought by the recycled product is being ignored. The fact is that if all impact categories are not assessed, then the "value" of a product cannot be determined. If the "value" cannot be determined, then a meaningful product selection decision cannot be made.

Need \#1: Any measurement system put in place for sustainable construction must take into account all potential impact assessment categories.

\section{Question \#2}

What common basis of value exists to appropriately assess the relative value of different impacts?

The inclusion of a wider group of assessment categories in the LCA process does not mean that all assessment categories are to be valued on an equal basis.

The current trend among proponents of sustainable product selection is to dismiss "single attribute" products as unworthy of consideration as a sustainable product simply because they are seen as having a single, strong attribute. The statement is often made that steel is not sustainable simply because it is recycled and that rating systems and standards should not recognize the use of structural steel as making a sustainable contribution to the project. However, the argument is misstated. It should not be that about "single attribute" products, but rather about "single attribute assessment."

As an alternative to a "single attribute assessment" model various rating systems, codes and standards have attempted to create a more holistic prescriptive approach to attribute assessment. 
ASHRAE 189.1 requires that a prescribed percentage of materials and products used in a project exceed a minimum of two compliance thresholds. The International Green Construction Code creates a meaningless metric using an apples plus oranges plus bananas approach adding up items like bio-based content, recycled content, recyclable content and indigenous materials on an equal basis to reach a prescribed total. Neither truly evaluates the relative value of each category and fails in the attempt to become a poor man's prescriptive LCA.

But even a LCA fails in this regard. The LCA process assesses the relative impacts of comparative products within certain impact categories. It does not provide any mechanism of assessing the relative value of each category compared to other categories. In the case of the cows this would mean that the difference in age, weight, feed consumption, milk production, calving potential and current health would all be valued equally. Clearly that is not the case.

Some systems advocating LCA usage such as LEED V4 have attempted to address this problem by requiring that one specific LCA category (global warming potential) show a minimum $10 \%$ improvement, two other categories also show a minimum $10 \%$ improvement and no category show more than a 5\% degradation. But even this does not reflect an actual weighting of the value of individual impact categories but only a statement of their relative priority.

Need \#2: The relative value of environmental impact categories needs to be defined before any sustainability "currency" can be coined.

\section{Question \#3}

How are impacts allocated over the service life of the product and subsequent product lives for recycled products?

This question has two aspects.

The first is the comparison of the embodied environmental impacts of comparative products over the life of the building of which they are a part. This issue has been addressed to a certain extent by considering the overall impact of the product to include not only the embodied impacts but also the impacts that would be associated with the maintenance and replacement of the product if the life of the expected life of the product is less than the service life of the building. However, a critical consideration has been ignored in that future impacts are assessed the same as current impacts. There is no time value associated with environmental impacts. In financial terms, environmental impacts are not present-valued or future-valued.

This is a complex issue. Is it better to have significant environmental impacts at the front end of a building's service life with no future impacts due to a lack of need for maintenance or replacement or to spread out the environmental impacts of required maintenance and replacement activities over the service life of the building? Is it better to emit 50 tons of CO2e in the production of the material used in the project and have no additional material related emissions over a 60 year service life or to emit 20 tons of $\mathrm{CO} 2 \mathrm{e}$ in the production of a different material, but anticipate maintenance and replacement activity every 10 years that would generate an additional 5 tons of $\mathrm{CO} 2 \mathrm{e}$ per cycle? 
The second aspect of this question is particularly applicable to recycled products such as structural steel. Under current LCA methodologies either a credit or a burden is added to the cradle-to-mill gate environmental impacts to account for the reuse of previously produced steel. Virgin steel produced in a BOF receives a credit while steel produced from recycled feedstock in an EAF is assessed a burden. The calculation methodology is a bit obtuse but the end result is that the difference between the environmental impacts of the BOF and EAF processes are amortized over the expected life of the steel in the product based on the recovery rate of that product. For example (and the actual calculation methodology will provide slightly different results) if the difference between average BOF production and EAF production in terms of greenhouse gases is 1.4 tons of $\mathrm{CO} 2 \mathrm{e}$ per ton of steel then that 1.4 tons of $\mathrm{CO} 2 \mathrm{e}$ would be assessed as a burden to the EAF product but amortized over the number of times the virgin steel in the product would be recycled.

For structural steel the recovery rate is $98 \%$. That means $2 \%$ of the virgin steel is lost each time the product is recycled or, looking at it from the other perspective, the product would travel through 50 product cycles before all of the original virgin steel would be lost.

The critical question is whether this level amortization of impacts is an appropriate approach for assessing environmental impacts or whether there needs to be some form of present-valuing these future impacts. A dollar today is not the same as a dollar tomorrow.

Need \#3: A time-value based methodology of combining present environmental impacts with future environmental impacts needs to be developed.

\section{Question \#4}

How are the environmental impacts of a virgin product transferred to subsequent products when the virgin product no longer has economic value?

Closely related to the discussion in question \#3 is the issue of determining what portion of the environmental impacts of a virgin product should be transferred down the chain to subsequent products made from material recycled from the original product.

The assumption of the current methodology used by metal producing industries is that the production of a product from recycled scrap simply displaces the production of that same product from virgin material. Therefore the relative value in terms of environmental impacts is that the virgin product and subsequent products are equal. When considering steel this may be the case when the product supply chain for the specific product contains both BOF and EAF produced products. But if the supply chain for the specific product is solely based on recycled steel feedstock and adequate scrap exists to maintain production through only using EAFs then this assumption is not valid as no displacement of virgin product occurs. Such is the case of domestically produced and consumed hot-rolled structural steel sections.

In addition, no steel product is produced for the sole purpose of being recycled into another steel product. Each steel product is produced based on the economic incentive of selling that 
particular product at a profit without concern for its future economic value as scrap. For the purchaser of the product the real cost of the product may be the current cost of the product less the present value of the scrap value of the product at the end of its life, but that is not the producer's economic justification for the original production of the product.

The answer to this issue of assessing environmental impacts associated with virgin production has two extremes. At one end of the spectrum all impacts associated with the production of the virgin product are assigned to the virgin product. At the other end of the spectrum, the virgin product is treated simply as an equal in a series of product cycles. Neither extreme seems appropriate. One potential answer may be based in factoring in the marketplace demand for the scrap material at the end of the product's life and allocating virgin impacts between initial and subsequent products based on the ratio of the product's selling price to the value of the scrap at the end of life.

Need \#4: A methodology needs to be determined to equitably allocate environmental impacts between virgin production and subsequent recycled material based production.

\section{Conclusions}

The monetary system that supports the trading of goods and services has evolved and matured over several millennia. It is not surprising that the development of a functional system of assessing metrics relating to the new economy of sustainability is still a future, yet critical goal. Any such system must take into account the full spectrum of environmental impacts, the relative value of those impacts, the time value of those impacts and address the economic distinction between virgin and recycled material production.

\section{References}

American Institute of Steel Construction, 2014. Structural Steel: An Industry Overview. American Society of Heating, Refrigeration and Air-Conditioning Engineers, Inc., 2011. ANSI/ASHRAE/USGB/IES Standard 189.1-2011, Standard for the Design of High-Performance Green Buildings. Aristotle (384 BC - 322 BC). Politics, Book 1. International Building Council, 2012. International Green Construction Code. United States Green Building Council, 2013. LEED Version 4. 
Davidson, Cliff I., Syracuse University, and Shahzeen Z. Attari, Indiana University

\title{
Metrics of Sustainability in Human Development: How Well Do People Understand the Impacts of their Activities?
}

\begin{abstract}
In this paper, we apply the results of current research to point out the importance of developing metrics for how well people understand the impacts of their daily activities and household decisions. The research shows that people generally have a poor understanding of their impacts related to energy use and energy savings. Overall, people underestimate the amount of energy they use and energy they could save by a factor of 2.8. Furthermore, the underestimate is greatest for use of appliances with the highest energy consumption. These findings suggest that additional research on metrics of people's understanding of their own impacts is important, along with research on what can be done to educate people and help them change habits that run counter to societal transition toward sustainability.
\end{abstract}

\section{Keywords}

Behavior, decision heuristics, energy, households, impacts, metrics

\section{Background}

Current methods of constructing buildings and infrastructure as well as modern manufacturing operations are known to be unsustainable. In particular, we know that continuing with "business as usual" activities will increase risks of various types. Rising prices of many building materials, eroding coastlines, and more frequent flooding due to stronger storms and increasing area of impermeable surfaces are all evidence of these risks. Such observations have accelerated interest in measuring society's move toward sustainability. Yet quantitative measures of change toward a more sustainable state are still in the early stages of development.

One area critically important to societal change toward sustainability is human behavior. Any movement in the direction of a more sustainable society will require changes in behavior: people are likely to have smaller living spaces, fewer personally owned household appliances, and shorter distances to school, shopping, work, and play. Making the transition is expected to be difficult: people are naturally resistant to change, especially change that they don't understand and may strongly disagree with.

To make progress on enabling societal change, we need metrics of what people understand and what they don't understand about the impacts of their activities. This is a necessary first step in making preparations for the difficult decisions ahead when change will become a necessity. In this paper, we begin by defining types of metrics of sustainability to provide a context for the unconventional metrics we describe related to human behavior. We then apply data from current research to assist in suggesting future work related to measuring people's understanding of how their personal decisions and activities impact environmental, economic, and social sustainability. 


\section{Types of Sustainability Metrics}

According to the U.S. Environmental Protection Agency (2003), we move toward greater sustainability when we "maintain or improve the material and social conditions for human health and the environment over time without exceeding the ecological capabilities that support them." Note that "sustainability" is a long-term goal, while "sustainable development" is the process of moving toward that goal (Clift, 2000).

One study of sustainability proposed four categories of systems for which the assessment of sustainability can be applied (Sikdar, 2003). Type I refers to Global Systems, where problems of climate change, the ozone hole, world-wide resource shortages, and other global-scale problems exist. Type II focuses on regional systems. The regions of interest can be defined by natural boundaries such as ecosystems or watersheds, or they can be defined by human boundaries such as cities or countries. Type III considers sustainability at the company scale, addressing use of resources and production of wastes by individual firms. Finally, Type IV considers the sustainability of specific products and technologies, even though their effects may involve spatial scales larger than their immediate surroundings due to extensive supply chains, long-distance shipping, and widespread transport of wastes.

In addition to varying spatial scales, sustainability can be characterized by the number of dimensions a metric refers to. Figure 1 illustrates the three dimensions of sustainability, showing the economic, environmental, and societal aspects.

Some metrics are strictly one-dimensional. The attitude of a supervisor toward his or her employees is an issue in social sustainability, while the number of years a company has been operating at a profit is a measure of economic sustainability. On the other hand, consider a manufacturing process where water is a necessary input, and the output wastewater must be treated before release to the environment. The amount of water used to manufacture each product can be considered a metric of sustainability of the process. The amount of water used per product has an economic impact on the company, both from purchasing the water and from treating the wastewater. But in addition, the extent of treatment (or lack of treatment) can have an effect on the receiving waters and could possibly cause environmental damage. Therefore this is a twodimensional metric. Another example of a two-dimensional metric is the cost of manufacturing a product. This cost affects both its purchase price on the open market and the economic viability of the company. Since the purchase price of the product influences who can afford to buy it, the cost of manufacturing a product has both economic and social sustainability implications. Figure 2 shows the possible 2-D interactions.

Some metrics encompass all three dimensions. The amount of fossil fuel used over a period of time is a key driver of our economy, and it impacts the environment through pollutant emissions as well as the release of carbon. But in addition, the supply of fossil fuels is finite, and our continued use is likely to affect the amount of non-renewable energy available for future generations which impacts social sustainability. Similarly, the amount of a metal used in manufacturing, e.g., copper, is also a three-dimensional metric for the same reasons. By extension, we reason that the amount of any non-renewable resource used over a period of time is a three-dimensional metric 


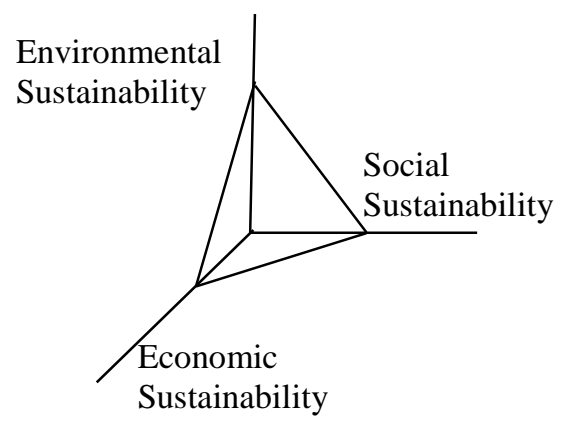

Figure 1. The Three Dimensions of Sustainability

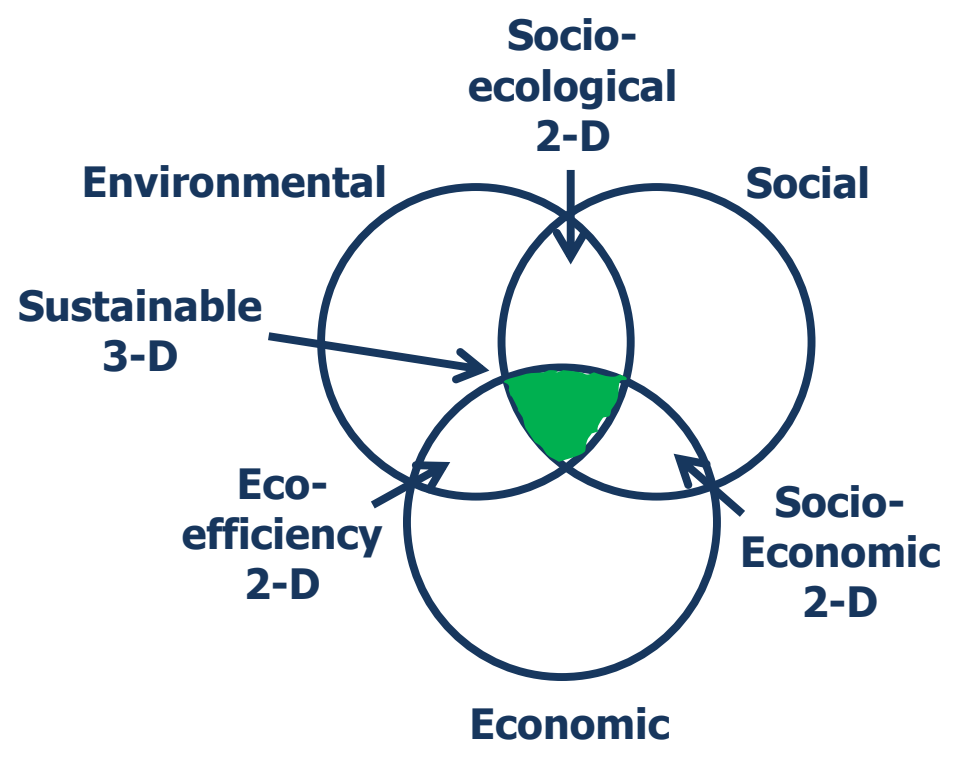

Figure 2. Two-Dimensional and Three-Dimensional Metrics of Sustainability

\section{Metrics Related to Human Understanding}

Human behavior is the key determinant of moving toward or away from sustainability in all three dimensions. Economic sustainability is influenced by an individual's career choices, purchasing decisions, and financial investments. Social sustainability is determined in part by how people interact with others, how they participate as members of organizations, and what decisions are made by the leadership of organizations. And environmental sustainability is a direct result of lifestyle decisions such as where to live, what form of transportation to use, what to buy, and how to spend free time. But how well do people understand the influence of their actions on sustainability? We can get a rough idea by examining people's perceptions of one activity, namely their use of energy. Energy use is one of the key factors affecting sustainability: most forms of energy involve combustion of hydrocarbons which impacts climate change, and current energy use is dominated by non-renewable hydrocarbon sources. Relevant to the theme of this workshop, the construction industry uses large amounts of energy in constructing buildings and infrastructure; cement production accounts for about $5 \%$ of the total global carbon dioxide emissions (World Resources Institute, 2014). Furthermore, the design of buildings has a major effect on their use of energy for space heating and cooling over their lifetime. Thus metrics of 
people's understanding of their energy use are of considerable value in knowing how to design buildings and infrastructure for a sustainable future.

Attari et al. (2010) conducted a national on-line survey of perceptions of energy use and energy savings from a variety of devices and activities. Since this workshop is concerned with construction and manufacturing, we focus on results of the survey related to building heating and cooling as well as use of household appliances. Subjects were asked to estimate the energy used by appliances, and additionally were asked to estimate the energy saved by household activities. The questions related to energy used by appliances were as follows (partial list):

"A 100-watt incandescent light bulb uses 100 units of energy in one hour. How many units of energy do you think each of the following devices typically uses in one hour?"

- A compact fluorescent light bulb that is as bright as a 100-watt incandescent light bulb

- An electric clothes dryer

- A portable heater

- A room air conditioner

- A central air conditioner

- A dishwasher

The questions related to energy saved by household activities were as follows (partial list):

"Turning off a 100-watt incandescent light bulb for one hour saves 100 units of energy. How many units of energy do you think each of the following changes will save?"

- Replacing one 100-watt incandescent bulb with equally bright compact fluorescent bulb that is used for one hour would reduce energy use by how many units?

- Replacing one 100-watt kitchen bulb with a 75-watt bulb that is used for one hour would reduce energy use by how many units?

- Drying clothes on a clothes line (not using the dryer) for one load of laundry would reduce energy use by how many units?

- In the summer: turning up the thermostat on your air conditioner (making your home warmer) by $5 \mathrm{oF}$ for one hour would reduce energy use by how many units?

- In the winter: turning down the thermostat on your heater (making your home cooler) by 5 oF for one hour would reduce energy use by how many units?

- Changing washer temperature settings from "hot wash, warm rinse" to "warm wash, cold rinse" for one load of laundry would reduce energy use by how many units?

The results for these twelve questions from the survey of Attari et al. (2010) are shown in Figure 3. Note that accurate perceptions would follow the dashed line with a 450 slope. The perceptions of energy used or saved for devices and activities with low energy consumption (light bulbs, changes in summer thermostat) are not far from the true average values. However, perceptions for higher energy devices such as air conditioners, washers, dryers and dishwashers are significantly underestimated. In fact, the perceptions of energy used or saved from all devices and behaviors in the original study were low by a factor of 2.8 compared to the true values. Attari et al. hypothesize that the shape of the curve could be due in part to two possible heuristics for thought processes. The first is the "availability heuristic" (Tversky and Kahneman, 1973), a judgment process in which the frequency of an event is judged according to the ease with which 
specific instances of the event come to mind, e.g., extreme weather events. It is assumed that similar thought processes apply to judging the amount of energy used or saved from these devices and activities. The second is the "anchoring and adjustment heuristic" (Tversky and Kahneman, 1974), in which an individual starts at a reference value or "anchor," in this case a 100-watt incandescent bulb, and then adjusts his or her judgment in the desired direction. The adjustment is usually smaller than it needs to be, and hence the individual overestimates values at the low end and underestimates values at the high end, resulting in a curve which is "flatter" than it should be. Such a trend is seen in Figure 3.

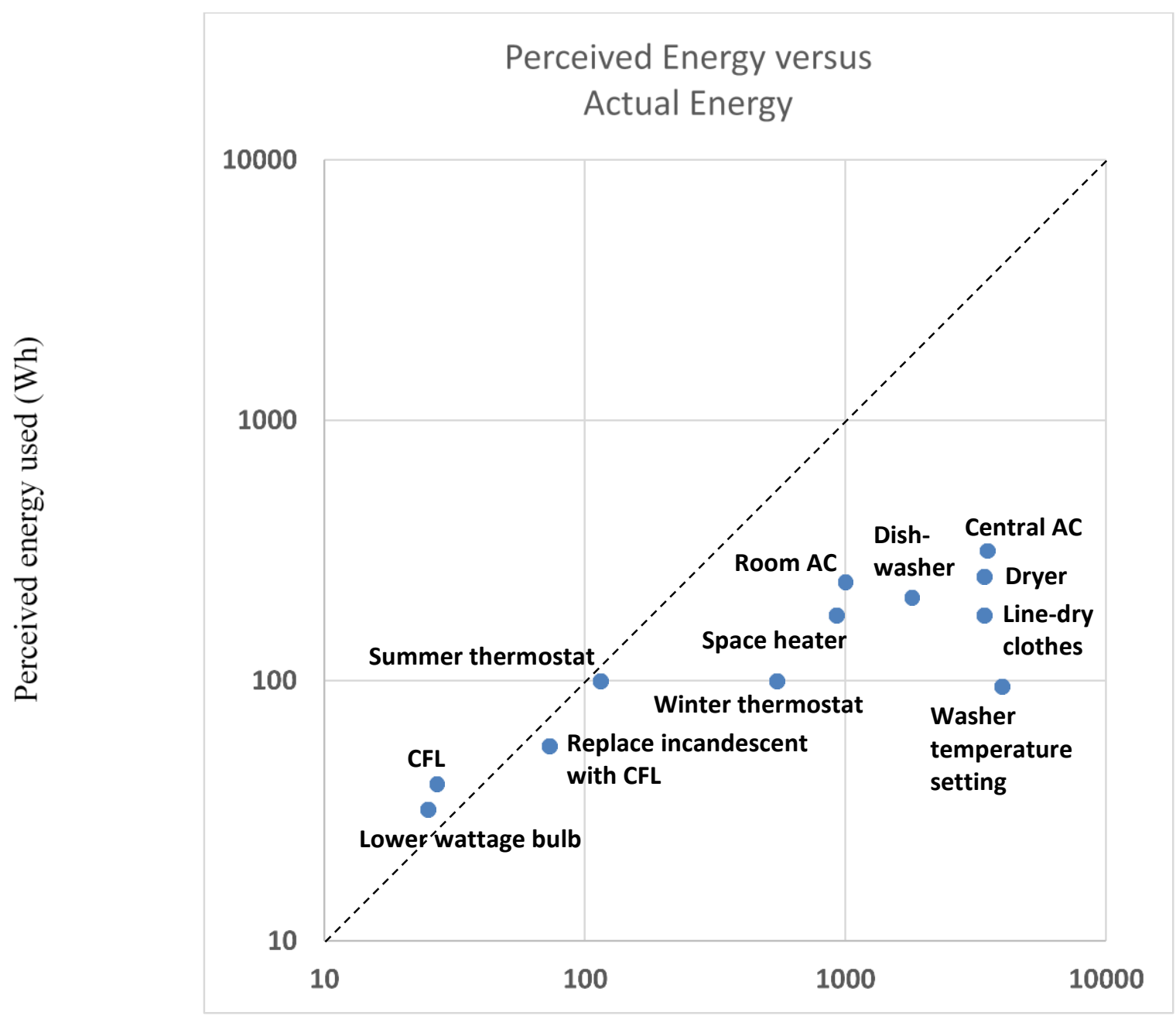

Actual energy used (Wh)

Figure 3. Results of the Survey of Attari et al. (2010) [in which subjects were asked to estimate the amount of energy used by various devices and the amount of energy saved by certain activities. Average values from the published literature, assumed to be "true" values, are shown on the $\mathrm{x}$-axis, while average values from responses to the survey $(\mathrm{N}=505)$ are shown on the $\mathrm{y}$ axis. All values are given in watt hours] 


\section{Discussion and Conclusions}

The results of the Attari et al. (2010) survey suggest that people are likely to have only limited understanding of their energy use as they go about their daily activities. Even those individuals who desire to reduce their energy consumption may be unaware of how to do so effectively. Additionally, recent work shows that people also have limited understanding of water use (Attari, 2014), where water use is underestimated by a factor of 2 on average with large underestimates for high water use activities. Thus, we suspect that individuals also have limited knowledge of how they can reduce material use, emissions of carbon, and in general how to adjust their lifestyles to become more sustainable.

Metrics of people's understanding or lack of understanding of the effects of day-to-day activities are thus shown to be important. Making progress on sustainability is likely to be enhanced by a combination of public education about impacts of devices and activities as well as education about ways to reduce these impacts. This has implications for the construction and manufacturing industries. People may be more willing to live and work in buildings that are less material, water, and energy-intensive if they are aware of the benefits associated with such buildings. They may also be willing to change their activities in buildings if they realize that such changes will reduce the use of materials, water, and energy. The same is true for manufactured products: people may desire to change their buying habits toward more sustainable products.

However, it must be cautioned that making changes in daily activities is known to be difficult for people, even those who want to change (Attari et al., 2011). The force of habit can be extremely strong. Research is needed not only on metrics of human behavior that influence sustainability, but also on ways to encourage change and achieve long-term stability in lifestyles that are more sustainable than at present.

\section{References}

Attari, S. Z. (2014). "Perceptions of water use," Proceedings of the National Academy of Sciences, Vol. 111(14), pp. 5129-5134.

Attari, S.Z., Michael L. Dekay, Cliff I. Davidson, and Wandi Bruine de Bruin, 2010. "Public Perceptions of Energy Consumption and Savings," Proceedings of the National Academy of Sciences, Vol. 107(37), pp. 16054-16059.

Attari, S.Z., Michael L. Dekay, Cliff I. Davidson, and Wandi Bruine de Bruin, 2011. "Changing Household Behaviors to Curb Climate Change: How Hard Can It Be?," Sustainability, The Journal of Record, Vol. 4(1), pp. 9-11.

Chapman, G. and E. Johnson, 2002. Incorporating the Irrelevant: Anchors in Judgments of Belief and Value, in Heuristics and Biases: The Psychology of Intuitive Judgment, T. Gilovich, D. Griffin, and D. Kahneman, editors, Cambridge University Press, New York, pp. 120-138.

Clift, R., 2000. Forum on Sustainability, Clean Products, and Processes, Volume 2(1), p. 67, Springer-Verlag, Berlin, Germany, May.

Sikdar, Subhas, 2003. "Journey toward Sustainable Development: A Role for Chemical Engineers," Environmental Progress, Volume 22(4), pp. 227-232. 
Tversky, A. and D. Kahneman, 1973. "Availability: A Heuristic for Judging Frequency and Probability,” Cognitive Psychology, Vol. 5(2), pp. 207-232.

Tversky, A. and D. Kahneman, 1974. "Judgment under Uncertainty: Heuristics and Biases," Science, Vol. 185, pp. 1124-1131.

U.S. Environmental Protection Agency, 2003. National Risk Management Research Laboratory, Cincinnati, Ohio.

World Resources Institute, http://www.wri.org/search/site/cement, Accessed May 2014. 
[This page is internationally left blank] 
Dise, David E., Rassa Davoodpour, and Eric R. Coffman, Montgomery County, Maryland

\title{
Vegetative Roofs and Rainwater Harvesting Systems on Montgomery County, Maryland Facilities - Long Term Data Needs
}

\begin{abstract}
Montgomery County, like many major jurisdictions is subject to stringent federal regulations under the National Pollutant Discharge Elimination System (NPDES). These requirements are enforced through the Municipal Separate Storm System (MS4) Permit. In addition, the County has implemented a series of local legislative mandates to expand green building in the public and private sectors. To comply with these local needs, Montgomery County has opted to implement extensive efforts to control storm water on-site and improve the quality of effluent. The County has incorporated vegetative roofs into many building designs. The County's flagship is the Equipment Maintenance and Transit Operations Center (EMTOC) includes over 4 acres of vegetative roof, much of which is connected to water recovery systems. Through the process, the County encountered numerous regulatory barriers to implementing these cutting edge systems. Furthermore, as a public entity, additional research from federal and other unbiased credible organizations will help bolster the business case for future vegetative roofs.
\end{abstract}

\section{Keywords}

Green Roof, International Plumbing Code, Water Reuse, Social Cost of Carbon, Vegetative roof, water conservation, National Pollutant Discharge Elimination System (NPDES)

\section{Background}

In 2006, Montgomery County implemented a series of regulations to expand green building practices across the community. Specifically, requiring new and renovated private buildings over 10,000 square feet to achieve certified under the United States Green Building Council (USGBC) Leadership in Energy and Environmental Design (LEED) rating system or equivalent. A key part of this package focused on leadership of government agencies through higher standards (LEEDSilver) for facilities substantially funded through local public funds.

Simultaneously, the County is facing one of the most aggressive MS4 permits in the Country. The County's permit requires a series of management practices to reduce the volume and improve the quality of effluent from non-point sources into the Chesapeake Bay Watershed. Between regulation of new construction and the requirements of the permit, the application of LEED in the County has shifted from the more typical approach to one focused on both energy and sustainable sites as local priorities.

The Montgomery County Department of General Services (DGS) has included vegetative roofs, storm water capture and reuse into a number of its key facilities. One of the most advanced is the County's Equipment Maintenance and Transit Operations Center (EMTOC). EMTOC is a collection of thirty buildings. EMTOC is a cornerstone of the County's Smart Growth Initiative and was designed to address the needs of the County's public transportation network for decades into the future. As a whole the County has installed many vegetative roofing systems including 
additional systems located at White Oak Recreation Center, a New Animal Shelter. Vegetative roofing systems are part of most upcoming County projects.

\section{Equipment Maintenance and Transportation Operations Center}

EMTOC was designed to achieve LEED Gold and among other energy saving and environmentally preferable features includes 4 acres of vegetated roof. The County's decided to install a vegetated roof to address multiple environmental challenges faced by the surrounding community including reducing energy consumption, reducing the amount of storm water that flows into the County's watershed, reusing captured water to reduce the need for water and sewer. The County believes using purified potable water for purposes like flushing toilets is a waste of a valuable resource. Treated rainwater harvesting system and proper use of it allows reduction in storm water runoff and associated pollution and supports the Environmental Site Design (ESD) mandates for a comprehensive approach to planned developments. This minimizes the impact on streams, rivers and the Chesapeake Bay.

\subsection{Description of System}

Extensive vegetated roofs are designed to be lightweight and maximize the performance and environmental benefits a green roof produces. EMTOC's system features a layer of growing media that is 6-inches deep or less and has simple irrigation and drainage systems. Vegetated roofs slow and reduce runoff from rainfall. As storm water filters through the soil and is taken in through plant root systems, pollutants are absorbed reducing the volume of pollutants that enter nearby streams. Water that is not used by the roof plants or released to the atmosphere is filtered and is to a Rain Water Harvesting System (RWHS) for flushing toilets, hose bibs, and washing buses. The cost of constructing the vegetated roof and rainwater harvesting system was approximately $\$ 2,000,000$ and approximately $\$ 5,000$ in maintenance costs annually. The system is expected to reduce water consumption 30 to $40 \%$.

\subsection{Results}

EMTOC's RWHS is designed to meet the MDE Class IV water quality requirements including the requirements listed in Tables 1 and 2 with turbidity shown in Figure 1. 
Table 1. Targeted Requirements

\begin{tabular}{|c|c|c|c|}
\hline Standard & Criteria & Design Approach & $\begin{array}{l}\text { Preliminary } \\
\text { Results (April } \\
\text { Sample) } \\
\end{array}$ \\
\hline $\begin{array}{l}\text { Biological Oxygen } \\
\text { Demand (BOD) }\end{array}$ & $\begin{array}{l}10 \\
\text { milligram/liter }\end{array}$ & $\begin{array}{l}\text { Filtration system will remove } \\
\text { particulate matter down to } 10 \\
\text { microns. } \\
\text { UV filter is expected to address } \\
\text { any remaining organic material. }\end{array}$ & None Detected \\
\hline $\begin{array}{l}\text { Suspended Solids or } \\
\text { Nephelometic } \\
\text { Turbidity (NTU) }\end{array}$ & $\begin{array}{l}2 \text { NTU average } \\
\text { daily/ no to } \\
\text { exceed } 4 \text { NTU }\end{array}$ & $\begin{array}{l}\text { Green roof will filter out } \\
\text { significant particulates. } \\
\text { Cascade facilities will remove } \\
\text { debris above } 280 \text { microns } \\
\text { Porous filter will remove debris } \\
\text { to } 10 \text { microns }\end{array}$ & $\begin{array}{l}2 \text { to } 6 \text { NTU with } \\
\text { several spikes. }\end{array}$ \\
\hline $\begin{array}{l}\text { E. Coli Most } \\
\text { Probable Number }\end{array}$ & 0 & Eradicated by UV filter & $\begin{array}{l}<1 \text { Most } \\
\text { Probable } \\
\text { Number }\end{array}$ \\
\hline Total Nitrogen & $\begin{array}{l}10 \\
\text { milligram/liter }\end{array}$ & $\begin{array}{l}\text { Not expected to be exceeded } \\
\text { based on design. Remote } \\
\text { monitoring installed. }\end{array}$ & $\begin{array}{l}0.7 \\
\text { milligram/liter }\end{array}$ \\
\hline $\begin{array}{l}\text { Total Residual } \\
\text { Chlorine }\end{array}$ & $\begin{array}{l}0.5 \text { to } 4 \\
\text { milligram/liter }\end{array}$ & $\begin{array}{l}\text { Chlorine may be introduced } \\
\text { from flushing due to municipal } \\
\text { water supply. } \\
\text { Not expected to exceed } 0.5 \mathrm{mg} / \mathrm{l}\end{array}$ & $\begin{array}{l}0.7 \\
\text { milligram/liter }\end{array}$ \\
\hline
\end{tabular}

Table 2. Maintenance Requirements

\begin{tabular}{|c|c|c|c|}
\hline Monthly & Quarterly & Semi Annually & Annually \\
\hline $\begin{array}{l}\text { Monitor } \\
\text { E Coli } \\
\text { PH } \\
\text { Nitrogen } \\
\text { Residual Chlorine } \\
\text { Nuisance Impacts } \\
\text { Weeding } \\
\text { Pruning }\end{array}$ & $\begin{array}{l}\text { Inspect and wash } \\
\text { cascade filters }\end{array}$ & $\begin{array}{l}\text { Inspect storage tanks } \\
\text { Inspect and clear } \\
\text { debris from roof } \\
\text { drains } \\
\text { Inspect and clear } \\
\text { debris from roofs }\end{array}$ & $\begin{array}{l}\text { Service ultraviolet } \\
\text { light filter } \\
\text { Inspect controls for } \\
\text { function } \\
\text { Inspect pumps, valves } \\
\text { for function } \\
\text { Inspect signage } \\
\text { Conduct cross } \\
\text { connection/backflow } \\
\text { prevention inspection. }\end{array}$ \\
\hline
\end{tabular}




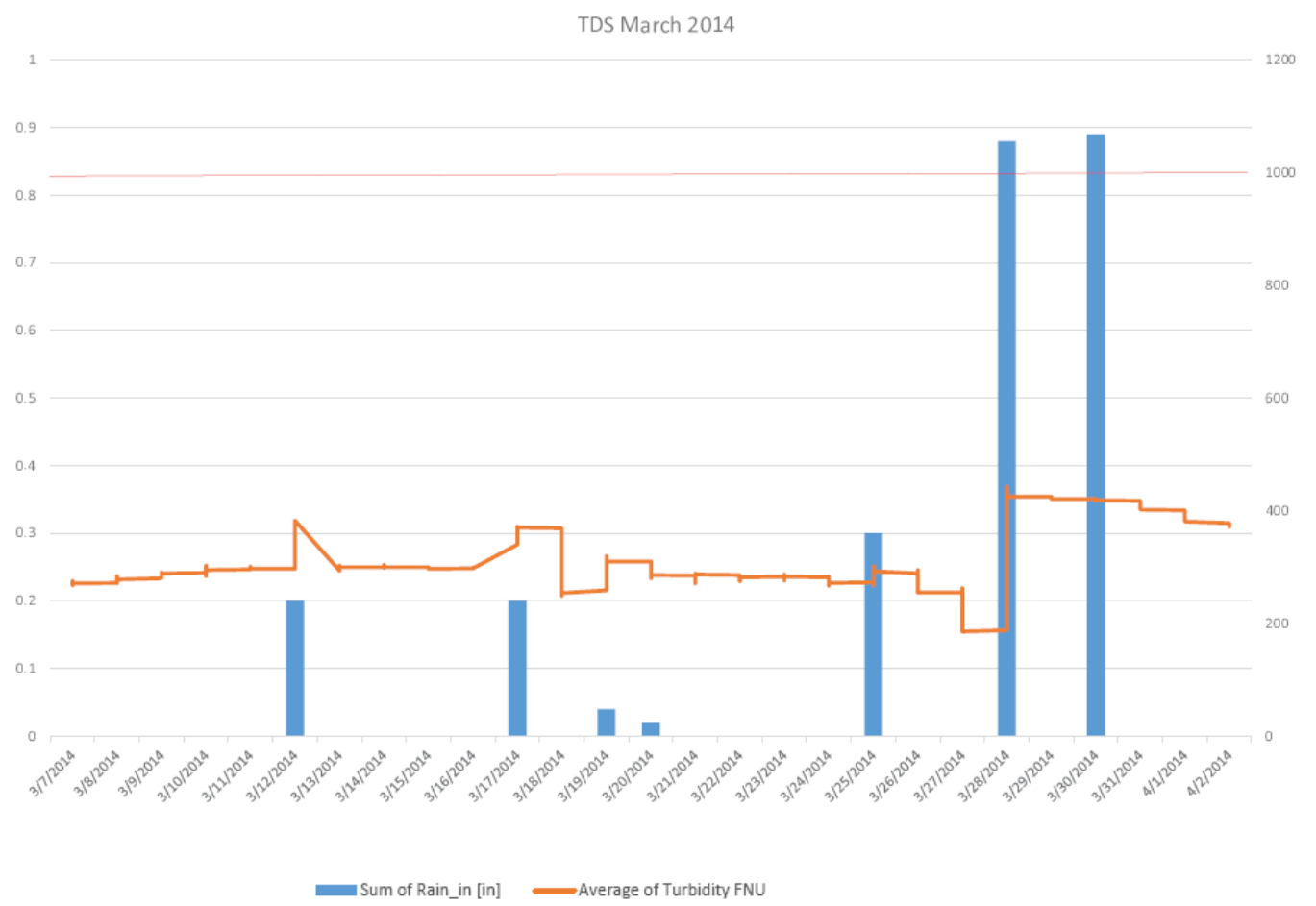

Figure 1. Total Dissolved Solids vs. Rainfall Volume

\section{Challenges and Research Needs}

Montgomery County's experience with vegetative roofs and water reuse systems have been positive and the business case has been bolstered by strong regulatory drivers such as the MS4 permit combined with relatively high energy and water costs. Montgomery County has encountered several issues with vegetative roofs and water reuse systems that inhibit deployment. These include (1) regulatory issues and (2) quantifying the full range of benefits that accrue over the life of a system.

\subsection{Regulatory Issues}

Awareness of local water, sewer and permitting authorities is a key challenge to implementing vegetative roofs coupled with rainwater harvesting systems. Montgomery County, in the design of the project had to pursue an extensive waiver process with the local water and sewer authority, specifically the Washington Suburban Sanitary Commission (WSSC). The WSSC Plumbing and Fuel Gas Code did not recognize non-potable water use. As the authority responsible for the public potable water system, WSSC's interest in ensuring reasonable standards was understandable. As a follow-up WSSC requested that the County provides extensive performance data to qualify for a waiver. Ultimately, WSSC amended the locally adopted plumbing code to include specific standards for certain non-potable water systems but other communities certainly struggle with the same issues. Federal research efforts could help collect and disseminate data on the safety and performance of non-potable water systems, particularly those systems coupled with vegetative roofing systems. Centralizing data from existing systems and use this results of these existing systems to justify streamlining of the International Plumbing 
Code and local codes to ensure reasonable requirements and clear processes for installing similar systems.

\subsection{Social Cost of Carbon}

In May 2014, Montgomery County became the first community in the nation to incorporate the social cost of carbon into calculations related to the energy consumption of planned public buildings and energy savings projects. Under the legislation, for all new capital improvement projects and retrofits, the County will need to estimate the social cost of carbon implications of both facility energy consumption as well as mitigation measures such as energy efficiency and renewable energy projects. The County is currently developing its administrative procedures to estimate the impacts of carbon from energy consumption and the impact avoided through energy efficiency projects. Reliable models of green roof performance will be essential to advancing the accuracy of these calculations.

\subsection{Assessment of Air Quality Benefits}

On-site energy savings from a green roof are relatively easy to estimate using conventional energy modeling and monitoring techniques. Similarly, translating water savings to energy savings due to reduced potable water use can be estimated with reasonable accuracy. However, while some work has been completed highlighting the direct air quality benefits due to nitrogen uptake of green roofs.

\subsection{Solar Integration}

Green roofs and solar photovoltaic systems often compete for the same roof space, specifically large, flat roofs capable of supporting significant weight. Few studies have been published that evaluate the relative total societal benefit to help designers choose between these two technologies. Also data identifying performance changes in both the green roof and solar photovoltaic system, when co-located would help drive synergies between these technologies.

\subsection{Amenity Value on a Community Scale}

Green roofs influence resident perceptions of their community; the value of this is not well understood. Collecting data on resident, business and other community perceptions in communities with a large density of green roofs, combined with those without would help expand interest in scaling up deployment.

\subsection{Green Roofs and Wildlife Interactions}

Many communities have struggled with wildlife interactions with green roofing infrastructure. Often interactions are positive with the roof providing habitat for various species. However, occasionally vegetative roofs attract wildlife that are a local nuisance or degrade green roof performance (e.g., increase fecal matter impacting E.Coli levels) Mitigation and deterrents are well studied. However, efforts to design green roofs to attract desirable or native wildlife are not well understood. Tracking the density of rare birds, pollinating insects, or other biological indicators may help justify advanced green roofs using native plans to preserve biodiversity.

\section{Conclusion}

Vegetative roofs and water reuse systems are becoming more common on local government and private buildings. However, additional research is needed to ensure regulatory barriers can be resolved in a timely manner that addresses concerns about non-potable water. In addition, additional quantification in both environmental benefits, particularly air quality and carbon, along with fair economic valuation would help ameliorate regulatory and budget barriers. 


\section{References}

Montgomery County Council Bill 5-14 Social Cost of Carbon.

Clark C., Adriaens P., Talbot B., Green Roof Valuation: A Probabilistic Economic Analysis of Environmental Benefits. 


\title{
Eckelman, Matthew J., and David Fannon, Northeastern University
}

\section{Information Barriers and Enablers for Sustainable Buildings and Construction}

\begin{abstract}
New modeling capabilities and standardization of data formats and reporting protocols is helping to increase the availability of performance information for those who design, construct, operate, and own buildings. Whole-building assessments that examine multiple indicators of performance using a life cycle paradigm are now common, but are still limited to single buildings. Widespread use of these tools will require efforts to overcome the many barriers that remain to effective monitoring and dissemination of building data, particularly during construction. These include an exclusive focus on cost, mismatches in incentives to track and report material and energy use, and the very structure of project delivery methods. At the same time, the development of open platforms for building data coupled with reporting requirements serve to increase our knowledge of building performance and improve design and operation. Several research areas are suggested, including adapting lessons from sustainable manufacturing.
\end{abstract}

\section{Keywords}

Building informatics, life cycle, green building standards, open data, performance metrics

\section{Background}

This is a transformative time in the assessment of sustainable buildings and construction. Many technologies and policies are coming online that could enable rapid, high-fidelity assessment of building sustainability; from materials to construction processes to building performance. There is ample opportunity to improve the quality and utility of building assessments by providing more location or building-specific information over a wider range of metrics more quickly than can has been done up to this point. Such 'forward guidance' will help fulfill the very purpose of these assessments, which is to inform building design and construction practices and codes.

There is much debate about what precisely makes a building sustainable, but early research and development focused on energy use, particularly after the energy crisis in the 1970s. This era witnessed accelerated development of energy-efficient building technologies and building energy use models, notably by the Center for Building Science and Lawrence Berkeley National Laboratory. Early on, there was recognition that building energy use should also consider embodied energy, that is, the energy needed to produce and transport building materials and fuel construction equipment and tools, thus considering the entire building life cycle (Bekker 1982). Several case studies subsequently quantified the percentage of life cycle energy use contributed by each stage, finding between $65-95 \%$ due to the use phase, depending on the building design, construction requirements, and intended use (Cole and Kernan 1996, Adalberth 1997, Cole, 1998, Keoleian et al 2000, Scheuer et al 2003). There was also recognition that energy use was not the only important metric to consider and that water use and indoor air quality among others were critical factors in evaluating buildings (Guggemos and Horvath 2006). 
The founding of the U.S. Green Building Council and the development of the LEED® standard served both to popularize green buildings and, importantly, to codify a range of technologies and practices that green building had come to encompass. LEED has been hugely successful, with nearly 3 billion square feet of certified projects in the United States and updating of its standards now in its fourth cycle. Although the LEED system has been extensively critiqued, one of the most important comments from an engineering point of view is that it relies largely on semiquantitative, categorical, or yes/no questions, which makes it difficult to analyze life cycle building performance across a range of metrics in a quantitative manner. This is the general goal of life cycle assessment (LCA), which has been applied for many years to the building and construction sector.

LCA is an integrated modeling framework that attempts to capture all direct and indirect emissions and impacts associated with a product, in this case a building. As with embodied energy methods, LCA encompasses building materials, construction, use, and end-of-life phases of a building, but for multiple metrics across resource use, environmental impacts, and human health concerns. One of the most ambitious early LCA case studies was conducted by Keoliean, Blanchard, and Reppe (2000) of a residence in Ann Arbor, Michigan, USA, encompassing major home systems including walls, floors, roof/ceiling, foundation/basement, doors/windows, appliances/plugs, sanitary/piping, and finishes. In the early days, conducting this kind of whole building assessment was extremely time-consuming and difficult, necessitating the use of life cycle inventory databases that described how individual materials and components were manufactured and transported. The National Institute of Standards and Technology (NIST) was a pioneer in this area with the development of the Building for Environmental and Economic Sustainability (BEES) model. This allowed analysts to model a building with pre-defined materials and components. Construction processes were not well-represented in many life cycle impact assessment methods, and in cooperation with academic institutions and industry partners, the Athena Sustainable Materials Institute developed a suite of tools that allowed users to consider a wider range of building designs and construction techniques, which remains to this day one of the most widely used toolboxes for whole-building life cycle assessment. With building energy efficiency improving, the relative contribution of the construction phase to life cycle impacts has increased, and newer construction techniques such as pre-cast concrete panels (Bilec et al 2006) and modular designs (Quale et al 2012) have also been evaluated.

Despite these significant efforts and advances in building assessment capabilities, the number of individual buildings that have been assessed using LCA and similar tools is quite small and usually after construction has been carried out. The primary barriers to wider implementation of comprehensive building assessments relate to bottlenecks or blockages in the flow of information among the actors involved in building design and construction, and in the way resource use (such as energy and water) in buildings is monitored, billed, and reported.

\section{Information Barriers}

In general, one of the most significant barriers to evaluating sustainability in the building and construction sector is the lack of information sharing and reporting. Other than cost, very little project data is shared by all the relevant stakeholders, or circulates in closed feedback loops to inform iterative decision making about any criteria other than first cost. Because each project is 
unique, a "prototype at full scale," there are limited opportunities to apply lessons learned from one project to others.

In part, these information barriers stem from the traditional project delivery structure, in which the design team (generally contracted to the architect) and the construction team (trades handled as subcontracts under a general contractor (GC)) each contract with the owner individually, but not to each other. This legal structure tends to limit bilateral communication to formal channels while promoting division, hierarchy and risk avoidance over collaboration, information exchange and problem solving. For example, under this structure, a specialist engineer will use drawings and specifications to describe a finished end state for the project that achieves the "design intent" performance, but cannot direct or interrogate the "means and methods" of building construction used to achieve that end. Meanwhile, the subcontractor who will ultimately perform the work cannot offer suggestions or ask questions about intention based on years of experience, and must guess at the performance goal based only on the selection and arrangement of physical components. Decisions about material selection and arrangement lie with the design team, while control of the suppliers, equipment, and techniques of construction lies with the contractor and subcontractors, making it essentially impossible to extract an accurate bill of materials or transportation fuel use, much less to use that data during the design process to aid decision making. Once construction begins, even simple questions or directives must be passed back and forth through a laborious Request for Information (RFI) process, mandated by the legal liability and too often abused to profit, postpone, or posture.

The only information that regularly (though not always reliably) moves through the hierarchy is cost: with subcontractors' estimates of material and labor rolled into the GC's larger project estimate. Unfortunately, relying on the financial signal results in odd incentives in the design process, including designers who pad or oversize specifications to leave room in the budget for reductions later, and multipliers added to each stage of a cost estimate. Even during the inaccurately-named "value engineering process" when stakeholders seek to reduce costs, the data that drives the costs remains stubbornly hidden.

The past several decades have witnessed increased interest in alternative project delivery methods such as Construction Managers, Design-Build Contracts, and Integrated Project Delivery (IPD), as owners seek to ameliorate the limitations of the traditional model. In addition to structural and communications improvement, these new models often apply lessons from manufacturing (e.g., Lean Production, Six Sigma) to construction, with direct cost, quality and time benefits, and some indirect sustainability ones. As surgeon and author Atul Gawande describes in his book The Checklist Manifesto on complex tasks (Gawande 2010), the construction industry has developed construction management systems based around detailed checklists and timelines specifically to ensure communication among subcontractors and with the GC, inspectors, and owners. Currently this approach focuses on project delivery and cost performance, affecting sustainability only inasmuch as it is 'checklistable' (e.g., the LEED rating system). However, this method could extend to any other systematic measure of sustainability.

In conjunction with, and often enabling these new models of practice, new digital tools under the broad label Building Information Modeling (BIM) are enabling easier information sharing. While many legal and technical issues remain, efforts to locate all the relevant project data in a 
single database promise new opportunities. For example, a new app called Tally ${ }^{\mathrm{TM}}$ developed by KieranTimberlake as a plugin for Autodesk's popular Revit BIM suite. Designers embed information about products into the model, and the tool performs rapid quantification of building the materials and calculates the embodied energy as well as other environmental impacts. Future development of tools like this, as well as the libraries on which they rely, could make rapid, iterative LCA ubiquitous in building design and allow architects and engineers to evaluate potential savings ahead of time, and integrate with other building performance simulations for other metrics, such as energy consumption.

Unfortunately, the same situation of information barriers extends beyond the construction of buildings, into the much longer - and more environmentally significant — period of occupation and use. Some higher-performing buildings do monitor critical indicators of performance, and some municipalities have begun mandatory reporting of these data (Altomonte and Schiavon 2010). However, systematic monitoring of energy and other sustainable metrics, as well as regular, reliable surveys of occupants and with feedback to inform the occupants, building operator, construction team and designers remains the exception. In most buildings, owners or tenants simply pay the aggregated utility bills and respond to the occasional complaints from occupants about temperature, lighting or other issues. These conditions will continue until a major problem or crisis, a substantial renovation or the eventual end of life prompts a major change or demolition. Virtually all information is lost at the end of building life. Few if any of the parties present at the construction will remain or return for the destruction: no "post-mortem" or autopsy will inform design or construction practices, and any ambition for organized deconstruction or reuse may have been lost over time.

\section{Information Enablers}

Given the problems caused by limited information flow, a range of new technologies, polices, and approaches promise - and in some cases are already enabling — quicker, more comprehensive, higher-fidelity sustainability assessments for buildings. One of the important contributions of the LEED rating system has been to publish the scorecards of most projects on the website http://www.usgbc.org/projects, offering case-studies of successful designs, enabling research as to the efficacy of various sustainability metrics, and prompting examination about ways buildings might improve. The recently-adopted LEED v4 extend the reporting beyond design by requiring projects to report aggregate energy and water consumption for at least five years, with minimum monthly resolution.

This dataset complements voluntary efforts such as the Department of Energy's EnergyStar Program and open Building Performance Database, and also municipally-mandated energy use reporting, now on the books in cities like New York and Boston. While these efforts offer many benefits about disclosure and opportunities for research and study, they also point the way towards future requirements to monitor and report other attributes of building environmental performance. They may also presage increased efforts to measure environmental impact during construction, particularly aspects that directly affect local citizens.

Ultimately, these efforts point towards the long-promised idea of so-called smart buildings, in which sensors and controls monitor and adjust building performance, while informing occupants and perhaps even influencing their behavior. The increased availability of low-cost networks, 
and the rapidly reducing cost of electronic sensors and actuators have moved this idea from the realm of fiction and experiment to an everyday reality. Products like the Nest thermostat offer not only increased performance at the building level, but aggregate information from thousands of buildings to promote systemic efficiency. Unfortunately, this flourishing of information and data runs the risk or remaining in walled information gardens based on individual corporate interest enforced through proprietary systems, formats, and user agreements. The possibility of a free and open standard for building data, such as that proposed by UC Berkeley's sMAP protocol (Dawson-Haggerty et al 2010) or the Building Energy Data Exchange Specification (BEDES) used by DOE will also promote the dissemination of building data for public use.

\section{What Can the Construction Sector Learn from the Manufacturing Sector?}

The manufacturing sectors in the U.S. are highly efficient, both in terms of economic, energy, and materials. There are obvious differences between manufacturing and construction, the most striking of which is that manufacturing strives for uniformity, producing many copies of an identical product with zero differences (considered defects), whereas in construction each building is a prototype, typically constructed according to a different design, on a different site, and by a different crew than others. The development of pre-fabricated panel or modular building practices has pushed at least some construction to factories with precision equipment, inventory space, and highly-skilled crews who produce standard units with quality control and testing measures, taking advantage of some manufacturing practices, but there are other areas where construction can learn from decades of engineering advances in manufacturing.

Manufacturing has benefitted tremendously from the field of industrial engineering, which has served to minimize waste, reduce production times, optimize layouts and sequencing, improve asset utilization, and most importantly, enable information flows up and down the process and supply chain. Supply chain management systems for manufacturing centralize information about both suppliers and the materials and component systems that they supply. Tracking systems use ubiquitous bar codes or, more recently, RFID tags to monitor how products move through logistics and distribution chains, and for some products even where they end up after they come out of use. Sophisticated optimization tools are used to maximize material usage and minimize waste, as this is clearly seen to benefit the bottom line of the manufacturer.

There is great potential to take advantage of the material and energy-related management systems that have been developed for manufacturers, to improve both the performance and the transparency of the construction sector. A general example typifies the prospective gains: it is a truism in manufacturing that waste equals money and this has driven analysis of waste generation to the process, equipment, and worker level; yet, in the construction sector, there is rarely any information about waste other than the total tonnage of material hauled off the job site and the common lack of vertical integration removes financial incentives for savings of any kind. In fact, construction estimates based on material and labor often include a percentage-based multiplier for profit. Thus not only does the subcontractor or GC who controls the material use not share the owner's financial incentive to limit material use, there is a perverse incentive to increase the material consumed, and therefore the profit earned on top of it. 


\section{Conclusions}

New applications and technology are helping overcome barriers to information sharing and improve our understanding of life cycle building performance. Additional efforts in a few key areas will boost sustainable construction efforts, specifically (1) Construction management platforms for sharing resource information in addition to cost. This could be a logical outgrowth or addition to the Building Information Modeling approach being used in design. It could also continue the work of groups like the Lean Construction Institute to apply industrial engineering methods from manufacturing to the building industry; (2) Targeting of efficiency incentives to specific buildings, based on analysis of reported data with more and finer-grained data; and (3) Linking different types of benefits in efficiency projects (energy benefit of water efficiency).

\section{References}

Adalberth, K. 1997, "Energy use during the life cycle of single-unit dwellings: Examples," Building and Environment, vol. 32, issue 4, pp. 321-329.

Altomonte, S., and Schiavon, S. 2013, "Occupant satisfaction in LEED and non-LEED certified buildings," Building and Environment, vol. 68, pp. 66-76.

Bekker, P. C. F. 1982, "A life-cycle approach in building," Building and Environment, vol. 17, issue 1, pp. 55-61.

Bilec, M., Ries, R., Matthews, H. S., and Sharrard, A. L. 2006. "Example of a hybrid life-cycle assessment of construction processes," Journal of Infrastructure Systems, vol. 12, issue 4, pp. 207-215.

Cole, R. J. 1998, "Energy and greenhouse gas emissions associated with the construction of alternative structural systems," Building and Environment, vol. 34, issue 3, pp. 335-348.

Cole, R. J. and Kernan, P. C. 1996, "Life-cycle energy use in office buildings," Building and Environment, vol. 31, issue 4, pp. 307-317.

Dawson-Haggerty, S., et al 2010, "sMAP: a simple measurement and actuation profile for physical information," In Proceedings of the 8th ACM Conference on Embedded Networked Sensor Systems (SenSys '10). ACM, New York, NY, USA, 197-210

Gawande, A. (2010). The checklist manifesto: how to get things right, Metropolitan Books, New York.

Guggemos, A. A. and Horvath, A. 2006, "Decision-support tool for assessing the environmental effects of constructing commercial buildings," Journal of Architectural Engineering, vol. 12, issue 4, pp. 187-195.

Keoleian, G. A., Blanchard, S., and Reppe, P. 2000, "Life-cycle energy, costs, and strategies for improving a single-family house," Journal of Industrial Ecology, vol. 4, pp. 135-56.

Quale, J., Eckelman, M. J., Williams, K. W., Sloditskie, G., and Zimmerman, J. B. 2012, "Construction matters: Comparing environmental impacts of building modular and conventional homes in the United States," Journal of Industrial Ecology, vol. 16, pp. 243253.

Scheuer, C., Keoleian, G. A., and Reppe, P. 2003, "Life cycle energy and environmental performance of a new university building: Modeling challenges and design implications," Energy and Buildings, vol. 35, pp. 1049-1064. 
Fiksel, Joseph, The Ohio State University

\title{
A Systems Approach to Sustainability and Resilience Based on the Triple Value Model of Coupled Human-Natural Systems
}

\begin{abstract}
A comprehensive systems approach is essential to enable progress toward global sustainability. Despite well-intentioned efforts, global resource consumption and waste generation continue to grow. Classical steady-state models of sustainable systems are inadequate to support effective policy and decision-making. We need to better understand the dynamic, adaptive behavior of coupled human-natural systems, so that we can improve their resilience in the face of unforeseen disruptions including natural disasters or technological failures. However, modeling of complex, self-organizing systems such as ecosystems and global supply chains is a formidable challenge. Integrated modeling techniques, exemplified by the Triple Value framework, can help to anticipate the impacts of major shifts such as climate change and the associated human responses. By exploring potential future scenarios, we can develop a more robust approach to sustainability assessment, beneficial intervention, and resilience enhancement.
\end{abstract}

\section{Keywords}

Sustainability, Resilience, Systems, Indicators, Life-cycle, Supply Chains, Communities

\section{Background}

Efforts to improve the sustainability of industrial practices, such as creating "greener" buildings or "greener" products, must account for potential life-cycle impacts on environmental, social, and economic systems. It has become increasingly unrealistic to evaluate the sustainability of a particular industry or company without considering upstream systems for provision of energy and materials as well as downstream markets. Thus, setting the boundaries for meaningful analysis has become a formidable challenge. A robust approach is needed that enables decision makers to understand how complex, coupled human-natural systems, including industrial supply chains, can be designed to achieve both short-term continuity and long-term ecological integrity.

Moreover, in view of increasing global volatility, the concept of sustainability must be expanded to consider the resilience of human and natural systems. We define resilience as the capacity for a system to survive, adapt, and flourish in the face of turbulent change; this notion applies equally to communities, ecosystems, and industrial enterprises. Companies need to grow, just as natural organisms do, but the challenge of sustainability is to increase shareholder value without increasing material throughput. An equally important concern is business continuity. Resilient systems are able to flourish in the face of uncertainty and unforeseen disruptions, even natural disasters. In contrast, traditional engineering practices have tried to anticipate and resist disruptions, but may be vulnerable to unforeseen factors. Perhaps the most cost-effective approach is to design systems with inherent resilience by taking advantage of fundamental properties such as diversity, efficiency, adaptability, and cohesion (Fiksel, 2003).

Over the last two decades, there has been a significant shift in the awareness of sustainability and resilience issues on the part of government, industry, and the general public. Leading 
manufacturers in the U.S. and abroad have begun to emphasize sustainability in their internal business processes, investor relations, and customer value propositions. Yet, paradoxically, the more efficient companies become in terms of resource utilization, the more rapidly the economy grows; this "rebound effect" results in a net increase in the ecological footprint of industrial society (Fiksel, 2006). The rapid growth of China, India, and other Asian economies will likely exacerbate this problem. To compound the challenge, the increasing connectedness of the global economy introduces "systemic" risks that may cascade into major disruptions. (WEF 2014)

The premise of this paper is that pursuit of global sustainability and resilience requires a systems approach to develop effective policies and intervention strategies. Without a full understanding of system implications, there is a risk of unintended consequences; for example, adoption of innovative technologies based on renewable resources (such as bio-based fuels) may have hidden adverse side effects upon agricultural productivity. Adopting a systems approach will help to support wise decision making by identifying critical indicators of change and shedding light on the intricate linkages among environmental, economic, and social systems.

\section{Systems Thinking}

Sustainability challenges cannot be addressed in isolation, because most problems are highly interdependent and most solutions have hidden consequences. For example, increasing the use of biomass for fuel production may lead to crop shortages and increased food prices in Mexico, while increased use of fertilizer to boost crop yield will increase nutrient runoff and degradation of surface waters. Similarly, there is a "nexus" between energy and water resources-we need water to generate energy and energy to convey water. Government agencies including EPA, DOE, USGS, and USDA, must work together to understand these complex relationships using scientific tools such as life cycle assessment, and to develop coherent sustainability policies.

It is helpful to adopt a view of ecosystems and industrial systems alike as dynamic, open systems that operate far from equilibrium, exhibiting non-linear and sometimes chaotic behavior. The complexity, dynamics, and non-linear nature of these interdependent systems imply that the notion of "sustainability" as a steady-state equilibrium is not realistic. Forces of change, such as technological, geopolitical, or climatic shifts will inevitably disrupt the cycles of material and energy flows. Therefore, achieving sustainability will require the development of resilient management and governance processes that mirror the adaptive behavior of ecological systems.

A "system" can be defined as an interrelated set of components that form a structure and perform a function. Systems range from biological systems (e.g., ant colonies) to engineered systems (e.g., electric power grid) to social systems (e.g., professional networks). "Systems thinking" is a holistic approach for understanding the dynamic interactions among complex economic, environmental, and social systems and for assessing the potential consequences of various interventions, such as new policies, new technologies, and new operating practices. There is vast and growing literature on systems thinking, and the environmental and ecological sciences have been an important domain of application. (Holling, 2001)

Application of systems thinking generally requires the use of models to characterize the structure and dynamics of the systems in question. In the field of sustainability, models are essential to investigate the interdependence, feedback loops and dynamic behaviors of complex, adaptive 
systems including biological and socioeconomic systems. The Triple Value (3V) Model described below was initially formulated as a conceptual model, but evolved into a template for development of computer-based models based on system dynamics. (Sterman, 2000) These models build upon a platform known as Threshold 21 (T21), which has been used by the World Bank and others for sustainability assessment, and more recently was adapted to analyze energy and environmental policy options in the state of Ohio. (Cimren et al, 2010)

\section{The Triple Value Framework}

The Triple Value (3V) framework, depicted in Figure 1, is a systems approach that captures the dynamic linkages and flows of value among industrial, societal, and environmental systems (Fiksel 2012). Industrial and societal systems are coupled by economic market transactions, including delivery of goods and services as well as financial investments, enabling growth in both shareholder value and community prosperity. However, the natural environment is the "life support system" for both industry and society. When markets fail to account for economic externalities, such as gradual degradation of critical natural resources, the result is a loss of opportunity for future generations; this is sometimes called an "inter-temporal market failure" (Binswanger \& Chakraborty). Research in the fields of natural resource economics and ecological economics seeks to prevent such market failures through explicit valuation of ecological goods and services and recognition of the limits on natural capital.

The $3 \mathrm{~V}$ framework has proved useful for exploring the potential future benefits of innovative policies, technologies and practices. Detailed 3V computer models have been developed to study the dynamic couplings among industrial systems (energy, transportation, manufacturing, food production, etc.), societal systems (urbanization, mobility, communication, etc.) and natural systems (soil, atmospheric, aquatic, biotic, etc.), including the flows of information, wealth, materials, energy, labor, and waste. One such example is an application of systems thinking to the problem of excessive nutrients in the Narragansett Bay watershed, undertaken by Region 1 of the U.S. Environmental Protection Agency (EPA). In consultation with a broad range of regional stakeholders, EPA developed a system dynamics model called Narragansett-3VS (Triple Value Simulation) to help policy makers explore solutions that would improve the sustainability and resilience of the Bay in the face of growing population and climate change. (Fiksel et al, 2014)

A simplified overview of the Narragansett-3VS model structure is shown in Figure 2. The system dynamics approach involves identifying causal links between key indicators, so that the probable effects of future changes can be estimated, at least roughly. For example, increased nutrient loadings may cause algal blooms, which may cause impairment to aquatic ecosystems, which in turn may adversely affect fishing and tourism. Figure 2 also depicts some of the potential interventions that have been simulated, including wastewater treatment, best management practices (BMPs), low-impact development (LID), and green infrastructure (GI). The model features a user-friendly, dashboard-style visualization interface that enables users to construct alternative intervention scenarios aimed at reducing adverse nutrient impacts to the watershed. The model then simulates over a 40-year time horizon the expected changes in a variety of economic indicators such as tourism revenue, social indicators such as beach visits, and environmental indicators such as stormwater overflows. EPA and its regional partners are actively utilizing this model to support strategic dialogue about alternative water resource 
management policies with diverse groups including technical experts, policy makers, and citizens. There is an important caveat: "All models are wrong, but some models are useful."

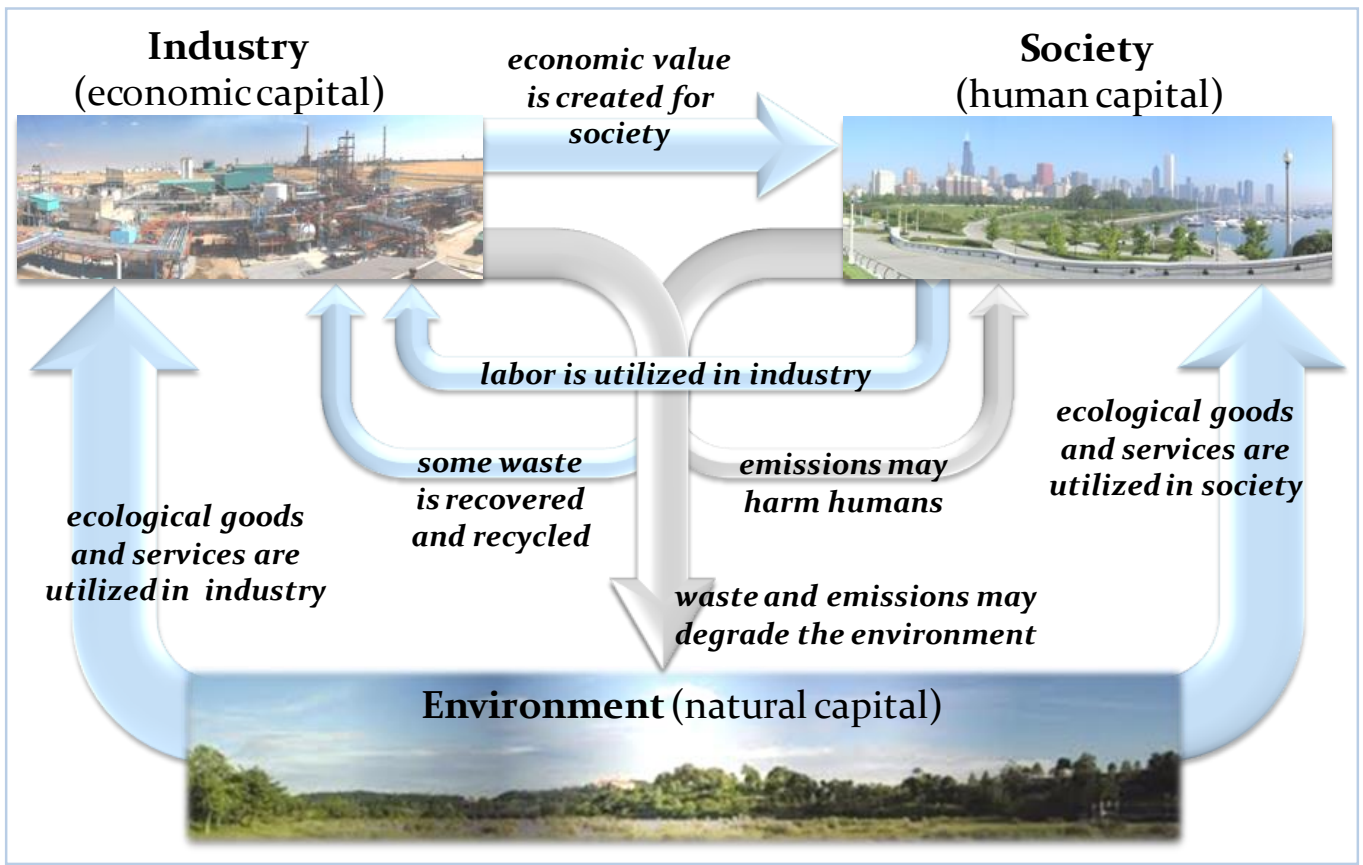

Figure 1. Overview of the Triple Value Framework

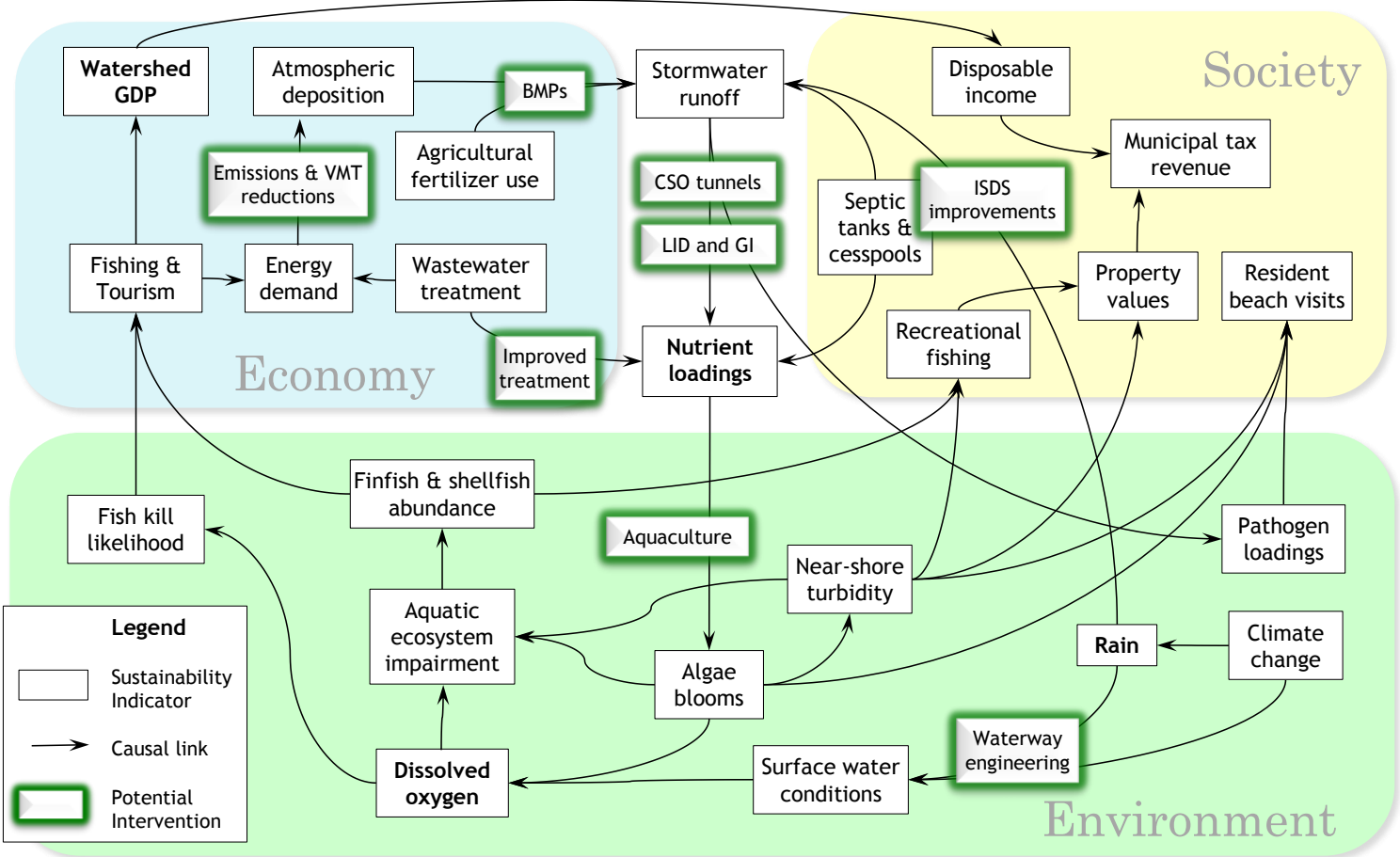

Figure 2. Simplified View of Narragansett-3VS Simulation Model Structure 


\section{Conclusions}

Sustainability is a systems problem requiring collaborative solutions. Only through a coordinated global effort with participation from all sectors of society can genuine progress be achieved. The disappointing results of the recent "Rio +20 " UN conference suggest that such coordination will not be easy. Indeed, global warming issues are perhaps the most tractable, since emissions dissipate in the atmosphere and do not concentrate geographically. There are a number of other pressing ecological issues - soil resilience, biodiversity, water quality, forest conservation - that involve interactions among complex local and regional systems. Therefore, an important priority for advancing the study of sustainable systems is development of modeling and decision making approaches that enable dynamic, adaptive management rather than static optimization. The $3 \mathrm{VS}$ model described above represents a promising example. To this end, it will be valuable to establish consensus on key indicators for improvement of sustainability and resilience in economic, ecological and societal systems. More generally, there is a need for increased transdisciplinary research, public communication, innovative policy development, and effective partnerships between government, business, and the scientific community.

\section{References}

Binswanger, H.C. and R.N. Chakraborty, "Economics of Resource Management," University of St. Gallen, Institute for Economy and the Environment. European Commission, October 2000.

Cimren, E., A. Bassi, and J. Fiksel, “T21-Ohio, a System Dynamics Approach to Policy Assessment for Sustainable Development: A Waste-to-Profit Case Study," Sustainability. Vol. 2. pp. 2814-2832, 2010.

Fiksel, J., "Designing Resilient, Sustainable Systems," Environmental Science \& Technology, December 2003, pp. 5330-5339.

Fiksel, J., "Sustainability and Resilience: Toward a Systems Approach," Sustainability: Science, Practice, and Policy, Vol.2, No. 2, pp. 14-21, 2006.

Fiksel, J. “A Systems View of Sustainability: The Triple Value Model,” Environmental Development, June 2012.

Fiksel, J., R, Bruins, A. Gatchett, A. Gilliland, and M. ten Brink. "The Triple Value Model: A Systems Approach to Sustainable Solutions." Clean Technology and Environmental Policy, June 2014.

Holling, C.S. Understanding the Complexity of Economic, Ecological, \& Social Systems, Ecosystems, Vol. 4, 2001.

Sterman, J.D. Business Dynamics-Systems Thinking and Modeling for a Complex World. McGraw-Hill, 2000.

World Economic Forum. Global Risks Report, 2014. Geneva, Switzerland.

\section{Acknowledgements}

The author is gratefully for the support of many talented collaborators, including Andrea Bassi, Gary Foley, Alan Hecht, Lek Kadeli, Ira Leighton, Eric Ruder, and Marilyn ten Brink. 
[This page is internationally left blank] 


\title{
Flanagan, William P., GE Global Research, General Electric Company
}

\section{Sustainable Manufacturing from a Life Cycle Perspective}

\begin{abstract}
Sustainable manufacturing implies a focus beyond the manufacturing stage, as the choice of manufacturing technology can influence environmental impacts across the entire life cycle of the part, component, product, or system that is being manufactured. For example, new manufacturing processes may enable different or novel materials or structural design choices that can reduce environmental impact while improving performance. Efforts focused on sustainable manufacturing should therefore consider all aspects of the life cycle to ensure that manufacturing processes are delivering net environmental improvement for the part, component, product, or system application. In many cases there may be trade-offs, and LCA can and should be applied to understand, quantify, and explore process, materials, and design alternatives to ensure that sustainable process and technology decisions are being made.
\end{abstract}

\section{Keywords}

Life Cycle Assessment, Life Cycle Costing, Sustainable, Additive, Manufacturing, Products

\section{GE and Sustainability}

The General Electric Company has a business strategy to create new value for customers, investors and society by solving energy, efficiency, and water challenges. We believe that our society has been presented with a false choice - great economics or great environmental performance. The real answer is that through innovation we can design and deliver both. And as a result, GE will grow faster and win. And it's working. ${ }^{3}$

GE has been involved with environmental life cycle assessment (LCA) since 2008. GE's Ecoassessment Center of Excellence (COE) was founded to assess the environmental impacts of products and technologies throughout their entire lifespan, from raw materials extraction through reuse, recycling, or disposal at the end of product life. The center works closely with GE Corporate Environmental Programs, GE Ecomagination, and many of the GE business units on life cycle management strategies that include qualitative approaches as well as quantitative LCA studies ranging from screening to detailed assessments in support of new product development, product evolution, and commercial and marketing activities.

Over the past several years, LCA efforts have been applied to a variety of GE product categories including gas and steam turbines, generators, wind turbines, thin film solar, aeroderivative gas engines, Jenbacher gas engines, biomass gasification, membrane ultrafiltration, nano-structured ferritic alloys vs. nickel super-alloys (i.e., powder metallurgy vs. cast and wrought forging), jet fuel from bio-oils, micro LNG, smart meters, single-use process technology for biopharmaceutical manufacturing, $+P L U S P A K^{\mathrm{TM}}$ vials for contrast agent solution, blood pressure cuffs, Durathon ${ }^{\mathrm{TM}}$ energy storage systems, composite materials for aircraft engine fan blades, appliances and appliances recycling, lighting, locomotives, and component re-

\footnotetext{
${ }^{3} \mathrm{http}: / /$ www.ge.com/globalimpact/ecomagination.html
} 
manufacturing. Insights gained from these studies have been selectively used to inform commercial and product development strategies as well as customer and policy engagement.

GE's experience driving sustainability-related projects within a business context has led to insight around enabling principles that it feels are important to consider when formulating product and technology sustainability strategies:

1. Be strategic and selective. Application of LCA, and more specifically the collection of inventory data to support LCA or supply chain initiatives, can be resource intensive. While LCA is a very powerful tool that can provide deep and valuable insight, it must be applied strategically and selectively to ensure maximum benefit.

2. Leverage screening and streamlined approaches. Insights can be gained by applying screening or streamlined approaches early in product development. The reduced time, effort, and expertise required to conduct screening approaches offers the potential for cost-effective application to a wider spectrum of product development activities. Screening approaches should serve as a funnel to identify those opportunities requiring further analysis using more sophisticated quantitative approaches.

3. Focus on value creation. For any initiative to thrive within industry, it must create value. There are many opportunities to create value from sustainability-based initiatives, particularly those focused on energy and resource efficiency.

\section{Emerging Sustainability Drivers}

Global environmental pressures continue to increase. The planetary boundaries concept suggests that we have already exceeded the safe operating range for humanity in 3 of 9 planetary ecosystems (rate of biodiversity loss, climate change, and human interference with the nitrogen cycle $)^{4}$. In addition to these issues, our economy is consuming critical material resources at unsustainable rates. Over the course of the $20^{\text {th }}$ century, fossil fuel use increased by a factor of 12 (which may not be surprising) ${ }^{5}$. Perhaps more surprising is the fact that material resource use during this same period increased by a factor of 34 . Global population is anticipated to reach 9 billion by the year 2050 (up from 7 billion in 2011) ${ }^{6}$, and a much greater proportion of the populated world will be economically developed. The demand for food, fuel, and fiber may increase by $70 \%$ by the year 2050 (meanwhile $60 \%$ of major ecosystems are already degraded or are being used unsustainably). At current growth rates, we'll need the equivalent of more than 2 planets to provide the needed resources. For human society to exist on just one planet, the World Business Council for Sustainable Development estimates that we'll need a 4-10x increase in resource efficiency.

Governments and markets are responding. We have seen a marked increase in environmental legislative policy focused on the life cycle of materials, products, and technologies. Policy instruments extend beyond traditional emissions and energy efficiency targets and now include the development of eco-design requirements for an expanding range of product categories ${ }^{7}$, and

\footnotetext{
${ }^{4}$ Rockstrom et al., “A safe operating space for humanity,” Nature 461(24): 472-475, 2009.

${ }^{5}$ Roadmap to a Resource Efficient Europe, European Commission COM (2011) 571 final, Brussels, September 2011.

${ }^{6}$ World Population to 2300, United Nations, http://www.un.org/esa/population/publications/longrange2/WorldPop2300final.pdf

${ }^{7} \mathrm{http}$ ://ec.europa.eu/energy/efficiency/ecodesign/eco_design_en.htm
} 
the introduction (or expansion) of green public procurement policy. ${ }^{8}$ Within the European Union, green public procurement requires traditional life cycle costing (LCC) supplemented by environmental procurement criteria, but emerging policy language signals the intent to more formally incorporate the cost of environmental externalities into life cycle costing methodologies. Based on these and other developments, process and technology development will need to increasingly align with sustainability drivers to ensure longer-term market vitality.

\section{Streamlined LCA/LCC in Defense Acquisitions}

The US Department of Defense has recently introduced draft guidance incorporating streamlined LCA/LCC into the acquisitions process, with the ultimate intent of enabling purchasing decisions based on total cost of ownership ${ }^{9}$. The methodology includes direct and indirect costs as well as external costs (i.e., environmental cost to society), and is based on traditional life cycle costing combined with environmental life cycle assessment. GE Aviation and several other companies have recently begun piloting the proposed DoD methodology on a variety of projects. GE Aviation and GE Global Research are applying the methodology to additive manufacturing of fuel nozzles for the CFM LEAP next-generation high-bypass turbofan jet engine. Traditional fuel nozzle designs are manufactured via forging \& machining processes. Additive manufacturing processes offer the potential for novel fuel nozzle designs that result in reduced life cycle environmental impact and total cost of ownership due to:

- Reduced part weight:

- Reduced fuel consumption over the life of the aircraft system

$\circ$ Increased mission range or payload capacity

- Net lower raw material consumption

- Enhanced performance

Environmental life cycle assessment and life cycle costing will be essential in understanding the net benefit and trade-offs associated with moving towards additive manufacturing, both from an environmental and cost perspective. The specific benefits and trade-offs may be unique to each application, but the development and implementation of practical assessment tools will help ensure that manufacturing capability developments are aligned with the sustainability requirements of our people and our planet.

\section{Sustainable Manufacturing}

Sustainable manufacturing implies a focus beyond the manufacturing stage, as the choice of manufacturing technology can influence environmental impacts across the entire life cycle of the part, component, product, or system that is being manufactured. For example, new manufacturing processes may:

- enable different or novel materials choices

- have different material and energy efficiencies

- have less (or more) manufacturing emissions and wastes

- enable unique part geometries or other features affecting performance

- offer enhanced repair-ability, re-usability, or recyclability at end of life

\footnotetext{
${ }^{8} \mathrm{http}: / /$ ec.europa.eu/environment/gpp/index_en.htm

${ }^{9} \mathrm{http} / / /$ www.ndia.org/Divisions/Divisions/Manufacturing/Documents/319A/7_Yaroschak-14801-

Sustainability\%20in\%20Acquis.pdf
} 
The possibility of different or novel materials choices may:

- impact supply chain impacts

- impact manufacturability

- offer enhanced performance properties (e.g., thermal, mechanical, lifetime)

- $\quad$ offer additional end-of-life options (e.g., recyclability, re-usability)

Efforts focused on sustainable manufacturing should therefore consider all aspects of the life cycle to ensure that manufacturing processes are delivering net environmental improvement for the part, component, product, or system application. In many cases there may be trade-offs, and LCA can and should be applied to understand, quantify, and explore process, materials, and design alternatives to ensure that sustainable process and technology decisions are being made.

\section{Recommendations for NIST}

Incorporate a life cycle perspective when addressing each of the four workshop themes or associated research objectives. A life cycle perspective can consist of qualitative and quantitative aspects (either or both).

1. Measurement science: The field of life cycle assessment (including related forms of sustainability assessment) has experienced issues related to conflicting definitions, metrics, and indicators along the way. For example, the term 'carbon footprint' means different things to different people. There are a variety of ecolabels or other environmental standards, some incorporating a life cycle perspective and others not; some prescriptive and others performance-based. Harmonization of conflicting or disparate programs and standards is always a worthwhile goal. Take care to understand the landscape of existing definitions, standards, indicators and ratings before implementing new programs in these areas.

2. Systems: A systems-oriented approach is essential when considering issues related to sustainability, as there are many interconnected issues and activities along the value chain and across economies and environmental impact categories. This vision paper has already articulated the need for a life cycle perspective when focusing on sustainable manufacturing, which serves as a good example of a focus area that is tightly connected to many other systems.

3. Planning, design and supply chain: Incorporate a life cycle perspective early in the planning and design stages to ensure that the appropriate systems-level thinking is incorporated early in the decision-making process.

4. Economic, environmental and social aspects: Ultimately, the previous three themes play out on a world stage dominated by economic (market-drivers) and social aspects (behaviors). Market-drivers can be influenced through regulatory process or a variety of policy initiatives but are often largely driven by market dynamics acting at a local level (i.e., individual purchasing entity). Social aspects (behaviors) can be influenced through a variety of complex societal / cultural adaptations, but again are often most influenced by local factors (i.e., cost, convenience). 
Futornick, Kathi, Mt. Hood Community College, Oregon

\title{
Greening the Supply Chain: Direct Influences on Sustainability Reporting and What We Measure
}

\begin{abstract}
During the 1990's, there emerged the basis for a series of regulations that would address risks associated with products and articles manufactured anywhere in the world and placed into European markets. The United States, which had been a world leader in environment, health and safety, was now playing catch-up as did other industrialized nations. These regulations hit at the Life Cycle of products from materials used in their manufacturing to risks associated with the users through to final disposal or reuse. The nature of these regulations requires manufacturers to identify toxic materials in their articles including subassemblies. Subassemblies come in through the Supply Chain and industry now needed to look closely at the integrity of the suppliers' Material Certifications. From here emerged two major issues: (1) how leading industry would ensure integrity of data reporting under the new regulations; (2) how the relationship of industry to the Supply Chain would evolve into a role of collaboration and partnerships. This paper provides a framework for how these two issues play a relevant role in defining corporate and facility sustainability practices and introduces a basic approach to dealing with an increasingly complex system.
\end{abstract}

\section{Keywords}

Sustainability, Codes of Conduct, Ethics, Outcome-Based Performance, Compliance

\section{Background}

David Packard, Founder of Hewlett Packard stated with respect to the purpose of business, that...

profit is what we do - it is a measure of our contribution and a means of selffinanced growth - but it has never been the point in and of itself. The point is, in fact, to win, and winning is judged in the eyes of the customer and by doing something you can be proud of. There is symmetry in logic in this, if we provide real satisfaction to real customers - we will be profitable.

The United States and other industrialized nations have traditionally focused on compliance with laws, regulations, and industry standards to support the growing demand for a sustainable environment, whether that has been the built environment or the natural environment. Metrics to define the outcome of sustainable practices have evolved from prescriptive to performance based, from singular measurements to consideration of holistic and interrelated systems. Laws, regulations, and industry standards have created a "silo" approach to doing business and our traditional approaches have not kept pace with the societal demand for sustainable practices and immediate transparency.

Four decades of environmental regulations, and yet in the 2014 State of Green Business report, published by GreenBiz in partnership with Trucost plc, the report, which measures the global progress of large, publicly traded companies in addressing a myriad of environmental challenges, 
reveals little meaningful progress across most metrics, including greenhouse gas emissions, water use, waste disposal and other pollutant impacts.

"While more and more companies are undertaking a growing number of initiatives to reduce their environmental impacts, there's very little progress to show for it. Company initiatives are not having an impact at the scale needed to address such challenges as climate change and the availability of water and natural resources," said Joel Makower, GreenBiz Group executive editor and the report's principal author.

"The environmental impacts of business - air pollution, biodiversity loss, ecosystem degradation and water scarcity - are threatening the ability of our finite stock of natural capital to deliver sustainable growth," said Richard Mattison, CEO of Trucost. "The challenge for business is to identify growth models that result in reduced environmental impact."

In looking back at more than 40 years of environmental laws and regulations, industry has recognized the limitations of those requirements and realized how complex and interconnected the impacts are. That can make measuring progress more difficult and identifying leading indicators more elusive. However, the challenges of air pollution, water scarcity, climate change, and social injustice facing industry are not optional for companies to thrive.

We live in a world with rapidly changing markets and products, innovation, government and industry requirements, and stakeholders who demand accountability and transparency. Rapidly changing markets and social forces are rewriting the roles and responsibilities of business. Stakeholders expect businesses to be "good citizens" and responsible stewards of their communities and environment while, at the same time, their businesses grow and seek profit.

In the publication, Business Ethics, A Manual for Managing Responsible Business Enterprise In Emerging Market Economics (U.S. Department of Commerce, International Trade Administration, 2004), the authors suggest that while businesses are dependent on good public governance for their growth and success, they are also "authors of their own destiny".

Enterprises that take responsibility for their decisions and actions, and impacts on their internal culture and external communities, will be best positioned for long-term growth and improved prospects for future generations.

Since the early 1980's, governments, global businesses, standards organizations, NonGovernmental Organizations (NGO's), and society collaborated about the role of business as responsible stewards. New laws, regulations, standards, and operating practices emerged. During the 1990's new leaders surfaced and enterprises not part of the dialogue either played catch-up or ran the risk of being left behind.

The European Union (EU) advanced the concept of "safe" products for its communities with extended producer responsibility (EPR) principles for the sustainable life cycle management of products. Important generic elements of EPR include:

- Product category or waste stream focus

- Standards for competing producers

- Assignment of responsibility for life cycle management, including product take-back and phase-out of hazardous materials

- Producer flexibility and accountability (e.g., through producer responsibility organizations) in program design and implementation 
- Transparency for the public (e.g., clear labeling of products)

- Performance requirements and deadlines

- Regular monitoring and reporting of progress

The EU's End of Life Vehicles (ELV) Directive (2000), Restriction of Hazardous Substance Directive (2002), Registration, Evaluation, Authorisation and Restriction of Chemicals (REACH) (2006) are just a few examples of EU Directives directly related to the EPR. Industries world-wide have focused on understanding the impacts of EU product legislation to their enterprises, collecting data to meet requirements of both the EU Directives and customer requests and by working with their Supply Chain collaboratively and at times, in partnership, to ensure integrity of their data.

There are certain common denominators throughout the business enterprise: product stewardship, product quality, transparency, workplace health and safety, protection of the environment, conservation of natural resources, protection of workers, and compliance with laws, regulations, and industry standards. Historically, each of these elements has been managed in a "silo", a framework engendered through specialization and optimization. Each has essentially been its own dynamic and in most cases, interrelationships among the elements have been discouraged either through laws and regulations or an enterprise's organizational structure.

With the advent of EU's Directives, other nations such as China, Norway, Japan have adopted similar legislation thereby forcing multi-nationals to consider the long-term impacts of what they produce and market, and to gather information to conform to the requirements of this new legislation. To not do so, can mean that markets will no longer be available to their products. Therefore, industry has invested millions of dollars in assessing the risks of their products, reporting to the EU and other countries with similar legislation, and assisting their Supply Chain. The "silo" approach to managing regulation gave way to a system approach to address thousands of data points from toxicity, to safety, life cycle, energy, Conflict Minerals etc.

Peter Senge suggests a system approach to organizational success in his book The Necessary Revolution: How Individuals and Organizations are Working Together To Create A Sustainable World (Senge et. al., 2008). Senge's Systems Thinking approach to long-term sustainability requires a holistic view to effectively redesign products, processes and business models. No one element can effectively address the whole. In the case of environmental compliance, laws and regulations, they made the environment "less bad" but did they optimize resources to make it better? How can - how is industry optimizing resources, often times limited resources, to make measurable improvements?

Many leading companies are reporting on sustainability through Corporate Sustainability Reports (CSR) while others through reviewed, transparent organizations such as the Global Reporting Initiative (GRI). But what is sustainability? Sustainability is a collective term leading to one outcome - progressive improvement to sustain future life. Sustainability, for some companies, includes corporate responsibility, and other elements such as environment, worker health and safety, a green supply chain, risk management, employee community involvement, corporate philanthropy, and social impacts. In a 2013 Ernst and Young/Boston College study on companies reporting on sustainability using the GRI (Global Reporting Initiative) framework, the 
top four motivations for reporting included transparency, competitive advantage, risk management, and stakeholder pressure. Industry's stakeholders have demanded sustainable practices but that is not one of the top motivations for reporting based on the Ernst \& Young/Boston College study. Is there a misalignment between corporate sustainability metrics and the needs of the stakeholders? Are we asking the right questions? Are we pulling the right levers? Where do the drivers, the processes, and the stakeholders fit into this scheme of metrics, outcomes and outputs?

\section{Authors of Their Destiny}

The metrics that are being measured and tracked by industry are either required by regulation or expected via stakeholder pressure. But even so, leading industry groups have "authored their own destiny". Leading industries have responded to product requirements and reported on chemicals in their products, energy (use, embedded and efficiency), life cycle, recycle/reuse through multi-variable laws and regulations. But they have also focused in on their Supply Chain and developed programs to mentor, assist and ensure consistency and accuracy in reporting.

What is the Supply Chain? The Supply Chain is not a uniform structure with identical capabilities and motivations. The Supply Chain ranges from the small shop to large conglomerates. Each has strength in their products but not necessarily in the infrastructure that made their products. Not all within the Supply Chain can respond with equal deliberation to global requirements for data validation or Material Certifications in response to their customers requests.

Over the years industry groups have developed Supply Chain requirements and Code of Conduct to help raise the Supply Chain to the standards of their customers. Certain codes focus on internal operations of their members such as the chemical industry's Responsible Care Program, while others focus on the supply chain, such as The Electronic Industry Citizenship Coalition (EICC).

Codes of Conduct can play an important role in the development of industry standards, and further define and refine these standards. As an example, the EICC approaches its supply chain code holistically. The EICC establishes standards to ensure that working conditions in the electronics industry supply chain are safe, that workers are treated with respect and dignity, and that business operations are environmentally responsible and conducted ethically. The Code outlines standards for Labor, Health and Safety, business ethics and elements of an acceptable system to manage conformity to the Code. For example:

Labor: Those who commit to the Code are committed to uphold the human rights of workers, and to treat them with dignity and respect as understood by the international community. The standards include: (1) Freely Chosen Employment; (2) Child Labor Avoidance; (3) Working Hours; (4) Wages and Benefits; (5) Humane Treatment; (6) Non-Discrimination; (7) Freedom of Association.

Health and Safety: Participants commit to minimize the incidence of work-related injury and recognize management systems such as IHSAS 18001 and ILO Guidelines on Occupational 
Safety and Health. The standards include: (1) Occupational Safety; (2) Emergency Preparedness; (3) Occupational Injury and Illness; (4) Industrial Hygiene; (5) Physically Demanding Work; (6) Machine Safeguarding; (7) Sanitation, Food and Housing.

Environmental: Participants recognize that environmental responsibility is integral to producing world class products and support management systems such as ISO 14001 and the Co Management and Audit System (EMAS). The standards include: (1) Environmental Permits and Reporting; (2) Pollution Prevention and Resource Reduction; (3) Hazardous Substances; (4) Wastewater and Solid Waste; (5) Air Emissions; (6) Product Content Restrictions.

Ethics: Participants, in order to meet social responsibilities must uphold the highest ethical standards, which include: (1) Business Integrity; (2) No Improper Advantage; (3) Disclosure Property; (4) Intellectual Property; (5) Fair Business, Advertising, and Competition; (6) Protection of Identity; (7) Responsible Sourcing of Minerals; (8) Privacy; (9) Non-Retaliation.

Management System: Participants must adopt/establish a management system that is related to the EICC and be designed to ensure (a) compliance with applicable laws; (b) conformance with the EICC; (c) identification and mitigation of operations risks to the EICC. It shall facilitate continual improvement. The management system elements are to include: (1) Company Commitment; (2) Management Accountability and Responsibility; (3) Legal and Customer Requirements; (4) Risk Assessment and Risk Management; (5) Improvement Objectives; (6) Training; (7) Communication; (8) Worker Feedback and Participation; (9) Audits and Assessments; (10) Corrective Action Process; (11) Documentation and Records; (12) Supplier Responsibility.

In addition to the Code, the EICC also provides tools and resources to its members to support their success. The tools are focused on both the corporate environment and the facility environment, recognizing that there are different drivers at each level of the organization. This is just one example of data collection currently underway that brings together several elements of sustainability.

\section{Recommendations}

The following recommendations are offered:

1. Define Outcomes: What is the purpose of a sustainability standard and who will this apply to? Industry has invested millions of hours and money in sustainability and regulatory reporting. How is this different and can the efforts be built upon? Are there elements in the current system that can be recycled and reused?

2. Maximize Current Programs:

a. Data Assessment: Assess data that is currently being collected for regulatory purposes, Supply Chain requirements etc. to determine whether these are leading or lagging indicators, data relevant to measuring progress towards a sustainable future. This should be conducted at the corporate and facility level. They are different. At minimum this would include the elements in the Codes of Conduct cited above and life cycle. 
b. Data Management: Determine a framework where data can be maximized and reused/recycled. Ensure that tools are provided that are uniform and have simple interfaces.

3. Management System: The importance of a systems approach is crucial to capturing the interrelationships and interdependencies of the issues across the value stream. These interdependencies should also reflect on a business model - the main drivers identified in the Boston College report, and optimize the business model around several inputs: the shareholder (economic), environment, health and safety, and social aspects. Consideration may also be given to improving the existing ISO 14001 Management System with the additions of Worker Feedback and Participation, Supplier Responsibility, Improvement Objectives - adding in some of the elements from the EICC.

\section{Conclusions}

In an interview with Senge (Bloomberg BusinessWeek, 2010), Senge states that for the past 140 years the shareholder has been protected, and with good reason. But today, he questions whether that still makes sense. Senge argues that we have a surplus of financial capital but yet great shortages of natural capital, human capital, and social capital. We have optimized our business model around one input.

Laws, regulations and standards have played an important role in making the environment and health and safety "less bad". Sustainability however, has sought to establish principles of continuous improvement to make the world better for present and future generations. Are all components of a robust program being used i.e. laws, regulations, industry standards, corporate responsibility commitments? Have we separated the elements of sustainability to the point where we have failed to recognize the interrelationships, and have measured only a part of an input/outcome?

Industries have embraced the concept of sustainability, have subscribed to reporting mechanisms with transparent outputs to prove to stakeholders that they are making progress. That progress has waned over the past few years but is it because of a lack of progress? Are there other factors such as not identifying the correct drivers or has the system become too complex, too abstract to measure accurately?

Is more of the "same" needed - more laws, more regulations, more standards? Or do we need to look in a different direction, to different mechanisms to supplement the programs in place? Can the standards for sustainability build on the Codes of Conduct developed by industries? They are holistic in their approach; they are interrelated and personal - personal in that a failure would be directly felt by the industry both individually and collectively. And they are measurable and verifiable.

\section{References}

www.ey.com/us/climatechange (Ernst and Young/Boston College GRI report download) www.eicc.info (Electronic Industry Citizenship Coalition) www.icca-chem.org (Responsible Care) 
http://www.ey.com/US/en/Services/Specialty-Services/Climate-Change-and-SustainabilityServices/Value-of-sustainability-reporting

Evans, Donald, 2004, Business Ethics: A Manual For Managing A Responsible Business Enterprise In Emerging Market Economies, U.S. Department of Commerce.

http://www.ita.doc.gov/goodgovernance/adobe/bem_manual.pdf

Senge, Peter, Bryan Smith, Nina Kruschwitz, Joe Laur, Sara Schley, 2008, The Necessary Revolution: How Individuals and Organizations are Working Together To Create A Sustainable World, Random House, New York. 
[This page is internationally left blank] 
Jawahir, I. S., F. Badurdeen, and K. E. Rouch, University of Kentucky

\title{
Towards Implementing and Advancing Sustainable Manufacturing: A Metrics-based Evaluation of Product and Process Sustainability
}

\begin{abstract}
This paper presents some promising strategic directions for implementing and advancing innovative sustainable manufacturing in industries for accelerated growth and economic development with an overview of the recent work completed by researchers at the Institute for Sustainable Manufacturing (ISM) in the University of Kentucky under a NIST-sponsored project on developing metrics for sustainable products and processes. A integrated "products - processes - systems" approach to sustainable manufacturing is shown with a justification for embarking on sustainable manufacturing through a metrics-based evaluation of sustainable products and processes to serve as the basis for achieving systems sustainability. A new evaluation method for quantifying the sustainability contents of sustainable products and processes through the use of a Product Sustainability Index (ProdSI) and Process Sustainability Index (ProcSI) is then presented with an implementation strategy followed by a summary of work with outlook.
\end{abstract}

\section{Keywords}

Manufacturing, Products, Processes, Metrics, Innovation

\section{Background}

\subsection{Sustainability Interactions: Innovation - Manufacturing - Education and Training}

Innovation plays a pivotal role in economic growth and societal and environmental wellbeing as it connects sustainability and manufacturing effectively and emphasizes the need for education and training for nurturing and promoting innovative approaches in industrial production.

Sustainability as the driver for innovation: Numerous studies and in-depth analysis of sustainability concepts and applications have shown that sustainability is a driver for innovation. The most notable among these studies include an early work published in the Harvard Business Review which presents a five-stage approach with central challenges and competencies required, and the innovation opportunities discussed for each stage (Nidumolu et al., 2009): Stage 1: Viewing compliance as opportunity; Stage 2: Making value chains sustainable; Stage 3: Designing sustainable products and services; Stage 4: Developing new business models; and Stage 5: Creating next practice platforms. A more recent MIT study (Kiron et al., 2013) shows that many companies are generating profits from sustainability. This study recommends five practices to accomplish this: (1) Need to change the business model; (2) Leading from the top to integrate the effects; (3) Measuring and tracking sustainability goals and performance; (4) Understanding the customer expectations for sustainability in terms of value and cost; and (5) Collaborating with individuals, customers, businesses and groups beyond the boundaries of the organization. Sustainable value creation has thus become the focus of all sustainability studies.

Innovation promotes accelerated growth in manufacturing: It is well-known that innovation in industrial production with advancement of product and process technologies leads to technological advances with competitive advantage, and this promotes accelerated growth in 
manufacturing. Sustainable products and processes are known to be innovative, and they contribute to societal and environmental benefits, too.

Manufacturing is the engine for wealth generation and societal well-being: National economy of any country heavily depends on the manufacturing capacity and the diversity of products and processes developed for its population, and for marketing to other nations. Developed and developing nations have shown the pivotal role of manufacturing in job creation, societal wellbeing and national economic advancement.

Societal well-being and economic growth heavily depend on the level and quality of education and training: Education and training of workforce are essential elements for economic and social growth of any nation. Such education and training programs in sustainability are also a strategic requirement for nations, communities and individuals.

\subsection{Sustainable Manufacturing Definitions}

There are numerous definitions and descriptions for sustainable manufacturing (US Department of Commerce, 2009; NACFAM, 2009; NIST, 2010; ASME, 2011; NSF 2013; ASME 2013). However, almost all such definitions fall short of showing the connectivity among the above integral elements, particularly connecting sustainability with innovation and value creation. Sustainable manufacturing offers a new way of producing functionally superior products using innovative sustainable technologies and manufacturing methods through the coordination of capabilities across the supply chain. Thus, integrated sustainable manufacturing enables sustainable value creation for all stakeholders. Sustainable manufacturing deals with three integral elements: products, processes and systems. To achieve sustainable production, each of these three integral elements is expected to demonstrate: (a) reduced negative environmental impact; (b) offer improved energy and resource efficiency; (c) generate minimum quantity of wastes; (d) provide operational safety; and offer improved personal health, while maintaining and/or improving the product and process quality (Jayal et al., 2010).

\section{Product and Process Innovation for Sustainable Manufacturing}

Developing innovative products, processes and systems is a significant aspect of sustainable manufacturing, and it involves a holistic approach to manufacturing different from the traditional manufacturing practices where the quality and performance characteristics are measured and quantified independently, often with no consideration of the effects of other integral elements. The emerging holistic and integrated approach requires all stakeholders to work together on common objectives with total commitment. To enable innovation in sustainable manufacturing, innovation must be embraced at the product, process and systems levels with close interactions among each other (Jawahir et al., 2013a). System innovation can be built on the foundation of product and process innovation.

\section{Sustainability Elements at Product and Process Levels}

Since there are multiple streams of energy, materials/resources and waste/emission involved at different stages over a product's life, the total life-cycle must be considered in order to evaluate a product's sustainability score for comparison between different designs, or between different production strategies. Graedel (1998) presented an extensive study of streamlined life-cycle analysis (SLCA) methods, including matrix approaches using target plots, and considering five major product life-cycle stages: pre-manufacture; manufacture; product delivery; use; and 
recycling. Subsequently, a simplified total life-cycle of a product was introduced including four key life-cycle stages - pre-manufacturing, manufacturing, use and post-use (Jawahir et al., 2006). To achieve multiple product life-cycles with the goal of near-perpetual product/material life, it was shown that design and manufacturing practices for next-generation products must consider these product life-cycle stages using a more innovative 6R approach (Reduce, Reuse, Recycle, Recover, Redesign and Remanufacture) with transformation from lean to green to sustainable manufacturing (Joshi et al., 2006). A comprehensive systems approach can then be developed to cover products, processes and systems to enable sustainable value creation.

Product sustainability: Several researchers have considered the environmental performance and the associated economic and societal effects of products, largely intuitively, and offering limited quantitative descriptions. Thus, these analyses mostly remain non-analytical and less scientific. The need for quantitative modeling of product sustainability continues to grow. Consideration of a total and comprehensive evaluation of product sustainability can lead to reduced consumer costs over the entire life-cycle of the product, while the initial product cost could be slightly higher in some cases. This benefit is compounded when a multiple lifecycle approach is adopted on the basis of continuous material flow. Recent research on product sustainability evaluation shows a consistent trend towards the long-range development of a product sustainability rating system for all manufactured products. This rating would be expected to represent the "level of sustainability" built in a product by taking into account all major contributing sustainability elements and their sub-elements. Work by Fiksel et al. (1998) is among the earliest in attempting to quantify product sustainability in terms of economic, environmental and societal elements affecting the product. Subsequent work shows the six major product sustainability elements, along with numerous sub-elements -- see

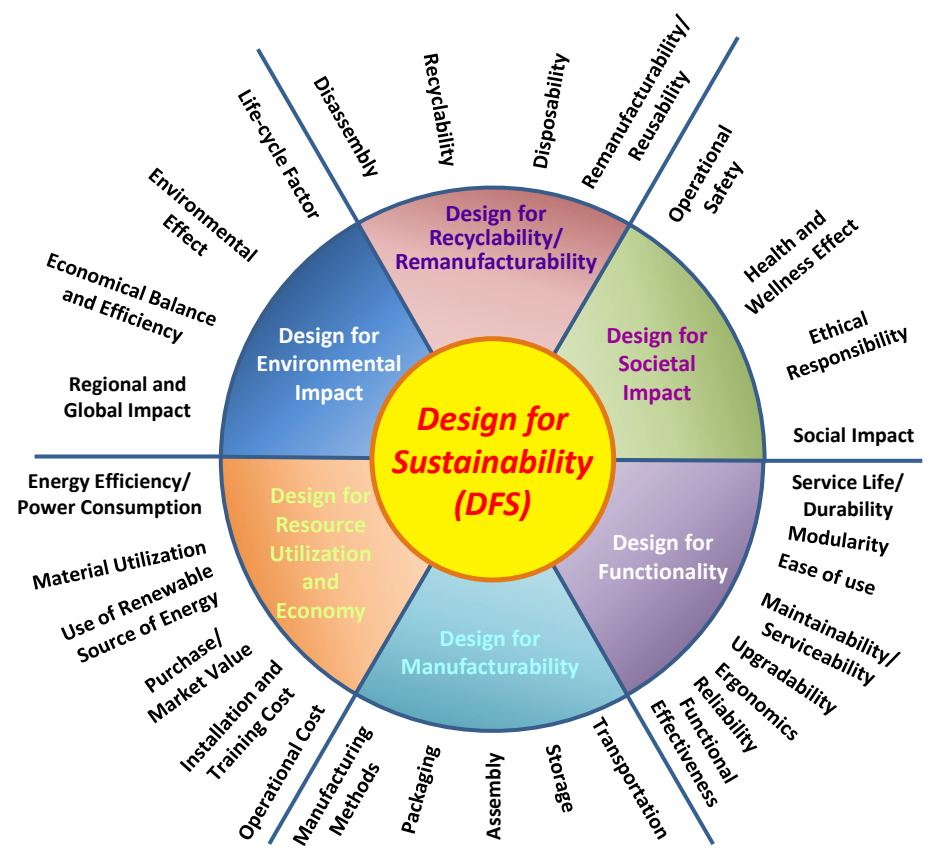

Figure 1. Major elements and sub-elements of product design for sustainability

(Jawahir et al., 2006)

Figure 1 (Jawahir et al., 2006). 
Process sustainability: The primary objective of identifying and defining the various contributing elements and subelements of manufacturing process sustainability is to establish a unified, standard scientific methodology to evaluate the degree of sustainability of a given manufacturing process. This evaluation can be performed irrespective of product life-cycle issues, recycling, remanufacturability, etc., of the manufactured product. Manufacturing processes are numerous, and depending on

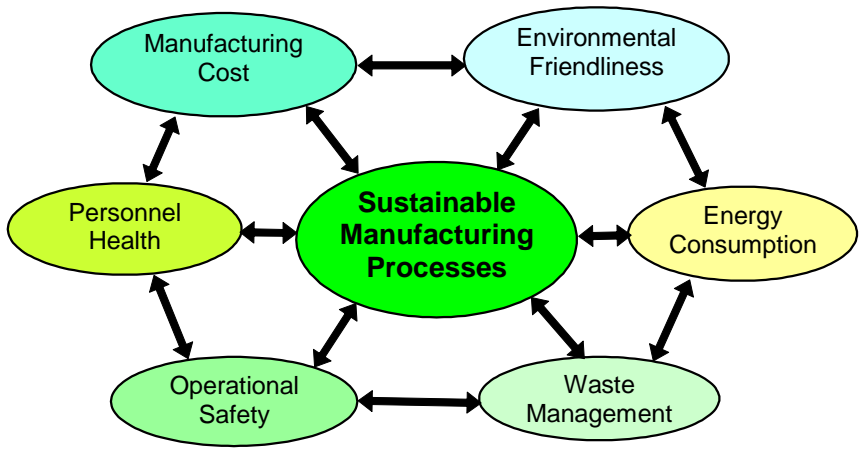

Figure 2. Major elements of process sustainability (Wanigarathne et al., 2004)

the product being manufactured, method of manufacture, and their key characteristics, these processes differ very widely. In an early work it was shown that sustainability of a manufacturing process can be evaluated in terms of six major interacting elements (Wanigarathne et al., 2004) -- see Figure 2. The motivation for recent sustainability studies of manufacturing processes comes from recent efforts in developing a manufacturing process sustainability index. The idea in developing this concept is to separate the manufacturing process from the global picture of sustainability, and to develop it up to the "level of acceptance" for common practice in industry.

\section{A Metrics-based Approach for Evaluating Product and Process Sustainability}

In a recent NIST-sponsored project, the researchers at the University of Kentucky developed a metrics-based approach for evaluating the sustainability content of a manufactured product using a five-level hierarchical structure, and this led to the derivation of a Product Sustainability Index (ProdSI), beginning with metrics through to sub-clusters, clusters and sub-index to index. This hierarchical structure, with identified relevant metric clusters, is shown in Figure 3 (Jawahir et al., 2013b). 


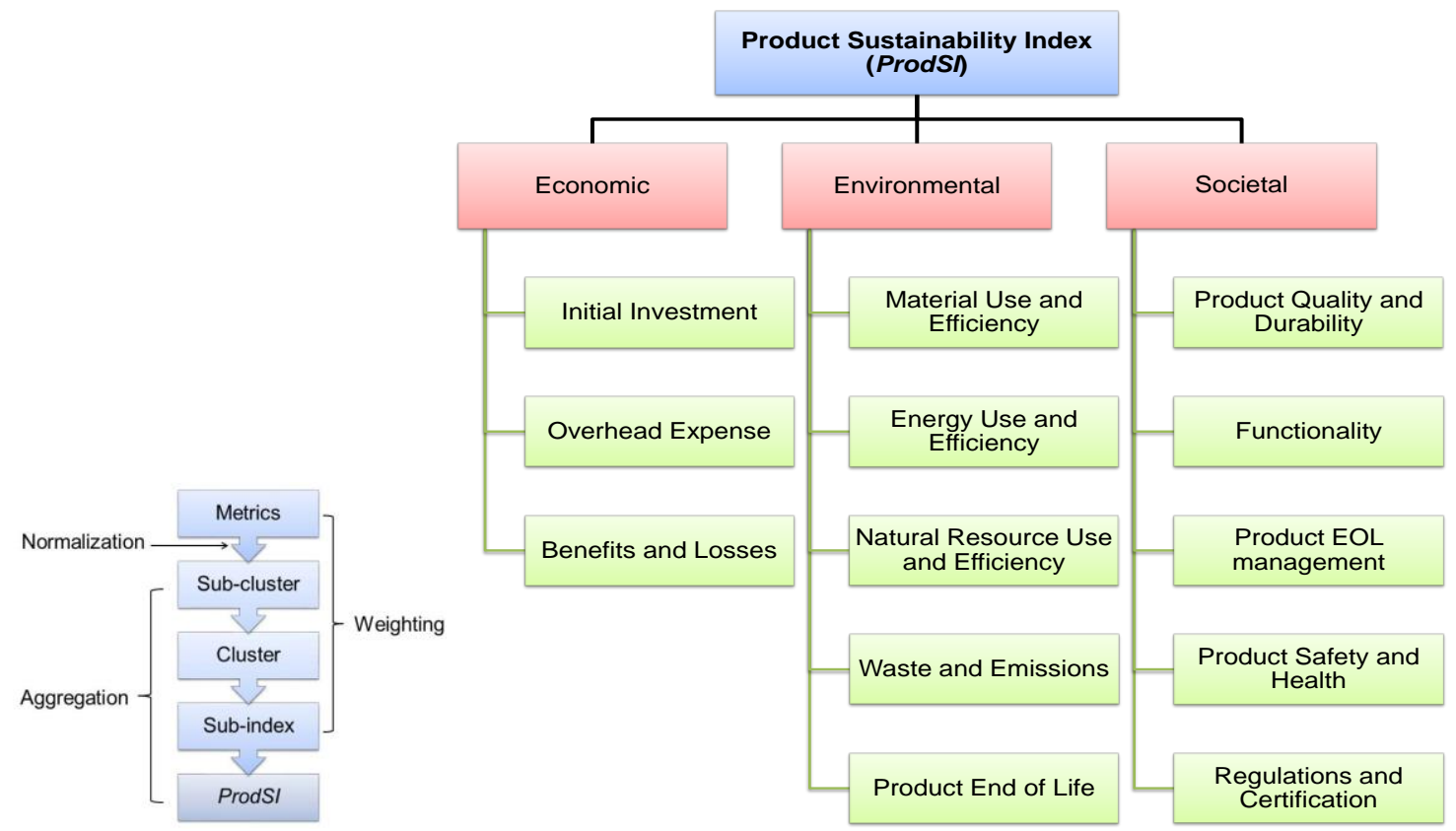

Figure 3. The hierarchical structure of product sustainability evaluation method with metric clusters (Jawahir et al., 2013b)

A total of 13 product clusters were developed, each with measurable metrics, applied to relevant life-cycle stage. The evaluation product sustainability can be made using the following integrated expression shown in Equation (1):

$\operatorname{Prod} S I=\frac{1}{3}(E c+E v+S o)=\frac{1}{3}\left(\sum_{i=1}^{3} w_{i}^{c} C_{i}+\sum_{i=4}^{8} w_{i}^{c} C_{i}+\sum_{i=9}^{13} w_{i}^{c} C_{i}\right) \begin{aligned} & C_{m}=\sum S C_{j} w_{j}^{s c} \forall j \\ & S C_{n}=\sum M_{k} w_{k}^{m} \forall j\end{aligned}$

Metric clusters with measurable example metrics, along with the corresponding life-cycle stage(s), are shown in Figure 4 (Jawahir et al., 2013b).

\begin{tabular}{|c|c|c|c|c|c|c|}
\hline Metrics Clusters & Example Metrics & $\begin{array}{c}\text { Unit } \\
\text { (D/L } \\
\text { dimensionless) }\end{array}$ & $\begin{array}{l}\text { PM } \\
\text { (pre- } \\
\text { mfg.) }\end{array}$ & $\underset{(m f g .)}{M}$ & $\begin{array}{c}\mathbf{U} \\
\text { (use) }\end{array}$ & $\begin{array}{l}\text { PU } \\
\text { (post- } \\
\text { use) }\end{array}$ \\
\hline Residues & $\begin{array}{c}\text { Emissions Rate (carbon-dioxide, sulphur- } \\
\text { oxides, nitrous-oxides etc.) }\end{array}$ & mass/unit & $\sqrt{ }$ & $\sqrt{ }$ & $\sqrt{ }$ & $\sqrt{ }$ \\
\hline \multirow{2}{*}{ Energy Use and Efficiency } & Remanufactured Product Energy & kWh/unit & & $\sqrt{ }$ & $\sqrt{ }$ & $\sqrt{ }$ \\
\hline & Maintenance/ Repair Energy & kWh/unit & & & $\sqrt{ }$ & \\
\hline $\begin{array}{c}\text { Product End-of-Life } \\
\text { Management }\end{array}$ & Design-for-Environment Expenditure & $\$ / \$(D / L)$ & & $\sqrt{ }$ & & \\
\hline Material Use and efficiency & Restricted Material Usage Rate & mass/unit & $\sqrt{ }$ & $\sqrt{ }$ & & $\sqrt{ }$ \\
\hline Water Use and Efficiency & Recycled Water Usage Rate & gallons/unit & $\sqrt{ }$ & $\sqrt{ }$ & & $\sqrt{ }$ \\
\hline Cost & Product Operational Cost & $\$$ /unit & & & $\sqrt{ }$ & \\
\hline Innovation & Average Disassembly Cost & $\$ /$ unit & & & & $\sqrt{ }$ \\
\hline Profitability & Profit & $\$ /$ unit & & $\sqrt{ }$ & & \\
\hline \multirow{2}{*}{ Product Quality } & Defective Products Loss & $\$ /$ unit & & $\sqrt{ }$ & & \\
\hline & Warranty Cost Ratio & $\$$ /unit & & & $\sqrt{ }$ & \\
\hline Education & Employee Training & Hours/unit & $\sqrt{ }$ & $\sqrt{ }$ & & $\sqrt{ }$ \\
\hline \multirow{2}{*}{$\begin{array}{l}\text { Customer } \\
\text { Satisfaction }\end{array}$} & Repeat Customer Ratio & $(\mathrm{D} / \mathrm{L})$ & & $\sqrt{ }$ & $\sqrt{ }$ & \\
\hline & Post-Sale Service Effectiveness & $(\mathrm{D} / \mathrm{L})$ & & & $\sqrt{ }$ & \\
\hline $\begin{array}{c}\text { Product End-of-Life } \\
\text { Management }\end{array}$ & Ease of Sustainable Product Disposal & $\$ /$ unit & & & $\sqrt{ }$ & \\
\hline \multirow{2}{*}{$\begin{array}{l}\text { Product Safety } \\
\text { and Societal Well-being }\end{array}$} & Product Processing Injury Rate & incidents/unit & $\sqrt{ }$ & $\sqrt{ }$ & & $\sqrt{ }$ \\
\hline & Landfill Reduction & mass/unit & $\sqrt{ }$ & $\sqrt{ }$ & $\sqrt{ }$ & $\sqrt{ }$ \\
\hline
\end{tabular}


Figure 4. Product sustainability metric clusters, example metrics and relevant product life-cycle stages (Jawahir et al., 2013b)

Similarly, the previously identified six major sustainability elements (Figure 1) of manufacturing processes are also organized into a metrics-based system to evaluate the process sustainability. Metrics involved in a three-level process sustainability evaluation for the energy cluster are shown in Figure 5. Figure 6 shows the clusters and sub-clusters used in deriving the Process Sustainability Index (ProcSI).

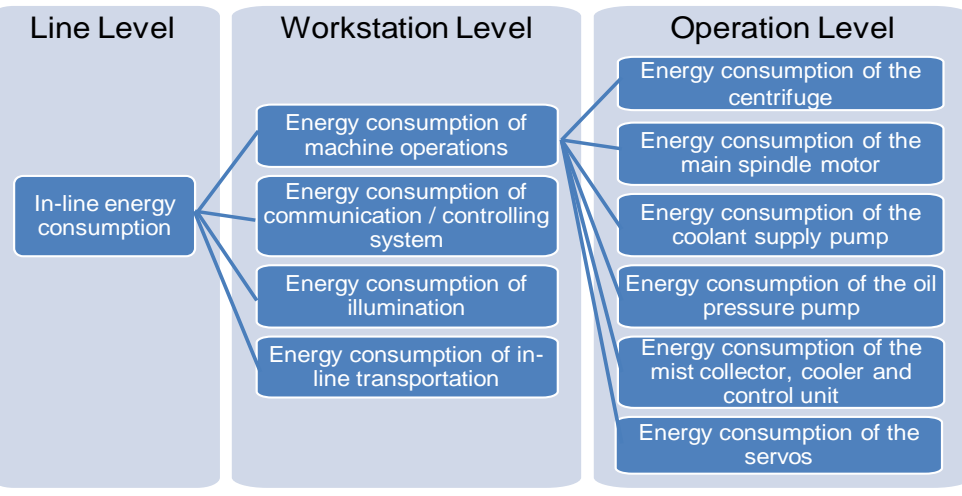

Figure 5. Structure of the three-level metrics involved in process sustainability evaluation for the energy cluster (Jawahir et al., 2013b)

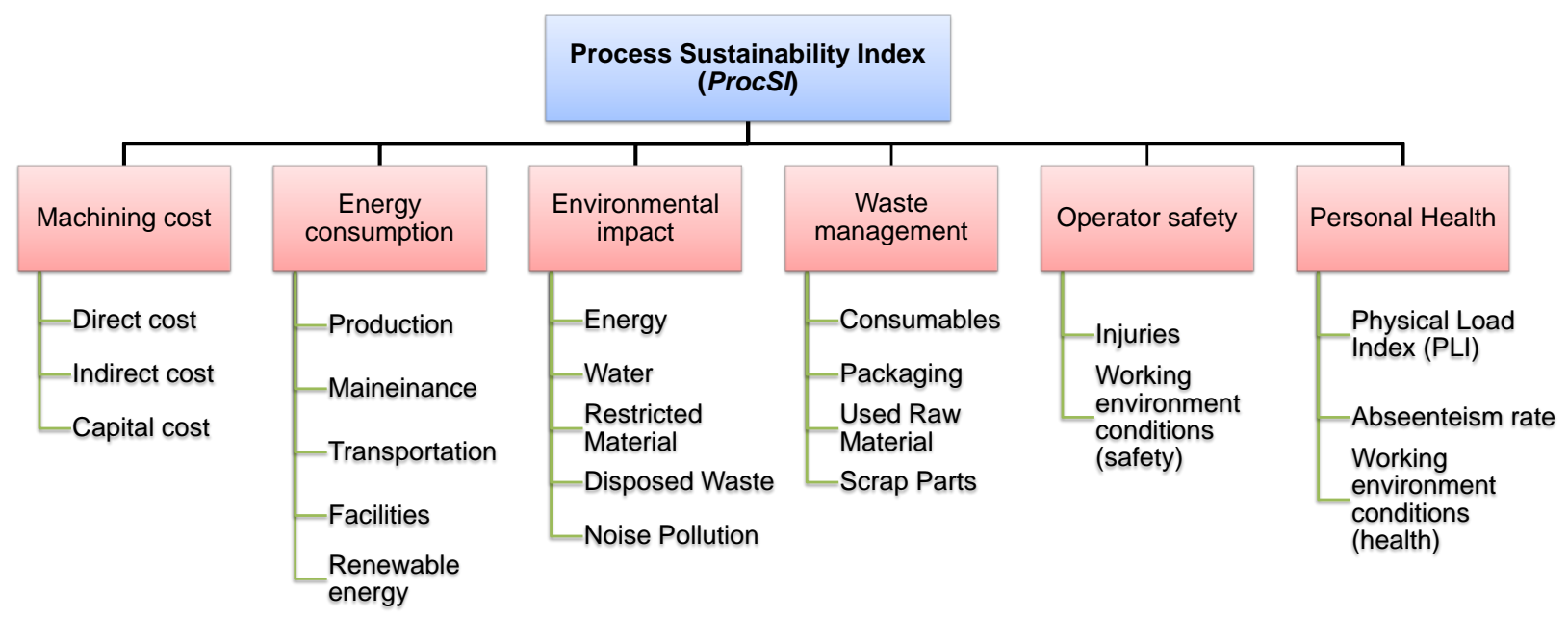

Figure 6. Clusters and sub-clusters developed for the ProcSI method (Jawahir et al., 2013b)

The overall Process Sustainability Index (ProcSI) is determined through using Equation (2):

$$
\begin{array}{r}
\text { Proc } S I=\frac{1}{6} \sum_{i=1}^{6} C_{i}=\frac{1}{6}\left(C_{1}+C_{2}+\frac{1}{5} \sum_{i=10}^{14} w_{i}^{s c} S C_{i}+\frac{1}{4} \sum_{i=15}^{18} w_{i}^{s c} S C_{i}+\frac{1}{3} \sum_{i=19}^{21} w_{i}^{s c} S C_{i}+\frac{1}{2} \sum_{i=22}^{23} w_{i}^{s c} S C_{i}\right) \\
S C_{n}=\sum w_{j}^{m} M_{j} \forall j
\end{array}
$$

Figure 7 shows examples of the overall results from the implementation of the newly proposed sustainability evaluation methodology for manufactured products and manufacturing processes in terms of ProdSI and ProcSI scores at sub-index levels. The overall ProdSI and ProcSI scores (on a scale of $0-1$, or $0-10$ ) can be derived with appropriate weighting. Details of the overall evaluation of product and process sustainability, including the derivation of Equations (1) and 
(2), with aggregation and normalization, along with three industry-based case studies, are welldocumented in the project report (Jawahir et al., 2013b).

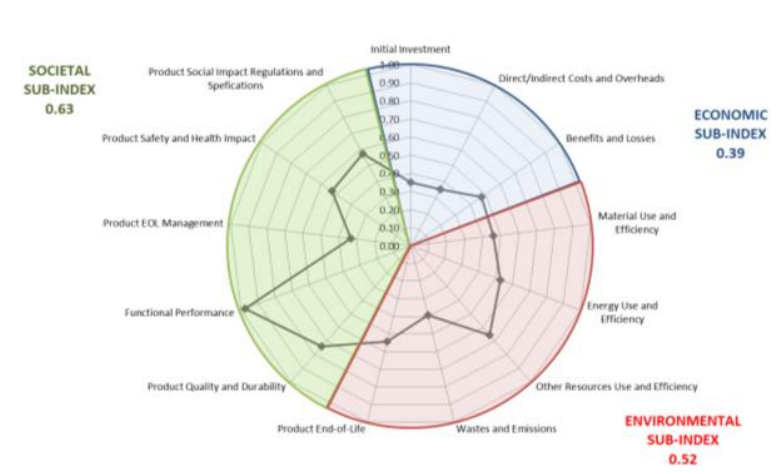

(a) ProdSI

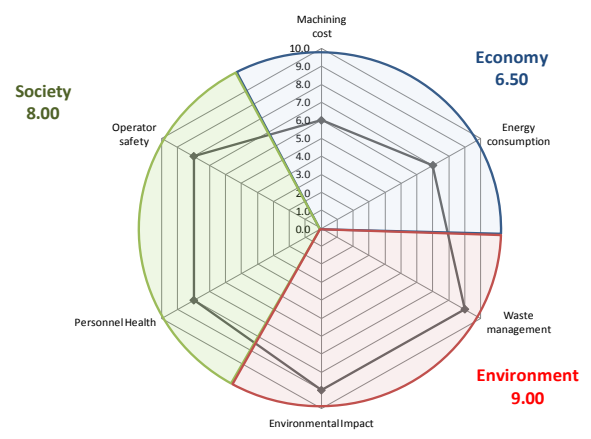

(b) ProcSI

Figure 7. Examples of product and process sustainability evaluation results

\section{Implementing Product and Process Sustainability Metrics}

There has been considerable effort in the manufacturing industry in recent years to develop and implement various sustainable manufacturing practices with corporate commitment to sustainability, including dedicated educational and training programs in place. However, the effectiveness of these activities has been somewhat limited, and the progress in implementing sustainability concepts in product manufacturing is rather slow due to the complexities involved in identifying relevant tools and techniques for measuring and quantifying the numerous sustainability elements in manufactured products and manufacturing processes. Metrics-based evaluation of sustainable products and processes offers an opportunity for embracing sustainable manufacturing, with clearly quantifiable outcome in terms of economic and environmental benefits and societal wellbeing. Effective implementation of sustainable manufacturing practices, with measurable and quantifiable metrics, can significantly improve manufacturing operations through product/process quality enhancement and productivity improvement.

Case studies were undertaken to validate the new methodology in manufactured products and manufacturing processes from three participating manufacturing companies representing three major segments of the manufacturing industry (GE-Aviation, representing aerospace industry; Toyota Motor Manufacturing, representing automotive industry; and Lexmark International, representing the consumer electronics industry).

Product/process metrics can be further developed to formulate relevant standards for evaluating the sustainability levels of manufactured products and manufacturing processes. Regulatory compliance with such new standards would be expected to open up opportunities for developing new and innovative product/process technologies, thus can pave the way for significantly advancing the field of sustainable manufacturing. A thorough understanding of sustainability principles in manufacturing, with total life-cycle and 6R considerations, is expected to form the basis for such innovative approach. Education and training would play a major role in implementing sustainable manufacturing principles in industry for products and processes. 


\section{Summary and Outlook}

This paper summarizes the work recently completed at the Institute for Sustainable Manufacturing (ISM) under a NIST-sponsored research project involving development of relevant metrics and evaluation technics for sustainable products and sustainable manufacturing processes. Relevant metrics were identified under sub-clusters and were placed within various clusters, and through normalization and aggregation methods, with suitable weighting applied, these metric clusters are placed under the three major sustainability elements (environment, economy and society), also known in this work as sub-index, and the sustainability contents of manufactured products and manufacturing processes were evaluated. Case studies were conducted to validate the new methods for evaluating sustainable products and processes.

Significant challenges are involved in implementing metrics-based evaluation of products and processes. It is hoped that the proposed metrics-based sustainability system can be used as a basis for developing new sustainability standards for manufactured products and manufacturing processes, and for advancing the field of sustainable manufacturing.

\section{References}

ASME Sustainable Manufacturing Open Research Forum: Preparing for a New Business Imperative, ASME, June 18, 2013, Washington, DC.

ASME Sustainable Products and Processes Strategic Plan, ASME, February 2011.

Fiksel, J., McDaniel, J., and Spitzley, D., 1998, Measuring Product Sustainability, J. Sustainable Product Design, pp. 7-18.

Graedel, T.E., Streamlined Life-cycle Assessment, 1998, Prentice-Hall, New Jersey, USA.

Kiron, D., Kruschwitz, N., Haanaes, K., Reeves, M., Goh, E., 2013, The Innovation Bottom Line, MIT Sloan Management Review Research Report, Winter 2013.

Jawahir, I.S., F. Badurdeen and K.E. Rouch, 2013a, Innovation in Sustainable Manufacturing Education, (Keynote Paper), Proc. $11^{\text {th }}$ Global Conference on Sustainable Manufacturing (GCSM) (Ed: G. Seliger), Berlin, Germany, pp. 9-16.

Jawahir, I.S., Badurdeen, F. and Rouch, K.E., 2013b, Metrics-based Evaluation of Product and Process Sustainability and Case Studies, NIST Project Final Report, Institute for Sustainable Manufacturing, University of Kentucky, Lexington, KY, USA.

Jawahir, I.S., Rouch, K.E., Dillon, O.W., Jr., Joshi, K.J., Venkatachalam, A., Jaafar, I.H., 2006, Total life-cycle considerations in product design for manufacture: A framework for comprehensive evaluation, (Keynote Paper), Proc. TMT 2006, Barcelona, Spain, 1-10.

Jayal, A.D., Badurdeen, F., Dillon Jr., O.W., Jawahir, I.S., 2010, Sustainable Manufacturing: Modeling and Optimization Challenges at the Product, Process and System Levels, CIRP Journal of Manufacturing Science and Technology, 2: 144-152.

Joshi, K., A. Venkatachalam and I.S. Jawahir, 2006, A New Methodology for Transforming 3R Concept into 6R Concept for Improved Product Sustainability, Proc. IV Global Conference on Sustainable Product Development and Life Cycle Engineering, São Carlos, Brazil.

NACFAM: http://www.nacfam.org/PolicyInitiatives/SustainableManufacturing/tabid/64/Default.aspx

Nidumolu, R., Prahalad, C.K., Rangaswami, M.R., 2009, Why Sustainability is Now the Key Driver of Innovation, Harvard Business Review, September 2009, 3-10.

NIST Report: Sustainable Manufacturing: Metrics, Standards, and Infrastructure - NIST Workshop Report, (Editors: S. Rachuri et al.), NIST, April 2010. 
NSF Report: Sustainable Manufacturing Advances in Research and Technology (SMART) Coordination Network: Output from the Roadmap Workshop on Sustainable Manufacturing, Compiled by IMTI, Inc.; Report on NSF-sponsored Workshop, Cincinnati, Ohio, August 1516, 2013; Document Released on September 8, 2013.

US Department of Commerce: http://www.trade.gov/competitiveness/sustainablemanufacturing Wanigarathne, P.C., J. Liew, X. Wang, O. W. Dillon, Jr. and I. S. Jawahir, 2004,"Assessment of Process Sustainability for Product Manufacture in Machining Operations", Proc. Global Conf. on Sustainable Product Development and Life Cycle Engineering, Berlin, Germany, September 2004, pp. 305-312.

\section{Acknowledgements}

The authors gratefully acknowledge the funding for the work presented in this position paper by NIST through a grant (Award No: 60NANB10D009) during 2010-13. Also, special thanks are extended to the three manufacturing companies (GE-Aviation, Toyota Motor Manufacturing and Lexmark International) who participated in this project by providing specific case studies and testbed development. 


\title{
Kasal, Bohumil, Carolo-Wilhelmina University, Braunschweig, Germany
}

\section{International Perspectives on Metrics}

\author{
Abstract \\ This papers attempts to summarize some of the international (European) standards covering the \\ assessment of sustainability of buildings. While some parameters are quantifiable and can be \\ objectively measured, many are speculative in character and can only be estimated.
}

\section{Keywords}

Metrics, sustainability, Europe, Germany, LCA, standards

Sustainable construction and manufacturing are a part of the complex issue of maintaining the living standards and conditions of the industrially developed world and simultaneously allowing underdeveloped countries to achieve acceptable living conditions. The definition of "acceptable living conditions" is not clear and will not be discussed here. In this paper, I will focus on technical issues and make an attempt to relativize my statements at the end of the text. I will also focus on the European experience in the context of construction systems.

To decide whether or not a structure is sustainable or to which degree sustainability can be defined, one needs to define a set of parameters that can be measured and evaluated in a quantitative fashion. Such a set of parameters, however, varies in time and space and is affected by non-technical factors such as energy costs, demographics, economic models, and even politics. Very few structures are monitored beyond the standard data related to energy consumption, and measurements are driven by economic models (cost of operation) and not technical or engineering drivers. Of course, the data collected are always related to the questions asked, such as cost of electricity or gas per given time, which requires a simple cumulative, scalar measurement of gas/electricity consumption without any relationship to other parameters such as weather. Sustainable construction contains several phases that affect overall building performance and its sustainability:

1. land development phase

2. material production phase

3. construction phase

4. building function/use phase

5. maintenance and repair phase

6. deconstruction and recycling phase

It is clear that many parameters related to sustainability assessment are subjectively defined, such as transportation distance from raw material source to manufacturing site or energy demand to produce certain components. These soft or estimated parameters significantly affect the overall estimate of the footprint of a final system and are, in my view, a weak point of the life-cycle analysis. I will focus on phase 4, which offers opportunities for the scientific assessment of system performance and allows implementing measurements that can yield objective data sets necessary for evaluation of building performance. 
European, and more specifically German, construction systems are heavily biased toward massive construction systems (reinforced concrete, lightweight masonry or steel) and energy demand during system use is a driving force in defining sustainability of a building. The use of renewable materials is, of course, positively evaluated but is viewed in the context of building life expectancy. Active control systems such as light-intensity and temperature controlled shades or ventilation systems are commonly used in public buildings but not in residential construction. Air conditioning systems are not commonly used or are even prohibited in certain public buildings but air quality is becoming a significant issue.

Controlled heating systems tied to exterior temperature and interior temporal and spatial temperature distribution is commonly installed. All of these systems require measurements of temperatures at various locations of the building and programmable controllers that consider time delays, energy accumulation in the system, and losses. Forced-air heating systems are not common in Germany and most European countries due to the lack of air-conditioning in most buildings, but mechanical air-exchange systems will be necessary in the future due to the demand for and regulations of indoor air quality that is becoming poor in buildings solely focused on minimizing energy demand. It appears that a lack of ventilation due to natural infiltration of buildings negatively affects indoor air quality, increases the risks associated with health hazards, and negatively affects the material performance of the structure, mainly due to the high relative humidity of air. Indoor air quality must become a part of the metrics used to evaluate the sustainability of a structure and it does include, beside typical parameters such as temperature, relative humidity, and air exchange rate, the presence of formaldehyde, VOC's and solid particles (including nanoparticles) in the air. Air exchange rate is an easy and indirect way of limiting pollutants in the air but may be of limited relevance if high concentrations of VOC's are generated by the building contents. It is therefore necessary to measure the VOC's (including formaldehyde concentrations) as a function of time and relate this data to the operation of ventilation systems.

\section{Building Instrumentation and Measured Parameters}

The table below (Table 1) proposes parameters to be measured to obtain real-time information about the performance of the building. The parameters listed in the table are intended for experimental structures, where the frequency of monitoring is significantly different from common control parameters or cumulative energy use parameters. Use of renewable materials such as ligno-cellulosic fiber insulation or wood-based construction elements is associated with risks resulting from the biodegradability of such materials. It is therefore necessary to monitor moisture conditions that affect the biodegradation processes and relate them to the aging models.

Predicting the life expectancy of a building is a necessary condition for a complete life-cycle analysis. The models for aging of materials are still not fully validated - there is a known discrepancy between accelerated aging tests and real in-situ aging. It is not even clear what metrics need to be used to predict the life expectancy of a construction system. Besides purely physical parameters such as temperature and load history, moral aging is probably more prevalent; it can be hardly predicted but can be set a priori.

Parameters related to the performance of a building envelope are well known and most investigated. They are used to determine the energy efficiency of a building. Acoustics and vibrations significantly affect system performance and comfort. These parameters are prescribed 
in Europe, where a significant percentage of the population lives in apartment buildings. Light construction systems (such as wood frame structures) suffer from poor performance with regard to noise penetration and vibrations induced by occupants.

Indoor air quality has been a concern in recent years and VOC concentrations can exceed allowable levels, especially in buildings with low air exchange rates. Formaldehyde emissions from wood composite materials (furniture, floor systems, and adhesives) are considered hazardous even in small concentrations. Although formaldehyde concentrations are measured at the material and product levels, what is really important is the exposure of occupants, and not necessarily emissions from a product.

Water consumption and discharge are commonly measured and are naturally parameters that affect the sustainability of a system.

Parameters related to exterior conditions are needed to estimate the deterioration of the system, energy efficiency, as well as correctors for indoor-air quality assessment (indoor air is significantly affected by the outdoor pollution).

\section{Standards and Codes Related to Sustainability}

Attempts are made to establish common rules geared towards achieving certain degree of sustainability in construction. In some countries, such as Germany, the regulations are heavily biased towards energy either embodied or consumed in the process of building use. Table 2 lists some of the International standards that are applicable to the sustainability evaluation of buildings. Many of the criteria are subjective by nature and offer various interpretations. The use and interpretation of the tools to evaluate sustainability has spatial constraints. While in highly developed countries the engineering measures can contain relatively sophisticated systems and solutions at relatively high initial costs, the developing world cannot potentially use the sophisticated technologies and absorb high initial costs. The applicability of existing standards to societies where mere survival is a challenge is limited, at best. It appears however, that it is the developing world that will significantly influence if not completely determine our ability to sustain our living conditions. Here realistic solutions with maximum use of local resources are required. 
Table 1. Suggested matrix of physical quantities to be monitored in a building and surrounding environment

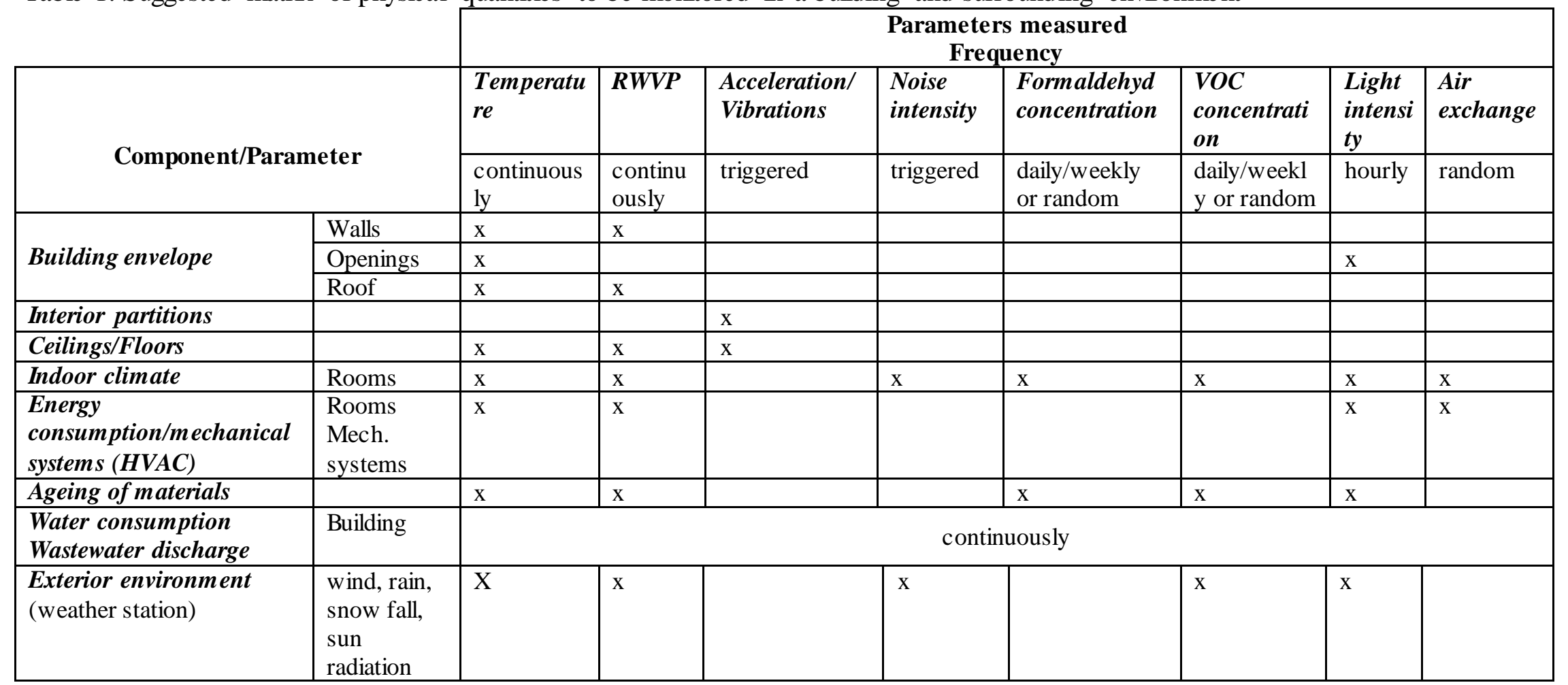

RWVP=relative water vapor pressure

Table 2. Standards applicable in Germany to assessment of building sustainability

\begin{tabular}{|l|l|l|l|}
\hline Code title & Designation & Issued & What it covers \\
\hline $\begin{array}{l}\text { Sustainability of construction works - } \\
\text { Environmental product declarations - } \\
\begin{array}{l}\text { Methodology for selection and use of } \\
\text { generic data }\end{array}\end{array}$ & $\begin{array}{l}\text { CEN/TR } \\
15941\end{array}$ & 2010 & $\begin{array}{l}\text { Generic data, data quality, LCA of materials and processes, quality assessment of } \\
\text { generic data, spatial and temporal data validity, data consistency, data validity, } \\
\text { completeness, uncertainty of data, reliability of data sources, sensitivity analysis }\end{array}$ \\
\hline $\begin{array}{l}\text { Sustainability of construction works - } \\
\text { Sustainability assessment of buildings - } \\
\text { Part 1: General framework }\end{array}$ & EN 15643-1 & 2010 & $\begin{array}{l}\text { Requirements for assessment methods, Object of assessment and the system } \\
\text { boundary, Scenarios, Transparency, Environmental, social and economic } \\
\text { requirements from client's brief and/or regulations }\end{array}$ \\
\hline Sustainability of construction works - & EN 15643-2 & 2011 & Approach to assessment of environmental performance, Requirements for \\
\hline
\end{tabular}




\begin{tabular}{|c|c|c|c|}
\hline $\begin{array}{l}\text { Assessment of buildings - Part 2: } \\
\text { Framework for the assessment of } \\
\text { environmental performance }\end{array}$ & & & $\begin{array}{l}\text { assessment methods, Type of data and their assignment to the building life cycle, } \\
\text { Impacts and aspects specific to the building fabric during the building life cycle, } \\
\text { Impacts and aspects specific to building in operation, Requirements for } \\
\text { calculation methods for assessment of environmental performance of buildings }\end{array}$ \\
\hline $\begin{array}{l}\text { Sustainability of construction works - } \\
\text { Assessment of buildings - Part 3: } \\
\text { Framework for the assessment of social } \\
\text { performance - }\end{array}$ & EN 15643-3 & 2012 & $\begin{array}{l}\text { Requirements for assessment methods, Type of data and data allocation in the } \\
\text { assessment of social performance, Requirements for data quality in the } \\
\text { assessment of social performance, Requirements for assessment methods of } \\
\text { social performance of buildings }\end{array}$ \\
\hline $\begin{array}{l}\text { Sustainability of construction works - } \\
\text { Assessment of buildings - Part } 4: \\
\text { Framework for the assessment of } \\
\text { economic performance }\end{array}$ & EN 15643-4 & 2012 & $\begin{array}{l}\text { Objective of economic performance assessment of the building, Requirements for } \\
\text { assessment methods, Economic aspects and impacts specific to the building, } \\
\text { Requirements for calculation methods for assessment of economic performance } \\
\text { of buildings, Economic aspects of building performance through the life cycle of } \\
\text { the building }\end{array}$ \\
\hline $\begin{array}{l}\text { Sustainability of construction works - } \\
\text { Environmental product declarations - Core } \\
\text { rules for the product category of } \\
\text { construction products }\end{array}$ & $\begin{array}{l}\text { EN } 15804 \\
+\mathrm{A} 1\end{array}$ & $\begin{array}{l}2012 \\
2013\end{array}$ & $\begin{array}{l}\text { Environmental declaration of products, Product Category Rules for LCA, } \\
\text { Declaration of environmental parameters derived from LCA, Additional } \\
\text { information on release of dangerous substances to indoor air, soil and water } \\
\text { during the use stage }\end{array}$ \\
\hline $\begin{array}{l}\text { DIN SPEC } 18941 \text { Environmental product } \\
\text { declarations - Methodology and data for } \\
\text { generic data }\end{array}$ & $\begin{array}{l}\text { CEN/TR } \\
15941\end{array}$ & 2010 & $\begin{array}{l}\text { German editions of CEN/TR 15941. LCA. Use of generic data. Materials and } \\
\text { processes. Data verific ation procedures. Sensitivity analysis. }\end{array}$ \\
\hline $\begin{array}{l}\text { Sustainability of construction works - } \\
\text { Environmental product declarations - } \\
\text { Communication format business-to- } \\
\text { business - }\end{array}$ & EN 15942 & 2011 & $\begin{array}{l}\text { Construction, Buildings, Construction works, Construction materials, } \\
\text { Construction systems parts, Sustainability, Sustainable development, } \\
\text { Environmental management, Environmental engineering, Declarations, Life } \\
\text { cycle, Wastes, Information exchange, Technical documents, Enterprises }\end{array}$ \\
\hline $\begin{array}{l}\text { Sustainability of construction works - } \\
\text { Assessment of environm ental performance } \\
\text { of buildings - Calculation method - }\end{array}$ & EN 15978 & 2011 & $\begin{array}{l}\text { LCA of buildings. Calculation methods to evaluate the environmental quality of } \\
\text { buildings. }\end{array}$ \\
\hline $\begin{array}{l}\text { Sustainability in building construction -- } \\
\text { General principles }\end{array}$ & ISO 15392 & 2008 & $\begin{array}{l}\text { General principles for sustainability in building construction from their inception } \\
\text { to the end of life. Applicable to buildings and other construction works } \\
\text { individually and collectively, as well as to the materials, products, services and } \\
\text { processes related to the life cycle of buildings and other construction works. ISO } \\
15392 \text { does not provide levels (benchmarks) that can serve as the basis for } \\
\text { sustainability claims. It is not intended to provide the basis for assessment of } \\
\text { organizations or other stakeholders. }{ }^{1 \text { ) }}\end{array}$ \\
\hline $\begin{array}{l}\text { Sustainability in building construction -- } \\
\text { Sustainability indicators -- Part 1: } \\
\text { Framework for the development of } \\
\text { indicators and a core set of indicators for }\end{array}$ & ISO 21929-1 & 2011 & $\begin{array}{l}\text { A core set of indicators to take into account in the use and development of } \\
\text { sustainability indic ators for assessing the sustainability performance of new or } \\
\text { existing buildings, related to their design, construction, operation, maintenance, } \\
\text { refurbishment and end of life. Provides measures to express the contribution of a }\end{array}$ \\
\hline
\end{tabular}




\begin{tabular}{|c|c|c|c|}
\hline buildings & & & building(s) to sustainability and sustainable development. ${ }^{1)}$ \\
\hline $\begin{array}{l}\text { Sustainability in building construction -- } \\
\text { Environmental declaration of building } \\
\text { products }\end{array}$ & ISO 21930 & 2007 & $\begin{array}{l}\text { Principles and requirements for type III environmental declarations (EPD) of } \\
\text { building products. Contains specific ations and requirements for the EPD of } \\
\text { building products. }{ }^{1)}\end{array}$ \\
\hline $\begin{array}{l}\text { Sustainability in building construction -- } \\
\text { Framework for methods of assessment of } \\
\text { the environmental performance of } \\
\text { construction works -- Part 1: Buildings }\end{array}$ & $\underline{\text { ISO 21931-1 }}$ & 2010 & $\begin{array}{l}\text { Provides a general framework for improving the quality and comparability of } \\
\text { methods for assessing the environmental performance of buildings and their } \\
\text { related external works. }{ }^{1)}\end{array}$ \\
\hline $\begin{array}{l}\text { Sustainability in buildings and civil } \\
\text { engineering works -- A review of } \\
\text { terminology }\end{array}$ & $\underline{\underline{\text { ISO/TR }}}$ & 2013 & $\begin{array}{l}\text { A compilation of terms and definitions of concepts related to both the } \\
\text { construction and use of a building or civil engineering works, and the effect of } \\
\text { such construction works on sustainability and sustainable development, as } \\
\text { applied in the documents of ISO/TC 59/SC 17, Sustainability in buildings and } \\
\text { civil engineering works } 1 \text { ) }\end{array}$ \\
\hline $\begin{array}{l}\text { Guidelines for the application of the } \\
\text { general principles on sustainability }\end{array}$ & $\begin{array}{l}\text { ISO/ TS } \\
12720\end{array}$ & 2014 & $\begin{array}{l}\text { Provides guidance for the application of the general principles of sustainability in } \\
\text { buildings and civil engineering works elaborated in ISO } 15392 \text {. It shows the } \\
\text { different actors involved with the construction works how to take these principles } \\
\text { into account in their decision-making processes in order to increase the } \\
\text { contribution of the construction works to sustainability and sustainable } \\
\text { development. }{ }^{1)}\end{array}$ \\
\hline
\end{tabular}

1) Source: ISO Standards Catalog. http://www.iso.org/ 
Kearney, Michael S., University of Maryland

\title{
Coastal Infrastructure, Storms, and Sea Level Rise: Measuring the Effects
}

\begin{abstract}
Sea levels are predicted to increase substantially in rate during this century. At the same, there are also predictions that tropical and extra-tropical storms (hurricanes and cyclones; nor'easters) could become more frequent and intense. The impacts on coastal infrastructure could be immense, but the methods that could be used, especially on sandy shorelines, depend not just on the forecasts for sea level rise, but also knowing both the long term trends in shore processes and position. Such information is critical to plan for sustainable coastal residential and commercial infrastructure, even where considerable development already exists. This paper identifies problems encountered in planning for the amount of freeboard above predicted sea levels, mitigation of storm surge, wave, and wind damage from coastal storms, the utility of shoreline setbacks, and the application of "soft" and "hard" solutions to shoreline stability.
\end{abstract}

\section{Keywords}

Shore protection, coastal storms, storm surge, wave damage

\section{Background}

Concerns about the effects of future climate change on infrastructure range from challenges facing maintaining transportation infrastructure in areas that experience already hot summers and how typical road materials will fare if summers become even warmer, to enhanced rates of corrosion in others areas where temperatures become even warmer but also wetter. Preserving and monitoring of existing (and new) coastal infrastructure - let alone construction of new structures - presents some of the greatest challenges. Not only are there the typical problems of designing infrastructure to survive the corrosive effects of salt in either the water or air, but the prospect of accelerated sea level rise to consider, especially for many low-lying areas that become characterized by frequent coastal storms (either tropical or subtropical). In such cases, it attention cannot be paid to just the design, building, and monitoring of structures, but also their physical setting. Indeed, for some coasts, physical setting may be the consideration that trumps all others. Thus, in this paper, not only elements of coastal infrastructure design will be examined from the perspective of sustainability, but also physical setting, especially in the context of how human activities have often compounded the engineering problems.

\section{Storm Surge and Wave Damage}

Sandy beaches, particularly those on barrier islands, pose special problems. A primary problem is determining frontage from the surf zone and "freeboard" (vertical space above mean high high water, MHHW) that incorporates estimates of the potential for large wave runup (and secondarily, wave setup) during storms. The simplest factor contributing to this problem is the seasonal change that occurs in the width of the foreshore (the "beach") along much of the middle Atlantic Coast. In winter the foreshore is much narrower than the average width due to erosion and transport offshore by short period wave typically produced by winter storms (generally nor'easters). In summer, much of the sand (but not all) moves back onshore driven by the long period swell approaching the coast from the southeast. However, though this phenomenon is well known, there are often not sufficient data to estimate the average amount of narrowing of the 
foreshore during winter vs. the average widening during summer. Moreover, as noted, not the all the sand returns during the yearly seasonal beach cycle. Over the long term, even less sand may return since rising sea levels are progressively eroding the beach and, in the case of barrier islands, driving shoreward up the coastal profile. In fact, some of the sand lost from the beach during exceptional winter storm events may take decades to return.

In addition to problems of the amount of freeboard from storm surge and waves, coastal infrastructure, especially residential infrastructure, presents obstacles to designing and monitoring sustainable infrastructure that has nothing to do with the structures themselves, but often the unplanned and chaotic character of coastal communities particularly in older developments. This lack of a planned arrangement of houses and other building makes it difficult to construct flood water diversion routes, creating natural or artificial wave buffers, wind breaks, and other mitigative measures. The desire for beach frontage, even where the risks are well known, continues to hinder sustainable coastal development. Short of zoning restrictions that may be subject to litigation as well as being politically unpopular, passing land use tax incentives is perhaps the best option for promoting land use more conducive to adaptive strategies for sustainability.

Shore protection strategies for coastal sustainability, on the other hand, have had a mixed history. There can be no doubt concerning the effectiveness of some "hard" structural solutions for sustaining coastal infrastructure like seawalls - the Galveston sea wall is irrefutable example of this statement. This sea wall has prevented for more than a century a recurrence of the catastrophic wave damage experienced by that city in the infamous 1900 hurricane for over a century (Larson 1999). The sea wall in Seabright, New Jersey, is another case. Other "hard" shore protection features, like groins and jetties, have contributed to beach maintenance but at a cost of often severe beach loss down drift. Hence, federal and state permitting processes have become less receptive to the implementation of these features.

"Soft" shore protection solutions, like beach nourishment, are supposed to increase beach (foreshore) width and elevation. They meet the criteria of increasing the buffer between coastal infrastructure and storm hazards. However, they also have been denounced for being a waste of tax payer money because the longevity of the projects can be very short, as well as potentially damaging to benthic habitats because from dredging. The first objection, the lack of a sufficiently longevity to make the expense worthwhile, is certainly true of sandy coasts in the U.S. middle Atlantic and northeast Atlantic coasts. The annual recurrence of winter storms (nor'easters) can erode re-nourished beaches back to their pre-restoration condition in a few years. On the other hand, at latitudes where nor'easters are comparatively rare (essentially, South Carolina and southward), beach nourishment has been more effective and longer lasting. Miami Beach has few major re-nourishments projects since the first major beach nourishment project almost 50 years ago. Tropical storms (e.g., hurricanes), of course, do occur in these latitudes, but not with any frequency approaching that of nor'easters and other extra-tropical storms farther north.

There are other "soft" beyond beach protection strategies whose objectives are to raise land elevations and foster development of "natural" storm surge buffers. Reconstruction of the foredune on sandy beaches and barrier islands is often discussed as a method of achieving both 
objectives of raising shore elevation and creating a buffer. The major obstacle to successful adoption of this practice is the fact that most of the natural dune areas in many cases are already developed. There have been attempts at creating foredunes seaward of existing development Ocean City, Maryland, is one example. But whether plantings of American beach grass (Ammophila sp.) or sea oats (Uniola sp.) atop linear piles of sand bulldozed into place will function as dunes is questionable. For one, these grasses depend on sending out leaders from their rhizomes to propagate, and examination of cross-sections through existing dunes reveals a network of older rhizome and roots as well as complex sedimentary structures as deposition varies with changes in wind direction over long periods of time. In other words, a coastal dune as a structure exists because there is an interaction between the plants (mainly grasses) that trap the sand, the changes in wind direction and strength, and shore processes seaward of the dune. To have a successful dune construction program, at the very least, some idea of how the plants, winds, and sediment dynamics operate in area is essential. This has not always been the case, and the efficacy of artificial dunes for coastal protection has been less than could have been. Moreover, the nascent dunes need constant attention and husbandry to insure stability. Overall, however, where possible, dune creation is relatively speaking a low-cost way of enhancing the sustainability of infrastructure on sandy beaches. They also contribute to the ecology of the area and the enjoyment of the beach experience. As a strategy, though has to been implemented with other approaches.

Solutions for accommodating risks associated with sea level rise and coastal storms depend on the age of the structure and characteristics of the site. Clearly, in considering new structures in areas where development has been modest, two factors need to be taken into account: freeboard of the structure and the amount of frontage facing the ocean. The importance of the first has been already discussed, and for residential structures, pilings and/or columns are the typical construction practices. Where these structures have failed, generally there have flaws relating to the lack of adequate anchoring (piles not driven deep enough to overcome instability due to erosion of overlying sediment), rot or corrosion of the columns, and excessive width creating opportunities for increased concentration of wave power. Moreover, owners often try to recover the space within the footprint of the columns by constructing walls between the columns, or large secondary structures within the column space. In either case, such features run the risk of interrupting the flow of surge waters or waves. Break-away walls and structures are design answers to the potential of having buildup of flood water or wave energy on the pilings.

The second problem, the amount of frontage a structure presents to oncoming storm surges and waves, can be addressed easily with new construction. Owners of beach houses generally want to orientate their houses to maximize the opportunity for large patios and decks facing the ocean, in addition to allow for placement of large picture windows. All this is understandable, since a beach house is built for enjoyment, and features like large decks facing the ocean certainly contribute to that experience. Nonetheless, by placing the long axis (assuming the building is rectangular) in a shore-parallel orientation limits engineering options for controlling and diverting flood waters and the emplacement of natural and artificial structures for mitigating wave damage.

The last options for limiting storm surge and wave damage concern land use policies that: i) either control how long structures can stay in place before being moved to account for shoreline 
retreat and increasing flood and wave risk; or ii) set aside areas where there no is development and erosion rates are slow. The first falls under the rubric of shoreline setbacks and similar approaches, and can realistically be only applied to low intensity residential development. The second approach runs the chance of litigation in line with the principle of "takings", where the government contravenes a landowner's right to full and free use of her or his property. Tax incentives or other legislative devices constitute ways of avoiding such conflicts, but recalcitrance on the part of an owner always remains a possibility.

\section{Wind Damage}

Though few of these structures still remain with the pace of development south Florida in recent decades, the older coastal structures, mainly residences, that pre-dated the housing boom were generally small, one story masonry buildings with flat, slightly-pitched roofs that had very little overhang. Windows were also small and easily protected in the case of a storm. Generalizations are always heir to exceptions, but it would not be inaccurate to say that housing construction in recent decades has not followed this old relatively wind-resistant design. Wooden frame construction, multistory plans, and roofs with overhangs that promote wind damage can be observed in many of the new beach properties both on the Gulf and Atlantic Coasts of Florida (and elsewhere for that matter). FEMA and other agencies have produced documents - most recently, the Coastal Construction Manual released by FEMA IN 2011 (FEMA 2011) - that provide guidance for diminishing the likelihood of damage from strong (hurricane) winds on coastal buildings. It is not possible to say what influence these publications have had on coastal construction and especially with respect to what regulatory actions have been enacted (likely at the state and municipal level). The National Flood Insurance Program (NFIP) of FEMA is voluntary. However, the real incentive for compliance may ultimately lie with private insurers, who may mandate certain construction features before granting coverage. For older structures, denial of coverage (if new requirements are not met) could be a prerogative of insurers, though politically it would not be prudent to do so. Despite these caveats, there is one other avenue for compliance that could spur municipalities and counties to regulate the type and quality of coastal infrastructure which is discussed next.

\section{Collateral Damage}

Surveys of storm damage from hurricanes or exceptional nor'easters in recent years from Florida to New York have highlighted an issue that could lead to new views and policies on coastal infrastructure and storm protection: collateral damage. It is no longer a question of encouraging individual owners (or even developers) for their own sakes to consider implementing features that lower risks for damage from storm surges, waves, and winds, but also for the overall good of the community. Damage assessments from mega-storms like Hurricane/Super Storm Sandy along the middle Atlantic Coasts and Hurricane Katrina in the Gulf Coast, have documented the hazards posed by flood-borne and wind-borne debris from inadequately-constructed buildings on other structures that might have gone undamaged from coastal storms. The example of Homestead, Florida, after Hurricane Andrew, is salutary. Not only did the lack of safety straps securing roofs to the main house studs cause losses to individual homeowners, but flying debris from displaced roofs caused damage to other buildings in the vicinity. Along the coast of Mississippi there were many instances of structures damaged by large rafts of crushed debris from demolished structures crashing into them, and not directly by the storm surge and waves of Katrina. A much older, but still powerful illustration of the power of surge- and wave-power 
debris is provided by pictures taken in the aftermath of the Galveston Hurricane of 1900 (Larson 1999) 112 years ago. The huge moving ridge of crushed materials from smashed buildings and other structures also proved deadly to people trying to evacuate their homes and places of business during the storm (Larson 1999).

As the damage by debris from demolished buildings associated with inadequate construction becomes better known, it will be recognized that sustainability in coastal infrastructure means not just preserving individual buildings, but also limiting the wider hazard of debris impacts.

\section{Conclusions and Gaps in Knowledge}

Insuring that coastal infrastructure is sustainable in a future that may see an acceleration in global sea level rise coupled with more intense (and possibly more frequent) coastal storms is not only a question of infrastructure design and siting decisions. Instead, to be successful, involvement of government (local and regional) will be essential because however wellconstructed any building may be, its likelihood of sustaining the effects that the future holds depends on a concerted communal effort to make the community sustainable. As in so many other instances, engineering alone will not solve the problem.

That said, however, there gaps are our understanding of how infrastructure orientation and density influence the potential for decreasing risk of coastal damage in an era of rising sea levels and possible increases in coastal storm severity and frequency. The following gaps need consideration:

- First, while the amount of freeboard required for coastal infrastructure (mainly, buildings), can be incorporated into new construction using the results of global sea level rise models (tailored for an individual coast), more research needs to be done on the application of "soft" storm and wave protection features, like vegetative wave and surge buffers.

- Second, more research is needed on using the landscape to effect natural diversions of surge waters and waves from structures, as well as optimizing siting of structures to lessen Bernoulli effects between structures on surge waters and winds.

- Third, creation of new foredunes has been a matter of piling up sand in a linear ridge with the planting of dune grasses to stabilize (theoretically) the new dunes. More analysis of local wind dynamics needs to be undertaken, particularly along sandy coasts where extensive development with high rise structures. The pre-existing wind fields that supported natural dune development may no longer occur, and any quasi-dunes features sited where sand transport is scanty and irregular will not be sustainable on their own, without continued intervention.

- Lastly, where beach nourishment can work (generally, south of the usual track of nor'easters), the science again seems to be incomplete with respect to the whether the profiles thus constructed are stable. There has been much discussion of "normal beach profiles" (Dean 1977), but the concept is still needs more analysis.

\section{References}

Dean, R. G. 1977. Equilibrium Beach Profiles: U.S. Atlantic and Gulf Coasts. Department of Civil Engineering, Ocean Engineering Report No. 12. Newark, Delaware: University of Delaware. 45. p. 
FEMA. 2012. Coastal Construction Manual. FEMA P-55, Volume I.

Larson, E. 1999. Isaac's Storm: A Man, A Time, and the Deadliest Hurricane in History. New York, Crown Publishers. 
Kocak, Fulya, Clark Construction Group, LLC

\title{
Perspectives for Sustainability in Construction Industry
}

\begin{abstract}
Environmental sustainability, which could mean simply maintaining the earth and its resources for the survival of future generations, usually has various meanings for different industries based on their operations, challenges and priorities. To be able to measure sustainable construction consistently throughout the industry, a consistent definition for sustainability is needed. In this paper, various meanings of sustainability and measurement tools are discussed.
\end{abstract}

\section{Keywords}

Green construction, contractor, sustainability, environmental construction

\section{Introduction}

Change is constant in the construction industry. All contractors, regardless of size, recognize that sustainability is not a fad, but a fundamental change in how buildings are constructed. As sustainable development evolves, the construction industry's impact grows greater: contractors are responsible for extraction and transportation of raw materials, final disposal of waste materials, and the energy consumption of construction operations.

Environmental sustainability, which could simply mean maintaining the earth and its resources for the survival of the future generations, usually has various meanings for different industries based on operations, challenges and priorities. To be able to measure sustainable construction consistently throughout the industry, a consistent definition for sustainability is needed.

\section{What Does Sustainability Mean in Construction?}

Currently in the construction industry, there are two paths a construction company may follow, mostly one or the other and occasionally both.

- Environmental Management which focuses on compliance with local and federal environmental laws,

- Corporate Sustainability which focuses on long and short term strategic sustainability goals for an organization, including green building services and LEED certification.

The choice is usually based on the scope of work a company provides and the risks and liabilities they face as well as the opportunities and competitive advantage they can gain. For example, a building contractor focusing on vertical construction would most likely focus on green building services. A civil construction company on the other hand, would focus on environmental compliance, due to horizontal construction spreading and impacting larger sites.

Based on these two paths, sustainability may have various meanings, such as green buildings, green building services, having sustainability initiatives to reduce impact of operations, waste recycling, indoor air quality management, implementing an environmental management system or being an advocate of sustainability and taking a leadership role to increase awareness while "walking the talk." 


\section{How Is It Measured?}

Most of the time, when sustainability is brought up in the construction industry context, first thing that comes to mind is the LEED rating system. The success in sustainability is usually measured with the number and size of the LEED certified projects a company builds coupled with the number of LEED Accredited Professionals on the staff. For example, the influential trade publication Engineering News Record's (ENR's) annual top green contractors list is based on the dollar value of LEED certified projects each organization completes in the respective year. Corporate sustainability initiatives or innovative green building services are not relevant in this significant industry rating.

This "LEED projects as metric" philosophy also pertains to requests for proposals (RFPs). Most of the public and private RFP's for medium to large scale projects now include a section about sustainability. And almost all of the questions pertain to a contactor's LEED experience and capabilities.

Contractors are usually in the middle of green building decision-making process between the owners and designers. Owners decide what they want and pay the price of their decisions. Architects guide the owners, design spaces and specify materials, products and equipment to meet the owner's goals.

So where does the contractor's influence happen in green buildings?

While some contractors take a passive approach to sustainability do exert minimal effort, progressive firms lead the way and influence green building trends. These firms strive to understand and sometimes decipher their client's priorities in sustainability while staying up to date with the latest green trends, technologies and products to serve as more of a partner. And some contractors will do even more by reducing their operational impact on the environment regardless of any rating system's inclusion of these measures or client demand. A contractor may identify itself as a green contractor by:

- Completing LEED certification documentation for construction credits successfully, and/or,

- Providing green building services, and/or,

- Operating responsible to reduce environmental impact during construction, and/or,

- Playing a leadership role in the future of green, healthy and high performance buildings.

\section{Examples Environmental Construction Operations}

Examples of environmental construction operations include:

- Minimizing its consumption of energy, water and natural resources.

- Limiting land disturbance due to material staging, portable bathrooms, vehicle traffic and compaction

- Minimizing air, water and noise pollution

- Reducing workforce transportation impact

- Utilizing local businesses and materials

- Reduce and recycle construction waste

- Manage indoor air quality 


\section{Change and Expectation}

The winds are changing in the green building industry, so are the expectations from contractors.

In the past decade, the heart of green buildings has been energy efficiency and high performance. The contractor's role has been pricing green building measures and procuring environmental products based on project documents. In the recent years, especially with the major changes in LEED $\mathrm{v} 4.0$, the meaning of green buildings is taking a new turn towards occupant health and material transparency. With this change, the contractor's role will transform from being the final link of the chain in green buildings to being the major player in procuring environmental materials while gathering material transparency information and managing the costs and uncertainties.

\section{What Next?}

With these changes, the need for information sharing is pressing the construction industry more than ever. There is a need for a knowledge sharing and collaboration platform to reduce negative impact of construction activities on the environment while providing leadership in sustainable solutions for healthier and more sustainable buildings. Stronger contractor influence in green building movement and sustainability trends will accelerate positive change and make sustainability solutions realistic and cost effective.

A culture change within the construction industry for true commitment to sustainability that exceeds achieving LEED certification will be a result of increased demand and awareness. Some examples are:

- Government policy for sustainable construction operations

- Stakeholder (clients, employees, community) interest in contractor's commitment to sustainability

- Increased awareness that sustainability is profitable

\section{Examples of Commitment to Sustainability and Green Buildings}

Clark is currently ENR's second-ranked green contractor and has a 55 million square-foot portfolio of green buildings, including the first-ever LEED Platinum project. Our green construction volume exceeds $\$ 2.8$ billion a year.

At Clark, true commitment to sustainability exceeds simple LEED certification goals. We transfer our extensive knowledge, experience and resource to achieve increased sustainability results on every single project cost effectively, addressing our clients' priorities.

We believe that sustainability starts at home. We put key focus on awareness of our employees in sustainability and latest green building technologies. We also believe in sharing knowledge between all stakeholders, including owners, end users, design team, subcontractors and vendors. In 2013, our Clark Corporate University provided 24 classes on sustainability and green buildings. We distributed over 20 green building articles for continuing education in green buildings.

\section{Beyond Building: Shaping a Green Future}

Clark's sustainable efforts in the nation go well beyond simply constructing green buildings. We also believe that green buildings should be accessible for everyone. Our employees take 
leadership role in many environmental organizations, help with advocacy efforts for green and healthy buildings, education and awareness of both the building industry and public.

Company personnel are active and involved with numerous local sustainability groups and act as evangelists for the nation's efforts. For example, Clark's sustainability leader helped shape the District of Columbia's much-lauded new green building codes. Our role was to ensure that the codes were both ambitious and achievable, evaluating proposals and advising on matters of feasibility, effectiveness, and cost. With the District's green codes on the horizon, Clark's sustainability team have engaged the D.C. community - meeting with clients, designers, and subcontractors to talk about the new regulations, how they impact construction, and how to best plan new projects for sustainable success.

In addition to the District's green codes committee, Clark personnel are involved with the U.S. Green Building Council's National Capital Region (Clark staff is the current chairwoman of the group), Association General Contractors of America's Environmental Forum, National Institutes of Health Healthy Buildings Roundtable, and the USGBC's Materials \& Resources Technical Advisory Group. Each of these organizations promotes sustainable living and building - and we bring their research, recommendations, and best practices to our projects and communities. 


\title{
Kontokosta, Constantine E., New York University
}

\section{The Urban Quantified Community}

\begin{abstract}
The "Quantified Community" (QC) is a fully instrumented urban neighborhood that uses an integrated, expandable sensor network to support the measurement, integration, and analysis of neighborhood conditions. Through a diverse range of sensor and automation technologies, information on physical and environmental conditions can be processed in real-time to maximize operational efficiencies and improve quality of life for residents and visitors. The goal is to create a model for future urban development that provides a healthy, productive, and resilient environment that responds to the changing needs and preferences of those that live in cities.
\end{abstract}

\section{Keywords}

Urban Sensing; Urban Systems; Big Data; Urban Sustainability; Computational Planning and Design

\section{Background}

Given the importance of cities to the world's future, the interaction of urban infrastructure, environment, and people must be better understood [1]. While advances in data collection and modeling tools have improved planning and operations within specific urban domains, new sensing technologies (both proliferated in situ and synoptic) enable new sources of data that could be harnessed to understand and improve urban life. For example, mobile phones that can capture, classify, and transmit audio, video, and location data, create the opportunity to actively engage citizens in this process and, in so doing, overcome persistent challenges in large-scale data collection [2]. This "participatory sensing" allows researchers to explore critical quality of life issues previously unobservable, such as health status and physical activity [3]. Synoptic observations in diverse spectral bands or with RADAR or LiDAR offer complementary ways of sensing the city [4]. However, attempts to collect new data from urban sensors remain episodic and insular - video imagery from cameras collected for public safety purposes is rarely used to understand mobility, air sensors deployments are limited in space and time, etc [5].

While fully instrumenting an entire city would require a massive commitment of time and resources, significant progress could be achieved at the neighborhood scale by focusing diverse, comprehensive, and persistent real-time data collection and analysis on a "Quantified Community" (QC). The resulting unique experimental environment would provide a testing ground for new physical and informatics technologies, policies, and behavioral interventions, allowing unprecedented studies in urban engineering, urban systems operation and planning, and the social sciences.

\section{Modeling the City}

Modeling and measuring a "slice of the city" is an extremely important step in creating a dynamic simulation of the urban environment. Data from a QC of sufficient scale could be used to calibrate and validate models of urban infrastructure, the environment, and its population. Theories of urban form and function could be re-evaluated and developed, hypotheses could be tested, and interventions could be measured to evaluate their effectiveness and support evidence- 
based decision-making in the urban context. Understanding various quality-of-life metrics could promote substantial improvements in the lives of urban dwellers and have important implications for economic development indicators such as land and real estate values and tax assessments. Sensors could measure energy and water consumption in buildings, stormwater runoff quantity and quality, sound levels and classifications, air contamination and pollution plumes, and any number of other conditions. The flow of people in, out, and within the QC could be monitored, creating the opportunity to use agent-based modeling and simulation techniques to recognize, predict, and optimize movement patterns across the city. Measurement of health, nutrition, communications, and economic activities would also yield important insights. As importantly, new technologies could be tested and demonstrated in a real-world environment, creating opportunities for entrepreneurs to better understand their impacts beyond an individual building or system.

Of particular interest is the measurement and analysis of data relating to physical infrastructure, the natural environment, and human and social behavior. Examples of the types of information that would provide the basis for further study are shown in Table 1.

These capabilities create value for a QC district, and ultimately for cities, through (1) the measurement, monitoring, and analysis of critical systems and infrastructure; (2) a better understanding of environmental conditions and indicators, both indoors and outdoors, and the ability to react to sub-optimal conditions; (3) the ability to collect, process, and utilize large amounts of data to improve quality of life for residents, workers, and visitors; (4) the measurement and analytics to support operational efficiencies to lower operating expenses; (5) the potential to generate greater market demand for space and attract investment; and (6) the opportunity to develop and test business models, such as new leasing structures and performance-based revenue and expense models, and analyze the economic effects of datadriven optimization of operations, resource flows, and quality-of-life indicators.

The design, planning, and operation of cities are predominantly based on theories of human and social interaction with the built environment that have not been systematically validated on a significant scale [6]. For example, the design of a commercial space is deemed successful based on revenue per square foot, rather than on health and productivity measures that have thus far proven much harder to evaluate [7]. The success of public space is judged, if at all, based on the number of users. Land use decisions are evaluated ex ante, and actual outcomes are rarely considered [8]. These evaluation criteria are based on metrics that often provide relatively little granular information on the actual use of a specific site, neighborhood, or the city as a whole. Collecting data on access, mobility, and user engagement would provide the basis for testing assumptions that developers, planners, designers, and engineers make in crafting urban space. 
Table 1. Proposed Data Measurement, Collection, and Analysis in the QC

\begin{tabular}{|l|l|l|}
\hline Physical / Infrastructure & Environmental & Human/Social \\
\hline -Buildings resource & -Carbon emissions & -Health, nutrition, and \\
consumption & -Particulate levels and & activity levels \\
-Indoor environmental & concentrations & -Social networks and \\
quality & -Noise & connectivity \\
-Solid waste & -Heat Island & -Mobility \\
-Stormwater management & -Climate conditions & -Metagenomics \\
-Power generation \& & and microclimate & -Individual and collective \\
distribution & -Use of public space & behavior \\
-Condition (failure & -Ecology & -Equity and justice issues \\
prediction) & & \\
\hline
\end{tabular}

3. A Fully-Instrumented and Data-integrated Urban Environment

The QC presents four unique opportunities to observe, model, and subsequently intervene in the urban environment. The data and resultant analytics can be used to: (1) test and validate the fundamental assumptions of site planning and design of dense, mixed-use environments; (2) assess the environmental and social impacts of new large-scale urban developments on existing neighborhoods and ecosystems; (3) achieve operational efficiencies and decrease resource consumption; and (4) create a living lab and real-world experimental platform to test new technology, design theories, and conservation strategies.

Compact, mixed-used land use patterns have been associated with improved outcomes along measures of health, resource efficiency, social connectivity, and transportation access. For instance, there are widely-accepted assumptions that mixed-use environments support activity and improve health outcomes for those living in areas that contain a variety of uses [9]. Despite some empirical work, limited robust, comparative evidence exists to define the relationship between urban design and human behavior and social outcomes and understand causal linkages $[10,11,12]$. In relation to a specific site, a fully instrumented and data-integrated environment would allow for the systematic, real-time observation of the use of public space and the relationship in mixed-use environments could be characterized and modeled.

Another important element of study includes transportation, mobility patterns across and between transportation modes, and mobility within the neighborhood. This would address rather common, but persistent, questions of locational access, propensity of residents/visitors to use different modes of transport, and the relationship between land use and transportation. In addition, such a mobility baseline would provide an important reference for measuring perturbations and responses to disasters and other unexpected events. Moreover, the quantification of mobility patterns could be used to assess physical activity and significant social science, engineering, and public health questions of how the built environment shapes and influences health-related outcomes [13].

While the first objective is focused on validating widely-held theories of urban design and planning, the second objective is to capture the impact of greenfield and greyfield developments on existing ecosystems and surrounding communities. Understanding the social and environmental impact of a project over time is critical to reduce uncertainty around future land 
use effects. Once built, monitoring changes in the ecosystem is necessary to promote user diversity and achieve a sustainable environment.

Due to the current development timeframe of the initial QC deployment, it will be possible to establish environmental and social benchmarks prior to the project's completion and monitor how the project impacts the surrounding neighborhoods' commercial activity, rate of development, and neighborhood characteristics (i.e., income, profession, race, education, crime, age, household size, rents, property values, vacancy rates, apartment size, streetscapes, and civic engagement). Similarly, it will also be possible to precisely assess the project's environmental impact across a range of indicators, including congestion, air quality, storm water runoff, utility consumption, and access to green space.

The QC provides an opportunity to vastly improve operational efficiencies and support resource conservation. This objective switches the focus from understanding the dynamics of a site to modeling resource flows and how environmental, physical, and social conditions influence consumption. By analyzing water, waste, and energy flows, among others, operational inefficiencies can be identified based on expected and predicted consumption patterns given various conditions present within the QC district at any specific point in time.

Finally, urban technologies are emerging rapidly; however, the link between research and development and eventual deployment at scale necessitates demonstration opportunities for realworld application and testing. The QC could provide a platform to evaluate new technologies and a range of policy and behavioral intervention strategies. This 'living lab' would provide an important experimental environment for real-time assessment of urban decision-making.

\section{Applications}

The application of the above measurement and "informatics overlay" approach is guided by the goal of improving quality of life within cities and to develop scalable, transferable models to support the sustainability and resilience of global cities. The following is an illustrative list of specific applications in the urban design and planning context:

\subsection{Quality-of-Life for Urban Residents}

Health, activity, and physiology:

- Collecting, aggregating, and disseminating data on physical activity and nutrition through voluntary, opt-in data-sharing platforms.

- Create a system of customized alerts based on air quality and weather for the elderly and residents with chronic illnesses, such as asthma.

- Provide a medical alert system within apartments that can detect falls, strokes, heart attacks, and other medical emergencies.

Environment:

- Increase indoor-air quality through continuous monitoring and controls.

- Reduce noise pollution through sound measurement, classification, and targeted mitigation and attenuation measures.

- Synoptic imaging of the urban heat island effect, within and surrounding the district.

Social justice, social services, and community development:

- Support data-enabled social interactions and networks within the neighborhood.

- Create targeted, place-based services for vulnerable populations. 
- Measure patterns of potentially harmful environmental conditions across socioeconomic groups.

- Support access to information for populations typically under-served by access to technology and broadband connectivity.

Bridging the physical and virtual experience of place:

- The relationship between a user's onsite, physical experience and their virtual, social media interactions remains little understood.

\subsection{Evidenced-based Urban Planning and Design}

- Economists have established that a significant driver of innovation is collaboration, and certain office layouts have been designed, in theory, to encourage collaboration.

Mapping mobility patterns within an office would allow companies to gauge the actual level of collaboration among employees.

- Monitoring patterns of actual space usage could result in space efficiencies and higher utilization rates.

- The theoretical benefits of mix-use developments have been thoroughly discussed; but there is only indirect evidence of the actual dynamic between public, retail, office, and residential spaces.

\subsection{Infrastructure Operations and Resource Flows}

- Increase efficiencies through continuous measurement and feedback.

- Provide detailed consumption reports and comparative benchmarking based on use type, climate, user conditions, etc.

- Monitor infrastructure conditions to predict failures and maintenance needs.

\subsection{Transportation and Mobility}

- Facilitate access to and from a neighborhood and reduce congestion by identifying residents' primary mode of transportation throughout the day-e.g. morning taxi demand, Friday weekend departures, bike and car share availability-and coordinating public transportation with peak demand.

- Model congestion and resultant public health impacts - noise, air pollution, vehiclepedestrian accidents, etc.

\subsection{Emergency Response and Safety:}

- Mobility patterns and pedestrian simulation can be used to test and develop contextual emergency response plans. For example, if police reports can be cross-referenced with access, mobility, and use patterns, along with environmental parameters, then site conditions, such as ambient light, foot traffic, and entry points, can be modified to increase safety.

- The intersection of the physical and virtual environment could support first responders in assessing, and responding to, various emergency situations.

\section{Privacy and Data Access}

Privacy issues have become a paramount concern in the collection and use of urban data [14]. The QC presents unique challenges in balancing the security of data and the need for transparency and citizen engagement, bridging and integrating participatory sensing deployments with remote and fixed, in-situ modalities [15]. The opportunities to provide value to those living and working in a QC, and to generate lessons for urban operations, design, and planning more 
broadly, are a function of the availability of and access to granular spatio-temporal data - what would be considered by most as "sensitive" or personally identifiable information. However, the optimal balance between access to potentially sensitive information and the extent of data needed to achieve the range of objectives stated above needs to be explored.

While new opportunities are emerging to develop technical solutions to issues of data security and privacy, technical fixes alone will not address the very real concerns of private citizens regarding the appropriate control and use of personal data [16, 17]. The QC environment provides an opportunity to explore alternative data collection and use restrictions and controls, ranging from "opt-in", voluntary data collection standards through individual and community ownership of personal and neighborhood-level data, with full control over their use [18].

\section{Implications and Next Steps}

The Quantified Community will be a fully instrumented urban neighborhood that uses an integrated, expandable sensor network to support the measurement, integration, and analysis of neighborhood conditions. Through a diverse range of sensor and automation technologies, information on physical and environmental conditions can be processed in real-time to maximize operational efficiencies and improve quality of life for residents and visitors. The goal is to create a model for future urban development that provides a healthy, productive, and resilient environment that responds to the changing needs and preferences of those that live in cities.

Next steps include the initial deployment of the QC concept as part of a major urban development in New York City. The ability to test, refine, and scale the types of senor technologies and modeling techniques described here would represent a significant advancement. This platform and the data derived would yield a rich experimental environment to study human behavior in the urban context and to test various interventions with real-time feedback. In the near term, a pilot project is being implemented in an existing mixed-use building to field test certain sensing technologies and develop the database architecture and simulation platform to expand to the full-scale, neighborhood-level deployment.

\section{References}

1. Albeverio, Sergio, Denise Andrey, Paolo Giordano, and Alberto Vancheri. "The dynamics of complex urban systems." Physica, Heidelberg (2008).

2. Reades, Jonathan, Francesco Calabrese, Andres Sevtsuk, and Carlo Ratti. "Cellular census: Explorations in urban data collection." Pervasive Computing, IEEE 6, no. 3 (2007): 30-38.

3. Kanhere, Salil S. "Participatory sensing: Crowdsourcing data from mobile smartphones in urban spaces." In Mobile Data Management (MDM), 2011 12th IEEE International Conference on, vol. 2, pp. 3-6. IEEE, 2011.

4. Priestnall, G., J. Jaafar, and A. Duncan. "Extracting urban features from LiDAR digital surface models." Computers, Environment and Urban Systems 24, no. 2 (2000): 65-78.

5. Voogt, James A., and Tim R. Oke. "Thermal remote sensing of urban climates." Remote sensing of environment 86, no. 3 (2003): 370-384.

6. Lynch, Kevin. The image of the city. Vol. 11. MIT press, 1960.

7. Fisk, W. J. (2000). Health and productivity gains from better indoor environments and their relationship with building energy efficiency. Annual Review of Energy and the Environment, 25(1), 537-566. 
8. Johnson, Michael P. "Environmental impacts of urban sprawl: a survey of the literature and proposed research agenda." Environment and Planning A 33, no. 4 (2001): 717-735.

9. Frank, L. D., \& Engelke, P. O. (2001). The built environment and human activity patterns: exploring the impacts of urban form on public health. Journal of Planning Literature, 16(2), 202-218.

10. Jackson, Laura E. "The relationship of urban design to human health and condition." Landscape and urban planning 64, no. 4 (2003): 191-200.

11. Frumkin, Howard. "Healthy places: exploring the evidence." American journal of public health 93, no. 9 (2003): 1451-1456.

12. Leyden, Kevin M. "Social capital and the built environment: the importance of walkable neighborhoods." American journal of public health 93, no. 9 (2003): 1546-1551.

13. Handy, S. L., Boarnet, M. G., Ewing, R., \& Killingsworth, R. E. (2002). How the built environment affects physical activity: views from urban planning. American journal of preventive medicine, 23(2), 64-73.

14. Lane, J., Stodden, V., Bender, S., \& Nissenbaum, H. (Eds.). (2014). Privacy, Big Data, and the Public Good. Cambridge University Press.

15. Christin, D., Reinhardt, A., Kanhere, S. S., \& Hollick, M. (2011). A survey on privacy in mobile participatory sensing applications. Journal of Systems and Software, 84(11), 19281946.

16. Bélanger, F., \& Crossler, R. E. (2011). Privacy in the digital age: a review of information privacy research in information systems. Mis Quarterly, 35(4), 1017-1042.

17. Krontiris, I., Freiling, F. C., \& Dimitriou, T. (2010). Location privacy in urban sensing networks: research challenges and directions [security and privacy in emerging wireless networks]. Wireless Communications, IEEE, 17(5), 30-35.

18. Mun, M., Hao, S., Mishra, N., Shilton, K., Burke, J., Estrin, D., ... \& Govindan, R. (2010, November). Personal data vaults: a locus of control for personal data streams. In Proceedings of the 6th International COnference (p. 17). ACM.

\section{Acknowledgements}

The author would like to thank comments and suggestions from Steven Koonin, Claudio Silva, William Vidal, Jeongki Lim, and several participants of the CUSP Quantified Community Workshops. All errors remain the responsibility of the author. 
[This page is internationally left blank] 


\title{
Kralik, Nancy J., Fluor Corporation
}

\section{Sustainable Construction: An EPC Perspective}

\begin{abstract}
Engineering, Procurement, and Construction companies have a key role, in concert with owners, in developing and implementing sustainability solutions on capital projects. Solutions are optimal when they are considered as part of the life cycle of a project. Economic indicators tend to be well defined, environmental indicators typically are site specific, and social indicators on construction sites are primarily safety related. Research teams have generated a number of practices and tools to assist implementation of sustainability activities on construction project sites. During the course of that research, a number of gaps have been identified, including several related to social metrics and life-cycle assessments.
\end{abstract}

\section{Keywords}

Construction, Social, Life Cycle, Metric, EPC, Construction

\section{Framework}

EPC companies - companies that engage in Engineering, Procurement, and Construction activities - have a key role in designing and implementing sustainability solutions throughout the life cycle of an asset. Many EPC companies also provide operations and maintenance, thereby potentially extending their involvement in sustainability activities related to facilities and other assets. Fluor is an EPC company that plans and designs projects and builds them for operating companies around the globe. The perspectives in this paper relate to sustainability, particularly sustainability in construction, from the standpoint of EPC companies.

While an EPC company, also termed a contractor, may be hired by an owner to execute a specific phase of a project, a partnership of the owner and the EPC company throughout project phases provides opportunities to maximize the sustainability of the overall asset. If sustainability is viewed only during discrete phases - consideration of design and installation of a capital project for example, without consideration for operations or maintenance - the tendency (and often the contract obligation) is to seek opportunities within a specified phase.

As depicted in Figure 1, the Influence Curve highlights that during the planning and design phases, there is significant influence that can be exerted on design objectives. The earlier in the project that sustainability initiatives and objectives are considered, the higher the potential savings and the greater the influence because there are many more opportunities that can be considered. Opportunities can be incorporated into the design to take advantage of the project life cycle. The operating and capital cost commitments typically occur during planning and early engineering. The opportunity to incorporate sustainability features into the designed infrastructure is significantly reduced once early engineering occurs - unless the budget can be increased for the engineering rework and possible fabrication changes and the schedule of the project can be extended appropriately. 
The life of an asset continues upon commissioning and turn-over to the owner. The time line can be extended to include operations and decommissioning, and the design may be instrumental in operating sustainably and deconstructing the asset in a sustainable manner.

This paper focuses specifically on the sustainability activities during the construction phase. During the construction phase, there are significant opportunities to impact the economic, social, and environmental impacts of how these projects are built and operated. The construction phase shown in Figure 1 commences when personnel are mobilized to the project site. Planning for construction, however, starts much earlier, especially in the area of procurement. Contracts to purchase equipment and hire specialty companies, constructability sessions to determine how to construct the project safely, on schedule, within budget, and to a high standard of quality, and preparation of programs to be implemented on the site - all of these activities occur prior to the first work boot setting foot on the project site to begin construction.

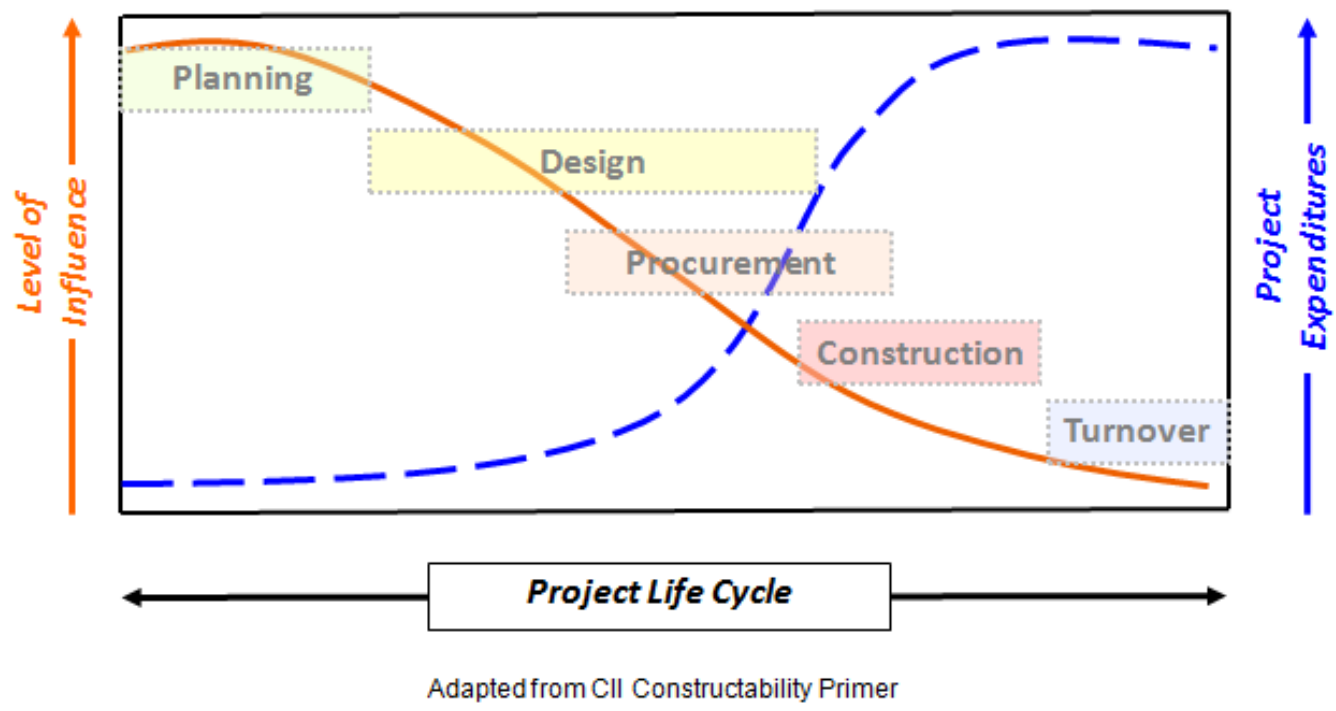

Figure 1. Project Influence Curve

\section{Current Sustainability Metrics}

The most prevalent sustainability statistics relate to occupational safety, and they tend to be lagging indicators related to injuries - lost time incidence rate, recordable incidence rate, restricted duty incidence rate, etc. These indicators can be used at any phase of a project, but are particularly useful during the construction phase. While lagging indicators are excellent for showing whether your programs are working - in this case, whether people are going home safely - leading indicators are more desirable as a management tool because they are designed to prevent an incident from occurring. We're seeing more leading indicators, related to areas such as audits, inspections, and training, but there is no general industry agreement on which leading indicators are best for all industries, and therefore it is difficult to benchmark companies' performances. Internal benchmarking can occur, of course, resulting in better management of behaviors and processes.

A key economic metric for the construction phase is whether the project came in at or under budget. Associated with that metric is whether the construction project was finished on schedule 
or earlier than scheduled. Close attention is given throughout the project to these two measurements, with tracking and reporting occurring on typically a weekly basis. Other economic metrics include the cost of energy, raw materials, or water consumed.

On the environmental aspect of sustainability, construction metrics vary based on whether the project is built as a brownfield site (on a site with an existing facility) or a greenfield site (no facility exists on the site). Typically, on a brownfield site, water is provided by the existing facility and water and wastewater discharges and spill control occur through the owner's discharge permits; air emissions are addressed in the facility's air permit; and waste is managed under the facility's disposal licenses. On a greenfield site, the contractor is responsible for controlling and permitting discharges and emissions. This distinction makes it difficult to standardize on common indicators and therefore benchmark. In some cases, environmental regulations set the measurement parameters.

Social indicators are even more difficult to standardize. Typical statistics on a project relate to human rights (e.g., use of child labor, worker living conditions), labor practices (e.g., local employment, purchase of local goods), community impact and involvement (e.g., donations to local public facilities, volunteer hours) and, as noted previously, worker safety. The choice of parameters is wide-ranging and determined by the owner and the contractor (either due to contract conditions or as a part of their company culture).

\section{Gaps in Metrics}

The Construction Industry Institute, a consortium of owner, engineering-contractor, and supplier firms from the public and private arenas, seeks to enhance the capital facility life cycle partially through CII research. Research Team (RT) 304 is charged with creating guidance to its members and industry on processes, decisions, actions, and metrics during the construction phase of capital projects to enhance sustainability implementation. The RT will report its findings this summer and issue several reports and tools.

RT 304 will provide the following documents and tools.

- Seven-step process to incorporate the RT 304 work products into projects

- Construction Phase Sustainability Action (CPSA) catalog containing 54 CPSAs grouped into eight construction functions (project management, contracting, field engineering, site facilities and operations, craft labor management, materials management, construction equipment management, and quality management, commissioning, and handover)

- CPSA screening tool to assist construction teams in prioritizing CPSAs that are expected to have maximum impact on a project

- Input metric (CPSA Implementation Index) that provides a numeric measure of the breadth and extent of implementation of the 54 CPSAs

- Output metrics for each CPSA - 2 per CPSA

- Guidance related to specific CPSAs

As a part of the research, gaps in knowledge were identified, resulting in recommendations for future research. An earlier RT (250) likewise identified gaps related to measurements. 
The most frequently noted gap relates to the social aspect of sustainability, other than metrics associated with safety. While a number of qualitative social indicators are available, quantitative social metrics are significantly less prevalent. Part of the issue is the difficulty in obtaining meaningful data for a particular project, thereby minimizing the ability to benchmark. Benchmarking would provide opportunities to standardize metrics, which could drive progress in implementing sustainability actions.

Research also identified easy-to-generate life-cycle assessments as another major gap. The construction team of owner and contractor may desire to consider the life-cycle implications of construction methods or equipment or components of the facility being constructed, but assessments typically are laborious to perform. They require a great deal of data, which may be difficult to obtain or quantify.

\section{Research Needs}

RT 304 identifies several social metrics (other than safety), but they tend to be percentage measurements of activities. Examples are:

- Percent of community issues addressed

- Percentage of stakeholder engagement plan that is implemented

- Number of complaints from community residents

A quantification of benefits that accrue from community social responsibility initiatives is more difficult, but it is needed in order to progress to the level of safety as an indicator.

RT 304 also identifies a need for development of case studies that implement one or more of the CPSAs on a project. These case studies could generate new metrics that would be helpful for implementation on other projects. Broad-based benchmarking of construction sustainability performance by industry sector could further enhance implementation.

During research on sustainability practices and technology, CII's RT 250 developed the concept of a hypothetical assessment metric for evaluating the environmental consequences associated with the production and use of construction materials. This Industrial Sustainability Index Metric (ISIM) is intended to be a guide for decision makers to provide information on the sustainability of products and services by rating their sustainability aspects in the supply chain. ISIM scores could be generated based on the triple bottom line throughout the life cycle of products and encompassing manufacturing and fabrication, assembly, transport, installation, operation and maintenance, demolition, and reuse.

\section{Next Steps}

In addition to the research needs identified above, there is a need to make assistance as available as possible for field use. For construction sites, that assistance is increasingly related to tablets and smart phones. Web-based tools and apps that allow users to collect data easily will make it easier to measure performance.

Safety indicators are used across industries around the world. Our challenge is to develop a few good, widely used sustainability metrics that can serve the same population. 


\section{References}

Construction Industry Institute, 2006. Constructability Implementation Guide, Special Publication 34-1, Austin, TX.

Construction Industry Institute, 2009, Sustainable Design and Construction for Industrial Construction: Implementation Resources, Implementation Report 250-3, Austin, TX. Construction Industry Institute, 2014 (unpublished), RT-304 work. 
[This page is internationally left blank] 
Kremer, Gül E. Okudan, The Pennsylvania State University, Karl Haapala, Oregon State University, and Ratna Chinnam, Leslie Monplaisir, Kyoung-yun Kim, and Alper Murat, Wayne State University

\title{
A Plan of Action for Economic and Environmental Sustainability in Product Supply Chains
}

\begin{abstract}
Although sustainability is now a salient topic in product development literature, the often segmented scope of prior works limits the potential benefits of the industrial application of methods, models, and tools developed by the research community. The vantage point presented herein has the goal of coalescing relevant, recent work supporting the economic and environmental aspects of sustainability for early stage product development. In presenting this vantage point, we intend to highlight past accomplishments and call for action to the research community for the development of integrated methods, models, and tools to support sustainability initiatives across product supply chains. Our literature review spanning product design, manufacturing, and supply operations management reveals several near-term research needs, which are organized into four highly promising foci addressing reengineering of product architecture, assembly/disassembly operation modeling, manufacturing process modeling, and joint optimization of life cycle activities.
\end{abstract}

\section{Keywords}

Product supply chain, Life cycle, Metric, Economic, Environmental

\section{Background}

Supply chain performance cannot be optimized without considering the compatibility of product and supply chain attributes (Fisher, 1997). Attesting to this, a survey-based study conducted in Sweden covering 148 manufacturing companies found that when there is a good match between the product offerings and the relevant supply chains, companies performed better in terms of cost, delivery speed, and delivery dependability (Selldin and Olhager, 2007). The same study showed that $38 \%$ of the companies did not have product and supply chain compatibility.

The integration of supply chain network design and product design stimulates Design for Supply Chain Management (DfSCM), or "design[ing] products and processes to more effectively manage supply chain related cost and performance" (Sasser, 1995). DfSCM utilizes product line structure, bill of materials, and customization processes of a product, in order to optimize the logistics costs and customer service performance. Examples of DfSCM include Product Chain Decision Model, by Blackhurst et al. (2005), that compares the benefit of supplier selection and information sharing according to bill of materials, and a product family selection and supply chain design method, by Lamothe et al. (2006), that can optimize supply chain costs while choosing variant components based on a generic bill of materials.

As seen in the examples above, typically the supply chain perspective is considered at the detail design stage -- the final phase of the product design, and when much of the design flexibility has been removed. Relatively few studies consider the supply chain perspective early in product 
design (e.g., Nepal et al., 2011; Chiu and Okudan, 2011 \& 2014). Further, there has been only limited attention directed to the interplay between selection of design alternatives and life-cycle processes (e.g., Chiu et al., 2010). Further, prior work mostly focuses on forward supply chains, and there is very limited work on closed loop chains. Krikke et al. (2003) developed a MixedInteger Programming (MIP) model for product structure design considering modularity, reparability, and recyclability and logistics network design and applied the model using real R\&D data for the European operations of a Japanese consumer electronics company. They considered environmental impacts predicted by linear-energy and waste functions as well as supply chain costs modeled with variable flow and fixed set-up for facilities. More recently, the supply chain literature has been integrating environmental sustainability with standard supply chain models such as inventory, transportation, and network design models. Earlier efforts focused on reducing environmental impact at the plant level at the expense of increasing impacts at other supply chain areas. Life Cycle Assessment (LCA) has been proposed to evaluate environmental impacts associated with products, processes, and activities (De Benedetto and Klemes, 2009). Ilgin and Gupta (2010) present an extensive review of the environmentally conscious product design and forward and reverse manufacturing and logistics system design. Authors conclude that environmentally conscious product design literature fails to consider the environmental impact of production processes.

A number of studies considered environmental impacts of supply chain designs (e.g., Hugo and Pistikopoulos, 2005; Frota Neto et al., 2008; Guillen-Gosalbez and Grossmann, 2009). Several studies considered carbon footprint in sourcing, inventory, and distribution processes (e.g., Bonney and Jaber, 2010; Hoen et al., 2010; Reuter et al., 2010;). In general, however, there is a significant gap in capturing the economic and environmental sustainability of forward and reverse supply chain implications of product design variants. As Gan and Grunow (2013) attest, "... researchers in product design (PD) and supply chains (SC) management have kept mainly within their domains for various reasons such as complexity of cross-disciplinary research..." These findings motivate an integration of supply chain decisions and product design decisions, including costs and environmental impacts, so that the optimal component acquisition and supply chain alternatives can be determined and evaluated in the earlier product design stages.

\section{Promising Foci for Improving Sustainability in Supply Chains}

Based on our review, we postulate that the development of supply chain models that account for the dependencies between product design, manufacturing, and supply chain decisions to minimize cost and environmental impacts (e.g., carbon footprint) can be enabled through the concepts of integral, modular, and hybrid product architectures, as well as manufacturing process and assembly analyses. The research community addressing the economic and environmental sustainability across product supply chains is mostly organized around four thrusts: 1) Sustainability through effective product development processes/practices, 2) Sustainability through effective manufacturing processes/practices, 3) Sustainability through effective supply chain processes/practices, and 4) Sustainability through effective and integrated consideration of life-cycle processes. Given our primary interest in addressing sustainability at the earliest stages of the product life cycle, in particular product development, we have identified four distinct foci for further investigation and exploitation to improve the sustainability in product supply chains. This is not to suggest that there aren't other gaps or opportunities for promoting sustainability. Our focus is on opportunities for action at the front end of the product life cycle. 


\subsection{FOCUS AREA 1: Reengineering the Design to Match the Intended Product End-of- Life Option}

The use of modular design is gaining popularity in industry with several successful cases of implementation reported in the literature; however, the science to support modular product architecture is still evolving (Gupta and Okudan, 2008). For example, a recent study by Okudan Kremer and Gupta (2013) shows that modularization of the same product using three different modularity approaches, i.e., the Function Heuristic Method (FHM), the Behavioral driven Function-Environment-Structure (B-FES) modeling framework, and the Decomposition Approach (DA), results in different product architectures. Another study by Nepal et al. (2011) introduces the use of a multi-objective optimization model in configuring the supply chain during modular product development. In addition to using various production and inventory costs, the model makes use of subjective criteria such as alignment of business practices and financial objectives of member companies in configuring the supply chain. Further, in prior studies, modularity has been considered as a Boolean variable with no intermediate levels. To respond to these gaps in the literature, we note that experimentation is needed with different modularization methods, and in varying modularization levels. Among the relevant research questions are: 1) Can a modular structure where components are clustered according to reuse or recycling objectives positively impact sustainability measures (e.g., cost and carbon footprint)?; and 2) Can an increased level of modularity positively impact sustainability measures across the supply chain? 3) What is the impact of product architecture and platform decisions early in product development on supply chain sustainability measures? The research to provide insights into these questions can be challenging especially in the design of breakthrough and innovative. Defining sustainability and re-manufacturability targets early in the design of a product can be difficult when requirements and design specifications are still evolving. Some attempts (Nepal et al., 2011; Ülkü and Schmidt, 2011; Chung et al., 2011) have been made at a holistic design approach but the science is still evolving.

Ülkü and Schmidt (2011) have found analytically that supplier relationship and product architectural design are interdependent. However, to our knowledge, there are no mathematical models in the literature that quantifies the influence of product architecture design on supply chain configuration considering sustainability metrics. Another notable gap is the lack of consideration of the environmental compatibility of partners into the SCM decisions. The development of robust models to address these issues through is necessary.

Newcomb et al. (1998) stated that the modularity of a product influences its initial cost, ease of service (assembly and disassembly), and effort required to retire the product (reuse, recycling, and disposal). In general, modular products need to be designed with redundant physical components and limited function sharing for compatibility across other products, which might result in increased part numbers and variable costs (Ulrich and Tung, 1991). Future work relevant to this focus area should take into account minimization of cost and environmental impact by clustering components based on their design intent for reuse, recycling, and service. For this purpose, the components of the designed product can be first represented through a connectivity graph, and then the graph can be partitioned based on modularity for sustainability (see Figure 1); Chung et al. (2013) presented recently one of the first attempts of this with promising results. 
Future work on product architectures that are reengineered for increased sustainability should enlist support from industry partners, as credibility of the information used during the investigation is paramount. This information pertains to components and feasible configurations of the product architecture, for which the full set of concept combinations (product architecture variants) with varying levels of modularity and supplier options for each product (sub-assembly) component and modular design permutations can be studied.

\section{Product}

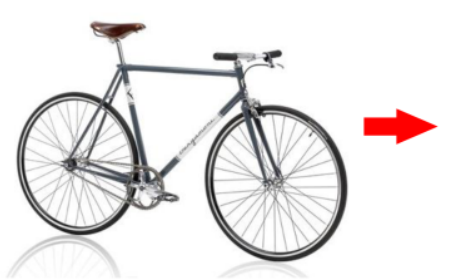

\section{Connectivity Graph}

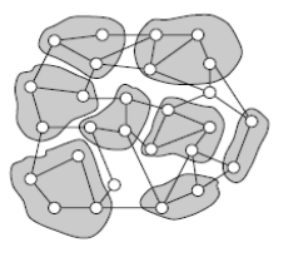

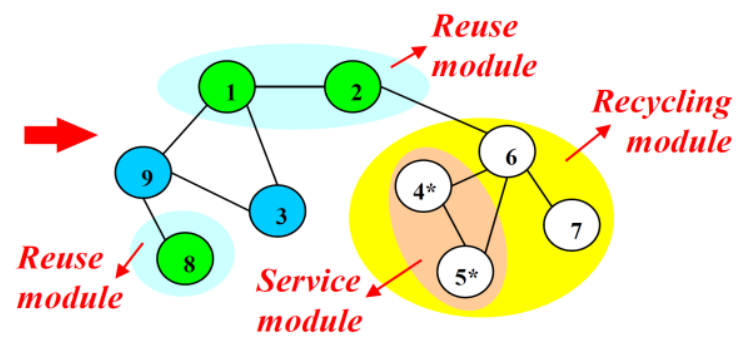

Figure 1. Project Influence Curve

\subsection{FOCUS AREA 2: Assembly/Disassembly Operation Modeling and Analysis for Environmental Sustainability}

Joints on a product architecture are inevitable because of the limitations on component geometric configuration and material property and the requirements of inspection, accessibility, repair, portability, and recyclability (Kim et al., 2004). The problem of joining components is therefore a key issue in the sustainable product design process. Joining components often provides a way of realizing simpler forms of the individual components of products, which can make it easier and cheaper to manufacture each component. However, the environmental effects of assembly operation selection and joint design are often ignored in the current research efforts (Rajemi et al., 2010; Pusavec et al., 2010a\&b). Balancing the design requirements and environmental requirements, selecting an optimal assembly operation method is a complicated process. As an illustration, welding or mechanically fastened (or riveted) joints can be considered as alternatives for an automotive frame design. Conventionally, welded joints have been preferred, due to the complex geometry of frames and cost efficiency. The traditional trade-off analysis focuses on a heat affected zone, which causes a potential structural crack propagation point. However, the environmental pollutants (e.g., fumes and gases) caused by the welding operation often receive little attention in the design stage joining decisions (Fleischer and Schaedel 2013). A mechanically fastened joint could eliminate these pollutants; however, it will cause other design changes (such as bonding effects of rivets and vibration of bolted joints).

Thus, the existing research questions related to the aforementioned challenges are: 1) how can the cost and environmental sustainability performance of different assembly operations be systematically analyzed, while balancing the design and environmental requirements and be woven into the assembly design process?; and 2) how can the optimal assembly operations be determined, while still considering conflicting objectives (e.g., cost vs. recyclability) without sacrificing the functional design requirements?

To achieve an integrated assembly operation modeling and analysis, assembly operation implications for design requirements and environmental sustainability should be considered 
simultaneously. The evaluation of all possible assembly operation alternatives is a timeconsuming process. Thus, high quality/feasible assembly operation alternatives should be selected before detailed analysis occurs. For this, meta-heuristics algorithms (e.g., neural networks and genetic algorithms) can be used to generate a set of feasible assembly operation alternatives. However, the optimal parameter set (e.g., learning rates, termination criteria, etc.) could potentially be a challenge to be systematized.

\subsection{FOCUS AREA 3: Manufacturing Process Modeling for Sustainability Assessment}

Unit manufacturing processes utilize mechanical, thermal, and/or chemical energy to alter material input(s) into a desired output (e.g., a product component). Processes are linked into production systems for new products, or into reverse production systems to remanufacture end of life products. Manufacturing process models can assist in the reduction of materials and energy use and wastes and emissions, while enhancing productivity and reducing costs (Arinez et al., 2010). The relevant research questions for consideration in this focus area include: (1) How do design variants impact supply chain sustainability measures (e.g., cost and carbon footprint) through materials, manufacturing processes, and assembly operations?; and (2) How are these sustainability measures impacted by manufacturing and assembly locations (e.g., energy sources in China vs. Belgium)?

Indeed, there are myriad manufacturing processes, and perhaps development of process models should begin with conventional manufacturing processes (e.g., cutting, forming, and injection molding) using traditional materials (e.g., metals and polymers), with the collaboration of industry. Industry can assist in access to date supporting empirical model development and validation of physics-based process models. In these studies, direct (e.g., process generated) and indirect (e.g., due to electricity) emissions should be considered. The models can parametrically relate design parameters (e.g., materials and geometry) to process characteristics. Thus, changes to and sensitivity of economic and environmental sustainability measures can be evaluated for design variants. The models will require design information associated with product alternatives to determine sustainability performance for processes and activities across the supply chain. Process models can provide cost and environmental performance information in the appropriate form for supply chain level optimization.

The importance of carbon footprint as an environmental performance measure for manufacturing activities has been reported widely (Boguski, 2010; Jeswiet and Nava, 2009; and Joyce et al., 2010). Work in this area is needed foremost for improving data quality and process model scalability for predictive sustainability analysis. Specifically, parametric unit process models can address several problems with LCA-based approaches in predicting product environmental impacts, which include (Reap et al., 2006): 1) limited spatial resolution, 2) lack of dynamics, 3) neglecting existing levels of pollution and eventual pollutant disposition, 4) use of linear process models, and 5) reliance on value judgments and subjectivity. By interfacing with semantic reasoning and supply chain optimization methods described below, this focus will lead to fundamental, science-based process models linked with design and production system information to inform early stage design of manufacturing and assembly sustainability performance based on product architecture. 


\subsection{FOCUS AREA 4: Joint Optimization of the Best Subset of Design Variants with Mathematical Models of Life Cycle Processes}

Building on the existing set of models in DfSCM, the joint optimization of design and life cycle processes must be extended by including the reverse logistics costs, energy efficiency and emissions. While the large number of bill of material (BOM) alternatives in the early concept phase makes it prohibitive to consider as part of DfSCM efforts (Taghavi and Chinnam, 2014), the accounting for environmental sustainability in addition to standard supply chain cost models and metrics further makes this complexity even more serious (Umpfenbach, 2013). Hence, one main component of this focus area might be to develop novel optimization methods to address these challenges. The main advantage in aligning supply chain network design and cost decisions with sustainability is to allow more effective decisions while understanding what the tradeoffs are between economic and environmental performance.

This focus on developing optimization methods should respond, for example, to the following questions: 1) What is the impact of joint consideration of design variant selection, supply chain configuration, and optimization of life cycle processes on economic and environmental sustainability?; and 2) What is the Pareto frontier as a result of trading supply chain metrics and environmental metrics including carbon footprint of materials used, emissions from selected manufacturing processes and supply chain operations, and in the creation of the energy used?

Carbon footprint predictions can be incorporated into forward and reverse supply chain models through the selection of the energy source for each process. The GHG Protocol Corporate Standard, which is widely used for companies to quantify and report GHG emissions in three levels of scope, can be used to capture the effects of all supply chain and life cycle processes. Scopes 1 and 2 represent direct emissions due to the company's operations and scope 3 represents all other indirect emissions, including upstream and downstream emissions. Scope 1 primarily corresponds to manufacturing, assembly, and related transportation operations. Scope 2 corresponds to emissions from the generation of purchased or acquired electricity, steam, and heating or cooling consumed by the company. Scope 3 emissions include upstream activities such as the production of goods and services purchased by the company, as well as downstream activities such as disposal of products. For scope 2, publicly available and private company data for cost and emission information can be used. For instance, the location decisions for manufacturing, distribution and logistics facilities can be evaluated using the Green Power Network (GPN) by the U.S. Department of Energy, which illustrates the green utility pricing programs per state. The resultant models can then include supply chain configuration decisions where the company can select the composition of energy sources for scope 2 emissions. Overall, including energy source portfolio decisions allows trading-off emissions and cost of energy and provides more flexibility in managing the economic and environmental sustainability across product supply chains.

\section{Conclusions}

While the research community has recognized and begun to address the challenges of product life cycle design for economic and environmental sustainability, much work needs to be done before operationalized methods and tools can emerge to assist design engineers and other supply chain decision makers in sustainable product design and manufacturing. Critical to the development of methods and tools is the understanding and quantification of the dependencies 
between product design, manufacturing, and supply chain decisions in terms of cost and environmental impacts. In exploiting these dependency relationships, special emphasis should be given to product architecture decisions (e.g., integral, modular, and hybrid), as well as to manufacturing process and assembly/disassembly analyses.

\section{References}

Arinez J., Biller S., Lyons K., Leong S., Shao G., Lee B.E., and Michaloski J., 2010, Benchmarking Production System, Process Energy, and Facility Energy Performance Using a Systems Approach, Proceedings of the 10th Performance Metrics for Intelligent Systems Workshop, ACM, New York, NY, USA, pp. 88-96.

Blackhurst, J., T. Wu, and P. O’Grady, 2005, PCDM: A Decision Support Modeling Methodology for Supply Chain, Product and Process Design Decisions, Journal of Operations Management 23 (3-4).

Boguski, T., 2010, Life Cycle Carbon Footprint of the National Geographic Magazine, The International Journal of Life Cycle Assessment, 15(7), 635-643.

Bonney, M. and Jaber, M.Y., 2011, Environmentally responsible inventory models: Nonclassical models for a non- classical era, International Journal of Production Economics, 133(1), 4353.

Chiu, M-C., Alsaffar, A. J., Haapala, K. R. and Okudan, G.E., 2010, Reducing Supply Chain Costs and Carbon Footprint during Product Design, IEEE International Symposium on Sustainable Systems and Technology (ISSST), Washington, D.C., 1-6.

Chiu, M-C. and Okudan, G.E., 2011, An Integrative Methodology for Product and Supply Chain Design Decisions at the Product Design Stage, ASME Journal of Mechanical Design, 133, 0211008-1-15.

Chiu, M-C. and Okudan, G.E., 2013, An Investigation on Centralized and Decentralized Supply Chain Scenarios at the Product Design Stage to Increase Supply Chain Performance, IEEE Engineering Management, 61(1), 114-128.

Chung, W.H., Okudan, G.E. and Wysk, R.A., 2011, Modular Design to Optimize Product Life Cycle Metrics in a Closed-looped Supply Chain, Proceedings of the Industrial Engineering Research Conference, May 21-26, 2011, Reno, NV.

Chung, W.H., Okudan, G.E. and Wysk, R.A., 2013, A Modular Design Approach to Improve Product Life Cycle Performance Based on the Optimization of a Closed-Loop Supply Chain, ASME Journal of Mechanical Design 136(2), MD-12-1278, 021001-21.

De Benedetto, L. and Klemes, J., 2009, The Environmental Performance Strategy Map: An integrated LCA approach to support the strategic decision-making process, Journal of Cleaner Production, 17, 900-906.

Fisher, M., 1997, What is Right Supply Chain for your Product?, Harvard Business Review, March/April.

Fleischer, J., and Schaedel, J., 2013, Joining Automotive Space Frame Structures by Filament Winding," CIRP Journal of Manufacturing Science and Technology, 6(2), 98-101

Frota Neto, J.Q., Bloemhof-Ruwaard, J.M., van Nunen, J.A.E.E. and van Heck, E., 2008, Designing and evaluating sustainable logistics networks, International Journal of Production Economics, 111, 195-208.

Gan, T-S. and Grunow, M., 2013, Concurrent Product-Supply Chain Design: A Conceptual Framework \& Literature Review, Procedia of CIRP Conference on Manufacturing Systems, 7, 91-96. 
Guillen-Gosalbez, G. and Grossmann, I.E., 2009, Optimal Design and Planning of Sustainable Chemical Supply Chains Under Uncertainty. AICHE Journal, 55(1), 99-121.

Gupta, S. and Okudan, G.E., 2008, Computational Modularized Conceptual Designs with Assembly and Variety Considerations, Journal of Engineering Design, 19(6), 533-551.

Hoen, K.M.R., Tan, T., Fransoo, J.C. and Van Houtum, G.J., 2010, Effect of carbon emission regulations on transport mode selection in supply chains, Eindhoven University of Technology Working Paper, 1-32.

Hugo, A. and Pistikopoulos, E.N., 2005, Environmentally conscious long-range planning and design of supply chain networks, Journal of Cleaner Production, 13, 1471-1491.

Ilgin, M.A. and Gupta, S.M., 2010, Environmentally conscious manufacturing and product recovery (ECMPRO): a review of the state of the art, Journal of Environmental Management, 91, 563-591.

Jeswiet, J. and Nava, P., 2009, Applying CES to Assembly and Comparing Carbon Footprints, International Journal of Sustainable Engineering, 2(4), 232-240.

Joyce, T., Okrasinski, T.A. and Schaeffer, W., 2010, Estimating the Carbon Footprint of Telecommunications Products: A Heuristic Approach, Journal of Mechanical Design, 132(9), 094502 (4pp.).

Kim, K.Y., Wang, Y., Muogboh, O.S. and Nnaji, B.O., 2004, Design Formalism for Collaborative Assembly Design, Computer-Aided Design (CAD), 36(9), 849-871.

Krikke, H., Bloemhof-Ruwaard, J. and Van Wassenhove, L.N., 2003, Concurrent Product and Closed-loop Supply Chain Design with An Application to Refrigerators, International Journal of Production Research, 41(16), 3689-3719.

Lamothe, J., Hadj-Hamou, K. and Aldanondo, M., 2006, An Optimization Model for Selecting a Product Family and Designing its Supply Chain, European Journal of Operational Research, 169(3), 1030-1047.

Lee, H.L. and Sasser, M.M., 1995, Product Universality and Design for Supply Chain Management, Production Planning \& Control, 6(3), 270-277.

Nepal, B., Famuyiwa, F., Monplaisir, L., 2011, A Multi-Objective Supply Chain Configuration Model for New Products, International Journal of Production Research, 49(1), 7107-7134.

Newcomb, P.J., Bras, B. and Rosen, D.W., 1998, Implications of Modularity on Product Design for the Life Cycle, Journal of Mechanical Design, 120(3), 483-490.

Okudan Kremer, G.E. and Gupta, S., 2013, Analys is of Modularity Implementation Methods from Assembly and Variety Viewpoints, The Journal of Advanced Manufacturing Technology, 6(9), 1959-1976.

Pusavec, F., Krajnik, P., Kopac, J., 2010a, Transitioning to Sustainable Production - Part I: Application on Machining Technologies, Journal of Cleaner Production, 18(2), 174-184.

Pusavec, F., Kramar, D., Krajnik, P., Kopac, J., 2010b, Transitioning to Sustainable Production Part II: Evaluation of Sustainable Machining Technologies, Journal of Cleaner Production, 18(12), 1211-1221.

Rajemi, M.F., Mativenga, P.T., Aramcharoen, A., 2010, Sustainable machining: selection of optimum turning conditions based on minimum energy considerations, Journal of Cleaner Production, 18(10-11), 1059-1065.

Reap, J., Román, F., Guldberg, T. and Bras, B., 2006, Integrated Ecosystem Landscape and Industrial Modeling for Strategic Environmentally Conscious Process Technology Selection Abstract." In 13th CIRP International Conference on Life Cycle Engineering, 213-18. Leuven, Belgium. 
Reuter, C., Foerstl, L., Hartmann, E. and Blome, C., 2010, Sustainable Global Supplier Management: The Role of Dynamic Capabilities in Achieving Competitive Advantage, Journal of Supply Chain Management, 46(2), 45-63.

Selldin E., Olhager J., 2007, Linking Products with Supply Chains: Testing Fisher's Model, Supply Chain Management: An International Journal, 12(1), 42-51.

Taghavi, A. and Chinnam, R.B., 2014, Assortment Planning of Automotive Products: Considerations for Economic and Environmental Impacts of Technology Selection, Journal of Cleaner Production, doi:10.1016/j.jclepro.2014.02.004.

Umpfenbach, E., 2013, Optimization of Strategic Planning Processes for Configurable Products: Considerations for Global Supply, Demand, and Sustainability Issues, Wayne State University Dissertations. Paper 710, http $/ /$ digitalcommons. wayne.edu/oa_dissertations/710 Ülkü, S. and G. Schmidt. 2011, Matching product architecture and supply chain configuration, Production and Operations Management, 20 (1), 16-31.

Ulrich, K.T. and Tung, K., 1991, Fundamentals of Product Modularity, Proceedings of the ASME Design Engineering Technical Conferences - Conference on Design/Manufacture Integration, 39, pp. 73-79. 
[This page is internationally left blank] 
Lambert, James H., and Michelle C. Hamilton, University of Virginia

\title{
Emergent and Future Conditions Influencing Risk, Sustainability, and Resilience of Infrastructure Systems
}

\begin{abstract}
This chapter reviews efforts to incorporate scenarios of diverse risk factors that influence priority setting for infrastructure systems. Several of the efforts extend the theory of robust decision making to include sensitivity and resilience to stakeholder preferences. The efforts address risk as an influence of scenarios to priorities for infrastructure systems. Scenarios are comprised of emergent and future conditions including regulations, technologies, economics, markets, environmental change, population and workforce behaviors, etc. The efforts span infrastructure systems involving energy, transportation, security, and coastal protection. The efforts individually and collectively describe relationships among metrics, models, and datasets related to risk, sustainability, and resilience of large-scale systems.
\end{abstract}

\section{Keywords}

Resilience, infrastructure, systems engineering, scenario-based preferences, robust decision making, resilience, risk management, sustainability

\section{Introduction}

Risk was defined by Lowrance as a measure of the likelihood and severity of adverse effects (Lowrance 1976). Kaplan and Garrick (1981) described risk as what can go wrong, what are the likelihoods, what are the consequences. Haimes (1991) described risk management to be: What can be done in what time frames; what are the tradeoffs among costs, benefits, and risks; and what are the impacts of current decisions to future options. Teng, Thekdi, and Lambert (2012, 2011) described risk programs to address: What are the scope of risks under consideration; what are the allocations of resources in time, geography, topics, etc.; and what is the monitoring of the efficacy of risk management. The ISO standard on risk management described risk as the effect of uncertainty on objectives (ISO 2009). Finally, Lambert et al. have described risk as the influence of scenarios on priorities (Lambert et al. 2013, 2012, 2011). The following sections identify metrics, models, data that have addressed risk, sustainability, and resilience for a variety of emergent and future conditions for infrastructure systems. The review suggests gaps for measurement science and sustainability research in the area of large-scale systems engineering.

\section{Emergent Conditions of Energy Systems Islanding and Electricity Microgrids}

Research and development for energy systems (e.g., smart and secure microgrids for industrial and military installations, solar cogeneration technologies, etc.) must account for deep uncertainties and emergent conditions including economic, regulatory, technological, mission, demographic, environmenta//ecological, and others. Energy managers and stakeholders for military or industrial installations need a rationale for selecting among innovative technologies and methodologies for energy quality and quantity in support of their critical missions. Energy managers must consider various strategic objectives for $\mathrm{R} \& \mathrm{D}$, including: reducing consumption, increasing efficiency, reducing dependence on fossil fuels, judicious use of renewable resources, and reducing adverse impacts to the environment. The pace and variety of technology 
innovations are increasing even as the horizons that are the basis for evaluating current $\mathrm{R} \& \mathrm{D}$ investments are extended. Emergent and future conditions, to the extent they can be known or predicted, should influence the priorities for research and development portfolios. For example, federal, military, and market forces influence what technologies are viable for particular missions. Escalating renewable energy consumption requirements at federal facilities will continue to have a dramatic influence in this topic. Changing state and local regulations such as carbon taxes, renewable portfolio standards, and utility tariff regulations will significantly influence the financial feasibility of various innovative technologies. The volatility in supplies and demands of fossil fuels will continue to affect availability and market prices of a variety of energy resources, and in turn influence priorities for energy research and development.

Hamilton et al. (2013), Karvetski et al. (2012) and Karvetski et al. (2011c) discuss the influence of deep uncertainties in strategic priority setting for facility energy investments. Hamilton et al. (2013) use ten criteria to evaluate six energy R\&D portfolio alternatives across five scenarios representing diverse stakeholder perspectives/emergent conditions including energy islanding, national security perspective. Karvetski et al. (2012) evaluate seven alternatives including microturbines and microgrids against seven criteria under five scenarios including economic fear, an increase in natural disasters, terrorism, and others. Martinez et al. (2010) describe a scenario-based methodology to compare alternative risk communications strategies for liquefied natural gas terminals.

\section{Coastal Infrastructure Systems Impacted by Climate and Other Factors}

The impacts of emergent and future condtions are an important consideration for managers of coastal regions. E.g., climate may influence sea levels, severity and frequency of extreme weather and precipitation, and other phenomena of importance to natural resource and infrastructure systems (Karvetski et al, 2011a; Karvetski et al, 2011b). Evaluating and designing adaptive alternatives over the full spectrum of climate change conditions should increase the chance of selecting projects that will satisfy a variety of community needs (Karvetski et al., 2011; Zhou et al, 2012). Karvetski et al. (2011) describe scenario-based preferences complementing an analysis of robust decisions, adding understanding of the uncertainties contributed by climate change and sea-level rise and with coastal engineering initiatives. The effort assesses the relative sea level and other climate-change scenarios that could affect the performance of coastal protections. The methodology quantifies the robustness of alternative portfolios across a variety of scenarios and identifies the scenarios that greatly affect the assessments. Karvetski et al. (2011) discuss climate change scenarios for Alaska coastal infrastructure. Zhou et al. (2012) describe how flood protection diversification can be used to reduce probabilities of extreme losses. The study compares the performance of portfolios each consisting of four types of flood protection assets in a large region of dike rings. The analysis suggests conditions in which diversifications of the types of included flood protection assets could decrease losses in extreme floods. Increased return periods of extreme losses are associated with portfolios where the asset types have low correlations of economic risk. The effort highlights the importance of correlations across asset types in planning for large-scale flood protection. It allows explicit integration of climate change scenarios in developing flood mitigation strategy. You et al. (2014) describe a quantification of the influence of climate change to priorities for infrastructure projects. 


\section{Mobility, Accessibility, and Sustainability for Transportation Corridors}

Understanding diverse emergent and future conditions is of course important for transportation planning. Transportation infrastructure can be vulnerable to local manifestations of global climate change, such as storm frequencies, intensity and durations of seasons. To adapt, transportation agencies need methodologies for reprioritizing their assets subject to the new sources of vulnerability. Lambert et al. (2013) discuss how transportation agencies might prepare for tropical cyclone-related needs and anticipate various storm scenarios that could bring widespread damage to transportation infrastructure. The paper develops a method to consider investment alternatives for highway equipment (signs, signals, and lights) through the evaluation of tradeoffs between cost and damage. Considering the various consequences of five hurricane categories enables the decision maker an opportunity to understand the tradeoffs and invest in equipment consistent with individual needs and values of the agency. Lambert et al. (2013) extend a scenario-based multicriteria decision framework that can assist decision makers in effectively allocating limited resources to adapt transportation assets to a changing climate. Scenarios of climate and other factors are used to update the criteria weighting, which results in several reprioritizations of the assets. The results help to identify the most influential scenarios and characterize the sensitivity of the baseline prioritization across multiple scenarios. With such results, additional scientific and investigative efforts can be focused effectively to study and understand the influential scenarios. Schroeder et al. (2011) describe a similar scenario-based analysis for infrastructure policy impacts and planning, extending the reach of robust decision making to sensitivity to evolving stakeholder preferences.

\section{Population and Workforce Behaviors and Infrastructure Performance}

Considerable attention is focused on plans for sheltering or evacuating the population of urban areas in response to a regional emergency such as a terrorist attack or natural disaster. Such planning engages multiple disciplines spanning infrastructure engineering, emergency management, health care, mass communication, water and food supply, logistics, and others. Knowledge of population and workforce behaviors should influence the many dimensions of protection, prevention, response, and recovery (Guterbock et al., 2011, 2010); Parlak et al. 2012; Meyer et al. 2012). Of particular interest are the behaviors and needs of the resident and nonresident populations in the aftermath of a regional disaster, including those at home, at work, and traveling. Parlak et al. (2012) deployed a 30-min telephone survey to 2700 residents of the National Capital region to gain knowledge of their intended behaviors in the event of a variety of potential dirty bomb attacks and used the results to identify and model the assumptions of population behaviors that most affect agency priorities for emergency planning including regional sheltering and evacuation following a radiological disaster such as a dirty bomb. The technical approach assessed several planning initiatives across performance criteria derived from strategic plans and applied combinations of behavioral assumptions to vary the relative importance of each criterion. The results identify the behavioral scenarios that are most significant to the prioritization of planning initiatives and identify the highest and lowest priority initiatives across the criteria used. Lambert et al. (2013) analyze transportation system demand and system performance for emergency management in three disaster scenarios. A two-step methodology first estimates the number of trips evacuating the region, and second, assigns these trips to a regional highway network, using geographic information systems software.

Performance measures are generated for each scenario including maps of volume-to-capacity ratios, geographic contours of evacuation time from the center of the region, and link-specific 
metrics such as weighted average speed and traffic volume. The methods are applied to three scenarios involving attacks from radiological dispersion devices (e.g., dirty bombs). The results include: (1) a single detonation would degrade transportation system performance two to three times more than that which occurs during a typical weekday afternoon peak hour, (2) volume on several critical arterials within the network would exceed capacity in the represented scenarios, and (3) resulting travel times to reach intended destinations imply that un-aided evacuation is impractical. The results assist emergency responders who provide traveler information and who make operational adjustments to improve the network (e.g., signal retiming) and public health officials who maintain shelters, food and water stations, or first aid centers along evacuation routes. Lambert and Farrington $(2007,2006)$ address metrics and models for the allocation of devices for localized hazard protection for a similar scale of emergency.

\section{Land and Economic Development Affecting Infrastructure Systems}

Thekdi and Lambert (2014) describe the quantification of scenarios and stakeholders influencing priorities for risk mitigation in transportation infrastructure systems. They integrate scenario identification, priority-setting analysis, stakeholder preferences, and consensus building with application to a 10,000-kilometer (6000-mile) critical multimodal transportation network that is vulnerable to nearby economic development and land uses. Thekdi and Lambert (2014) describe decision analysis and risk models for land development affecting infrastructure systems. Coordination and layering of models to identify risks in complex systems such as large-scale infrastructure of energy, water, and transportation is of current interest across application domains. Such infrastructures are increasingly vulnerable to adjacent commercial and residential land development. Land development can compromise the performance of essential infrastructure systems and increase the costs of maintaining or increasing performance. The approach integrates to a decision framework of strategic considerations based on assessing risk, cost, and opportunity in order to prioritize needs and potential remedies that mitigate impacts of land development to the infrastructure systems. Linthicum and Lambert (2010) describe risk management for transportation and other infrastructure corridor vulnerable to adjacent land development. Lambert et al. (2012) describe prioritizing infrastructure investments in Afghanistan with multiagency stakeholders and deep uncertainty of emergent conditions. Relatedly, Karvetski et al. (2009) describe emergent conditions that influence prioritization of infrastructure investments for the developing world.

\section{References}

Haimes, Y.Y. 1991. Total risk management. Risk Analysis. 11(2): 169-171.

Hamilton, M.C., J.H. Lambert, J.W. Keisler, I. Linkov, and F.M. Holcomb. 2013. Research and development priorities for energy security of military and industrial installations. ASCE Journal of Infrastructure Systems. 19(3): 297-305

Hamilton, M.C., S.A. Thekdi, E.M. Jenicek, R.S. Harmon, M.E. Goodsite, M.P. Case, C.W. Karvetski, and J.H. Lambert 2013. Case studies of scenario analysis for adaptive management of natural resource and infrastructure systems. Environment Systems \& Decisions. 33:89-103.

ISO 2009. ISO Standard on Risk Management. International Standards Organization.

Joshi, N. and J.H. Lambert 2007. Equity metrics for the prioritization and selection of transportation projects. Transactions on Engineering Management. 54(3). 539-547. 
Joshi, N.N. and J.H. Lambert 2011. Diversification of engineering infrastructure investments for emergent and unknown non-systematic risks. Journal of Risk Research. 14(4): 1466-4461.

Kaplan, S. and B.J. Garrick 1981. On the quantitative definition of risk. Risk Analys is 1(1):1127.

Karvetski, C.W., and J.H. Lambert 2012. Evaluating deep uncertainties in strategic prioritysetting with an application to facility energy investments. Systems Engineering. 15(4): 483493.

Karvetski, C.W., J.H. Lambert, and I. Linkov 2009. Emergent conditions and multicriteria analysis in infrastructure prioritization for developing countries. Journal of Multiple Criteria Decision Analysis. 16(5): 125-137.

Karvetski, C.W., J.H. Lambert, and I. Linkov 2011c. Scenario and multiple criteria decision analysis for energy and environmental security of military and industrial installations. Integrated Environmental Assessment and Management. 7(2):228-236.

Karvetski, C.W., J.H. Lambert, J.M. Keisler, and I. Linkov 2011b. Integration of decision analysis and scenario planning for coastal engineering and climate change. IEEE Transactions on Systems, Man, and Cybernetics, Part A. 41(1): 63-73.

Karvetski, C.W., J.H. Lambert, J.M. Keisler, B. Sexauer, and I. Linkov. 2011a. Climate change scenarios: risk and impact analysis for Alaska coastal infrastructure. Int. J. Risk Assessment and Management, 15(2/3): 258-274.

Lambert, J.H. and M.W. Farrington 2007. Cost-benefit functions for the allocation of security sensors for air contaminants. Reliability Engineering and System Safety. 92(7):930-946.

Lambert, J.H., A.I. Parlak, Q. Zhou, J.S. Miller, M.D. Fontaine, T.M. Guterbock, J.L. Clements, and S.A. Thekdi 2013. Understanding and managing disaster evacuation on a transportation network. Accident Analysis and Prevention. 50(1): 645-659.

Lambert, J.H., and M.W. Farrington 2006. Risk-based objectives for the allocation of chemical, biological, and radiological air emissions sensors. Risk Analysis. 26(6):1659-1674.

Lambert, J.H., and P. Sarda 2005. Risk identification by superposition of infrastructure and terrorist networks. Journal of Infrastructure Systems. 11(4):211-220.

Lambert, J.H., B.L. Schulte, and N.N. Joshi 2008. Multiple criteria intelligence tracking for detecting extremes from sequences of risk incidents. Journal of Industrial and Management Optimization. 4(3): 511-533.

Lambert, J.H., C.W. Karvetski, D.K. Spencer, B.J Sotirin, D.M. Liberi, H.H. Zaghloul, J.B. Koogler, S.L. Hunter, W.D. Goran, R.D. Ditmer, and I. Linkov 2012. Prioritizing infrastructure investments in Afghanistan with multiagency stakeholders and deep uncertainty of emergent conditions. ASCE Journal of Infrastructure Systems. 18(2): 155-166.

Lambert, J.H., J. Tsang, and S. Thekdi 2013a. Risk-informed investment for tropical cyclone preparedness of highway signs, signals, and lights. ASCE Journal of Infrastructure Systems. 19(4): 384-394

Lambert, J.H., N.N. Joshi, K.D. Peterson, and S.M. Wadie 2007. Coordination and diversification of investments in multimodal transportation. Public Works Management and Policy. 11: 250-265.

Lambert, J.H., R.A. Jennings, and N.N. Joshi 2006. Integration of risk identification to business process models. Systems Engineering. 9(3):187-198.

Lambert, J.H., Y.J. Wu, H. You, A. Clarens, and B. Smith 2013b. Future climate change and priority setting for transportation infrastructure assets. ASCE Journal of Infrastructure Systems. 19(1):36-46. 
Linthicum, A.S. and J.H. Lambert 2010. Risk management for infrastructure corridors vulnerable to adjacent land development. Journal of Risk Research. 13(8): 983 - 1006.

Lowrance, W. 1976. Of Acceptable Risk.

Martinez, L.J., J.H. Lambert, and C. Karvetski 2011. Scenario-informed multiple criteria analysis for prioritizing investments in electricity capacity expansion. Reliability Engineering and System Safety. 96: 883-891.

Martinez, L.J., J.H. Lambert, and C.W. Karvetski 2010. Public perception of the risks of liquefied natural gas terminals in Mexico: A prioritisation of communication strategies. International Journal of Critical Infrastructures. 6(4): 327-346.

Meyer, T.S., Muething, J.Z., Lima, G.A.S., Torres, B.R.R., del Rosario, T.K., Gomes, J.O., Lambert, J.H. 2012. Radiological emergency response for community agencies with cognitive task analysis, risk analysis, and decision support framework Work: A Journal of Prevention, Assessment and Rehabilitation 41:2925-2932.

Parlak, A., J.H. Lambert, T. Guterbock, and J. Clements 2012. Population behavioral scenarios influencing radiological disaster preparedness and planning. Accident Analysis and Prevention. 48: 353-362.

Schroeder, M.J. and J.H. Lambert 2011. Scenario-based multiple criteria analysis for infrastructure policy impacts and planning. Journal of Risk Research. 14(2): 191-214.

Seager, T.P., J.H. Lambert, and K.H. Gardner 2007. Fostering innovation in contaminated sediments management through multi-criteria technology assessment and public participation. Risk Analysis. 27(4): 1043-1052.

Teng, K., S.A. Thekdi, and J.H. Lambert 2012. Identification and evaluation of priorities in the business process of a risk or safety organization. Reliability Engineering and System Safety. 99: 74-86.

Teng, K., S.A. Thekdi, and J.H. Lambert 2013. Risk and safety program performance evaluation and business process modeling. IEEE Transactions on Systems, Man, and Cybernetics: Part A. 42(6): 1504-1513.

Thekdi, S.A. and J.H. Lambert 2012. Decision analysis and risk models for land development affecting infrastructure systems. Risk Analysis. 32(7): 1253-1269.

Thekdi, S.A., and J.H. Lambert 2014. Quantification of scenarios and stakeholders influencing priorities for risk mitigation in infrastructure systems". ASCE Journal of Management in Engineering. 30(1):32-40.

You, H., J.H. Lambert, A.F. Clarens, and B. McFarlane 2014. Quantifying the influence of climate change to priorities for infrastructure projects. IEEE Transactions on Systems Man and Cybernetics: Systems. 44(2):133-145.

Zhou, Q., J.H. Lambert, C.W. Karvetski, J.M. Keisler, and I. Linkov 2012. Flood protection diversification to reduce probabilities of extreme losses. Risk Analysis. 32(11): 1873-1887. 
Mahadevan, Sankaran, Vanderbilt University

\title{
Uncertainty Quantification in Sustainability Assessment
}

\begin{abstract}
This paper focuses on uncertainty quantification (UQ) with respect to the sustainability evaluation of construction and manufacturing processes. Various sources of uncertainty, such as natural variability, information uncertainty, and modeling uncertainty need to be included in such evaluation. This is not straightforward, given the empirical nature of many of the component processes. The information available is heterogeneous, available from many sources and in different formats; it is also qualitative in many cases. In some cases the data is sparse, and in some others it is very large. Research is needed for systematic fusion of all available information, in order to facilitate both forward and inverse problems in uncertainty quantification. The forward propagation helps quantify the overall uncertainty in evaluating the appropriate metrics, and the relative contributions of different sources to the overall uncertainty. The inverse problem can facilitate uncertainty reduction through process optimization, and resource allocation for optimal data collection.
\end{abstract}

\section{Keywords}

Uncertainty quantification, Variability, Data uncertainty, Model uncertainty, Information fusion, Data analytics, Decision-making

\section{Introduction}

Today's advanced manufacturing processes and production networks increasingly push the envelope in building complex, optimized products. Along with these developments, concerns regarding sustainability, agility, smart manufacturing etc. have become increasingly important. However, a 2009 NIST workshop report states that "industry is unable to measure economic, social, and environmental consequences of their activities and products accurately during the entire life cycle and across their supply chain" [1]. Therefore recent efforts towards assessment of production networks and supply chains with respect to economic, social and environmental effects have focused on defining various metrics and measurement methods. However, measurement science also requires the quantification of uncertainty in the measurement, in terms of bias and precision, or in terms of systematic and random errors. Given the complexity of modern production networks, quantification of performance metrics such as sustainability, agility etc. is quite complicated in itself. In addition, many sources of variability and uncertainty present in different processes contribute to significant uncertainty in the overall performance evaluation. Therefore, it is essential to develop a systematic and rigorous methodology for quantifying the uncertainties in performance measurement in a complex production network.

The errors and uncertainty need to be quantified at multiple levels and stages of the manufacturing supply chain. Uncertainty sources in various components of the network may broadly be classified into three categories: natural variability in the manufacturing processes (aleatory uncertainty), information uncertainty due to inadequate, qualitative, missing, or erroneous data (epistemic uncertainty), and modeling uncertainty induced by assumptions and approximations (epistemic uncertainty). Much previous work has focused on variability in individual manufacturing processes in order to accomplish quality control and robustness 
objectives. The focus of this document is different; it is to explore research towards a systematic methodology that quantifies the overall uncertainty in the computation of performance metrics related to sustainability in construction and manufacturing, and the contributions of individual sources of uncertainty to the overall uncertainty in the metrics assessment.

\section{Uncertainty Quantification: Current Status}

Uncertainty in the measurement of various performance metrics in manufacturing networks has been addressed in a few studies. (The literature on statistical process control is mature and vast, and is not addressed here). Yu and Heng (2006) explore methods to synthesize expert opinion about the agility of a manufacturing enterprise [20]. Uncertainty and variability are prominent in the measurement of flexibility, as discussed by several studies, i.e., uncertainty in external factors (consumer-led) such as demand, resource availability, supplier and labor availability, and technology changes, and variability in internal factors (company-led), such as machine downtime, material input variability, raw materials, schedule, and variations in workforce [21]. Measurement of sustainability has mainly focused on developing appropriate metrics [22]; while it is recognized that many factors contribute to uncertainty in the measurement of energy and resource consumption, environmental impact etc., a systematic methodology for uncertainty quantification in such metrics is yet to be developed. A 2010 National Science Foundation workshop on decision-making under uncertainty with respect to manufacturing identified several opportunities for the use of UQ methods in job shop assignment and scheduling [23].

One of the challenges in construction and manufacturing process assessment is in collecting and processing data about the quantities to be used in the calculation of performance metrics. Such information is sometimes inadequate, due to sparse, imprecise, qualitative, subjective, faulty, or missing data. Sometimes the available data may be very large in volume, leading to big data issues. The data is quite often heterogeneous, coming from different sources and available in different formats (e.g., test data, operational data, legacy system data, model-based simulations, and expert opinion).

A second challenge in sustainability assessment is to develop a computational framework that mathematically represents all the components of the construction or manufacturing enterprise, input and output variables, the relationships within and among the component processes, and their relation to the system-level performance metric. The models for various processes could be based on physics (first principles), regression of empirical data, system dynamics, or agent-based simulation. For some components (e.g., software, or even hardware components such as valves, seals, fittings, etc.), there may not be any mathematical models available, but perhaps reliability data from past experience or literature. Quantification of the model uncertainty resulting from such heterogeneous information could be studied w.r.t. three categories, namely, model parameters, model form, and solution approximations.

Uncertainty quantification in the presence of above data and model uncertainties is not straightforward. The various sources of uncertainty do not combine in a simple manner to give the uncertainty in the overall system-level performance metric; the combinations might be linear, nonlinear, nested, or require iterative analyses. Various types of methods are being vigorously investigated at present within the UQ research community, but most of the research is currently limited to physical systems, not processes. Thus substantial new research is needed to develop new uncertainty quantification techniques in sustainability assessment for construction and 
manufacturing processes. These techniques need to be capable of fusing information that is available in heterogeneous formats (numerical, categorical, text, image). Data from different components of the process are available at different times during the life cycle, and the UQ technique should be able to handle this time factor. Also, the information fusion needs to account for different levels of fidelity in different types of data.

\section{Uncertainty Quantification Research Needs}

Several research questions with respect to uncertainty quantification in construction and manufacturing processes can be posed, as below:

1. How to quantify the uncertainty in sustainability evaluation of construction and manufacturing processes and supply chains?

a. What are the theoretical issues?

b. What are possible methodologies?

c. How to evaluate the existing methodologies and identify promising ones?

2. If a UQ methodology is identified, is it scalable to high dimensional problems?

a. How to address issues of composability and modularity?

b. Is the approach generalizable to different construction and manufacturing scenarios?

c. What is the cost of sustainability evaluation (i.e., effort and resources needed for modeling, data collection, computation)?

d. How to quantify and optimize the trade-off between cost and benefit?

3. How to fuse available information?

a. How to construct constitutive models for various processes and components?

b. How to handle data issues, such as heterogeneous data and missing data?

c. How to take advantage of monitoring systems in manufacturing processes?

4. How to facilitate decision-making for sustainability?

a. How to connect macro-level performance metrics to micro-level considerations?

b. How to perform sensitivity analysis to assess the contributions of various uncertainty sources to the sustainability evaluation?

c. How to use the resulting information from the above investigations in decisionmaking under uncertainty?

Investments are needed towards investigating the basic research questions above, as well as in developing tools and standards. Coordination with the industry will be needed, especially in methodology and tool testing, verification and validation, and in application demonstrations at increasing levels of complexity. Involvement of technical committees in related professional organizations will further facilitate progress in this direction.

\section{References}

Rachuri, S., R. D. Sriram, A. Narayanan, P. Sarkar, J.H. Lee, K. W. Lyons, and S. J. Kemmerer, "Sustainable manufacturing: metrics, standards, and infrastructure - NIST Workshop report," National Institute of Standards and Technology (NIST), Gaithersburg, MD, USA, NIST interagency/internal report (NISTIR) 7683, 2010.

$\mathrm{Yu}$, L., and Z. Heng, "Measuring Agility of Enterprise using Analytic Hierarchy Process and Bayesian Belief Networks," Proceedings, International Conference on Management Science and Engineering, Lille, France, pp. 551-556, 2006. 
Kara, S., and B. Kayis, "Manufacturing flexibility and variability: an overview" Journal of Manufacturing Technology Management, Vol. 15, No. 6, pp. 466-478, 2004.

Feng, S.C., and C.B. Joung, "Development overview of sustainable manufacturing metrics," Proceedings, 17th CIRP International Conference on Life Cycle Engineering, Hefei, 2010.

Schmitz, T. L., J. Karandikar, N. H. Kim, and A. Abbas, 'Uncertainty in machining: Workshop summary and contributions," Journal of Manufacturing Science and Engineering, ASME, Vol. 133, pp. 051009-1 to pp. 051009-9, 2011. 
McDowell, Bruce D., Intergovernmental Management Associates, MD

Balancing Sustainability's Triple Bottom Line

\begin{abstract}
The triple bottom line definition of Sustainability, adopted by ASCE and many others, includes environmental, economic, and social dimensions. Infrastructure--engineered, built, operated, maintained, modified, renovated, and finally repurposed, recycled or decommissioned at its end of life--impacts the natural and human environments in which it is placed. But, compared to environmental impacts, much less attention is paid to the effects on the social and economic dimensions of sustainability. This paper focuses attention on the need to upgrade how we measure and manage the social and economic impacts of engineered infrastructure.
\end{abstract}

\title{
Keywords
}

Users, engagement, equity, measurement, performance, management

\section{Origins of Imbalance}

Environmental Impact Statements (EIS) have a long, solidly established history. The National Environmental Policy Act (NEPA), upon which the EIS process is based, was enacted by Congress in 1969 and signed into law in 1970 by President Nixon. Its passage was buoyed by a strong wave of public concern and support for moving toward a clean environment in response to the publication of Rachel Carson's famous book, Silent Spring. Despite the sometimes very substantial costs of cleaning up the environment, this wave of public support has firmly sustained the environmental clean-up movement over the past four decades. Sure, there is resistance from those who must bear the costs, and sometimes progress has not been as fast as many hoped for. But major progress has been achieved. Combined with the Endangered Species Act, the EIS process now provides the gold standard of impact statements. We now know almost everything about the plants and animals of the Earth, and their ecological habitats - and how to protect them.

When NEPA passed, it also contained the seeds of social and economic impact statements, but that part of the Act was not implemented. It lay fallow until 1994 when President Clinton issued Executive Order 12898: Federal Actions to Address Environmental Justice in Minority Populations and Low-Income Populations. The path to this action was much more tortured than the path to enacting NEPA. Its roots went back to the Civil Rights legislation of the 1960s. Numerous public demonstrations in the 1970s, and citizen lawsuits about unequal levels of service that would be provided to different population groups by planned transit system improvements in Los Angeles brought environmental justice forward. This was a very contentious and long drawn-out process - unlike the wave of public support that swept in NEPA and the EIS process. Even now, social equity and environmental justice processes are little known and mostly still just struggling for recognition.

The reality is that we now know more about the impacts of planned infrastructure projects on endangered species such as the snail darter than we know about the potential impacts on many 
types of people-especially those of minority and low-income status who have little influence in the regular political process.

As for economic impacts, the path has been different, still. For many decades, the federal government funded large shares of the costs of major highway, transit, water and sewer, waterways and ports, and airport systems. Good, solid planning was required, but most of the planned facilities were heavily cost-shared by the federal government. Now, those federal resources are drying up and the state and local governments are taking on more of the financial responsibility. And, in turn, the state and local governments are turning increasingly to publicprivate partnerships to shift part of the financial load into the private sector. So, fiscal impact statements are becoming more important and more common. The urgent question is, where will future revenues come from to repay construction costs and take care of maintenance and operations? In other words, if a community develops in any given form, what will be its return on investment? Will this be a good, sustainable investment, considering the impact on future tax rates and other financial obligations? One prominent author (Katz) has called this The Missing Metric, and EPA's Office of Sustainable Communities offers a webinar on the subject.

The bottom line is this: a good solid EIS of the traditional type is no longer enough to guarantee Sustainability. The United States needs a larger and better-balanced array of reliable social, economic, and environmental measures.

The remainder of this paper focuses on improving social indicators, the analysis of social impacts, and the equitable distribution of social benefits across population groups.

\section{What is Social Equity?}

First, social equity and environmental justice are roughly equivalent terms. Because of past history, the emphasis is placed on ensuring special attention to minority and low-income groups that have traditionally been discriminated against by living in less healthy, more dangerous, and less well-served locations where they disproportionally bear the burdens present in those locations. Federal guidelines specifically identify these groups as Black or African American, Hispanic or Latino, Asian, American Indian or Alaskan Native, Native Hawaiian or other Pacific Islander, and Low-Income. With respect to these groups, federal programs are directed to:

- Avoid, minimize, or mitigate disproportionately high and adverse human health and environmental effects, including social and economic effects

- Ensure the full and fair participation by all potentially affected communities in the decision making process

- Prevent the denial of, reduction in or significant delay in the receipt of benefits

Traditionally, these groups have been less well-represented and influential in local, state, and national decision making processes, and less able to effectively represent their views in political arenas. Indeed, for a host of reasons, these groups have often been deemed "hard to reach." They often are outside the mainstream culture, not used to the cultural norms of governmental processes, not English speaking, and sometimes fearful of adverse consequences that might result from contact with the government. Immigration status, of course, is a particularly hotbutton concern at the present time, and is even interfering with attempts to enroll eligible people 
in the new affordable healthcare programs. So this is a tough nut to crack, and it needs special attention.

\section{Social Equity Tools}

Two types of tools are especially valuable in addressing social equity. One is the environmental justice screening method being developed at the University of Southern California (USC). The other is community engagement programs, specially adapted to the minority and low-income groups identified above.

Equity screening works like this (Pastor, August 2013). First, identify neighborhoods where low-income and minority residents are found, and the concentrations of these residents. Also measure such conditions as their degree of linguistic isolation, low homeownership, low car ownership, and long commutes to work.

Then, identify areas where air quality is below standard, and by how much. Also where toxic soils (known as Brownfields) present dangers to health, where the quality of schools is deficient, where community facilities and services are sub-par, where there is a lack of choices for economical shopping and fresh/healthy foods, where there are not safe and convenient opportunities for walking and bicycling, and more. A widening variety of old and new measures, and standards for what is acceptable, is coming into use, little by little, and they need to be added to the social equity toolkit. Several are listed in the list of references provided at the end of this brief paper.

Finally, compare the demographic characteristics with services available to identify disparities. Map the disparities, using geographic information system (GIS) technologies to graphically visualize and communicate them. One of the most striking features of social equity screening is the extent to which demographics is central to it.

The goal of social equity programs is to reduce such disparities over time. So the results of these mitigation programs need to be re-measured and re-analyzed regularly to track their results.

Reducing social disparities, of course, requires effective management of a large array of infrastructure and other programs on a non-discriminatory basis. How well is each of those programs working to produce the intended facilities and services in each neighborhood? It is the aggregate of all these programs over time, that improves (or does not improve) the conditions in a neighborhood, compared to the conditions in other neighborhoods.

These two types of results - program provided facilities and services (called program outputs) and comparative neighborhood conditions (called community outcomes) - are different from each other. They measure different things and need to be measured separately. The connection between them is provided by some kind of causation based logic model linking aggregate program results with community impacts upon diverse demographic groups.

\section{Performance Management: Making a Difference}

Effective achievement of social equity goals requires good solid performance measures with sufficient variety to accurately describe program goals and program results, as well as equitable 
outcomes. These measures need to be easy enough and affordable enough to be made readily available to support the timely management decisions needed to improve both types of results. And regular program evaluation studies need to be used to validate and update the measures and the vital causal links between program outputs and community outcomes.

\section{Viewing Infrastructure through the User's Lens}

In general, it is vital to engage the public that will be using infrastructure in the planning, design, construction, operation, maintenance, and end-of-life stages in the engineering process. Without these vital inputs, the infrastructure project runs the risk that it will not be supported and funded adequately, will not be sustained over time, and will not be used as intended, or will not provide all the benefits that were promised. And the infrastructure agency's reputation also may be diminished.

But, for social equity purposes, there is yet another reason to view infrastructure projects through the user's lens. The low-income and minority members of these frequently disadvantaged groups may be more or less invisible. The U. S. Census counts them, as well as it can, but they may not be engaged in local, state, and federal decision making processes to the same extent that others are. Out of sight, out of mind. Even some pretty good community involvement processes may leave low-income and minority people unengaged. They may be hard to reach, and they often do not put themselves forward.

So, special efforts are needed to engage them. Their needs and desires and abilities may be quite different than those of the mainstream population. Without engaging them, there is no way of knowing - at least not until the project is under construction and beginning to have an obvious impact on the groups -- who were left behind in the engagement process.

Public opposition to projects at this stage can be quite disruptive and unfortunate. It can even stop some projects, or at least set them back while important controversies are resolved. Upfront engagement of everyone potentially served or impacted helps to avoid setbacks like thisand even more importantly-helps to provide better plans and proposals than an incomplete public engagement process could.

As part of its Continuing Education program, ASCE provides a Community Participation Course, on-line, to help fill this gap (http://mylearning. asce.org/diweb/catalog?dp=0\&c=79\&q=Community+Participation \&fl=1.) In addition to laying out the entire engagement process, this course makes the point that some groups are harder to reach than others, and it shows the special means available to reach them.

Again, demographics comes front and center. Where are these hard-to-reach groups, neighborhood by neighborhood? What are their characteristics? What languages do they speak? Do they have informal or indigenous leadership structures that could be useful in engaging them? What sort of special approaches might be most effective in engaging each special group?

Don't be surprised if you hear different, unexpected concerns, needs, and ideas about how to approach your project from these groups. Work toward better understandings and a better project. Identify the existing equity gaps perceived by those being impacted, and watch for 
opportunities to mitigate them. It is also possible that this process will suggest some new performance measures that have not been suggested from other sources. Once again, you may find that demographics are important sources of creativity.

It is time to bring social equity issues more fully into the practice of Sustainable Infrastructure Engineering.

\section{References}

American Planning Association, October 2007. Fair and Healthy Land Use: Environmental Justice and Planning, Planning Advisory Service Report Number 549/550, Chicago, IL.

Carson, Rachel L., 1962. Silent Spring, Mariner Books, Houghton Mifflin Company, Anniversary Edition, 2002, New York.

Forsyth, Ann, May 7, 2013. Measuring Walkability: The Health Question, Webinar. Volpe, The National Transportation Systems Center, U. S. Department of Transportation, Research and Innovative Technology Administration.

Gose, Joe. Construction That Focuses on Health of Residents. New York Times, March 5, 2013.

Guttenplan, Martin and Seleta Reynolds, Measuring Multimodal Mobility with the Highway Capacity Manual 2010 and Other New Analysis Tools. TR News, May 2012, pp. 46-52.

Katz, Peter, August 2013. The Missing Metric, Government Finance Review, pp. 20-32.

National Civic League, National Civic Review Special Issue: Twenty-Five Years of Healthy Communities: Part 1, Winter 2013 (Vol. 102, Issue 4).

Pastor, Manuel, Rachel Morello-Frosch, and Jim Sadd, August 2013. Screening for Justice: Proactive Spatial Approaches to Environmental Disparities, EM Magazine

U. S. Department of Transportation, Federal Highway Administration, undated/downloaded. Environmental Justice and NEPA in the Transportation Arena: Project Highlights. http://www. fhwa.dot.gov/environment/environmental justice/.

U.S. Department of Transportation, Federal Highway Administration. Operations Performance Measures: The Foundation for Performance-Based Management of Transportation Operations Programs. http://www.ops.fhwa.dot.gov/perf_measurement/index.htm

U. S. Environmental Protection Agency, February 2013. Creating Equitable, Healthy, and Sustainable Communities: Strategies for Advancing Smart Growth, Environmental Justice, and Equitable Development (Report EPA 231-K-10-005).

Transportation Research Board, October 16, 2012. Performance Measures for Public Involvement: A Webinar. Washington, D.C. 
[This page is internationally left blank] 
Mujumdar, Vilas, Consulting Engineer, VA

\section{Sustainable Built Environment - Measurement questions}

\section{Abstract}

The emphasis of this paper is on the built environment. For built environment to be sustainable, resilience must be either built-in or developed in the system. This is needed whether the degradation of the quality and use is due to environmental factors, use of the facilities beyond the design capacity or due to exposure to natural or man-made hazards. Complete life cycle of the built environment system must be studied. This cycle includes site selection, design, construction, operations, maintenance and demolition, disposable and reuse.

Since built environment has numerous categories depending on the function, it is necessary to develop certain common characteristics that can be applied to all categories. To be sustainable, all systems must be resilient. The focus of this paper is, therefore, resiliency of systems and specifically, physical performance of built environment systems. This author also raises questions related to measurement of acceptable functionality as systems are interdependent and functionality related impact on the community.

\section{Keywords}

Built environment, resilience, systems, complete cycle, physical performance, natural hazards

\section{Background}

Sustainable built environment reduces resources consumption, combats environmental degradation and creates better environment for living through trade-offs. In general, the tradeoffs are among performance in four areas: physical, economic, environmental and social (National Research Council of Canada, 2013). Rigorous predictions of performance, based on robust analysis/data are required. Such predictions may be quantifiable in some areas such as physical behavior and economic consequences, however, environmental and social areas may not be measurable easily.

\section{Built Environment Defined}

Built environment comprises of various types of facilities and structures. Each has its own requirements. This author has categorized these based on their type first, and then within each category, based on their function.
1. Building Systems
2. Transportation Systems
3. Utility Systems
4. Communication Systems

\section{Building Systems}

Building systems category has several types depending on their functions:
a. Residential facilities - continued habitability
b. Office buildings - normal business functions
c. Educational facilities - student learning and research
d. Medical facilities- hospitals and medical office buildings, laboratories 
e. Emergency/rescue facilities - fire stations, police stations, emergency management offices, military offices

f. Government offices - administrative functions, legislative and executive functions

g. Other facilities such as sport stadiums, manufacturing plants, etc.

2. Transportation Systems

All transportation systems are designed either to carry or transport people and/or cargo.

Therefore, transportation systems can be categorized by their modes of transport.

a. Surface transport networks - railroads, highways, bridges, tunnels, and related facilities such as bus depots, train stations etc.

b. Air transportation systems - airports, aviation facilities, control towers etc.

c. Water transportation systems - cargo ferries, boats, and associated facilities

3. Utility Systems

Included in these systems are the networks that are necessary for societal functioning:

a. Water and water distribution networks- collection systems, treatment works, distribution networks, pump stations, storage facilities such as overhead water tanks

b. Wastewater networks - collection systems, pipes, treatment facilities, disposal networks

c. Electrical networks - generation plants, transmission towers, sub-stations, distribution systems, and connections to users

d. Gas and fuel pipe networks - source facilities, and distribution networks

4. Communication Networks

While these networks do not have many physical facilities, some are important such as main communication towers, and satellite communication devices mounted on the top of buildings, and underground cable networks.

\section{Commonalities among Systems}

As each system has specific function and thus has the unique demand for its performance under the entire life cycle from site selection, design, construction, operations, maintenance and demolition, disposable and reuse, finding common measurable attributes is a challenge. Perhaps commonalities can be found as attributes that need to be considered for all built environment systems to be considered sustainable.

a. Resource depletion. Resources are limited and must be conserved. Primary considerations would be use of materials, energy consumption, and water use.

b. Operationally efficient. In the built environment area, these would be smart buildings, efficient production and distribution

c. Conservation. This area would cover not only current resources but developing and enforcing a methodology of conservation and use of new techniques, new materials and innovation that is conservation driven. Education in this area and financial disincentives are some examples.

\section{Current Methodologies}

Currently, many attempts are being made to measure sustainability. Different agencies and entities have developed benchmarks, indices, and indicators. Prominent among them are Environmental Sustainability Index (ESI) and Environmental Performance Index (EPI) 
developed for UN. For resiliency the attempts to define measurability have been very few. ASCE's "Envision" rating system is developed for the infrastructure systems considering all three pillars of sustainability, i.e. environmental, social and economic.

This author recognizes that the three pillars act interactively and must be considered but proposes that focus be physical performance, as that is an important area for built environment functionality. It is proposed that de-aggregation be done, creating environmental and social factors as initial filters for evaluation in decision-making for the built environment viability and then performance indicators developed.

\section{Proposed Methodology}

A hierarchy towards sustainability after a system is built is shown in Figure 1.

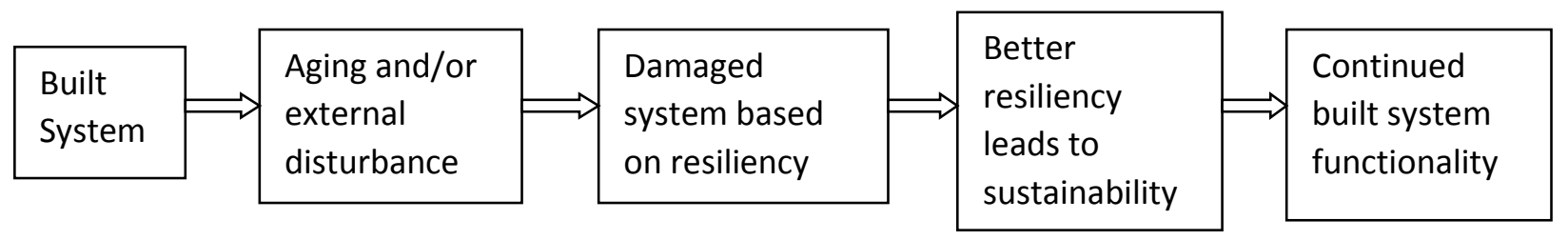

Figure 1. Sustainability Hierarchy

The ultimate goal in sustainability is to have continued functionality of the system. It is essential that after an event that leads to some damaged state, full functionality resume quickly. Resiliency of the system determines the time taken to full functionality. Although robustness, redundancy, resourcefulness, and rapidity are suggested as dimensions of the system resiliency (Bruneau, M., etal 2007), this author contends that robustness and redundancy are different concepts and should not be dimensions of resiliency.

A system is considered robust when it can continue functioning in the presence of internal and external challenges without fundamental changes to the original system. Even the ISO definition of robustness "ability of a structure or a component to withstand events (like fire explosion, impact) or consequence of human errors, without being damaged to an extent disproportionate to the original cause" (ISO 22114) clarifies that a robust system remains functional. Similarly, redundancy is meant to increase the reliability of a system. In engineering it is defined as "the duplication of critical components or functions of a system with the intention of increasing reliability of the system, usually in the form of a backup or fail-safe". Again, the system is supposed to remain functional due to provision or existence of more than one means or resources to perform an activity or function.

For the built environment, complete life cycle of site selection, design, construction, operation, maintenance, and possible demolition functions and disposal can be viewed through social, economic and environmental lenses. Various issues that are associated with each stage are shown in Figure 2. 


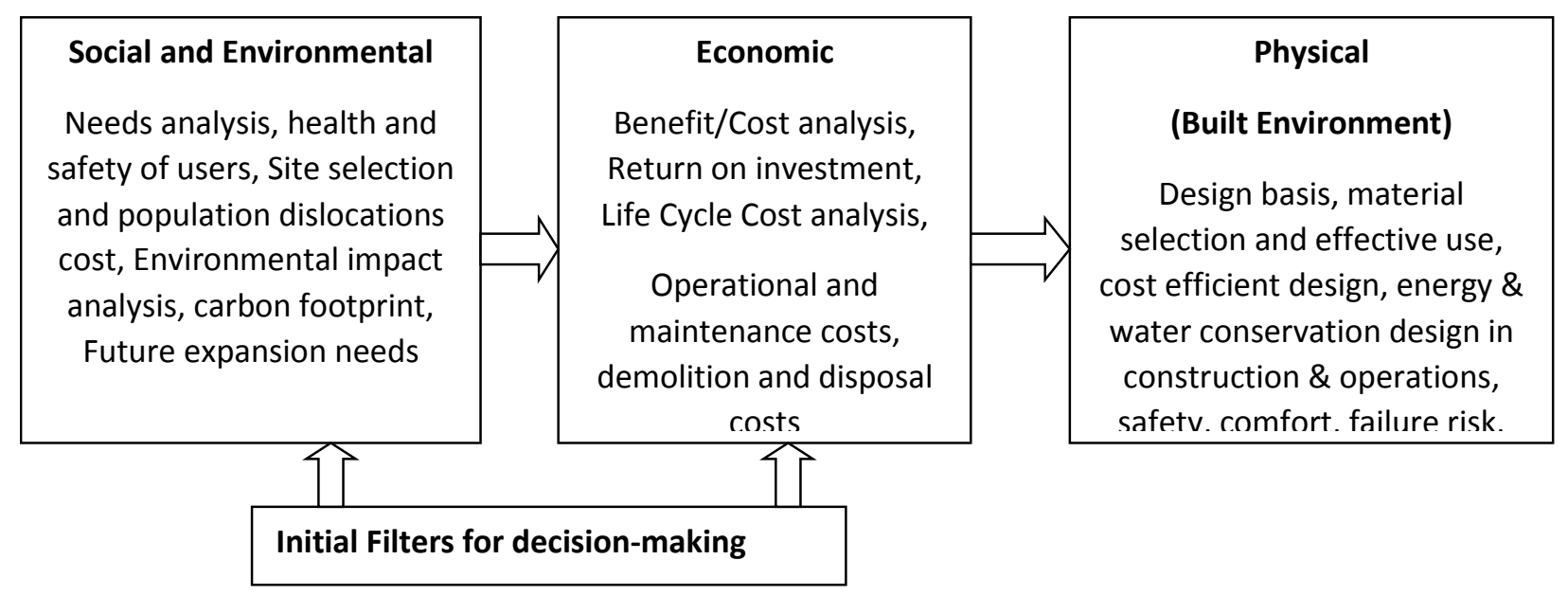

Figure 2. Initial Filters and Performance Basis - Built Environment

Ranking of different aspect can be developed and score and weight can be assigned to each area in the physical box in figure 2 . This measurement is possible only because de-aggregation technique is used. However, it is to be recognized that the systems are interdependent, and because sustainability depends on functionality, following questions are raised for further analysis and research towards measurement of built environment.

\section{Research Needs}

a. How do we determine functionality of interdependent infrastructure systems?

b. How does level of functionality relate to sustainability? Is reduced functionality acceptable?

c. What physical attributes need to be quantified apart from those that are safety focused?

d. Is determining residual capacity after a hazard related damage, useful as a measure of sustainability?

e. Because resiliency is essential, how do we create and determine different levels of resiliency for different hazards and different levels of the same hazard?

f. If reduced functionality is acceptable to community, how do we deal with legal responsibility and regulatory impacts?

g. Is the time for recovery to acceptable functionality as the impact on society a truly all encompassing measure of resilience?

\section{Conclusions}

Built environment is separated from the social, environmental and economic considerations and these are suggested as initial filters for decision-making. In the built environment, it is possible to de-aggregate physical performance for measurement purposes. Several attributes can be graded and assigned weights and scores depending on their importance in the system. However, the systems are not independent. The interdependency needs to be taken into consideration. Measurement becomes difficult as the functionality of an interdependent system need to be quantified. Further research in this area is needed. 


\section{References}

American Lifelines Alliance Power Systems, Water, Transportation and Communications

Lifeline Interdependencies March 2006.

ASCE, 2011, Envision rating system.

Bruneau, M., etal, 2007, Conceptualized and Measuring Resilience, TR News 250, pp. 14-17.

Mujumdar, V., A Need for Risk-Consistent Approach to Multi-Hazard Engineering., Symposium on Emerging Developments in Multi-Hazard Engineering, New York, New York, Sept. 18, 2007.

Mujumdar, V., Multi-hazard Vulnerability, Mitigation, Resilience, Decision-making, and Public policy for civil infrastructure, Course lecture, Shanghai Jiao Tong University, Shanghai,

China, May 2014.

National Research Council of Canada, 2013.

United Nations Report on Sustainability indicators, 2011. 
[This page is internationally left blank] 


\title{
Nasr, Nabil, and Michael Thurston, Rochester Institute of Technology
}

\section{Measurements for Sustainable Manufacturing}

\begin{abstract}
Effective and unified measurements for sustainable manufacturing can significantly accelerate progress toward meeting global sustainability objectives in these areas. This paper discusses many of the existing standards or metrics and discusses the opportunity for expansion and integration of these systems with a focus on energy and Green House Gas emission (GHG).
\end{abstract}

\section{Keywords}

Sustainable manufacturing, life-cycle engineering, life-cycle assessment, measurements, metrics

\section{Background}

Concerns over global environmental degradation and climate change and the role that human activity may play in global warming have accelerated discussions about what can be done to address these challenges. The per-capita energy (and GHG) footprint of different regions of the world is highly linked to the quality of life; large portions of the world population have a much lower per-capita footprint than the developed world but are rapidly increasing. The Triple Bottom Line of sustainability is concerned not only with global environmental concerns such as global warming, but also local environmental issues such as pollution, economic fairness, and social stability and welfare. While the effects of global climate change are shared, social and economic equity considerations suggest that the developed world needs to lead in reducing the overall worldwide GHG footprint while allowing for growth in the developing countries.

Production and consumption have the greatest environmental impact. Most large companies now maintain a Corporate Sustainability Report which summarizes their activities in this area, these reports link to energy use and carbon emissions reporting (which may be mandated in some countries) and activities to improve health and safety of employees and within the communities in which they operate. These reports often link to the principles of the UN Global Compact (http://www.unglobalcompact.org/, last accessed 5/15/14), and companies are increasingly considering these factors within their supply chains.

For companies that design and manufacture products, the term Sustainable Manufacturing encapsulates many of the activities and decisions that can impact the sustainability of the company's products and operations. A workshop sponsored by the U.S. National Institute for Standards and Technology provides a definition for Sustainable Manufacturing which includes the entire product life-cycle (Sudarsan, et al, 2010).

"Sustainable manufacturing is a systems approach for the creation and distribution (supply chain) of innovative products and services that: minimizes resources (inputs such as materials, energy, water, and land); eliminates toxic substances; and produces zero waste that in effect reduces greenhouse gases, e.g., carbon intensity, across the entire life cycle of products and services." 
Energy use and GHG emissions are two of the key considerations in Sustainable Manufacturing, especially in light of global climate change, and will be considered here particularly in regards to product design and supply chain performance.

\section{Product Life-Cycle}

In order to assess the energy or GHG implications of a product development decision, it is often necessary to consider the implications on the entire product life-cycle. For example, a material with a lower production energy footprint might shorten the product life or reduce reuse or recycling options at end of life. Figure 1 shows a view of the product life-cycle adapted from

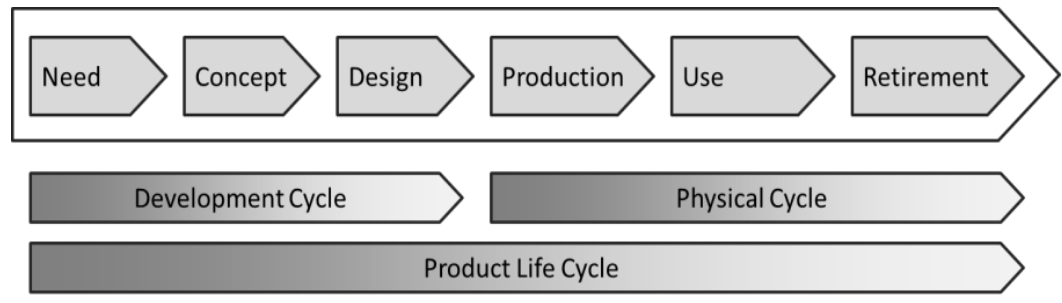

Figure 1. Product Life-Cycle

Guidice et al., 2006. It is widely recognized that the physical cycle dominates the life-cycle cost and energy footprint of a product; however, it is also acknowledged that the factors that affect cost and energy footprint are determined during the development cycle.

"Need" represents consumer or customer demand, and a goal of Sustainable Manufacturing is to meet that need with the greatest overall social and economic benefit and with a minimum of environmental impact. Many high-impact innovations identify market needs (or wants) that may not have been previously recognized and create a new market, therefore resulting in more consumption (e.g., the Apple iPod). The Sustainable Manufacturing definition above suggests that innovation should be focused on developing new ways to meet market needs that have lower overall impact. There is increasing corporate focus on this approach due to increased demand for greener products and synergy with improvements in production cost efficiencies.

A more detailed view of the product physical life cycle is shown in figure 2. A primary goal of Sustainable Manufacturing should be to meet the market demand while minimizing the consumption of nonrenewable materials and energy sources and the emission of potentially harmful substances to the environment over the entire product lifecycle. The performance of a product with respect to lifecycle energy and carbon footprint will be affected by product design, supply chain, manufacturing process, how the

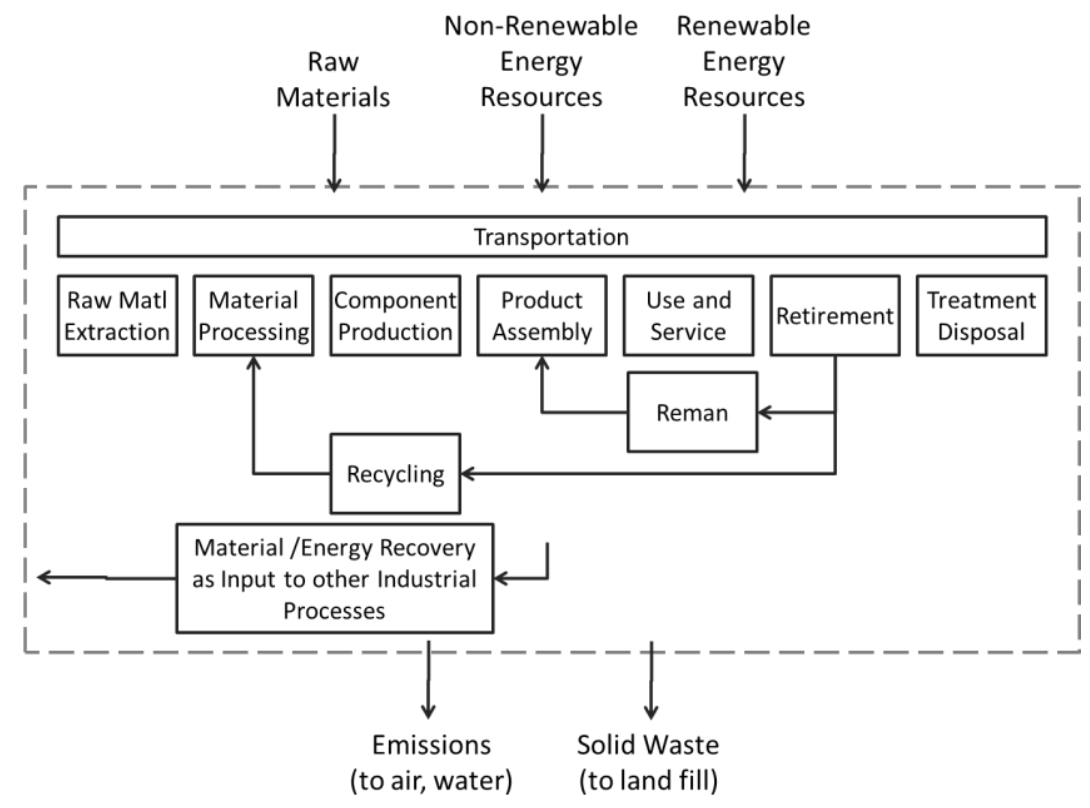

Figure 2. Product Physical Life-Cycle 
end-user uses the product, service support system, and end-of-life management. If the product manufacturer is not responsible for a particular downstream phase it may not be strongly considered when design and support decisions are made. Extended producer responsibility (EPR) is a strategy that makes the manufacturer responsible for the cost of recovery and disposal. This adds incentive for the producer to consider end-of-life strategies when designing the product and product support network. The Waste Electrical and Electronic Equipment (WEEE) directive is an example of EPR action taken by the European Community that requires manufacturers to pay an annual fee to cover the cost of take-back and recycling of electronic equipment such as small household appliances.

Many of the attributes of a product system are locked in during the design stage. This is not only limited to product design but inclusive of manufacturing process and business process design (supply chain, sales/ownership model, service, and retirement processes). Processes for Design for the Environment (DfE) are often applied to product design; however for the greatest impact they should also be applied manufacturing and business process development concurrently. DfE principles are usually presented as guidelines for designers, often in the form of 10 (sometimes more) rules for environment focused design (OTA 1992, Fiksel 1996). Applying these principles to Sustainable Manufacturing and GHG emissions, some specific areas for focus include:

- Improving product efficiency and process efficiency through-out the supply chain

- Reducing GHG footprint of materials and processes throughout supply chain (e.g. design for use of low impact or recycled materials, use renewable or lower carbon energy sources)

- Extending the useful life of products through improved design and service

- Recovering energy value of components and materials at as high a value as possible at end-of-life: reuse, remanufacture and upgrade, recycle

- Reducing emissions related to transportation

\section{Measurement and Analysis of Energy Use and GHG Emissions}

The primary process that is used to systematically evaluate the environmental burden associated with a product or a manufacturing process over its life-cycle is Life Cycle Assessment (LCA). The International Organization for Standardization (ISO) provides a standard framework for performing an LCA (ISO 14040). LCA is a general process that can be applied to assess the impact of design or process options, or the impact of supply chain decisions. A number of LCA software tools and databases exist to facilitate LCA analysis, a summary of which is provided by the US Environmental Protection Agency (http://www.epa.gov/nrmrl/std/lca/resources.html\#Software, last accessed 5/15/14).

LCA Impact indicators may be classified as midpoint or endpoint indicators. Midpoint indicators are notionally closer to the process and have lower uncertainty, while endpoint indicators more directly link to the impacts on society and the environment and often include an aggregation of different impact categories. With respect to energy and GHG footprint, midpoint indicators that might be used include Greenhouse Gas Protocol, IPCC 2007, and Cumulative Energy Demand (CED). The Greenhouse Gas Protocol (GHG Protocol) relates to an accounting standard of greenhouse gas emissions. This method estimates the 100-year global warming potential (GWP) of $\mathrm{CO}_{2}$ and $\mathrm{CO}_{2}$ equivalence for other GHG (WBCSD \& WRI, 2009). IPCC 2007 is an update of the method IPCC 2001 developed by the International Panel on Climate Change and includes 
indicators for global warming potential of air emissions over 20, 100 and 500 years (IPCC, 2007). Cumulative Energy Demand is an accounting of the primary energy demand including both renewables and non-renewables. While CED does not link directly to GHG emissions, it provides a means of aggregating across different energy sources and can be useful for many design comparisons (Klöpffer, 1997). Cumulative Fossil Energy Demand is an alternative to CED that does not include renewables or nuclear energy and therefore has a better linkage to GHG emissions.

Consumer attitudes are one factor that drives company behavior, and, as noted in Figure 1, customer (or market) needs are the driver for product consumption. A common consumer comment about the evaluation of purported "green" products is that they do not understand how to evaluate the potential benefits, particularly if there is a cost penalty. This is also a problem for purchasing professionals that may be trying to compare bids from multiple suppliers. ISO provides direction for both environmental labeling (14021-type II, and 14024-type I) and environmental product declarations (EPD) (14025-type III). Type I labels are more useful than type II as they have clear rules within an industry and also external verification. According to the standard, EPDs should be based upon an LCA which covers the product life-cycle and has transparency (source information is available to interested parties). Product Category Rules (PCR) are also covered by ISO 14025 and for a particular product category provide guidelines and scope for the LCA process and for the information that is required to be reported in the EPD. The EPD is being increasingly used for a wide variety of product classes, particularly in Europe, however there is still a need to align PCRs, as several other standards exist in addition to ISO 14025 (Subramanian, et al., 2012).

At the corporate level, there are a number of different sets of indicators that are being used to assess corporate sustainability performance, including for manufacturing companies. The various sets of indicators and metrics are summarized in Feng 2009, Feng 2010, and Joung 2013. Three of the more widely used indicator sets are the Global Reporting Initiative (GRI), the Carbon Disclosure Project (CDP), and the family of Dow Jones Sustainability Indices (DJSI). The CDP has the most detailed disclosure requirements, including direct emissions (scope 1), indirect related to purchased energy (scope 2), and other indirect emissions (scope 3). Recent reports have indicated that the DJSI is working to synchronize its reporting around climate change related issues with the CDP (http //www.sustainability-indices.com/images/robecosam-adoptscdp-approach-to-climate-change-final-release tcm1071-364881.pdf, last accessed 5/15/14). Similarly, the CDP and GRI are collaborating to harmonize their reporting frameworks, with the stated goal to "improve the consistency and comparability of environmental data, making corporate reporting more efficient and effective and easing the reporting burden for companies" (https://www.globalreporting.org/information/news-and-press-center/Pages/Companies-tobenefit-as-CDP-and-GRI-collaborate-to-harmonize-reporting-frameworks.aspx, last accessed 5/15/14). Other reporting frameworks for GHG and carbon reporting include the GHG Protocol and a draft ISO standard (14067) for Carbon Footprinting, among others (Finkbeiner, 2009). The reporting schemes being developed by various countries to track corporate emissions and the relationships to these reporting standards are summarized in Kauffmann, 2012. 


\section{Gaps and Research Needs}

Corporate sustainability frameworks provide information that can be used to guide decisions by investors, consumers, and businesses evaluating potential suppliers. These frameworks are also being used to track national performance with respect to GHG emissions. Continued

standardization of reporting metrics and increased transparency in reported data will also help to provide actionable information about energy use and GHG emissions. However, corporate GHG emissions data is very difficult to compare between different companies, even if normalized to a level of economic activity, due to boundary issues (what economic activity is included within the boundaries of the reported emissions). Increased detail in reporting of scope 3 emissions will help in this regard; however, detailed accounting of scope 3 emissions is an area that needs additional methodological research. As more companies within the overall supply chain comply with scope 1 and 2 reporting (to a consistent framework), the data may exist to support a more detailed consolidation of scope 3 emissions within the upstream supply chain. However, downstream scope 3 emissions also may overlap with another company's scope 1 emissions. In LCA terms, this creates both a boundary and allocation problem to be resolved.

EPD provides another level of information for consumers and manufacturing companies (design and manufacturing engineers, and purchasing professionals) to include environmental impacts in their purchasing decisions. However, being LCA-based, the effort to complete an EPD is significant. In consumer products, market forces may encourage development of a PCR and increased use of the EPD. In commercial transactions, purchasers could make this a requirement for some purchased products, or suppliers could provide this information to differentiate their offering if it is important to the purchaser.

Although the PCR provides standardization, many of the challenges inherent in LCA still apply to EPD. With a narrowed focus on GHG and climate change, a number of the general LCA challenges do not apply. Some of the issues which remain, including research and implementation challenges are: how to handle products with multiple functions (functional unit definition); boundary issues such as differing supply chain boundaries (both upstream and downstream); boundary and allocation issues associated with multi life-cycle (e.g. remanufactured) products; and uncertainty estimation. An additional barrier to LCA implementation in general is the significant effort involved in completing an analysis. The research community continues to address this through enhancement of LCA databases; however, much of the available data has some geographical limitations. A research opportunity which may help to address several of these challenges is the development of improved hybrid methods that couple unit-process-based analysis with input/output techniques. The complexity of temporal issues associated with GHG impacts also comes into play when comparing systems with very different lifetimes or considering the timing of significant technology changes.

In product development, design goals and constraints are typically established outside of the product development team (PDT). The PDT consisting of design, manufacturing, and quality engineers, and often a supplier development or purchasing member will work together to make appropriate trade-offs between requirements. Many of the business and strategic issues that may affect product sustainability are determined outside of the PDT, for example: location of manufacturing, plant energy resources, and product life-cycle and support strategies. In order to achieve the best results from a sustainability standpoint, any of these strategic factors that are not 
fixed due to strong business constraints should be considered jointly along with the other development considerations. In addition, measureable sustainability goals should be passed down to the development team as part of the overall product requirements. The PDT can use tools such as DfE and Streamlined LCA (SLCA) to provide qualitative direction to the development process; however, at some point, an LCA should be performed to evaluate major factors that impact product sustainability. Due to the time-intensive nature of LCA, it is suggested to use an iterative approach that allows for appropriate levels of resolution and consideration of factors appropriate to the phase of the development process. There is a need for additional research to develop better approaches to cost effectively integrate quantitative LCA into the product development process.

\section{Conclusions}

Progress toward meeting global sustainability objectives is dependent on many factors including technology, policy, and increased awareness of the challenges we face. Standard methods and unified metrics for sustainable construction and manufacturing are needed. It is critical to develop integrated approaches to standards and metrics that are feasible to implement across the supply chains.

\section{References}

Sudarsan, R., et al., 2010, "Sustainable manufacturing: metrics, standards, and infrastructureNIST Workshop report." National Institute of Standards and Technology (NIST), Gaithersburg, MD, USA, NIST interagency/internal report (NISTIR) 7683.

Giudice, Fabio, Guido La Rosa, and Antonino Risitano, 2006, Product design for the environment: a life cycle approach. CRC press, 2006.

Frost, S. and Burnett, M. (2007), "Case study: the Apple iPod in China", Corporate Social Responsibility and Environmental Management, Vol. 14, pp. 103-13.

WBCSD \& WRI. 2009. Product Life Cycle Accounting and Reporting Standard. Review Draft for Stakeholder Advisory Group. The Greenhouse Gas Protocol Initiative. November.

Intergovernmental Panel on Climate Change (IPCC). 2007. IPCC Fourth Assessment Report. The Physical Science Basis. http://www.ipcc.ch/ipccreports/ar4-wg1.htm, last accessed 5/15/14.

Klöpffer, Walter, 1997 "In defense of the cumulative energy demand." The International Journal of Life Cycle Assessment 2.2: p. 61.

United States Congress, Office of Technology Assessment (OTA). 1992. Green products by design: Choices for a cleaner environment. Office of Technology Assessment, 1992.

Fiksel, Joseph R. 1996, Design for environment: creating eco-efficient products and processes. New York: McGraw-Hill.

Subramanian, Vairavan, et al. 2012, "Comparing product category rules from different programs: learned outcomes towards global alignment." The International Journal of Life Cycle Assessment 17.7: 892-903.

Feng, Shaw C., and Che B. Joung. 2009, "An overview of a proposed measurement infrastructure for sustainable manufacturing." Proceedings of the 7th Global Conference on Sustainable Manufacturing.

Feng, Shaw C., C. Joung, and Gang Li. 2010, "Development overview of sustainable manufacturing metrics." Proceedings of the 17th CIRP international conference on life cycle engineering. 
Joung, Che B., et al., 2013, "Categorization of indicators for sustainable manufacturing." Ecological Indicators 24: 148-157.

Finkbeiner, Matthias. "Carbon footprinting_opportunities and threats." The International Journal of Life Cycle Assessment 14.2 (2009): 91-94.

Kauffmann, Céline, Cristina Tébar Less, and Dorothee Teichmann. Corporate greenhouse gas emission reporting: A stocktaking of government schemes. No. 2012/1. OECD Publishing, 2012. 
[This page is internationally left blank] 
Pyke, Christopher R., and Maija Krizmane, US Green Building Council

\title{
Challenges and Opportunities Integrating Measures of Energy and Human Performance for Residential and Commercial Buildings
}

\begin{abstract}
Green building represents a coordinated series of market interventions to define, promote, and recognize aspects of building performance that benefit people and the environment. Over the last two decades, the movement has transformed the building industry by changing expectations and practice around energy efficiency, water conservation, materials selection, and other issues. As part of this transformation, the green building movement has contributed to and benefited from a relatively rich set of measures for energy performance. Moving forward, many stakeholders are increasingly interested in expanding measures of performance to explicitly incorporate dimensions human performance [1]. This perspective is motivated by growing demand for integrative performance measures and rapidly emerging technologies to quantify and compare relevant aspects of human performance at unprecedented spatial and temporal scales. As new metrics and quantification strategies emerge, they have the potential to underpin a new era of performance-based green building market transformation.
\end{abstract}

\section{Keywords}

Green building, energy performance, human performance, health, wellness, experience, interoperability

\section{Background}

Green building represents a broad-based movement to create places that benefit people and the environment. This movement is premised on the observation that the building sector faces pervasive market failures due to the lack of relevant, actionable information on many important dimensions of building performance. The lack of information creates information asymmetries and compromises the ability of the market to effectively assess risk and allocate resources.

Over the last twenty years, the green building movement has created a variety of tools to fill this information gap and promote more efficient market functioning, including recognition and differentiation of superior performance. These tools include green building rating systems and building certification. Green building rating systems represent a technical language to define the characteristics of superior buildings. These languages typically consist of required and optional elements, each associated with specific intents, metrics, and documentation requirements. This language allows rating system developers to articulate different levels of market outperformance and communicate clearly with trained practitioners. Certification processes evaluate the attributes and performance of individual buildings against these criteria. When criteria are met, buildings receive recognition that helps communication their status to stakeholders, such as potential tenants or investors. Taken together, the combination of rating systems and certification addresses information asymmetries and allows markets to identify superior performers. 


\section{Prevailing Performance Metrics}

The concept of "performance" is central to the design and operation of green building rating systems. The goal is typically to create market interventions (e.g., rating systems, credits, training, etc.) that shift "performance" from a business-as-usual condition toward a superior level of achievement.

For many stakeholders, the concept of building "performance" is associated with strong emotional connections (e.g., "demanding performance), but surprisingly opaque definitions (e.g., what level of which measure or metric over what time frame constitutes "performance"). For many, "performance" is intuitively associated with the notion of energy efficiency and, most often, operational energy consumption. Consequently, it is useful to begin this discussion by reviewing widely used efforts to define "performance" in specific, actionable terms (Table 1). For the sake of illustration, we will consider definitions and measured in different versions of the US Green Building Council's Leadership in Energy and Environmental Design (LEED®) rating systems.

LEED rating systems are differentiated for major stages in the design, construction, and operational lifecycle of buildings, including LEED for New Construction (LEED-NC), LEED for Commercial Interior Design and Construction (LEED-IDC) and LEED for Existing Buildings Operations and Maintenance (LEED-EBOM). LEED-NC is intended create points of intervention during the planning, design, and construction process. Consequently, LEED-NC evaluates energy efficiency with respect to a baseline building compliant with increasingly stringent requirements of ASHRAE 90.1 (or Title 24 in California). Performance is evaluated based on simulation to estimate the percentage reduction in operating cost.

LEED-IDC addresses the fit-out of interior spaces, often associated with a core and shell construction or renovation. In these circumstances, the building location and envelope are already established, and performance is evaluated with respect to interventions around HVAC system performance, lighting power, and specifications for equipment and appliances. Common performance metrics such as lighting power density.

LEED-EB focuses on operational energy use. LEED-EB typically references the ENERGY STAR benchmark, and, in LEED version 4, ENERGY STAR and LEED-EB both require a minimum benchmark score of 75 for certification. The ENERGY STAR benchmark is based on a statistical regression that estimates the rank of an individual asset relative to a representation of the US building stock. A score of 100 means that an asset is in the Top 1\% of less of the US stock, while a score of 50 indicates average performance. ENERGY STAR scores are based on annual whole building energy use normalized for a variety of factors including weather, schedule, and space utilization.

Public communications about commercial space are often simplified further to derivative measures such as "Energy Use Intensity" (typically kbtu per square foot), often described as a measure of "energy efficiency". This is the prevailing performance metric in real estate energy benchmarking (e.g., New York City's Local Law 84) and municipal labeling programs (e.g., Arlington County, Virginia). 
It is interesting to consider these definitions of "performance" in light of the actual functional goals of energy use in buildings. Simplistically, these measures take the form of metrics such as:

Building Energy Use (per second, minute, year, etc.) / Work (floorspace)

Source Energy Consumption (kBtu) / square foot (Gross Leasable Area)

The denominator - the normalization factor - is typically conditioned space, although variants like Gross Floor Area, Gross Internal Area, or Net Internal Area are often used interchangeably. The numerator is often some variant of whole building energy consumption over some time period (e.g., seconds, minutes, years, etc.) as site or source energy (e.g., with or without consideration for generation, transmission, and distribution losses). These kinds of metrics have the quality that they reach a minimum at either an unconditioned, dark, empty space or an exceptionally efficient, self-generating facility. Conversely, they reach a maximum at an intensely utilized space or an intensely inefficient space. In isolation, these measures do not allow these cases to be separated without additional information. So, while are often touted as simple measures of "performance" their interpretation can be challenging and potentially impossible.

Moreover, it is interesting to consider the implicit definition of "efficiency" underlying these measures of performance. Generally, efficiency is a measure of productivity or output per unit energy. For example, widgets produced per unit energy required on an assembly line. In the case of buildings, providing space conditioning, lighting, and support for ancillary loads for a unit of floor space is considered output. This is a practical definition, but it is not necessarily consistent with the actual function of built space. Alternatively, we could consider output (the numerator) as a level of service or experience provided to an occupant or some function of the health, productivity, comfort, or satisfaction of the occupants that are being served by the energy (e.g., to provide conditioning, light, computers, etc.).[2,3] In other words, current "energy efficiency" metrics do not control for account for the actual work being done for a given level of service. In an industrial setting, this might be comparable to measuring the energy used to run a machine for a certain number of hours per day without regard to the output from the machine.

Of course, today's prevailing measures of energy efficiency in buildings reflects the practical challenges of creating comparable, actionable information based on relatively limited information. In many cases, we are lucky to know whole building energy consumption and have, at best, some idea of the size of the building. Measures of actual work done (e.g., interpretations of human performance in buildings) have typically been impossible to predict or collect. Consequently, rating systems and public disclosure schemes have typically the concept of building "performance" to discussions of energy performance and used a patchwork of prescriptive measures to communicate achievements related to human performance (Table 2). The industry has yet to broadly adopt practical ways to integrate human and energy performance. 
Table 1. An Illustrative List of Energy Performance Measures Building Phases and Associated LEED Rating Systems

\begin{tabular}{|c|c|c|c|c|}
\hline Intent & $\begin{array}{c}\text { Building } \\
\text { Phase }\end{array}$ & $\begin{array}{c}\text { LEED } \\
\text { Rating System }\end{array}$ & Assessment Method & $\begin{array}{l}\text { Performance } \\
\text { Measures }\end{array}$ \\
\hline $\begin{array}{l}\text { Energy } \\
\text { Performance }\end{array}$ & $\begin{array}{l}\text { New } \\
\text { Construction }\end{array}$ & $\mathrm{NC}$ & ASHRAE 90.1 & $\begin{array}{l}\text { Operating cost } \\
\text { reduction ( } \% \\
\text { savings) }\end{array}$ \\
\hline $\begin{array}{l}\text { Energy } \\
\text { Performance }\end{array}$ & $\begin{array}{l}\text { Existing } \\
\text { Building }\end{array}$ & EBOM & EPA ENERGY STAR & $\begin{array}{l}\text { Relative ranking } \\
\text { (ENERGY } \\
\text { STAR score) }\end{array}$ \\
\hline Lighting & Interior fit-out & IDC & ASHRAE 90.1 & $\begin{array}{l}\text { Lighting power } \\
\text { density (watts) }\end{array}$ \\
\hline HVAC & Interior fit-out & IDC & ASHRAE 90.1 and 62.1 & $\begin{array}{l}\text { Operating cost } \\
\text { reduction ( } \% \\
\text { savings) }\end{array}$ \\
\hline $\begin{array}{l}\text { Equipment and } \\
\text { Appliances }\end{array}$ & Interior fit-out & IDC & EPA ENERGY STAR & $\begin{array}{l}\text { Fraction } \\
\text { ENERGY STAR } \\
\text { rated }\end{array}$ \\
\hline $\begin{array}{l}\text { Energy } \\
\text { Performance }\end{array}$ & $\begin{array}{l}\text { New } \\
\text { Construction }\end{array}$ & HOMES & $\begin{array}{l}\text { Home Energy Standards } \\
\text { (HERS) and International } \\
\text { Energy Conservation Code } \\
\text { (IECC) } 2004\end{array}$ & $\begin{array}{l}\text { Relative ranking } \\
\text { (ENERGY } \\
\text { STAR score) }\end{array}$ \\
\hline $\begin{array}{l}\text { Energy } \\
\text { Performance }\end{array}$ & $\begin{array}{l}\text { New } \\
\text { Construction }\end{array}$ & MIDRISE & ASHRAE 90.1 & $\begin{array}{l}\text { Operating cost } \\
\text { reduction (\% } \\
\text { savings) }\end{array}$ \\
\hline
\end{tabular}

Table 2. An Illustrative List of Prescriptive Actions and Measures of Human Performance across Building Phases and Associated LEED Rating Systems Intent

Building

Phase

$\begin{array}{lll}\text { Acoustics } & \begin{array}{l}\text { New } \\ \text { Construction }\end{array} & \text { NC } \\ \text { Thermal Comfort } & \begin{array}{l}\text { New } \\ \text { Construction }\end{array} & \text { NC } \\ \text { Physical Activity } & \begin{array}{l}\text { New } \\ \text { Construction }\end{array} & \text { NC } \\ \text { Indoor Air Quality } & \begin{array}{l}\text { New } \\ \text { Construction }\end{array} & \text { NC } \\ \text { Psychological } & \begin{array}{l}\text { New } \\ \text { Construction }\end{array} & \text { NC } \\ \text { Occupant } & \begin{array}{l}\text { Existing } \\ \text { Building }\end{array} & \text { EBOM } \\ \text { satisfaction } & & \end{array}$

Prescriptive Actions

Rating

System

Meet the requirements of corresponding

standard depending on space type, e.g.

ANSI S 12.60

Meet ASHRAE 55 criteria in heating, Survey

ventilation, air conditioning and building envelope design

Site assessment, distance to amenities, Survey number of bike racks

Air intake according to standard, elimination of pollutants

Percentage of areas with direct outdoor views and view assessment, social interaction areas CBES Occupant IEQ survey
Operational Performance Measures Noise level (dBA)

Air quality (CO2), ventilation rate (CFM)

Survey

Survey 


\section{Integrating Human and Environmental Performance}

Looking forward, we can begin to see the need and opportunity for change in the understanding of human and environmental performance. This opportunity is rooted in the recognition of significant the limitations of prevailing energy performance metrics, demand for more relevant, integrative measures, and changes in technology and analytics that will enable more robust and representative measures of performance in and around buildings.

As we have discussed, prevailing energy performance metrics represent a limited concept of performance. They stop short of measuring performance of the actual design function of most buildings (e.g., enabling human performance) and default to a practical, but limited concept of the provision of space. We have also shown that widely used metrics, such as energy use intensity, have the unfortunately characteristic of being unable to separate empty space from highly efficient space.

As recognition of these limitations becomes more widespread, we see growing demand for information on the quality of human experiences in built environments. In other words, many stakeholders want to understand the quality of the services and functions provided by buildings for people in terms other than simply the quantity of conditioned space [4,5]. These stakeholders fully recognize the roots of green building in energy efficiency and other dimension of environmental performance. However, they envision that uses more robust and integrative measures of energy efficiency that more fully reflect the quality of space and its implications for health, wellness, and occupant experience.

Fortunately, rapid changes in information technology are creating the conditions necessary to move beyond today's metrics and create fundamentally new mechanisms to address both energy and human performance over more compatible spatial and temporal scales. Perhaps surprisingly, we can envision many scenarios where the quantity and quality of information on human performance and experience in buildings quickly come to rival and then dwarf energy information. Given the proliferation of enabling technology, this transition could happen quite quickly in certain space types, such as healthcare, high quality office, and schools. The explosion of human performance data will gradually allow the availability of performance data to more closely match the ratio of cost and value associated with most built environments, e.g., human occupants typically drive $95 \%$ of operational costs and value creation. Figure 1 illustrates the relative volume of available data on energy and human performance for typical commercial buildings in the United States. The trajectory of the lines illustrates a potential scenario where the volume of data on human performance eventually dramatically exceeds energy data. The pie chart inset illustrates the typical ratio of human to operational energy costs for commercial office buildings. 


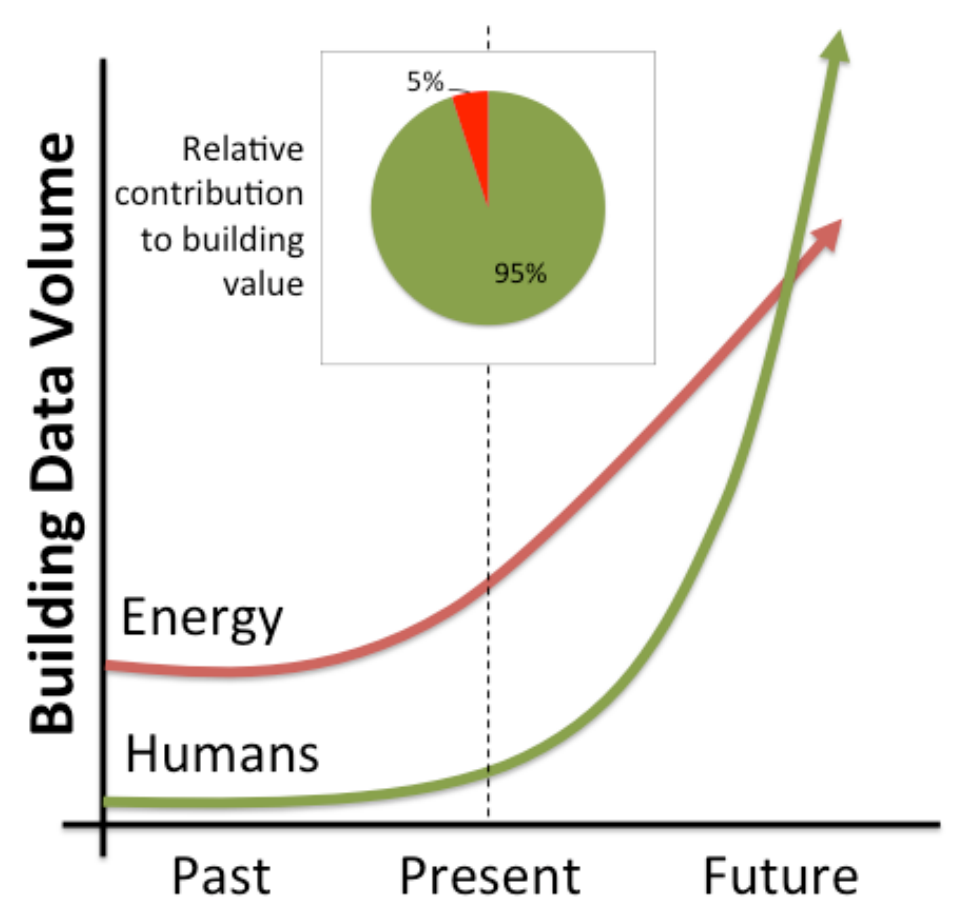

Figure 1. Schematic Illustration of the Relative Volume of Available Data on Energy and Human Performance for Typical Commercial Buildings in the United States

\section{Emerging Measures of Human Performance}

Historically, measures of human performance are often considered qualitative or, at a minimum, less concrete than measures of energy performance. Measures of human performance are rarely explicitly linked to measures of energy performance or the attributes of associated built environments. However, there are clear limitations to this artificial separation and new technology is rapidly emerging to provide direct empirical information on human performance in and around built environments. Over the next several years, we will see a revolution in the scope and quality of analytics available to quantify and interpret human responses. In the following sections, we will consider several emerging approaches to the measure and evaluation of human performance in and around buildings.

\subsection{Location}

Unlike other aspects of buildings, humans move, and, historically, it has been difficult to quantify presence or integrate exposures to different built environments. Consequently, the ability to locate occupants and trace their association with buildings over range of spatial and temporal scales is a prerequisite for performance evaluation. Technologies are rapidly emerging to provide unprecedented spatial and temporal referencing within and between spaces, buildings, and public realms. Two of the most promising technologies include aggregated cellular data and indoor location based services.

Aggregated cellular data uses passively collected information from wireless networks to characterize broad patterns of population distribution and mobility patterns around specific locations [6Error! Reference source not found.]. This technology has recently been applied to haracterize and compare site-specific patterns of occupant commuting [3Error! Reference 
source not found.]. Aggregated cellular data does not require active interaction with individuals. Rather, information from millions of mobile devices is analyzed to understand the flows of devices to, from, and through individual locations, typically 100-meter or 1-kilometer grid cells. This technology has the decisive advantage that maps of mobility patterns can be generated for all locations within a given domain for the same period of time. This allows for the comparison of actual mobility patterns between sites and over time. This technology creates the potential to replace "form-" or "location"-based measures of occupant mobility with direct, empirical observations.

Advances in the application of cellular data at regional scales are complemented by the explosive growth of indoor location based services to generate spatially and temporally specific data inside buildings. Today, technologies allow rapid detection and spatial location of individuals and occupant populations from wireless Internet, Radio Frequency Identification, Near Field Communications, Blue Tooth, among many other technologies. These technologies provide information on the use of space by populations and, in some cases, individuals. These technologies can overlap with cellular-based strategies to characterize occupant behavior and space utilization adjacent to buildings, in areas such as public plazas, streets, or parking lots.

Taken together, these technologies provide the foundational infrastructure needed to provide spatial and temporal reference frames for data on individual- and population-level performance.

\subsection{Experiential Performance}

Human experience is a dimension of building performance. We understand that the design, construction, and operation of buildings can directly contribute to human experiences, such as satisfaction, comfort, fear, anxiety, disorientation, or happiness [7]. Until recently, these dimensions have been considered qualitative domains or, at best, co-benefits of energy-efficient design strategies (e.g., daylighting). However, the Internet and "web analytics" have provided a wide array of robust, mature tools to characterize human perceptions and satisfaction. In fact, these tools underlie all of the most successful Internet platforms, such as Google, Facebook, Yelp, and Amazon. For example, Google's Page Rank system is directly informed by the notion of the "long click", an assessment of the relative quality of individual search results for individual users. Google collects billions of observations of link quality in response to different queries and uses this information to improve search experiences. Facebook allows hundreds of millions of users to "Like" content, effectively tagging and, collectively, ranking preferences. Yelp allows millions of users to share experiences about previous intangible aspects of quality or service. Amazon constantly conducts online experiments, exposing users to variations of webpages and tracking changes in behavior. In effect, these platforms represent a global system to quantify, analyze, and act on human preference.

With this context, it becomes conspicuous and perhaps surprising that we lack any equivalent analytic infrastructure to understand and improve experiences in built environments. As an industry, we operate in a pre-Internet era of long, slow, disconnected cycles between user experience and feedback. The ability to locate and interact with users in built environments changes this situation and creates the potential for Internet-style analytics on occupant experiences in real world spaces. 


\subsection{Health Performance}

Information available from individuals and populations goes far beyond experiences and preferences. Increasingly we see the emergence of the concept of health information collected outside of healthcare settings [8]. Foundational health information is now routinely collected by millions of individual. A recent study by the Pew Center found that approximately $80 \%$ of US adults engaged in some kind of formal or informal tracking behavior. Body trackers like Nike+ or Fitbit routinely provide detailed information on physical activity and mobility. New technologies are emerging to continuously monitor many additional performance dimensions, including respiration rate, posture, heart function, and stress.

When coupled with increasingly detailed information on location, these self-tracking tools create the ability to explore all manner of connections between design, construction, and operation and specific health endpoints among individuals and populations. These explorations may initially take the form of research studies, but many of the basic tools are embedded in consumer electronics. This creates a growing opportunity to operationalize human performance data collection through Citizen Science, gamification, or incentivized populations.

These emerging data could be used to consider fundamental relationships between building performance dimensions, such as the role of lighting energy use and stress or heating cost on occupant thermal comfort. Today, these relationships are understood from idiosyncratic laboratory studies and various aggregations of technical literature. In the future, the health dimensions of occupant performance are like to become as accessible as a building's utility meter. Of course, these data will come will significantly more concern regarding privacy and related issues.

\subsection{Economic Performance}

As a final example, we also have emerging opportunities to consider the economic dimensions of building performance. Traditional measures of energy efficiency consider economic output per unit energy. As we have discussed, the building industry uses a convolution of this concept in measures such as "energy use intensity". Recent research has demonstrated the potential to combine diverse datasets to create new measures of economic productivity as a function of operational energy use. One example is the Building Economic Intensity Index [9]. The BEII combines information from multiple sources to look at occupant wages in commercial buildings subject to energy use disclosure under New York City's Local Law 84. The BEII is a metric that quantifies a building's relative contribution to the [regional] economy based on the mix of tenants it houses. Higher BEII scores are associated with relatively greater economic contributions, as measured by the relative wages of the space occupants.

BEII illustrates one or many innovative approaches to representing and comparing the economic output from different types of buildings. It demonstrates the potential to provide richer and more nuanced interpretations of energy performance data with the consideration of economic performance.

\section{Conclusions}

Traditional measures and metrics of energy use for residential and commercial buildings provide a practical, but limited frame to understand performance. Moving forward, there is a fundamental need to expand the concept of performance to address multiple dimensions of 
human performance. This is not necessarily a novel observation; however, the rapid emergence of new technologies creates unprecedented opportunities for innovation in performance

measurement and evaluation. Addressing these issues will challenge the scientific and technical community to create, interpret, and operationalize a new generation of synthetic measures and metrics of building performance to support the next generation of green building market transformation.

\section{References}

1. Altomonte, S., Schiavon, S. 2013. Occupant satisfaction in LEED and non-LEED certified buildings. Building and Environment. October 2013, pages: 66-76

2. Kim, J., de Dear, R. 2013. Workspace satisfaction: The privacy-communication trade-off in open-plan offices. Journal of Environental Psychology, December 2013, pages: 18-26

3. Pyke, C.R., L. Schewel, R. Zhang. 2014. Performance-based measures of office commuting: Potential applications of aggregated, anonymous cellular data. Insight Technical Report. GBIG IR 14-03, 20 pages, URL: http://www.usgbc.org/sites/default/files/GBIG.Accessibility\%20Metrics_2014-03-24.pdf

4. Baumgartner, S., J. Coleman, A. Aboff. 2013. Linking NYC Energy Database to Tenant Contribution to Economy. Greenbuild 2013, 7 pages.

5. Gou, ZH., Lau, SSY., Shen, J. 2012. Indoor Environmental Satisfaction in Two LEED Offices and its Implications in Green Interior Design. Indoor and Build Environment, August 2012, pages: 502-514

6. Gopal, A., L. Schewel, S. Saxena, A. Phadke., 2013. The Transport Leapfront: Using Smart Phones to Collect Driving Data and Model Fuel Economy in India. Environmental Energy

Technologies Division, Lawrence Berkeley National Laboratory, May 2013, 12 pages, URL: http://eande.lbl.gov/sites/all/files/lbnl-6293e_pdf.pdf.

7. Todorovic, M.S.; Kim, J.T. 2012 Buildings energy sustainability and health research via interdisciplinarity and harmony. Energy and Buildings, April 2012, pages: 12-18

8. Stevens, R., Brown, B. 2011. Walkable new urban LEED_Neighborhood-Development (LEED-ND) community design and children's physical activity: selection, environmental, or catalyst effects? International Journal of Behavioral Nutrition and Physical Activity. December 2011, article number: 139

9. Baumgartner, S. 2013. Beyond EUI: Linking energy and economy in buildings. GBIG Insight. November 6, 2013, URL: http//insight.gbig.org/beyond-eui-linking-energy-andeconomy-in-build ings/

\section{Acknowledgements}

The authors appreciate conversations with Dr. Matthew Trowbridge and Steven Baumgartner with helping to inform and shape our thinking on these issues. 
[This page is internationally left blank] 


\title{
Ratterman, David B., American Institute of Steel Construction ${ }^{\mathbf{1 0}}$
}

\section{Sustainability, Society, and the Law As Applied to the Built Environment}

\begin{abstract}
American construction lawyers need help from American engineers and scientists. Lawyers who draft construction contracts and building code provisions need additional research assistance from the engineering and scientific communities to test and, where necessary, augment existing sustainability standards for the built environment. Sustainability standards developed for the built environment must bear a direct relationship to the actual value that sustainable design and construction of the built environment can provide to society and the economy. Such standards must be practical and measurable if they are to be legally enforceable. The legal consequences of attempted enforcement of ill-conceived standards to those who design, construct, and own elements of the built environment can be significant. Continuing, focused research and collaboration between the engineering and legal professions is needed to optimize application of sustainability theory to the design profession, construction industry, and general public.
\end{abstract}

\section{Keywords}

Contracts, building codes, measurable standards, enforceability, sustainability, built environment

\section{Background}

Sustainability in the design, construction, and occupancy of the built environment has evolved from the realm of engineering theory into the hard world of economic and societal reality. This evolution has come with economic and social consequences, not the least of which has been the exposure of the theory of sustainability in the built environment to the harsh light of the American legal system.

The positive consequence of this evolution has been that application of the principles of sustainability to the built environment is now seen as providing environmental value to the earth and society and economic value to building owners and occupants. As is the way in American culture, where value exists, the legal system is almost always engaged in an attempt to define and preserve any ownership rights involved; and therein, as the saying goes, is the rub!

The world of courts and commercial contracts works best when it deals in the finite, the tangible, the measured. If something of value, in this case the value of sustainability in the built environment, is to be bartered, bought, sold, leased, pledged, and enforced, it must be capable of being accurately and objectively measured. And the parameters that are being measured must bear a clear relationship to the perceived value being bought, sold, bartered, leased, pledged, or enforced.

Most engineering and scientific disciplines that are applied to the design, construction, and occupancy of the built environment utilize metrics that are straightforward, well-defined and

\footnotetext{
${ }^{10}$ The views expressed in this paper are the authors and not those of his law firm, the American College of Construction Lawyers, or the American Institute of Steel Construction.
} 
developed through a recognized consensus process involving all disciplines and interest groups involved. In the world of sustainable building design, construction, and occupancy, the metrics, and the means of measuring those metrics, are not always so well developed and defined.

There is concern that lack of effective, consensus metrics may be inhibiting the application of the science of sustainability to the built environment and the consequent advancement of the public welfare and economic value of sustainability to society.

Normally science precedes the law; but not in this instance. In this instance the law has leaped ahead of science in an effort to satiate our culture's current hunger for all things sustainable.

The legal profession is awash with attempts of varying degrees of effectiveness to legally quantify and enforce that which the legal profession scarcely understands and with which it is often ill-equipped to deal. The legal profession is in need of leadership from and collaboration with the practitioners of science and engineering.

\section{The Issue}

Heightened concerns over damage to the environment, danger to living organisms (most particularly human beings), global warming, fear of scarcity of consumable energy, and scarcity of other natural resources has given rise to a zeal for sustainability. This zeal is often expressed in terms of social responsibility, patriotism, economic necessity, and moral imperative. This zeal has been transformed into a desire by society to apply the concept of sustainability to nearly every facet of our lives. In some instances application of the vocabulary of sustainability to commercial transactions could be considered little more than window dressing. ${ }^{11}$

The societal value of sustainability to public welfare in the built environment is preserved by a system of laws, regulations, and building codes. The economic value of sustainability to the built environment is preserved by a system of contracts, deeds, and zoning laws.

Interest among the general public in all things sustainable has created a forced-emersion of all things sustainable in the built environment into these two systems - the system of laws and regulations and the system of contracts. This, in turn, has spawned at least three separate sets of standard form "green" construction contract documents, at least four separate "green" construction codes, and at last count twenty-eight (28) agencies, public and private, that certify, require, or "encourage" sustainability in the built environment.

Some public agencies, and some construction owners, require posting of "green" performance bonds to assure compliance with "green" code and contract requirements. ${ }^{12}$ In other instances substantial incentives are provided by taxing authorities for successful compliance with "green" code requirements. In at least one instance, tax free "green" investment bonds were issued to

\footnotetext{
${ }^{11}$ Pardon the author's skepticism when checking into a hotel room and being as ked if he would prefer the "green option." Upon inquiry, the "green option" is revealed to often mean no maid service.

12 These bonds, of course, come at a price to the bond obligee and with potentially significant consequences to the bond issuer if the bonded "green" project fails to reach the bonded "green" performance goal. The potential challenges to a bond is suer in covering the performance failures of a defaulting bond principal are significant, and well beyond the scope of this paper.
} 
assist in financing a "green" construction project ${ }^{13}$ The results of at least one credible research project indicate that commercial properties that achieve "green" certification status can expect higher rental income and sales values. ${ }^{14}$

So in addition to social responsibility, patriotism, and moral imperative driving sustainability in the built environment, there is now a significant, potential economic reward driving the process as well. This pushes the process further into the legal arena. And, as lawyers are wont to do, we lawyers must now ask, "what are the legal consequences for failure to realize the "green" code requirements and economic rewards that are attached to the design, construction, and operation of the built environment?"

Potential liability for failure to meet "green" design and construction obligations could include assessment of damages ranging from the increased cost of compliance, to diminution in value of the facility, to lost rent and tax incentives, to reimbursement of the project owner's attorney fees. Claims and litigation to date of which the author is aware include suits involving allegedly deficient "green" materials, ${ }^{15}$ allegedly deficient post-construction energy performance, ${ }^{16}$ and alleged failure to achieve an anticipated level of "green" certification. ${ }^{17}$

The process of "green" certification raises an entirely separate set of issues of concern to those who question the relevance of some standards' criteria to the overall values to society and the economy of sustainability in the built environment. That is, do current codes, standards, and contract requirements actually reflect that which is of real and optimum value to society and the economy?

If there is, in fact, a disconnect between that which is required and that which is actually of value, it is not difficult to imagine a situation in which, say, a building's mechanical system is cutting edge, its energy use reduced, and its occupants healthier, but perhaps because it is being judged by a standard that might not accurately measure these parameters, it is disallowed certified status, its owner loses tax incentives and increased rental benefits, and the performance of its designer and builder are called into question and become the subject of litigation.

It is also not difficult to imagine a similar building with a less efficient mechanical system, no substantial energy savings after the building is actually occupied, and no measurable increase in the health of its occupants, that meets the standard being applied. That building receives certification; its owner receives tax benefits and increased rental income; and its designer and constructor receive the accolades of the community and promotional value in the process.

With this in mind, and without wishing to appear critical of current contract provisions and code requirements or the administrators of agencies that have undertaken "green" oversight in the built environment, it is very fair for society to ask the following question:

$13 \mathrm{http}: / /$ www.investopedia.com/articles/bonds/07/green-bonds .asp.

14 Kok, Nils, The Economics of Green Building, www.slideshare.net/nilskok/economics-of-green-building-kok .

${ }^{15}$ Chesapeake Bay Foundation, Inc., et al. v. Weyerhaeuser Co., No. 8:2011cvoo47 (Md. Dist. Ct. Jan. 6, 2011)

${ }^{16}$ Gidumal v. Site 16/17 Development, LLC, No. 105958/10 (N.Y. Sup. Ct. filed May 6, 2010).

17 Southern Builders, Inc. v. Shaw Development, LLC, No. 19-C-07-01145 (Circuit Court of Somerset County, Md., 2006). 
Just how effectively have current codes, agencies and contract provisions advanced the sustainability goals that are of the most significant health and environmental value to society and of the most significant economic value to building owners and occupants?

The author submits that enough concerns have been raised within the design and construction communities to suggest that additional engineering and scientific research in this area is warranted. Whether these concerns are well-founded or not; it is impossible to dismiss them as unfounded without scientific confirmation of the current standards and metrics and their relevance to society's sustainability goals and values. If the standards are not directly relevant to society's goals and values, then the legal process of enforcing compliance is essentially meaningless.

\section{Questions Concerning Current Sustainability Codes, Standards, Contract Terms, and Certification Agencies Operating in the Built Environment}

It is not the purpose of this paper to either present a comprehensive analysis of all questions that have been raised over current application of the science of sustainability to design and construction of the built environment, or to provide any judgment on the accuracy or viability of any of the questions raised. However, it is helpful to list, in very general terms and without judgment one way or the other, some of the questions and concerns that have been raised in the design profession and construction industry. For example:

1. As a threshold question, should sustainability of the built environment be judged by:

a. Prescriptive regulation of the elements incorporated into the design and construction process; or

b. The actual performance of the built environment after design and construction are complete, including, where applicable, the full, potential life cycle uses of the built environment; or

c. Some combination of the two? ${ }^{18},{ }^{19}$

2. As a second threshold question, (this a public policy question and not an engineering or scientific question) should sustainability standards be developed by:

a. Public agencies, in the manner of internationally-developed but locally adopted building codes; or

b. Balanced consortiums of stakeholders and the public in the nature of the American National Standards Institute (ANSI) process; or

c. "For profit" research organizations or academic institutions?

\footnotetext{
18 On March 15, 2014, the National Institute of Building Sciences released for public review and submitted as a proposed code change to the International Green Construction Code (IgCC) what it described as an "OutcomeBased Pathway" to address a number of challenges facing the building industry. This approach had been highlighted by the Institute's Consultative Council in its 2010 Moving Forward report submitted to the President of the United States:

"The building community needs a better baseline of actual building performance against which to measure progress. More importantly, the application and use of prescriptive criteria must be eliminated in favor of stated performance goals or expected outcomes (although, after setting those goals or outcomes, prescriptive guidance to achieve them can be developed)."

Moving Forward: findings and Recommendations from the Consultative Council. National institute of Building Sciences 2010 Annual Report to the President of the United States, 2010. 43-49.

${ }^{19}$ Significantly, LEED V4 requires projects to submit post-occupancy energy consumption data to confirm actual performance versus projected performance submitted with the project's LEED certification application.
} 
3. As a third threshold question, is there a hierarchy of sustainability goals that should be taken into consideration when regulating design and construction of the built environment? For example:

a. Does a significant decrease in global warming emissions offset the potential danger caused by an increase in land or resource consumption; and

b. Must all potential impacts on the natural environment be balanced in regulating the built environment; or is it legally and scientifically acceptable to treat potential impacts separately?

4. Where it is appropriate to utilize prescriptive regulation of the design and construction process, how does the entity tasked with establishing the prescriptive regulations involved ensure consistency in the manner in which all elements of the design and construction process are evaluated and rated for application in the built environment?

5. Where it is appropriate to utilize prescriptive regulation of the design and construction process, has the entity undertaking development of the prescriptive regulations fully and consistently evaluated the entire supply chain and the entire life cycle of all elements of the design and construction process and the completed structure itself?

6. Where it is appropriate to utilize prescriptive regulation of the design and construction process, should the entity undertaking development of the prescriptive regulations consider the elements of sustainability in absolute terms or in terms of relative improvement compared with past content or performance?

7. Should there be any effort to balance the sustainability metrics of the design and construction process with the economic cost of that process to the project's designer/developer/owner/occupant; recognizing what one author has described as "the iron law of climate policy?" 20

\section{Assessment of Societal and Economic Values and Research Needs}

Any evaluation of the seven question areas set out above, including research spawned by those questions, should initially be focused on those factors that most nearly represent the societal and economic value of sustainable design, construction, and occupancy of the built environment. It is submitted that the following comprise a logical starting point for such evaluation:

1. What materials, systems, and building environments pose the least health risks to building occupants and the surrounding community while optimizing the long term health benefits to building occupants and the surrounding community?

2. What materials, systems, and building environments provide the least life-cycle drain on natural resources during their operational lives?

3. What materials, systems, building environments and supply chain sources expend the least overall resources and create the least environmental impact when incorporated into the construction process?

4. How can the three foregoing areas of evaluation be optimized over the entire, expected life cycle of a structure in a manner that will also optimizes the economic viability of the structure's construction and operation?

\footnotetext{
${ }^{20}$ Pielke, Roger, Jr., The Climate Fix, Basic Books, New York, 2010. “...when [national] policies focused on economic growth confront policies focused on emissions reductions, it is economic growth that will win out every time." P 47, [parsing added].
} 


\section{Acknowledgements}

The author acknowledges with great appreciation the contributions of Stites \& Harbison, PLLC, Construction Lawyer and Civil Engineer Angela Stephens, LEED-AP, for providing advance copies of several articles on the subjects discussed in this paper that Ms. Stephens is currently preparing for publication. 
Renschler, Chris S., The State University of New York, Buffalo

\title{
The PEOPLES Resilience Framework: Integrating Quantitative Measures and Modeling for Disaster Risk Reduction and Sustainable Development
}

\begin{abstract}
The assessment of disaster risk reduction (e.g. water harvesting with flood risk reduction and increase of biodiversity through wetlands) and sustainable development and use of natural resources (e.g. increase crop yields with soil and water conservation) is currently viewed as independent issues. To better integrate both, quantitative measures for both - resilience and sustainable development - need to be accounted for the complexities across disciplinary and administrative boundaries. The so-called 'PEOPLES Resilience Framework' was developed to create partnerships and communicate pre- and post-disaster recovery of extreme events. As an example, PEOPLES can be combined with environmental, infrastructure, economic or any other quantitative model to assess future scenarios.
\end{abstract}

\section{Keywords}

Community, Infrastructure, Natural Resources, Measure, Modeling, Resilience

\section{Background}

This paper introduces a holistic methodology of a National Institute of Standards and Technology (NIST)-funded study towards a more integrated assessment: the PEOPLES Resilience Framework (Renschler et al., 2010) is a quantitative, scalable resilience framework, with the possibility to integrate process-based modeling capabilities for managing continuous use and extreme events at the watershed scale. PEOPLES is an interdisciplinary combination of prior research on community resilience focusing solely or only a few disciplines and/or a specific hazard such as Chang and Miles (2004), Chang and Shinosuka (2004), Cutter et al. (2008), Norris et al. (2008), Tierney (2009), Alesch et al. (2009). The more holistic PEOPLES Resilience Framework has the capacity to act as an umbrella-like, transdisciplinary methodology for the engineering and science community to assess, monitor, model and communicate the functionality of systems, their performance and recovery after extreme events objectively and across scale in order to systematically collect a temporally variable global reference data set based on qualitative and quantitative data sources across national, regional and other local administrative borders.

\section{Extreme Events Management Cycle}

In a disaster management cycle (response $\rightarrow$ recovery $\rightarrow$ mitigation $\rightarrow$ risk reduction $\rightarrow$ prevention $\rightarrow$ preparedness; or risk reduction $\rightarrow$ prevention) each stage requires a practical adaptation of reasonable measures based on the data and a future prediction derived from a past disaster. Without this step, the cycle of disaster management doesn't complete. Extensive and numerous categories of a future national resilience framework structure might need to be simplified to make it easier for the participants to implement such practical measures. To be able to move from the management challenge of disasters - trying to save lives - to avoiding the disaster if possible, the term Extreme Events Management Cycle is more appropriate and 
desirable as an outcome. That means, measuring the status of preparedness and being able to manage anticipated, naturally reoccurring events - even under global and/or climate change will enable the community to set benchmarks and clear goals for more resilient communities and a sustainable path for development.

In the United States, FEMA has established the National Planning Frameworks (FEMA, 2013a) that consist of four sub frameworks - National Prevention Framework, National Mitigation Framework, National Response Framework and National Disaster Framework, Recovery The National Disaster Recovery Framework (NDRF) was established 'to ensure coordination and recovery planning at all levels of government before a disaster, and defines how we will work together, following a disaster.' (FEMA, 2013b, 2013c). NDRF's Recovery Support Function consists of six functions, in which, as of September 2011, 26 U.S. government agencies are involved. FEMA's National Preparedness efforts are very extensive and require the participation of national, state, local governments and volunteers. Although the plan is thorough, it is understandable that, considering the size of the United State government and its complexity, FEMA's frameworks are hierarchical and structured as agency based. Establishing a cross agency resilience and recovery assessment is always an issue in such a large organization.

\section{Proposed Methodology: The PEOPLES Resilience Framework}

The 'PEOPLES' acronym stands for a series of seven holistic, quantitative resilience dimensions and hierarchical lead indicators that stand for the state of functionality of systems in communities: Population and Demographics, Environmental/Ecosystem Services, Organized Governmental Services, Physical Infrastructure, Lifestyle and Community Competence, Economic Development, Social-Cultural Capital (Figure 1; Renschler et al., 2010).

\subsection{Population and Demographics}

This dimension measures social vulnerability of a community. As described in Renschler et al. (2011), a measure of functionality of population and demographics Qp within a given community could be quantified by using the social vulnerability index (SoVI) proposed by Cutter et al. (2008). Social vulnerability (a counterpart of social resilience) is defined as the inability of people, organizations, and societies to withstand adverse impacts from multiple stressors to which they are exposed. These impacts are due in part to characteristics inherent in social interactions, institutions, and systems of cultural values. Social vulnerability is a preexisting condition of the community that affects the society's ability to prepare for and recover from a disruptive event. It affects and is affected by both evolutionary occurrences (e.g., slow changes in median age) and transformative events (e.g., wholesale shifts in dominant ethnicity).

\subsection{Environmental/Ecosystem}

Ecological or ecosystem resilience is typically measured by the amount of disturbance an ecosystem can absorb without drastically altering its functions, processes and structures, or by the ability of an ecosystem to cope with disturbance. This dimension measures disturbance and recovery progress (resilience when combined) of environmental or ecological systems. In the context of the PEOPLES Resilience Framework, environmental and ecosystem resources serve as indicators for measuring the ability of the ecological system to return to or near its pre-event state or a state defined by the community. A special attention needs to be paid that disturbance and resilience depend on timescale and geographical scale. For example, ecosystem services 
could include net primary production of biomass (Frazier et al, 2013), quality of air, water, and/or soil, biodiversity, or organic matter content in the soil etc.

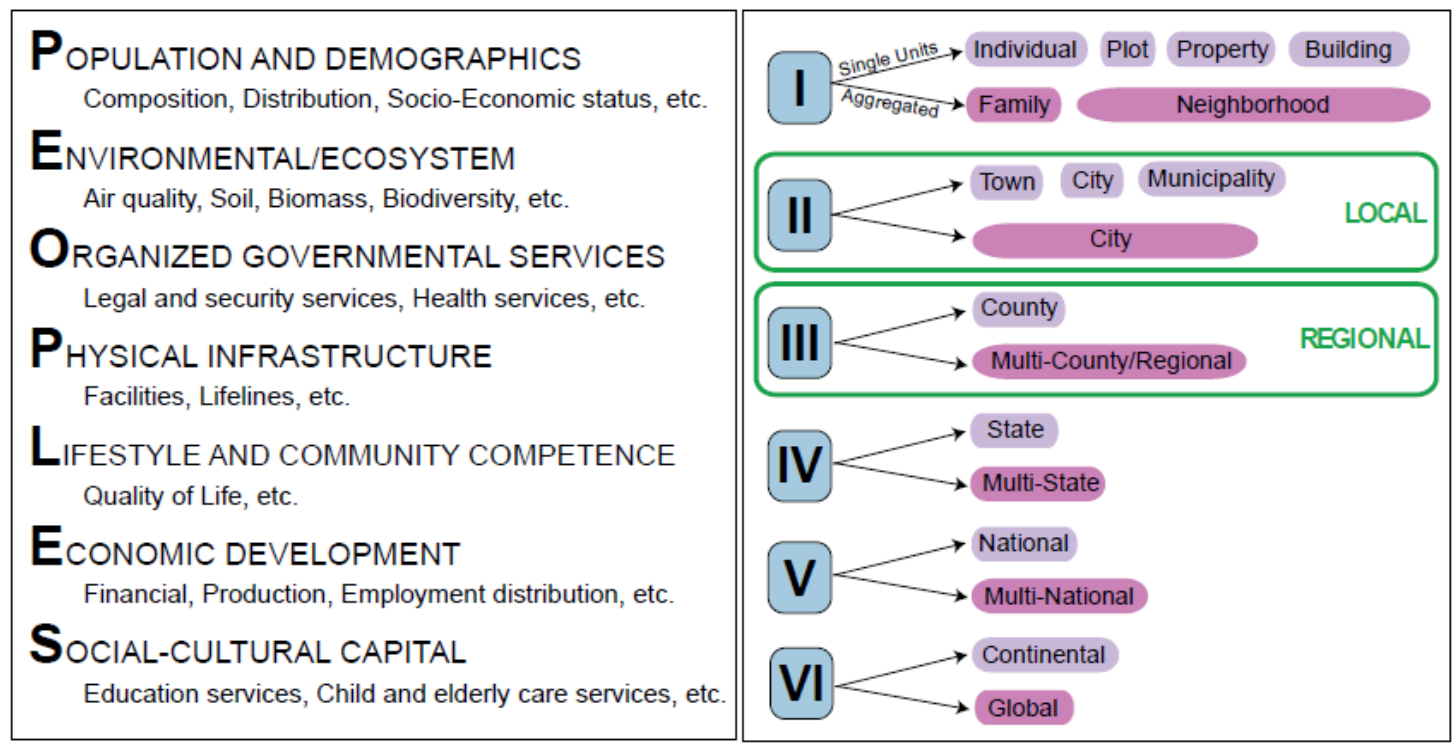

Figure 1. PEOPLES Resilience Framework description and its associated geographical scale. (For more detailed information on key indicators of PEOPLES go to http://peoplesresilience.org)

\subsection{Organized Governmental Services}

In contrast to the more or less spontaneous individual and neighborhood responses to extreme events, organized governmental services are designed to allow an orderly response (Renschler et al. 2011). Organized governmental services include traditional legal and security services such as police, emergency and fire departments and in extreme cases, the military. In this dimension, we also include the services provided by public health and hygiene departments as well as cultural heritage departments. Each of these organized government services plays a key role in sustaining communities both before and after extreme events.

\subsection{Physical Infrastructure}

The physical infrastructure dimension incorporates both facilities and lifelines. Within the category of facilities, we include housing, commercial facilities, and cultural facilities. Within the category of lifelines, we include food supply, health care, utilities, transportation, and communication networks. In terms of housing, key indicators may include proportion of housing stock not rated as substandard or hazardous and vacancy rates for rental housing (Tierney, 2009). In terms of communication networks, key indicators may include adequacy (or sufficiency) of procedures for communicating with the public and addressing the public's need for accurate information following disasters, adequacy of linkages between official and unofficial information sources, and adequacy of ties between emergency management entities and mass media serving diverse populations.

\subsection{Lifestyle and Community Competence}

This dimension measures the impact and recovery progress as a community. Community competence deals with actions and problem solving skills, flexibility and creativity, collective efficacy, empowerment, and political partnerships as a community. This dimension reflects the reality that community resilience is not simply a passive "bouncing back" to pre-disaster conditions but rather a concerted and active effort that relies on peoples' ability to creatively 
imagine a new future and then take the requisite steps to achieve that desired future. It captures both the raw abilities of the community (e.g., ability to develop multifaceted solutions to complex problems, ability to engage in meaningful political networks) and the community's perceptions of its ability to effect positive change. Communities that collectively believe that they can rebuild, restructure, and revive themselves are more likely to be persistent in the face of environmental, governmental, and other obstacles. Communities with positive experience dealing with extreme events may be more likely to possess high degrees of community competence.

\subsection{Economic Development}

This dimension measures a diverse array of products and services that are both produced in and available to the community. This dimension includes employment and financial services related to economic activities. Resilient communities are characterized by their involvement in a diverse array of products and services that are both produced in and available to the community.

Diversity in production and employment is linked to a community's ability to substitute goods and services and shift employment patterns as the situation demands. Efficient redundancy in operations and information systems enables relatively swift reopening of critical employers. The PEOPLES Resilience Framework incorporates three illustrative subcategories within this dimension: industry - production, industry - employment distribution, and financial services. Primary indicators of this dimension include the proportion of the population that is employed within the various industries, and the variability that might characterize a community's industrial employment distribution. This dimension is closely interwoven with the Population and Demographics dimension.

\subsection{Social-Cultural Capital}

Measuring social/cultural capital requires acquisition of tallies, such as the number of members belonging to various civil and community organizations. It also requires surveys of community leaders and their perceptions (e.g., quality of life surveys). Communities with high degrees of social-cultural capital create "friction to exit" for their members, encouraging people to invest in those activities and organizations that make the community a "good place to live," and encouraging people to return and reinvest in their communities after an extreme event. Disasterspecific indicators include existence of community plans targeting transportation- disadvantaged populations, adequacy of post-disaster sheltering plans, adequacy of plans for incorporating volunteers and others into official response activities, adequacy of donations management plans, and the community's plans to coordinate across diverse community networks (Tierney, 2009).

\section{Measuring Policy Impacts on Systems: Infiltration \& Wetlands vs. Harvest \& Floods}

The above-mentioned seven dimensions can be assessed independently or interdependently on fixed time intervals, on all dimensions or focusing on the interdependence of one particular dimension to others. Table 1 illustrates the use of the PEOPLES Framework dimensions and their interdependencies in a policy analysis (e.g. to promote infiltration through water harvesting and to delay of runoff through wetland creation or preservation) to reduce the risk of floods and its impacts on water management issues in the sustainable development and infrastructure investment in the Cattaraugus Creek Watershed (Boyer et al, 2013). 
Table 1. Interdependency assessment of water management issues in Cattaraugus Creek Project (' $\mathrm{x}$ ' is minor and ' $\mathrm{X}$ ' is major)

\begin{tabular}{llllllll}
\hline PEOPLES Dimensions & $\mathrm{P}$ & $\mathrm{E}$ & $\mathrm{O}$ & $\mathrm{P}$ & $\mathrm{L}$ & $\mathrm{E}$ & $\mathrm{S}$ \\
\hline Promote water harvesting/ground water recharge & & $\mathbf{X}$ & $\mathbf{X}$ & $\mathbf{X}$ & $\mathbf{x}$ & $\mathbf{X}$ & \\
Create wetland/nature reserve/impoundment & & $\mathbf{X}$ & $\mathbf{X}$ & $\mathbf{X}$ & $\mathbf{x}$ & $\mathbf{X}$ & $\mathbf{X}$ \\
Sustained crop/timber/fishing harvest yields & $\mathbf{X}$ & $\mathbf{X}$ & & $\mathbf{x}$ & & $\mathbf{X}$ & $\mathbf{X}$ \\
Design resilient bridge/culvert against runoff/flood & $\mathbf{X}$ & $\mathbf{x}$ & $\mathbf{x}$ & $\mathbf{x}$ & & $\mathbf{X}$ & $\mathbf{X}$ \\
\hline Access to shelter/food/hospital/emergency facility & $\mathbf{X}$ & $\mathbf{X}$ & $\mathbf{X}$ & $\mathbf{X}$ & $\mathbf{x}$ & $\mathbf{X}$ & $\mathbf{x}$ \\
\hline
\end{tabular}

The interdependencies can also be quantified by their relevance or weighted by their level of interdependencies with values between 1 (100\% dependent) or 0 ( $0 \%$ or independent). Using data or imagery on a fixed or non-fixed time interval, the PEOPLES data can be monitored or analyzed for each dimension (Figure 2) or modeled as overall sustainability and/or resilience.

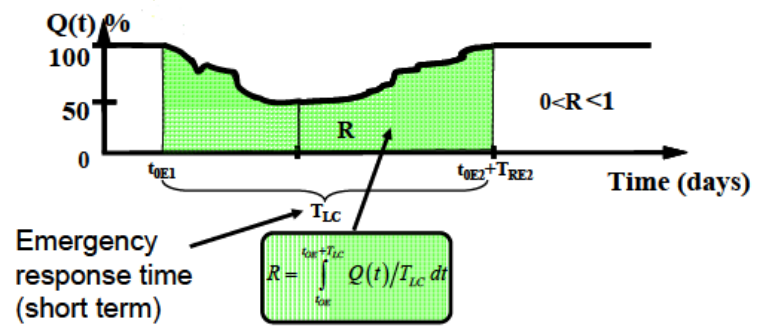

\begin{abstract}
Please note that Resilience (R) may be defined as a function indicating the capability to sustain a level of functionality or performance for a given service of an ecosystem, a building/bridge/lifeline network, an economic system, a community, etc., over a period defined as the control time TLC. The TLC is usually decided by a model planner and corresponds to the expected $100 \%$ functionality of infrastructure or a system. Resilience is defined graphically as the normalized shaded area underneath the functionality function of a system, defined as $Q(t) \cdot Q(t)$ is a non-stationary stochastic process, and each ensemble is a piecewise continuous function as shown in Figure 2 where $Q(t)$ is the functionality function of the region considered. The functionality is the combination of all
\end{abstract}

Figure 2. Quantitative Mathematical model of the PEOPLES Resilience Framework

\title{
5. Conclusions
}

The PEOPLES Resilience Framework is a performance-based management framework applicable at scales ranging from individual, local, regional and national to global. It allows monitoring at each of those scales the performances on integration of disaster reduction measures and institutionalization of recovery providing parameters and measures for the review. The standardized PEOPLES Resilience Framework with its simple structure is capable to incorporate any mathematical model describing systems including those using Geographic Information Systems (GIS) data and remote sensing images. The data format consists of the respective PEOPLES dimension, functionality and interdependency percentages at a particular time and geographical scale.

Once entered into the framework, the data can be reviewed in a tabular format or in a graph, stored, shared and analyzed, enabling:

- the sharing data among administrative entities, local/state/federal agencies, groups,

- data conversion to a tabular format, graphics (including maps and videos),

- data conversion to other measurement units (international/imperial/local),

- data for statistical and analysis (including time -space statistics and trend analysis),

- easier review and reproducibility of the analysis and/or modeling progress, and

- identifying strength/weakness of each dimension for a target region and necessary adjustment. 


\section{References}

Alesch, D. J., Arendt, L. A., and Holly, J. N. 2009. Managing for long-term recovery in the aftermath of disaster. Fairfax, VA: Public Entity Risk Institute (PERI).

Boyer, B., Carpenter, B., Renschler, C.S. and Vallone Kellam, R. 2013. Cattaraugus Creek Watershed Resource Guide and Proposed Watershed Planning Strategy. URL: http://www.lake-erie-fff.org/FILES/Cattaraugus_Creek_Watershed.pdf (Dec 30 2013)

Chang, S. E., and Miles, S. B. 2004. The dynamics of recovery: A framework. In: Modeling the spatial economic impact of disasters. Y. Okuyama and S. E. Chang. Springer, New York.

Chang, S. E., and Shinozuka, M. 2004. Measuring Improvements in the Disaster Resilience of Communities. Earthquake Spectra 20(2): 739-755.

Cutter, S.L., Barnes,L., Berry,M., Burton, C., Evans, E., Tate,E., Webb, J. 2008. A place-based model for understanding community resilience to natural disasters. Global Environmental Change 18(4):598-606.

FEMA. 2013a. National Planning Frameworks. Federal Emergency Management Agency. September 12, 2013. Web. November 27, 2013. < http//www.fema.gov/national-planningframeworks>.

FEMA. 2013b. National Disaster Recovery Framework. Federal Emergency Management Agency. September 5, 2013. Web. November 27, 2013. <http:/www.fema.gov/nationaldisaster-recovery-framework>.

FEMA. 2013c. National Disaster Recovery Framework: Strengthening Disaster Recovery for the Nation. Federal Emergency Management Agency. September 2011. Web PDF. November 27, 2013. <http://www.fema.gov/pdf/recoveryframework/ndrf.pdf >.

Frazier, A.E., Renschler, C.S., Scott B. Miles, S.B. 2013. Evaluating post-disaster ecosystem resilience using MODIS GPP data. Intl. Journal of Applied Earth Observation and Geoinformation. Vol.21:43-52.

Norris, F.H., Stevens, S.P., Pfefferbaum, B., Wyche, K.F., and Pfefferbaum, R.L. 2008. Community Resilience as a Metaphor, Theory, Set of Capacities, and Strategy for Disaster Readiness. American Journal of Community Psychology 41(1-2): 127-150.

Renschler, C.S., Fraizer A.E., Arendt, L.A., Cimellaro, G.P., Reinhorn, A.M., and Michel Bruneau, M. 2010. A Framework for Defining and Measuring Resilience at the Community Scale: The PEOPLES Resilience Framework. U.S. Department of Commerce National Institute of Standards and Technology, Office of Applied Economics Engineering Laboratory NIST GCR 10-930. Gaithersburg, MD.

Tierney, K. 2009. Disaster response: Research findings and their implications for resilience measures. CARRI Research Report 6. Oak Ridge, TN: Community and Regional Resilience Initiative (CARRI). URL: www.resilientUS.org. 2009. 
Sikdar, Subhas K., National Risk Management Research Laboratory, US EPA, and Humberto

S. Brandi, Instituto Nacional de Metrologia, Qualidade e Tecnologia, INMETRO, Xerém -

Duque de Caxias - RJ, Brazil

\title{
How to Quantify Sustainability Advancement in Construction and Manufacturing and the Needs for Standards
}

\begin{abstract}
Construction and manufacturing employ material and energy resources in refined forms and in large quantities. For sustainability, these two beneficial activities should be subject to scrutiny for upstream impacts of material and energy use intensity, for impacts from emissions and discharges during operations, and for downstream impacts of wastes generated. Quantitative accounting of these impacts requires indicators that reveal the overall sustainability footprints. There are various suggested ways of gathering required information for this objective, but the community of practice has not converged to a uniformity of approach either in choosing the required indicators or in standardized methods for analyzing the results. This article provides a critical look at the state of the art, and makes suggestions for research needed to advance our understanding of quantitative sustainability for these commercial activities.
\end{abstract}

\section{Keywords}

Indicators, metrics, sustainability assessment, metrics aggregation

\section{Introduction and Background}

Sustainability and sustainable development are two terms used in a variety of situations. A simple but useful way to distinguish the two is to recognize sustainable development as the path to the destination of sustainability. Started as a sociopolitical movement under the aegis of the World Council of Environment and Development (WCED), the concept grew out of widespread environmental degradation and unsavory industrial practice with attended health impacts. Also of concern to WCED are growing intra-general inequity between the rich and the poor, and intergenerational inequity resulting from accelerating depletion of finite natural resources by the current generation. The call to action was presented in the manifesto, Our Common Future (1987), which proposed elevating the economic, environmental, and social conditions of all by means of sustainable development. Thus the concept is essentially global in nature. First the non-governmental organizations (NGO), then industry and governments embraced the idea.

Practitioners of science and engineering have limited influence over actions that might be needed at global scale to implement sustainable development. Thus we need to recognize sustainable development at essentially four different scales (Sikdar, 2003): global where politics prevail; national or regional scale, where government policy, regulations, and jurisdictional authority are dominant; institutional scale, where regulations, science, engineering, and economics determine actions taken by industrial companies, and finally technology scale, where science and technology have a free hand in determining how technologies can be profitable, while obeying, or designing beyond, regulations. In the context of construction and manufacturing, we are primarily concerned about the fourth scale, perhaps even the third. At these scales the mantra 
should be: think globally, act locally. The presumption is that performance at lower levels integrates to a favorable global sustainability outcome.

Viewed from an engineering viewpoint, the pursuit for sustainability is a systems analysis approach. A Venn diagram of three intersecting circles each representing one of environmental, societal, and economic dimensions is useful in this context, as shown in Fig 1 (Azapagic and Perdan, 2000). Sustainability happens at the intersection of these three circles. For a system, picking indicators that represent one, two, or all three dimensions, can be used in sustainability analyses, and these indicators can be shown to belong in the various intersections, one type only of three dimensional indicators, three two-dimensional, and three one-dimensional types (Sikdar, 2003). The chosen indicators together are understood to characterize the system adequately. Additionally it is paramount to recognize that there is no absolute sustainability; it is always relative to some reference.

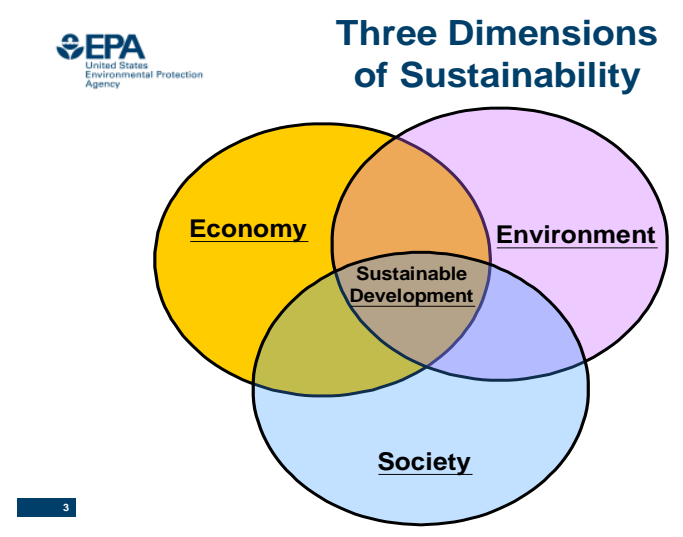

Figure 1. Three Dimensions of Sustainability

Now, an engineering definition of sustainable development for a man-made system can be given: sustainable development is continual improvement in one or more of the three domains of sustainability, i.e., economic, environmental, and societal, without causing degradation in any of the rest, either now or in the future, when compared, with quantifiable metrics, to a similar system it is intended to supersede.

Sustainability of systems at the fourth scale has been studied and reported in essentially one of two ways. First, representative indicators for a system can be chosen, data on them collected, and presented in a form conducive to inference making. Multinational corporations report corporate sustainability this way, simply by reporting year over year use reduction of various resource categories, and reduction of greenhouse gas (GHG) emissions. A report of this type pertains to the corporation as the system, but this same method can be used for all other system types: for national, regional, or a single process or product. The second method involves modeling the chosen system so that the various interacting components of the system are mathematically captured in an algorithm in which the variables or factors are optimized for the best sustainability performance. Many chemical processes are modeled this year, and are successful in accomplishing some specific sustainability goals, such as energy use minimization by heat integration, material and energy use minimization by various highly mathematical 
process integration tools (El-Halwagi, 2011). In principle, environmental, economic, and societal impacts conducted on cradle to grave life cycle assessment (LCA) basis should be reflected in the indicators characterizing the system. Because of the difficulty of collecting such LCA-based data on resource use and pollution generation in cradle to gate and gate to grave domains, this is rarely practiced, and the data often reflect "gate to gate" accounting. In gate to gate LCA, the sustainability impacts inherited through the inputs, and those caused by the product in the environment are not accounted for.

There are suggested standard methods of collecting life cycle data for environmental impacts determination, such as ISO standards $(2006,2009,2012)$. There are also voluntary standards for reporting sustainability stance of corporate enterprises, such as Dow Jones Industrials Index, some being more popular with corporations than others. Corporations tend to rely upon reporting mainly resource and emission data on key pollutants of concerns. Though this is not an example of exhaustive and systematic sustainability accounting, when viewed from relative sustainability, year over year improvements of these indicators do provide a clear sense that the reporting entity is becoming more proficient in sustainable development.

Standards are an effective tool for incorporating the three dimensions of sustainable development into sustainability policies. Sustainability may be introduced through standards and regulations that guide the sustainable development of a product, a service or a process, demanding reliable and widely accepted measurements. Standardization, Conformity Assessment with accreditation, and Metrology constitute the three interdependent pillars of knowledge for developing a technical infrastructure, also known as "Quality Infrastructure", thereby enabling sustainable development and full participation in international trade (Senetra and Marban ,2007; ISO 2006; DCMAS 2005).

\section{Standards}

A standard is a repeatable, harmonized, agreed and documented way of doing something. Standards contain technical specifications or other precise criteria designed to be used consistently as a rule, guideline, or definition. Standards, to be accepted in the market, must be from a credible body, which can demonstrate that the standards have been developed with due diligence and on a consensus basis (e.g., IRENA report, 2013). Standards are often established using PCI schemes where Principles incorporate the general idea, concept or goal to be achieved; Criterion denotes an assessable requirement that defines what to reach in order to achieve the principle; and Indicator which is a quantitative, qualitative or descriptive measure which supports the assessment of the criterion.

Standards are used by businesses and governments to optimize production, health, consumer protection, security, quality and environment. Their effective implementation supports sustainable development, social welfare, and facilitates trade. The Quality Infrastructure (QI) provides through Standardization the tools for government, business and organizations to express a clear understanding of their needs, aims and wishes. Conformity Assessment establishes the assurance that the requirements specified in Standardization are fulfilled. Metrology is the basis for accurate measurements, the accepted performance of which can then be written in international documentary standards, and be used as the basis for standardization and conformity 
assessment activities (Brandi and de Souza, 2009). A well written sustainability standard must fulfill certain requirements such as to be measurable (indicators), to be established on a minimum consensus of expert opinions, to be harmonized across borders with other standards, to have coherence and credibility, to adopt core requirements, terminology, and definitions, to be frequently updated, to add value to products, processes or services, to be friendly and flexible, to have transparency and accountability and to be used as base for regulation or voluntary guidance. The three pillars of sustainable development/ QI, are described in details elsewhere (Brandi and de Souza 2009, ISO 2006, DCMAS 2005).

Standards can be broadly sub-divided into three categories: product, process and management systems. Product standards refer to the quality and safety of goods or services. Process ones refer to the conditions under which products and services are produced, packaged or refined.

Management system standards help organizations manage their operations and are often used to create a framework within which an organization consistently achieves the requirements set out in product and process standards (DCMAS 2005). Standards, by definition, must be measurable but we still do not have a consensus on how to measure sustainability for construction and manufacturing; hence there are no commonly accepted sustainability standards in this area. Nevertheless, we may model a conceptual sustainability standard for construction and manufacturing as a process standard and describe the steps to establish a model standard, as performed in establishing a real standard. This conceptual process standard could have the following general attributes (ISO 2009): (1) The standard provides sustainability principles, criteria and measurable indicators for the processes involved throughout the construction and/or manufacturing supply chain. These principles, criteria and measurable indicators are intended to provide objective information for the assessment of sustainability aspects. The standard shall define PCIs regarding social, economic and environmental aspects considered necessary to evaluate degree of sustainability. (2) The sustainability of a product is assessed by looking at its whole life cycle (3) The standard does not contain thresholds, does not describe specific processes and production methods and is not a certification system. Conformity with this standard does not imply sustainability, but rather will provide information that can inform the judgments of economic operators or external evaluators - therefore additional systems are needed to provide guidance for demanded level of sustainability. (4) The standard is intended to facilitate comparison between various constructions and manufacturing processes. (5) The indicators give a checklist/scorecard to which the economic operator shall give answers. (6) The customer, end user, a governmental body etc. can then decide whether the sustainability level is good enough. Examples of general principles of economic, social and environmental aspects that may be incorporated to any sustainability standard are given in Figure 2. 


\begin{tabular}{|l|l|l|}
\cline { 2 - 3 } General Requirements/Principles: & Social principles: & \\
Be measurable & Human rights & \\
Legality & Labour rights & \\
Monitoring/evaluation procedures & Land use rights, & \\
Continuous improvement & Water use rights, Water & En vironmental principles: \\
Coherence and credibility & GHG emission \\
Transparency and accountability & & Water use or withdrawal \\
Flexibility/Relevance & Economic principles: & Soil contamination \\
Terminology and definitions & Economic sust ainability & Air quality \\
Comparability & Fair business practices & Waste genrated \\
Stakeholder involvement & Financial viability & Mineral resources used \\
Not undue administrative burden & Market transparency & \\
& & \\
& & \\
\hline
\end{tabular}

Figure 2. Examples of General Principles of Economic, Social and Environmental Aspects

\section{Indicators and Metrics}

Indicators (or metrics) provide quantitative measures that reveal the condition of sustainability of a system, much like the vital signs of a living human reveal the physical health of the person. Some of these indicators are fundamental such as energy consumed, others are derived from fundamental variables but are more difficult to measure, such as emergy or exergy, and still others are composite such as impacts on human health or ecosystems. The number and nature of indicators needed for a specific system are scale-, and system-dependent. Thus there is not a set of indicators that apply to all systems.

For industrial processes there are some common indicators that are suggested for measuring by nearly all methods. As an illustration the list that was composed by an industry consortium led by the Center for Waste Reduction Technologies of the American Institute of Chemical Engineers (in Dal Pont, 2012) had energy intensity, material intensity, water intensity, pollution intensity, toxics intensity and GHG emission intensity. From a standard perspective all these result from the PCI principle. The relative sustainability of a process, using indicators, can be assessed by comparing different modifications of a process, or by comparing dissimilar processes producing the same product. One could plot the indicator data on one of several options, the most popular being a spider diagram, and make sustainability inferences about the competing processes. Similar analyses can be done for a process over time intervals. UK's Institute of Chemical Engineers (in Cavani et al., 2009)) produced an indicator list that followed the categories of environmental, societal, and economic dimensions. This indicator system was designed to apply to enterprise (i.e, institutional scale) as well as to individual processes (technology scale). Corporate sustainability reporting follows some of the commercial services such as Dow Jones Sustainability Index, Global Reporting Initiative, etc. These systems are described in details elsewhere (Blackburn, 2007). Manufacture of mechanical products and building of structures may require additional indicators, such as product quality, customer satisfaction, product safety, and end-of-life management ((Lu et al., 2011).

There is no formal way to choose indicators for a chosen system but PCI is a good place to begin. Generally resource use, GHG emission, land use and pollutant emissions are compatible with the idea of sustainability. Since the toxicity of pollutants can be of many types, some prefer to compute human health and ecosystems impact from the releases, for instance, by using a software called TRACI (Bare, 2011). However, such level of granularity may not be needed when one is focused on comparing similar alternatives for which the indicator set is exactly the same. 


\section{Sustainability Analysis}

Computational algorithms belonging to the technique of process integration use combinations of process synthesis, process intensification, and process optimization to design systems that are more sustainable. The approach is multi-criteria optimization where some of the criteria can be seen as indicators, derived PCI framework. These modeling tools can consider many realistic process modifications to arrive at an optimized course of operation which serves sustainability quite well, provided no important indicator is left out. However process integration techniques suffer from not being able to compare different systems producing the same product. The other consideration of life cycle based data requirement for raw materials, products and wastes is important but both computational and non-algorithmic approaches are equally handicapped by lack of such data. The process integration is a vibrant field of research at this time. To date, research has encompassed only energy, raw material, water use, and GHG emissions in the multi-objective optimization.

When discrete indicator datasets are available, sustainability analysis can be made transparent. But comparing data sets in which some indicators are up and some down, inference can be a difficult task. Furthermore, whenever indicators in a dataset are incompatible with each other, or involve different measurement units, it is necessary to bring these indicators to the same basis through a proper normalization procedure. Many practitioners prefer to use an aggregate index for such data sets for easy determination of comparative sustainability. There are many ways of creating such aggregate index and the most recent ones are statistically based (Sikdar et al., 2011). One of those, for instance, uses a normalized Euclidean distance measure to make inferences (Mukherjee et al., 2012). A more recent attempt uses a Canberra distance (Brandi et al. 2013). Finally one still needs to check if all the applied indicators are needed (sufficiency) and also the order of importance of the indicators that are significant in inference making. Mukherjee et al. has recently produced a calculation based on multivariate partial least squares variable importance in projection (PLS-VIP) method to make decisions on sufficiency as well as order of importance of the indicators. Given credible data these conclusions are statistically valid.

\section{Conclusions}

In summary, for comparative assertion on sustainability of products and processes we need indicators that need to be chosen using the PCI framework that ensures consideration of the three dimensions of sustainability. These indicators should be chosen to preserve the principle of necessity and sufficiency. Under the leadership of international organizations, business groups and professional societies some guidance on the choice of indicators, especially for manufacturing, are available, though no uniform guidance is yet generally accepted or practiced. Standardization is important so that harmonized methods are used and the results are accepted by all interested parties for facilitating regulatory compliance, public perception, and international trade. Much research is being done on modelling that attempts to do sustainability analysis using multi-criteria optimization. In parallel, indicator data are being treated statistically leading to successful decision making on relative sustainability.

\section{References}

Azapagic A, Perdan S (2000), Indicators of sustainable development for industry: a general framework. Process Safety Environ Prot, (78) 243 
Bare J (2011). TRACY 2.0, Clean Technologies and Environmental Policy 13 (5), 687-696 Blackburn WR (2007). The Sustainability Handbook: The Complete Management Guide to Achieving Social, Economic, and Environmental Responsibility. Environmental Law Institute, 2007. ISBN 9781585761029

Brandi HS, and de Souza TL (2009), Accred Qual Assur, 14:567-573 and references therein. Brandi HS, Daroda R and Olinto A C (2013), The use of the Canberra metrics to aggregate metrics to sustainability, CTEP, DOI 10.1007/s 10098-013-0690-7

Cavani F, Cent G., Perathoner S. And Trifiro F., Ed.(2009), Sustainable Chemistry: principles, tools, and industrial examples. Wiley-VCH, Weinhein, Germany

DCMAS 2005-Joint Committee on coordination of assistance to developing countries in metrology, accreditation and standardization (JCDCMAS). "Building corresponding technical infrastructures to support sustainable development and trade in developing countries and countries in transition". The original document is available on www.dcmas.net,

Dal Pont JP (2012), Process Engineering and Industrial Management, John Wiley \&Sons, Hoboken, NJ

El-Halwagi MM (2011), Sustainable design through process integration, Elsevier, New York. IRENA Report (2013), International Standardization in the Field of Renewable Energy. http://www.irena.org/documentdonloads/pyblications/international standardization \%20 in the field of renewable energy.pdf, accessed March 2014

ISO 2006. "Three pillars of sustainable development - Metrology, standardization and conformity assessment"- ISBN 92-67-10416-0 • C ISO, 2006-02/3 000

http://www.iso.org/iso/home/store/publication_item.htm?pid=PUB100031, accessed March 2014

ISO 2009- ISO 13065/ PC 248 -Sustainability criteria for bioenergy - for facilitating trade of sustainable bioenergy

ISP 14031 (1999),International Standards Organization. Env Management- environmental performance evaluation, guidelines.

Lu T, Gupta A, Jayal AD, BadurdeenF, Feng SC, Dillon OW, and Jawahir IS (2011), A framework of product and process metrics for sustainable manufacturing p333, in Advances in Sustainable Manufacturing, Seliger G, Khraisheh MK, and Jawahir IS, Ed. Springer, Heidelberg, Germany

Mukherjee R, Sengupta D, Sikdar SK (2013), Parsimonious use of indicators for evaluating sustainability systems with multivariate statistical analyses. Clean Technologies and Environmental Policy, DOI 10.1007/s 10098-013-0614-6

Senetra C and Maraban RM (2007) The Answer to the Global Quality Challenge: A National Quality Infrastructure. PTB, OAS and SIM, 137p

Sikdar, SK (2003), Sustainable development and sustainability metrics, AIChE J, (49) 1928

Sikdar SK, Sengupta D, Harten P. (20121), More on aggregating multiple indicators into a single index for sustainability analyses. Clean Technologies and Environmental Policy, 14(5): p. 765-773.

WCED, Our Common Future (1987), Oxford University, Oxford, UK. 
[This page is internationally left blank] 


\author{
Srebric, Jelena, and Mohammad Heidarinejad, University of Maryland
}

\title{
Sustainability in the Built Environment
}

\author{
Abstract \\ Green building (GB) rating systems typically represent prescriptive, innovative, and \\ advantageous sustainable building design scenarios in the built environment. In principle, the \\ aim of these GB rating systems is to mitigate the buildings' life cycle costs, environmental \\ impacts, and energy consumption. Originally, the GB rating systems have focused on an \\ individual building. In the past decade, BREEAM Communities, CASBEE for Urban \\ Development, and LEED for Neighborhood Development (ND) have established GB rating \\ systems at the neighborhood scale. Computer simulation tools usually are one of the methods for \\ the GB rating systems to assist designers during the design phase, especially in the water and \\ energy efficiency categories, to establish the building's water and energy baselines. Due to the \\ lack of efficient design tools and methodologies at the neighborhood scale, there are \\ opportunities to improve the existing simulation tools and methodologies, to disseminate the \\ accumulated knowledge through the GB rating systems for the built environment at the \\ neighborhood scale.
}

\section{Keywords}

Green rating systems, LEED ND, BREEAM Communities, Urban built environment, Energy consumption of buildings, Energy Efficiency

\section{Background}

A method to evaluate sustainability in the built environment uses the Green Building (GB) rating systems. The aim of different GB rating systems is to reduce the building life cycle costs that account for environmental impacts as a part of the building performance optimization process. In general, to compare different optimized solutions, GB rating systems consider five categories of sustainability measures including (1) energy, (2) Indoor Air Quality (IAQ), (3) materials, (4) water, and (5) land use. In different countries, GB rating systems differ in the distribution of the credits for the certification process primarily due to the cultural and climatic differences.

Sometimes the distribution of the credits within a GB rating system depends on the location of the building. For example, GBCA Green Star considers different distribution of the credits for different locations in Australia (Zuo and Zhao 2014). In addition, most of the GB rating systems entail different rating systems based on the building types. Examples of the GB rating systems based on the building type include LEED EBOM and BREEAM In-Use for existing buildings, LEED NC and BREEAM New Construction for new construction buildings, as well as LEED for Homes and BREEM New Construction: Multi-Residential for residential buildings (Happio and Viitaniemi 2008, LEED 2013, BREEAM New Construction 2013, BREEM In-Use 2012). A simple method to quantitatively account for all life cycle costs and environmental implications does not exists yet because the fundamentals of understanding urban eco-systems are still under development (Srebric 2010). Therefore, the existing GB rating systems are prescriptive suggestions to promote sustainable practices in the built environment. Table 1 presents examples of the existing GB rating systems in the world. 
Table 1. Commonly used GB rating systems in the world (Note: It is important to notice that this list is by no means an exhaustive list, and many new GB rating systems have been developed recently; this list only provides examples of GB rating systems in different countries)

\begin{tabular}{|c|c|}
\hline Country & Examples of Green Building Rating System(s) \\
\hline United States & $\begin{array}{l}\text { - Leadership in Energy and Environment Design (LEED) } \\
\text { - Living Building Challenge - Living Future }\end{array}$ \\
\hline Canada & $\begin{array}{l}\text { - LEED (US / Canada) } \\
\text { - Green Globes Rating System (Canada / U.S.) }\end{array}$ \\
\hline $\begin{array}{l}\text { United } \\
\text { Kingdom }\end{array}$ & $\begin{array}{l}\text { - Building Research Establishment's Environmental Assessment Method } \\
\text { (BREEAM) }\end{array}$ \\
\hline Australia & - Green Building Council of Australia Green Star (GBCA) \\
\hline France & - High Quality Environmental standard \\
\hline Germany & - DGNB (German Sustainable Building Council) \\
\hline Singapore & - Green Mark Scheme \\
\hline Malaysia & - Green Building Index \\
\hline Japan & $\begin{array}{l}\text { - Comprehensive Assessment System for Building Environment Efficiency } \\
\text { (CASBEE) }\end{array}$ \\
\hline Hong Kong & - Hong Kong Building Environmental Assessment Method (HK-BEAM) \\
\hline India & - LEED India \\
\hline
\end{tabular}

\section{Quantitative vs. Quantitative Criteria}

An observation from direct comparisons between the GB rating systems show that the energy and water efficiency criteria are mostly quantitative, while the Indoor Environmental Quality (IEQ) criteria tend to be prescriptive (Srebric 2010). Additional detailed comparisons among different GB rating systems from different regions of the world are available in the literature (Bunz et al. 2006, Happio and Viitaniemi 2008, Happio 2012, Lee and Burnett 2008, Mao et al. 2009). Energy efficiency in the GB ratings systems is a good example of quantitative criteria to evaluate the energy performance of buildings. Typically, building energy compliance codes, such as ASHRAE Standard 90.1 or California Title 24, determine the minimum requirement for the building components and systems for energy efficient buildings. A common methods to design energy efficient buildings utilizes computer simulation tools (LEED 2013, BREEAM New Construction 2013). In fact, the new construction buildings, representing the largest building stock assessed by GB rating systems, are designed with assistance of computer simulation tools during the design phase. Due to the influence of the building occupants and other changes in the building operation, the energy consumption of constructed buildings during the operational and maintenance phases may be different from the expectations set in design phase (Perez-Lambard et. al 2009). Therefore, providing building owners with realistic performance expectations for energy efficient buildings is important (Heidarinejad et al. 2013).

\section{GB Rating Systems for the Built Environment}

The GB rating systems originally were developed to evaluate sustainability of an individual building. In the past decade, these GB rating systems have considered to include neighborhood 
developments in their rating systems. BREEAM Communities, CASBEE for Urban Development, and LEED for Neighborhood Development (ND) are examples of green rating systems to measure sustainability in the built environments at a scales much larger than a single building (Happio 2012). Due to a relatively long process of certification and a relatively recent establishment of these rating systems, only few case studies have received the fully certification at the neighborhood scale. Examples of the case studies are available on the BREEAM Communities page and USGBC project directory (BREEAM Communities Case Studies 2014, LEED ND Projects 2014).

Table 2 provides the primary categories required to achieve the certification in BREEAM Communities and LEED ND (BREEAM Communities 2012, LEED ND Version 4). Both of the GB rating systems endeavor to decrease environmental impacts in the built environment by emphasizing the quantitative energy and water efficiency criteria at the neighborhood scale. The criteria to optimize the building energy performance for these two GB rating systems are in the "Resources and Energy category" for BREEAM Communities, and in the "Green Infrastructure and Buildings" for LEED ND. It is important to note that these GB rating systems include opportunities to use software tools to evaluate the building energy performance at the neighborhood scale. Therefore, the existing modeling methodologies and simulation tools need to enable accurate energy and water modeling at the neighborhood scale to support assessments in the GB rating systems.

Table 2. Categories in BREEAM Communities and LEED ND

\begin{tabular}{|l|l|}
\hline BREEAM & LEED ND \\
\hline Governance & Smart location and linkage \\
\hline Social and economic wellbeing & Neighborhood pattern and design \\
\hline Resources and energy & Green infrastructure and build ings \\
\hline Land use and ecology & Innovation \\
\hline Transport and movement & Regional priority \\
\hline Innovation & \\
\hline
\end{tabular}

\section{Opportunities to Facilitate the Building Design at the Built Environment Scale}

Existing simulation tools for the building energy efficiency modeling focus on individual buildings. Therefore, the GB rating systems would benefit from the improvements in the existing simulation tools that would need to provide accurate evaluations of the environmental parameters, economic outcomes, occupant's health and productivity, IEQ, and indoor/outdoor thermal comfort at the neighborhood scale. Even with the development of the methodologies and tools that can focus on the neighborhood scale, the simulations at the neighborhood scale in the built environment are computationally intense. Therefore, a potential solution is to develop methodologies and tools that define urban design performance metrics to simplify the modeling while the accuracy of the simulations is not sacrificed. Figure 1 illustrates an example of building energy modeling at the neighborhood scale. In the following, two requirements for the building energy simulation methodologies and tools at the neighborhood scale are provided as examples:

a. Connection of the local outdoor conditions with the building energy performance: The neighborhood configuration influences (i) the outdoor airflow pattern around the buildings, resulting in different outdoor convective heat transfer coefficient patterns and infiltration rates for the built environment (Liu et al. 2013), and (ii) outdoor solar 
radiation on the building and ground surfaces (Gracik et al. 2014). Therefore, the neighborhood configuration changes the energy use pattern buildings. Some of the building energy simulation tools, such as EnergyPlus, have features to account for the neighborhood's influence on an individual building by including the shading from the neighboring buildings. However, accurate consideration of the building energy efficiency at the neighborhood scale requires more detailed modeling of local outdoor airflow and temperature.

b. Building size: GB rating systems at the neighborhood scale usually focus on a new neighborhood development or renovation of the existing neighborhoods. One consideration in the tool development is to provide a simulation tool enabling modeling small-sized buildings (less than 5,000 $\mathrm{ft}^{2}$ such as Building 1 in Figure 1) and spacious buildings (more than 500,000 $\mathrm{ft}^{2}$ such as Building 2 in Figure 1). Simulation methods to account for the energy losses due to the longer loops in the heating and cooling systems, simplifications for the reduced order energy modeling, and occupant's behavior are different for these two types of buildings. Building size is one of the key features that need to be addressed with the simulation tools since statistically most of the new construction buildings tend to have smaller sizes compared to the existing buildings. For example, LEED NC buildings are one order of magnitude smaller than the LEED EBOM buildings (Todd et al. 2013).

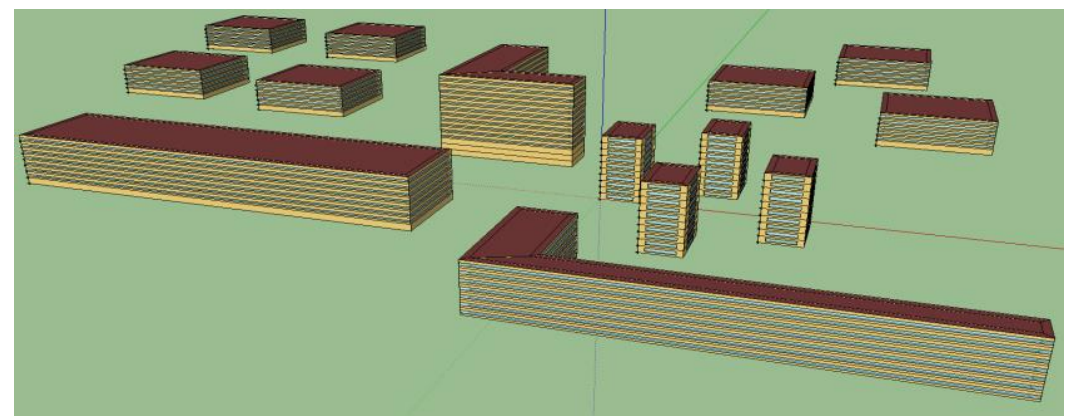

Figure 1. An Example of Building Energy Modeling at the Neighborhood Scale

\section{Conclusions}

In conclusion, there are many comparative studies focusing on the GB rating systems. A potential contributions to support improvements of the existing GB rating systems at the neighborhood scales could be to develop simulation tools enabling to support the simulation based compliance with the GB rating system requirements. In this way, the effectiveness of the existing prescriptive recommendations could be improved and the accumulated knowledge could be used for continuous maintenance of the existing energy efficiency recommendations and standards. This approach is already underway, and different simulation tools at the neighborhood / city scales are under development to support the mission of GB rating systems.

\section{References}

BRE Environmental \& Sustainability Standard, BREEAM In-Use., 2012, BRE Global 2012. BREEAM International New Construction Technical Manual., 2013, Technical Manual: SD5075 Version: 2013 - Issue: 1.0 - Issue Date: 09/04/2014.

BREEAM Communities, 2012. Technical Manual: SD202 Version: 2012 Issue: 0.2 Issue Date:

21/08/2013. 
BREEM Communities UK, 2014, Accessible link: http://www.breeam.org/page.jsp?id=372.

Bunz K.R., Henze G.P., and Tiller D.K., 2006, Survey of Sustainable Building Design Practices in North America, Europe, and Asia, Journal of Architectural Engineering, 2006: 33-62.

Gracik, S., Sadeghipour Roudsari, M., Heidarinejad, M., Liu, J., Pitchurov, G., Liu, K., and Srebric, J. 2014, A Parametric Analysis on Limitations and benefits of using EnergyPlus, Radiance, and Daysim for Outdoor Computational Fluid Dynamics Simulations for Buildings Built in Urban Environments (Submitted to ASHRAE Building Simulation 2014).

Happio, A., 2012, Towards sustainable urban communities, Environmental Impact Assessment Review 32 (2012) 165-169.

Haapio, A. and Viitaniemi, P., 2008, A critical review of building environmental assessment tools, Environmental Impact Assessment Review 28 (2008) 469-482.

Heidarinejad, M., Dahlhausen, M., McMahon, S., Pyke, C., and Jelena Srebric, J., 2013, Building classification based on simulated annual results: Towards realistic building performance expectations, Proceedings of Building Simulation 2013, Chambéry, France, August 26-28, pp. 1706-1713.

Lee, W.L. and Burnett, J., 2008, Benchmarking energy use assessment of HK-BEAM, BREEAM and LEED, Building and Environment 43 (2008) 1882-1891.

LEED v4 Guide., 2013, October 2013, Accessible link: http://www.usgbc.org/sites/default/files/LEED\%20v4\%20User\%20Guide_Final_0.pdf

LEED ND version 4, 2013. Accessible link: http://www.usgbc.org/credits/neighborhooddevelopment-plan/v4/green-infrastructure-\%26-buildings

LEED ND Projects, 2014. Accessible link: http//www.usgbc.org/projects/neighborhooddevelopment.

Liu, J., Srebric, J., Yu, N., 2013, Numerical simulation of convective heat transfer coefficients at the external surfaces of building arrays immersed in a turbulent boundary layer, Intentional Journal of Heat Mass Transfer, 61 (0) (2013) 209-225.

Mao X., Lu H., Li Q., 2009, A Comparison Study of Mainstream Sustainable/Green Building Rating Tools in the World, Proceedings of the 2009 International Conference on Management and Service Science.

Perez-Lombard, Ortiz, J., Gonzalez, R., Maestr, I.R., 2009, A review of benchmarking, rating and labelling concepts within the framework of building energy certification schemes, Energy and Buildings 41 (2009) 272-278.

Srebric, J., 2010, Opportunities for green building (GB) rating systems to improve indoor air quality credits and to address changing climatic conditions, Report prepared for the Indoor Environments Division Office of Radiation and Indoor Air, U.S. Environmental Protection Agency.

Todd, J.A., Pyke, C., and Tufts R., 2013, Implications of trends in LEED usage: rating system design and market transformation, Building Research \& Information, 41:4, 384-400.

Zuo, J. and Zhao, Z.Y., 2014, Green building research-current status and future agenda: A review, Renewable and Sustainable Energy Reviews 30 (2014) 271-281.

\section{Acknowledgements}

This study is sponsored by the EFRI-1038264 award from the National Science Foundation

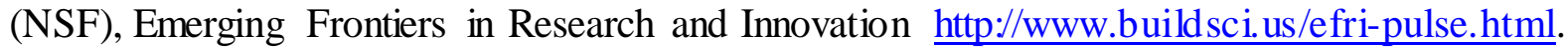


[This page is internationally left blank] 
Stumpf, Annette L., Franklin H. Holcomb, Ilker Adiguzel, and James C. Dalton, U.S. Army Corps of Engineers

\title{
Measuring High Performance Army Facility Construction and Renovation
}

\begin{abstract}
The Army manages almost 1 billion sq $\mathrm{ft}$ of buildings and is the largest user of facility energy in the Federal Government. Facility managers seek to reduce the total cost of ownership while complying with Executive Orders, federal laws, mission requirements, and Army net-zero energy, water, and waste goals. Understanding and predicting how facility performance and repair expenses change over time and with building occupancy is difficult. Army facility managers at-tempt to determine the total cost of facility ownership by understanding the scientific interrelationship of building systems. Predictive building sustainment models are being developed to help minimize the total cost of ownership. However, a key technical gap is the need for a feedback loop to calibrate and improve the performance of both buildings and models over time and at different occupancy levels, in various geographic locations and climate zones.
\end{abstract}

\section{Keywords}

Military, Construction, LEED, Resiliency, Performance, Metrics, Measurement

\section{Background}

The Army manages almost 1 billion sq $\mathrm{ft}$ of buildings. It is the largest user of facility energy in the Federal Government, using 72.7 trillion British Thermal Units (BTUs) of energy in FY13 (DASA(E\&S) 2013). The Army has been working hard to reduce energy and water consumption, with total Army facility energy use in 2013 being 14 trillion Btu lower than 2003 consumption (DASA(E\&S) 2013). Approximately 2\% of 165,000-plus buildings in the inventory are certified at LEED Silver or higher, and are designated as high-performance sustainable buildings (DASA(E\&S) 2013). Total square footage of Army facilities was reduced by more than 15 million sq $\mathrm{ft}$ in FY13. However, the impact of training simulator buildings and significant new MILCON buildings, combined with exogenous factors and limitations of the square-footage metric, resulted in a $1.5 \%$ increase in energy-use intensity (DASA(E\&S) 2013). It is very challenging to operate and maintain such a large facility footprint in an austere financial environment, so energy and water conservation is taken very seriously. Facility managers seek to reduce the total cost of ownership while complying with Executive Orders, laws, and federal requirements in the context of the Army's Triple Bottom Line: Cost, Environment, and Mission.

Federal government facilities must meet performance metrics established by Executive Orders, laws, and agency policies. Strict mandates to reduce consumption of fossil fuels, energy, water, waste - and to increase renewable energy use - must be accomplished throughout the organization. Performance measurement is key to understanding how to build, renovate and operate Army facilities so they satisfy mandates such as the Energy Policy Act of 2005 (EPAct 2005), Energy Independence and Security Act of 2007 (EISA), Code of Federal Regulations, Executive Orders 13423 and EO 13514, Department of Defense (DoD) Unified Facilities Criteria (UFCs), and relevant Army and U.S. Army Corps of Engineers (USACE) policies. 


\section{Holistic Life-Cycle Approach to Facility Management}

The Army uses a life-cycle approach to master planning, planning, designing, constructing, operating, and repurposing or deconstructing buildings. Integrated collaborative planning processes are used to ensure that mission requirements are met while incorporating innovative technologies that are life-cycle cost effective (Napier 2012). DoD collaborates to update and use Unified Facilities Criteria (UFCs) whenever possible to standardize planning, design, construction, sustainment, restoration and modernization criteria among the services. Most recently, the Army directive on Net Zero Installations has given additional emphasis on a holistic life-cycle approach to master planning and facility management.

The Army operates buildings for many years, adapting and updating them over time to meet new functional requirements, so it is important that new buildings are designed to be as sustainable as possible. Post-occupancy performance is measured against the design energy-use intensity (EUI), modeled using commercial standards compared to actual metering data. Performance metrics include energy and water efficiency, building envelope tightness, LEED certification, ASHRAE 189.1, and compliance with the High-Performance Sustainable Building (HPSB) Guiding Principles captured on the Energy \& Sustainability Record Card (ECB 2013-25).

UFC 2-100-01 Installation Master Planning (05-15-2012) defines sustainable planning principles for military bases, including compact, mixed-use, transit-oriented development to encourage people to walk, bicycle, and use mass transit. The quality of life of people living and working on installations is key to attracting and retaining military families and skilled personnel.

EO 13423 establishes high-performance and sustainable goals for the federal government. New construction and major renovations must comply with the Guiding Principles for Federal Leadership in High Performance and Sustainable Buildings ("Guiding Principles") as described in http://www.wbdg.org/references/fhpsb.php.

UFC 1-200-02 High Performance and Sustainable Building Requirements (03-01-2013) defines how the Army and other services will apply the "Guiding Principles" to new construction, additions, renovations, operation and maintenance activities and leased buildings. (Reference UFC 1-200-02, Table 1.1 Project/Work Type Compliance). Life Cycle Cost Analysis is key to evaluating new technologies and system alternatives which are being considered.

The goal of the Army's Sustainable Design and Development Policy Update (12-16-2013) is to "provide productive, safe, and healthy facilities and installations that enhance mission effectiveness, reduce the Army's environmental footprint, and achieve levels of energy independence that enhance continuity of mission-essential operations. Guided by federal mandates, the Army will plan, design, build, and operate facilities to achieve the highestperforming sustainable de-sign that is life-cycle cost-effective within the program amount." Facility performance is important, but the Army has bigger mandates to encourage installations and facilities to reach towards net zero energy, water and waste as defined by the Army Directive 2014-02 Net Zero Installations Policy (1-28-2004). This directive explains the Army's "vision to appropriately manage our natural resources with a goal of Net Zero in energy, water, and solid waste at installations." This holistic strategy helps increase resiliency where fiscally responsible 
and will enable the Army to appropriate steward available resources, manage costs and pro-vide Soldiers, Families and Civilians with a sustainable future.

\section{Role of Technology and Innovation}

The U.S. Army Engineer Research and Development Center, Construction Engineering Research Laboratory (ERDC-CERL), U.S. Army Corps of Engineers (USACE) Districts, and Army installations are all working to adopt new technologies and investigate innovative solutions to work toward Army energy and sustainability goals. Highlights of several ongoing efforts are described in Center for the Advancement of Sustainability Innovations (CASI) 2014 Work Plan (ERDC/CERL TN-14-1). Recent innovations include the Army's implementation of LEED, Building Information Modeling (BIM) standards, Construction Operations Building information exchange (COBie), and Corps development and adoption of an Air Tightness Standard for new construction and major renovation. A new and expanding area of research is focused on reducing the resource and logistics footprint of contingency bases for improved mission sustainment.

In 2009, on behalf of the Army, ERDC-CERL won the US Green Building Council (USGBC) Leadership in the Public Sector Award for
commitment to LEED certification in the facility acquisition process, with far-reaching impacts on the multi-billion-dollar annual Military Construction (MILCON) program both in the United States and overseas. Beginning in 2008, the team instituted a policy that requires all new MILCON projects to achieve LEED Silver certification and that all design teams are required to include at least one LEED AP. The Army team was able to carry out a major change of culture in a long-standing facility acquisition process, committing to improving its infrastructure for current and future generations.

The Army has 380 LEED Certified buildings as of March 2014: Certified - 12; Silver - 229; 134 - Gold; and 5 - Platinum. The Army has been actively involved in continuing development and application of LEED Rating Tools.

The Corps of Engineers is a nationwide leader in adopting Building Information Modeling (BIM). USACE has developed BIM requirements that Architectural/Engineering firms could apply to military construction projects (JBIM 2012):

USACE did not want to develop BIM Contract Requirements in a "black box"; and the collaborative effort with industry representatives has proven to be a winning formula. The USACE BIM Contract Requirements were an essential component of USACE's successful BIM delivery on the MILCON program, as demonstrated by the 500-plus single- and multi-facility BIM projects executed since January 2008, comprising 46 million-plus square feet, and more than $\$ 9$ billion in construction programming. More than 600 facilities, comprising 25 million-plus square feet, have been constructed as of January 2013. Accordingly, the committee has been recognized within USACE as a thought leader in developing groundbreaking contract requirements that serve as a model for the industry.

USACE is working with the National Institute of Building Sciences and the building S MART alliance to create tools and standards that allow projects to be built electronically before they are constructed using BIM. The Construction Operations Building Information Exchange (COBie) 
data specification enables project team members to enter data as it is created during design, construction, and commissioning to provide the owner with electronic as-built data.

Another success was Army adoption of an Air Tightness Standard for new construction and major renovation projects. In the face of some skepticism, the Army initiated a higher standard for air tightness to conserve energy, eliminate mold growth, and improve indoor air quality. The results have far exceeded the initial goals. In 2009 the Army became one of the first major building owners in the United States to implement a requirement for air tightness in all new building construction and building enclosure renovation projects. The mandatory whole-building air leakage test, "Air Leakage Test Protocol for Building Envelopes," was developed jointly by USACE, the Air Barrier Association of America (ABAA), and ABAA industrial partners.

ERDC-CERL and the industry partners of ABAA have collected and published performance data on over 200 of these newly constructed or newly renovated Army buildings and found that the average air leakage rate for these buildings was 0.17 cubic feet per minute (cfm) per square foot of exterior envelope at $0.3 \mathrm{in}$. of water gage $(75 \mathrm{~Pa})$ pressure difference. The Army air tight-ness requirement has proven to be achievable, applicable to all building types and locations, and does not limit the design and construction process to any single set of materials or systems. The requirement for air tightness is already rewarding the Army with more durable buildings that consume less energy to operate, eliminate mold growth, and improve indoor air quality.

\section{Partnerships and Communication}

Public/private partnerships are key to achieving the Army vision to build, operate, and maintain installations and facilities in a sustainable, resource-efficient, cost-effective manner. Due to an unprecedented surge in Army construction requirements in 2004, USACE transitioned to centrally managed designs under the Centers of Standardization and transformed contracting procedures from Design-Bid-Build to primarily Design-Build. USACE sought industry input on how best to accomplish its goals on a regional and national basis and under a national acquisition strategy. The improved process relies on national industry standards to define criteria and clearly articulate requirements to contractors in quantifiable terms for new construction, renovation, repairs, and operations and maintenance. There is less risk to the bidder when UFCs and industry standards are used because the design/construction industry should be familiar with the requirements. When appropriate industry standards are not available, the Army will initiate an effort to update or develop new standards with national standardization bodies such as ASHRAE. Innovative acquisition strategies have been tested on recent projects such as the National Geospatial Intelligence Agency Campus East (NGE).

All projects are planned, programmed, budgeted, designed, built, and reported to meet the requirements of UFC 1-200-02, High Performance and Sustainable Building Requirements. The Army standard for high-performance sustainable building/project rating and certification is the U.S. Green Building Council's Leadership in Energy and Environmental Design (LEED) rating system. UFC 1-200-02 contains references to ASHRAE Standard 189.1-2011 and ASHRAE Standard 90.1-2010, and helps project teams comply with EPAct 2005, EISA 2007, EO 13423, EO 13514, and the federally required HPSB guiding principles. USACE has developed templates to help contractors to meet EPACT 05 compliance standards, meet Federal mandates for 
the five most common Army standard designs, and to help project teams accomplish deep energy retrofits (Schneider, Stumpf 2006).

The recently constructed National Geospatial Intelligence Agency Campus East (NGE), located near Fort Belvoir, was the largest USACE construction undertaking since the Pentagon. The 2.4 million sq ft building was completed under budget and reached substantial completion 6 months ahead of time while pilot-testing a new acquisition strategy. The LEED Gold Certified building was a successful partnership between three government contracting entities and six prime contractors using the Fast-tracked Early Contractor Involvement implementation strategy. The NGE project was recognized by Engineering News Record Southeast as the Region's Best Government/Public Building project. The key lessons learned from this Fast-tracked Early Contractor approach were that it was (1) very flexible, resulting in significant cost and schedule benefits, but (2) very complicated to administer. The $\$ 1.7$ billion project was the largest U.S. Federal Government building to earn LEED certification, and is a contemporary building that provides a collaborative work environment with state of the art technology such as chilled beams.

\section{Closing the Loop}

Current and future projects are expected to consider renewable energy systems and new, underutilized technologies that are proven to be life-cycle cost effective while fulfilling the total building commissioning requirements prescribed in UFC 1-200-02. To ensure buildings operate efficiently, there is a major emphasis on post-occupancy performance assessment. The Energy and Sustainability Record Card (ECB 2013-25) directs project teams on how to report compliance with multiple policies related to energy and sustainability for new and renovated facilities. The Record Card is intended to capture design goals and measured performance post occupancy, and will be transferred to the building owner documenting compliance with multiple policies and mandates related to energy and sustainability. It also provides guidance on determining and re-porting the new "Sustainability Code" for new and renovated facilities. The Record Card will be updated at each phase of the facility delivery process, starting at Concept/Parametric Design, then 100\% Design, Solicitation/Request for Award Authority, Completing of Design/Build Con-tractor's Design, Initial Beneficial Occupancy Date (BOD), and at the Final Turnover. The Record Card documents energy and water use intensity; waste diversion; baseline, model and actual Annual Energy Usage (kBTU); and has a compliance dashboard for EPAct 2005, EISA 2007, Low Impact Development, and the Guiding Principles.

To address the need for energy-related maintenance and repair of the Army's building portfolio, DoD uses the BUILDER Sustainment Management System (SMS) as an asset-management solution. BUILDER helps to ensure facility mission readiness, optimizing infrastructure investment and reducing the total cost of ownership. With data about building condition, degradation trends, and remaining service life, BUILDER can be used to develop short- and long-range work plans based on strategic investment concepts, mission-prioritization criteria, and budget constraints. The life-cycle emphasis on sustainability and adaptive reuse also requires consideration of non-condition related problems such as functional obsolescence and energy inefficiencies in buildings. ERDC-CERL is currently executing interdisciplinary research to provide the SMS toolset needed to develop these new sustainability-related capabilities. Tenets 
of SMS theory are being extended through an enhanced analysis framework that considers facility performance up-grades using a holistic approach.

\section{Conclusions}

The Army is one of the largest facility stakeholders in the United States, and uses a holistic life cycle approach to meeting numerous federal and Army requirements while minimizing the total cost of ownership. Technology and innovation play a big role in the life cycle approach to master planning, new construction, post occupancy evaluation, management and renovation of existing buildings, and finally deconstruction. The Army utilizes industry standards when available, and leads adoption of new standards when needed. A key metric for success is how the building performs post occupancy as compared to how it was designed to perform. Finally, an ongoing, continuous challenge is planning and obtaining resources to upgrade facilities so they meet the high performance sustainable building requirements that are mandated. Due to limited resources and the large building footprint, public private partnerships will be necessary to help the Army achieve installation net zero energy, water, and waste goals.

\section{References}

Army Directive 2014-02. 28 January 2004. Net Zero Installations Policy. Washington, DC: Headquarters, Department of the Army.

ASHRAE Standard 189.1-2011.2011. Standard for the Design of High-Performance Green Buildings. Atlanta, GA: ASHRAE.

ASHRAE Standard 90.1-2010. 2010. Energy Standard for Buildings Except Low-Rise

Residential Buildings. Atlanta, GA: ASHRAE.

Energy Policy Act of 2005. Washington, DC: US Department of Energy.

Energy Independence and Security Act of 2007. Public Law 110-140.

Executive Order (EO) 13423. 2007. Strengthening Federal Environmental, Energy, and Transportation Management.

Executive Order (EO) 13514. 2009. Federal Leadership in Environmental, Energy, and Economic Performance.

CASI. 2014. Center for the Advancement of Sustainability Innovations (CASI) 2014 Work Plan. ERDC/CERL TN-14-1. Champaign, IL: ERDC-CERL.

Deputy Assistant Secretary of the Army for Energy and Sustainability. 2013. FY 2013 Annual Energy Management Report. 2013. Washington, DC: DASA (E\&S).

ECB 2013-25. Implementation of the Energy \& Sustainability Record Card and New DD 1354 Sustainability Codes. Washington, DC: Headquarters, U.S. Army Corps of Engineers.

Foster, S., Hutsell, S., Journal of the National Institute of Building Sciences. January 2013.

"Win-Win BIM: How USACE and Industry Established Mutually Beneficial BIM Requirements." JBIM Edition; Building Information Modeling. Washington DC: National Institute of Building Sciences.

Napier. T., Schneider R., Stumpf, A., Goran, W., 2012. 'Building Green.” Army Sustainability and National Security. Carlisle, PA: Army War College.

Schneider, R., Stumpf, A., 2006. Implementation of the U.S. Green Building Council's LEED® as the Army's Green Building Rating System. ERDC/CERL TR-06-1. Champaign, IL: ERDC-CERL.

Unified Facilities Criteria UFC 2-100-01. 2012. Installation Master Planning. 
Unified Facilities Criteria UFC 1-200-02. 2013. High Performance and Sustainable Building Requirements. 
[This page is internationally left blank] 
Tatari, Omer, Murat Kucukvar, and Nuri C. Onat, University of Central Florida

\title{
Towards a Triple Bottom Line Life Cycle Sustainability Assessment of Buildings
}

\begin{abstract}
Buildings consume significant amount of energy and natural resources as well as provide direct and indirect social and economic impacts through all of their life cycle phases. Instead of focusing only environmental impacts of buildings, there is a vital need for sustainability metrics that would take the direct and indirect environmental, economic and social impacts into account. To achieve this goal, triple bottom line economic input-output based hybrid life cycle assessment model is identified and developed for assessing building sustainability. This approach can extend life cycle sustainability assessment framework for buildings in two directions; horizontal direction by integrating several social and economic indicators, and vertical direction by consideration of all indirect supply chain related impacts within the LCSA framework.
\end{abstract}

\section{Keywords}

Buildings, Life cycle sustainability assessment, Triple bottom line, Economic input-output analysis

\section{Background}

\subsection{Impact of Buildings}

Buildings consume significant amount of energy and natural resources through all of their life cycle phases from construction to disposal. Construction sectors are the largest raw material consumers in mass (USGS 2009). Energy consumption of residential and commercial buildings accounts for roughly $40 \%$ of the total U.S. energy consumption in 2012 (US EIA 2013). 30\% of landfill content is composed of construction demolition and debris (NRC 2009). Building construction and operations are responsible for 38.9\% of greenhouse gasses (GHGs) emitted in the U.S. (EIA 2008). Several national initiatives put certain goals and initiated action plans toward decreasing or in the very least stabilizing the exponential growth in steeply increasing GHG emissions trend by the middle of the 21 st century.

According to the U.S. Environmental Protections Agency's annual report, the earth's climate continue to change and global climate change could affect our environment through sea-level rise, drought, loss of natural capital, decrease in agricultural productivity; society through occurrence of diseases, loss of household income, increasing poverty, etc.; and economy through disruption of power generation and transportation activities, productivity loss in industrial facilities, and reduced gross domestic product (U.S. Environmental Protection Agency 2012). From a complex system perspective, triple bottom line (TBL) consequences of the climate change impacts are inevitably interconnected, and therefore such complexity requires a novel system thinking approach in which all possible outcomes, ripple effects, and unforeseen impacts must be estimated. Although there is a wide range of studies addressing carbon footprint of buildings, there has been limited research on quantifying the TBL impacts of U.S. buildings or to understand their relationship (Kucukvar and Tatari 2013). 


\subsection{Life Cycle Assessment}

Life cycle assessment (LCA) is a widely used approach to quantify the environmental impacts of products or processes from cradle to grave including material extraction and processing, transportation, use, and end-of-life phases (Finnveden et al. 2009). LCA was developed in the early 1990s as powerful methodology in which potential environmental impacts are analyzed in a systematic way. LCA has been utilized extensively to analyze the environmental impact of the buildings from cradle to grave. LCA is a well-known and widely used approach for assessing the potential environmental impacts and resources used throughout a product's life cycle, including raw material acquisition, production, use, and end of life phases (Rebitzer et al., 2009).

Three LCA approaches, including process-based LCA (P-LCA), economic input-output LCA (EIO-LCA), and hybrid-LCA have been mainly used in environmental analysis of products or processes (Finnveden et al., 2009). The EIO-LCA model augments the environmental impact data with the EIO tables of the nation's economy to form a comprehensive system boundary (Joshi, 2000). This approach quantifies the environmental impacts of the products or processes of direct and indirect suppliers considering the interactions among the economic sectors (Suh and Huppes, 2005; Hendrickson et al. 2005). The EIO based LCA models have been extensively used to analyze the environmental impacts of buildings in the U.S. (Bilec et al. 2009; Guggemos and Horvath 2006; Junnila et al. 2006; Ochoa et al. 2005; Sharrard et al. 2005; Tatari and Kucukvar 2012a). Most of the reviewed studies focused on the direct and indirect environmental performance of buildings considering several important environmental impact categories such as toxic releases, waste generation, energy use, and global warming potential using the EIO-LCA tool. However, due to the large impacts on economy and the society, it is necessary to account for the direct and indirect social and economic implications from holistic perspective.

GHG emissions resulting from energy consumption in buildings depend on various factors and these factors constitute a wider complex system that includes numerous interacting components from the TBL. Taking all three dimensions of sustainability into consideration is vital to enable decision-makers to quantify trade-offs between different dimensions of sustainability. Effective green building strategies such as shifting to renewable energy resources and energy-efficient building retrofitting towards reducing GHG emissions of U.S. buildings will have a significant impact not only on the environment, but on the economy and the society, as well. While LCA studies are able to quantify environmental pressures of buildings, the TBL approach is capable of quantifying not only environmental pressures, but also the social and economic impacts (Kucukvar and Tatari 2013; Wiedmann et al. 2009). The TBL concept focuses on the three main pillars of sustainability: environment, economy, and the society (Elkington 1999; Jeurissen 2000). This analysis can be achieved by employing an integrated approach, which takes these three dimensions into consideration.

\section{Research Needs}

With the increasing concerns related to integration of social and economic dimensions of sustainability into LCA, a traditional LCA approach has been transformed into a new concept, which is called as Life Cycle Sustainability Assessment (LCSA). This concept was suggested by Kloepffer (2008) and Life Cycle Cost (LCC) and Social Life Cycle Assessment (SLCA) methods were integrated into the LCA framework in order to evaluate economic and social dimensions (Zamagni 2012). In accordance with the recent developments in LCSA research, there is a dire 
need to extend the existing LSCA framework in two directions; namely (1) horizontal direction: integrating several social and economic indicators into LCSA framework, and (2) vertical direction: consideration of all indirect supply chain related impacts within the LCSA framework, which was called as economy-wide macro-level analysis in (Guinee et al. 2011). Although previous studies analyzed the life cycle environmental impacts successfully, there is a need to identify metrics for assessing and quantifying the sustainability of the U.S. residential and commercial buildings using LCSA framework.

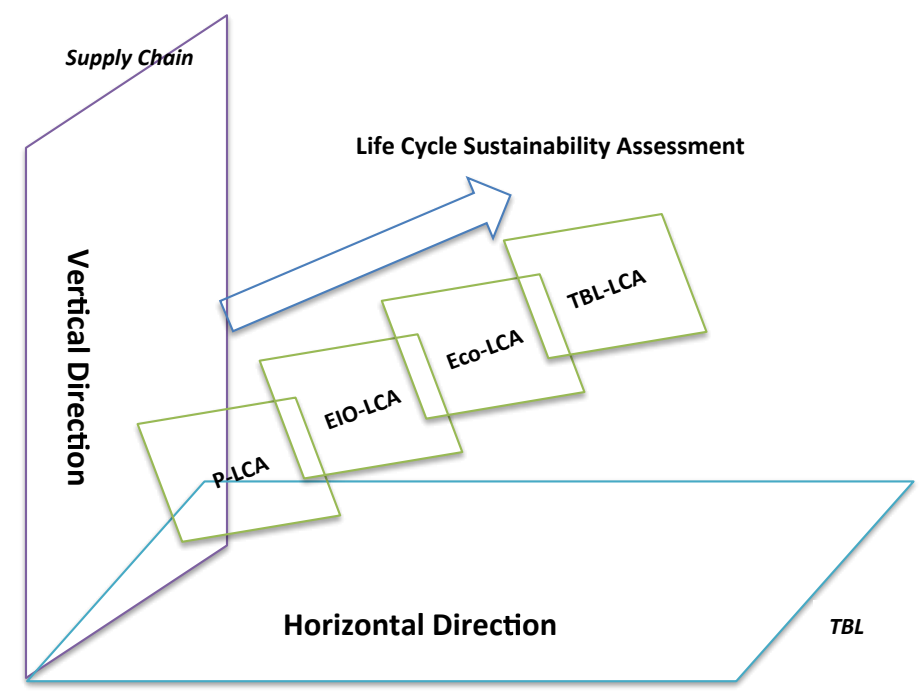

Figure 1. Future Research Direction in Life Cycle Sustainability Assessment for Buildings

\section{Method}

In order to fill this gap, the first input-output based TBL based LCA (TBL-LCA) model for the entire U.S. economy was developed by researchers at the University of Central Florida. This holistic life-cycle sustainability assessment tool has been utilized for environmental, economic, and social impact analysis of electricity production from wind turbines, U.S. construction industry, highway designs, and manufacturing sectors (Egilmez et al. 2014; Kucukvar and Tatari 2013; Kucukvar et al. 2014; Noori et al. 2013). This research is in need to be extended to include more metrics and to be utilized in hybrid LCA methods.

The TBL-LCA, is based on the EIO analysis, which was developed by Wassily Leontief in the 1970s (Leontief 1970). The EIO model consists of identical sectors and monetary transactions among those sectors which make up the economic structure of a country (Hendrickson et al. 2006). EIO based models integrate the environmental impacts and the financial flow data derived from the supply and use tables of an economy. In addition to environmental impact indicators, the TBL-LCA model merges comprehensive social and economic indicators with the EIO accounts.

Many countries publish their EIO tables routinely. Financial flow data are represented by the supply and use tables. The U.S. Bureau of Economic Analysis, as a part of the International System of National Accounts, publishes the supply and use tables in the United States (BEA 2010). All sectors within the supply and use tables are classified according to North American Industry Classification System (NAICS). Typical processes that are well represented in EIO 
categories at sector level can be accounted through EIO models, while the rest the processes can be modeled through process level data (Suh et al. 2004). This approach is known as hybrid LCA, which has been mostly preferred for studies at county, city and national scales (Peters 2010). Moreover, with the hybrid approaches, it is possible combine the advantages of both the process and EIO models (Suh and Lippiatt 2012).

Table 1. A brief summary of the sustainability indicators

\begin{tabular}{|c|c|c|}
\hline TB L Indicators & Unit & Definition \\
\hline \multicolumn{3}{|l|}{ Environmental } \\
\hline Carbon Footprint & $\mathrm{t} \mathrm{CO}_{2}$-eqv & $\begin{array}{l}\text { Total GHG emissions of each sector in terms of } \mathrm{CO}_{2} \\
\text { equivalent. }\end{array}$ \\
\hline Water Footprint & kgal & The total water withdrawals and consumption of each sector. \\
\hline Energy Footprint & MJ & The total energy consumption of each sector. \\
\hline Toxic Footprint & Mt & $\begin{array}{l}\text { Toxic chemical emissions into air, water and soil by industrial } \\
\text { sectors. }\end{array}$ \\
\hline Built-up land & gha & $\begin{array}{l}\text { The area of land used by human infrastructure, such as } \\
\text { transportation, housing, industrial structures and reservoirs for } \\
\text { hydroelectric power generation. }\end{array}$ \\
\hline $\mathrm{CO}_{2}$ uptake land & gha & $\begin{array}{l}\text { The amount of forestland required to sequester given carbon } \\
\text { emissions. }\end{array}$ \\
\hline \multicolumn{3}{|l|}{ Economic } \\
\hline $\begin{array}{l}\text { Total Economic } \\
\text { Output (TEO) }\end{array}$ & $\$ M$ & $\begin{array}{l}\text { The total economic transaction (direct plus indirect) related to } \\
\text { the output of each sector in the national economy. }\end{array}$ \\
\hline $\begin{array}{l}\text { Gross Operating } \\
\text { Surplus (GOS) }\end{array}$ & $\$ \mathrm{M}$ & $\begin{array}{l}\text { The capital available to corporations, to pay taxes and to } \\
\text { finance their investments. }\end{array}$ \\
\hline Import & $\$ M$ & $\begin{array}{l}\text { The value of goods and services purchased from foreign } \\
\text { countries to produce domestic commodities by industries. }\end{array}$ \\
\hline $\begin{array}{l}\text { Gross Domestic } \\
\text { Product (GDP) }\end{array}$ & $\$ M$ & $\begin{array}{l}\text { The market value of goods and services produced within the } \\
\text { country in a given period of time. }\end{array}$ \\
\hline \multicolumn{3}{|l|}{ Social } \\
\hline Tax & $\$ \mathrm{M}$ & $\begin{array}{l}\text { Government revenue, which includes the taxes on production } \\
\text { and imports. }\end{array}$ \\
\hline Income & $\$ \mathrm{M}$ & The compensation of employees, including wages and salaries \\
\hline Employment & emp-hr & $\begin{array}{l}\text { The net employment hours represent the full-time equivalent } \\
\text { employment for each U.S. sector in the units of hours per } \\
\text { year. }\end{array}$ \\
\hline Injuries & person & Rate of nonfatal injuries per 100 equivalent full-time workers. \\
\hline
\end{tabular}

Many macro-level sustainability assessment indicators can be chosen as environmental, social, or economic indicators. Several federally available public data sources, including Bureau of Economic Analys is (BEA, 2007), Energy Information Administration (EIA, 2011), Bureau of Labor Statistics (BLS, 2007), U.S. Geological Survey (USGS, 2007), Global Footprint Network (GFN, 2007), and U.S. Environmental Protection Agency (EPA, 2011) will be utilized to obtain these multipliers. Table 1 includes some of the multipliers that has been used in previous studies, 
and is not exhaustive. Other indicators may be added to quantify different aspects of sustainability.

\section{Conclusions}

Sustainability is not only limited to the environment, and other indicators of sustainability, such as economic and social should also be taken into consideration for a more holistic analysis. LCA studies that consider all dimensions of sustainability impacts of civil infrastructures are very limited, and it is imperative to integrate economic and social indicators. Considering the recent trends also emphasize the inclusion of three pillars of sustainability, as well as, supply chain related indirect impacts; the proposed methodology perfectly fits to the needs of such a comprehensive sustainability assessment understanding. To achieve this goal, triple bottom line economic input-output based hybrid life cycle assessment model is identified and developed for assessing building sustainability. This approach can extend life cycle sustainability assessment framework for buildings in two directions; horizontal direction by integrating several social and economic indicators, and vertical direction by consideration of all indirect supply chain related impacts within the LCSA framework.

\section{References}

BEA. (2010). "Benchmark Input-Output Data."

Egilmez, G., Kucukvar, M., Tatari, O., and Bhutta, M. (2014). "Supply chain sustainability assessment of the US food manufacturing sectors: A life cycle-based frontier approach." Resources, Conservation and Recycling, 82, 8-20.

Elkington, J. (1999). Cannibals with Forks: Triple Bottom Line of 21st Century Business. Capstone Publishing Ltd.

Finnveden, G., Hauschild, M. Z., Ekvall, T., Guinée, J., Heijungs, R., Hellweg, S., Koehler, A., Pennington, D., and Suh, S. (2009). "Recent developments in Life Cycle Assessment." Journal of environmental management, Elsevier Ltd, 91(1), 1-21.

Hendrickson, C. T., Lave, L. B., and Matthews, H. S. (2006). "Environmental life cycle assessment of goods and services: an input-output approach." Resources for the Future.

Jeurissen, R. (2000). "John Elkington, Cannibals with forks: The triple bottom line of $21 \mathrm{st}$ century business." Journal of Business Ethics.

Kloepffer, W. (2008). 'Life cycle Sustainability assessment of products." International Journal of Life Cycle Assessment, 13(2), 89-94.

Kucukvar, M., Noori, M., Egilmez, G., and Tatari, O. (2014). "Stochastic decision modeling for sustainable pavement designs.” International Journal of Life Cycle Assessment, 1-15.

Kucukvar, M., and Tatari, O. (2013). "Towards a triple bottom-line sustainability assessment of the US construction industry." The International Journal of Life Cycle Assessment.

Leontief, W. (1970). "Environmental Repercussions and the Economic Structure: An InputOutput Approach." The Review of Economics and Statistics, 52(3), 262-271.

Noori, M., Kucukvar, M., and Tatari, O. (2013). "A macro-level decision analysis of wind power as a solution for sustainable energy in the USA." International Journal of Sustainable Energy, $1-16$.

Peters, G. P. (2010). "Carbon footprints and embodied carbon at multiple scales." Current Opinion in Environmental Sustainability, 2(4), 245-250.

Suh, S., Lenzen, M., Treloar, G. J., Hondo, H., Horvath, A., Huppes, G., Jolliet, O., Klann, U., Krewitt, W., Moriguchi, Y., Munksgaard, J., and Norris, G. (2004). "System Boundary 
Selection in Life-Cycle Inventories Using Hybrid Approaches." Environ. Sci. Technol, ACS Publications, 38(3), 657-664.

Suh, S., and Lippiatt, B. C. (2012). "Framework for hybrid life cycle inventory databases: a case study on the Building for Environmental and Economic Sustainability (BEES) database." The International Journal of Life Cycle Assessment, 17(5), 604-612.

U.S. Environmental Protection Agency. (2012). Climate Change Indicators in the United States. Washington, DC, USA.

Wiedmann, T. O., Lenzen, M., and Barrett, J. R. (2009). "Companies on the Scale." Journal of Industrial Ecology, Blackwell Publishing Inc, 13(3), 361-383.

Zamagni, A. (2012). "Life Cycle Assessment and Sustainability." The International Journal of Life Cycle Assessment, (R. Cassidy, D. Barista, J. Yoders, L. Nigh, B. Patton, and B. James, eds.), Reed Business Inc., 86(November), 256-263. 
Tinkleman, Michael, Point of Contact, ASME

\title{
ASME Sustainable Products \& Processes Strategic Plan, February 2011
}

\begin{abstract}
ASME's Center for Research and Technology Development (CRTD) Research Committee on Sustainable Products and Processes has been working since 2006 to examine the societal, environmental, and economic aspects of sustainability and to identify what ASME and its members can do to help improve and promote a more sustainable economy. A Sustainable Products and Processes Strategic Plan was developed from the recommendations of participants at a June 2010 workshop. The Plan outlines activities that ASME can accomplish that have the most potential for improving sustainability. The collection of activities such as sustainability standards and methodologies, conferences and seminars, education for engineers and consumers, and collaborative research projects outlined in the Strategic Plan have provided ASME with a targeted path forward for achieving a more sustainable manufacturing sector.
\end{abstract}

\section{Keywords}

Sustainability, Sustainable Manufacturing, Sustainable Products

\section{ASME's Role}

Despite economic pressures on and trends in the manufacturing industry, there is an expressed need to enable managers and policymakers to evaluate different solutions, options, policies, and programs. In a recent survey by Autodesk, 63\% of companies expected that their companies would have an increasing involvement with green or sustainable design specifications over the next year, due in large part to regulatory requirements, rising energy costs, and client demand. The American Society of Mechanical Engineers (ASME) could have a significant role by bringing objectivity and expertise to defining what constitutes a sustainable product or process.

ASME's Center for Research and Technology Development (CRTD) Research Committee on Sustainable Products and Processes has been working since 2006 to examine the societal, environmental, and economic aspects of sustainability and to identify what ASME and its members can do to help improve and promote a more sustainable economy. On June 17, 2010, the committee convened leading experts at the ASME Washington, DC office for a strategic planning workshop devoted to the development of a strategic plan identifying high-priority projects that ASME can pursue to enhance sustainable manufacturing. Experts representing the U.S. Department of Energy, the U.S. Environmental Protection Agency, the U.S. Army, national laboratories, universities, and leading auto manufacturers and suppliers joined the committee to identify projects that use ASME's unique resources and capabilities to address sustainability concerns.

The following material from the Sustainable Products \& Processes Strategic Plan are a result of these efforts. They reflect the suggestions and recommendations from the Sustainable Products \& Processes Strategic Plan Workshop participants. It outlines activities that ASME can accomplish that have the most potential for improving sustainability. This collection of sustainability standards and methodologies, conferences and seminars, education for engineers 
and consumers, and collaborative research projects will provide ASME with a targeted path forward for achieving a more sustainable manufacturing sector.

\section{Ideas for Enhancing Sustainability}

As previously emphasized, the actions taken to improve the sustainability of the manufacturing sector must minimize negative environmental impacts while aiding in economic growth and the advancement of the manufacturing sector. Advances in the following areas stand to have the most significant impact on improving sustainability in an economically feasible way:

- Product design for sustainability - Improvements to components of the product in the conceptual phase of development that make the product more sustainable as a whole

- Sustainable manufacturing processes - Improvements to parts of the manufacturing process that are determined to be inefficient and/or wasteful

- Systems approach to water management - An approach that takes all aspects of water management into account-from the flow of water into the plant through the handling of used water at the end of the manufacturing process - including its interaction with energy use

Within each of these areas that aim to improve sustainability are activities that ASME can use its vast engineering expertise and unbiased third-party status to accomplish. These activities include sustainability standards and methodologies; conferences, seminars, and meetings; education for engineers and consumers; and research and products.

\section{Product Design for Sustainability}

Sustainable product design encompasses the "redesign" aspect of the six Rs of global sustainability. To truly become more sustainable, designers must consider and improve each step along the entire life cycle, and potentially multiple life cycles, of the product - from material extraction through processing, use of the product, and disposal or remanufacture. Optimizing material and energy resources; making sure materials are produced responsibly with environmental best practices; choosing materials that are nontoxic, bio-based, or made from renewable resources; and designing for resources recovery or reintegration back into nature after use are among the many methods that could potentially help to improve sustainability through product design. Factoring these ideas into the conceptual phase of design is an even more efficient and effective way to ensure the overall sustainability of the product.

The following four specific actions have the greatest potential to enhance sustainability through product design:

\section{- Create a sustainable product rating systemincluding a national standard and testing procedures to ass ess conformity}

The nationwide focus on environmental responsibility is convincing an increasing number of consumers to buy "green" products. Third-party rating systems, such as Energy Star, enable consumers to quickly spot such a product and select it for purchase. The unbiased nature of these systems also builds a sense of trust in the consumer. By appealing directly to the consumer, rating systems provide manufacturers with an incentive to meet environmental standards and, as a result, encourage more manufacturers to do so. 
The development of a green product rating system requires not only that the standards be set but that there are a set of testing procedures in place to ensure that manufacturers are truly in compliance. In applying such a system to sustainability, ASME should first determine which sustainability attributes are desired in products from both a consumer appeal standpoint as well as a potential environmental impact standpoint. ASME should use these definitions as a guide to develop a set of standards and metrics for sustainability that could be translated into a rating "score" for a particular product to make cross-comparison easy for the consumer. As an unbiased, third-party organization known for its standard-setting abilities, ASME could tackle some or all of the components of developing a sustainable product rating system.

\section{- Develop methodologies and technologies for verification of performance with respect to sustainability metrics}

Manufacturers are, at times, unwilling to invest in sustainable product design because of a perceived low return on investment. Performance metrics are an essential part of ensuring that products designed in a sustainable way are achieving the reductions in negative environmental impacts, wasted energy and resources, and cost that they were designed to attain without sacrificing productivity. Ways to measure this performance are also needed to provide insight to the development of future sustainable products.

ASME can facilitate the collaboration and support the research needed to develop these methodologies and technologies. An important first step of this process is to ensure that sustainability metrics are defined and in place so that the methodologies and technologies can consistently reflect them. These methodologies and technologies can help show manufacturers that incorporating sustainable product design are performing at intended levels, which makes the investment less risky to their operations.

\section{- Develop common, standard terminology for sustainability, using the ASME Y14.5 dimensioning and tolerancing standard as a possible model from the tolerances field}

Because sustainability is a relatively new concept, common language for talking about it does not yet exist. The definition of sustainability itself varies from person to person, making it difficult to address the aspects of the issue and develop effective ways to measure it. Establishing consistent, standard terminology for talking about sustainability will help to align researchers and manufacturers communicating about common issues and designing products that address those needs.

Much as ASME did when developing the Y14.5 standard for the tolerance field, it can also use its position as a respected mechanical engineering authority to develop a common terminology for sustainability. The Y14.5 standard establishes uniform practices for stating and interpreting dimensioning, tolerancing, and related requirements for use on engineering drawings and in related documents. ASME should use this standard as a model to ease the development of this terminology. ASME should also develop a manual to educate designers and manufacturers about the standard terminology to ensure that it is known by those who need to use it. 
- Create an online toolkit for sustainable product design regarding water, energy, and materials

A major part of encouraging manufacturers to implement sustainable product designs is sharing best practices and methodologies. Being informed about methods for sustainable product design in water, energy, and materials use could encourage researchers to think a way they had not yet considered before. Having this information at the conceptual phase of the development process makes it more likely to be incorporated and, therefore, to have an impact.

ASME should develop a toolkit to address the front end of the development process before design. The kit should include standards that consider end-of-life recover and reuse in the design phase. It could also serve as a portal to other similar toolkits (e.g., Autodesk). By providing howto information and the tools with which to accomplish it, this toolkit can help make it easier for manufacturers and designers to consider sustainability in the conceptual phase of product design.

\section{Sustainable Manufacturing Processes}

Significant sustainability improvements can be made in the process of manufacturing products. By rethinking and improving the technology used or the flow of the process itself, manufacturers can reduce the amount of water, energy, chemicals, and fuel used. In doing so, manufacturers can help conserve resources and minimize their negative effect on the environment while, in many cases, also reducing cost. Minimizing outputs such as waste produced and resulting GHG emissions can also have a similar cost benefit. To make these improvements to current processes, researchers and plant engineers can gather and use data on inputs and outputs that can help determine where inefficiencies lie and make specific improvements to those areas to improve overall sustainability and reduce cost.

The following four specific actions have the greatest potential to enhance sustainability through improvements to the manufacturing process:

\section{- Define the critical factors that determine the sustainability of manufacturing processes}

Before any amount of refining of the manufacturing process design occurs, manufacturers and researchers as a whole must determine and agree on the critical factors that can help make manufacturing processes more sustainable. Identifying and sharing these critical factors can help researchers and manufacturers reflect on those aspects of their own processes and determine where sustainability improvements can be made.

ASME can convene field experts, manufacturers, and researchers to identify a set of consensusdriven factors that determine the sustainability of manufacturing processes. As an unbiased thirdparty, ASME can also use these factors to develop standard measurement methodology in the manufacturing processes. By setting this standard, ASME can help manufacturers focus on what improvements they can make to their own processes and help researchers and designers take a targeted approach to sustainable process innovation going forward.

- Develop a standard that could brand sustainable manufacturing and that addresses all utilities (e.g., energy, water, steam, etc.), including metrics, verification, and branding 
Similar to the sustainable product rating system for products, manufacturing processes can also be labeled as "sustainable" to encourage manufacturer adoption and consumer purchase. Providing a well-publicized standard, ways to measure and verify that processes meet the standard, and a label to make this adherence visible to consumers could encourage manufacturers to adopt practices into their manufacturing processes that are more sustainable.

ASME can help develop and act as third-party verification for such a standard. Since the standard will need to be developed for a wide range of manufacturers, ASME could also play a pivotal role in addressing the challenge of including small- and medium-sized enterprises in the standard. ASME should also ensure that the standard is transparent.

\section{- Educate manufacturing plant engineers on how to conduct an energy audit and on best practices for all utilities}

A key component of improving the sustainability of manufacturing processes is making energy use more efficient. Reducing energy consumption, relying on more renewable energy sources, and utilizing byproducts of energy use, like waste heat, in other parts of a manufacturing process can all contribute to a more sustainable process. Enabling plant engineers to measure the energy involved in their processes and to indicate areas where improvements can be made can help improve sustainability and energy costs for a manufacturer.

By developing how-to information on conducting an energy audit, ASME can serve as a source of information for manufacturing plant engineers interested in determining where improvements can be made in their own processes. ASME can distribute this information, as well as information about working with utilities, in a variety of ways: making it available on their website, providing a guide to interested engineers, or hosting conference and seminars to disseminate this information.

\section{- Conduct a remanufacturing survey measuring market size; new technologies; and how much energy, cost, and $\mathrm{CO} 2$ is saved}

Remanufacturing involves disassembling products, replacing or refurbishing worn out or obsolete components, and putting the product back together for sale "like new." Because remanufactured products should match the same customer expectation as new products, there are some sustainability benefits to this procedure on the manufacturing scale. However, current knowledge about the demand for remanufactured products, the technologies that can help achieve it, and its benefits is minimal.

ASME can support efforts to understand the role of remanufacturing in sustainable processes by conducting a survey measuring market size; new technologies; and how much energy, cost, and $\mathrm{CO} 2$ is saved. Using its members as a base to reach out to manufacturers currently employing remanufacturing techniques in their processes, ASME can garner knowledge based on real-world experience to determine whether or not there are substantive sustainability benefits to using remanufacturing. ASME can then use the results to educate researchers looking to advance this technique and manufacturers interested in employing it to improve sustainability. 


\section{Systems Approach to Water Management}

The manufacturing sector is a heavy user of water, relying on it as a coolant and a cleaner throughout material extraction, production, and disposal or remanufacturing processes. However, in the United States, an aging water infrastructure and inefficient water usage are combining to make the current growth in water demand unsustainable. While some major industrial water users, such as the pharmaceutical, electronics, and semiconductor industries, have paid attention to water issues, water conservation today has not received as much attention as energy conservation. Water use needs to be viewed as the essential part of the many aspects of the manufacturing sector that it is and made more sustainable through an approach that takes all aspects of water management into account, including its interaction with energy use. Engineering professionals, like ASME members, must take a leadership role in educating political leaders, industry, leaders, and the general public if the complex issues surrounding water usage are to be thoughtfully addressed.

The following three specific actions have the greatest potential to enhance sustainability through a systems approach to water management:

\section{- Develop a research consensus document for water reuse in industrial operations}

Water reuse has the potential to improve the sustainability and reduce the cost of manufacturing processes by reducing the need for "new" water to be introduced into the process. However, there is currently no overarching consensus document on the logistics and best practices of water reuse, making it difficult for plant engineers to determine if and how they can safely and efficiently integrate water reuse to improve the sustainability of their manufacturing processes. ASME should support the development of a research consensus document for water reuse in industrial operations. This effort involves surveying real-world manufacturing processes that incorporate water reuse as well as researching new ways to achieve it. ASME should then convene leading researchers in this field to reach a consensus on the methods for and merits of water reuse in industrial operations. ASME should publicize the findings in a research consensus document, distributing it to water treatment plants, manufacturing plant engineers, and government regulators.

\section{- Link the flow of gray water from wastewater treatment plants to steam-electric power plants and link the flow of gray water to its use in manufacturing facilities in general}

As demands for scarce or more costly potable drinking water increase, industry will increasingly be asked to find ways to use nonpotable "gray" water. Determining how water is used in manufacturing processes and whether the infrastructure to transport it exists is a key factor in determining the economic feasibility of incorporating this type of water into plants. By mapping the flow of gray water to its use in manufacturing facilities, such as steam-electric power plants, manufacturers can determine whether or not it is feasible for them to use gray water in their processes and, in turn, aid in the sustainable use of water.

ASME can support the development of a map of the flow of gray water from wastewater treatment plants to its use in manufacturing facilities. Steam-electric power plants are well known for using gray water, so determining the link for that facility will serve as a good model 
for the development of a more general map for all manufacturing facilities. ASME can support the research needed to develop this map and aid in publicizing it to manufacturing facilities to ensure that they are aware of the ways gray water can be incorporated into their plants.

\section{- Develop life cycle analysis methodologies for assessing water use and develop a water- content metric for products and processes}

Reducing the amount of water used in a product or process is a way to improve overall sustainability. To effectively determine where improvements can be made, designers and plant engineers should examine water use from a life cycle perspective-from the material extraction part of the product's development or manufacturing process through disposal. Designers and engineers need consistent methodologies that can be applied across plants and product types to enable them to effectively measure water use and content and identify where sustainability improvements can be incorporated.

ASME should develop life cycle analysis methodologies for assessing water use in manufacturing products and processes. ASME should also develop water-content metrics that can help characterize water content in products separately from water used in manufacturing processes. Providing consistent methodologies for measuring water use and content helps engineers and designers to better identify areas of wasted water, associating cost and efficiency losses with wasteful water use. This could help to encourage the use of less water in products and processes or perhaps different sources for water, such as gray water or reuse within processes.

\section{Other ASME Sustainability Programs}

ASME 8th Annual International Conference on Energy Sustainability http://www.asmeconferences.org/ESFUELCELL2014/ 
[This page is internationally left blank] 
Uddin, Nasim, University of Alabama at Birmingham and Craig Taylor, Imagecat, Inc.

\title{
Advances in Measurement Science to Enhance the Resilience of Infrastructure to Natural and Manmade hazards
}

\begin{abstract}
Standard methods of predicting, evaluating, and assessing the disaster resilience of structures as they respond to extreme loads are much needed by the engineering community. Moreover standard methods of assessing disaster resilience and measurement metrics for use in making disaster preparedness and mitigation decisions are lacking. In addition extensive research is needed to address the gap between basic research and building codes, standards, and practice through measurement science research to predict structural performance up to failure under extreme loading conditions, predict disaster resilience at the building and community scale, assess and evaluate the ability of existing structures to withstand extreme loads. The papers discusses approaches for improvement in performance prediction of infrastructure, risk consistent design approach for designing innovative hazard resistant structures and for ensuring infrastructure performance under all weather conditions, risk consistent design approach for multiperil, and robust simulation as assessment tools to predict consequences of disasters, leading in turn to increased resilience.
\end{abstract}

\section{Keywords}

Infrastructure, Robust Simulation, natural and manmade hazards, Measure, Measurement

\section{Background}

The US infrastructure sector and its design professionals are facing several fundamental challenges that pose both threats and opportunities. In the area of sustainability, construction wastes constitute minimum $25 \%$ to over $40 \%$ of all waste representing both environmental challenges and lost opportunities with societal pressure is growing to reduce the environmental footprint of construction. Infrastructure is deteriorating accelerated by climate change - growing deficit in maintenance and replacement. Natural resources are being challenged with construction consuming over $50 \%$ of primary resources. Climate change impact needs to be addressed including how does one identify infrastructures most at risk for climate change impacts, the possible method for prioritization as a first step in climate change adaption, how to explore the types of adaptation strategies which would be most beneficial in terms of social, economic and environmental value. Moreover, global climate trends and the consequent global sea level rise and increased temperature, combined with potentially increased rates of extreme natural hazards, necessitate the consideration or reconsideration of current planning, engineering and management practices of infrastructure. All these forces discussed above create a great need for more effective materials, methods, and techniques for designing sustainable structures. In addition, there have been major revisions to the structural codes to better withstand natural phenomena, such as hurricanes, floods and earthquakes. Despite the widespread attention given to hazard mitigation and sustainability in the last decade, societal interest has been minimal. Adoption of green build ing (sustainability) or building code 'plus' standards (resilience) has been poor. The barriers for implementation are not well understood, although socioeconomic factors are generally seen as the constraints. Current civil infrastructure design is based on 
designing each "member" for its "most critical" combination of multiple load combinations based on code prescribed load. The sensitivity of the final design to sustainable alternatives, for example unexpected deviations in flood or wind loads (for example, black swan) on a structure whose final design have been dominated by an assumed earthquake load is routinely ignored. Potential consequences due to occupational loads, indoor health effect, targeting energy efficiency with low carbon foot print and reduced environmental effect, environmental degradation of construction materials with resulting interaction, and socio-economic effects from natural hazards and intentional hazards have not been fully incorporated into structural design.

\section{Gaps and Research Needs}

\subsection{Improvement in Performance Prediction of Infrastructure}

To accommodate the performance of current and novel materials and/or design and construction techniques, as well as different conditions (such as different climatic conditions), a better prediction of how infrastructure assets will perform is needed. Current best practices have a large uncertainty in the prediction of infrastructure performance, which is largely based on empirical knowledge making design, construction and maintenance tend to be conservative. In addition, the introduction of new materials, systems and techniques is time consuming. New (e.g. probabilistic or deterministic) models need to be developed for the prediction of material and structural performance and deterioration including testing protocol for full scale flood, storm, and hurricane level wind testing at the system level (Fig. 1 shows full scale flood testing). Their validation and demonstration in practice shall prove their ability to predict infrastructure performance with appropriate accuracy. This shall include various conditions, current designs and materials as well as novel design materials for which no knowledge exists at present. The models should be based on sound physical principles and they might be either numerical or/and empirical methods, e.g. through the application of artificial intelligence, requiring a minimum of (time-consuming) empirical testing.

For example, probabilistic frameworks for performance assessment of low buildings under hurricane multi-hazards are mostly limited to non-engineered timber structures. The Performance-Based Design (PBD) approach, originally developed in seismic engineering, offers the potential for designing smarter, hurricane-resilient structures. Previous studies on performance-based wind engineering (PBWE) mostly focused on light-frame wood buildings for which construction quality and workmanship issues, including missing fasteners, are common. Many past failures were attributed to inadequate building code enforcement and poor workmanship, rather than to shortcomings of prescriptive requirements. The discrepancy between what is designed and what is built makes application of PBWE to light-frame wood buildings difficult. If a building can be assembled from a few large engineered components using well engineered connection methods, then quality control moves from the building site to the much more easily controlled conditions of the factory floor. A systematic performance-based design approach for engineered low-rise buildings, validated through test-based results, remains to be developed. This gap in scientific knowledge hinders performance-based design of engineered low-rise structures, and impairs the nation's ability to prevent hurricane hazards from becoming disasters. The multi-hazard nature of the phenomena related to hurricanes and their effects on the built environment should be modeled in the following three different scenarios (Barbato et al. 2013): (a) Independent hazards that can occur individually or simultaneously, e.g., wind borne debris and flood hazard can be considered as independent of each other because no 
mutual interaction between the two hazards has the effect to f modifying the intensity of the corresponding actions; (b) Interdependent hazards, e.g., wind and windborne debris hazards are interacting hazards as the actions produced on a structure by these hazards are interdependent (increase in wind speed will enhance the kinetic energy of wind-borne debris and escalate the risk of building envelope breach); (c). Sequential hazards, e.g., windborne debris damage to the envelope may increase the wind loading due to internal pressurization and modify sequentially the vulnerability of the structure; wind induced deformation of member joints can sequentially lead to rainwater ingress.

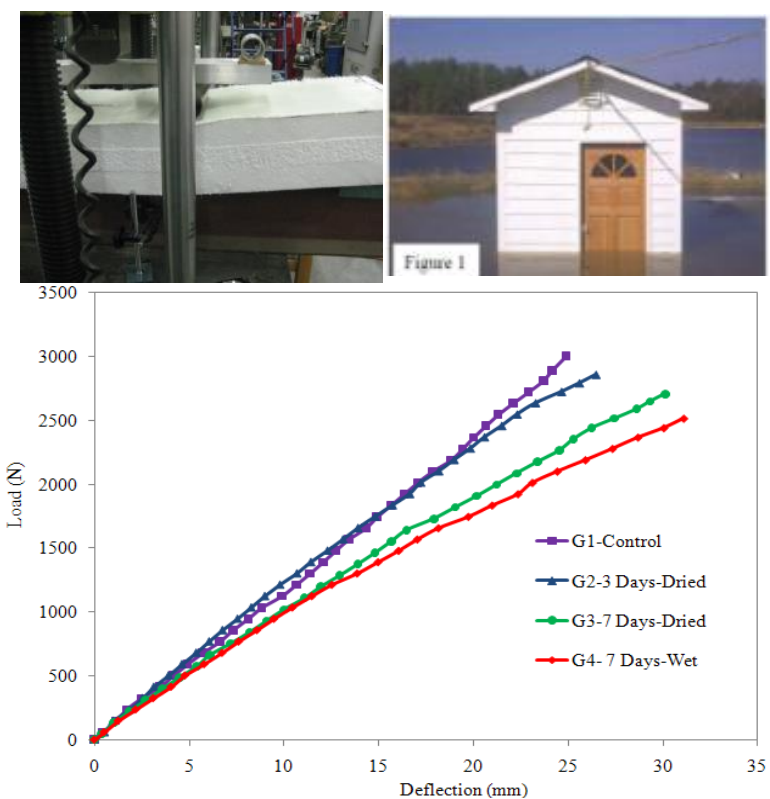

Figure 1. Full scale flood testing and performance assessment

\subsection{Developing Risk Consistent Design Approach for Innovative Hazard Resistant Structures and Ensuring Infrastructure Performance under all Weather Conditions}

Extreme weather events, will increase over the coming years and decades with the changing climate. Solutions are needed that mitigate these impacts to the extent that service performance levels are maintained regardless of the weather conditions. This requires advanced systems, materials and processes that strongly reinforce the infrastructure's resistance to the adverse impacts of extreme weather. Novel materials and techniques will be needed and demonstrated that allow full service under wide-ranging weather conditions. These might include materials that are highly resistant to cold weather (e.g. freeze-thaw), survive extended flooding and other extreme events. In addition, focus is on the development of specific infrastructure assets that enable rapid repair actions in case of major disasters and emergency situations, such as through the use of composite lightweight materials.

Uddin et al (2014) first introduces an innovative Composites Structural Insulated Panels (CSIPs) for structural wall and floor applications against multiple hazards, and then presents an innovative risk consistent design approach for designing such system. The proposed composite panel is made of low cost thermoplastic orthotropic glass/polypropylene (glass-PP) laminate as a facesheet and Expanded Polystyrene Foam (EPS) as a core with very high facesheet/core moduli ratio. The proposed CSIPs are intended to overcome problems of traditional wood panels against multiple natural hazards including earthquake, flood and windstorm to poor penetration 
resistance against wind borne debris, termite attack and mold buildups etc. Wide spread failure of structures due to recent hazards has shown the weakness of the available design methods and therefore has highlighted the need for a new design procedure for building and other infrastructures that are hazard-prone. The main reason of the failures is that the uncertainty in both loading and material strength was not taken in to consideration accurately during the design process. To achieve the desired balance between the high initial cost and the damage costs due to structures' failure, the life-cycle cost (LCC) and the uncertainty in both loading and system strength should be considered. In an effort to design structures against multi-hazard load, a method will be investigated that accounts for the uncertainty in both loading and strength. A new type of structural sandwich panel was presented in this study for structural wall applications. These panels are namely as Composite Structural Insulated Panels (CSIPs) and are made of orthotropic glass-PP laminates as facesheets with EPS foam as a solid core. Further, an approach for optimum design for structures against multiple natural hazards was developed. The proposed methodology is based on the LCC and target safety index $(\beta)$. The LCC method accounts for future damage costs resulting from hazards based on the QRA concept. The safety indices were calculated for the two main criteria controlling the design (strength and drift). The uncertainty in loading, strength was considered. The main purpose of the QRA concept is to reduce the cost due to structures' damages as a result of hazard loading. Further, involving the safety indices would enable optimum design of structure to significantly reduce the consequences expected to occur from any potential future hazard effect. In addition, considering the epistemic uncertainty in the calculated probability of failure and safety index will minimize the expected risk. To this end, a methodology is presented to achieve the combination of LCC and safety indices for strength and drift developed for structure model. The structural engineer can then optimize the design by selecting the most appropriate structure that satisfies the project requirements. The approach was demonstrated with case studies on two structures: one for traditional wood and another for CSIP. Seismic and wind hazard were considered in the analysis. Two locations were considered; Los Angeles, CA and Charleston, SC. These locations are critical for seismic and wind load; respectively. The results showed that CSIP building is cost effective and provides higher safety indices than traditional wood structure. Based on the findings of the case study, the optimum design (Fig. 2) was observed to be different than that of the code demonstrating the shortcoming of the current code design and potential of the proposed method. 


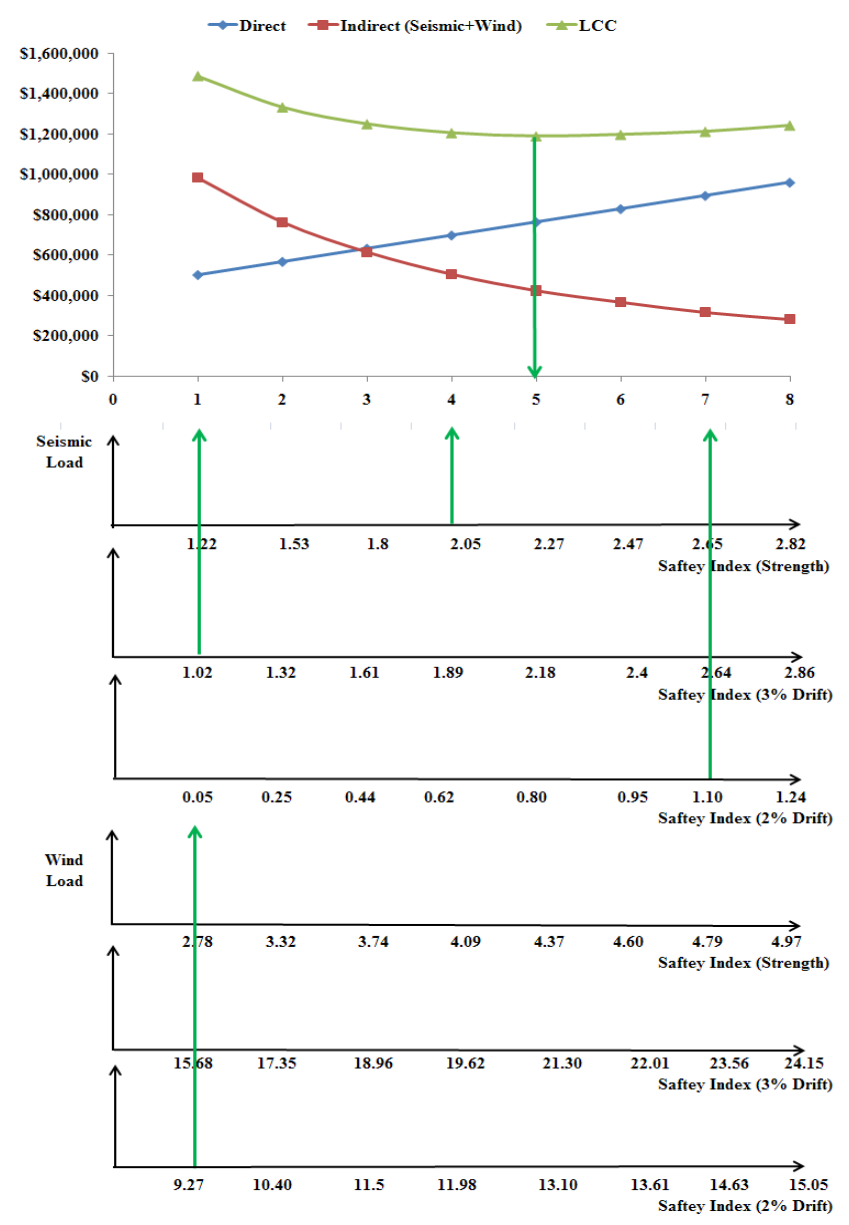

Figure 2. LCC and safety indices for wood building models in Los Angeles

\subsection{Developing Risk Consistent Design Approach for Multiperil}

Multi-peril design criteria are often ignored if only because it is time-consuming to become expert in one peril and controversies can rage over design levels for any one peril. For quake and wind perils, it is often assumed that one peril dominates the design criteria. However, a prima facie case of considerable interest has been developed to indicate that there needs to be multi-peril design criteria at least for quake and wind, and for risk reasons this design level is greater than the level for either quake or wind. Reformulating the reasoning in Datinh and Simui (2010), one begins by assuming that for each site there is a PML of total loss for each peril. One assumes that for a given return interval, one of the two perils has the higher PML of total loss. If for the lesser of the two perils, there is some probability that this peril can exceed this higher PML of total loss, then at the specified return interval, PML of total loss is higher for the combined perils than for either peril. This reformulation does not assume that total loss is identical with collapse, a fairly good assumption for quake but not for wind.). The importance of this procedure is to illustrate how persuasion, not compulsion, should be a prominent approach in developing major decisions on multi-peril issues (or other issues such as those pertaining to climate change). Using ensemble outcomes and a variety of quantitative decision procedures can illuminate this (Toulmin-like) hypothesis about how persuasion rather than compulsion is desirable in major social and scientific issues. 
Based on Taylor et al (2014) this multi-peril consideration can be evaluated with respect to (a) multiperil, and (b) with regard to different acceptable risk criteria. First, only a uniform risk level can be postulated. Second, marginal design costs can be used to limit cases in which designs against collapse become very steep at a certain return interval. Third, instead of using collapse criteria, life-safety criteria can be used. Incorporating "marginal cost" criteria may appear to be a "welfare" issue, but these criteria have been used in for instance seismic design criteria. Given these three perspectives on the multi-peril issue, methods can be used to show various alternative design levels and design combinations that may be suitable in a multi-peril setting. The methods proposed also can be readily extended to a community basis as needed. The goal will be to identify a robust ensemble of such combinations rather than a single "optimal" combination. Moreover, a decision making framework can be formulated to assess mitigation and adaptation to future uncertainty projections in terms type I error i.e., the decision to design for a future condition and to eventually find out reliably through empirical evidence that the original condition persists, and type II error where the decision to not design for a future condition and to eventually find out reliably through empirical evidence that the future condition is defensible as discussed by Ayyub and Klir (2006).

\subsection{Robust Simulation as Assessment Tools to Predict Consequences of Disasters, Leading in Turn to Increased Resilience}

Robust simulation based on Taylor et al (2014) consciously acknowledges the scientific challenges when adopting the diverse but plausible models into modeling the catastrophic risk in a region, and makes the best effort to reveal the uncertainties associated with these models in the risk analysis results, through a coherently designed simulation approach. This approach has become common for instance in climate change studies and used in 100-year planning studies. And future uncertainties may appear to increase when we include or know more (e.g., how rupture propagation moves onto secondary branches). Or, future data may reduce uncertainties. And this of course depends on how we measure "uncertainty." In general, what future science will yield is not a measurable uncertainty. As portfolio methods have evolved, they are wellsuited to address this issue. However, additional insights into catastrophe risk methods have arisen chiefly as a result of the presences of very enhanced computer techniques, policies that have encouraged different teams of investigators to compete in developing some key sub-models in catastrophe risk modeling, and the increasing recognition that there are profound reasons why alternative professional investigative teams may indeed develop divergent sub-models regardless of the size of the "base" [finite] database to which all investigative teams have access. An advantage of robust simulation is that it forces us to confront the limitations and uncertainties of our catastrophe models. It is better to acknowledge and tolerate this uncertainty, rather than using methods that conceal or suppress uncertainty. Acknowledging the limitations in models will highlight the value of improved exposure data (age and quality of construction) and encourage efforts to gather and manage exposure data to reduce the impacts of exposure uncertainty.

One of the desirable features of robust simulation is the ability to identify and trace back through consequence trajectories that produce extreme consequences. Rather than focusing on mean or median responses and effects, robust simulation can readily be used to explore the paths and sequences of events and conditions that produce optimal success or catastrophic failure. This can provide unforeseen opportunities to improve the outcomes, as means are used to enhance the most positive outcomes and reduce or eliminate the most negative consequences. The contrast in solutions provided by these rival models can help identify the full span of potential 
consequences. Conversely, with logic trees and conventional (atomistic) models, these cases are lost, and so never get explored. Furthermore, the random-walk methods employed in robust simulation are ideally suited to the evaluation of challenges such as aftershocks exposing buildings to multiple ground shaking events before repairs can be completed. In this case, the building models must "remember" previous damage. The statistical sampling techniques can allow the exploration of the consequences of maximum direction ground motions for buildings with disparate systems and capacities in different framing directions. Models capable of representing both wind and earthquake response can be integrated within random walks to explore the life-safety and economic consequences of multi-peril environments.

\section{Conclusions}

Traumatic failure and destruction caused by the massive storm, earthquake and tsunami motivated renewed emphasis on sustainable approaches to managing public infrastructure. Technologies that help reduce climate change are in demand more than ever before. In the future, ecology and the economy will become inseparably connected, as preventive measures will be more cost effective in the long term than remedying the damage caused. Research is needed to enhance the resilience and robustness of structures by focusing on improvement in performance prediction, risk consistent design approach, multiperil design and robust simulation as assessment tools to predict consequences of disasters, leading in turn to increased resilience

\section{References}

Barbato, M., Petrini, F., Unnikrishnan, V. U., Ciampoli, M. (2013).’Performance-based hurricane engineering (PBHE) framework." Structural Safety, 45, 24-35.

Uddin, N., Mousa, M. A., Dong, L,. (2014).’Risk consistent design approach for designing innovative hazards resistant structures." Second International Conference on Vulnerability and Risk Analysis and Management (ICVRAM2014, University of Liverpool, UK, 13 - 16 July 2014.

Duthinh, Dat and Emil Simiu, 2010, "Safety of Structures in Strong Winds and Earthquakes: Multihazard Considerations," pp. 330-333, ASCE Journal of Structural Engineering, Volume 136, Issue 3 (March 2010)

Ayyub, B. M., and Klir, G., 2006, Uncertainty Modeling and Analys is in Engineering and the Sciences, Chapman \& Hall/CRC Press.

Taylor, C.E., Uddin, N., Graf, W., Liu, F., and Lee, Y. Robust Simulation: Why and When Needed and What Should be Qualified" Second International Conference on Vulnerability and Risk Analysis and Management (ICVRAM2014) 13 - 16 July 2014, University of Liverpool, UK, Michael Beer, Ivan S.K. Au \& Jim W. Hall (editors). 
[This page is internationally left blank] 
Wallace, William A., Founder and President, Wallace Futures Group, LLC

\title{
Research Needs for Sustainable Infrastructure Engineering for a New Harsh and Resource-Constrained World
}

\begin{abstract}
Projects in the built environment, e.g., buildings, roads, bridges, dams, water treatment plants, have always been planned, designed, constructed and operated based on assumptions of stationarity. That is, project owners and engineers assumed with good confidence that the cost and availability of resources, and environmental operating conditions will be relatively constant and predictable throughout the project lifecycle. Unfortunately, multiple decades of working under a non-sustainable economic development model have made these assumptions unreliable. Increasing shortages of energy and fresh water along with more frequent, extreme weather events provide ample evidence of this change. Continuing application of these assumptions creates a significant risk to health, life, property, and the environment. Research is urgently needed to learn how these assumptions are changing and affecting infrastructure performance. New timeand risk-based design assumptions and associated methodologies are needed to create projects that operate safely and effectively in this new and continually changing world.
\end{abstract}

\section{Keywords}

Infrastructure, Measurements, Risk, Stationarity, Sustainability, Vulnerability.

\section{Purpose}

This paper shows that multiple decades of excessive resource consumption and environmental degradation have changed significantly the conditions under which buildings and infrastructure are expected to operate. Research and development efforts are urgently needed to provide project owners and engineers with adequate knowledge of how key design variables are changing, along with a new project delivery methodology capable of addressing this level of change. Without this new knowledge and methodology, the engineering community will continue to deliver buildings and infrastructure that add unnecessary risks to human health, life, property and the environment.

\section{Background}

Contrary to Shakespeare, what is past is no longer prologue, at least not for engineers working in the built environment." William A. Wallace

Over the last twenty years, the notion that society's approach to economic development is not sustainable has moved from extremist thinking toward mainstream opinion. Spiking energy prices, water shortages, extended droughts and heat waves, record storms and flooding, frequent forest fires - incidents once seen as disturbing but manageable - are now viewed as serious challenges to sustaining and improving our quality of life.

These trends and events should not be surprising. Decade after decade of excessive resource consumption and environmental degradation has seriously depleted important non-renewable resources and damaged the provisioning and regulating functions of the Earth's ecological systems. The consequences of this behavior are starting to emerge, expressed as shortages of fuels and fresh water, more frequent extreme weather events, ocean dead zones, and more. 
These consequences create serious problems for engineers working in the built environment. They alter significantly the cost and availability of important resources, and change the operating conditions under which buildings and infrastructure are supposed to operate.

Engineers have responded to these problems, at least in part. They are working to improve sustainable performance by reducing resource consumption and protecting the environment. In doing so, they are learning that such efforts can yield significant benefits in terms of operating cost reductions and public acceptance. They are also finding new ways to generate energy from renewable sources, use recycled materials, and protect, enhance and restore ecosystem resources and functions.

Unfortunately, engineers are working on the wrong problem, or at least not the complete problem. Today's critical issue in buildings and infrastructure project sustainability is not just how to improve sustainable performance, but also how to address the consequences of multiple decades of non-sustainable performance. Recent events such as the devastation from Hurricane Sandy, flooding in Colorado and the upper mid-west, extreme drought and forest fires in California, and a mudslide in the Pacific Northwest suggest that our existing buildings and infrastructure designs are not sufficiently robust or resilient to handle these new conditions.

\section{Three Challenges to Solve Simultaneously}

In delivering projects in the built environment, engineers are now faced with three challenges:

a) Meet the project owner's needs, objectives and specifications. The project must be designed and delivered so that it performs in the way the owner intended. However, these may have to be modified to address the changes noted in "c" below.

b) Contribute to improved sustainable performance. The project should also set objectives for maintaining, enhancing and/or restoring ecosystem and social/cultural services. Not doing so makes the project a contributor to further depletion and degradation. Such objectives should be incorporated into decisions made in response to "a."

c) Account for a changing operating environment. The project must identify and address any significant changes in the environmental operating conditions the project may face over its design life. Changing conditions must be managed so that the project will still meet owner needs, objectives and specifications determined in "a." However, if the probable extent of these changes exceeds the capacity of the project design to accommodate, the owner may be forced to reset project objectives and specifications accordingly.

These challenges need to be addressed through an iterative process. That process must balance owner needs for certain levels of functionality and performance against the need to perform satisfactorily under new extreme conditions while reducing the lifecycle ecological and social impacts of the project.

\section{Gaps and Research Needs}

"If we want things to stay as they are, things will have to change." Giuseppe di Lampedusa, The Leopard (1957)

The current processes for planning, design, construction and operation of buildings and infrastructure assume a high degree of what is called "stationarity." Stationarity means that the design assumptions about resource costs and availability, and environmental operating 
conditions closely follow stable historical trends, and can be applied confidently as a predictor of future conditions. Unfortunately, multiple decades of resource depletion and ecosystems degradation have made those assumptions questionable. See Figure 1 below. Consequently, using historical assumptions, especially for long-lived infrastructure projects, could result in a degradation of project functionality and performance. Worse, that project could pose a significant risk to human health, life, property and the environment.

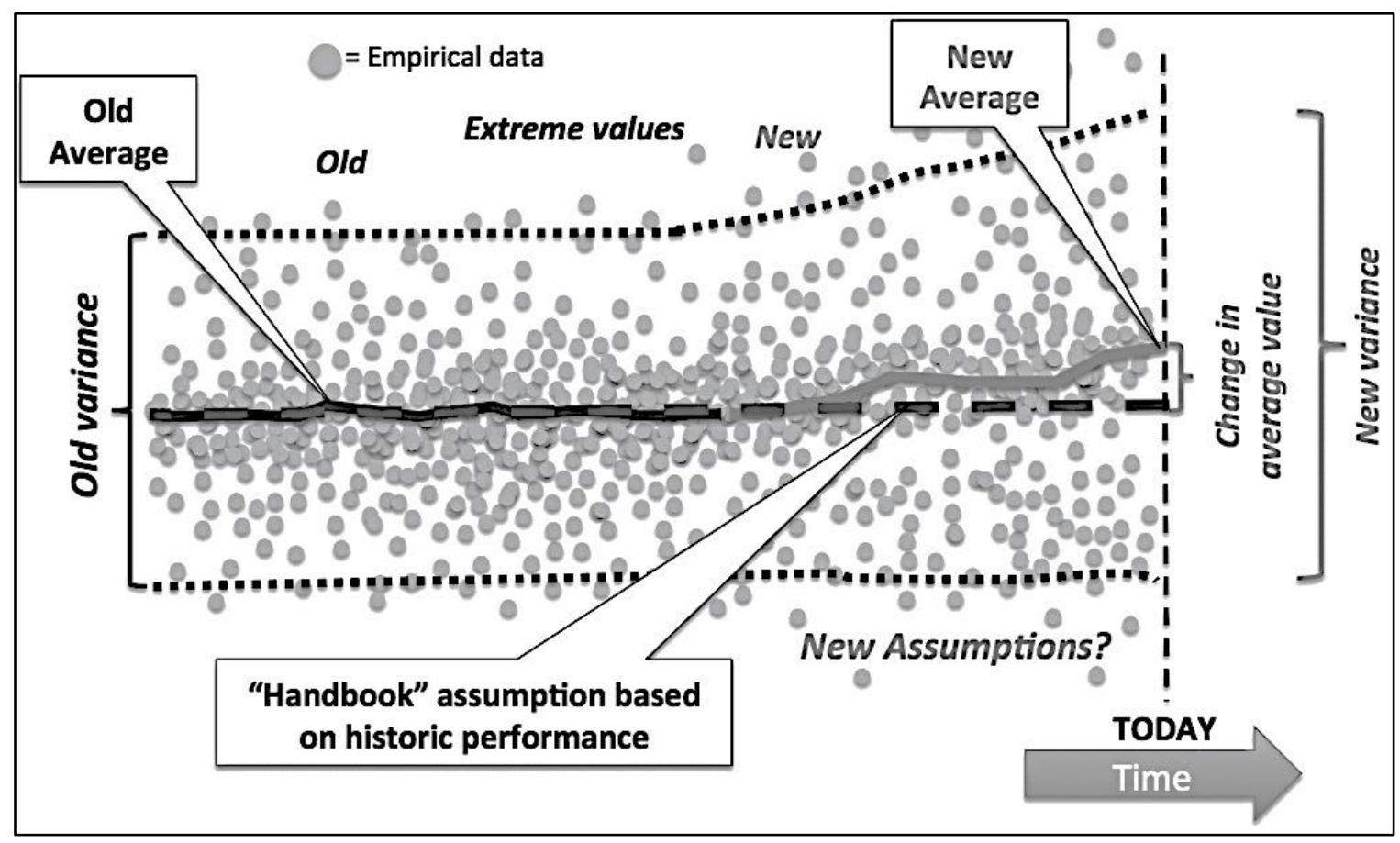

Figure 1. Design Assumptions: Historic vs. New Mean, Variance and Plausible Extremes

Conditions of "non-stationarity" have created three significant gaps in project delivery for the built environment. These are:

- Little or no understanding of how and the extent to which changes in resource costs and availability, and changes in environmental operating conditions will affect key design variables over time. The implications of non-stationarity are that many of the current design assumptions for buildings and infrastructure need to be scrapped, replaced by dynamic, time- and risk-based assumptions about future conditions.

- Lack of accepted practices for designing and delivering projects under conditions of nonstationarity. The current linear project delivery practices are not sufficient to address the high degree of change, particularly when the rates of change and possible secondary and tertiary effects are poorly understood. The engineering community needs to develop new project delivery methods that anticipate and account for significant changes in design and operating variables.

- A huge disconnect between what should become standard engineering practices and the current legal standard of care. The legal yardstick for determining negligence, the standard of care that governs engineering work in the built environment is essentially, 
"Did you design and build the project like everyone else would have done?" This is a standard based on assumptions of stationarity. In our highly litigious society, advances in the application of different but more appropriate design assumptions and project deliver methods will be curtailed significantly.

\section{Research Needs}

The processes for planning, design and construction of buildings and infrastructure need to be revised to address these challenges. As part of those processes, new design assumptions need to be established that take into account the changing nature of resource cost and availability, and environmental operating conditions. These assumptions need to be both time based and risk based. They need to be time based in the sense that the values of key design variables (mean, variance and plausible extremes) are expected to change over time in ways that are not readily predictable. They also need to be risk based in the sense that the variables could reach values that create significant risks to human health, life, property and the environment. Some values of these variables may hit tipping points, creating additional effects which are significant but not necessarily intuitive.

This raises a number of important questions that can only be answered through coordinated and systematic research programs.

- Can we bound with confidence the expected design variable change to a range that is within the economic design life of the project and is still protective of human health, life, property and the environment? If not, can we develop satisfactory ways to handle these changes?

- Can we identify significant secondary and tertiary effects that may emerge at certain values of these variables, and which in turn may have significant effects on project performance?

- Can we design economically into projects sufficient levels of robustness, adaptability and resiliency that can account for changes in the mean, variance and extremes of key design variables?

- Can we identify, measure and set thresholds for values of operating performance metrics which if exceeded, would trigger predetermined operational and/or structural modifications? These modifications would be implemented to maintain economic and effective operation, protect health, safety, property and the environment.

The objective of this research program would be to develop a workable set of engineering design information and project delivery processes appropriate for these challenges. One outcome would be a dynamic building and infrastructure design database containing time- and risk-based information about design variables and associated assumptions. The database would be maintained and updated regularly as resource costs and availability and environmental operating conditions change. Another outcome would be new, iterative project design and delivery processes that enable engineers to address these challenges effectively and systematically.

The following steps are suggested.

1. Disaggregate the various forms of buildings and infrastructure into various project types, classified by the design variables associated with resource requirements and environmental exposures. 
2. For each project type, determine the values of the mean, variance and reasonable extremes of the variables typically used in the planning, design, construction and operation of these projects. These will vary based on geographic location, intended operation and other factors. Existing engineering standards and building codes should be taken into consideration.

3. For each variable, conduct research to determine the probable ranges of the variables (mean, variance and reasonable extremes) over time. These ranges should be based on location, intended operation, and other factors.

4. For each variable, conduct research to determine the existence of potential secondary and tertiary effects that may emerge at certain variable values. Determine the significance of these effects on project performance. For example, an extreme storm could cause high velocity stormwater runoff, which would test the adequacy of early warning systems and stormwater controls.

5. For each project type, conduct research to determine ways to balance the economies of long-lived designs against the risk of premature loss of functionality due to unanticipated changes in resource availability or environmental operating conditions. Factor in alternatives such as additional robustness, adaptability and resiliency. Also consider issues such as overall system redundancy.

6. For each project type, conduct research to determine the kinds of measurements, performance assessments and controls that could be put in place to determine if the operating performance metrics (e.g., cost, availability of operating supplies, environmental operating conditions) are still within an acceptable range. This research should also determine the thresholds for values of these operating performance metrics. If these thresholds were exceeded, those events would trigger operational and/or structural changes to maintain efficient and effective operation.

\section{Conclusions}

This research work is both important and urgent. As author and educator Mathis Wackernagel pointed out, "We are building 2050 today." With no other basis to proceed, owners and engineers are delivering buildings and infrastructure using flawed assumptions about future cost and availability of resources and environmental operating conditions. In addition, they are using project delivery methodologies that do not take into account the consequences of change. Finally, the current legal test for engineering negligence ("Did you design and build the project like everyone else would have done?") creates significant resistance to the necessary modification of current practices.

Regardless, the engineering community needs press forward to develop new set of design assumptions and project delivery methodologies commensurate with the challenges at hand. Any delays will inevitably result in additional risk to health, life, property and the environment.

\section{References}

Wallace, William A., "Working to Engineer Infrastructure Resiliency in a Changing Operating Environment," ASCE GeoCongress, Atlanta, GA. (2014)

Institute for Sustainable Infrastructure. (2012). Envision, Version 2.0: A Rating System for Sustainable Infrastructure. Washington, DC, Institute for Sustainable Infrastructure. 
McKibben, Bill. (2010). Eaarth: Making a Life on a Tough New Planet, New York, NY. Times Books, Henry Holt and Company.

\section{Acknowledgements}

The author acknowledges and greatly appreciates the contributions by S. David Ellison, President of Synergy Connects, Inc. for his contributions to the development of a process for sustainable project management. Dave designed and delivered the recorded ASCE course, "Sustainable Project Management: Delivering Projects for a More Sustainable Infrastructure." 
Wang, Zhichao, Shapour Azarm, and P. K. Kannan, University of Maryland

\title{
Design for Supply Chain and Interoperability in Profit-Sustainable Market Systems
}

\begin{abstract}
This paper describes some of the main challenges in the design for supply chain and interoperability considerations in profit-sustainable market systems. Some previous works in this area are briefly reviewed, a few gaps are identified and research needs are described. Highlights of a research framework are presented which accounts for upstream suppliers and interoperability by considering: (i) product modularity, (ii) interoperability among the modules of a product, and (iii) valuation of a product design from a marketing perspective. In such a context, sourcing components upstream and focusing on interoperability among all interfaces in order to achieve the product's functionalities can become an important undertaking in the design for profit-sustainability.
\end{abstract}

\section{Keywords}

Design Decisions, Modularity, Supply Chain, Interoperability, Profit-Sustainability

\section{Background}

According to the International Trade Administration's Sustainable Manufacturing Initiative $(\mathrm{SMI})^{21}$, sustainable manufacturing is defined as: "the creation of manufactured products that use processes that minimize negative environmental impacts, conserve energy and natural resources, are safe for employees, communities, and consumers and are economically sound." Among others, SMI considered goals such as: "analyzing inputs, processes and products; linking improvements to financial costs and benefits and providing frameworks to help make decisions; providing information and links to more detailed metrics and guidance; using normalized indicators to allow for comparison between facilities..." Also, in 2009, in a workshop ${ }^{22}$ entitled: "NIST Workshop on Sustainable Manufacturing: Metrics, Standards, and Infrastructure," different viewpoints of sustainability by experts from government, industry and academia were presented. These viewpoints include sustainable information based manufacturing, supply chain sustainability, economic opportunities, regulations and standards - metrics for sustainable performance, sustainable design and manufacturing methods, and design for sustainability.

An important precursor to manufacturing sustainability is through product design decisions. By some accounts, the solution to manufacturing sustainability is anchored to design decisions (e.g., Ramani 2009). For instance, while about 5\% of the Product Development Cost (PDC) is spent during a design stage, by the time the design is complete, $70 \%$ or more of PDC has already been decided (e.g., Suh 1990).

One can consider manufacturing to be as profit-sustainable as its supply chain. The conventional wisdom has always been to start first with the design decisions - which specify the features that

${ }^{21} \mathrm{http}: / / \mathrm{www}$. trade.gov/competitiveness/sustainablemanufacturing/how doc defines SM.asp (last visited on 4/13/2014)

${ }^{22}$ http://www.mel.nist.gov/msid/conferences/Agenda SMW.htm (last visited on 4/13/2014) 
the product should contain - and then tackle the other decisions such as manufacturing and supply chain considerations. However, not much attention has been given to the linkages or interoperability among design, manufacturing and supply chain considerations. Indeed, the supply chain focused manufacturing continues to challenge product decision makers in finding profit-sustainable design solutions. One possible way to overcome this challenge is by design solutions that are modular and interoperable. Modularity means that the product is configured from smaller subsystems or modules. Modular products lend themselves well to outsourcing. However, modularity also requires attention to interoperability. Interoperability means to have compatible interfaces and smooth operations among the modules.

Sourcing different modules (e.g., parts, components, assemblies or subsystems) for modular products from domestic and overseas suppliers has become increasingly prevalent. For example, manufacturers of electronic products such as laptops, smartphones and tablet computers outsource a majority of their product modules from upstream suppliers. Such practice has also been common in other industries such as automobiles, aircrafts and shipbuilding for decades. However, as shown in Figure 1, meeting the specifications of product modules by suppliers, in particular the interoperability among modules (i.e., whether the sourced modules can work well together) remains a challenge particularly when the manufacturer does not have full control of its global supply chain and when there is uncertainty. For example, Boeing recently experienced significant interoperability problems among the parts that were outsourced to different suppliers across the globe so much so that their Dreamliner 787 deliveries were significantly delayed (Guardian, 2013).

The design outlining the specific components and modules making up a product system specifically in the context of suppliers and sourcing of the components is an important factor that determines the cost of the product, the reliability of the input supply, and interoperability of the components. As seen in recent times, global sourcing of components to reduce costs can increase the vulnerability to significant supply chain disruptions - due to earthquake, floods, riot and political unrest - which, in turn, can lead to increased cost and time to re-source supplies or delay in delivery due to interoperability concerns. The cost and reliability of supply chain, in turn, have a significant impact on the market share and demand of the product and, ultimately, its profitability.

\section{Gaps and Research Needs}

Several modular and platform based design approaches have been reported (e.g., Dahmus et al., 2001), including modularity definition, commonality measurements and cost modeling techniques (e.g., Kota et al., 2000). From a supply chain perspective, several articles have considered supply chain and its integration with product design (e.g., Huang et al., 2005). For example, a concurrent engineering framework was developed to assess concepts such as commonality, product platforms and modularity when product platform design is to link process and supply chain design decisions (Fixson, 2005). A number of case studies and literature reviews reports on models and methods for product design and planning with supply chain design considerations, e.g., Appelqvist et al. (2004). A preliminary model in this domain was recently presented by Wang et al. (2014) that can consider modularity and supply chain design with interoperability considerations. However, there is a need for a more comprehensive framework. 
From the interoperability perspective, existing works have proposed standards and qualitative recommendations for improving interoperability in IT systems, for instance, in software engineering applications and in a network of systems to exchange information, e.g., Tolk and Muguira (2003). Also, examples of methods that handle couplings (or interoperability) are reported in a different context, in multidisciplinary design optimization. Yet these methods can become difficult to implement in a market system where manufacturers source modules from different suppliers and often do not have full control over suppliers, when compared to designing and building all of the modules in-house (e.g., Wang, 2012).

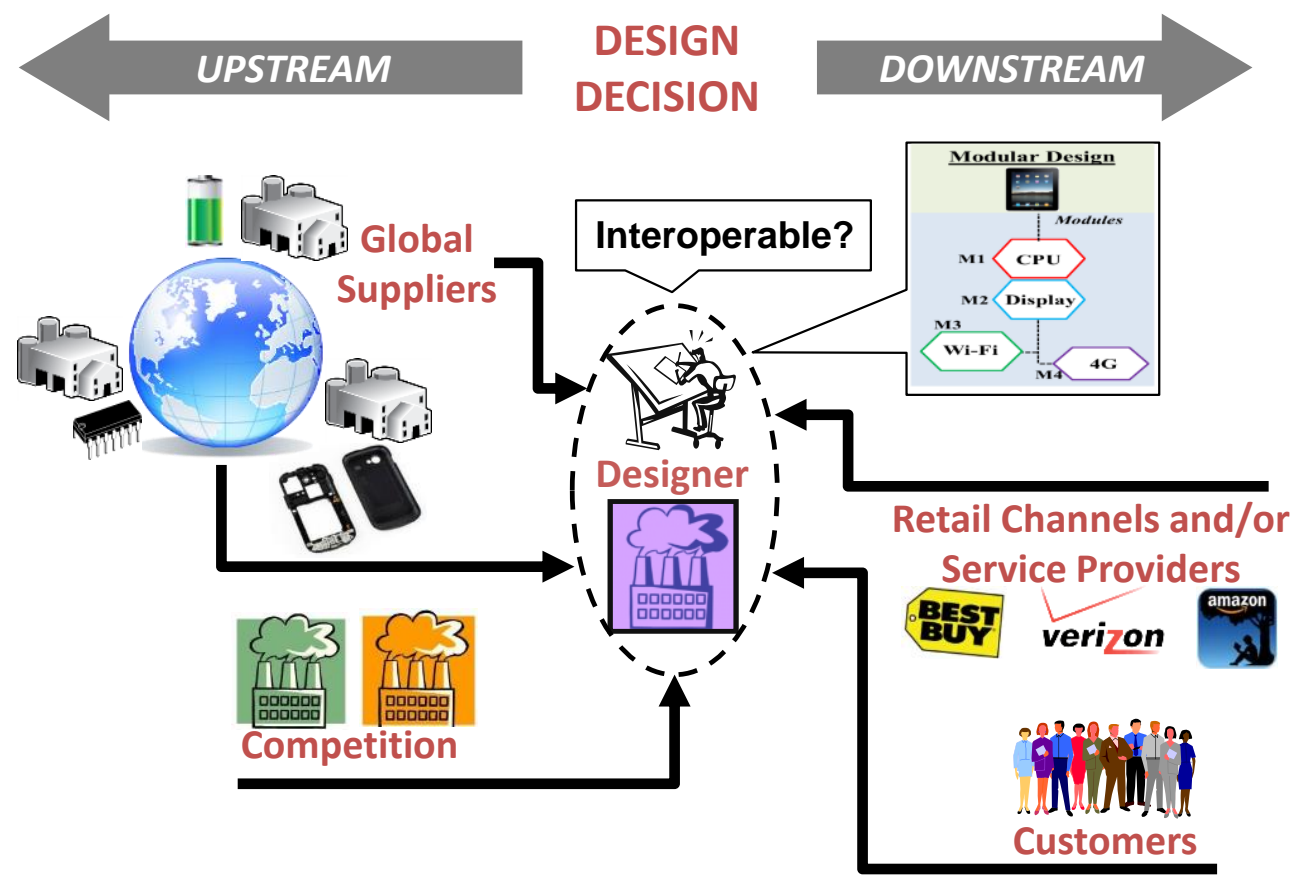

Figure 1: Elements of Design for Supply Chain and Interoperability in a Market System

\section{Design for Supply Chain and Interoperability Considerations}

A supply chain configuration can be obtained by a mapping from the modular product design to the upstream supply chain design space (Wang et al., 2014). In an upstream supply chain, there can be raw material suppliers, part suppliers, module suppliers, subassembly suppliers and so on, all the way to the supplier who does the final product assembly. The upstream supply chain configuration model may consider several factors (Murphy, 2012). These can include: i) Redundancy: Depending upon criticality of the supplier(s), there can be redundant (backup) suppliers considered in the model. Note that the redundancy increases the cost and does not payoff unless there is a disruption in the supply chain. The disruption can last for a significant period of time and can even be due to a catastrophic event, such as the Icelandic volcano eruption of 2010, the catastrophic earthquake in Japan in the spring of 2011, factory collapse in Bangladesh in the spring of 2013, and when a government collapses. ii) Speed and flexibility of suppliers: It is important that the suppliers are selected so that they are fast and flexible in their response to a demand change. iii) Coordination of supplies: This is an important factor and can be a challenging task to model. For example, in the case of Apple Inc., there are over 150 primary (and many more secondary) suppliers whose activities need to be coordinated. It has 
been reported that poor coordination among suppliers can cost as much as $\$ 30$ billion dollars (Fisher, 1997). iv) Parameters such as the needed material/part/module/sub-module variety that suppliers can deliver; price of item to be delivered; lead time; inventory (\% of demand met by instock goods). v) Supplier responsiveness to unexpected change in demand. And finally vi) interoperability which can become critical.

Interoperability can refer to a range of operations or interactions along which two (or more) coupled modules operate well together. One possible direction is to further explore the notion of interoperability and devise a measure of interoperability in the context of modular design and find ways for determining an acceptable level of interoperability for a product system. Determining an acceptable level of interoperability is important because it will give the designer an indication as to whether or not coupled modules in a product system can work with each other under uncertainty. This information can be used to assess interoperability feasibility. There are a number of questions and challenges. For example, how can interoperability be quantified and what is an acceptable level of interoperability between two (or more) coupled modules? As the number of coupled modules increases, does the computational effort for solving interoperability change. The ultimate goal is to determine whether interoperability in the design of a modular product system is within an acceptable threshold and decide on that threshold.

Using a model of interoperability as discussed above, the designer will be able to evaluate the reliability (or risk) involved in the supply chain. Specifically, the risks in a product's supply chain can be considered to be design-related or manufacturing-related. Design-related supply chain risks result from uncertain changes of design from one or more upstream suppliers. Such changes can happen due to discontinuation of an existing part, upgrade or refresh of an existing part, or introduction of a new product module as a replacement. The changes of design for one module can influence its interoperability with other modules which are coupled with it; the effect can also ripple through the rest of the supply chain and eventually impact the product's ability to function properly. The challenge for the designer is to quantitatively model, evaluate and minimize such risks. On the other hand, the product can also be subject to manufacturing-related supply chain risks. Such risks can be represented as the variations of key performance indicators (KPIs) such as total production lead time, supply chain availability. Given the configuration of a supply chain, some modules can have a higher impact on the KPIs than others. By identifying the "bad actors" for KPI and redesigning the configuration of supply chain the manufacturing-related supply chain risks can be minimized. However, once the product design is fixed the manufacturer would have limited flexibility to execute such changes. Considering that the configuration of the supply chain is ultimately dictated by the synthesis of product functions and/or modules, such decisions regarding supply chain needs to be incorporated into the early stages of product design.

Finally, interoperability and creation of supply chain redundancies, identification and development of suppliers who can be flexible with speedy deliveries, all come at increased costs. Given this, it is important to prioritize which design components need to be modular and interoperable and which components need to be designed with redundancy consideration in the supply chain. It is argued that cost is only one aspect of consideration for such prioritization. It is also important to understand the role the component or component system plays in determining market demand (e.g., Wang et al. 2011; Williams et al. 2011). This can be performed in two 
complementary ways. First, it is important to determine how much customers value the different functionalities inherent in the product. Extant research (e.g., Ofek and Srinivasan 2002) provides some economic based approaches to determine how much consumers are willing to pay for different functionality, and one can adopt such methods to "price" functionalities and through them to price the different components. Second, the value of components can be determined through the development of scenarios as to how consumers would change their choices if the firm's products were to have reduced functionality or non-availability for a period of time. Using demand modeling of consumer choices, such scenarios should provide alternate methods to price the components. Combining the costs of interoperability and supply chain modifications with tradeoffs against the benefits (values) of the components will allow the firm to develop metrics such as value per dollar of cost to prioritize the components for interoperability and supply chain efforts.

\section{References}

Appelqvist, P., Lehtonen J. M., and Kokkonen, F., 2004, "Modeling in Product and Supply Chain Design: Literature Survey and Case Study," Journal of Manufacturing Technology Management, 15(7), pp. 675-686.

Dahmus, J.B., Gonzalez-Zugasti, J.P., and Otto, K.N., 2001, "Modular Product Architecture," Design Studies, 22(5), pp. 409-424.

Fisher, M. L., 1997, "What is the Right Supply Chain for Your Product," Harvard Business Review, Reprint Number 97205.

Fixson, S. K., 2005, "Product Architecture Assessment: A Tool to Link Product, Process and Supply Chain Design Decisions," Journal of Operations Management, 23, pp 345-369.

Huang G. Q., Zhang X. Y., and Liang L., 2005, "Toward Integrated Optimal Configuration of Platform Products, Manufacturing Processes, and Supply Chains," Journal of Production Management, 23, pp. 267-290.

Kota, S., Sethuraman, K., and Miller, R., 2000, “A Metric for Evaluating Design Commonality in Product Families," Journal of Mechanical Design, 122(4), pp. 403-410.

Murphy, M., 2012, "Reinforcing the Supply Chain: Disasters Spur Companies to Assess Potential for Disruptions," The Wall Street Journal, January 11.

Ofek, E., and Srinivasan, V., 2002, "How Much Does the Market Value an Improvement in a Product Attribute?" Marketing Science, 21(4) , pp. 398-411.

Ramani, K., 2009, "Sustainable Early Design Methods," NIST Workshop on Sustainable Manufacturing: Metrics, Standards, and Infrastructure, Gaithersburg, MD, October 13-15.

Suh, N.P., 1990, The Principles of Design, Oxford University Press, Oxford, UK.

Tolk, A., and Muguira, J. A., 2003, 'The Levels of Conceptual Interoperability Model”, 2003 Fall Simulation Interoperability Workshop, Orlando, Florida, September.

Wang, Z., 2012, "Strategic Product Design Decisions for Uncertain, Converging and Service Oriented Markets," Ph.D. Thesis, University of Maryland, College Park, MD.

Wang, Z., S. Azarm, and P. K. Kannan, 2011, "Strategic Design Decisions for Uncertain Market Systems Using an Agent Based Approach," Journal of Mechanical Design, 133(4), pp. 041003-1 to 041003-11.

Wang, W., Azarm, S., and Kannan, P.K., 2014, "Design for Upstream and Downstream Market Systems with Interoperability Considerations," ASME International Design Engineering Technical Conferences, Buffalo, NY (to appear). 
Williams, N., P. K. Kannan, and S. Azarm, 2011, "Retail Channel Structure Impact on Strategic Engineering Product Design," Management Science, 57(5), pp. 897-914. 
[This page is internationally left blank] 
Wei, Hsi-Hsien, and Miroslaw J. Skibniewski, University of Maryland

\title{
Catastrophe Modeling for Assessing Sustainability of Hazard Mitigation
}

\begin{abstract}
While the economic and social performance of natural hazard mitigation have been widely investigated and understood, the environmental performance has not been fully recognized due to its inherent unpredictability and lack of reliable measurement methodology. As a result, the suitability of hazard mitigation cannot be fully assessed due to the lack of consideration on its environmental impacts, such as embodied energy, waste generation and greenhouse gas emission (CO2) from demolition of damaged buildings and reconstruction of new buildings. Therefore, a standardized methodology and metrics for assessing environmental impacts is needed to conduct a comprehensive assessment on sustainability of hazard mitigation.
\end{abstract}

The particular objectives of this study are to: (1) identify factors affecting sustainability of hazard mitigation in terms of environmental impact, (2) measure environmental performance of hazard mitigation using life cycle greenhouse emission analysis with considering all aforementioned factors, and (3) verify the applicability of the present methodology by a case study. This study intends to provide public decision makers and stakeholders with a standardized methodology for measuring the environmental performance of seismic mitigation so that a comprehensive seismic mitigation strategy can be developed to achieve sustainable development.

\section{Keywords}

Catastrophe Modeling, Greenhouse Emission, Hazard Mitigation, HAZUS, Seismic Risk Assessment, Sustainability

\section{Background}

\subsection{The Triple Bottom Lines of Sustainability}

The concept of sustainability is defined by the triple bottom lines- economic, social and environmental aspects (USGBC 2008). The three lines determine the goal of sustainability. The economic bottom line produces a long-term, positive economic impact. The social bottom line improves human lives. Environmental bottom line determines the benefit to the natural environment by removing negative externalities to the environment.

\subsection{Performance Measures}

A performance measure is a means of quantifying the consequences associated with the response of a system to hazards in terms that are meaningful to stakeholders (Hamburger et al. 2012). In the Next-Generation Building Seismic Performance Assessment Methodology developed by Federal Emergency Management Agency (FEMA 2012), performance of a build in seismic events us expressed as the resulting consequences using following performance measures: (1) casualties, including loss of life or injury requiring hospitalization, (2) repair cost, necessary to reconstruct or replace a damaged building to its pre-hazard condition, (3) repair time, necessary to reconstruct or replace a damaged building to its pre-hazard condition, and (4) unsafe placarding, a post-hazard inspection on damaged buildings which poses immediate risk to safety. Although the economic and social performances of buildings in a hazard event are recognized by those performance measures, the environmental performance is not addressed by any of them. 
Therefore, to achieve a comprehensive assessment of sustainability of disaster mitigation by considering all three bottom lines, additional metrics, such as embodied energy for reconstruction, and waste generation and greenhouse gas emission due to damaged buildings, are needed to develop.

\subsection{Catastrophe Theory and Modeling}

Catastrophe modeling was originally developed in the field of property insurance and the science of natural hazards to manage the risks of natural disasters (Grossi et al. 2005). Although it is not rooted in any particular field or study, it is convinced by most relevant studies that the Framework for Performance-based Earthquake Engineering developed by the Pacific Earthquake Engineering Research Center (Moehle and Deierlein 2004) built the foundation of the modern catastrophe models. Applying the framework of the catastrophe risk model, a basic hazard assessment model can be comprised by four modules: (1) hazard module, characterizing hazards in a system at risk to be investigated. In this study, a ground motion hazard is defined by its location, magnitude and frequency of occurrence; (2) inventory module, collecting data of geological characteristics such as site effects and soil attenuation for calculating local seismic intensity, and data of built environment such as occupancy types and building structural types; (3) vulnerability module, calculating social and physical vulnerability of built environment exposed to hazard. The social vulnerability generally includes social-economic information like income, ethnicity, age or ownership of property. The information of social vulnerability is the main factor in estimating the number of displaced household and temporary shelters after earthquakes. Physical vulnerability is usually defined by the fragility curve of a structure, which determines the expected building damage in a particular level of seismic intensity; and (4) loss module, evaluating the loss to the inventory by interpreting its corresponding vulnerability to the hazard. Losses, characterized as direct or indirect, can then be assessed in terms of social, economic and environmental losses. Adopting the four modules of catastrophe model, the state of damage of a building during an earthquake and the consequences of that damage, which is represented by its three performance measures, is determined by all aforementioned factors.

\section{Methodology}

\subsection{Seismic Risk Assessment Tools}

Several hazard risk assessment methodologies have been developed based on the typical seismic risk assessment model. (Erdik et al. 2005) and (Korkmaz 2009) provided losses assessment models for long-term disaster management considering probabilistic seismic hazards. Also, different methodologies and frameworks for seismic loss estimation have been developed and used to conduct a benefit-cost analysis for different seismic retrofit alternatives (Smyth et al. 2004), (Kappos and Dimitrakopoulos 2008) and (Valcárcel et al. 2013). Correspondingly, a number of standardized software packages have been developed with friendly user-interface and open-source database. Most also utilize Geographic Information System (GIS) in presenting the geographic distribution of losses for analyzing particular issues like emergency facilities layout.

\subsection{HAZUS Methodology and Application}

Hazard United States (HAZUS), developed by the US Federal Emergency Management Agency, is a free standardized GIS-based risk assessment tool for hazard analysis and it have been widely validated for its applicability in the U.S. (Kircher et al. 2006) (Tantala et al. 2008) (Schmidtlein et al. 2011) (Remo and Pinter 2012) (Rein and Corotis 2013). Despite the fact that HAZUS was originally designed for the use in the United States, this standardized seismic risk estimation 
software has been adopted and validated worldwide because it was possible to allow for its modification for international use (Gulati 2006) (Peterson and Small 2012) (Ploeger et al. 2010). The possibility to supplant the databases and to modify the default functions with local parameters forms the basis for the application of HAZUS in an international setting. Therefore, adopting HAZUS for an international local scale setting requires careful performance of a series of operations with each module. HAZUS comprises four major modules: hazard identification, built environment inventory, physical and socio-economic vulnerability, and the loss module. The estimated loss is calculated by linking the hazard scenario to the inventory collection with consideration of its vulnerability. The output of loss estimation includes the number of damaged buildings at different levels of damage, the number of casualties, injuries, displaced households and shelters, the amount of generated debris, and both direct and indirect economic losses.

\subsection{Life Cycle Greenhouse Gas Analysis for Reconstruction and Replacement}

In a process of building construction, greenhouse gas $\left(\mathrm{CO}_{2}\right)$ emissions come mainly from sources that can be placed in four categories: site preparation, material production, equipment usage and waste management (Liu et al. 2012). In this study, a similar framework is modified to the needs of the process of post-hazard reconstruction of damaged buildings, as depicted in Fig.1.

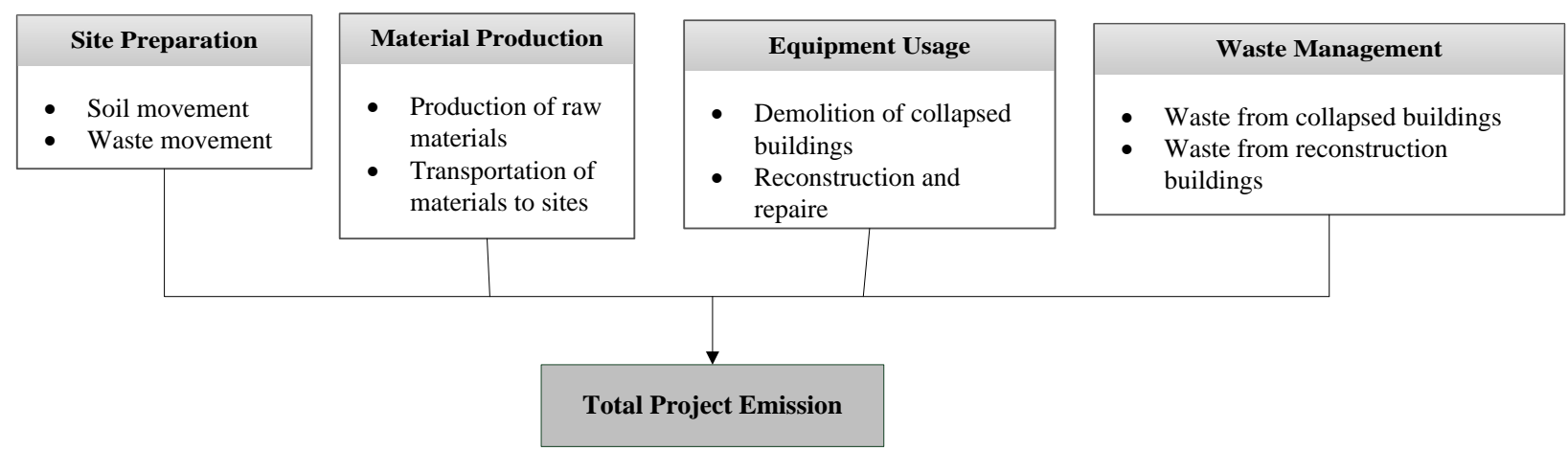

Figure 1. Scheme of the life cycle greenhouse gas analysis for post-hazard reconstruction

Emissions from Equipment Usage - The $\mathrm{CO}_{2}$ emission based on equipment usage is affected by the type of equipment used, its operation hours and consumption of fuel during construction work. The equation is for any building model type under any repair/rebuild stage, including slight, moderate, extensive and complete stage.

GHG Emission by Equipment Usage:

$i$ : Repair/Rebuild stage

$$
E_{E}=\sum_{l}\left(\sum_{m} E D_{i m} \cdot F R E_{l m}\right) \cdot F E_{l}
$$

1: Fuel Type (Electricity included)

$m$ : Equipment Type 


\begin{tabular}{|c|l|l|}
\hline$E D_{i m}$ & $\begin{array}{l}\text { Net Operation Duration for Equipment } \mathrm{m} \text { in Repair/Rebuild } \\
\text { Stage i }\end{array}$ & hrs \\
\hline$F E_{l}$ & $\mathrm{CO}_{2}$ Emission Factor for Fuel Type 1 & tons/gal \\
\hline$F R E_{l m}$ & $\begin{array}{l}\text { Fuel Type l's Requirement for Using Equipment } \mathrm{m} \text { for unit } \\
\text { time period }\end{array}$ & gals/hr \\
\hline
\end{tabular}

Emissions from Material Usage - The $\mathrm{CO}_{2}$ emission based on material usage is mainly affected by the type of material used for a construction work. The equation is for any building model type under any repair/rebuild stage.

i: Repair/Rebuild stage

$$
E_{M}=\sum_{j} Q S_{i j} \cdot E M_{j}
$$

j: Material Type

\begin{tabular}{|c|l|l|}
\hline$Q S_{i j}$ & Quantity of Material $\mathrm{j}$ for Repair/Rebuild Stage $\mathrm{i}$ & tons \\
\hline$E M_{j}$ & Embodied $\mathrm{CO}_{2}$ Emission for Material $\mathrm{j}$ & 1 \\
\hline
\end{tabular}

Emissions from Transportation - The $\mathrm{CO}_{2}$ emission based on transportation can be affected by several factors, such as the quantity of material or waste transported to/from construction site and the distance of transportation. The equation is for any building model type under any repair/rebuild stage.

$$
\begin{gathered}
E_{T}=\sum_{l}\left[\sum_{k}\left(\sum_{j} \frac{M T_{j k}}{C_{k}} \cdot D M_{j k}+\sum_{n} \frac{W T_{k n}}{C_{k}} \cdot D W_{k n}\right) \cdot F R T_{k l}\right] \cdot F E_{l} \\
\text { s.t. } \sum_{k} M T_{j k}=Q S_{i j}, \forall j ; \\
\sum_{k} W T_{k n}=W_{i n}, \forall n
\end{gathered}
$$

$i$ : Repair/Rebuild stage

$j$ : Material Type

$k$ : Transportation Type

$l$ : Fuel Type (Electricity included)

$n$ : Waste Type 


\begin{tabular}{|c|l|l|}
\hline$Q S_{i j}$ & Quantity of Material j for Repair/Rebuild Stage $\mathrm{i}$ & tons \\
\hline$W_{i n}$ & $\begin{array}{l}\text { Quantity of Waste } \mathrm{n} \text { Collected from Demolition/Waste } \\
\text { Management in Repair/Rebuild Stage i }\end{array}$ & tons \\
\hline$D M_{j k}$ & $\begin{array}{l}\text { Transporting Distance for Material } \mathrm{j} \text { from Source to Site Using } \\
\text { Transportation Method } \mathrm{k}\end{array}$ & miles \\
\hline$C_{k}$ & $\begin{array}{l}\text { Transporting Capacity for Each Unit of Transportation Method } \\
\mathrm{k}\end{array}$ & tons \\
\hline$F R T_{k l}$ & Fuel l's Requirement for Transportation k for unit distance & gals/mile \\
\hline$F E_{l}$ & $C O_{2}$ Emission Factor for Fuel Type 1 & tons/gal \\
\hline$M T_{j k}$ & $\begin{array}{l}\text { Quantity of Material } \mathrm{j} \text { Transported from Source to Site Using } \\
\text { Transportation Method } \mathrm{k}\end{array}$ & tons \\
\hline$W T_{k n}$ & $\begin{array}{l}\text { Quantity of Waste } \mathrm{n} \text { Disposed from Site to Plant Using } \\
\text { Transportation Method } \mathrm{k}\end{array}$ & tons \\
\hline
\end{tabular}

Total CO2 Emission Calculation - The net $\mathrm{CO}_{2}$ emission for one rehabilitation or rebuild project can be calculated by summing up the GHG emission from equipment usage, material usage and transportation in all activities of the work.

$$
E=\sum_{\text {building activity }}\left(E_{E}+E_{M}+E_{T}\right)
$$

Emissions from Site Preparation - This section outlines a systematic approach for calculating $\mathrm{CO}_{2}$ emissions resulting from carbon stock changes in biomass, dead organic matter and mineral soils, for all managed lands. The six top-level categories of land use form the basis of this estimation - forest land, cropland, grassland, wetlands, settlements and other land. The categories are broad enough to classify all land areas in most countries and to accommodate differences in national land-use classification systems, and can be identified through use of approaches provided by Intergovernmental Panel on Climate Change (Eggleston et al. 2006). Emissions from soil movement: although both organic and inorganic forms of $\mathrm{C}$ are found in soils, land-use conversion typically has a larger impact on organic C stocks (Eggleston et al. 2006). Where the organic matter had been removed, the annual $\mathrm{CO}_{2}$ efflux rates measured from the mineral soil are lowered to around $314 \mathrm{~g} \mathrm{CO}_{2} / \mathrm{m}^{2}$, accounting for $1.6 \%$ of the soil carbon pools. On the other hand, site preparation enhances the rate of decomposition by forming mounds, the mix of organic material with mineral soil.

Emissions from Material Production - This section outlines a systematic approach for calculating $\mathrm{CO} 2$ emissions resulting from materials manufacture. $\mathrm{CO} 2$ emissions from materials manufacture mean mainly embodied $\mathrm{CO} 2$ emissions in construction materials. Embodied $\mathrm{CO} 2$ emissions are primarily from materials' stoichiometric relationships based on respective chemical compositions and energy consumption for manufacture installations before transporting to construction sites.

Emissions from Equipment Usage - This section outlines a systematic approach for calculating $\mathrm{CO} 2$ emissions resulting from the operation of off-road equipment. $\mathrm{CO} 2$ emissions from 
equipment operation are estimated from the daily use hours, operation duration, and equipmentspecific parameters, such as emission factor and horsepower.

In this study, adopting HAZUS software to fully assess the sustainability of hazard mitigation considering all three aspects: social, economic and environmental performances, we first evaluate the seismicity of the study area through careful consideration of soil condition and attenuation function. Next, the data of building inventory and demographics data are collected. Finally, adopting the aforementioned life cycle greenhouse gas methodology, the embodied energy for reconstruction and waste generation and green gas emission can be obtained by analyzing the output of HAZUS including the number of damaged buildings and generated debris and the number of needed shelters.

\section{Research Needs and Conclusions}

Much research has been performed in the last few years on the application of information technologies for greenhouse gas emissions monitoring and control in relation to various aspects of engineering and construction processes. Examples of such recent works include Wong et al. (2013), Hasan et al. (2013), Jaillon and Poon (2013), Pignataro et al. (2014) and Akbarnezhad et al. (2014). However, the majority of these studies mainly focused on new construction process but did not address the environmental impact of construction activities in hazard mitigation process, which includes demolishment and waste generation of collapsed buildings, and repair or reconstruction for damaged buildings.

The issues and problems presented in this paper point at the fragmentation of effort among the research and development community and at the need to develop a comprehensive approach to the use of consistent metrics in hazard mitigation works. This need requires development of a new quantitative analysis toolbox to allow engineering practitioners a reliable collection and processing of design documentation and field data for the purpose of determining various environmentally relevant parameters related to environmental performance of hazard mitigation activities. Together with the catastrophe modeling and life cycle greenhouse gas analysis, the relevance and applicability of existing software environments such as HAZUS for triple bottom line determination should be considered, but new approaches taking advantage of the latest data modeling and processing, and web-based communication technologies should be explored to their full potential.

\section{References}

Akbarnezhad, A., Ong, K. and Chandra, L. (2014), "Economic and environmental assessment of deconstruction strategies using building information modeling", Automation in Construction, Vol. 37, pp. 131-44.

Eggleston, S., Buendia, L., Miwa, K., Ngara, T. and Tanabe, K. (2006), "IPCC guidelines for national greenhouse gas inventories", Institute for Global Environmental Strategies, Hayama, Japan.

Erdik, M., Rashidov, T., Safak, E. and Turdukulov, A. (2005), "Assessment of seismic risk in Tashkent, Uzbekistan and Bishkek, Kyrgyz Republic", Soil Dynamics and Earthquake Engineering, Vol. 25 No. 7, pp. 473-86.

FEMA. (2012), "Seismic Performance Assessment of Buildings, FEMA P-58", Federal Emergency Management Agency. 
Grossi, P., Kunreuther, H. and Patel, C.C. (2005), "Catastrophe Modeling: A New Approach to Managing Risk", Springer.

Gulati, B. (2006), "Earthquake risk assessment of buildings: applicability of HAZUS in Dehradun, India", in Enschede, ITC.

Hamburger, R., Rojahn, C., Heintz, J. and Mahoney, M. (2012), "FEMA P58: Next-Generation Building Seismic Performance Assessment Methodology", Fifteenth World Conference on Earthquake Engineering, Lisbon, Portugal.

Hasan, S., Bouferguene, A., Al-Hussein, M., Gillis, P. and Telyas, A. (2013), "Productivity and $\mathrm{CO} 2$ emission analysis for tower crane utilization on high-rise building projects", Automation in Construction, Vol. 31, pp. 255-264.

Jaillon, L. and Poon, C. (2013), "Life cycle design and prefabrication in buildings: A review and case studies in Hong Kong", Automation in Construction, Vol. 39 No. 1, pp. 195-202.

Kappos, A.J. and Dimitrakopoulos, E. (2008), "Feasibility of pre-earthquake strengthening of buildings based on cost-benefit and life-cycle cost analysis, with the aid of fragility curves", Natural hazards, Vol. 45 No. 1, pp. 33-54.

Kircher, C.A., Seligson, H.A., Bouabid, J. and Morrow, G.C. (2006), "When the Strikes Again Estimated Losses due to a Repeat of the 1906 San Francisco Earthquake", Earthquake Spectra, Vol. 22, pp. S297.

Korkmaz, K.A. (2009), "Earthquake disaster risk assessment and evaluation for Turkey", Environmental Geology, Vol. 57 No. 2, pp. 307-320.

Liu, X., Hsu, S. and Cui, Q. (2012), "Carbon Accounting Protocol in Construction", paper presented at Carbon Management Technology Conference, 7-9 February 2012, Orlando, Florida, USA.

Moehle, J. and Deierlein, G.G. (2004), "A framework methodology for performance-based earthquake engineering", in Proceedings of the 13th World Conference on Earthquake Engineering, pp. 3812-14.

Peterson, J. and Small, M.J. (2012), "Methodology for benefit-cost analysis of seismic codes", Natural hazards, Vol. 63 No. 2, pp. 1039-1053.

Pignataro, M.A., Lobaccaro, G. and Zani, G. (2014), "Digital and physical models for the validation of sustainable design strategies", Automation in Construction, Vol. 39, pp. 1-14.

Ploeger, S., Atkinson, G. and Samson, C. (2010), "Applying the HAZUS-MH software tool to assess seismic risk in downtown Ottawa, Canada", Natural hazards, Vol. 53 No. 1, pp. 1-20.

Rein, A. and Corotis, R.B. (2013), "An overview approach to seismic awareness for a "quiescent" region", Natural hazards, Vol. 67 No. 2, pp. 1-29.

Remo, J.W. and Pinter, N. (2012), "Hazus-MH earthquake modeling in the central USA", Natural hazards, Vol. 63 No. 2, pp. 1055-1081.

Schmidtlein, M.C., Shafer, J.M., Berry, M. and Cutter, S.L. (2011), "Modeled earthquake losses and social vulnerability in Charleston, South Carolina", Applied Geography, Vol. 31 No. 1, pp. 269-281.

Smyth, A.W., Altay, G., Deodatis, G., Erdik, M., Franco, G., Gulkan, P., Kunreuther, H., Lus, H., Mete, E. and Seeber, N. (2004), "Probabilistic benefit-cost analysis for earthquake damage mitigation: Evaluating measures for apartment houses in Turkey", Earthquake Spectra, Vol. 20 No. 1, pp. 171-203.

Tantala, M.W., Nordenson, G.J., Deodatis, G. and Jacob, K. (2008), "Earthquake loss estimation for the New York City metropolitan region", Soil Dynamics and Earthquake Engineering, Vol. 28 No. 10, pp. 812-835. 
USGBC. (2008), "LEED 2009 for Existing Building: Operations \& Maintenance Rating System", US Green Building Council.

Valcárcel, J.A., Mora, M.G., Cardona, O.D., Pujades, L.G., Barbat, A.H. and Bernal, G.A. (2013), "Methodology and applications for the benefit cost analysis of the seismic risk reduction in building portfolios at broadscale", Natural hazards, Vol. 69 No. 1, pp. 845-868.

Wong, J.K., Li, H., Wang, H., Huang, T., Luo, E. and Li, V. (2013), "Toward low-carbon construction processes: the visualisation of predicted emission via virtual prototyping technology", Automation in Construction, Vol. 33, pp. 72-78. 
Wright, Richard N., and Bilal M. Ayyub, University of Maryland

\title{
Measurement Needs for Adaptation to Climate Change
}

\begin{abstract}
Advances in measurement science are needed for the building community to provide facilities and systems that will be functional, safe and sustainable throughout the 21st century while exposed to changing climate, weather and their extremes. Uncertainties in projections for climate, weather and their extremes are described, robust decision making strategies are recommended to deal with the uncertainties, and cooperative research involving climate scientists and the building community is recommended to meet the measurement needs.
\end{abstract}

\section{Keywords}

Buildings, Climate, Design, Extremes, Infrastructure, Weather

\section{Background}

Weather, climate and extreme events are key considerations in sustainability of the built environment. Weather is defined as "the state of the atmosphere with respect to wind, temperature, cloudiness, moisture, pressure, etc." (NWS, 2013). Weather generally refers to short-term variations on the order of minutes to about 15 days (NSIDC, 2012). Climate, on the other hand, "is usually defined as the average weather, or more rigorously, as the statistical description in terms of the mean and variability of relevant quantities over a period of time ranging from months to thousands or millions of years" (IPCC, 2007). An extreme event is a weather event that is rare at a particular place and time of year (IPCC, 2007). For instance for Washington Reagan National Airport on June 25 (Washington Post June 26, 2013): the normal high temperature is $87 \mathrm{oF}$ (climate), the high on June 25, 2013 was $93 \mathrm{oF}$ (weather) and the record high was $100 \mathrm{oF}$ in 1997 (extreme event).

Scientists have reached a consensus that weather, climate and extreme events of the past generally will not be representative of those of the future. Moreover, climate science is not able to precisely forecast the climate, weather and extreme events of future decades. This nonstationarity and uncertainty pose a challenge to those who design, construct, operate and maintain the built environment because their standards are based on the assumptions of stationary - climate, weather and extreme events as observed in the past. The Committee on Adaptation to a Changing Climate (CACC) of the American Society of Civil Engineers (ASCE) is addressing this challenge in its white paper Bridging the Gap between Climate Change Science and Civil Engineering Practice (ASCE 2014). The purpose of this paper is to describe the measurement needs for support of the building community's response to the challenge.

Two recent reports summarize current knowledge of weather, climate and extreme events and the links between the science and decision making.

The Intergovernmental Panel on Climate Change (IPCC) is the leading international body for the assessment of climate change. It was established by the United Nations Environment Programme (UNEP) and the World Meteorological Organization (WMO) in 1988 to provide the world with a clear scientific view on the current state of knowledge in climate change and its potential 
environmental and socio-economic impacts. Table 1 shows the recent, qualitative IPCC assessment, based on observations and global climate models, of future weather and extreme events relevant to structural engineering design (IPCC 2012). Additional information is available in the Fifth Assessment Report (IPCC 2014).

The U.S. Global Change Research Program (USGCRP) involves thirteen federal agencies, is led in the White House Office of Science and Technology Policy, and has prepared the Third National Climate Assessment (NCA 2014). The NCA was prepared by the National Climate Assessment and Development Advisory Committee involving over 240 authors including climate and social scientists and engineers. It has sustainability-related chapters on urban systems, infrastructure and vulnerability, U.S. regions, mitigation and adaptation.

Figure 1, U.S. Average Temperature Projections, taken from (NCA 2014), illustrates both the potential significance of climate change for the built environment and why climate science cannot now quantitatively forecast future climate, weather and extreme events.

The solid line for the 20th century shows an increasing trend, amounting to about $20 \mathrm{~F}$ for the century, with the observed variations from the trend as large as $20 \mathrm{~F}$. The projections for the 21 st century are derived from global climate models which consider a variety of scenarios for economic development and control of green house gas emissions (Moss et al. 2010). The lowest curve is based on green house gas concentrations peaking at 490 ppm carbon dioxide (CO2) equivalent and then declining; it leads to an additional $2 \mathrm{oF}$ increase in U.S. average temperature in the 21 st century. The highest curve is based on emissions continuing to produce green house gas concentration of $1370 \mathrm{CO} 2$ equivalent in 2100; it leads to an additional $9 \mathrm{oF}$ increase. The historical trend of atmospheric $\mathrm{CO} 2$ is shown in Figure 2. The $\mathrm{CO} 2$ data (red curve), measured as the mole fraction in dry air, on Mauna Loa constitute the longest record of direct measurements of $\mathrm{CO} 2$ in the atmosphere. The black curve represents the seasonally corrected data.

Greenhouse gas emissions in the 21st century will depend upon worldwide private and public policy decisions and actions, which are unpredictable, but can be represented by scenarios such as those used in preparing Figure 1. 
Table 1 Extreme Events from IPCC (2012)

Physical Impact Observed Changes

Temperature Very likely decrease in number of unusually cold days and nights at the global scale. Very likely increase in number of unusually warm days and nights at the global scale. Medium confidence in increase in length or number of warm spells or heat waves in many (but not all) regions. Low or medium confidence in trends in temperature extremes in some subregions due either to lack of observations or vary ing signal within subregions. Precipitation Likely statistically significant increases in the number of heavy precipitation events (e.g., 95th percentile) in more regions than those with statistically significant decreases, but strong regional and subregional variations in the trends.

Winds Low confidence in trends due to insufficient evidence.

Tropical

Cyclones

Extratropical

Cyclones

Droughts

Floods

Extreme Sea

Level and

Coastal Impacts

Limited to medium evidence available to assess climatedriven observed changes in the magnitude and frequency of floods at regional scale. Furthermore, there is low agreement in this evidence, and thus overall low confidence at the global scale regarding even the sign of these changes. High confidence in trend toward earlier occurrence of spring peak river flows in snowmelt- and glacier-fed rivers.

Likely increase in extreme coastal high water worldwide related to increases in mean sea level in the late 20th century.

Other Impacts (Landslides and Cold Regions)
Projected Changes

Virtually certain decrease in frequency and magnitude of unusually cold days and nights at the global scale. Virtually certain increase in frequency and magnitude of unusually warm days and nights at the global scale. Very likely increase in length, frequency, and/or intensity of warm spells or heat waves over most land areas.

Likely increase in frequency of heavy precipitation events or increase in proportion of total rainfall from heavy falls over many areas of the globe, in particular in the high latitudes and tropical regions, and in winter in the northern mid-latitudes.

Low confidence in projections of extreme winds (with the exception of wind extremes associated with tropical cyclones).

Likely decrease or no change in frequency of tropical cyclones. Likely increase in mean maximum wind speed, but possibly not in all basins. Likely increase in heavy rainfall associated with tropical cyclones.

Likely impacts on regional cyclone activity but low confidence in detailed regional projections due to only partial representation of relevant processes in current models. Medium confidence in a reduction in the numbers of mid-latitude storms.

Medium confidence in projected increase in duration and intensity of droughts in some regions of the world, including southern Europe and the Mediterranean region, central Europe, central North America, Central America and Mexico, northeast Brazil, and southern Africa. Overall low confidence elsewhere because of insufficient agreement of projections.

Low confidence in global projections of changes in flood magnitude and frequency because of insufficient evidence. Medium confidence (based on physical reasoning) that projected increases in heavy precipitation would contribute to rain-generated local flooding in some catchments or regions. Very likely earlier spring peak flows in snowmelt- and glacier-fed rivers.

Very likely that mean sea level rise will contribute to upward trends in extreme coastal high water levels. High confidence that locations currently experiencing coastal erosion and inundation will continue to do so due to increasing sea level, in the absence of changes in other contributing factors.

High confidence that changes in heavy precipitation will affect landslides in some regions. High confidence that changes in heat waves, glacial retreat, and/or permafrost degradation will affect high mountain phenomena such as slope instabilities, mass movements, and glacial lake outburst floods. 


\section{U.S. Average Temperature Projections}

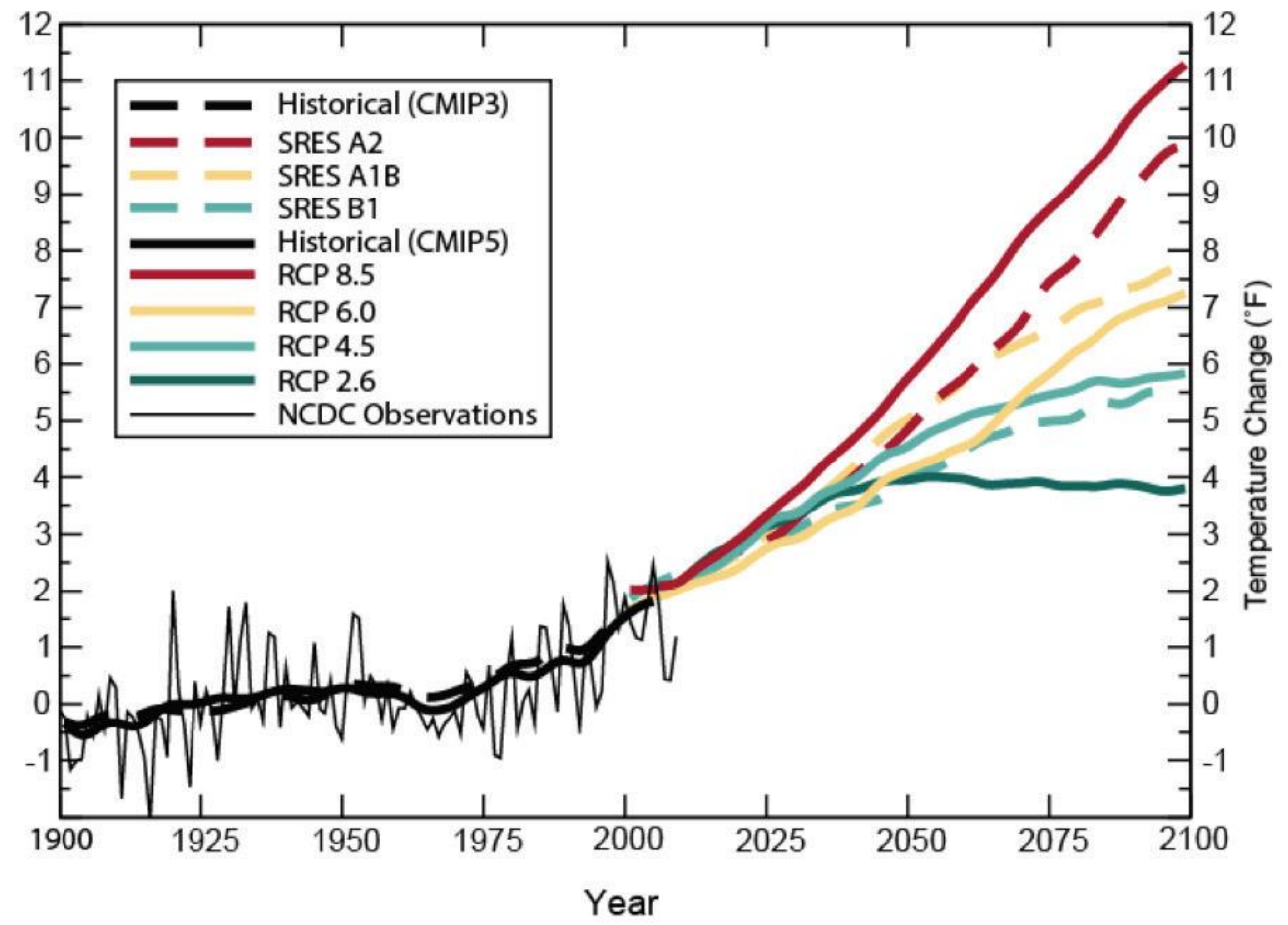

Figure 1. U.S. Average Temperature Projections (NCA 2014)

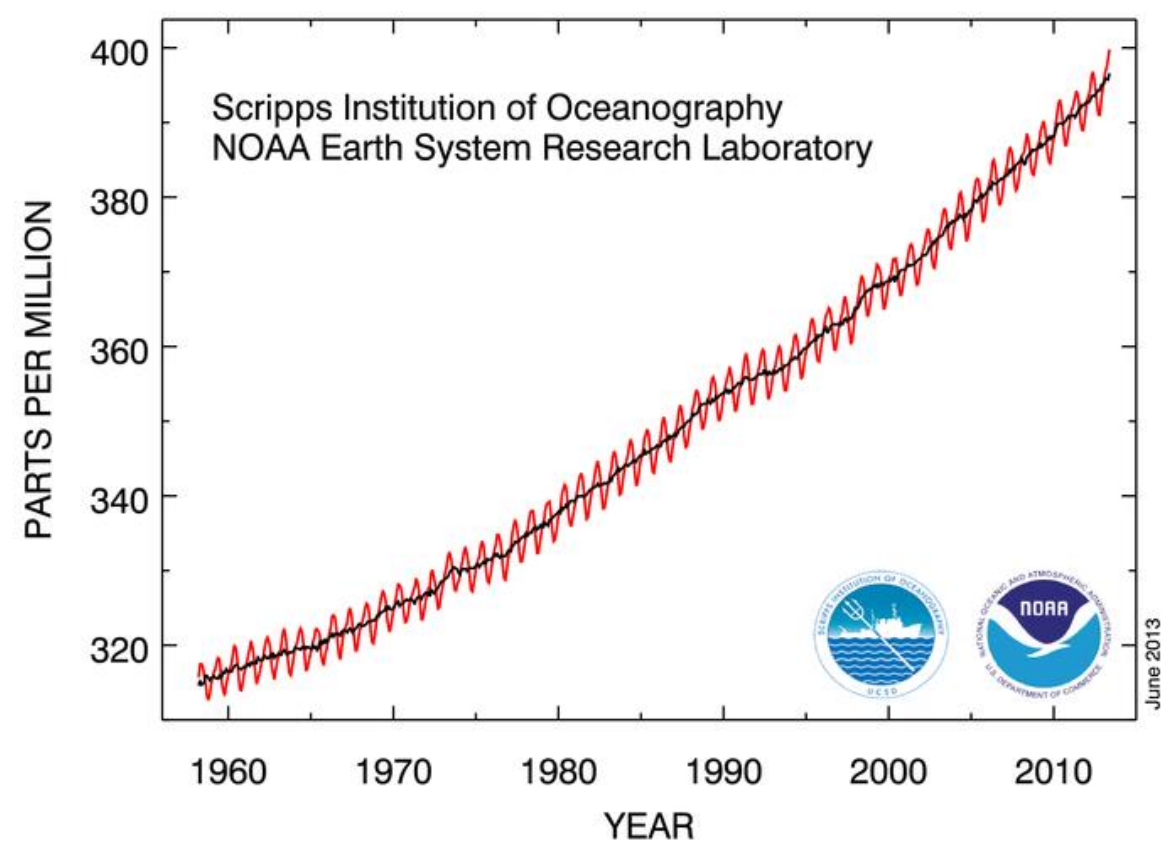

Figure 2. Atmospheric CO2 at Mauna Loa Observatory (http://www.esrl.noaa.gov/gmd/ccgg/trends/) 


\section{Measurement Needs of the Building Community}

The writers have been working with the ASCE Committee on Adaptation to a Changing Climate (CACC) to develop the white paper Bridging the Gap between Climate Change Science and Civil Engineering Practice (ASCE 2014). Its purpose is to:

- Foster understanding and transparency of analytical methods necessary to update and describe climate, weather and extreme events for planning and engineering design of the built and natural environments.

- Identify (and evaluate) methods to assess impacts and vulnerabilities caused by changing climate conditions on the built and natural environments

- Promote development and communication of best practices for addressing uncertainties associated with changing conditions, including climate, weather, extreme events and the nature and extent of the built and natural environments, in civil engineering practice.

The CACC study has evaluated methods for uncertainty analysis and transforming uncertainties into robust designs (related to the cascading uncertainties associated with vulnerability assessments and climate change science). Engineers use statistical methods to quantify uncertainty for empirical probability distributions used in engineering design. However, the uncertainty associated with climate projections is not completely quantifiable and, therefore, if it is to be used in engineering practice it will require engineering judgment. Decision methods that account for this uncertainty may be employed, such as robust decision making (Groves and Lempert, 2007; Groves et al, 2008; Lempert et al., 2003). One approach to decision making is to choose robust alternatives that do well across a range of possible future conditions. The mathematical objective here could be to "minimize the maximum regret," where regret is the difference between a plan's payoff in a given scenario and the payoff of the best performing plan under that same scenario. In common usage, low regret strategies are policies that would work well under both the current climate and an uncertain future climate.

\section{Recommendations}

Engineers and other building community professionals should join in research with climate and weather scientists to improve observations and develop integrated models for climate, weather and extreme events at local levels (National Academies 2012), which can give probabilistic guidance for the conditions for which facilities and systems should be designed, constructed, operated and maintained.

Measurement science should be advanced to systematically inform practices and standards implementing robust and sustainable decision making strategies for the facilities and systems of the built environment contributing to and affected by climate change.

The quantification of uncertainty in trends, projections and predictions is necessary as a basis for risk-informed decision making. Appropriate methods for this purpose and quantifications are necessary for bridging the gap between science and engineering.

Understanding and measuring interdependence among temperature, precipitation, winds, cyclones, droughts, floods, etc. are necessary for addressing sustainability issues. For example, Lombardo and Ayyub (2014) recently examined the correlation between high temperature and low wind for heat wave cases in order examine and urban heat islands. 


\section{References}

ASCE (2014) "Bridging the Gap between Climate Change Science and Civil Engineering Practice," ASCE Committee on Adaptation to a Changing Climate, will be available later in 2014 on the ASCE web site.

IPCC (2012) "Managing the Risks of Extreme Events and Disasters to Advance Climate Change Adaptation," Intergovernmental Panel on Climate Change, available at www.ipcc.ch.

IPCC (2014) "Fifth Assessment Report," Intergovernmental Panel on Climate Change, available at www.ipcc.ch.

Groves, D.G., and R.J. Lempert, (2007). "A new analytic method for finding policy-relevant scenarios," Global Environmental Change 17: 73-85.

Groves, D. G., D. Yates, and C. Tebaldi, (2008). Developing and Applying Uncertain Global Climate Change Projections for Regional Water Management Planning," Water Resources Research, 44, W12413, doi:10.1029/2008WR006964, 2008.

Lempert, R. J., S.W. Popper, and S.C. Bankes, (2003). Shaping the Next One Hundred Years New Methods for Quantitative Long-Term Policy Analysis, Rand Corporation.

Lombardo, F., and Ayyub, B. M., (2014) "Climate Change Adaptation: Wind and Temperature Extremes for Washington, DC," ASCE-ASME J. of Risk and Uncertainty in Engineering Systems, to be submitted.

Moss, et.al. (2010), "The next generation of scenarios for climate change research and assessment," Nature, 463, 747-756, [Available online at: http://emf.stanford.edu/files/docs/262/nature08823_proofl(2).pdf]

National Academies (2012). A National Strategy for Advancing Climate Modeling, National Academies Press.

NCA (2014) "Third National Climate Assessment," available at http:/www.globalchange.gov/

NSIDC (2012) Arctic Climatology and Meteorology Glossary (http://nsidc.org/arcticmet/glossary/weather.html; accessed October 9, 2012).

NWS (2013) National Weather Service Glossary (http///w1.weather.gov/glossary/; accessed on March 14, 2013. 
Yudelson, Jerry, Green Building Initiative, Portland, Oregon

\title{
Problems with Measuring and Achieving High-Performance Green Buildings: Case Studies from 18 Countries
}

\begin{abstract}
This paper presents results of a two-year investigation by the author and a colleague into the measured energy performance of nonresidential buildings around the world that achieved the highest ratings in third-party certifications (e.g., in the US, LEED Platinum). The research reported on 55 projects in 18 countries, in buildings ranging from approx. 5,000 sq.m. $(50,000$ sq.ft.) to approx. 50,000 sq.m. (500,000 sq.ft.), with building types ranging from commercial office and corporate headquarters, to university and government facilities. The research also investigated the basis for high-performance design in terms of design process. Based on results of this research, the author concludes that in a new building project, designers should be able to achieve the same energy use as High-Performance buildings around the world, because there is nothing magical or geographically specific about good design. What is required is a specific (and early) designers' intention to meet clear numerical targets for energy use, such as an EUI of less than 35 (i.e., less than 35,000 BTU/sq.ft./year) prior to subtracting any contributions from onsite renewables. Key issues remain in terms of standardizing the measurement of annual energy use, with respect to such parameters as occupancy, weather, process loads and occupant engagement.
\end{abstract}

\section{Keywords}

Green building, energy use, LEED, high-performance design, energy efficiency, design process

\section{Background}

For two years, my colleague Ulf Meyer and I worked on a book, The World's Greenest Buildings: Promise vs Performance in Sustainable Design (London and New York: Routledge Taylor \& Francis, 2013), published in January of 2013. We were interested particularly in reviewing high-performance green buildings from both the US and Canada, as well as those from Europe and the Asia/Pacific region, to see if we could discern some "universal" goals for green building projects. We aimed at getting operating data from LEED Platinum (or equivalent buildings) built since 2003 that represented non-residential typologies and were at least 50,000 square feet in size, in other words, the typical commercial/institutional building type. In many ways, this work was a follow-on to my 2009 book, Green Building Trends: Europe (Island Press), which looked specifically at European examples and focused on particularly green building technologies and design approaches. What we found was a series of great examples of sustainable design and a lively tradition of such buildings that went back 15 years or more. But what was lacking was real information on actual performance. In other words, the same problem is in Europe (and elsewhere): a lack of solid information on actual field performance that would help us link design approaches with actual energy and water use. So the most recent effort attempts to remedy that deficiency.

The most surprising result of our two years of research: how few "high performance" build ings were actually willing (or even able) to share operating results, even those built on university campuses or for government agencies, which should in theory be more open about such matters. 
In fact, nothing in law or professional practice compels building owners to share results, but how are designers supposed to do a better job without feedback from actual operating data? (To my mind, it is a scandal that the standard AIA contract does not require building owners to disclose operating data to the Building Team and to allow them to publish it, a change that AIA could easily make in support of its commitment to the 2030 Challenge.)

Fortunately, the landscape is shifting dramatically, partly as a result of a number of local initiatives in large cities requiring buildings over 50,000-sq.ft. to disclose operating data in publicly accessible databases. (California's AB 1103 law now requires energy use disclosure but only when a whole building is sold or leased, so it's going to be a while before we have any significant data from that mandate.) But if we could fast forward to 2015, we're likely to have much more data to feed back to building designers, contractors, owners and operators. In The World's Greenest Buildings, we did our best to locate and solicit data from 55 highperformance projects from 18 countries in the three major regions of the world where sustainable design has taken off: North America, Europe and Asia/Pacific, especially Australia. In fact, we were able to gather building operating data from projects in 18 countries in these regions and to compare it within a region and across regions.

Here are five key findings from the book:

1. In a new building project, designers should be able to achieve the same energy and water use as High Performance buildings around the world, because there is nothing magical or geographically specific about good design. What is required is a specific (and early) designers' intention to meet clear numerical targets for energy and water use, such as an EUI of less than 35 (i.e., less than 35,000 BTU/sq.ft./year) before adding any contributions from renewables.

2. What makes high-performance projects stand out is the commitment of owners, designers and builders to achieving 'best in class' results. The projects we studied were all LEED Platinum, which means they started with high-performance energy-efficiency goals. What also stands out is the commitment to an integrated design process; it's almost the case that without the right process, one doesn't get the best outcome.

3. Most surprisingly, high performance green design uses about the same energy everywhere in the world, from Northern Europe to the tropics. Typically, once there is a good building envelope and efficient HVAC systems, half the building energy use comes from plug/process loads and lighting, which tend to be geographically about the same in office buildings, leaving only about $15 \%$ to $20 \%$ for heating/cooling loads. In the northern latitudes, most loads are then for heating in winter, and in the tropics most loads are for cooling, which more or less balance out over the year.

4. Finally, great green buildings are just as beautiful, if not more so, than ordinary performing buildings. Perhaps it is beauty itself that should be our goal in sustainable design. One of our core tenets is that there is no inherent conflict between buildings with architectural merit and those with a full range of high-performance green characteristics (such as represented by LEED Platinum status) and low-energy outcomes.

5. The last finding of our research is that there are no standard definitions of building energy use, no good way to find out core energy use from special operations such as onsite data centers, retail, food service, etc. In fact, in Australia, we were surprised to find that building energy use is typically reported only for the base building, leaving out 
tenant loads in commercial offices, a practice that dramatically understates actual energy use. (This is the case also in many European countries.) We hope that researchers in this field will make sure that we can arrive at common definitions, so that comparisons across building types, regions and even countries will become much easier in the future.

\section{Energy Use in Case Study Projects}

Figures 1a, b and c shows the measured site energy use intensity for case-study buildings, organized by region. Operating data is from the individual case studies in The World's Greenest Buildings. For this research project, there was simply neither data nor time to calculate the primary (source) energy use for each building, but this can be done by interested researchers. Figure 1 shows that certain building types such as research laboratories and healthcare facilities have much higher energy use intensities than office or academic buildings, a result to be expected.

What one can see in Table 1 and Figures 1a, b, and c, is that most projects' site energy use exceeded $100 \mathrm{kWh} / \mathrm{sq} \mathrm{m} /$ year (EUI of about 32), although about 20 percent were able to reduce that number to 50 or $60 \mathrm{kWh} / \mathrm{sq} \mathrm{m} /$ year, or even lower ${ }^{23}$. To reach a truly "stretch" goal of 100 $\mathrm{kWh} / \mathrm{sq} \mathrm{m}$ /year of primary (source) energy use would require most projects, with such technologies as ground-source heat pumps or free cooling from a nearby cold-water body, to reduce total energy use to nearly $50 \mathrm{kWh} / \mathrm{sq} \mathrm{m} / \mathrm{year}$ (EUI of $16 \mathrm{kBtu} / \mathrm{sq} \mathrm{ft} / \mathrm{year}$ ), an achievable number in theory, but not typically achieved in practice. Of course, with on-site solar-power generation (or in the case of one building, a neighboring forest set aside for permanent conservation and carbon-fixing), it's possible to have a zero-carbon building with an EUI of 30$35 \mathrm{Btu} / \mathrm{sq} \mathrm{ft} /$ year, results achieved at the NREL RSF I building in Golden, Colorado and the Singapore Building and Construction Authority's Zero Energy Building.

Table 1 Median Energy Use Intensity, by Region

$\begin{array}{lll}\text { Region } & \text { Energy } & \text { Number of Examples } \\ \text { Americas } & 156 \mathrm{kWh} / \mathrm{sq} . \mathrm{m} . / \text { year } & \text { (15 examples) } \\ \text { Europe } & 135 \mathrm{kWh} / \mathrm{sq} . \mathrm{m} . / \text { year } & \text { (15 examples) } \\ \text { Asia Pacific } & 158 \mathrm{kWh} / \mathrm{sq} . \mathrm{m} . / \text { year } & \text { (15 examples) }\end{array}$

So, for designers, there are now clear targets: achieve at least the median energy use of similar LEED Platinum, BREEAM Excellent/Outstanding, 6-Star Green Star buildings in a specific geographic region. Of course, many projects now aim at the low end of the energy-use range and have a clear goal to match the "best in class" results already obtained in that region. Some projects are achieving EUI results below 20 in fully realized commercial office buildings. ${ }^{24}$

Beyond actual results, it's useful to look at what projects should achieve to meet the 2030 Challenge goals. Table 8.4 shows what these goals would be for 2010 , representing a 60 percent reduction in energy use from US national averages in 2005. Recall that by 2015 new buildings

\footnotetext{
${ }^{23}$ European results need to be interpreted with some caution because they often include only "regulated" use: heating, cooling, hot water, and lighting, which can understand total energy use by one-third or more.

${ }^{24}$ Personal communication, Paul Schwer, PAE Consulting Engineers, Portland, Oregon.
} 
should be performing 16 percent lower than these levels, to meet the 2030 Challenge goal of a 70 percent reduction (by 2015). One can see that the median energy use of the world's greenest buildings barely misses the target in Europe and the Americas, but exceeds it by about 15 percent in Asia/Pacific, region, demonstrating that in some places the best buildings are on a path toward carbon-neutral energy use by 2030 , but that in other places, designers, builders and operators still have a way to go, to meet even interim energy demand targets.
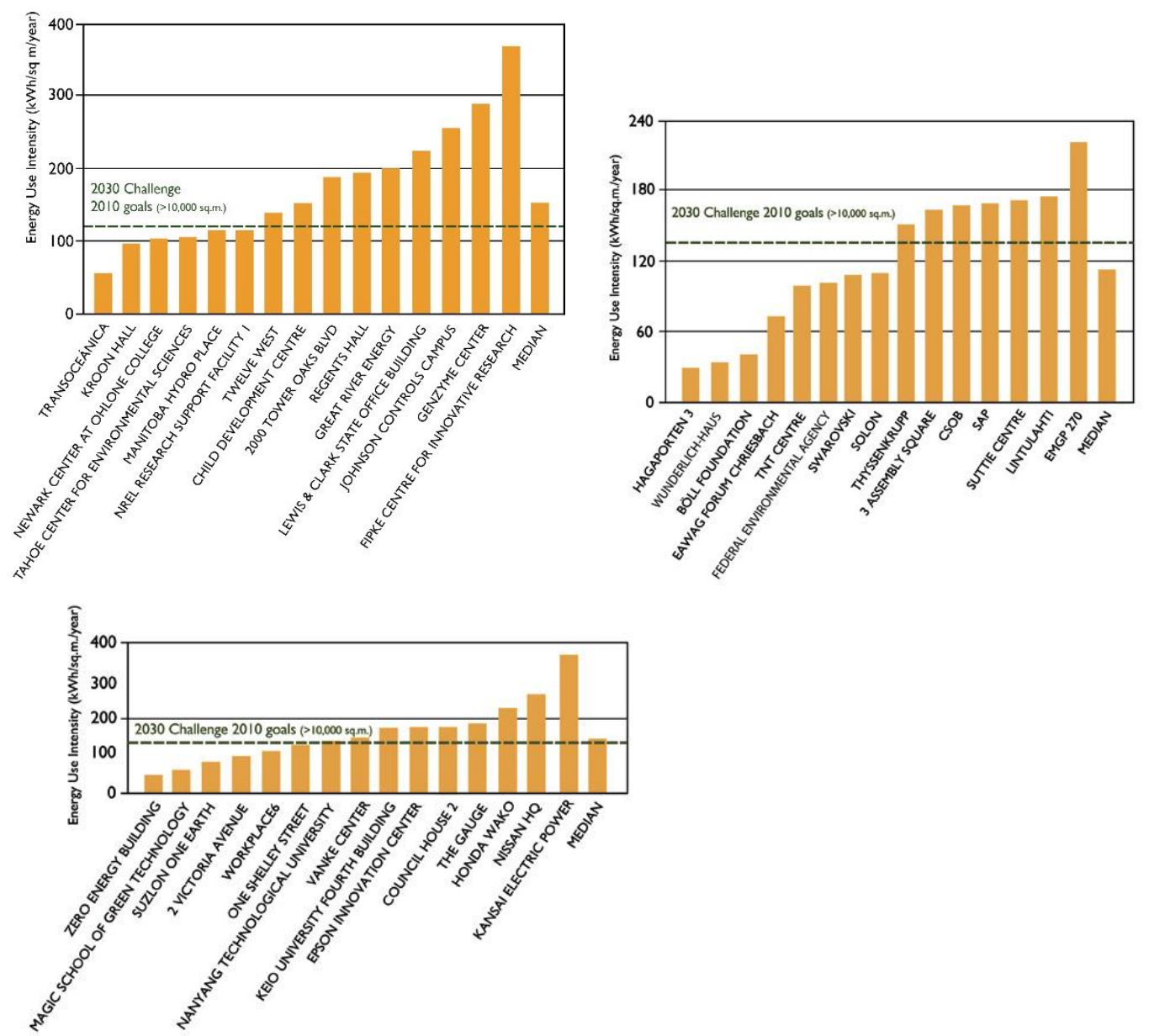

Figures 1a, b, and c. Median Energy Use by Region ${ }^{25}$

Table 2. 2030 Challenge Target for 2010: 60\% Reduction from US National Average ${ }^{26}$

\begin{tabular}{|l|l|l|}
\hline Building Type & $\begin{array}{l}\text { Energy Use Intensity } \\
(1000 \text { 's of Btu/sq.ft./year) }\end{array}$ & $\begin{array}{l}\text { Energy Use Intensity } \\
(\mathrm{kWh} / \mathrm{sq} . \mathrm{m} . / \mathrm{a})\end{array}$ \\
\hline Education & 30 & 95 \\
\hline Healthcare - Inpatient & 91 & 287 \\
\hline Office, $10,000-100,000$ sq.ft. & 36 & 113 \\
\hline Office, > 100,000 sq.ft. & 42 & 132 \\
\hline
\end{tabular}

${ }^{25}$ Source: World's Greenest Buildings, page 200.

${ }^{26}$ AIA 2030 Commitment Reporting Tool, www.aia.org/about/initiatives/AIAB079458, accessed February 4, 2012. 
What does this mean for ASCE, ASME and NIST? Several conclusions emerged from our study of building energy use worldwide.

First, building operating-energy needs to be the core of design and operations discussions, if we are to meet ambitious goals for "zero net energy buildings" in the US by 2030. This means robust metrics and public disclosure of operating energy use.

Second, operating energy needs to be discussed and measured in absolute terms, not in terms of 'relative improvement' or 'top 25 percentile' (as in the US EPA Energy Star program). If our goal is to reduce carbon emissions, we must go beyond even site energy use measurements and include a full carbon accounting in such measures.

Third, it is possible to set absolute performance goals for each building type: for example, we should aim at having every office and academic building use less than 35,000 Btu/sq.ft./year for "core" uses (i.e., excluding data centers and special process loads such as wet labs), before adding any contribution from renewables. In most low rise buildings, the predominant building type in the US, this will allow "zero net energy" use in most regions with today's solar PV technology.

Fourth, an integrated design process in new construction is essential for achieving great results. High performance projects almost invariably employ some version of this process, which typically involves setting energy use goals at the beginning of a project and then evaluating the design at each stage to achieve those results.

Finally, we need to look beyond building operating energy use and begin to develop measures of total carbon emissions from buildings that also include the life cycle assessment of building materials, components and systems; moreover, these measurements need to be normalized for the varying carbon emissions from the electric supply grid in different parts of the country. 
Co-Moderators: I. S. Jawahir and Subhas Sikdar

\section{Outcomes of Breakout Session 1 on Measurement Science (Definition, Standards, Metrics, Indicators and Ratings)}

\section{Problems Covered}

The participants listed in Appendix A.3 discussed the objective and scope of the breakout session and produced the following list of problems and descriptions:

- Lack of clarity on sustainability science and engineering: Bring together physical, natural, and social sciences and engineering for defining sustainability

- Challenges in measuring: Identify metrics and requirements for assessing sustainability

- Unmeasurable sustainability values/factors/elements: Find ways of introducing weights for these factors/elements

- Vetting of valuing issues: Develop a framework for incorporating different value judgments

- Uncertainty in measurement: Develop methodologies for assessing uncertainty

The remaining sections expands on these five problems discussed.

\section{Lack of Clarity on Sustainability Science and Engineering}

\section{Description:}

It was felt that there is no clear scope or definition for sustainability that can be found for sustainability in the context of science or engineering. It is therefore necessary to bring together the disciplines of physical, natural, and social sciences and engineering for defining sustainability. Sustainability is also not in essence a scientific word, but as sustainability has become a rallying cry in anthropogenic activities, which cause environmental, economic, and societal impacts, and therefore, we need quantitative methods to assess sustainability. Thus, we need to express sustainability in scientific terms. More clarity is needed in defining sustainability so that a common ground can be established in evaluating and making judgment on sustainability in terms of these impacts.

\section{Root Cause:}

Not all aspects of sustainability is measurable, especially the societal impacts, which depend on value judgment.

Multi-facets of sustainability exist. Sustainability involves a system. Establishing a framework for agreeing on a definition of system boundary of particular cases is an important task.

Sustainability also depends on the scale of the system to be assessed. The choice of quantitative metrics or indicators for measuring relative sustainability of systems will be different for different scales. Scales can be global, regional, business, or technology levels.

Subjectivity and selectivity are involved in sustainability evaluation.

For measuring sustainability of a chosen man-made system, metrics are used. These metrics may not all be on an equal footing. Some need to be weighted heavier than other metrics in this 
determination. Assigning these weights while assessing sustainability is a societal choice, hence it is subjective. These weights will therefore depend on situations. The value of the weights to be used for a specific metric in one country or business enterprise, for example, will be different to another because the value judgments will be different.

\section{Recommendations:}

- Integration of multi-disciplinary aspects

- Develop quantitative methodologies for evaluating sustainability

\section{Action Plan:}

- Identify experts in social, economic and behavioral sciences along with urban planners (e.g., organizing and hosting dedicated workshops, meetings, etc.)

- Integrate deterministic and non-deterministic methodologies for sustainability evaluation

- Promote educational and training programs (need for new knowledge and data)

Roles (Industry, Government, Academia, NGO, Software/Hardware):

All stakeholders to collaborate. All segments of construction and manufacturing industries must be engaged.

\section{Challenges in Measuring}

Description:

Sustainability is not absolute in time and space. It is relative to a reference state to be defined. Measuring relative sustainability depends on our ability to identify a necessary and sufficient number of metrics to describe a state of the system. Once this is done, some algorithmic technique is needed to computationally determine the sustainability of the state of system relative to a reference state of the same system. For instance, when we follow the sustainability performance of a system over time, the reference state can be the state at a specified time instant.

Measuring is also challenging, and not all sustainability elements can be measured as some of these elements can only be evaluated qualitatively:

- Identify measurements and requirements for assessing sustainability in terms of all affecting elements

- Find ways of introducing weights for all involved sustainability values/elements

$\underline{\text { Root Cause: }}$

Societal metrics often are not quantitative. Sustainability values are sometime relative, and are not easily quantifiable.

Recommendation:

- Depending on the nature and scale of a system to be studied, determine a list of potential metrics to be chosen from.

- Identify experts in social sciences, along with engineering experts, for workshops and training programs

- Consider the dynamics of the multidimensional nature of issues

Action Plan:

- Organize workshops 
- Develop educational materials

- Create a framework for system identification

- Identify metrics and indicators, and make the choice on weights to the metrics transparent

- Identify or create methodology for assigning relative weights to all relevant sustainability values/elements

- Convert qualitative measures to a generally agreed and understood quantitative measures (e.g., non-deterministic)

- Identify or create assessment methodology for decision making

Roles (Industry, Government, Academia, NGO, Software/Hardware):

All stakeholders to collaborate. All segments of construction and manufacturing industries must be engaged.

\section{Unmeasurable Sustainability Values/Factors/Elements}

\section{Description:}

Socio-economic impacts of anthropogenic actions are not internalized. When these externalities are internalized we have the true outcome of our actions. Assigning quantification to these impacts is essentially dealing with the unmeasurable sustainability values/factors/elements. While there is reasonable progress and incentives for establishing metrics for implementation in the manufacturing industry, there is only very little or no incentive and/or progress in identifying relevant metrics for sustainability evaluation of products and processes in the construction industry.

\section{Root Cause:}

Societal impacts are inherently difficult to measure

Recommendation:

- Discuss all sustainability issues with social scientists who have skills and experience on societal sustainability issues. These discussions should be done in the context of sustainability of systems endowed with scales.

- Create practical and consistent data and data collection methods

- Request construction companies to enter data through the portals

- Make data available to public

- Develop sustainability scorecards

Action Plan:

- Convene common workshops with natural and social scientists, and engineers

- Create industry consensus group to decide

○ What data to collect

○ How to collect

- How to disseminate

- Consider ANSI's role in creating a user/consensus group

- Include publically available portal 
Roles (Industry, Government, Academia, NGO, Software/Hardware):

All stakeholders of building/construction and manufacturing industries should be included.

Industry

Participate in consensus group

Government

Perhaps NIST to begin the process to create a user/consensus group and participate throughout the process. GSA, DOD, etc. to participate, and ANSI (standards and codes group) to agree to lead consensus group

Academia

Participate in the user/consensus group, serving as a technical resource for generating new knowledge for dissemination

$N G O$

Provide support for developing a user/consensus group

Software/Hardware Developers

Create and manage database and server space; follow-on for sensors (personal end area)

\section{Vetting of Valuing Issues}

Description:

The weighting factors for various metrics to be used and the assessment methodologies for sustainability, when done by industry, are opaque and highly subjective. Some mechanism must exist by which thoughts that go into valuing metrics can be understood and generally agreed upon by all stakeholders.

Root Cause:

Integrating scientific, engineering, and societal measures has not been the realm of science.

Sustainability decisions are a combination of science and value judgments. It is critical to assure that these are clearly distinguished.

Recommendation:

- Determine a framework for choosing metrics in the context of system and scale, and an agreeable thought process for assigning relative weights.

- Provide frameworks for prioritizing and valuing the relative importance of all components or elements of sustainability.

Action Plan:

- Organize and host a workshop to discuss and finalize sustainability value issues

- Assess the state of the science and application, as well as identify research gaps needed by industries

- Fund research on value framework that is translational, multidisciplinary and includes elements of sustainability that are challenging to measure and prioritize

- Demonstrate and apply the framework in construction and manufacturing

Roles (Industry, Government, Academia, NGO, Software/Hardware):

All stakeholders need to be included.

Industry

Collaborate with researchers, fund projects and define new challenges 
Government

Fund research, prioritize and conduct assessment

Academia

Conduct research, assess, demonstrate, and disseminate sustainability evaluation methods

$N G O$

Fund projects, collaborate and demonstrate feasibility and usefulness

Software/Hardware Developers

Develop algorithms, measurement/data collection

\section{Uncertainty in measurement}

Description:

There is uncertainty in any measurement. This is especially true for sustainability. It is important that sustainability decisions are based on sound science, and the numerical values used in such determination are subject to quality check. It is necessary to develop relevant methodologies for assessing uncertainty.

\section{Root Cause:}

Most of the uncertainty in measurement of sustainability emanates from the need to quantify societal impacts of anthropogenic actions.

Recommendation:

There needs to be a vetting process for the quality of numerical values we use in measuring societal impacts.

- Identify sources of uncertainty with definition, time horizon and system interaction elements

- Identify types of uncertainty with variability, lack of information, approximations

- Develop frameworks/methods to assess uncertainty through quantitative means (probabilistic \& non-probabilistic frameworks)

Action Plan:

Convene a workshop to discuss the following:

- Identify high-value problem areas as anchors for uncertainty-related tasks.

- For each problem area, follow recommendation above.

- Generalize Step 2 outcomes.

- Formalize best practices, guidelines and standards.

- Disseminate and educate.

- Obtain feedback and improve steps 1 to 5.

Roles (Industry, Government, Academia, NGO, Software/Hardware):

All stakeholders should be included.

Industry

Establish relevance, feasibility

Government

Provide leadership, policy, investment and incentives 


\section{Academia}

Fundamental research, training

Human resource development

$N G O$

Provide liaison among society, researchers and practitioners

Software/Hardware

Software needed to implement methods 
[This page is internationally left blank] 
Co-Moderators: Joseph Fiksel and John Carberry

\section{Outcomes of Breakout Session 2 on Systems (aggregation, linkages, system of systems, sustainability- resilience synergy and interdependencies)}

\section{Problems Covered}

The participants listed in Appendix A.3 discussed the objectives and scope of the breakout session and produced the following list of problems and descriptions. Due to time constraints, only the first three problems were selected for detailed discussion.

- Coupled human-natural systems: What methods are useful for characterizing the linkages among mechanistic processes designed by humans and organic processes that have evolved in nature?

- Predictive system assessment: How can decision makers assess a priori the potential system impacts on sustainability and resilience, including ecological, economic, and social consequences of new policies or technologies, without empirical knowledge based on past experience?

- Cross-scale interactions: Are there tractable methods available for practitioners to understand the complex interactions within a system of systems across multiple spatial and temporal scales? In particular, how can one establish boundaries for analysis, and how can one avoid loss of fidelity in aggregation from fine scale to coarse scale?

- General vs. specified resilience: Can systems be designed for "inherent" resilience to disruptions in general, rather than to specified threats?

- Justification of need for systems approach: How can issues that require systems thinking be identified and communicated, with an appropriate business case?

- Establishment of accepted practice: How can we establish commonly accepted, credible methods, practices, and data, with compelling examples?

The remaining sections below expand on the three selected problems.

\section{Coupled human-natural systems}

\section{Description:}

What methods are useful for characterizing the linkages among mechanistic processes designed by humans and organic processes that have evolved in nature?

\section{Root Cause:}

Economic development has led to undesired ecological impacts, leading to greater awareness of interdependence between human and natural systems.

Recommendation:

Improve the scientific capabilities to measure and quantify resource flows, emissions, and other interactions between human and natural systems. 


\section{Action Plan:}

- Identify the ecological constraints (such as scarce minerals, land availability, ecological carrying capacity) that may influence construction and manufacturing decisions.

- Develop a full understanding of resource depletion, ecosystem degradation, and other ecological impacts of human activities.

- Identify critical ecological conditions, such as biodiversity, soil quality, nutrient cycling, that are disrupted by human activities.

- Characterize beneficial ecosystem services that enhance the sustainability of construction and manufacturing activities, e.g., enhanced stormwater management through green infrastructure.

- Develop early warning indicators of systemic change, such as indicator species.

- Develop indicators of system resilience to unexpected shocks, e.g., diversity, buffering.

Roles (Industry, Government, Academia, NGO, Software/Hardware):

See Section 5. below.

\section{Predictive system assessment}

Description:

How can decision makers assess a priori the potential system impacts on sustainability and resilience, including ecological, economic, and social consequences of new policies or technologies, without empirical knowledge based on past experience?

\section{Root Cause:}

In an age of rapid innovation and globalization, systems are becoming more complex, and their emergent properties are poorly understood.

\section{$\underline{\text { Recommendation: }}$}

Develop possible future scenarios, and utilize advanced measurement science tools and techniques to monitor and interpret observable outcomes.

\section{Action Plan:}

- Engage stakeholders in developing alternative future scenarios to understand the envelope of possible system evolution.

- Characterize the relevant baseline system conditions, including ecological, economic, and social aspects, as well as the historical changes that have occurred.

- Enable extensive data collection, validation, and interpretation, using "big data analytics" to characterize the systems in question.

- Inventory the available system modeling tools and provide guidance on appropriate applications for the benefit of practitioners.

- Utilize multi-criteria decision-making tools to establish collective stakeholder priorities for complex system decisions.

- Adopt an adaptive management approach to respond to changing conditions and unexpected outcomes.

- Encourage the development of a common ontology for indicators to characterize the sustainability and resilience of complex systems. 
Roles (Industry, Government, Academia, NGO, Software/Hardware):

See Section 5. below.

\section{Are there tractable methods for practitioners to understand the complex interactions within a system of systems across multiple spatial and temporal scales?}

Description:

Are there tractable methods for practitioners to understand the complex interactions within a system of systems across multiple spatial and temporal scales?

\section{Root Cause:}

Complex, dynamic, non-linear systems are heavily influenced by cross-scale linkages, from micro to macro and vice versa (e.g., climate change drives local flooding, isolated incidents can cascade into large-scale supply disruptions).

Recommendation:

Develop protocols and scientific methods for system characterization, dynamic modeling, and measurement to capture cross-scale interactions, enabling system aggregation and decomposition across time and space.

Action Plan:

- Develop guidance for establishing system boundaries, enabling analysis of the broader implications of manufacturing or construction design decisions. The analysis must go beyond conventional "life cycle assessment" to capture the dynamic behavior of industrial systems, ecological systems and human communities.

- Expand the concepts of energy, water, and material balance beyond individual structures and processes to a regional or even global scale.

- Encourage research on how to perform aggregated, high-level system-level analysis without losing important fine-grain details

- Utilize analytic methods to understand the sensitivity of system sustainability or resilience indicators to key variables at higher or lower scales of resolution.

- Develop meta-data standards to assure compatibility and interoperability of measurement technologies across different types of systems and across scales.

Roles (Industry, Government, Academia, NGO, Software/Hardware):

See Section 5. below.

\section{Roles of Stakeholders}

The participants agreed that each of the stakeholder groups identified (Industry, Government, Academia, NGO, Software/Hardware Vendors) would play similar roles in the context of the three problems discussed. The roles are as follows: 
- Industry: The private sector should provide the needed level of transparency (e.g., carbon disclosure) to support investigation of system-level indicators of change. Businesses should identify important decision criteria and data needs, and can help to validate new measurement science techniques.

- Government: the Federal government should provide research priorities and funding for research on systems-level sustainability indicators. State \& local governments can provide test-beds for application of new measurement methods and can help in selecting indicators by setting priorities for the desired outcomes of system interventions, such as new policies or technologies.

- Academia: Researchers can contribute to sustainable systems measurement research in a variety of ways - through innovation, research, education, advocacy, and formation of partnerships with industry.

- NGOs also can contribute in a variety of ways - through consensus building among stakeholders, public education, advocacy, development of standards, and formation of partnerships with industry and government.

- Software/hardware vendors will play the key role of developing the required measurement tools, technologies, models, and methods, and to perform systems integration in response to the needs listed in the previous sections.

\section{Additional Discussion}

Note: This section is based on a write-up by Ryan Colker.

Underpinning the entire discussion of metrics and systems thinking is the ability to link existing data from numerous sectors/users/uses to support understanding of the whole. Naturally, this leads to huge challenges across disciplines. Even within the building industry, depending on the discipline creating the data and the stage in the process, the metrics and information can vary widely - often without opportunities to link them. For example, in Building Information Modeling (BIM) the value of information relies on the ability to use it across the life-cycle for various different purposes, facilitated by open standards for interoperability and information exchange. The data within the BIM also need to be capable of linking with other adjacent systems including civil infrastructure and GIS. The ability to integrate metrics from the manufacturing up through assemblies and ultimately to buildings would be ideal. This would add to the ability to understand economy-wide impacts and measure progress towards societal goals.

This leads to questions of scale and system boundaries. A systems approach needs to focus on at least two scales - first, the manageable scale (say of a building or community) and second (albeit with less precision) at the more macro level. Ultimately, one could create the mechanisms to allow "rolling up" of indicators to the macro scale. Such a roll-up can certainly lose fidelity for the overall system, but one should ensure that the more granular data remains accessible within the individual data or assessment activities. This approach is complicated by the fact that in coupled, dynamic systems the effects can cascade from macro to micro or vice versa. 
Creating the business case for systems thinking is also complicated. Typically it falls under noone's responsibility to examine integrative effects - and those that could potentially bear that responsibility (e.g., CEOs) are either too preoccupied or do not have the depth of knowledge or interdisciplinary comfort to address such "wicked" problems. Systems thinking is largely the domain of a small group of enlightened people (typically in academia or think tanks) who recognize the elegance of such an approach and the need to move in that direction. For the most part we have solved the "easy" issues facing our society-the ones with single-discipline solutions. To make the next leap will require a more difficult effort focused on multi-disciplinary and interdisciplinary engagement.

Resilience is a perfect example - if a building owner were to approach resilience in isolation for his/her building and not consider the utilities and workforce associated with that building, then the investment may be for naught. If the building still stands but the employees (or customers) are unable to get access, or if electricity or communication services are down, the net result may be the same as if there were no investment in resilience.

This leads to several recommendations on measurement science for sustainability are:

1. All metrics should be usable across sectors and products (or at least translatable to a common metric). This supports utility across supply chains and across systems, and also relates to the need for interoperability of data sets.

2. To the extent practical, one should focus on metrics that can be used to assess performance across a product/building life-cycle. Today, many metrics focus on expected results from the design process, but realization of sustainability goals relies on actual achievement. This type of design-focused thinking results in discounting (or simply ignoring) the potential for synergistic effects.

3. Metrics should be focused on the performance of products and materials and not based on the products or materials themselves. This requires a function-based approach rather than a component specification approach. This will lead to overall efficiency in the products rather than supporting manufacturer inertia and protectionist activities for traditional products that no longer meet societal needs. 
[This page is internationally left blank] 
Co-Moderators: Nabil Nasr and Fazleena Badurdeen

\section{Outcomes of Breakout Session 3 on Planning, Design and Supply Chain (lifecycle analyses and treatments, and material and energy efficiency)}

\section{Problems Covered}

The participants listed in Appendix A.3 discussed the objective and scope of the breakout session and produced the following list of problems and descriptions:

a) Systems and supply chains not designed for end-of-life management (EOL) reduces capability for increased reuse, remanufacturing and recycling.

b) Limited data sharing and lack of interoperability: increase capability to share information between relevant stakeholders across the supply chain.

c) Lack of predictive models that can realistically estimate future cross-company and crosssupply chain economic, environmental or societal impacts.

d) Lack of a systems-based approach to planning, design and management of supply chains for sustainability.

e) Lack of resilience in designed systems make them more vulnerable to unpredictable and disruptive events.

f) Lack of a common sustainability nomenclature that can be used across companies in the supply chain.

The remaining sections expand on selected problems.

\section{Systems not Designed for EOL}

Description:

To enable closed-loop material flow across multiple life-cycles of products, they must be designed and manufactured to enable better remanufacturing, recycling and end-of-life

management. How to design products, processes and systems to increase remanufacturing, recycling and end-of-life management?

\section{Root Cause:}

Lack of design methodologies, incentives, tools

Recommendation:

Metrics, methods, measurements

Action Plan:

- Lead/support development of design tools and methodologies for design for EOL with metrics and targets

- Support development of sector based metrics for design for EOL

- Benchmark data (design and implementations) sharing

- Lessons learned from EOL products 
Roles (Industry, Government, Academia, NGO, Software/Hardware):

Industry: Participate in development, provide data, validation

Government: Lead development, provide incentives, fund research

Academia: Development, research

NGO

Support

Software/Hardware: Integrative software, validation equipment

\section{Limited data sharing and lack of interoperability}

Description:

In this electronic age, companies amass considerable data related to their products, processes and systems. However, this data is not used effectively to produce actionable information; in situations where such information is available, it is not shared across the supply chain to increase benefits to all stakeholders; there is insufficient integration across the supply chain to enable improvements in energy efficiency and material efficiency. Thus, how can companies increase data sharing and interoperability between relevant stakeholders across the supply chain?

\section{Root Cause:}

- Lack of knowledge related to data sharing and interoperability related to sustainability in supply chain

- Lack of knowledge related to supply organization and tiers. For example some supply chains have multiple tiers and sharing information across tiers requires a more robust framework. There is a lack of integrated approaches for addressing sustainability through data sharing particularly when the supply chain is multi-tiered.

- Companies are often reluctant to share information across the supply chain for fear of losing competitive edge (trade secrets, losing price)

- The lack of protocols to maintain information integrity when shared the supply chain is another factor that contributes to limited data sharing. For example, at what point in the procurement process do you ask questions and what questions do you ask?

- There is no clarity on what the appropriate metrics are, what a suitable corresponding threshold is or what measures of goodness for supply chain must be used.

- There is a lack of governance and resources to implement a supplier code of conduct/ethics

- There is no clearly defined process of managing inoperability in the supply chain during disruptions (war, natural disaster that disrupt your supply chain)

- Benefits through a supply chain are unknown and/or diffuse (principal agent type problem).

- Supply chains are highly variable, and estimating as well as allocating benefits is complicated.

Recommendation:

- Define interoperability from a manufacturing, construction and sustainability perspective

- Establish data sharing and interoperability roadmap for a supply chain

- Identify incentives that do not compromise business integrity and trade secrets. 
- Establish guidelines to share information across supply chains so companies will not have a fear of sharing information and losing their competitive edge.

- Build off of existing, appropriate tools/models, and ultimately standardize underlying data and tool architectures.

Action Plan:

- Standardize basic common terminology and language related to interoperability and data sharing as it pertains to the supply chain (NIST + software).

- Multi-industry data sharing and interoperability for supply chain case study that demonstrates solid examples of the benefits of these practices (NIST + industry partners)

- Establish data sharing and interoperability roadmap for a supply chain (NIST+NGO)

- Create framework that defines type of supply chains and associated layers (Academia)

- Define materials efficiency and energy efficiency in this context.

- Identify existing, appropriate tools/models - possibly include embodied energy; materials flows through the economy; cross-sector energy impacts; energy use of (specific) products through their lifecycle;

- Build upon those tools/models (one example framework could be embodied energy and cross-sectoral energy impacts tools being develop by DOE; another could be BEES tool at NIST).

- Materials certification: currently, certifications are required for products marketed to EU; underlying data analysis should be standardized/verified and then utilized for improved material efficiency and certification.

- Include in the existing tools/models, or develop additional model frameworks to include other materials-associated "externalities" that directly or indirectly impact costs such as environmental, labor, regulatory, risks.

Roles (Industry, Government, Academia, NGO, Software/Hardware):

Industry: engage in standards development, and implementation

Government: NIST work with standards groups (ISO, ANSI, etc.); DOE work with industry on voluntary programs; USG to collaborate on tools/models/databases

Academia: engage in standards development, and work with local regulatory agencies. Take leadership role in defining sustainability, materials efficiency, etc., and develop

training/tools/etc. useful to industry and society.

NGO: None

Software/Hardware: None

\section{Lack of Predictive Models}

\section{Description:}

Sustainability impacts occur at different points during the life of the product or structure and may take a long-term to materialize as benefits are likely to accrue across the supply chain. However, existing frameworks do not lend themselves to accurately determine time dependent cross-

company benefits (environmental, economic or societal). Can predictive models be developed to realistically predict the influence of such improvement efforts? Can models be developed to predict impacts of emergent and future conditions; to evaluate and design adaptive alternatives? 


\section{Root Cause:}

Analysis approaches tend to take a unit process view and overall impacts are treated on an additive basis rather than a time series, integrated system view.

\section{Recommendation:}

- Not only collect LCI/LCA data for materials and products in a national database but also typical use statistics such as recovery and reuse rates, typical product lifespans, and incremental impacts to assembly or building operational cycles.

- Research should be conducted on developing a system of prioritization matrices that quantify the tradeoffs of various impacts over time and "present-values" those impacts into a comparable form. Note: this may seem to be impossible but only if it is looked at in absolute terms rather than a tool that could be used to assess a variety of scenarios.

- Develop a tool to utilize these matrices in relation to product and building design decisions across the cradle-to-cradle lifecycle of the product or building as a contribution to the initial decision making process.

Action Plan:

- Develop guidance for establishing system boundaries for analyzing broader implications of manufacturing or construction design decisions (beyond conventional "life cycle")

- Expand concepts of energy, water, and material balance beyond individual structures and processes to a regional or even global scale

- Encourage research on how to perform aggregated, high-level system-level analysis without losing important fine-grain details

- Utilize analytic methods to understand the sensitivity of system sustainability or resilience indicators to key variables at higher or lower scales of resolution.

- Develop meta-data standards to assure compatibility and interoperability

Roles (Industry, Government, Academia, NGO, Software/Hardware): Industry: Industry should be prepared to collect and share necessary data (reuse and recovery rates, operational impacts and typical lifespans) just as EPD data is shared.

Government: Serve as a catalyst to this process through further definition of the issues involved, sponsoring research projects and promoting the concept. Government should maintain and manage the database. Perhaps the tool development should be driven through an organization such as NIST so that the base level of the tool is cross-disciplinary, cross-industry and extensible.

Academia: Engage in meaningful, creative research

NGO: Industry trade organizations need to take the lead in collection of industry wide data and support the effort.

Software/Hardware: Tool has to be credible but not overly complex in order to encourage its utilization.

\section{Lack of Systems-based Approach}

Description:

Sustainability-oriented interventions often involve trade-offs between various activities along the value chain. Without a systems-oriented approach, the impacts of these interdependencies are difficult to evaluate. How can systems thinking-based approach be applied during planning and 
design of systems to consider interdependencies \& trade-offs between economic, environmental and societal impacts?

$\underline{\text { Root Cause: }}$

- Lack of information about the total life cycle issues of, materials, processes, and products, data ownership, lack of understanding of process capabilities in terms of energy, material, and water

- Perception that sustainability cost more

Recommendation:

- Develop design for sustainable supply chain for risk-based, better multi-criteria decision making.

- Develop data standards, analytical tools that can readily use available data

Action Plan:

- Develop industry challenge problems for benchmarking and understanding of process capabilities in terms of energy, material, and water.

- Develop a framework and mechanisms for seamless information flow across supply network for all lifecycle phases through data standards

- Promote code for America makes (crowd sourcing) for developing analytical tools for risk-based better multi-criteria decision making

- Promote better lifecycle thinking of cradle to cradle process and explain it in terms of value system than first cost.

- Develop robust and adaptable models of life cycle analysis and synthesis for spatial and temporal uncertainties

Roles (Industry, Government, Academia, NGO, Software/Hardware):

Industry: Challenge problems, change perspective on sustainability as competitiveness

Government: Promote and enable standards, better informed policy instruments, consumer

awareness, promote high risk research for long term benefits

Academia: Education and training, work with industry to develop science for sustainable construction and manufacturing, develop curriculum that reflects industry and society needs and requirements

NGO: Industry and technology roadmap, help develop better policy instruments, better balance of public and private good. And partnership

Software/Hardware: Open architecture platforms for software and hardware to enable life cycle information flow, information models, implementation of data standards and development tools

\section{Lack of Resilience in Designed Systems}

Description:

Global supply chains are increasingly exposed to uncertain events and disruptions. The sustainability performance of supply chains is catastrophically affected when such unpredictable events occur. Quantitatively models for evaluating interdependent risks between supply chain partners and methods to analyze their propagation through the supply chains are lacking. How can systems and supply chains be design to have the resilience to withstand disruptive events and operational turbulence? 


\section{Root Cause:}

- Lack of performance criteria at a component level: For building system components, performance data is lacking. Say for a screw, what additional performance spec data do we need to address climate change? Maybe we need to know how resistant that screw is to rusting if we expect more rain.

- Lack of performance data of components against the climate change spectrum: So, the additional strain caused by climate change, such as higher risk of fire, more intense rainfall events, flooding, mold, roof load due to snow can be expanded for products. Typically, examples of codes are by region (California expanded seismic code, Florida hurricane code), but we need to have that knowledge down to more climate situations so we can build resilience into our construction and maintenance programs.

- Sensitivity of matrices in life cycle cost analysis and risk assessment modeling: So what are the low cost measures? Is there a cheap brace we can install in our roof systems to help our facilities withstand tornadoes? Maybe our basic design in our region is for an F2, but are there upgrades we can perform to make it more likely for the building to survive an F4?

Recommendation:

NIST should define performance criteria against the climate change spectrum at the component and building levels. This will allow decision makers to use the appropriate indicators for better decisions. Identify the different risks climate change present to new and existing buildings, and a methodology for determining how to mitigate - from cheap to expensive, from proven to experimental.

Action Plan:

- Develop and publish component-level performance criteria: Need to know how common and important building components need to add other performance data and guidance to their specifications, installation instructions, operating instructions to best help the systems survive against climate change.

- Evaluate and compare US regional codes to develop climate change spectrum: We need to identify how buildings can be constructed and modified at better than existing code and see some proposals for expanded code that helps fight climate risks.

- See "Roles" section for further actions.

Roles (Industry, Government, Academia, NGO, Software/Hardware):

Industry: Provide all the basis of design at a molecular level to NIST so they can test and define criteria. Provide system integration modeling so NIST can complete testing.

Government: Use and enforce criteria through acquisition regulation.

Academia: Provide criteria to students, the future implementers and building owners.

NGO: Use criteria to propose changes to policy and regulation.

Software/Hardware: Tools utilizing NIST performance criteria to allow for users to predict for better decision making. 


\section{Lack of a Common Sustainability Nomenclature}

Description:

Sustainability is a relatively new concept and common language for talking about it does not yet exist. The definition of sustainability itself varies from person to person, making it difficult to address the aspects of the issue and develop effective ways to measure it. Establishing consistent, standard terminology for talking about sustainability will help to align researchers and manufacturers communicating about common issues and designing products that address those needs. Thus, a common nomenclature and terminology related to sustainability that can be used across the supply chain must be developed.

Root Cause:

Many times, organizations define sustainability to fit their own agenda to receive invalid recognition. To be able to measure sustainability consistently throughout the construction industry, a consistent definition and measurement methodology is necessary.

\section{Recommendation:}

- Define common grounds for sustainability in both construction and manufacturing industries based on their needs to sustain business and operations while reducing impact on critical environmental areas.

- Quantify uncertainties in statements and criteria. Account for subjectivity such as social aspects.

- Define needs and impacts (tangible, intangible)

Action Plan:

Needs such as profitability, productivity, operational efficiency should be determined. Then, solutions for sustainability will make sense for business and can help reduce environmental impact. In addition, there is also a need to determine and quantify intangible impacts such as health and well-being, social injustice, etc., that are difficult to measure.

Roles (Industry, Government, Academia, NGO, Software/Hardware):

Industry: Provide sets of criteria relevant to their operations and ensure practicability.

Government: Defining priorities and fund accordingly.

Academia: Develop scientific framework to minimize subjectivity and deal with uncertainty. NGO: Supporting role

Software/Hardware: None 
[This page is internationally left blank] 
Co-Moderators: Cliff Davidson and William Flanagan

\section{Outcomes of Breakout Session 4 on Economic, Environmental and Social Aspects (Valuation, Impacts and Behavior)}

\section{Problems Covered}

The participants listed in Appendix A.3 discussed the objective and scope of the breakout session and produced the following list of problems and descriptions:

- Measuring the value to society of incorporating sustainability

- Big data collection

- Reducing social inequity

- Multi-criteria decision support

- Human health, feelings of well-being, and work performance in green buildings

The remaining sections expand on these problems.

\section{Measuring the value to society of incorporating sustainability}

Description:

It is widely acknowledged that current practices for construction, $\mathrm{O} \& \mathrm{M}$, and decommissioning of the built environment are not sustainable. How can we measure the value to society of making the investment to change these practices so that they are sustainable?

Root Cause:

There is little incentive to make such measurements, since there is little demand for the data.

Recommendation:

Create demand for this type of data by educating consumers, so they will have an appreciation for the importance of sustainability constraints in construction practices.

Action Plan:

- Take steps that could result in a decision by GSA to mandate collection of sustainable practices data.

- Expand LEED data collection, especially during the construction phase.

- Set up management systems so that collection of sustainability data would fit naturally.

Roles (Industry, Government, Academia, NGO, Software/Hardware):

- Industry: Play a leadership role in showing that sustainability data has value to consumers.

- Government: Require companies to collect and show sustainability data.

- Academia: Research the types of data that are most valuable and yet easy to collect. 


\section{Big data collection}

\section{Description:}

We now have the capability of collecting data on energy, water, and material use during construction, O\&M, and decommissioning of the built environment. We can also collect data on the movement of occupants throughout the built environment, and even on characteristics of individual occupants. This can be done throughout a neighborhood or even throughout a city. How can this type of dataset be used for maximum benefit of society?

Root Cause:

There is now an unprecedented opportunity for collection of large amounts of data of all types using automated sensors. But there are privacy issues that must be overcome as well as need for protection against misuse of the data.

Recommendation:

Bring together experts in sensors, data analys is, and ethicists to identify what data to collect, how to collect the data, how to use it for the society's benefit.

\section{Action Plan:}

- Identify what data could have the greatest value to society.

- Explore costs and benefits as well as risks of collecting these types of data for use by public and private organizations.

- Explore how data could be collected, analyzed and used with low risk to individuals but maximum benefit to society as a whole.

- Explore data accuracy depending on use, and explore calibration and establishing "ground truth" for new sensors.

Roles (Industry, Government, Academia, NGO, Software/Hardware):

Industry: Develop the sensors, data analysis tools, and distribution methods.

Government: Protect individuals from potential misuse of data that could cause harm, while encouraging business to invest in data collection and distribution; also ensuring privacy rights are not violated.

Academia: Research and education on sensors, use of data, ethical frameworks for decisions. NGO: Work with government, industry, academia to ensure communities have input to decisions on which data to collect and how to collect it as well as use of the data.

Software /hardware: Collection and use of big data depend on advanced software as well as sensors and interfaces to computing.

\section{Reducing social inequity}

Description:

We know that infrastructure can worsen social inequity between neighborhoods of a city, for example, by dividing neighborhoods so that interaction among diverse groups of people is inhibited. Is there a way social inequity can be reduced through changes in infrastructure design? 


\section{Root Cause:}

Geographical, economic, political, and cultural isolation leads to a feedback loop that reduces upward social mobility.

\section{Recommendation:}

1. Community engagement in development projects

2. Democratization of technology facilitates social mobility

\section{Action Plan:}

- Develop a framework for two-way communication between the community and project leaders through an engagement scheme

- Create opportunities and motivations for the community members to receive better education by:

- Introducing role models from similar background

○ Awarding scholarships based on socio-economic factors

- Provide micro-financing for local small businesses including manufacturing

- Include organic, community-based economies and multi-purpose centers (e.g., green gardens)

Roles (Industry, Government, Academia, NGO, Software/Hardware):

Industry: Participate in community programs

Government: Support community programs

Academia: Research and education

NGO: Support and participate in community programs

Software/Hardware: n/a

\section{Multi-criteria decision support}

\section{Description:}

Many commercial, technology, and policy decisions are based on non-holistic perspectives due to the lack of integrated or systems-level decision support. How can we better incorporate broader perspectives (people, planet, profit) into the decision-making process?

\section{Root Cause:}

Conflicting drivers, goals, values, and belief systems are not allowing rationale evaluation of increasingly important criteria.

\section{$\underline{\text { Recommendation: }}$}

Multi-criteria decision support must be further developed and applied to address incommensurate goals and drivers to achieve holistic decisions. 
Action Plan:

- A variety of multi-criteria decision analysis (MCDA) tools exist, but need to be adapted such that they can be incorporated early in ideation and product/project development activities.

- NIST should prepare a report containing industry roadmap and roadmap for MCDA tools implementation to address sustainability issues. The roadmap should address interoperability of tools (such as LEED, BEES, BIMs) and delivery systems.

- NIST should fund a study focused on understanding how trends in society, markets, or regulations could disrupt existing programs (e.g., LEED/BEES/BIRDS/BIMs/other). How robust are method/tool criteria to changing fact patterns? Robust MCDA approaches should be resilient or adaptable to changing trends and fact patterns.

- Sensitivity analyses: understand where uncertainties matter. What parameters and changes in valuation have a directional impact on decision outcome as opposed to those that have little influence? Leverage risk assessment methodologies.

- Address scenarios that mix climate change with factors of economics, demographics, regulations, technology innovations, maintenance and repair, infrastructure maintenance/build/re-build. Are there any "perfect storm" scenarios? Consider transport, hospitals, grid, food and water supply.

- Leverage big data and data transparency to enable insights and remove barriers to criteria incorporation/consideration in decision-making processes.

- Engage all key stakeholders early in process.

Roles (Industry, Government, Academia, NGO, Software/Hardware):

Industry: Participate and provide guidance regarding applicability and implementability. Pilot tools. Contribute to development of industry consensus standards.

Government: Regulators need to be involved early in process to ensure alignment. Acknowledge that regulations can change playing field, costs. Seek consensus alignment around holistic goals.

Academia: Participate in research and education.

NGO: Active participation.

Software/Hardware: Tools development.

\section{Human health, feelings of well-being, and work performance in green buildings}

Description:

Green buildings are often claimed to increase human productivity and health and well-being, but most evidence is anecdotal. What claims are true and which are not borne out by data?

Root Cause:

Little data have been collected on the effects of green buildings on the occupants of those buildings. 
Recommendation:

Research is needed to better understand the benefits of green buildings over conventional buildings.

Action Plan:

- Identify green and conventional buildings with high occupancy and for which it is possible to measure human performance as well as human health and satisfaction with the building environment. For example, there are large databases on building characteristics of public schools across the country.

- Survey those buildings and their occupants to collect the desired information. In schools, the performance of students can be assessed. Opinions of occupants on the use of sustainable technologies (e.g., gray water, clock thermostats, non-toxic indoor materials, etc.) could be surveyed.

- Identify statistically what properties of buildings have significant effects on the performance, health, and well-being of occupants.

Roles (Industry, Government, Academia, NGO, Software/Hardware):

Industry: Develop sensors for the building environment (ventilation, air quality, water quality, noise, vibrations, etc.) as well as the health of individuals (heart rate, breathing rate, etc.).

Government: Provide funding for research.

Academia: Conduct the research.

NGO: Enable researchers to get access to members of the community who spend time in the target buildings.

Software/hardware: needed for collecting and treating the data. 
[This page is internationally left blank] 
Appendices

\section{Appendix A. Participants}

\section{A.1. Registrants}

\begin{tabular}{|c|c|c|c|c|}
\hline First name & Last name & Title & Email address & Affiliation (i.e., organization) \\
\hline llker & Adiguzel & Lab Director & ilker.adiguzel@us.army.mil & Corps of Engineers \\
\hline Lauren & $\begin{array}{l}\text { Alexander- } \\
\text { Augustine }\end{array}$ & Director & laugustine@nas.edu & $\begin{array}{l}\text { US National Academy of } \\
\text { Sciences }\end{array}$ \\
\hline William & Anderson & Director & wanderson@tisp.org & TISP \\
\hline Bill & Anderson & Director & wanderson@tisp.org & TISP \\
\hline Bilal & Ayyub & Professor & ba@umd.edu & University of Maryland \\
\hline Shapour & Azarm & Professor & azarm@umd.edu & University of Maryland \\
\hline Fazleena & Badurdeen & Associate Professor & badurdeen@uky.edu & University of Kentucky \\
\hline Bala & Balachandran & Professor & balab@umd.edu & University of Maryland \\
\hline Alex & Barraza & engineer & aljobaca@gmail.com & Thermotar \\
\hline Loida & Begley & $\begin{array}{l}\text { Lead for } \\
\text { Sustainable } \\
\text { Buidlings, } \\
\text { DOE/NNSA }\end{array}$ & loida.begley@nnsa.doe.gov & $\begin{array}{l}\text { Department of Energy, NNSA } \\
\text { and Federal Facilities Council }\end{array}$ \\
\hline Bill & Bertera & Executive Director & bertera@sustainableinfrastructure.org & $\begin{array}{l}\text { Institute for Sustainable } \\
\text { Infrastructure }\end{array}$ \\
\hline William & Bertera & President \& CEO & bertera@sustainableinfrastructure.org & $\begin{array}{l}\text { Institute for Sustainable } \\
\text { Infrastructure }\end{array}$ \\
\hline Haralamb & Braileanu & Management Intern & hgbra10@yahoo.com & USPS \\
\hline Anne & Caldas & $\begin{array}{l}\text { Sr Director, } \\
\text { Procedures \& } \\
\text { Standards } \\
\text { Administration, } \\
\text { ANSI }\end{array}$ & acaldas@ansi.org & ANSI \\
\hline John & Carberry & Adjunct Professor & johncarberry01@comcast.net & University of Delaware \\
\hline Daniel & Castro & $\begin{array}{l}\text { Associate Professor } \\
\text { and Chair }\end{array}$ & dcastro@gatech.edu & Georgia Institute of Technology \\
\hline Daniel & Castro & $\begin{array}{l}\text { Associate Professor } \\
\text { and Chair }\end{array}$ & dcastro@gatech.edu & Georgia Institute of Technology \\
\hline
\end{tabular}




\begin{tabular}{|c|c|c|c|c|}
\hline Robert & Chapman & Chief & robert.chapman@nist.gov & $\begin{array}{l}\text { Applied Economics Office, } \\
\text { Engineering Laboratory, } \\
\text { National Institute of Standards } \\
\text { and Technology }\end{array}$ \\
\hline Joannie & Chin & $\begin{array}{l}\text { Acting De;puty } \\
\text { Director }\end{array}$ & joannie.chin@nist.gov & NIST \\
\hline Eric & Coffman & $\begin{array}{l}\text { Chief - Energy and } \\
\text { Sustainability }\end{array}$ & eric.coffman@montgomerycountymd.gov & Montgomery County, MD \\
\hline Ryan & Colker & Presidential Advisor & rcolker@nibs.org & $\begin{array}{l}\text { National Institute of Building } \\
\text { Sciences }\end{array}$ \\
\hline Amy & Costello & $\begin{array}{l}\text { Sustainability } \\
\text { Manager }\end{array}$ & aacostello@armstrong.com & Armstrong World Industries \\
\hline Joe & Cresko & $\begin{array}{l}\text { Strategic Analysis } \\
\text { Technology } \\
\text { Manager }\end{array}$ & joe.cresko@ee.doe.gov & DOE/EERE \\
\hline John & Cross & Vice President & cross@aisc.org & $\begin{array}{l}\text { American Institute of Steel } \\
\text { Construction }\end{array}$ \\
\hline Matthew & Dahlhausen & $\begin{array}{l}\text { Graduate Research } \\
\text { Assistant }\end{array}$ & matthew.dahlhausen@gmail.com & University of Maryland \\
\hline James & Dalton & $\begin{array}{l}\text { Chief, Engineering } \\
\text { and Construction }\end{array}$ & Sharon.Edmonds@usace.army.mil & U.S. Army Corps of Engineers \\
\hline Cliff & Davidson & Professor & davidson@syr.edu & Syracuse University \\
\hline Rassa & Davoodpour & Manager & rassa.davoodpour@montgomerycountymd.gov & $\begin{array}{l}\text { Montgomery County, } \\
\text { Department of General } \\
\text { Services, Office of Special } \\
\text { Projects }\end{array}$ \\
\hline David & Dise & Director & eric.coffman@montgomerycountymd.gov & $\begin{array}{l}\text { Department of General } \\
\text { Services, Montgomery County }\end{array}$ \\
\hline Matthew & Eckelman & Assistant Professor & m.eckelman@neu.edu & Northeastern University \\
\hline Joseph & Fiksel & $\begin{array}{l}\text { Director, Center for } \\
\text { Resilience }\end{array}$ & fiksel.2@osu.edu & The Ohio State University \\
\hline Bill & Flanagan & $\begin{array}{l}\text { Director, } \\
\text { Ecoassessment } \\
\text { Center of } \\
\text { Excellence } \\
\end{array}$ & flanagan@ge.com & General Electric \\
\hline Damon & Fordham & Principal & damon.fordham@cadmusgroup.com & The Cadmus Group, Inc. \\
\hline Kathi & Futornick & Instructor & kmfutornick@gmail.com & Mt. Hood Community College \\
\hline Howard & Harary & $\begin{array}{l}\text { Acting Director, } \\
\text { Engineering }\end{array}$ & howard. harary@nist.gov & Government \\
\hline
\end{tabular}




\begin{tabular}{|c|c|c|c|c|}
\hline & & Laboratory & & \\
\hline John & Harrald & Professor & jharrald@vt.edu & Virginia Tech \\
\hline Mohammad & Heidarinejad & Research Associate & muh182@umd.edu & University of Maryland \\
\hline I. S. & Jawahir & Director / Professor & heathermichele@uky.edu & $\begin{array}{l}\text { University of Kentucky Institute } \\
\text { for Sustainable Manufacturing }\end{array}$ \\
\hline Michael & Kearney & Professor & kearneym@umd.edu & University of Maryland \\
\hline Melissa & Kenney & $\begin{array}{l}\text { Research Assistant } \\
\text { Professor }\end{array}$ & Melissa.kenney@noaa.gov & University of Maryland \\
\hline Leidy & Klotz & $\begin{array}{l}\text { Assoc. Prof of Civil } \\
\text { Eng }\end{array}$ & leidyk@g.clemson.edu & Clemson University \\
\hline Joshua & Kneifel & $\begin{array}{l}\text { Research } \\
\text { Economist }\end{array}$ & joshua.kneifel@nist.gov & NIST \\
\hline Fulya & Kocak & $\begin{array}{l}\text { Director of } \\
\text { Sustainability }\end{array}$ & fulya.kocak@clarkconstruction.com & Clark Construction Group, Inc. \\
\hline Constantine & Kontokosta & $\begin{array}{l}\text { Deputy Director and } \\
\text { Assoc. Professor }\end{array}$ & ckontokosta@nyu.edu & $\begin{array}{l}\text { NYU Center for Urban Science } \\
\text { and Progress }\end{array}$ \\
\hline Nancy & Kralik & $\begin{array}{l}\text { Sr. Director, HSE \& } \\
\text { Sustainability }\end{array}$ & nancy.kralik@fluor.com & Fluor \\
\hline Gül & Kremer & Professor & gkremer@psu.edu & Penn State/NSF \\
\hline James & Lambert & Research Professor & lambert@virginia.edu & University of Virginia \\
\hline Gerald & Lemmon & $\begin{array}{l}\text { Mechanical } \\
\text { Inspector }\end{array}$ & Gerald.Lemmon@parsons.com & none \\
\hline Paula & Loomis & $\begin{array}{l}\text { Sustainability } \\
\text { Program Manager }\end{array}$ & paula.j.loomis@usace.army.mil & USACE \\
\hline Sankaran & Mahadevan & $\begin{array}{l}\text { Professor of Civil \& } \\
\text { Environmental } \\
\text { Engineering }\end{array}$ & sankaran.mahadevan@vanderbilt.edu & Vanderbilt University \\
\hline Stephen & Mawn & Manager, TCO & smawn@astm.org & ASTM International \\
\hline Bruce & McDowell & President & mcdowell@intergov.com & $\begin{array}{l}\text { Intergovernmental Management } \\
\text { Associates }\end{array}$ \\
\hline Nancy & McNabb & $\begin{array}{l}\text { Manager, Building \& } \\
\text { Fire Codes \& } \\
\text { Standards }\end{array}$ & nancy.mcnabb@nist.gov & $\begin{array}{l}\text { National Institute of Standards } \\
\text { and Technology }\end{array}$ \\
\hline Vilas & Mujumdar & Consultant & v_mujumdar41@yahoo.com & None \\
\hline Nabil & Nasr & $\begin{array}{l}\text { Associate Provost } \\
\text { and Director, } \\
\text { Golisano Institute } \\
\text { for Sustainability }\end{array}$ & nasr@rit.edu & $\begin{array}{l}\text { Rochester Institute of } \\
\text { Technology }\end{array}$ \\
\hline
\end{tabular}




\begin{tabular}{|c|c|c|c|c|}
\hline Mark & Nauman & Senior Specialist & mark.nauman@montgomerycountymd.gov & Montgomery County Govt. \\
\hline Lindene & Patton & $\begin{array}{l}\text { Chief Climate } \\
\text { Product Officer }\end{array}$ & lindene.patton@zurichna.com & Zurich Insurance Group \\
\hline Andrew & Persily & Group Leader & andyp@nist.gov & NIST \\
\hline Margaret & Phillips & $\begin{array}{l}\text { Associate Director } \\
\text { for Competititons }\end{array}$ & mphillips@nist.gov & NIST \\
\hline Chris & Pyke & $\begin{array}{l}\text { Vice President } \\
\text { Research }\end{array}$ & cpyke@usgbc.org & US Green Building Council \\
\hline Sudarsan & Rachuri & Program Manager & sudarsan@nist.gov & NIST \\
\hline David & Ratterman & Attorney & dratterman@stites.com & $\begin{array}{l}\text { Stites \& Harbison, PLLC } \\
\text { Construction Industry }\end{array}$ \\
\hline Chris & Renschler & PhD & rensch@buffalo.edu & $\begin{array}{l}\text { University at Buffalo / NCGIA / } \\
\text { MCEER }\end{array}$ \\
\hline Michele & Russo & $\begin{array}{l}\text { Director, Green } \\
\text { Content \& Research } \\
\text { Communications }\end{array}$ & michele.russo@mhfi.com & McGraw Hill Construction \\
\hline Charles & Schwartz & Professor and Chair & schwartz@umd.edu & University of Maryland \\
\hline Subhas & Sikdar & Dr. & sikdar.subhas@epa.gov & $\begin{array}{l}\text { Environmental Protection } \\
\text { Agency }\end{array}$ \\
\hline Mirosław & Skibniewski & Professor & mirek@umd.edu & University of Maryland \\
\hline Jelena & Srebric & Professor & jsrebric@umd.edu & University of Maryland \\
\hline Michael & Tinkleman & Director, Research & TinklemanM@asme.org & ASME \\
\hline Kostas & Triantis & $\begin{array}{l}\text { Professor/Program } \\
\text { Director }\end{array}$ & ktrianti@nsf.gov & NSF \\
\hline Nasim & Uddin & Professor & nuddin@uab.edu & $\begin{array}{l}\text { University of Alabama at } \\
\text { Birmingham }\end{array}$ \\
\hline Emily & Wallace & $\begin{array}{l}\text { Office for Coastal } \\
\text { Resource } \\
\text { Management }\end{array}$ & emily.wallace@noaa.gov & NOAA \\
\hline Bill & Wallace & President & bill.wallace@wallacefutures.com & Wallace Futures Group, LLC \\
\hline Richard & Wright & Research Professor & richard.n.wright@verizonnet & $\begin{array}{l}\text { University of Maryland College } \\
\text { Park }\end{array}$ \\
\hline Jerry & Yudelson & President & jerry@thegbi.org & Green Building Initiative \\
\hline Bohumil & Kasal & Director & & $\begin{array}{l}\text { Fraunhofer Wilhelm-Klauditz- } \\
\text { Institut WKI in Braunschweig, } \\
\text { Germany }\end{array}$ \\
\hline
\end{tabular}




\section{A.2. Pictures of Attendees}
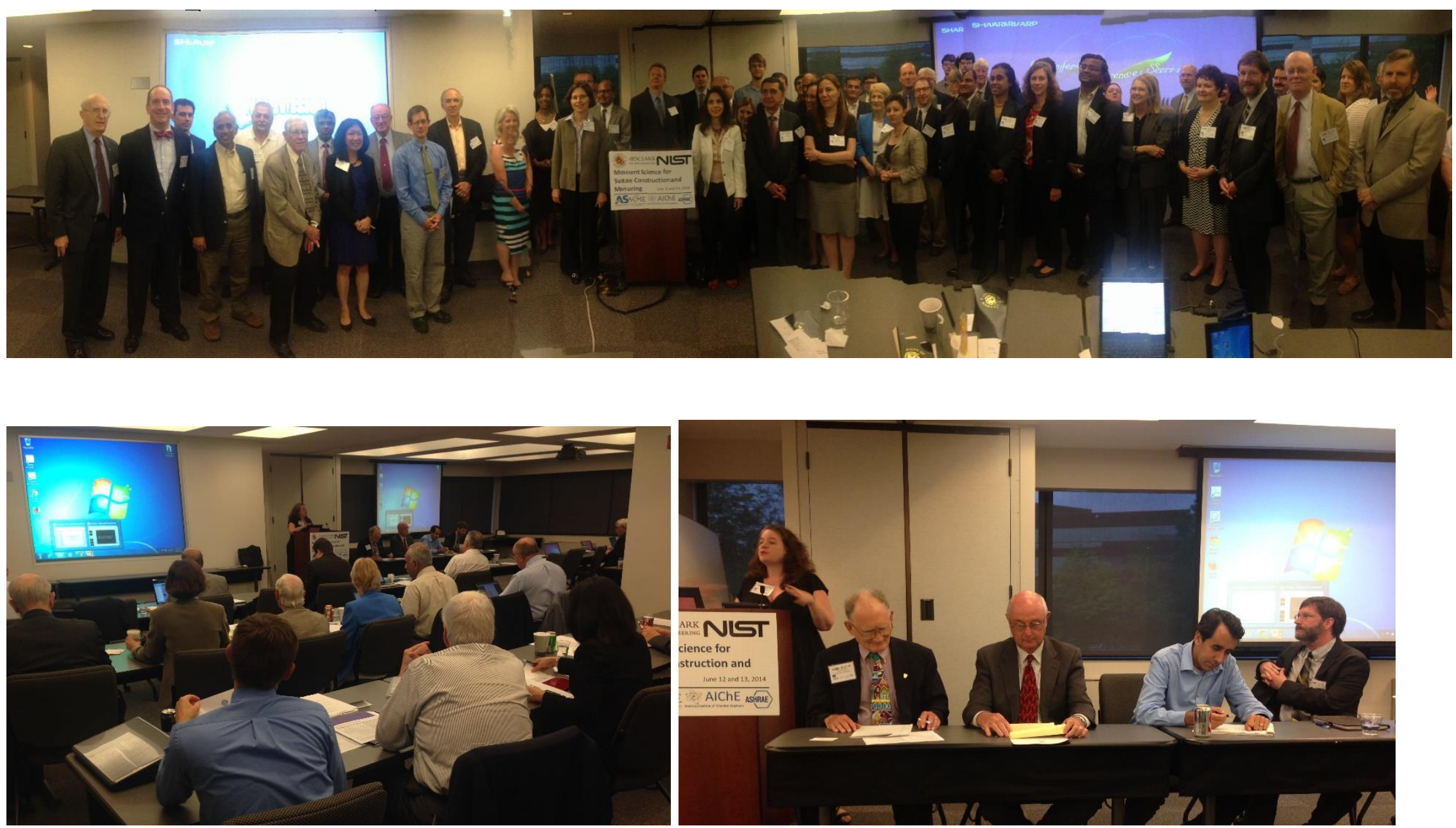

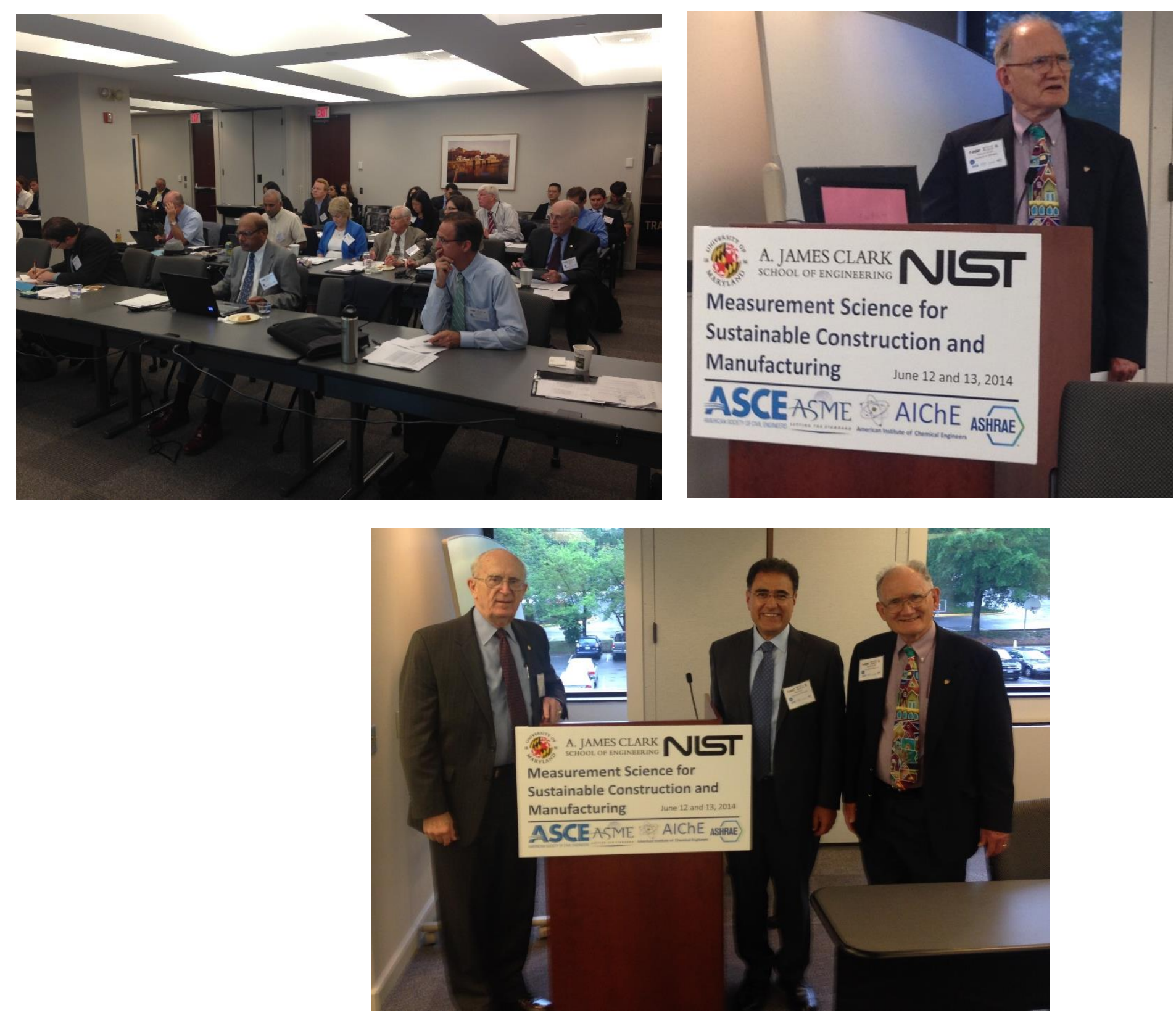


\section{A.3. Breakout Session Attendees}

\begin{tabular}{|c|c|c|c|c|c|}
\hline \multirow[b]{2}{*}{ Number } & & \multicolumn{4}{|c|}{ Breakout Session 1. Measurement science (definition, standards, metrics, indicators and ratings) } \\
\hline & & First Name & Last Name & Affiliation & email \\
\hline 1 & \multirow{2}{*}{$\begin{array}{l}\text { Co- } \\
\text { Moderators }\end{array}$} & I. S. & Jawahir & University of Kentucky & jawahir@engr.uky.edu \\
\hline 2 & & Subhas & Sikdar & Environmental Protection Agency & sikdar.subhas@epa.gov \\
\hline 3 & \multirow{9}{*}{$\begin{array}{l}\text { Session } \\
\text { Members }\end{array}$} & Anne & Caldas & ANSI & acaldas@ansi.org \\
\hline 4 & & Bilal & Ayyub & University of Maryland & ba@umd.edu \\
\hline 5 & & Melissa & Kenney & University of Maryland & Melissa.kenney@noaa.gov \\
\hline 6 & & Joannie & Chin & NIST & joannie.chin@nist.gov \\
\hline 7 & & Nasim & Uddin & University of Alabama at Birmingham & nuddin@uab.edu \\
\hline 8 & & Stephen & Mawn & ASTM International & smawn@astm.org \\
\hline 9 & & Sankaran & Mahadevan & Vanderbilt University & $\begin{array}{l}\text { sankaran.mahadevan@vanderbilt } \\
\text {.edu }\end{array}$ \\
\hline 10 & & Daniel & Castro & Georgia Institute of Technology & dcastro@gatech.edu \\
\hline 11 & & Mohammad & Heidarinejad & University of Maryland & muh182@umd.edu \\
\hline
\end{tabular}




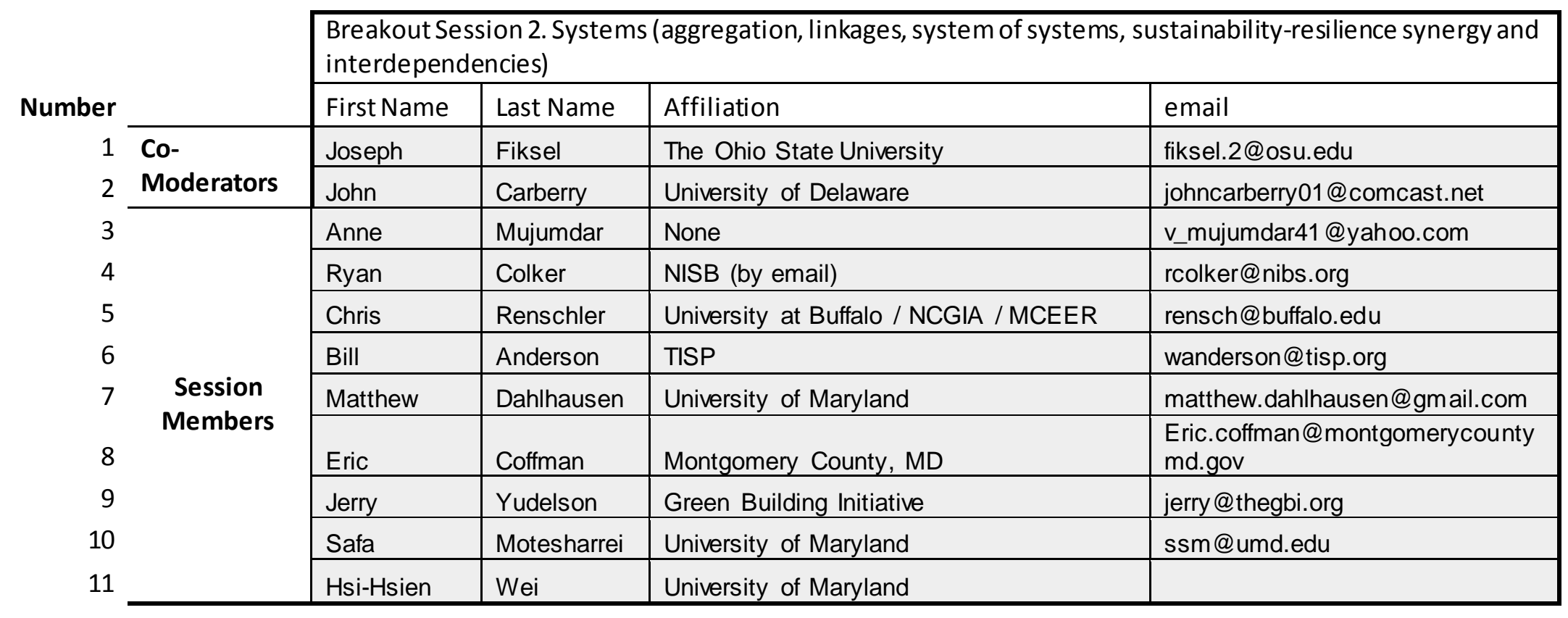




\begin{tabular}{|c|c|c|c|c|c|}
\hline \multirow[b]{2}{*}{ Number } & & \multicolumn{4}{|c|}{$\begin{array}{l}\text { Breakout Session 3. Planning, design and supply chain (lifecycle analyses and treatments, and material and } \\
\text { energy efficiency) }\end{array}$} \\
\hline & & First Name & Last Name & Affiliation & email \\
\hline 1 & \multirow{2}{*}{$\begin{array}{l}\text { Co- } \\
\text { Moderators }\end{array}$} & Fazleena & Badurdeen & University of Kentucky & badurdeen@uky.edu \\
\hline 2 & & Nabil & Nasr & Rochester Institute of Technology & nasr@rit.edu \\
\hline 3 & \multirow{14}{*}{$\begin{array}{l}\text { Session } \\
\text { Members }\end{array}$} & Ilker & Adiguzel & Corps of Engineers & ilker.adiguzel@us.army.mil \\
\hline 4 & & Loida & Begley & $\begin{array}{l}\text { DOE, NNSA and Federal Facilities } \\
\text { Council }\end{array}$ & loida.begley@nnsa.doe.gov \\
\hline 5 & & Rassa & Davoodpour & Montgomery County, Maryland & $\begin{array}{l}\text { rassa.davoodpour@montgomeryc } \\
\text { ountymd.gov }\end{array}$ \\
\hline 6 & & Amy & Costello & Armstrong World Industries & aacostello@armstrong.com \\
\hline 7 & & Fulya & Kocak & Clark Construction Group, Inc. & $\begin{array}{l}\text { fulya.kocak@clarkconstruction.co } \\
\text { m }\end{array}$ \\
\hline 8 & & Joe & Cresko & DOE/EERE & joe.cresko@ee.doe.gov \\
\hline 9 & & Sudarsan & Rachuri & NIST & sudarsan@nist.gov \\
\hline 10 & & John & Cross & American Institute of Steel Construction & cross@aisc.org \\
\hline 11 & & Michael & Tinkleman & ASME & TinklemanM@asme.org \\
\hline 12 & & Kathi & Futornick & Mt. Hood Community College & kmfutornick@gmail.com \\
\hline 13 & & Bohumil & Kasak & $\begin{array}{l}\text { Fraunhofer Wilhelm-Klauditz-Institut WKI } \\
\text { in Braunschweig, Germany }\end{array}$ & \\
\hline 14 & & Gul & Kremer & $\begin{array}{l}\text { Industrial \& Manufacturing Eng., Penn } \\
\text { State }\end{array}$ & gkremer@psu.edu \\
\hline 16 & & Shapour & Azarm & University of Maryland & azarm@umd.edu \\
\hline 17 & & Neda & Yaghoobian & University of Maryland & neyaghoo@umd.edu \\
\hline
\end{tabular}




\begin{tabular}{|c|c|c|c|c|c|}
\hline \multirow[b]{2}{*}{ Number } & & \multicolumn{4}{|c|}{ Breakout Session 4. Economic, environmental and social aspects (valuation, impacts and behavior) } \\
\hline & & First Name & Last Name & Affiliation & email \\
\hline 1 & \multirow{2}{*}{$\begin{array}{l}\text { Co- } \\
\text { Moderators }\end{array}$} & Cliff & Davidson & Syracuse University & davidson@syr.edu \\
\hline 2 & & Bill & Flanagan & General Electric & flanagan@ge.com \\
\hline 3 & \multirow{15}{*}{$\begin{array}{l}\text { Session } \\
\text { Members }\end{array}$} & Joshua & Kneifel & NIST & joshua.kneifel@nist.gov \\
\hline 4 & & Richard & Wright & University of Maryland College Park & richard.n.wright@verizonnet \\
\hline 5 & & Gerry & Galloway & University of Maryland & gegallo@umd.edu \\
\hline 6 & & James & Lambert & University of Virginia & lambert@virginia.edu \\
\hline 7 & & Bruce & McDowell & $\begin{array}{l}\text { Intergovernmental Management } \\
\text { Associates }\end{array}$ & mcdowell@intergov.com \\
\hline 8 & & Nancy & Kralik & Fluor & nancy.kralik@fluor.com \\
\hline 9 & & Michele & Russo & McGraw Hill Construction & michele.russo@mhfi.com \\
\hline 10 & & Haralamb & Braileanu & USPS & hgbra10@yahoo.com \\
\hline 11 & & Robert & Chapman & Applied Economics Office, EL NIST & robert.chapman@nist.gov \\
\hline 12 & & Chris & Pyke & US Green Building Council & cpyke@usgbc.org \\
\hline 13 & & Matthew & Eckelman & Northeastern University & m.eckelman@neu.edu \\
\hline 14 & & Michael & Kearney & University of Maryland & kearneym@umd.edu \\
\hline 15 & & Safa & Motesharrei & University of Maryland & ssm@umd.edu \\
\hline 16 & & David & Ratterman & Stites \& Harbison, PLLC & dratterman@stites.com \\
\hline 17 & & David & Webb & University of Maryland & web29110@gmail.com \\
\hline
\end{tabular}




\section{Appendix B. Biographical Information on Speakers, Panelists and Moderators}

\section{Bilal M. Ayyub}

Dr. Ayyub is the Director of the Center for Technology and Systems

Management at the University of Maryland. He is also a Professor of Civil and Environmental Engineering since 1983, Professor of Reliability Engineering since 1985, Professor of Applied Mathematics and Scientific Computation since 2009. Dr. Ayyub's main research interests are risk, uncertainty and decision analysis, and systems engineering applied to civil, infrastructure, energy, defense and maritime fields. Dr. Ayyub is a fellow of ASCE, ASME, SRA and the Society of Naval Architects and Marine Engineers (SNAME). He is also IEEE senior member. Dr. Ayyub completed research and development projects for governmental and private entities. Dr. Ayyub is the recipient of awards from ASCE, ASNE, ASME, NAFIPS, the Department of the Army, and the Governor of the State of Maryland. Dr. Ayyub is the author and co-author of more than 600 publications (including 8 textbooks and 14 edited books) in journals, conference proceedings, and reports.

\section{Bill Bertera}

Mr. Bertera is the President and CEO of the Institute for Sustainable Infrastructure in Washington, D.C. He has served as the Executive Directors of the Water Environment Federation, the American Public Works Association and the Rebuild America Coalition. He has also served in senior management positions with the International City Management Association, the National Association of Counties and the National Solid Wastes Management Association, and worked for the U.S. House of Representatives as a Congressional chief of staff. He has degrees in business and public administration.

\section{John B. Carberry}

Mr. Carberry retired from DuPont as Director of Environmental Technology. There, he was responsible for recommending technology programs and product development based on environmental issues. Since 1989, he led that function to provide excellence in treatment and remediation while in transition to waste prevention and product sustainability. Mr. Carberry presently consults on environmental issues, emphasizing energy, renewable energy, persistent materials and nanomaterials. He chaired the AIChE Project on Metrics for Liquid Bio-fuels, has given over 135 presentations at universities and public conferences, is an adjunct professor of Chemical Engineering at the University of Delaware and served on the National Academy of Engineering's Roundtable for Sustainability. Mr. Carberry is a founding member of the Green Power Market Development Group. He recently was Chair of the National Academy Committee on the Destruction of the Non-Stockpile Chemical Weapons, and served on nine previous National Academy Committees. He holds a B.ChE. and an M.E. in Chemical Engineering from Cornell University, an MBA from the University of Delaware, is a Fellow of the AIChE and is a Registered Professional Engineer. 


\section{Robert Chapman}

Dr. Chapman is the Chief of the Applied Economics Office within the Engineering Laboratory at the National Institute of Standards and Technology (NIST). In his current position, he leads a group of economists that evaluate new technologies, processes, government programs, and codes and standards to determine efficient alternatives and to measure economic impacts. Dr. Chapman's main research interests are energy efficiency, sustainability, performance-based standards, and disaster resilience. Dr. Chapman is the recipient of awards from the U.S. Department of Commerce and ASTM International. Dr. Chapman is the author and co-author of numerous publications, including: journal articles, conference proceedings, and technical

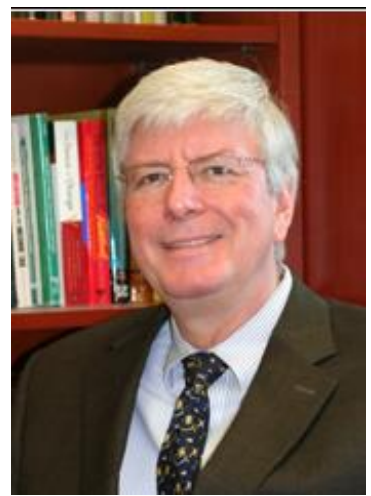
reports.

\section{Joannie Chin}

Dr. Chin is the Acting Deputy Director of the Engineering Laboratory. Dr. Chin joined NIST in 1995 as a Materials Research Engineer. She has led research and published extensively on service life prediction for polymeric materials. Dr. Chin was a co-recipient of the Department of Commerce Bronze Medal in 2002 for the development of the NIST integrating spherebased weathering device. She is also a co-recipient of the Department of Commerce Gold Medal in 2010 for being part of a NIST team that revealed root causes of field failure in soft body armor and developed standards to address them. Dr. Chin received Best Paper and Best Presentation Awards from ASTM Committee D30 on Composite Materials in 1996, and the American Society of Composites in 2001, respectively. Dr. Chin was the recipient of the Federation of the Societies for Coatings Technology's 2005 Technical Focus Award, for her work in service life prediction and accelerated aging of polymeric materials.

\section{James C. Dalton}

Mr. Dalton, SES, PE, is Chief, Engineering and Construction, Headquarters US Army Corps of Engineers and is responsible for policy, program, and technical expertise in the execution of the world wide engineering and construction missions of the Civil Works program; the Military Construction programs for the Army and other DOD agencies and technical services in support of Interagency and International services for other Federal agencies and foreign governments. He provides leadership to a field organization of 8 Divisions and approximately 15,000 engineering personnel. His career includes service in the Corps' Wilmington District, Egypt and Saudi Arabia; Korea, and Alaska. His senior leadership positions have been with the South Atlantic Division in Atlanta and the Gulf Region in Baghdad, Iraq. He

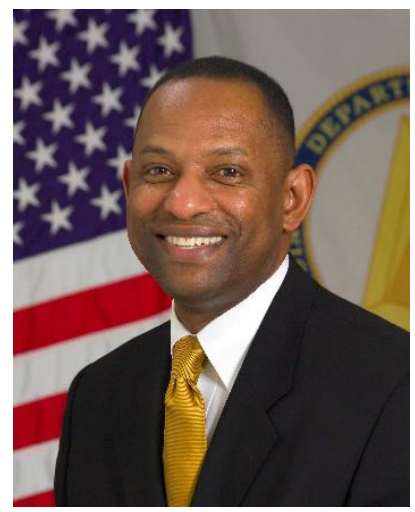
earned his BSc in Architectural Engineering, from North Carolina A\&T and his MSc in Civil Engineering from North Carolina State. He is a member of the ABET Industry Advisory Council and the National Academy of Construction. 


\section{Cliff Davidson}

Dr. Davidson is the Director of the Center for Sustainable Engineering at Syracuse University. He is also the Thomas and Colleen Wilmot Professor of Engineering in the Syracuse Center of Excellence for Environmental and Energy Systems and the Civil and Environmental Engineering Department. He has held this position since 2010. Prior to this appointment, he was Professor in the Department of Civil \& Environmental Engineering and the Department of Engineering \& Public Policy at Carnegie Mellon University for 33 years. Dr. Davidson's main research interests for many years were in the area of aerosol fate and transport in the environment, and have evolved over time to his current research in human perceptions of the environmental impacts of day-today activities, sustainable urban development including the use of green infrastructure for stormwater management, and sustainability in engineering education. Dr. Davidson is a Fellow of the American Association for Aerosol Research, and is also active in several other associations. He has received numerous awards for his teaching and research. Dr. Davidson is the author and co-author of more than 200 publications including journal articles, conference papers, book chapters, and books.

\section{David E. Dise}

David Dise, CPPO is Director, Department of General Services in Montgomery County, MD, and has worked in the public sector for over 30 years. He directs procurement, facilities management, fleet maintenance and operations, real estate acquisition and disposition, planning and development, and capital project design and construction services for all county departments. Prior to this he served as Director of Montgomery County's Office of Procurement, deputy director of Purchasing and Supply Management for Fairfax County, Virginia and chief procurement officer and chief of engineering technical resources for Fairfax Water, one of the nation's largest public water utilities. He has been active in the American Public Works Association (APWA), the National Institute of Governmental Purchasing (NIGP), the Virginia

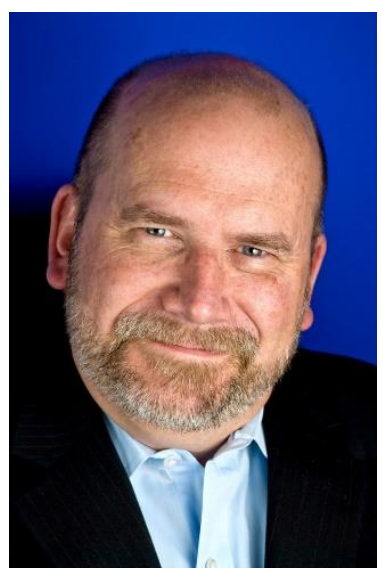
Association of Governmental Purchasing (VAGP), the Institute for Supply-chain Management (ISM), and the National Electronic Commerce Coordinating Council (NECCC), serving on the board of directors and committees for these organizations. He has also chaired or participated in various intergovernmental, business and private sector committees throughout the National Capital Region. 


\section{William Flanagan}

Dr. Flanagan leads the Ecoassessment Center of Excellence for the General Electric Company and is based at GE Global Research in upstate New York. The team works with the GE businesses, GE Corporate Environmental, and GE Ecomagination leadership to develop and implement life cycle management and life cycle assessment strategies focused on GE's product and service portfolio. Dr. Flanagan graduated from Virginia Tech in 1985 and received a $\mathrm{PhD}$ in Chemical Engineering from the University of Connecticut in 1991. He serves on GE's extended corporate ecomagination team, is a member of the Advisory Council for the American Center for Life Cycle Assessment (ACLCA), and also serves on the External Advisory Board for the University of Michigan's Center for Sustainable Systems. He is an ACLCA-certified LCA Professional.

\section{Damon Fordham}

Mr. Fordham is Sustainable Transportation Practice Lead for The Cadmus Group, Inc., where he supports environmental, energy, and sustainability projects for clients across the transportation sector. Mr. Fordham is Vice Chair of the TRB Committee on Transportation and Sustainability, a member of the TRB Committee on Transportation Energy, and a board member for the Center for Environmentally Sustainable Transportation in Cold Climates - a federally-funded University Transportation Center. Mr. Fordham was previously Program Manager for Environment at the American Association of State Highway and Transportation Officials (AASHTO), where he led the delivery of environmental technical assistance to state DOTs and local transportation agencies. Prior to his role at AASHTO, Mr. Fordham was the first Sustainability Program Manager at the

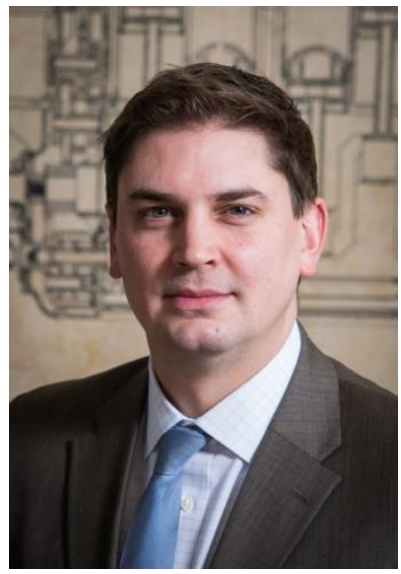
Oregon DOT, where he conceptualized, designed, and implemented a structured sustainability program for the management of Oregon's transportation system and ODOT's internal operations. Mr. Fordham has been a national expert panel member for ten sustainability-related TRB research projects. 


\section{Gerald E. Galloway}

Dr. Galloway, PE is a Glenn L. Martin Institute Professor of

Engineering, Department of Civil and Environmental Engineering and an Affiliate Professor, School of Public Policy, University of Maryland, College Park, Maryland, where his focus is on water resources policy, resilience, and disaster risk management. He also serves as a consultant to several international, federal, state and non-governmental agencies and has been involved in water projects in the US, Europe, Asia and South America. He recently chaired a National Research Council (NRC) Study on Levees and the National Flood Insurance Program and is currently a member of the US National Academies' Risk, Resilience and

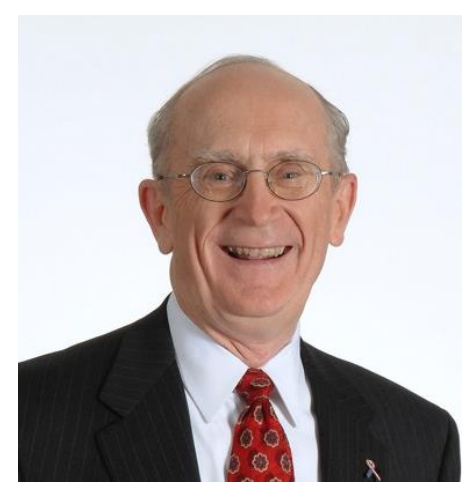
Extreme Events Roundtable and the Louisiana Governor's Advisory Commission on Coastal Protection and Restoration. He is a member of the National Academy of Engineering and the National Academy of Public Administration. He served for 38 years in the US Army, retiring as a Brigadier General.

\section{Howard Harary}

Dr. Harary has been with the National Institute of Standards and Technology since 1985. Dr. Harary began his NIST career in the Precision Engineering Division of the Manufacturing Engineering Laboratory (MEL), working in the area of dimensional metrology. He was appointed Deputy Director of MEL in October 2004, and Acting MEL Director in August 2007. After the NIST re-alignment, he served as the Deputy Director for Manufacturing of the new NIST Engineering Laboratory. Dr. Harary is currently the Acting Director of the Engineering Laboratory. Dr. Harary was awarded the Commerce Department Bronze Medal for his work in three-dimensional measurement, and the NIST Edward Bennett Rosa Award for his collaboration with industry in re-establishing traceability for gear measurements. Dr. Harary currently serves on the visiting panel of the

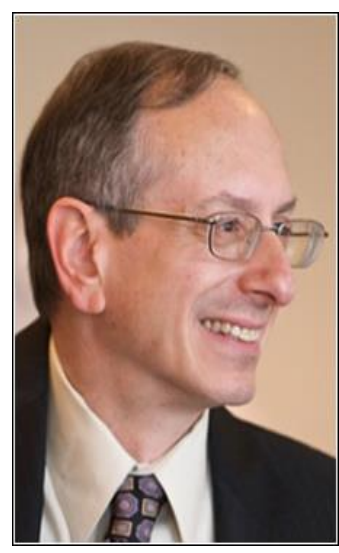
University of Maryland Mechanical Engineering Department, is the government liaison to the board of PDES, Inc., and is a member of the ASME Council on Standards and Certification. 


\section{I.S. Jawahir \\ Dr. Jawahir is a Professor of Mechanical Engineering, James \\ F. Hardymon Endowed Chair in Manufacturing Systems, and the Director of the Institute for Sustainable Manufacturing (ISM) at the University of Kentucky. He received Ph.D. from the University of New South Wales (Sydney, Australia) in 1986. His current research interests are in sustainable manufacturing at product, process and system levels, focusing on developing predictive performance models and optimization methods for sustainable machining. He has produced over 280 technical research papers, including 120 refereed journal papers, and has been awarded with 4 U.S. patents. He has received significant research funding from U.S. Federal

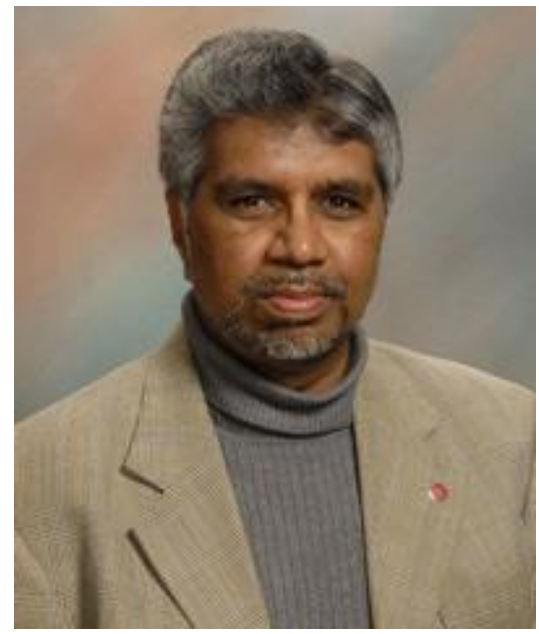 Agencies and major U.S. manufacturing companies. He is a Fellow of CIRP, ASME and SME.}

\section{Eugenia Kalnay}

Prior to her coming to UMD, Eugenia Kalnay was Branch Head at NASA Goddard, and later the Director of the Environmental Modeling Center (EMC, ex Development Division) of the National Centers for Environmental Prediction (NCEP, ex NMC), National Weather Service (NWS) from 1987 to 1997. During those ten years there were major improvements in the NWS models' forecast skill. Many successful projects such as the 60+years NCEP/NCAR Reanalysis (the paper on this Reanalysis has been cited over 10,000 times), seasonal and interannual dynamical predictions, the first operational ensemble forecasting, 3-D and 4-D variational data

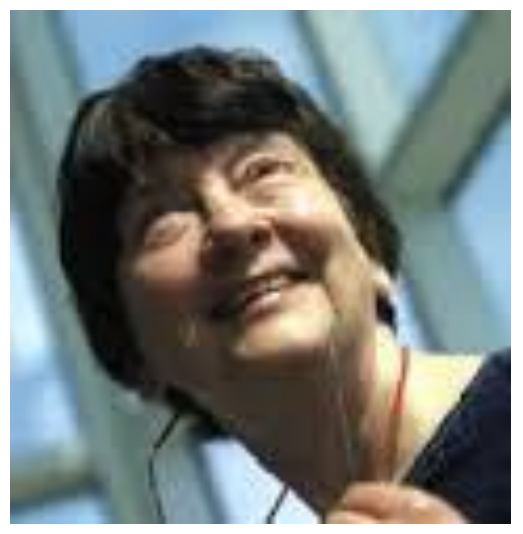
assimilation, advanced quality control, and coastal ocean forecasting. EMC became a pioneer in both the fundamental science and the practical applications of numerical weather prediction. Kalnay has received numerous awards, including the 2009 IMO Prize of the World Meteorological Organization. She is a member of the National Academy of Engineering and the UN Scientific Advisory Board on Sustainability created by the UN Secretary General. 


\section{Bohumil Kasal}

Dr. Kasal is the Director of Fraunhofer Wilhelm-Klauditz-Institut WKI in Braunschweig, Germany, which is the world's largest research Institute focusing on lignocellusic biomaterials. The Fraunhofer-Gesellschaft is, with over 22,000 employees and over 60 institutes, the largest applied research organization in Europe. Kasal concurrently holds a Chair in Organic and Wood-based Construction Materials at the Carolo-Wilhelmina University in Braunschweig, Germany. He holds an Ing. degree (engineer) from University of Zvolen, Slovakia, an MS in Wood Science from Virginia Tech, MS in Civil Engineering and $\mathrm{PhD}$ in Wood Structures from Oregon State University. Kasal has received number of awards and in 2001-2002 he

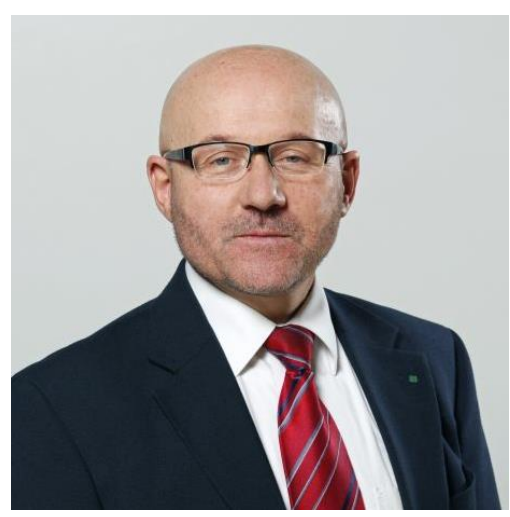
was a Senior Fulbright Fellow in Germany. During 2005-2010, Dr. Kasal was a Hankin Chair and Professor of Civil Engineering and Professor of Architectural Engineering at the Pennsylvania State University, and Director of the Pennsylvania Housing Research Center. Prior to joining the faculty at Penn State, Dr. Kasal was a Professor at the North Carolina State University in Raleigh, NC.

\section{Joshua Kneifel}

Dr. Kneifel is a research economist in the Applied Economics Office of the Engineering Laboratory at the National Institute of Standards and Technology. Dr. Kneifel's research at NIST implements whole building energy simulation, life-cycle costing, and life-cycle environmental assessment to determine the economic and environmental consequences of increasing the energy efficiency of building construction. Dr. Kneifel is the lead for the Metrics and Tools for Sustainable Buildings Project in the Net-Zero Energy, High Performance Buildings Program. Two outcomes of this project are the Building for Environmental and Economic Sustainability (BEES) software, which allows a user to compare the sustainability

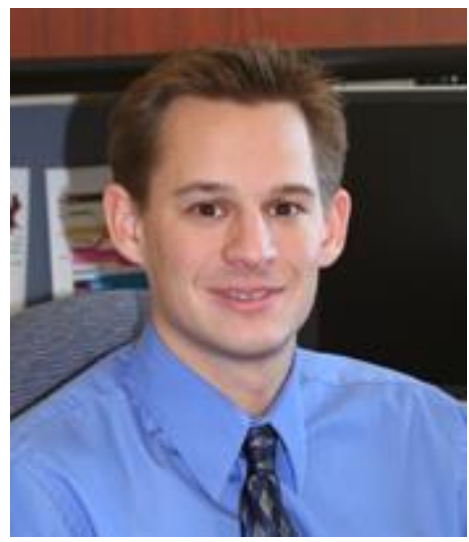
performance of individual building products, and Building Industry Reporting and Design for Sustainability (BIRDS), which expands the BEES framework to whole building design comparisons. The first version of BIRDS will be publically available this year. Dr. Kneifel is also involved with energy and economic research related to the performance of the NIST Net Zero Energy Residential Test Facility (NZERTF). 


\section{Fulya Kocak}

As Clark Construction Group's Director of Sustainability, Fulya Kocak develops the company's sustainability strategy, coordinates environmental responsibility efforts, and represents the company on numerous sustainable and green committees. In addition, Fulya manages Clark's nationwide Sustainability Committee which develops continuing education curriculum for employees and works with operations staff to ensure all projects meet their sustainability and LEED certification goals. Fulya's integrated approach emphasizes the key importance of knowledge sharing and crossdiscipline collaboration. Under her direction, ongoing commitment to education and sustainable construction practices is evident in every aspect of Clark's projects. Fulya inspires innovative ideas,

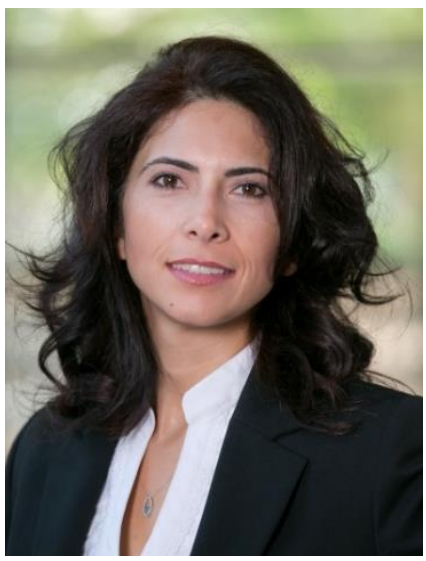
assists with decision-making by developing project-specific preconstruction tools, and works with subcontractors and suppliers to create and implement innovative sustainable solutions. Relying on her experience in the field and in preconstruction, Fulya understands key client priorities and jobsite challenges. This background enables her to develop sustainable solutions that help teams reach their certification goals and benefit the environment throughout a project's lifecycle. Fulya serves as the Chairwoman of the board at the USGBC National Capital Region Chapter. As a voting member of the DCRA Green Technical Advisory Group, she has been influential in developing the District of Columbia's first green building codes. Fulya also is a member of the USGBC's Materials \& Resources Technical Advisory Group's LEED Committee and the Associated General Contractors of America's Environmental Forum.

\section{Constantine E. Kontokosta}

Dr. Kontokosta, PE, AICP, LEED AP is Deputy Director of the NYU Center for Urban Science and Progress (CUSP), Founding Director of the Center for the Sustainable Built Environment at the NYU Schack Institute of Real Estate, and Associate Research Professor of Civil and Urban Engineering at the NYU Polytechnic School of Engineering. Bridging urban planning, data science, and systems engineering, Dr. Kontokosta leads CUSP's Building Informatics research group, and has worked with numerous city agencies on issues of urban sustainability and resilience, most recently providing the data analysis for the Local Law 84 Building Energy Benchmarking Reports for the NYC Mayor's

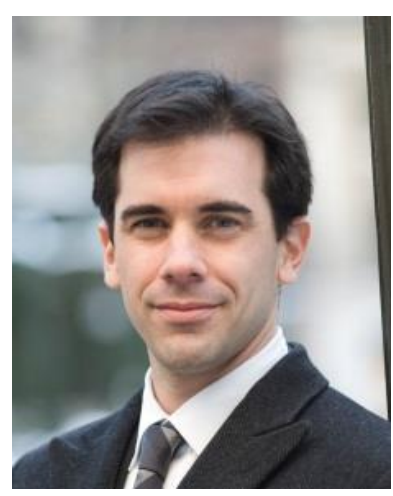
Office of Long-Term Planning and Sustainability. He is also the Principal Investigator and Head of the CUSP Quantified Community research facility, which will create a fully instrumented urban neighborhood in New York City. Dr. Kontokosta holds a Ph.D., M.Phil, and M.S. in Urban Planning, specializing in econometrics, from Columbia University, a M.S. in Real Estate Finance from New York University, and a B.S.E. in Civil Engineering Systems from the University of Pennsylvania. 


\section{Nancy Kralik}

Ms. Kralik is the Senior Director of Health, Safety, and Environmental (HSE) and Sustainability at Fluor Corporation. She is a licensed civil and environmental engineer with over 30 years of experience in the development and application of HSE policies and procedures in a global arena. Nancy has served as HSE project manager on diverse enterprises, including onshore and offshore facilities, refineries, and chemical plants for major oil and gas companies, conducted field investigations in the U.S. and international locations, and managed global HSE regulatory issues for oil and gas interests. At Fluor, Nancy led the corporate initiative to integrate HSE activities and is engaged in sustainability and HSE

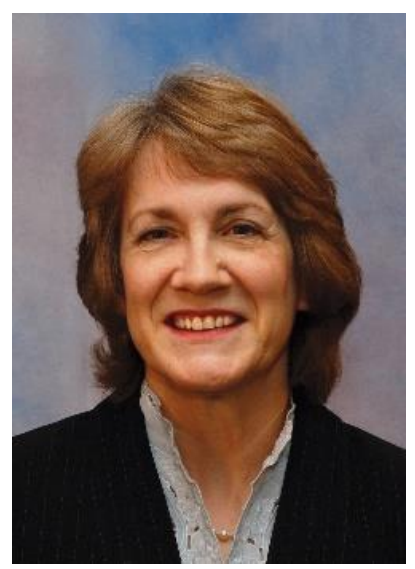
engineering and field issues in a corporate role. She serves as the chair of Fluor's executive-level Sustainability Committee. Nancy holds P.E. licenses in Texas and Ohio, with M.S. degrees in civil/environmental engineering and fisheries biology and a B.S. in biology. She is a LEED (Leadership in Energy and Environmental Design) Accredited Professional and Envision Sustainability Professional. She chairs the Construction Industry Institute's research team on sustainability during construction and recently led an Engineers Without Borders team on a El Salvadoran water project. Nancy is a member of ASCE's Committee on Sustainability and its subcommittee that develops sustainability education.

\section{Gül Kremer}

Dr. Kremer is a Professor of Engineering Design and Industrial Engineering at Penn State University. Dr. Kremer's research mission is to investigate the design and implementation of decision analysis methods for improvement of products and systems. This is accomplished through research that is focused on modeling the complex decision contexts to develop more efficient decision making tools for alternative evaluation with the ultimate goal of improving designed artifacts and systems for increased productivity, and benefit to stakeholders. Dr. Kremer is a fellow of ASME and a senior member of IIE. Dr. Kremer completed research and development projects for governmental and private entities. She is the recipient of awards (best paper awards, outstanding teaching, and service) from

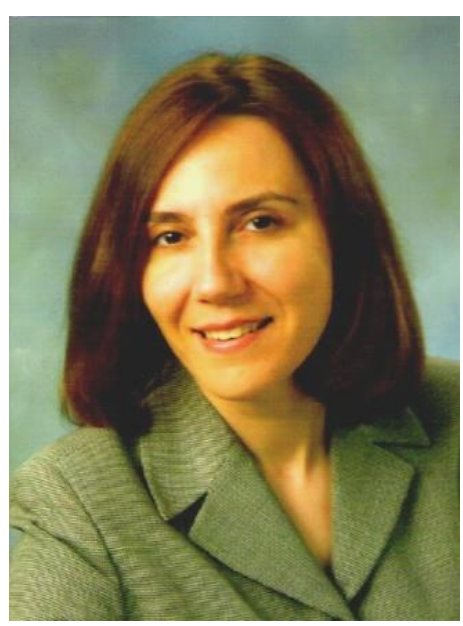
ASME, IIE and Penn State University. Dr. Kremer is the author and co-author of more than 270 publications (including 3 books) in journals, and peer reviewed conference proceedings. She is a former AFRL Faculty Fellow, and a Fulbright Scholar. She is currently serving as a program officer within NSF's EHR Directorate. 


\section{Safa Motesharrei}

Dr. Motesharrei is a Systems Scientist at SESYNC, and a PhD candidate in Physics (Econophysics) at the University of Maryland (UMD), College Park. He has Bachelor degrees in Electrical Engineering and Physics, Master degrees in Physics and Mathematics, and $\mathrm{ahD}$ in Applied Mathematics/Public Policy from UMD. The focus of his work is on integration of the Human System and Population into the Earth System Models. He works with a crossdisciplinary team of renowned scientists including Eugenia Kalnay (Atmospheric Science), James Yorke (Mathematics), Matthias Ruth (Public Policy), Victor Yakovenko (Econophysics), Klaus Hubacek

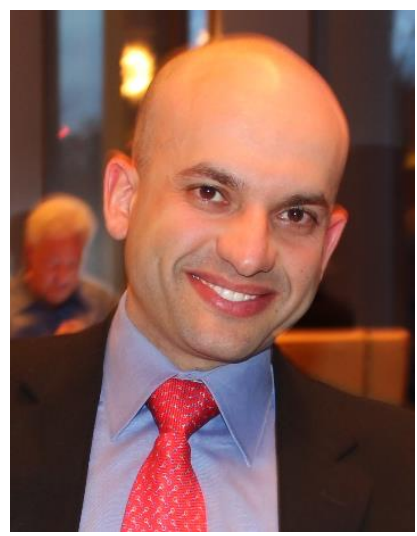
(Geography/Economics), Jelena Srebric (Engineering/Energy Sustainability), Robert Cahalan (Climate Physics), and Fernando Miralles-Wilhelm (Hydrology). Safa's studies were supported by doctoral fellowships from the School of Public Policy and the Department of Mathematics at UMD. In summer 2013, he was named the first recipient of the Lev Gandin Fellowship, awarded by Dr. Genia Brin.

\section{Nabil Z. Nasr}

Dr. Nasr is currently the Associate Provost for Academic Affairs as well as Director, Golisano Institute for Sustainability at Rochester Institute of Technology (RIT). He also founded the Center for Remanufacturing and Resource Recovery (C3R) at RIT. Dr. Nasr's main research interests are remanufacturing, life cycle engineering, cleaner production, sustainable product development, and manufacturing strategies. Dr. Nasr served as the chair of the Organization for Economic Cooperation and Development's (OECD) Advisory Expert Group on Sustainable Production. He currently serves on the advisory board of ResCoM consortium. He also served as an expert delegate with the U.S. Government in several international forums such as the Asia Pacific

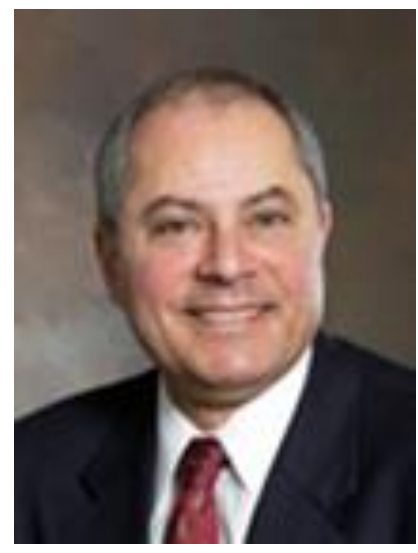
Economic Cooperation (APEC), United Nations, World Trade Organization, and the OECD. He recently served as an invited expert to the 13th and 14th International Resource Panel of the United Nations Environment Programme. 


\section{Andrew Persily}

Dr. Persily leads the Indoor Air Quality and Ventilation Group in the National Institute of Standards and Technology, where he works on indoor air quality and ventilation in commercial and residential buildings. His work includes the development and application of measurement techniques to evaluate airflow and air quality characteristics in a variety of building types, including large, mechanically ventilated buildings and single-family dwellings. He is also involved with the development and application of multi-zone airflow and contaminant dispersal models. Dr. Persily was a vice-president of the American Society of Heating, Refrigerating and Air Conditioning Engineers (ASHRAE) from 2007 to 2009, and is past chair of ASHRAE SSPC 62.1, responsible for the

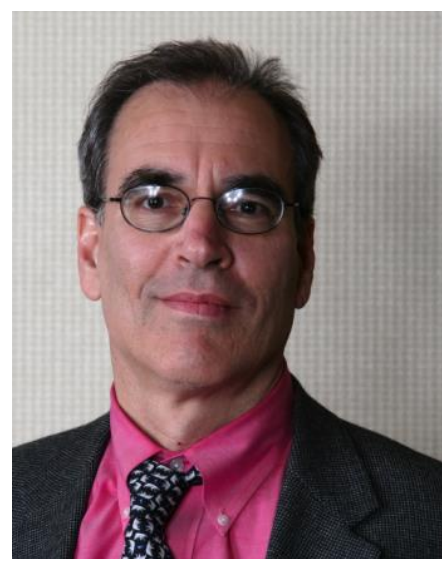
revision of the ASHRAE Ventilation Standard 62. He is currently chair of Standard 189.1, Design of High-Performance Green Buildings.

\section{Subhas K. Sikdar}

Dr. Sikdar is the Associate Director for Science for the National Risk Management Research Laboratory. Before joining EPA in 1990, Dr. Sikdar held managerial positions at the National Institute of Standards and Technology, and General Electric Corporate Research \& Development Center in Schenectady, New York. Dr. Sikdar is a Fellow of AAAS, ACS, AIChE, and IIChE, winner of five EPA bronze medals, two R\&D 100 awards. He is recipient of AIChE's Larry Cecil Award, Research Award for Sustainability, and Distinguished Alumnus Award from The University of Arizona and the University of Calcutta. He is the Editor-in-Chief of Clean Technologies and Environmental Policy, and a section editor of Current Opinions in Chemical Engineering. He is the current Chair of Engineers' Forum on Sustainability, and past Chair

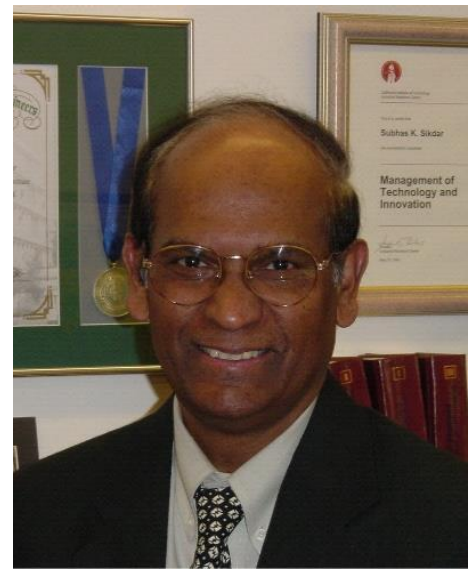
of AICHE's Institute for Sustainability and Sustainable Engineering Forum. Dr. Sikdar has published more than 90 technical papers in reputed journals, has 26 U.S. patents and edited 15 books. 
Michele A. Russo

Ms. Russo is the Director of the Green Content \& Research

Communications, McGraw Hill Construction (MHC). Since its inception in 2005, Michele has directed MHC's SmartMarket Report and market

insights program, tracking key industry trends affecting the construction industry. At MHC, Michele also acts as a subject matter expert in trends related to energy efficiency, high performance buildings, green building and corporate sustainability drawing from her more than eighteen years of experience in tracking these industry trends, notably through her prior work

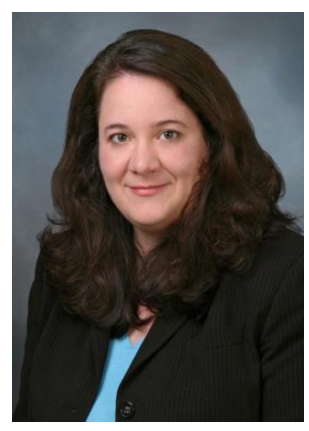
in the nonprofit and state government sectors. She is also responsible for helping direct the green content across MHC's portfolio of products and service, including drawing key high performance building trends from MHC's Dodge Construction Project Starts data. Michele is a frequent speaker and writer on key industry trends and has been quoted in major media outlets. Michele has a B.S. in Chemical Engineering from Cornell University and a Masters in Public Policy from Harvard's Kennedy School of Government where she served as a course assistant in statistics and econometrics.

\section{Sudarsan Rachuri}

Dr. Rachuri is a computer scientist at National Institute of Standards and Technology (NIST). He is the program manager for the Smart Manufacturing Systems Design and Analysis program at NIST. His primary research objectives are to develop and transfer knowledge to industry about information models for smart and sustainable manufacturing, green products, assembly representation, system level analysis, and tolerance representation. Specific focus is on identifying integration and technology issues that promote industry acceptance of information models, and standards that will enable designers to develop products that are sustainable and manufactured in a distributed and collaborative environment. Dr. Rachuri's primary areas of interest are

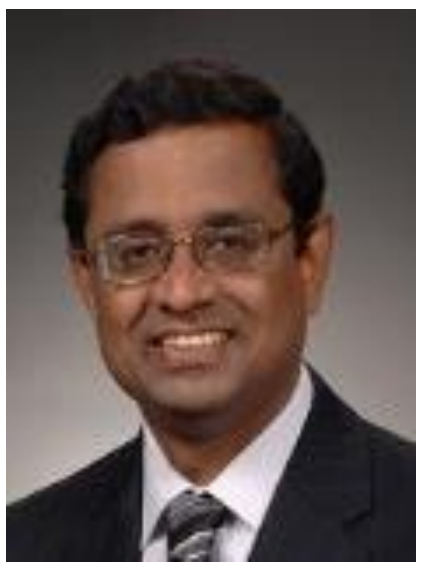
sustainable manufacturing, scientific computing, CAD/CAM/CAE, design for sustainability, data analytics, object-oriented modeling, and ontology. Dr. Rachuri is an ASME Fellow, having been elected in 2012 for his significant contributions in the areas of information and semantic modeling of product life cycle management, and the application of measurement science for sustainable manufacturing. 


\section{Richard N. Wright}

Dr. Wright is a Research Professor of Civil and Environmental Engineering at the University of Maryland College Park, vice chair of ASCE's Committee on Adaptation to a Changing Climate, member of the ASCE Committee on Sustainability, and chair of its Sustainable Infrastructure Education Subcommittee. He is a Distinguished Member of ASCE and member of the National Academy of Engineering. He is retired as director of the Building and Fire Research Laboratory of the National Institute of Standards and Technology and as Professor of Civil Engineering at the University of Illinois at Urbana-Champaign. He has been president of the International Council for Research and Innovation in Building and Construction (CIB); and president of the Liaison Committee of International Civil Engineering Organizations. He received bachelor's and master's degrees from Syracuse University, and the

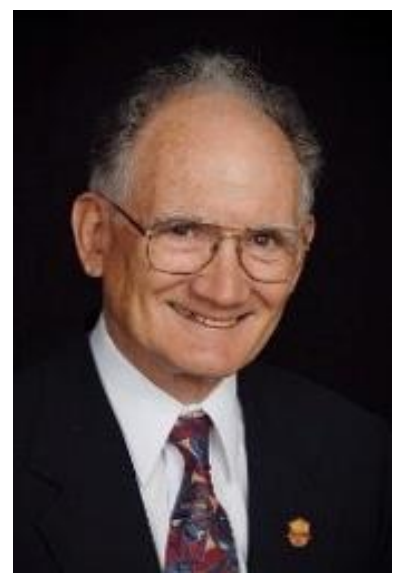
Ph.D. from the University of Illino is at Urbana-Champaign, all in Civil Engineering. He has registered as a professional engineer in New York and a structural engineer in Illinois. 


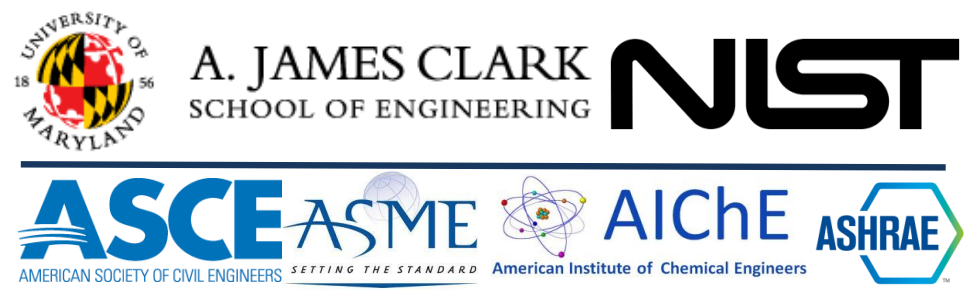

